\title{
Ciências agrárias: Inovação e responsabilidade social
}
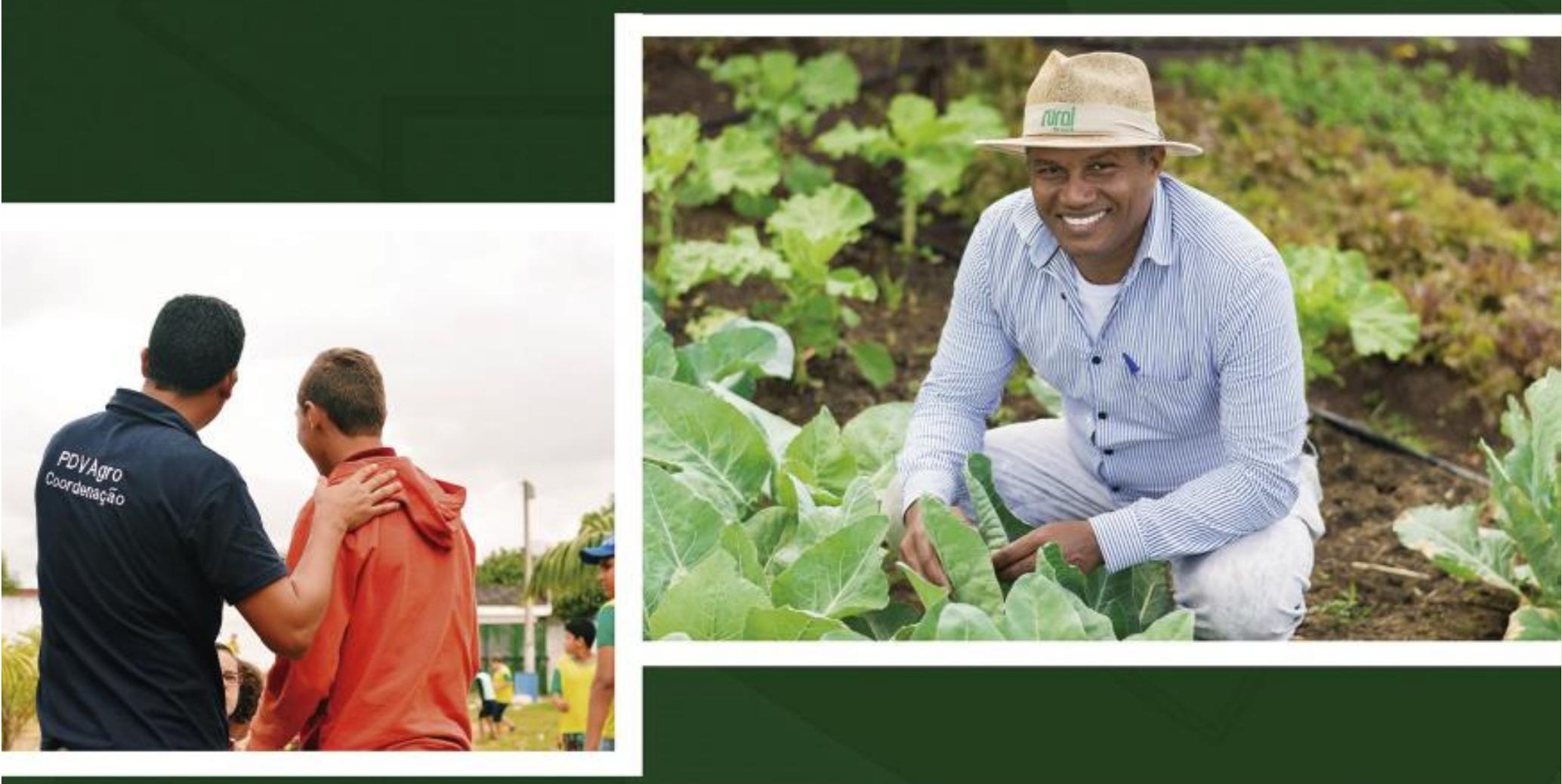

DJALMA VITORINO COSTA FILHO (org.) REGIANE RIBEIRO DOS SANTOS (org.) THALES RAMON DE QUEIROZ BEZERRA (org.) 
Dados Internacionais de Catalogação na Publicação (CIP)

(Câmara Brasileira do Livro, SP, Brasil)

Ciências agrárias : inovação e responsabilidade

social [livro eletrônico] / organização Djalma

Vitorino Costa Filho, Regiane Ribeiro dos

Santos, Thales Ramon de Queiroz Bezerra. --

1. ed. -- Recife : Instituto Internacional

Despertando Vocações,

2019. $1 \mathrm{Mb}$; PDF

ISBN 978-65-991061-4-9

1. Agricultura 2. Ciências da terra

3. Desenvolvimento sustentável 4. Educação Finalidade e objetivos 5. Geociências 6. Inovação tecnológica 7. Responsabilidade social I. Costa Filho, Djalma Vitorino. II. Santos, Regiane Ribeiro dos. III. Bezerra, Thales Ramon de Queiroz.

\section{Índices para catálogo sistemático:}

1. Ciências agrárias: Estudo e ensino 630.07

Maria Alice Ferreira - Bibliotecária - CRB-8/7964 


\title{
CIÊNCIAS AGRÁRIAS: INOVAÇÃO E RESPONSABILIDADE SOCIAL
}

\author{
$1^{\text {a Edição }}$
}

$$
\text { Recife - PE - Brasil }
$$

INSTITUTO INTERNACIONAL DESPERTANDO VOCAÇÕES 


\section{LIVRO DOS TRABALHOS PREMIADOS DO IV CONGRESSO \\ INTERNACIONAL DAS CIÊNCIAS AGRÁRIAS - IV COINTER PDVAgro 2019}

ORGANIZADORES: Djalma Vitorino Costa Filho

Regiane Ribeiro dos Santos

Thales Ramon de Queiroz Bezerra

EDITOR: Ayrton Matheus da Silva Nascimento

DIAGRAMAÇÃO: Anderson Soares da Silva / Mariana Almeida Ferreira de Lima

ISBN: 978-65-991061-4-9

DOI: $\underline{10.31692 / 978-65-991061-4-9}$

EDITORA: Instituto Internacional Despertando Vocações (IIDV)

Edição Digital 2019. Direitos exclusivos reservados para todos os países. Proibida sua reprodução total ou parcial, para uso privado ou coletivo, em qualquer meio impresso ou eletrônico de acordo com as leis de Propriedade Intelectual.

Digitalizado no Brasil / Digitalizado en Brasil/ Digitized in Brazil. 


\section{PREFÁCIO}

Este livro faz parte dos trabalhos aprovados, apresentados e premiados no IV Congresso Internacional das Ciências Agrárias - IV COINTER PDVAgro foi uma realização do Instituto Internacional Despertando Vocações (IIDV), que teve o compromisso com a democratização do conhecimento e com uma Educação de qualidade e teve como objetivos: discutir os caminhos e perspectivas dos estudos na área; divulgar os conteúdos e resultados de pesquisas; estabelecer trocas de experiências entre docentes investigadores do Brasil e do exterior, contribuir na formação dos estudantes e estimular a geração de novas redes de cooperação multicêntricas.

A intenção é, dessa forma, foi estimular, numa perspectiva plural, conversações e reflexões sobre a área, em diversos âmbitos. A importância do IV COINTER PDVAgro, foi a necessidade de ofertar aos estudantes e docentes, maior possibilidade de participação em eventos internacionais, que permitiram a troca de saberes e fazeres entre instituições parceiras e potenciais parceiras. Foram convidados pesquisadores do Brasil e do exterior com ampla experiência e produção em seus campos de estudo, onde apresentaram em conferências e mesas redondas os resultados de suas pesquisas. Todas as sessões foram seguidas de debates, possibilitando maior interface entre pesquisadores, estudantes de pós-graduação e graduação, professores universitários, de Educação Básica, além de pessoas da comunidade interessadas no tema.

Destacamos que as discussões contemplaram os seguintes eixos temáticos: Ciências Agrárias, Agroecologia, Sociologia Rural, Formação Agrícola, Educação do Campo, Saúde e Meio Ambiente, Agricultura, Administração e Economia Rural, Ciência, Tecnologia e Engenharia dos Alimentos, Tecnologia e Inovação, Engenharia de Pesca e suas Tecnologias, Agropecuária e suas Tecnologias. 
PRESIDENTE DO IIDV 2019

$\mathrm{Dr}^{\mathrm{a}}$. Kilma da Silva Lima Viana

COORDENADOR GERAL DO PDV 2019

MSc. Erick da Silva Lima Viana

COORDENADOR GERAL DO PDVAgro 2019

Dr. Edísio Raimundo da Silva

COORDENADOR EXECUTIVO DO COINTER PDV 2019

Esp. Ayrton Matheus da Silva Nascimento

PRESIDENTE DA COMISSÃO CIENTÍFICA DO COINTER PDVAgro 2019

Dr. Thales Ramon de Queiroz Bezerra

PRESIDENTE DA COMISSÃO CIENTÍFICA DO COINTER PDVAgro 2019

$\mathrm{Dr}^{\mathrm{a}}$. Regiane Ribeiro dos Santos

PRESIDENTE DA COMISSÃO CIENTÍFICA DO COINTER PDVAgro 2019

Rubenice Maria de Freiras

PRESIDENTE DA COMISSÃO CIENTÍFICA DO COINTER PDVAgro 2019

Adjair José da Silva

MEMBRO DA COMISSÃO CIENTÍFICA DO IV CONGRESSO INTERNACIONAL DAS CIÊNCIS AGRÁRIAS - COINTER PDVAgro 2019

\begin{tabular}{|c|c|}
\hline NOME & ÁREA \\
\hline ADJA CRISTINA LIRA DE MEDEIROS & Engenharia de Pesca e suas Tecnologias \\
\hline ADJAIR JÓSE DA SILVA & Agroecologia \\
\hline ALEXANDRE DUARTE RODRIGUES DA SILVA & Engenharia de Pesca e suas Tecnologias \\
\hline ÁLVARO ITAÚNA SCHALCHER PEREIRA & $\begin{array}{l}\text { Ciência, Tecnologias e Engenharia de } \\
\text { Alimento }\end{array}$ \\
\hline ANNY KELLY VASCONCELOS & Agropecuária e suas Tecnologias \\
\hline ANTONIO MARICÉLIO BORGES DE SOUZA & Agricultura \\
\hline AYRTON MATHEUS DA SILVA NASCIMENTO & Formação Agrícola \\
\hline BARBARA CHRYS GOMES BALDUINO & $\begin{array}{l}\text { Ciência, Tecnologias e Engenharia de } \\
\text { Alimento } \\
\end{array}$ \\
\hline BÁRBARA DANTAS FONTES SOARES & Saúde e Meio Ambiente \\
\hline BRUNA RAFAELA DA SILVA MONTEIRO WANDERLEY & Tecnologia e Inovação \\
\hline CINTHIA CARLA CLAUDINO GRANGEIRO & Saúde e Meio Ambiente \\
\hline CRISTIANE AYALA DE OLIVEIRA & $\begin{array}{l}\text { Ciência, Tecnologias e Engenharia de } \\
\text { Alimento }\end{array}$ \\
\hline DANISE MEDEIROS VIEIRA & $\begin{array}{l}\text { Ciência, Tecnologias e Engenharia de } \\
\text { Alimento }\end{array}$ \\
\hline DAVID MARX ANTUNES DE MELO & Educação do Campo \\
\hline DIJACI ARAÚJO FERREIRA & Engenharia de Pesca e suas Tecnologias \\
\hline DRAUSIO VERAS & Engenharia de Pesca e suas Tecnologias \\
\hline EDNÉIA DE LUCENA VIEIRA & $\begin{array}{l}\text { Ciência, Tecnologias e Engenharia de } \\
\text { Alimento }\end{array}$ \\
\hline ELAINE CRISTINA MOREIRA MARQUES & Agroecologia \\
\hline ELANNE DE PAIVA FONSECA & Agroecologia \\
\hline ERICK VIANA DA SILVA & Agricultura \\
\hline
\end{tabular}




\begin{tabular}{|c|c|}
\hline FABIANA MARIA DA SILVA & $\begin{array}{c}\text { Ciência, Tecnologias e Engenharia de } \\
\text { Alimento }\end{array}$ \\
\hline FÁBIO SANDRO DOS SANTOS & Administração e Economia Rural \\
\hline FELIPE DAS NEVES MONTEIRO & Agropecuária e suas Tecnologias \\
\hline FLAVIANO FERNANDES DE OLIVEIRA & Agricultura \\
\hline GEOGE CARLOS VIEIRA DA SILVA & Agricultura \\
\hline GIZELIA BARBOSA FERREIRA & Tecnologia e Inovação \\
\hline HALLYSON DIEGO MENDES BRAZ & Agricultura \\
\hline HOUTRAN LIMA DA SILVA & Agricultura \\
\hline IGOR CESAR BEZERRA DA SILVA & $\begin{array}{l}\text { Ciência, Tecnologias e Engenharia de } \\
\text { Alimento }\end{array}$ \\
\hline IVAN CARLOS DA COSTA BARBOSA & Saúde e Meio Ambiente \\
\hline JAMILY DA SILVA FERNANDES & Agroecologia \\
\hline JEFFERSON DA SILVA LOPES & Agricultura \\
\hline JENIFFER VIVIANY DOS SANTOS FONSECA & $\begin{array}{c}\text { Ciência, Tecnologias e Engenharia de } \\
\text { Alimento }\end{array}$ \\
\hline JOELLINGTON MARINHO DE ALMEIDA & $\begin{array}{l}\text { Ciência, Tecnologias e Engenharia de } \\
\text { Alimento } \\
\end{array}$ \\
\hline JORDÂNIA KELY BARBOSA DA SILVA & Agropecuária e suas Tecnologias \\
\hline JOSÉ LUCAS FARIAS DA SILVA & Agricultura \\
\hline KEROLÉM PRÍCILA SOUSA CARDOSO & Agroecologia \\
\hline KEROLLY KEDMA FELIX DO NASCIMENTO & Tecnologia e Inovação \\
\hline LAILLA SABRINA QUEIROZ NAZARENO & Agricultura \\
\hline LEVY FRANCO DOS SANTOS & Agropecuária e suas Tecnologias \\
\hline LUÍSA VALENTIM MELO DE VASCONCELOS QUEIROZ VÉRAS & Saúde e Meio Ambiente \\
\hline MAURÍCIO DOS SANTOS ARAÚJO & Agricultura \\
\hline MILENA KELLY CRUZ ARAUJO DO NASCIMENTO & Agroecologia \\
\hline MOISÉS FELIX DE CARVALHO NETO & Agricultura \\
\hline NARDIELE DE SOUZA SOUTO FREITAS & Agricultura \\
\hline NATANAELMA SILVA DA COSTA & Agroecologia \\
\hline NAYARA ROSE DA CONCEIÇÃO LOPES & Agricultura \\
\hline NEWTON CARLOS SANTOS & Educação do Campo \\
\hline OSWALDO PALMA LOPES SOBRINHO & Agricultura \\
\hline PAULO HENRIQUE OLIVEIRA DE MIRANDA & Saúde e Meio Ambiente \\
\hline PEDRO MOREIRA DE SOUSA JUNIOR & Saúde e Meio Ambiente \\
\hline RAPHAEL LUCAS JACINTO ALMEIDA & $\begin{array}{l}\text { Ciência, Tecnologias e Engenharia de } \\
\text { Alimento }\end{array}$ \\
\hline REGIANE RIBEIRO DOS SANTOS & $\begin{array}{l}\text { Ciência, Tecnologias e Engenharia de } \\
\text { Alimento }\end{array}$ \\
\hline
\end{tabular}




\begin{tabular}{|c|c|}
\hline ROBERTA MARQUES & Agropecuária e suas Tecnologias \\
\hline RODRIGO LIRA DE OLIVEIRA & $\begin{array}{l}\text { Ciência, Tecnologias e Engenharia de } \\
\text { Alimento }\end{array}$ \\
\hline RUANA CAROLINA CABRAL DA SILVA & Agropecuária e suas Tecnologias \\
\hline RUBENICE MARIA DE FREITAS & Agroecologia \\
\hline SÂMELA LEAL BARROS & $\begin{array}{l}\text { Ciência, Tecnologias e Engenharia de } \\
\text { Alimento }\end{array}$ \\
\hline SAMÍRIA PINHEIRO DOS SANTOS & Agricultura \\
\hline SHÊNIA SANTOS MONTEIRO & $\begin{array}{l}\text { Ciência, Tecnologias e Engenharia de } \\
\text { Alimento }\end{array}$ \\
\hline SHIRLEY SANTOS MONTEIRO & Agroecologia \\
\hline SONARA DE FRANÇA SOUSA & $\begin{array}{c}\text { Ciência, Tecnologias e Engenharia de } \\
\text { Alimento }\end{array}$ \\
\hline THALES RAMON DE QUEIROZ BEZERRA & Engenharia de Pesca e suas Tecnologias \\
\hline THIAGO BERNARDO DE SOUZA & Agropecuária e suas Tecnologias \\
\hline THIAGO FELIPH SILVA FERNANDES & Agricultura \\
\hline TIMÓTEO ANGELO NASCIMENTO & Educação do Campo \\
\hline UEMESON JOSÉ DOS SANTOS & Formação Agrícola \\
\hline VALÉRIA LOURO RIBEIRO & Agropecuária e suas Tecnologias \\
\hline VERUSKA DILYANNE SILVA GOMES & Agropecuária e suas Tecnologias \\
\hline VIRGÍNIA MIRTES DE ALCÂNTARA SILVA & Tecnologia e Inovação \\
\hline VIVIANE DA SILVA MEDEIROS & Saúde e Meio Ambiente \\
\hline WANDERSON BENERVAL DE LUCENA & Agricultura \\
\hline WELLINGTON COSTA DA SILVA & Educação do Campo \\
\hline WILLY VILA NOVA PESSOA & Tecnologia e Inovação \\
\hline
\end{tabular}




\section{SUMÁRIO}

EXPOSIÇÃO DE BIOINDICADOR A EXTRATOS AQUOSOS E A FITOTERÁPICO COMERCIAL DE AMBURANA E SUAS IMPLICAÇÕES NA PROLIFERAÇÃO CELULAR

Matheus Dias Santos; Bárbara Dantas Fontes Soares

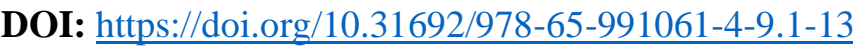

O USO DO PÓ DE ROCHA DA PEDRA CARIRI NO CRESCIMENTO INICIAL DE MUDAS DE PAU D'ARCO (Handroanthus impetiginosus (Mart. ex DC.)) IMPLANTADAS EM ÁREAS DEGRADADAS

Ana Cláudia do Nascimento Silva, Sayonara Rejane Lima Araújo, Luiz Francinélio Cavalcante Júnior, Josefa Maria Francieli da Silva; Sebastião Cavalcante de Sousa

DOI: https://doi.org/10.31692/978-65-991061-4-9.14-32

DESEMPENHO AGRONÔMICO DE VARIEDADES DE FEIJÃO-CAUPI NO PERÍODO DE ESTIAGEM EM CASTANHAL-PA

Lucas Fernando da Costa Lima; Breno Barbosa dos Santos; Gabriel Garreto dos Santos; Domingos Sávio Morais Tavares; Juliana Simões Nobre Gama

DOI: https://doi.org/10.31692/978-65-991061-4-9.33-46

DESENVOLVIMENTO INICIAL DE PLÂNTULAS DE JUÇARA IRRIGADAS COM ÁGUA SALINA.

Rosana Maria dos Santos Nani de Miranda; Rozane Franci Moraes Tavares; Tâmara Moreira Silva; Danilo Força Baroni; Almy Junior Cordeiro de Carvalho

DOI: https://doi.org/10.31692/978-65-991061-4-9.47-60

EFEITO DA DENSIDADE NO CRESCIMENTO DE Crassostrea gasar CULTIVADA EM SISTEMA FIXO NA COSTA DE MANGUEZAIS DE MACROMARÉS DA AMAZÔNIA, BRASIL

Ana Melissa de Moraes Câmara; Paulo Protásio de Jesus; Edivânia Oliveira Silva; Josinete Sampaio Monteles; Izabel Cristina da Silva Almeida Funo

DOI: https://doi.org/10.31692/978-65-991061-4-9.61-74

A CONFECÇÃO E USO DE UMA MINI ECOSFERA COMO PROPOSTA DE RECURSO DIDÁTICO NO ENSINO DE EDUCAÇÃO AMBIENTAL E SUSTENTABILIDADE

Levi Araujo Bezerra; Luiz Carlos Alves de Souza

DOI: https://doi.org/10.31692/978-65-991061-4-9.75-91

DESEMPENHO E RENDIMENTO DE CARCAÇA DE FRANGO DE CORTE DE CRESCIMENTO LENTO ALIMENTADOS COM FARELO DE PALMA FORRAGEIRA Cicero Cordeiro Pinheiro; Francisco Luan Fernandes Ferreira; Alexsandro de Andrade Silva; Ednardo Rodrigues Freitas; Irani Ribeiro Vieira Lopes

DOI: https://doi.org/10.31692/978-65-991061-4-9.92-105

DESEMPENHO AGRONÔMICO DA ABÓBORA HÍBRIDA POLINIZADA COM DIFERENTES DOSES DE FITORREGULADORES NA REGIÃO OESTE DA BAHIA

Naiane de Macedo Oliveira; Loanny de Souza Santos; Lucas Miguel Carvalho da Silva; Marilucia de Jesus Gomes; Alberto do Nascimento Silva

DOI: https://doi.org/10.31692/978-65-991061-4-9.106-110

DIAGNOSE FOLIAR DE FÓSFORO EM CULTIVARES DE CANA DE AÇÚCAR SOB IRRIGAÇÃO SUBTERRÂNEA: FOLHA +1 E FOLHA +3 
Thayane Leonel Alves; José de Arruda Barbosa; Victor Hugo de Farias Guedes; Mara Cristina Pessôa da Cruz; Vinicius Marchioro

DOI: https://doi.org/10.31692/978-65-991061-4-9.111-116

MORFOLOGIA DE CULTIVARES DE SOJA SUBMETIDO A ESTRESSE HÍDRICO

Acássio Nadson Gomes Freitas; Elaine de Souza Prado; Cleuber Oliveira de Sousa; Daniel Souza Barboza; Alberto do Nascimento Silva

DOI: https://doi.org/10.31692/978-65-991061-4-9.117-122

CARACTERÍSTICAS AGRONÔMICAS DE SORGO SOB NUTRIÇÃO FOLIAR DE MAGNÉSIO COM PRESENÇA E AUSÊNCIA DE SILÍCIO

Victor Hugo de Farias Guedes; Renato de Mello Prado; Antônio Carlos Buchelt; Thayane Leonel Alves; José Lucas Farias da Silva

DOI: https://doi.org/10.31692/978-65-991061-4-9.123-126

PROPRIEDADES QUÍMICAS DE UM LATOSSOLO VERMELHO IMPLANTADO COM PASTOS DE CAPIM-MOMBAÇA SOB EFEITO RESIDUAL DO NITROGÊNIO

Antonio Leandro Chaves Gurgel; Gelson dos Santos Difante; Alexandre Romeiro de Araújo; Manuel Cláudio Motta Macedo; Denise Baptaglin Montagner

DOI: https://doi.org/10.31692/978-65-991061-4-9.127-132

DINÂMICA DA ATIVIDADE MICROBIANA DO SOLO SOB DIFERENTES AGROSSISTEMAS NO CERRADO BAIANO

Vitória Oliveira Andrade; Inglid Lais Batista Cunha de Souza; Gabriel Amorim Luduvico; Thais dos Santos Rodrigues; Cristiane Nair Fabrício Nunes

DOI: https://doi.org/10.31692/978-65-991061-4-9.133-138

AVALIAÇÃO DA EFICÁCIA DA IVERMECTINA SOBRE NEMATOIDES GASTRINTESTINAIS DE ASININOS Equus asinus Linnaeus, 1758

Ruana Rafaela Lira Torquato Paiva; Lígia Vanessa Leandro Gomes; Maria de Lara Oliveira Lima; Eylha Pricilla Fernandes Menezes; Josivania Soares Pereira

DOI: https://doi.org/10.31692/978-65-991061-4-9.139-144

EFEITO DA ASSOCIAÇÃO DO FATOR DE CRESCIMENTO EPIDERMAL COM CISTEAMINA DURANTE A MATURAÇÃO IN VITRO DE OÓCITOS BOVINOS

Antonia Rafaela da Silva Oliveira; Maria Valéria de Oliveira Santos; Lhara Ricarliany Medeiros de Oliveira; Alexsandra Fernandes Pereira

DOI: https://doi.org/10.31692/978-65-991061-4-9.145-150

ANÁLISE ESPAÇO-TEMPORAL DE FOCOS DE CALOR NA ÁREA DE PROTEÇÃo AMBIENTAL DO MARAJÓ

Heloise de Sousa Castro; Eduarda Emilia Magalhães Cristóvão; Ingrid Leão Campos; Wenderson Holanda de Oliveira; Breno Pinto Rayol

DOI: https://doi.org/10.31692/978-65-991061-4-9.151-156

PRODUTIVIDADE E ACÚMULO DE N EM CANA-DE-AÇÚCAR SOB SISTEMAS DE COLHEITA SEM QUEIMA

Victor Vinicius Silva Barros; José Mauro de Sousa Paiva

DOI: https://doi.org/10.31692/978-65-991061-4-9.157-162

INTERFERÊNCIA DE PLANTAS DANINHAS NA CULTURA DA CENOURA EM DOIS SISTEMAS DE IRRIGAÇÃO LOCALIZADA

Antônio Batista C. Bisneto; Laís Tereza Rêgo Reginaldo; Maria Alice Formiga Porto; Tatiane Severo Silva; Daniel Valadão Silva

DOI: https://doi.org/10.31692/978-65-991061-4-9.163-168 
CARACTERIZAÇÃO DA FERTILIDADE DO SOLO DE UMA COMUNIDADE PERIURBANA EM BARCARENA, PARÁ, BRASIL.

Henrique Caetano Alencar; Gilson Sergio Bastos de Matos; Amanda Nascimento Monteiro; Vitória Malcher Nogueira Lima; Marcos André Piedade Gama

DOI: https://doi.org/10.31692/978-65-991061-4-9.169-173

AVALIAÇÃO DE ATRIBUTOS FÍSICOS EM CANAVIAL FERTIRRIGADO COM VINHAÇA E ADUBAÇÃO QUÍMICA

Adjair José da Silva; Anderson Ricardo Galdino da Silva; Andréa Renilda Silva Soares; Joanna Rafaella da Silva; Sandro Augusto Bezerra

DOI: https://doi.org/10.31692/978-65-991061-4-9.174-178

CARACTERÍSTICAS DE RENDIMENTO DE FRUTOS DE NOVOS HÍBRIDOS DE MAMOEIROS EM BARAÚNA - RN.

Lucas Matheus da Silva Sousa; Otacílio Filho Alves de Anchieta; Ivan Gabriel Garcia Peixoto; Patrícia Lígia Dantas de Morais; Jaeveson da Silva

DOI: https://doi.org/10.31692/978-65-991061-4-9.179-184

COMPORTAMENTO DE MANDIOCA PARA DUPLA APTIDÃO, MESA E INDUSTRIAL, NO CULTIVO IRRIGADO, EM SOLO ARENOSO E APÓS MAMOEIRO, EM CEARÁ MIRIM, RN

Lucas Matheus da Silva Sousa; Jonas Carapinta de Sousa; Enoch de Souza Ferreira; José Gleidson Laranjeira da Silva; Jaeveson da Silva

DOI: https://doi.org/10.31692/978-65-991061-4-9.185-191

SALINIDADE NA GERMINAÇÃO DE SEMENTES DE MADEIRA-NOVA INDUZIDA POR DIFERENTES SAIS

Emanuelle Marques Coutinho; Andrei dos Santos Souza; Mateus Pereira dos Santos; Jamil Sousa Silva; Gisele Brito Rodrigues

DOI: https://doi.org/10.31692/978-65-991061-4-9.192-198

NUANCES DA EXTENSÃO RURAL NO MUNICÍPIO DE ANGICAL, BAHIA

Kelly Santos Silva; Nattália Matos da Rocha; Rafael Guimarães Farias

DOI: https://doi.org/10.31692/978-65-991061-4-9.199-204

QUALIDADE PÓS COLHEITA DE MELOIRO FERTIRRIGADO COM DIFERENTES DOSES DE POTÁSSIO NA SOLUÇÃO NUTRITIVA SALINIZADA

Giordanio Bruno Silva Oliveira; Sandy Thomaz dos Santos; Jessilanne Plinia Barbosa de Medeiros Costa; Paulo Victor Menezes; Francisco de Assis de Oliveira

DOI: https://doi.org/10.31692/978-65-991061-4-9.205-210

DESEMPENHO AGRONÔMICO DE CULTIVARES DE FEIJÃO-CAUPI DE PORTE ERETO E PROSTRADO NO CERRADO DO ESTADO DO PIAUÍ

Williany Rêgo Lima; Jean Lucas Costa dos Santos; Gustavo Nobre Lima; Adão Vinicius Abreu Rabelo de Sousa; Wallace de Sousa Leite

DOI: https://doi.org/10.31692/978-65-991061-4-9.211-216

AVALIAÇÃO DA PREFERÊNCIA ALIMENTAR DE BARATAS DE MADAGASCAR (Gromphadorhina portentosa)

Breno Noronha Rodrigues; Jackeline Freire Moura; Lindolfo Henrique Gomes Simão; Maria Mariana Freitas Soares; Aracely Rafaelle Fernandes Ricarte

DOI: https://doi.org/10.31692/978-65-991061-4-9.217-220 
DIAGNÓSTICO DO PERFIL DOS AGRICULTORES FAMILIARES FEIRANTES E OS PRODUTOS COMERCIALIZADOS NA FEIRA MUNICIPAL DE SÃO MIGUEL DO GUAMÁ

Marinara de Fátima Souza da Silva; Adrielly Sousa da Cunha; Milton Garcia Costa; Washington Duarte Silva da Silva; Carlos Douglas de Sousa Oliveira

DOI: https://doi.org/10.31692/978-65-991061-4-9.221-226

\section{ASSENTAMENTO SERRA GRANDE: APROVEITANDO RESÍDUOS AGROINDÚSTRIAIS}

Valdenora Mateus da Silva Neta; Suelen Samili da Silva; Júlia Karoline de Lima Barbosa; Vínicius de Barros Monteiro; Djalma Vitorino Costa Filho

DOI: https://doi.org/10.31692/978-65-991061-4-9.227-229

\section{ELABORAÇÃO DE UM LICOR À BASE DA VINAGREIRA}

Eulane Rys Rufino Abreu; Weshyngton Grehnti Rufino Abreu; Ísis Valéria Borges da Silva; Oswaldo Palma Lopes Sobrinho; Álvaro Itaúna Schalcher Pereira

DOI: https://doi.org/10.31692/978-65-991061-4-9.230-233

PARTICIPAÇÃO AO PROGRAMA DE MONITORIA NA DISCPLINA DE CONTROLE DE QUALIDADE E ANÁLISE DE ALIMENTOS: UM RELATO DE EXPERIÊNCIA

Robson da Silveira Espíndola; Evelyn Ivana Trindade Damasceno Alves

DOI: https://doi.org/10.31692/978-65-991061-4-9.234-237

HORTA COMUNITÁRIA COMO PROMOÇÃO DE QUALIDADE DE VIDA PARA AS FAMÍLIAS EM SITUAÇÃO DE VULNERABILIDADE SOCIAL

Lorhana Franco Mesquita; David Aimar Sousa Silva; Mayara Pereira da Luz; Fernando José Sousa Borges; Edvar de Sousa da Silva

DOI: https://doi.org/10.31692/978-65-991061-4-9.238-241

DO PLANTIO AO PRATO: APRENDENDO DE FORMA LÚDICA A CONSUMIR ALIMENTOS SAUDÁVEIS E CUIDAR DA NATUREZA ATRAVÉS DE HORTA ESCOLAR NA PRIMEIRA INFÂNCIA

Samantha Santos Vieira; Juliane Carneiro Martins; Idenilson Lobo Santos; Mario Augusto Pereira Junior; Ana Maria Aquino dos Anjos Ottati

DOI: https://doi.org/10.31692/978-65-991061-4-9.242-245

FORMAÇÃO DOS ALUNOS DA REDE MUNICIPAL DE ENSINO SOBRE AS ZOONOSES E OS POSSÍVEIS IMPACTOS NA SAÚDE PÚBLICA

Italo Gleison Tarquinio da Silva; Maria Lucivania Diniz da Silva; Laércio Nogueira Medeiros; João Victor Dionísio da Silva; Viviane da Silva Medeiros

DOI: https://doi.org/10.31692/978-65-991061-4-9.246-249

PROJETO IMPLANTAÇÃO DE HORTA ORGÂNICA NA QUALIDADE DE VIDA E BEM-ESTAR DE IDOSOS EM ASILOS DE VITÓRIA DE SANTO ANTÃO-PE

Lenira Batista da Silva; Mércia Cardoso da Costa Guimarães; Marta Xavier; Marismênia de Siqueira Campos Moura; José Marcos Freitas de Oliveira

DOI: https://doi.org/10.31692/978-65-991061-4-9.250-253 


\title{
EXPOSIÇÃO DE BIOINDICADOR A EXTRATOS AQUOSOS E A FITOTERÁPICO COMERCIAL DE AMBURANA E SUAS IMPLICAÇÕES NA PROLIFERAÇÃO CELULAR
}

\author{
EXPOSICIÓN DEL BIOINDICADOR A EXTRACTOS ACUOSOS Y MEDICINA \\ HERBARIA COMERCIAL DE AMBURANA Y SUS IMPLICACIONES EN LA \\ PROLIFERACIÓN CELULAR
}

\begin{abstract}
BIOINDICATOR EXPOSURE TO WATER EXTRACTS AND COMMERCIAL PHYTOTHERAPIC OF AMBURAN AND ITS IMPLICATIONS IN CELLULAR PROLIFERATION
\end{abstract}

\author{
Matheus Dias Santos ${ }^{1}$; Bárbara Dantas Fontes Soares ${ }^{2}$
}

DOI: https://doi.org/10.31692/978-65-991061-4-9.1-13

\begin{abstract}
RESUMO
A amburana é uma das diversas plantas popularmente utilizadas no Brasil com fins medicinais. A realização de estudos dessas espécies vegetais é de extrema importância para garantir a segurança no uso das mesmas pela população. A utilização de testes como o Allium cepa é uma das formas de se ter uma boa primeira triagem e de alta confiabilidade. $\mathrm{O}$ presente trabalho tem por objetivo avaliar a implicação da exposição a fitoterápico e a diferentes concentrações do extrato aquoso de sementes de Amburana cearensis sobre a proliferação celular em bioindicador. Empregou-se o sistema teste Allium cepa, com 6 tratamentos: T1 - testemunha (água destilada); T2, T3, e T4 - extratos aquosos de $A$. cearensis $\left(10 \mathrm{~g} . \mathrm{L}^{-1}, 20 \mathrm{~g} . \mathrm{L}^{-1}\right.$, e $30 \mathrm{~g} . \mathrm{L}^{-1}$, respectivamente); T5 exposição ao fitoterápico; e T6, exposição à glifosato a $15 \%$, cada tratamento contou com 4 repetições, expondo-se as raízes dos bulbos de cebola aos tratamentos por 24 horas. Procedeu-se preparo e confecção das lâminas que foram observadas ao microscópio óptico com aumento de 40X e posterior análise do Índice Mitótico. Os dados foram analisados por meio do teste Tukey a $5 \%$ de probabilidade. As três diferentes concentrações do extrato aquoso de Amburana cearensis levaram a brusca redução do Índice Mitótico em relação à testemunha, se igualando ao controle positivo (glifosato a 15\%); a exposição ao fitoterápico também levou a redução do índice mitótico. As três diferentes concentrações $\left(10 \mathrm{~g} .{ }^{\mathrm{L}-1}, 20 \mathrm{~g} \cdot{ }^{\mathrm{L}-1} \mathrm{e} 30 \mathrm{~g} .{ }^{\mathrm{L}-1}\right)$ do extrato aquoso de Amburana cearensis bem como o fitoterápico a base de amburana levaram a redução do Índice Mitótico, dessa forma afetando proliferação celular em bioindicador evidenciando efeito citotóxico.
\end{abstract}

Palavras-Chave: Amburana cearensIs, Allium cepa, citotoxicidade, genotoxicidade, planta medicinal

\section{RESUMEN}

Amburana es una de varias plantas utilizadas popularmente en Brasil con fines medicinales. Los estudios de estas especies de plantas son de suma importancia para garantizar la seguridad en su uso por parte de la población. El uso de pruebas como el bioindicador Allium cepa es uno de los primeros y más confiables métodos de detección. El presente trabajo tiene como objetivo evaluar la implicación de la exposición a la medicina a base de hierbas y a diferentes concentraciones de extracto acuoso de semillas de Amburana cearensis en la proliferación celular en bioindicador. Se usó el sistema de prueba Allium cepa como bioindicador y se produjeron 6 tratamientos: T1 - control (agua destilada); T2, T3 y T4: extractos acuosos de A. cearensis (10 g. L-1, 20 g. L-1 y $30 \mathrm{~g}$. L-1, respectivamente); T5 exposición a la medicina a base de hierbas amburana; y T6, 15\% de exposición al glifosato, cada tratamiento tuvo 4 repeticiones, exponiendo las raíces de los bulbos de cebolla a los tratamientos durante 24 horas. Se prepararon y prepararon los portaobjetos, que se observaron bajo el microscopio óptico con un aumento de 40X y posterior análisis del índice mitótico. Los datos se analizaron mediante análisis de varianza y prueba de Tukey con una probabilidad del 5\%. Las tres

\footnotetext{
${ }^{1}$ Agronomia, Universidade Estadual do Sudoeste da Bahia, matheusdiassantos2013@gmail.com

2 Doutorado, Universidade Estadual do Sudoeste da Bahia, barbarafontes@uesb.edu.br
} 
concentraciones diferentes de extracto acuoso de Amburana cearensis (10 gL-1, 20 gL-1 y 30 gL-1) condujeron a una fuerte reducción en el índice mitótico en comparación con el control, igualando el control positivo (15\% de glifosato). mientras que la medicina herbal basada en amburano produjo una reducción en el índice mitótico. Por lo tanto, los tratamientos evaluados afectaron la proliferación celular en A. cepa que mostró un efecto citotóxico.

Palabras Clave: Amburana cearensis, Allium cepa, citotoxicidad, genotoxicidad, plantas medicinales

\begin{abstract}
Amburana is one of several plants popularly used in Brazil for medicinal purposes. Studies of these plant species are of utmost importance to ensure safety in their use by the population. The use of tests such as the Allium cepa bioindicator is one of the first and most reliable screening methods. The present work aims to evaluate the implication of exposure to herbal medicine and different concentrations of aqueous extract of Amburana cearensis seeds on cell proliferation in bioindicator. Allium cepa test system was used as bioindicator and 6 treatments were produced: T1 - control (distilled water); T2, T3, and T4 - aqueous extracts of A. cearensis (10g.L-1, 20g.L-1, and 30g.L-1, respectively); T5 exposure to amburana herbal medicine; and T6, 15\% glyphosate exposure, each treatment had 4 repetitions, exposing the roots of the onion bulbs to the treatments for 24 hours. The slides were prepared and made, which were observed under the optical microscope with 40X magnification and subsequent analysis of the Mitotic Index. Data were analyzed by analysis of variance and Tukey test at 5\% probability. The three different concentrations of Amburana cearensis aqueous extract (10 gL-1, $20 \mathrm{gL}-1$ and $30 \mathrm{gL}-1)$ led to a sharp reduction in Mitotic Index in relation to the control, equaling the positive control (15\% glyphosate). while amburan-based herbal medicine produced a reduction in the mitotic index. Thus, the treatments tested affected cell proliferation in A. cepa showing cytotoxic effect.
\end{abstract}

Keywords: Amburana cearensis, Allium cepa, cytotoxicity, genotoxicity, medicinal plant

\title{
INTRODUÇÃO
}

As plantas medicinais são uma importante fonte de produtos naturais biologicamente ativos dos quais, muitos, são utilizados na produção de um grande número de fármacos, sendo que as preparações fitoterápicas correspondem a até $80 \%$ dos medicamentos utilizados em países em desenvolvimento por motivos de ordem médica, social, cultural, econômica ou filosófica, sendo, algumas vezes, o único medicamento disponível à população. No entanto, apesar do amplo uso, ainda são poucos os estudos para avaliar a eficácia terapêutica e a toxicidade potencial dessas preparações fitoterápicas (BELCAVELLO, et al., 2012; DIAS, et al., 2014; PERON, et al., 2008).

A amburana, Amburana cearensis, também conhecida por ambaurana, baru, cumarudo-ceará, cumaru-das-caatingas, imburana-de-cheiro, louro-ingá, umburana, cerejeira-rajada e outros nomes populares é uma dessas plantas. Utilizada para a terapia de algumas doenças como dores abdominais, reumatismo, tosse, bronquite, asma, como analgésico e espasmolítico (ALVES, ALVES \& PEREIRA, 2016; MELLO, 2013) possui alguns estudos que verificaram ação tóxica, tendo sido recomendados novos estudos a fim de se garantir a segurança no uso da mesma (SANTOS \& SOARES, 2018; MELLO, et al., 2013).

Dentre os meios para avaliação de produtos naturais provindos de plantas medicinais, 
tem-se os sistemas testes vegetais que funcionam como estudos preliminares dos efeitos de extratos vegetais permitindo a detecção de possíveis efeitos tóxicos, servindo como uma primeira triagem. O sistema teste Allium cepa é um desses testes (DIAS, et al., 2014; VERRI, MOURA \& MOURA, 2017). Santos e Soares (2018) citam que os efeitos produzidos por substâncias presentes nos extratos vegetais e seus derivados podem ser avaliados mediante diversos bioensiaios citogenéticos que apresentam resultados com considerável sensibilidade e confiabilidade, onde, se o agente gerar alterações no ciclo celular, bem como danos ao DNA acredita-se que há potencial citotóxico, genotóxico e mutangênico para diferentes tipos de células, sejam elas vegetais, animais e microbianas.

Assim, o presente trabalho tem por objetivo avaliar a implicação da exposição a fitoterápico e a diferentes concentrações do extrato aquoso de sementes de Amburana cearensis sobre proliferação celular em bioindicador

\section{FUNDAMENTAÇÃO TEÓRICA}

A amburana é considerada uma planta nativa da Caatinga nordestina e possui ampla distribuição na América do Sul, com registros de sua ocorrência na Argentina, Bolívia, Paraguai e Peru. Árvore pertencente à família Fabaceae apresenta caule ereto, que chega a atingir de 10 a 12 metros de altura. Sua madeira é utilizada na movelaria e suas cascas e sementes tem apreciáveis propriedades terapêuticas na medicina popular. Apresenta atividade anti-inflamatória, analgésica, antiespasmódica e broncodilatadora, sendo utilizada no tratamento de doenças como gripes, resfriados, asmas, bronquite, alívio sintomático de dorde-dente, dor de barriga, reumatismo, entre outras (ALVES, ALVES \& PEREIRA, 2016; MELLO, 2013).

Vários compostos já foram isolados e identificados da Amburana cearensis e incluem ácido protocatecuico, cumarinas, flavonoides, glicosídeos fenólicos, dentre outros (ALVES, ALVES \& PEREIRA, 2016). Hoje, sabe-se que plantas medicinais, da mesma forma que os medicamentos sintéticos, possuem grupos de compostos farmacologicamente ativos que atuam no organismo (PERON, et al., 2008). No Brasil, essas plantas têm seu uso promovido pelo difícil acesso da população à assistência médica e farmacêutica, pelo custo dos medicamentos industrializados e pela tendência dos consumidores a utilizarem produtos de origem natural. No entanto, de forma equivocada, muitas vezes as plantas medicinais são utilizadas de forma indiscriminada, sem preocupação acerca de efeitos colaterais e/ou tóxicos (MACEDO et al., 2014).

Assim, o emprego dessas plantas exige seu conhecimento, para avaliação de suas 
potencialidades terapêuticas, tóxicas e para formulação de uma estratégia de uso adequada (PERON et al., 2008), estudos como esses servem para estabelecer a atividade, esclarecer mecanismos de ação, ou mesmo identificar componentes ativos e investigar os possíveis efeitos tóxicos de diferentes espécies vegetais dando segurança no uso, bem como servindo, também, para interesses farmacológicos (BELCAVELLO et al., 2012).

Dentre as formas de avaliar os efeitos de substâncias presentes nos produtos naturais, principalmente extratos vegetais e seus derivados, tem-se diversos bioensaios que apresentam considerável sensibilidade e confiabilidade dos resultados. O teste de Allium cepa destaca-se entre esses testes, sendo muito utilizado no monitoramento de genotoxicidade, citotoxicidade e toxicidade de produtos naturais devido sua alta sensibilidade e correlações com outros testes. Ele é considerado uma importante ferramenta e biomarcador no monitoramento da toxicidade de extratos e infusões de plantas medicinais e os resultados têm indicado como principais efeitos o aumento ou diminuição da proliferação celular, bem como estabelecer que muitas plantas podem apresentar efeito mutangênico e antimutangênico (VERRI, MOURA \& MOURA, 2017).

Esse bioensio é considerado uma das abordagens mais eficientes e é rotineiramente usado para determinar os efeitos tóxicos de compostos químicos no ambiente; foi validado por muitos pesquisadores que realizaram esse teste de forma conjunta à testes em animais in vivo e obtiveram resultados similares, o que proporciona que este teste traga informações valiosas para a saúde humana. Associa-se como vantagens a esse teste, sua alta sensibilidade e relação custo-benefício, possibilidade de medição de parâmetros macroscópicos e microscópicos e uma boa correlação com mamíferos (DIAS et al., 2014).

A utilização de bioensaios biológicos vegetais para o monitoramento da bioatividade de extrato, frações e compostos isolados de plantas têm sido incorporados frequentemente à identificação e monitoramento de substâncias potencialmente tóxicas. A citotoxicidade de uma substância pode ser avaliada por meio da verificação de alterações no processo de divisão celular sobre o organismo-teste e pela incidência de mutações cromossômicas (SILVA et al., 2013).

Muitas plantas são úteis de forma medicinal, no entanto é necessário realizar avaliações de toxicidade com a avaliação do índice mitótico, para a verificação do desenvolvimento normal das células do organismo e assim correlacionar com a seguridade no uso das mesmas pela população, uma vez que a mesma, por vezes, faz uso exagerado de determinada planta devido à crença popular de que não causa mal algum, pelo simples fato desta ser de origem natural (PORTIS et al., 2016). 
Pesquisas realizadas por Mello et al., (2013) verificaram que o extrato aquoso da amburana comprometeu o índice mitótico e provocou gradativo efeito genotóxico em meristemas radiculares de cebola; Santos e Soares (2018) verificaram efeito citotóxico pela diminuição do índice mitótico e ocorrência de apoptose das células meristemáticas de alface, ambos os trabalhos observando o efeito do extrato de amburana sobre os bioindicadores vegetais ao longo do aumento do tempo de exposição ao extrato aquoso das sementes dessa planta medicinal. A espécie também causou prejuízos na germinação, no crescimento radicular e no desenvolvimento de outras diferentes espécies vegetais (MANO, 2006; SILVA et al., 2006; FELIX, ONO, ARAÚJO, 2010).

Dessa forma, visto que a população faz amplo uso de fitomedicamentos e que ainda se carece de estudos para avaliar a sua toxicidade potencial, os quais podem apresentar vários agravos à saúde, investigações acerca dos efeitos produzidos por vegetais utilizados na medicina popular são de extrema importância (BELCAVELLO, et al., 2012; SANTOS \& SOARES, 2018).

\section{METODOLOGIA}

Este trabalho é de natureza quantitativa, do tipo experimental e foi conduzido no Laboratório de Citogenética da Universidade Estadual do Sudoeste da Bahia (UESB) Campus de Vitória da Conquista/BA.

As sementes de Amburana cearensis foram obtidas por coleta em árvores matrizes localizadas na Fazenda Santo Antônio das Flores, situada no Município de Anagé, BA; o fitoterápico medicinal foi adquirido em compra via internet em site de produtos naturais; e o glifosato, utilizando o produto comercial Roundup, cuja concentração nesse produto é de $36 \%$ $(\mathrm{m} / \mathrm{v})$, tendo sido a concentração da solução utilizada como tratamento ajustada para $15 \%$ após diluição em água destilada no momento do uso.

rcado local; retirou-se as cascas externas e que se encontravam secas e, com objeto cortante, removeu-se o excesso de raízes mortas a fim de facilitar o processo de enraizamento. Em seguida os bulbos foram submetidos a lavagem em água corrente e após remoção do excesso de umidade foram colocadas para enraizar. Para isso, inseriu-se 3 hastes de madeira nas laterais de cada bulbo de cebola de forma a mantê-los equilibrados sobre copos descartáveis e com a parte basal em contato com a água destilada contida nos mesmos. Após emissão das raízes, preparou-se, então, para exposição aos tratamentos.

As três diferentes concentrações do extrato aquoso de A. cearensis foram preparadas por meio de maceração mecânica a seco das sementes e trituração em liquidificador para 
melhor refinamento das mesmas, obtido o macerado, realizou-se pesagem e transferência de 2,5g, 5,0g, e, 7,5g de macerado para 3 respectivos béqueres contendo, cada um, $250 \mathrm{~mL}$ de água destilada fervente, mantendo sobre fonte de calor equivalente à fogo baixo por 10 minutos; após homogeneização, aguardou-se esfriamento em temperatura ambiente e, então, as soluções foram coados em papel filtro. Obteve-se os extratos nas concentrações finais de 10g. $\mathrm{L}^{-1}$ (usual), 20g.L $\mathrm{L}^{-1}$, e 30g.L $\mathrm{L}^{-1}$, respectivamente (LORENZI e MATOS, 2002; RECEITA NATURAL, 2019).

O experimento, configurado em delineamento inteiramente casualizado (DIC), contou com 6 tratamentos e cada tratamento com 4 repetições ( 4 bulbos), totalizado 24 parcelas (24 bulbos), expondo-se as raízes aos tratamentos por período de 24 horas.

O tratamento 1 (T1) - testemunha ou controle negativo, consistiu na exposição das raízes apenas à água destilada; o Tratamento 2 (T2) na exposição das raízes ao extrato aquoso de A. cearensis na concentração de $10 \mathrm{~g} . \mathrm{L}^{-1}$; o Tratamento 3 (T3) na exposição ao extrato na concentração de 20g.L -1 $^{-1}$ o Tratamento 4 (T4) na exposição ao extrato aquoso de A. cearensis na concentração de $30 \mathrm{~g} . \mathrm{L}^{-1}$; o Tratamento 5 (T5) consistiu na exposição das raízes ao fitoterápico; e, o Tratamento 6 (T6) - controle positivo - na exposição ao glifosato na concentração de $15 \%$. Para realização dessa exposição a água destilada dos recipientes em que os bulbos se encontravam para enraizar foi substituída pelos respectivos tratamentos, mantendo-se as raízes imersas. As soluções foram preparadas no dia de sua utilização.

Findado o tempo de exposição, as raízes foram coletadas e passaram por três lavagens de 10 minutos em água destilada e fixadas em carnoy (3 metanol: 1 ácido acético) realizandose 3 trocas em intervalos de 15 minutos, após terceira troca, manteve-se o material na solução que foi colocado em ambiente com refrigeração $\left(-6^{\circ} \mathrm{C}\right)$ por, no mínimo, 24 horas e assim permanecendo até momento de uso.

Para o preparo das lâminas, as radículas foram retiradas do carnoy e lavadas 3 vezes em água destilada com intervalos de 5 minutos. Em seguida, foram submetidas à hidrólise em $\mathrm{HCl} 1 \mathrm{~N}$ a $60^{\circ} \mathrm{C}$ por 8 minutos. A hidrólise foi interrompida em água destilada gelada e os meristemas foram transferidos para reativo de Schift para coloração. Cada lâmina foi confeccionada gotejando-se ácido acético $45 \%$ sobre a radícula com posterior excisão da região meristemática; após obter três meristemas radiculares por repetição, o material foi coberto com lamínula, realizando-se batidas sequenciais sobre a mesma e, posteriormente, envolveu-se o conjunto lâmina-lamínula com papel toalha para aplicação de pressão com o polegar a fim de favorecer o espalhamento das células e retirada do excesso de ácido acético (GUERRA e SOUZA, 2003, modificado). 
As lâminas foram observadas com auxílio de microscópio óptico Nova Optical Systems, com objetiva de 40X. Para realização do cálculo do Índice Mitótico, contou-se o número de células em cada fase da divisão mitótica (intérfase, prófase, metáfase, anáfase e telófase) e dividiu-se pelo número total de células analisadas e o resultado foi multiplicado por 100. Analisou-se 1 lâmina por repetição, observando-se 2000 células em cada uma, dessa forma totalizando 8000 células por tratamento.

As análises estatísticas foram realizadas por meio do teste de Cochran para avaliação da homogeneidade e teste de Lilliefors para avaliação da normalidade, os dados foram transformados e submetidos a análise de variância (teste F) e as médias obtidas dos diferentes tratamentos comparadas pelo teste Tukey a 5\% de probabilidade, utilizando-se o programa SAEG (Sistema de Análises Estatísticas e Genétias), versão 9.1, Ribeiro e Junior (2001).

\section{RESULTADOS E DISCUSSÃO}

A Tabela 1 mostra a análise de variância apresentando os quadrados médios daquelas características analisadas cujos valores foram significativos, dessa forma, as fases de metáfase, prófase, anáfase e intérfase apresentam diferenças significativas em função dos tratamentos, bem como o Índice Mitótico.

Tabela 1: Análise de variância e coeficiente de variação das características prófase (PRÓF), metáfase (MET), anáfase (ANÁF), interfase (INTER) e Índice Mitótico (IM) dos meristemas radiculares de cebola submetidas aos tratamentos Testemunha/controle negativo T1 (água destilada), T2, T3, T4 (T2 (extratos aquosos de amburana nas concentrações de $10 \mathrm{~g} . \mathrm{L}^{-1}, 20 \mathrm{~g} . \mathrm{L}^{-1}, 30 \mathrm{~g} . \mathrm{L}^{-1}$, respectivamente), T5 (fitoterápico a base de amburana) e Controle positivo T6 (glifosato a 15\%). Vitória da Conquista, BA. 2019.

\begin{tabular}{lcccccc}
\hline \multirow{2}{*}{ FV } & \multirow{2}{*}{ GL } & \multicolumn{5}{c}{ QUADRADOS MÉDIOS } \\
\cline { 3 - 7 } & & PRÓF & MET & ANÁF & INTER & IM \\
\hline TRATAMENTO & 5 & 85,4426 & 12,2370 & 1,4176 & 0,2177 & 4,8550 \\
\hline RESÍDUO & 18 & 0,8724 & 0,1510 & 0,2770 & 0,2924 & 0,3559 \\
\hline CV\% & & 20,44 & 19,29 & 91,21 & 0,26 & 12,38 \\
\hline
\end{tabular}

Fonte: Própria (2019).

A Tabela 2 mostra o comportamento das médias dessas características analisadas nos meristemas radiculares de cebola em relação aos tratamentos a que foram expostas. Em virtude da necessidade de transformação dos dados, as médias originais se encontram entre parênteses. Analisando os dados de metáfase, nota-se que o controle negativo, testemunha, em que as raízes foram submetidas apenas a água destilada, foi o que apresentou maior média de células em metáfase, seguida do tratamento em que os meristemas radiculares foram expostos ao fitoterápico, não havendo diferença significativa entre os demais tratamentos que obtiveram as menores médias de células na fase de metáfase.

Comportamento semelhante ocorre para a fase de prófase, diferindo apenas pelo fato 
de que o tratamento em que as raízes foram expostas ao extrato aquoso na concentração de $30 \mathrm{~g} . \mathrm{L}^{-1}$ obteve média de células em fase de prófase superior ao controle positivo $(15 \%$ de glifosato), no entanto, ambos não diferem estatisticamente das concentrações de 10 e $20 \mathrm{~g} . \mathrm{L}^{-1}$.

Tabela 2: Número de células em prófase, metáfase, anáfase, interfase e Índice Mitótico (IM) dos meristemas radiculares de cebola submetidas aos tratamentos Testemunha/controle negativo T1 (água destilada), T2, T3, T4

(T2 (extratos aquosos de amburana nas concentrações de 10g.L ${ }^{-1}, 20 \mathrm{~g} . \mathrm{L}^{-1}, 30 \mathrm{~g} . \mathrm{L}^{-1}$, respectivamente), T5

(fitoterápico a base de amburana) e Controle positivo T6 (glifosato a 15\%). Vitória da Conquista, BA. 2019.

\begin{tabular}{|c|c|c|c|c|c|}
\hline TRATAMENTO & PRÓFASE & METÁFASE & ANÁFASE & INTERFASE & IM (\%) \\
\hline Testemunha & $\begin{array}{c}11,562 a^{*} \\
(134,1)\end{array}$ & $\begin{array}{c}4,759 \mathrm{a}^{*} \\
(22,5)\end{array}$ & $\begin{array}{c}-0,257 b^{* * *} \\
(8,80)\end{array}$ & $\begin{array}{l}6,551 \mathrm{c}^{*} \\
(1812,5)\end{array}$ & $\begin{array}{c}3,237 \mathrm{a}^{*} \\
(10,04)\end{array}$ \\
\hline Extrato 10g.L $\mathrm{L}^{-1}$ & $\begin{array}{c}0,974 \mathrm{~cd}^{*} \\
(0,53)\end{array}$ & $\begin{array}{c}0,825 \mathrm{c}^{*} \\
(0,22)\end{array}$ & $\begin{array}{c}0,909 \mathrm{ab}^{* *} \\
(0,22)\end{array}$ & $\begin{array}{l}6,724 a^{*} \\
(1999,6)\end{array}$ & $\begin{array}{c}0,739 \mathrm{c}^{*} \\
(0,05)\end{array}$ \\
\hline Extrato 20g.L $\mathrm{L}^{-1}$ & $\begin{array}{c}2,048 \mathrm{~cd}^{*} \\
(4,90)\end{array}$ & $\begin{array}{c}0,807 \mathrm{c}^{*} \\
(0,18)\end{array}$ & $\begin{array}{c}1,000 \mathrm{a}^{* *} \\
(0,00)\end{array}$ & $\begin{array}{l}6,721 \mathrm{a}^{*} \\
(1997,6)\end{array}$ & $\begin{array}{c}0,855 \mathrm{c}^{*} \\
(0,25)\end{array}$ \\
\hline Extrato 30g.L $\mathrm{L}^{-1}$ & $\begin{array}{c}2,966 \mathrm{c}^{*} \\
(9,64)\end{array}$ & $\begin{array}{c}1,327 \mathrm{c}^{*} \\
(1,41)\end{array}$ & $\begin{array}{c}0,930 \mathrm{a}^{* *} \\
(0,19)\end{array}$ & $\begin{array}{l}6,716 a^{*} \\
(1989,9)\end{array}$ & $\begin{array}{c}1,013 \mathrm{c}^{*} \\
(0,56)\end{array}$ \\
\hline Fitoterápico & $\begin{array}{c}9,166 \mathrm{~b}^{*} \\
(83,91)\end{array}$ & $\begin{array}{c}3,660 b^{*} \\
(13,1)\end{array}$ & $\begin{array}{c}-0,119 \mathrm{ab}^{* *} \\
(9,38)\end{array}$ & $\begin{array}{l}6,618 b^{*} \\
(1871,4)\end{array}$ & $\begin{array}{c}2,594 b^{*} \\
(6,26)\end{array}$ \\
\hline Glifosato $15 \%$ & $\begin{array}{c}0,707 \mathrm{~d}^{*} \\
(0,00)\end{array}$ & $\begin{array}{c}0,707 \mathrm{c}^{*} \\
(0,00)\end{array}$ & $\begin{array}{c}1,000 \mathrm{a}^{* *} \\
(0,00)\end{array}$ & $\begin{array}{c}6,725 \mathrm{a}^{*} \\
(2000)\end{array}$ & $\begin{array}{c}0,707 \mathrm{c}^{*} \\
(0,00)\end{array}$ \\
\hline
\end{tabular}

Transformação: $* * \operatorname{Cos}(\mathrm{x}) ; * \sqrt{x+0,5}$. Médias seguidas de mesma letra na coluna não diferem entre si pelo teste Tukey $(\mathrm{P}>0,05)$. Fonte: Própria (2019).

Em relação a fase de anáfase, o grupo testemunha obteve maior média de células nessa fase em relação ao controle positivo e aos tratamentos em que as raízes foram expostas às concentrações de 20 e $30 \mathrm{~g} . \mathrm{L}^{-1}$, a concentração de $10 \mathrm{~g} \cdot \mathrm{L}^{-1}$ e a exposição ao fitoterápico levou a médias que não diferem entre os tratamentos.

Quanto à fase de interfase, as menores médias foram obtidas para o tratamento testemunha, seguido do tratamento em que se expôs ao fitoterápico, sendo as maiores médias obtidas para os tratamentos em que se expôs às diferentes concentrações do extrato aquoso de amburana e ao controle positivo ( $15 \%$ de glifosato), sendo as médias desses tratamentos estatisticamente iguais. Esse resultado está diretamente relacionado ao obtido na análise do índice mitótico, quanto maior o número de células em interfase, menor será o índice mitótico e, por isso obteve-se, então, maior índice mitótico no tratamento testemunha, seguido do tratamento com exposição ao fitoterápico e, por fim, os tratamentos que consistiram na exposição às três diferentes concentrações do extrato aquoso de amburana e ao glifosato a $15 \%$, tratamentos estes que não diferiram entre si.

Tais resultados permitem verificar que a exposição das raízes dos bulbos de cebola por 24 horas a qualquer uma das três concentrações do extrato aquoso de sementes de amburana levou a brusca queda no índice mitótico em relação ao tratamento testemunha, evidenciando ação citotóxica uma vez que afetou negativamente a divisão celular equiparando-se ao tratamento controle positivo. Nota-se que a exposição ao fitoterápico também levou a redução 
do índice mitótico, de uma maneira não tão severa quanto os extratos, no entanto, a concentração de amburana no fitoterápico comercial não é informada.

Redução do índice mitótico também foi verificada por Dias et al, (2014) ao analisar o efeito genotóxico e antiproliferativo de Mikania cordifolia sobre o ciclo celular de Allium сера relatando atividade antiproliferativa associando essa redução a grande quantidade, dentre outros compostos, de cumarina (1,2-benzenopirona) e flavonoides presentes no gênero Mikania e também relatados como presentes na amburana (ALVES, ALVES \& PEREIRA, 2016).

Silva et al, (2013) utilizando sistema teste Allium cepa como bioindicador de citotoxicidade de substâncias usadas na conserva, obteve efeito citotóxico caracterizado pela redução do índice mitótico apenas nas maiores concentrações por eles empregues. Já Macedo et al, (2014) realizando estudo da citogenotoxicidade de extrato de quiabo também pelo teste Allium cepa, não obteve nenhuma alteração que pudesse ser indicativo de toxicidade do quiabo tanto em baixas ou em altas concentrações o que considerou como seguridade para o uso dessa planta pela população.

Santos et al, (2018) relatam que os efeitos de chás, infusões ou soluções extrativas de plantas medicinais devem ser monitoradas utilizando ensaios toxicológicos, destacando-se os genotóxicos e/ou mutengênicos, objetivando orientar os usuários sobre possíveis consequências para a saúde.

Aspecto geral das células meristemáticas de cebola em virtude dos tratamentos a que foram submetidas pode ser verificado na Figura 1. Conforme apresentado em dados numéricos na Tabela 2, pode-se observar maior intensidade de células em divisão na Figura 1A, que foi submetida apenas à água destilada. Ao observar a Figura 1B, nota-se que praticamente cessa a divisão celular, bem como ocorre na Figura 1D, nessa nota-se ainda que além de afetar o processo de divisão celular a morfologia das mesmas também foi prejudicada, onde as células apresentam núcleos mais deformados, em decorrência do efeito do tratamento a base de glifosato. Observando a Figura 1C, verifica-se novamente processo de divisão celular, esse tratamento corresponde ao tratamento em que as raízes foram expostas ao fitoterápico, onde a redução do índice mitótico não foi tão drástica quanto em comparação com o que ocorreu em decorrência dos extratos e do controle positivo.

Experimento realizado por Santos et al, (2018) avaliando a ação citotóxica, genotóxica e mutangênica do extrato de Morinda citrifolia em diferentes concentrações sobre o teste Allium cepa, utilizando água mineral como controle negativo e paracetamol como controle positivo, observaram que todas as concentrações do extrato testado levaram a toxicidade sobre 
o sistema teste Allium cepa evidenciado pela inibição dos meristemas das raízes diminuição significativa do número de mitoses observadas nos tratamentos à medida que houve aumento na concentração do extrato da planta.

Figura 1: Aspecto geral das células meristemáticas de cebola submetidas aos tratamentos Testemunha/controle negativo T1 (água destilada) Figura 1A; T2, T3, T4 (aos extratos aquosos de amburana nas concentrações de 10g.L $\mathrm{L}^{-1}, 20 \mathrm{~g} . \mathrm{L}^{-1}, 30 \mathrm{~g} . \mathrm{L}^{-1}$, respectivamente), sendo representados pela Figura 1B; T5 (fitoterápico a base de amburana) Figura 1C; e Controle positivo T6 (glifosato a 15\%) Figura 1D. Vitória da Conquista, BA. 2019.
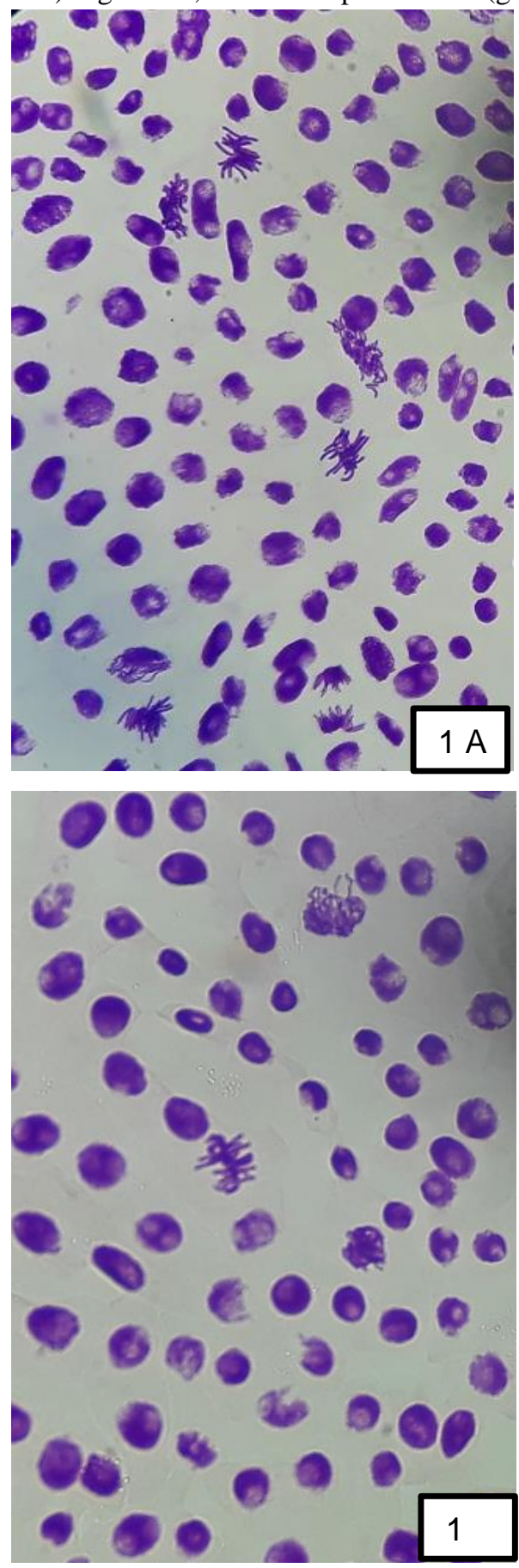
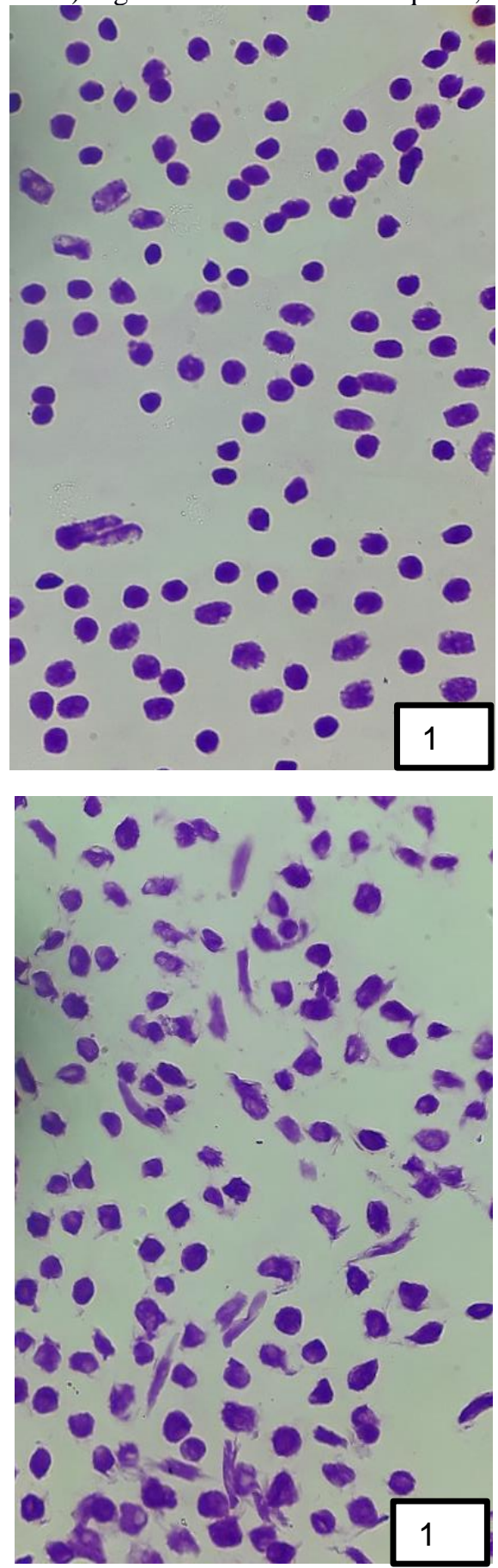

Coelho et al, (2013), avaliando compostos fenólicos e potencial genotóxico e antiproliferativo do extrato de erva-do-brejo (Echinodorus longiscapus Arech) em duas 
diferentes concentrações comparando com controle negativo - água - e controle positivo glifosato a $15 \%$ - mostraram que a espécie possui potencial antiproliferativo com o aumento da concentração e consequente aumento nos constituintes fitoquímicos, o que foi evidenciado pela redução do índice mitótico.

Em estudos realizados por Mello et al, (2014) utilizando a concentração de 23,4 g.L -1 $^{-1}$ do extrato aquoso de sementes de amburana levou a decréscimo do índice mitótico a medida que se aumentou o tempo de exposição ao extrato e relataram aumento gradativo de genotoxicidade. Já Santos e Soares (2018) utilizando a concentração de 20,0 g.L.-1 do extrato aquoso verificaram ação citotóxica tanto pela redução do índice mitótico quanto pelo aumento da porcentagem de apoptose também em relação ao aumento do tempo de exposição, relatando serem necessários maiores cuidados, uma vez que os resultados obtidos para a presença de substancias tóxicas não necessariamente desqualificam o seu uso medicinal, mas vem mostrar a necessidade de estudos para determinar dosagens, avaliar efeitos cumulativos ou dizer se são impróprias para o consumo.

\section{CONCLUSÕES}

As três diferentes concentrações (10 g. ${ }^{\mathrm{L}-1}, 20 \mathrm{~g} .^{\mathrm{L}-1}$ e $\left.30 \mathrm{~g} .^{\mathrm{L}-1}\right)$ do extrato aquoso de Amburana cearensis bem como o fitoterápico a base de amburana levaram a redução do Índice Mitótico, dessa forma afetando proliferação celular em bioindicador evidenciando efeito citotóxico.

\section{REFERÊNCIAS}

ALVES, H. B.; ALVES, H. B.; PEREIRA, F. R. A. Aspectos químicos e farmacológicos do cumaru (Amburna cearensis): um fitoterápico próprio do semiárido. I congresso Internacional da Diversidade do Semiárido. 2016.

BECAVELLO, L.; CUNHA, M.R.H.; ANDRADE, M.A.; BATITUCCI, M.C. Citotoxidade e danos ao DNA induzidos pelo extrato de Zornia diphylla, uma planta medicinal. Natureza online, 2012.

COELHO, A. P. D.; FRESCURA, V. D.S.; MAMBRI, A. P.; BOLIGON, A. A.; TEDESCO, S. B. Avaliação dos compostos fenólicos e potencial genotóxico e antiproliferativo do extrato de Echinodorus longiscapus Arech. Enciclopédia Biosfera, Centro Científico conhecer Goiânia, v.9, n.16, p.2698. 2013.

DIAS, M.G.; CANTO-DOROW, T.S.; COELHO, A.P.D.; TEDESCO, S.B. Efeito genotóxico e antiproliferativo de Mikania cordifolia (L. F.) Willd. (Asteraceae) sobre o ciclo celular de Allium cepa (L.). Revista Brasileira de Plantas Medicinais, v.16, n.2, p.202-208, 2014. 
FELIX, R. A. Z.; ONO, E. O.; ARAÚJO, F. P. Efeitos alelopáticos de extrato de Amburana cearensis na germinação de sementes de rabanete. Cultivando o Saber. Cascavel, v.3, p.18-31, 2010.

GUERRA, M.; SOUZA, M.J. Como observar cromossomos: um guia de técnica em citogenética vegetal, animal e humana. São Paulo: Funpec. 2003, 131p.

LORENZI H.; MATOS F.J.A. Plantas medicinais no Brasil: nativas e exóticas. Nova Odessa: Plantarum. 2002, 512p.

MACEDO, J.F.M.; SILVA, M.S.; BATISTA, N.J.C.; UCHOA, V.T.; ALVES, W.S. Estudo da genotoxicidade do extrato d Abelmoshus esculentus (quiabo) pelo teste Allium cepa. Revista Saúde em Foco, Teresina, v.1, art.2, p.15-28, jan./jul. 2014.

MANO, A. R. O. 2006. Efeito alelopático do extrato aquoso de sementes de cumaru (Amburana cearensis S.) sobre germinação de sementes, desenvolvimento e crescimento de plântulas de alface, picão-preto e carrapicho. Dissertação Mestrado em Agronomia, Centro de Ciências Agrárias, Universidade Federal do Ceará, Fortaleza, Brasil. 102 p.

MELLO, V.S.; VIEIRA, A.; MIRANDA, D.P.; TEIXEIRA, A.D.; KARSBURG, I.V. Genotoxicidade da infusão de Amburana cearensis (Allemão) A. C. Smith. Pelo sistema teste Allium cepa.In: I Seminário de Biodiversidade e agroecossistemas Amazônicos, Alta Floresta - MT. Genética e melhoramento, 2013.

PERON, A. P.; MARCOS, M. C.; VICENTINI, V. E. P. Avaliação do potencial citotóxico dos chás de Camellia sinensis L. e Cassia angustifólia vahl em sistema teste vegetal. Arq. Ciênc. Saúde Unipar, Umurama, v.12, n.1, p.51-54, jan./abr. 2008.

PORTIS, I. G.; FIGUEIREDO, F. R. G.; PENA, R. V.; HANUSCH, A. L.; SOUZA, L. P. de.; MACHADO, R. C.; SILVA, C. C. de.; CRUZ, A. D. de. Bioensaio citogenético para a caracterização da mutangenicidade e citotoxicidade da espécie Choclhospermium regium.

Refacer, v.5, n.1, 2016.

RECEITA NATURAL. Chá de emburana. Disponível em: $<<$ https://natural.enteernauta.com.br/cha-de-emburana $>>$.

SANTOS, M. D.; SOARES, B. F. Atividade Antimitótica e apoptótica provocadas por extrato de umburana em sistema teste vegetal. Anais de Evento. Artigo Completo. III Congresso Internacional das Ciências Agrárias. Jõao Pessoa, Paraíba. 08-13 dez. 2018.

SANTOS, I. M. C. dos.; MELO, H. M. de.; CARNEIRO, J. K. R.; OLIVEIRA, M. A. S. Avaliação citotóxica, genotóxica e mutangênica do extrato de Morinda citrifolia em diferentes concentrações sobre o teste Allium cepa. Revista de Ciências Médicas e Biológicas, Salvador, v.17, n.1, p. 40-45, jan./abr.2018.

SILVA, B.M. NISHIMUTA, H.A.; SANTOA, E.T.B.; COSTA, D.N.G.; ROSSI, A.A.B. Sistema teste Allium cepa como bioindicador de citotoxicidade de substâncias usadas na conserva de Olea europea L. In: I Seminário de Biodiversidade e Agroecossistemas Amazônicos, Alta Floresta - MT, 23 e 24 set. 2013. 
SILVA, W. A.; NOBRE, A. P.; LEITES, A. P.; SILVA, M. S. C.; LUCAS, R. C.; RODRIGUES, O. G. Efeito alelopático de extrato aquoso de Amburana cearensis A. Smith na germinação e crescimento de sementes de sorgo (Sorghum bicolor L.). Agropecuária científica no Semi-árido 2(1): 48-54, 2006.

VERRI, A. M.; MOURA, A. A.; MOURA, V. M. Testes citogenéticos na avaliação da genotoxicidade de produtos naturais provindos de plantas medicinais. Revista UNINGÁ Review, v.30, n.1, p.55-61, 2017. 


\title{
O USO DO PÓ DE ROCHA DA PEDRA CARIRI NO CRESCIMENTO INICIAL DE MUDAS DE PAU D'ARCO (Handroanthus impetiginosus (Mart. ex DC.)) IMPLANTADAS EM ÁREAS DEGRADADAS
}

\author{
EL USO DE POLVO DE ROCA DE PIEDRA CARIRI EN EL CRECIMIENTO \\ INICIAL DE LAS PLANTAS DE PAU D'ARCO (Handroanthus impetiginosus (Mart. ex \\ DC.)) IMPLANTADAS EN ZONAS DEGRADADAS
}
THE USE OF CARIRI STONE ROCK POWDER IN THE INITIAL GROWTH OF PAU D'ARCO (Handroanthus impetiginosus (Mart. ex DC.)) SEEDLINGS IMPLANTED IN DEGRADED AREAS

\author{
Ana Cláudia do Nascimento Silva ${ }^{1}$; Sayonara Rejane Lima Araújo ${ }_{2}^{2}$ Luiz Francinélio Cavalcante \\ Júnior $^{3}$; Josefa Maria Francieli da Silva ${ }^{4}$; Sebastião Cavalcante de Sousa ${ }^{5}$
}

DOI: https://doi.org/10.31692/978-65-991061-4-9.14-32

\begin{abstract}
RESUMO
O semiárido brasileiro vem sofrendo continua degradação ambiental, principalmente com o uso inadequado do solo, o que tem acarretado perdas consideráveis de produção nos diversos sistemas agrícolas no referido bioma. O presente estudo objetivou aplicar práticas de conservação do solo na implantação de sistemas agroflorestais no semiárido nordestino. As práticas de manejo avaliadas foram terraço de base estreita, pó da rocha pedra cariri em mudas de pau d'arco Handroanthus impetiginosus (Mart. ex DC.) Mattos. O experimento foi conduzido na comunidade de Triunfo, Nova Olinda- CE entre o período de março a junho de 2019 em delineamento inteiramente casualizado, com 5 estações envolvendo 4 terraços de base estreita, 4 tratamentos de pó de rocha: T1 - testemunha, T2$50 \mathrm{~g}$ de pó amarelo, T3- $50 \mathrm{~g}$ de pó cinza, T4- $25 \mathrm{~g}$ de pó amarelo $+25 \mathrm{~g}$ de pó cinza. A análise estatística foi realizada no programa SPSS Statistics. A análise do período hídrico apresentou $463 \mathrm{~mm}$ de chuvas e 3 períodos de déficits hídricos. A estação 3 entre os terraços 2 e 3 apresentou melhor crescimento no diâmetro do caule de plantas. A rochagem não apresentou diferenças significativas entre os tratamentos, mas na estação 3 o pó cinza apresentou melhor resultado. O terraço de base estreita apresentou resultado imediato no controle da erosão hídrica e na perda de água por escoamento superficial.
\end{abstract}

Palavras-Chave: Agroflorestas, Manejo de solo, Terraceamento

\section{RESUMEN}

La región semiárida brasileña ha sufrido una degradación ambiental continua, principalmente debido al uso inadecuado del suelo, lo que ha causado considerables pérdidas de producción en los diversos sistemas agrícolas en el bioma referido. El presente estudio tuvo como objetivo aplicar prácticas de conservación del suelo en la implantación de sistemas agroforestales en el semiárido del noreste. Las prácticas de manejo evaluadas fueron terrazas de base angosta, polvo de roca roca cariri en plántulas de pau d'arco Handroanthus impetiginosus (Mart. Ex DC.) Mattos. El experimento se realizó en la comunidad de Triunfo, Nova Olinda-CE entre marzo y junio de 2019 en un diseño completamente al azar, con 5 estaciones que involucran 4 terrazas de base angostas, 4 tratamientos de polvo de roca: control T1, T2- $50 \mathrm{~g}$ de polvo amarillo, T3- $50 \mathrm{~g}$ de polvo gris, T4- $25 \mathrm{~g}$ de polvo amarillo $+25 \mathrm{~g}$ de polvo gris. El análisis estadístico se realizó con el programa SPSS Statistics. El análisis del período de agua presentó $463 \mathrm{~mm}$ de lluvia y 3 períodos de déficit hídrico. La temporada 3 entre las terrazas 2 y 3 mostró un mejor crecimiento en el diámetro del tallo de la planta. La roca no mostró diferencias significativas entre tratamientos, pero en la temporada 3 el polvo gris mostró mejores resultados. La estrecha terraza de la base mostró un resultado inmediato en el control de la erosión y la pérdida de agua por la escorrentía.

Palabras Clave: Agroforestería, gestión de suelos, terrazas 


\begin{abstract}
The brazilian semi-arid region has suffered continuous environmental degradation, mainly due to the inadequate use of the soil, which has caused considerable losses of production in the various agricultural systems in this biome. The present study aimed to apply soil conservation practices in the implantation of agroforestry systems in the northeastern semi-arid region. The management practices evaluated were narrow base terrace, rock cariri stone powder in pau d'arco (Handroanthus impetiginosus (Mart. ex DC.)) Mattos. The experiment was conducted in the community of Triunfo, Nova Olinda-CE between march and june of 2019 in a completely randomized design, with 5 stations involving 4 terraces of narrow base, 4 treatments of rock dust: T1- control, T2- 50g of yellow powder, T3- 50g of gray powder, T4- 25g of yellow powder $+25 \mathrm{~g}$ of gray powder. Statistical analysis was performed in the SPSS Statistics program. The analysis of the water period showed $463 \mathrm{~mm}$ of rainfall and 3 periods of water deficits. Station 3 between terraces 2 and 3 showed a better growth in the stem diameter of plants. The rock powder did not present significant differences among the treatments but in season 3 the gray powder presented better results. The narrow base terrace presented an immediate result in the control of water erosion and loss of water by runoff.
\end{abstract}

Keywords: Agroforests, Soil management, Terrace

\title{
INTRODUÇÃO
}

O semiárido brasileiro abrange 1.262 municípios, $1.128 .697 \mathrm{Km}^{2}$ de área e 27.870.241 habitantes, sendo uma das regiões tropicais mais populosas dessa faixa climática, a vegetação predominantemente é a caatinga, composta de uma variedade de espécies arbóreas e arbustivas e, embora apresente alta diversidade biológica, vem suportando contínua degradação (GONZAGA et al., 2003).

A degradação ambiental é o resultado de um conjunto de ações e processos impactantes sobre o ambiente que, não respeitando a sua capacidade de suporte e/ou a sua aptidão, acarreta o comprometimento dos recursos naturais e, consequentemente, a qualidade de vida (LIMA, 1997). A agricultura é uma atividade que provoca essa degradação, pois à medida que é realizada sem critérios técnicos e sem práticas agronômicas adequadas pode trazer danos para o meio ambiente.

A utilização de espécies nativas para reflorestamento ou recomposição florística de áreas degradadas é de grande importância para reduzir o impacto ambiental gerado pela degradação e conservar a biodiversidade dessas áreas (CALDEIRA et al., 2008).

A erosão dos solos é um extenso, sério e crescente problema no Brasil, onde se perdem a cada ano milhões de toneladas de solo agrícola, devido à erosão e ao uso inadequado do solo (GRIEBELER, 2000).

A rochagem é uma prática importante para uma agricultura ecologicamente sustentável, por não ser um fertilizante industrializado. $\mathrm{O}$ pó de rocha possui um baixo valor agregado, sendo um insumo acessível tanto para o pequeno quanto para o grande produtor. (FERNANDES et al., 2010).

Diante do exposto, o presente estudo teve como objetivo avaliar a eficiência do pó de 
rocha da pedra cariri sobre o crescimento inicial de uma agrofloresta, implantada com pau d'arco (Handroanthus impetiginosus (Mart. ex DC.) Mattos), conduzida em terraços de base estreita.

\title{
FUNDAMENTAÇÃO TEÓRICA
}

\section{Semiárido Brasileiro}

O semiárido é um bioma que está presente em grande parte da região nordeste brasileira, o qual faz parte da vida dos nordestinos. Ele ainda é caracterizado pela aridez do clima e deficiência hídrica. Não se pode negar a existência do déficit hídrico, no entanto, isso não quer dizer, necessariamente, falta de chuvas, pois temos o semiárido mais chuvoso do planeta (MALVEZZI, 2007). "No semiárido brasileiro a evaporação é cerca de 3.000 $\mathrm{mm}$ /ano, três vezes maior do que a precipitação. Logo, o jeito de agasalhar a água de chuva é fundamental para aproveitá-la" (MALVEZZI, 2007, p. 10).

O semiárido está entrelaçado com o Nordeste, através da sua história, desde a sua criação. Silva (2006) diz que a primeira delimitação do semiárido foi estabelecida em 1936, com o polígono das secas, mas somente em 1988 foi que a área denominada semiárido passou a ter um conceito técnico, conforme menciona o mesmo (2006, p. 16):

\begin{abstract}
O conceito técnico de Semi-árido é decorrente de uma norma da Constituição Brasileira de 1988, mas, precisamente do seu Artigo 159, que instituiu o Fundo Constitucional de Financiamento do Nordeste (FNA). A norma constitucional manda aplicar no Semi-árido, 50\% dos recursos destinados ao fundo. A Lei 7.827, de 27 de setembro de 1989, regulamentando a Constituição Federal, define como Semi-árido a região inserida na área de atuação da Sudene, com precipitação pluviométrica média anual igual ou inferior a $800 \mathrm{~mm}$.
\end{abstract}

A precipitação pluviométrica do semiárido brasileiro é marcada pela variabilidade no espaço e no tempo, que, associada aos baixos totais anuais sobre a região, resulta na frequente ocorrência de dias sem chuva, ou seja, veranicos, e consequentemente, em eventos de "seca" (ZUFFO, 2019).

\section{Degradação ambiental}

De acordo com a Política Nacional do Meio Ambiente (Lei Federal $n^{\circ}$ 6.938/81), degradação ambiental é qualquer "alteração adversa das características do meio ambiente" (art. $3^{\circ}$, inciso II), neste sentido observa-se que trata de um "conceito amplo que abrange vários casos como prejuízo ao meio ambiente, ao bem-estar das pessoas, à biosfera, etc" (LIMA et al., 2004).

A degradação dos solos é a "alteração das propriedades do solo que acarreta efeitos negativos sobre uma ou várias funções do solo, a saúde humana ou o meio ambiente" (ISO 
11074- 1: 1996 apud SÁNCHES, 2006, p. 16). Os principais fatores da degradação do solo, o desmatamento, a agricultura, o superpastoreio, entre outros, constituindo em prejuízos econômicos, sociais e ambientais.

\section{Recuperação de áreas degradadas}

Áreas degradadas são definidas como ecossistemas que sofreram distúrbios que, pela amplitude, não têm a capacidade de se recuperarem até voltarem ao seu estado de equilíbrio dinâmico, perdendo a aptidão de se reorganizar e manter na essência as mesmas funções, estrutura e sustentabilidade (RODRIGUES et al., 2009; CURY; CARVALHO JR, 2011).

As atividades antrópicas, quando desenvolvidas desordenadamente, sem tomar em consideração aspectos conservacionistas, acarretam a degradação dos ecossistemas (VALCARCEL; SILVA, 1997). Nesses casos, em que a recuperação natural é muito lenta ou inexistente, a intervenção humana faz-se necessária, a fim de estabilizar e reverter os processos de degradação, estimulando e direcionando a sucessão natural (KAGEYAMA et al., 2003).

A recuperação de áreas degradadas (RAD) tem por objetivo permitir que o espaço danificado ou destruído volte a contar com recursos bióticos e abióticos suficientes para que se mantenha em equilíbrio, que pode ser atingido por meio da reintrodução de espécies nativas no ambiente que se pretende recuperar (RODRIGUES et al., 2009).

As presenças de árvores geram uma série de benefícios ao solo e ambiente, como a proteção contra a erosão, aumento da matéria orgânica, conservação da água, aumento de organismos benéficos ao solo, menor proliferação de pragas e doenças, menor ocorrência de plantas invasoras, conservação da biodiversidade, fauna e flora, proteção contra queimadas e sendo assim, imita um ecossistema florestal (COSTA, 2015).

A degradação dos solos é um problema que influencia todo o mundo e constitui um fenômeno de grande importância, em razão da rapidez com que se processa e pelo fato de acarretar grandes prejuízos para diversas atividades econômicas e para o meio ambiente, dentre as técnicas mais utilizadas pelos agricultores destacam-se o desmatamento, as queimadas e o preparo do solo, expondo o solo aos fatores climáticos intensificando a degradação (EDUARDO et al., 2013; SILVA, 2012).

Segundo Bertoni \& Lombardi Neto (2010), a erosão hídrica é a forma mais ativa do processo de degradação dos solos, ela consiste de uma série de transferências de energia e matéria provocadas por um desequilíbrio do sistema água/solo/cobertura vegetal, que resultam na perda progressiva de solo (DEMARCHI et al., 2019). Em consequência desses danos, 
torna-se essencial a aplicação de técnicas que permitam a conservação do solo.

Variadas práticas são utilizadas para controlar a erosão hídrica em solos agrícolas, sendo normalmente divididas em práticas edáficas, vegetativas e mecânicas. As práticas mecânicas são aquelas nas quais são utilizadas estruturas artificiais para a redução da energia do escoamento da água, sendo o terraceamento a difundida e utilizada (GRIEBELER, 2005).

Terraços são estruturas compostas por um dique e um canal, dispostos no sentido transversal à declividade do terreno, formando obstáculos físicos para reduzir a velocidade do escoamento superficial e ordenar o movimento da água sobre a superfície do solo (MAGALHÃES, 2013). Tem como objetivo conter as águas do escoamento superficial, reduzindo a velocidade do escoamento, armazenando a água no solo o que contribui para o abastecimento do lençol freático e reduz o efeito de veranicos (DENARDIN et al., 2011).

Os terraços são utilizados com a finalidade de reduzir a erosão porque a vertente é dividida em segmentos relativamente curtos, evitando que o escoamento superficial alcance velocidades erosivas, quando adequadamente planejados e construídos, podem atender a outra finalidade, como: aumentar a capacidade de retenção de água pelo solo para o uso das culturas (OLIVEIRA, 2010).

\section{Sistemas agroflorestais}

Sistemas agroflorestais (SAFs) são considerados como modelo sustentável de uso da terra, formados pelo plantio de espécies lenhosas perenes (árvores e arbustos) que se desenvolvem consorciadas com plantas herbáceas (vegetais, pastagens) ou animais, num arranjo espacial ou rotação para se beneficiar dos resultados ecológicos. (MONTAGNINI, 2005; HARVEY et al., 2008; ASSIS, 2008).

A escolha das espécies para compor um SAF está diretamente relacionada com o tipo de manejo do sistema e sua função, na recuperação de áreas degradadas, estas devem apresentar características intrínsecas às áreas a serem recuperadas (BENDITO et al. 2018).

Mesclar produtos madeireiros e não madeireiros pode ser a melhor escolha para o sucesso do empreendimento, pois proporciona fluxo de caixa maior ao agricultor, flexibilidade de comercialização e otimização de mão-de-obra (BENDITO et al. 2017).

\section{Pau-d'arco (Handroanthus impetiginosus (Mart. ex DC.) Mattos)}

Conhecida vulgarmente como pau d'arco, a espécie arbórea (Handroanthus impetiginosus (Mart. ex DC.) Mattos) cuja sinonímia é Tabebuia impetiginosa (Mart. ex DC.) tem origem nativa e pertence à família BIGNONIACEAE, podendo chegar a altura de 8 a 20 metros, com tronco de 60-90 cm de diâmetro, produz madeira de qualidade, tem importância 
econômica, medicinal, paisagística, e em programas de reflorestamento (SIQUEIRA FILHO et al., 2009).

Ocorre principalmente nos domínios fitogeográficos da Amazônia, Caatinga, Cerrado, Mata Atlântica e Pantanal, nas regiões Norte (Pará, Tocantins), Nordeste (Maranhão, Piauí, Ceará, Rio Grande do Norte, Paraíba, Pernambuco, Bahia, Alagoas, Sergipe), Centro-Oeste (Mato Grosso, Mato Grosso do Sul, Goiás e Distrito Federal) e Sudeste (Minas Gerais, Espírito Santo, Rio de Janeiro e São Paulo) (LORENZI, 1992; LOHMANN, 2012).

O pau d'arco (Handroanthus impetiginosus (Mart. ex DC.) Mattos) ocorre em locais com regime pluviométrico uniforme, porém aceita um déficit hídrico moderado, ocorre naturalmente em vários tipos de solo, cujos relevos podem ser desde planos a pouco ondulados, apresentado um melhor crescimento em solos com fertilidade química média a elevada, profundos, com boa drenagem (CARVALHO, 2003).

O desenvolvimento das mudas no campo é rápido, alcançando mais de 3,5 $\mathrm{m}$ aos dois anos (LORENZI, 1992). Devido à sua intensa exploração e por ser excelente para enriquecimento de capoeiras e vegetações empobrecidas é utilizada na recuperação de áreas degradadas (MAIA, 2004).

\section{Rochagem}

A Associação Nacional para a Difusão de Adubos (ANDA, 2018), relata a dependência do Brasil com relação à importação de fertilizantes. Dessa forma, é necessário encontrar mecanismos que possam diminuir esta dependência do mercado internacional. Com isso a tecnologia da rochagem pode-se configurar como excelente alternativa, uma vez que o Brasil é um país que possui diversidade de rochas que pode viabilizar o uso de diferentes tipos, em diferentes regiões para alcançar padrões de fertilidade compatíveis com as necessidades regionais e ainda facilitar mecanismos de desenvolvimento regional (LOPES, 2005).

A rochagem é uma prática que traz muitas vantagens para o desenvolvimento de diversas culturas na agricultura, quando comparada com fontes minerais altamente solúveis (THEODORO, et al., 2006), dentre as vantagens estão: não salinização do solo, a não absorção em excesso de potássio, assim beneficiando a absorção de cálcio e magnésio, menor lixiviação dos nutrientes, diminuição da fixação de fósforo solúvel pela presença de sílica, além da redução da mão de obra, pois com a aplicação do pó de rocha pode não haver necessidade frequente de adubar o solo, pois seu efeito é prolongado (AMPARO, 2003).

Para Theodoro et al. (2006) e Theodoro e Leonardos (2006) a viabilidade agronômica 
e econômica de fontes regionais de nutrientes do pó de rocha, também presente nos parques geológicos presentes na Chapada do Araripe, pode reduzir a ocorrência da agricultura migratória, sendo uma boa opção para os pequenos produtores, por serem mais acessíveis e de menor custo.

A região do Cariri cearense, constitui um importante polo mineral com a sua rica reserva de calcário laminado utilizado com pedra de revestimento sob o nome de "Pedra Cariri”, abrangendo principalmente os municípios de Santana do Cariri e Nova Olinda, esta atividade de exploração vem sendo desenvolvida há mais de 30 anos, gerando uma quantidade considerável de rejeitos (cerca de 70\%) (VIDAL; PADILHA; OLIVEIRA, 2015).

\section{METODOLOGIA}

\section{Caracterização da área de estudo}

O experimento foi conduzido na cidade de Nova Olinda- CE na comunidade Triunfo ( $7^{\circ} 08^{\prime} 47^{\prime \prime}$ S e $\left.39^{\circ} 43^{\prime} 02^{\prime \prime} \mathrm{W}\right)$, conforme Figura 1 . O clima caracteriza-se como tropical quente semiárido, com temperatura média entre 24 e $26^{\circ} \mathrm{C}$ e pluviometria anual de $682,7 \mathrm{~mm}$ (IPECE,2017). Sua geologia é composta por rochas Pré-Cambrianas do embasamento cristalino (quartzitos, xistos, gnaisses e migmatitos). No extremo sul ocorrem rochas sedimentares da bacia do Araripe, representadas por arenitos da Formação Mauriti (EoCambriano) e calcários da Formação Santana (Mesozóico) (CPRM, 1998).

O relevo tem a forma suave ondulada (6\%) e pouco dissecada da depressão sertaneja, produto da superfície de aplainamento em atuação no Cenozóico. As altitudes ficam próximas dos 500 metros acima do nível do mar. A vegetação predominante é caatinga arbórea ou floresta caducifólia espinhosa, encontrando-se também manchas de mata seca (floresta subcaducifólia tropical) (CPRM, 1998).

Na localidade encontra-se solos classificados como Luvissolos (SiBCS, 2018), os quais compreendem solos com elevada fertilidade natural, dotados de argilas com alta capacidade de retenção de íons trocáveis (argila de atividade alta) e saturação por bases também alta (elevada capacidade de retenção de nutrientes) nos horizontes sub-superficiais, sendo que áreas expressivas são encontradas no nordeste brasileiro, onde se distribuem principalmente na zona semiárida (MANZATTO et al. 2002).

\section{Precipitação em Nova Olinda}

A precipitação verificada no município de Nova Olinda, posto Nova Olinda (FUNCEME, 2019), entre o período de plantio e a primeira leitura que totalizou $410 \mathrm{~mm}$. Verificou-se que no dia do plantio, 23 de março, choveu $13 \mathrm{~mm}$ e ocorreu déficit hídrico no 
período de 16 a 23 de abril com duração de 8 dias.

Figura 1 - Mapa de localização do município

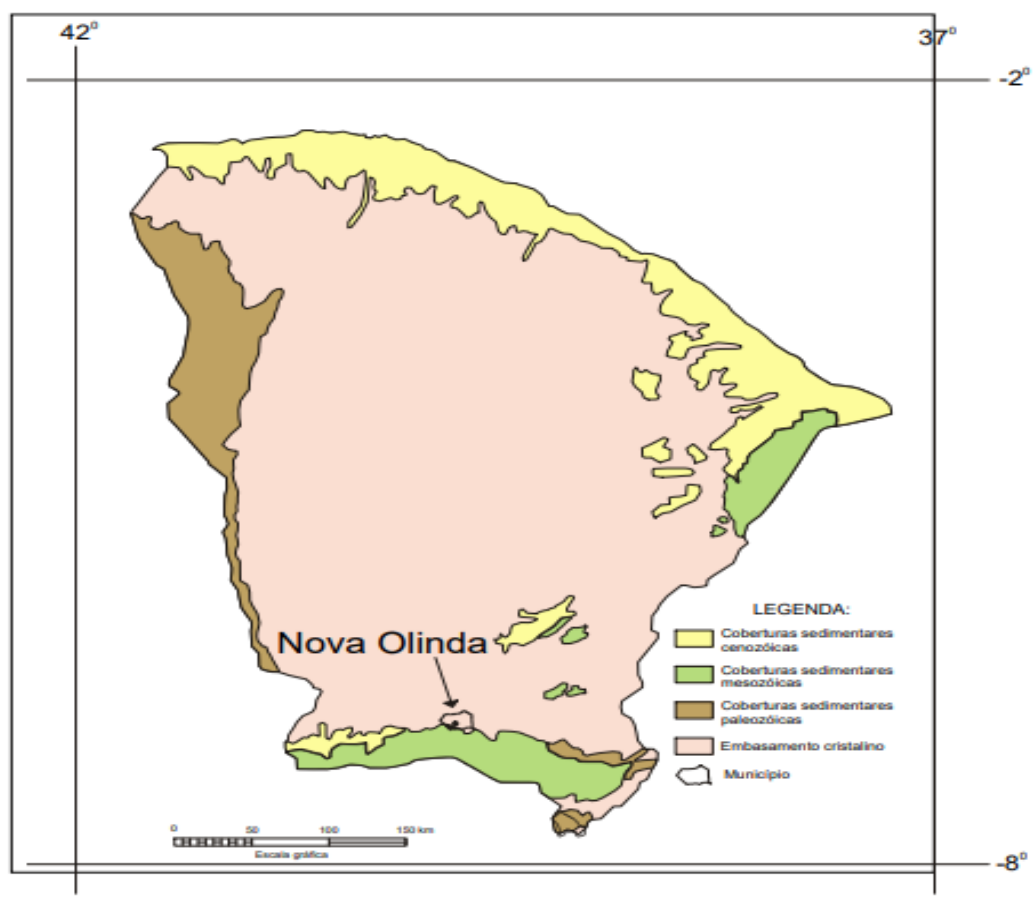

Fonte: CPRM (1998).

\section{Participação dos agricultores}

Foi realizada uma reunião no dia 13 de janeiro de 2019 com a Associação dos Criadores de Peixe de Triunfo (comunidade de Nova Olinda-CE) objetivando a sensibilização da pesquisa de recuperação de áreas degradadas e buscar a participação da comunidade.

\section{Implantação e delineamento experimental}

As sementes de pau d'arco utilizadas no experimento foram colhidas na safra de novembro de 2018, que foram semeadas em sacos plásticos de polietileno $(10 \mathrm{~cm}$ x $20 \mathrm{~cm})$, próprio para mudas contendo substrato, no dia 17 de fevereiro de 2019, pela associação dos criadores de peixe de Triunfo. As sementes emergiram 10 dias após a semeadura, permanecendo nos sacos até o dia 23 de março de 2019, totalizando 34 dias antes do plantio a campo.

Antes da instalação do experimento foi feito o terraceamento para construção de cada bloco (estações), o qual apresentou as seguintes dimensões: 0,30 $\mathrm{m}$ de largura, 0,30 $\mathrm{m}$ de profundidade, $0,30 \mathrm{~m}$ altura e $12 \mathrm{~m}$ de comprimento (Figuras 2 e 3). Os terraços foram distanciados um do outro em $20 \mathrm{~m}$, os quais foram posicionados na base de cada bloco. Eles foram construídos manualmente pelos próprios agricultores da associação, utilizando-se de 
enxada. Em seguida, o leito de semeadura foi preparado e adicionado o pó de rocha.

As mudas foram plantadas a campo no espaçamento de 5,5 metros entre plantas e 5,0 metros entre linhas (Figura 2) dispostas em delineamento experimental de blocos ao acaso, em cinco repetições, com cada unidade experimental composta por três plantas, totalizando 15 plantas por tratamento. Os tratamentos consistiram de uma testemunha (tratamento 1: T1), de $50 \mathrm{~g}$ do pó de rocha da pedra cariri amarelo (tratamento 2: T2), de 50g pó de rocha da pedra cinza (tratamento 3: T3) e de $25 \mathrm{~g}$ do pó de rocha da pedra cariri amarelo $+25 \mathrm{~g}$ do pó de rocha da pedra cariri cinza (tratamento 4: T4).

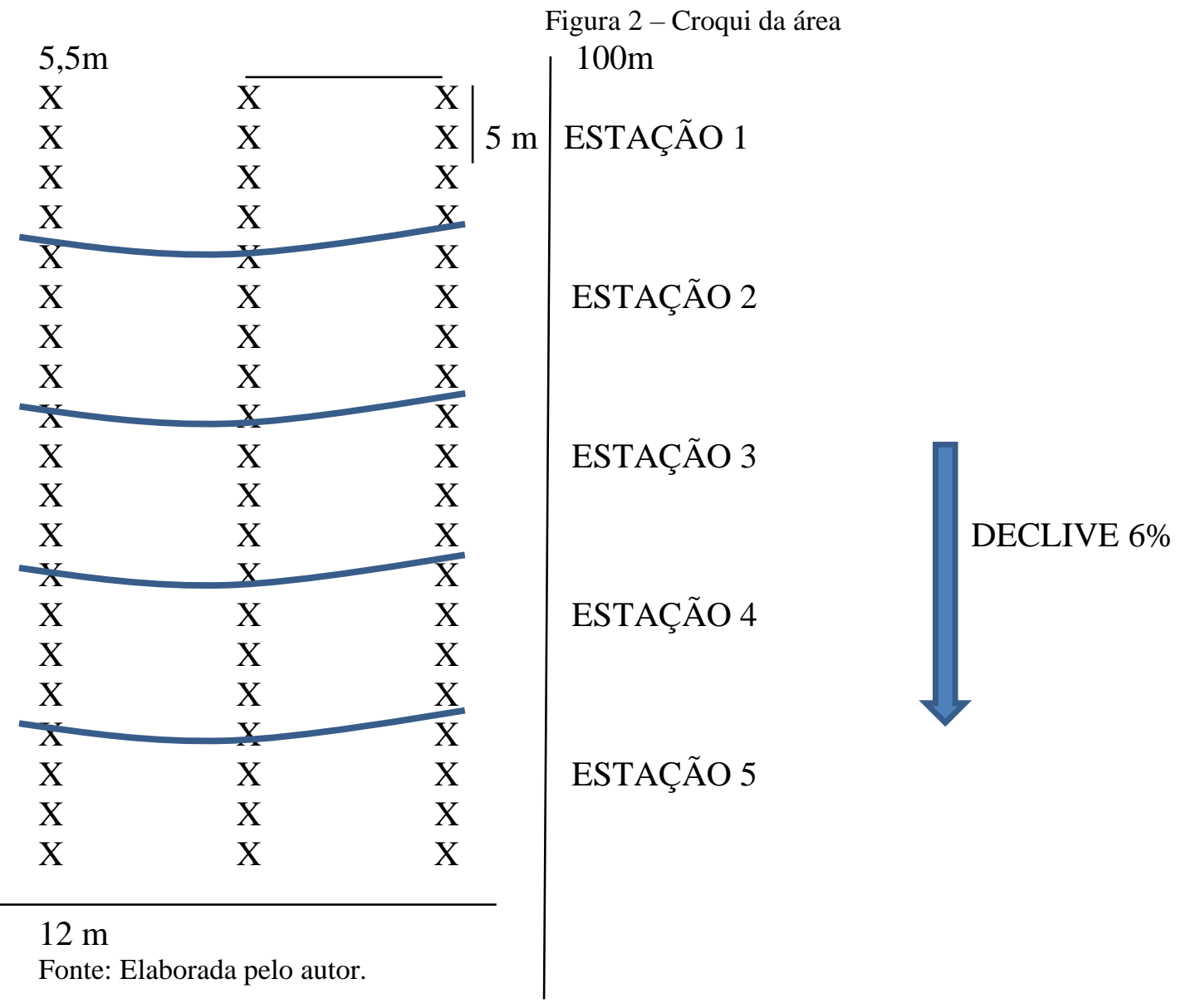


Figura 3 - Terraços de base estreita
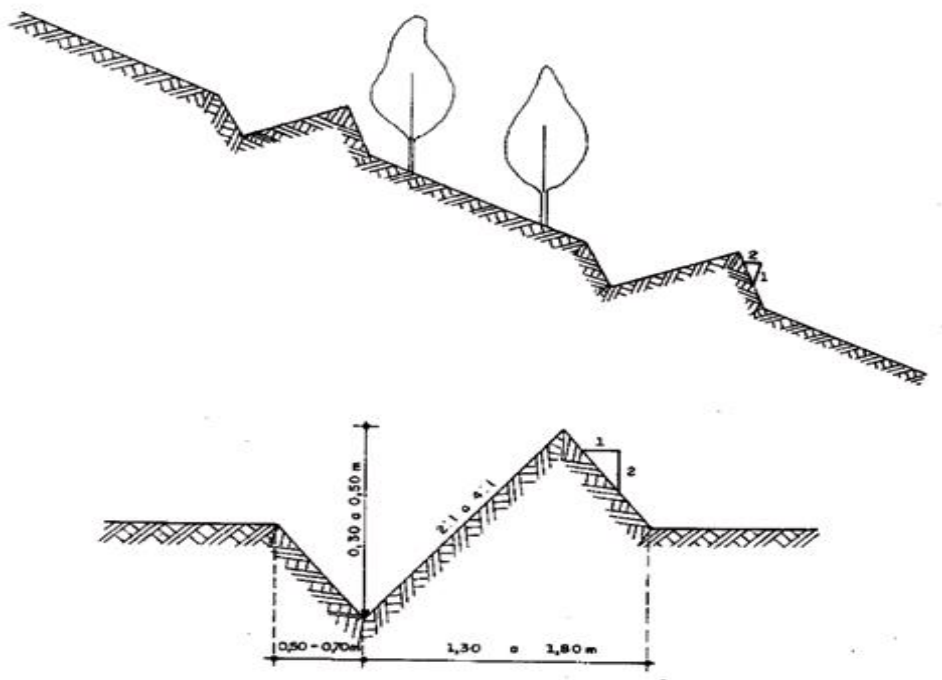

Fonte: Oliveira (2010)

\section{Parâmetros de avaliação}

Foram feitas avaliações com base na determinação da sobrevivência e crescimento do diâmetro do colo $(\mathrm{cm})$ no momento do transplante das mudas a campo, para servir de parâmetro de comparação nas avaliações seguintes.

As avaliações posteriores foram realizadas em 04 de maio e em 04 de junho do corrente ano, medindo em cada ocasião o diâmetro do caule $(\mathrm{cm})$ ao nível do solo, utilizandose um paquímetro digital.

\section{Análise de dados}

Os dados das avaliações referentes ao diâmetro do caule foram submetidos a análise de variância e as médias foram comparadas pelo teste de Tukey, ao nível de significância de 5\% $(<0,05)$ de probabilidade, utilizando o software SPSS Statistics (IBM, 2018).

\section{RESULTADOS E DISCUSSÃO}

As médias do diâmetro inicial da base das mudas de pau d'arco encontram-se apresentadas na Figura 4. Observa-se que a estação 4 apresenta maior média, seguida da estação 3, e as estações 1, 2 e 5 apresentam médias similares. 
Figura 4 - Bloxplot com as médias de diâmetros $(\mathrm{cm})$ iniciais no dia do plantio das mudas de pau d'arco.

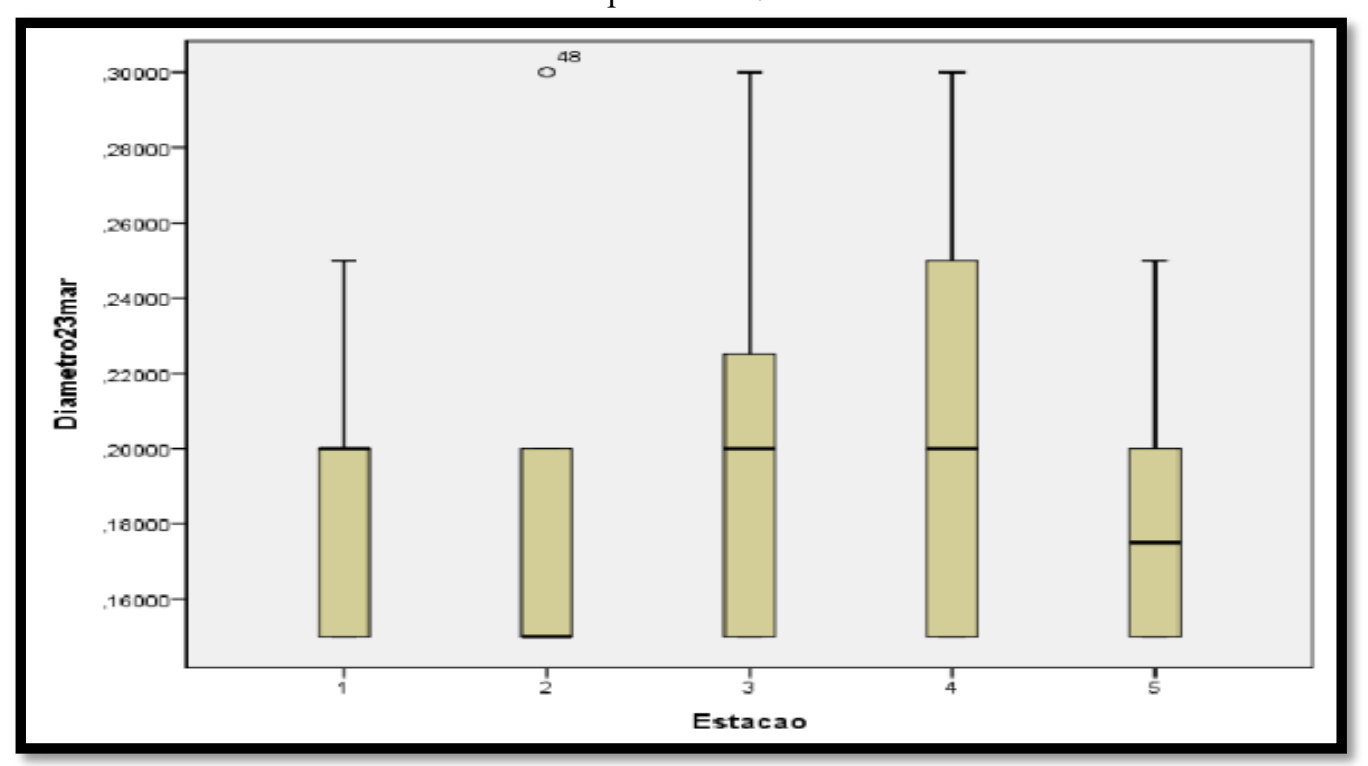

Fonte: IBM (2018).

\section{Terraceamento}

A primeira medição foi realizada no dia 04 de maio de 2019, e durante o período entre o plantio e a primeira medição o déficit hídrico provocou a morte de 7 plantas, sendo 2 na estação 1, 1 na estação 2, 3 na estação 4, e 1 na estação 5, provocando uma alteração na média dos diâmetros, conforme Figura 5. Entretanto a estação 3 não houve mortalidade em função do escoamento sub-superficial pela água acumulada nos terraços 1 e 2 posicionados mais acima, que proporcionou uma maior umidade, melhorando a qualidade ambiental nesta estação (Figura 6), conforme relatado também por Oliveira (2010).

Figura 5 - Bloxplot para diâmetro médio $(\mathrm{cm})$ das plantas na primeira medição

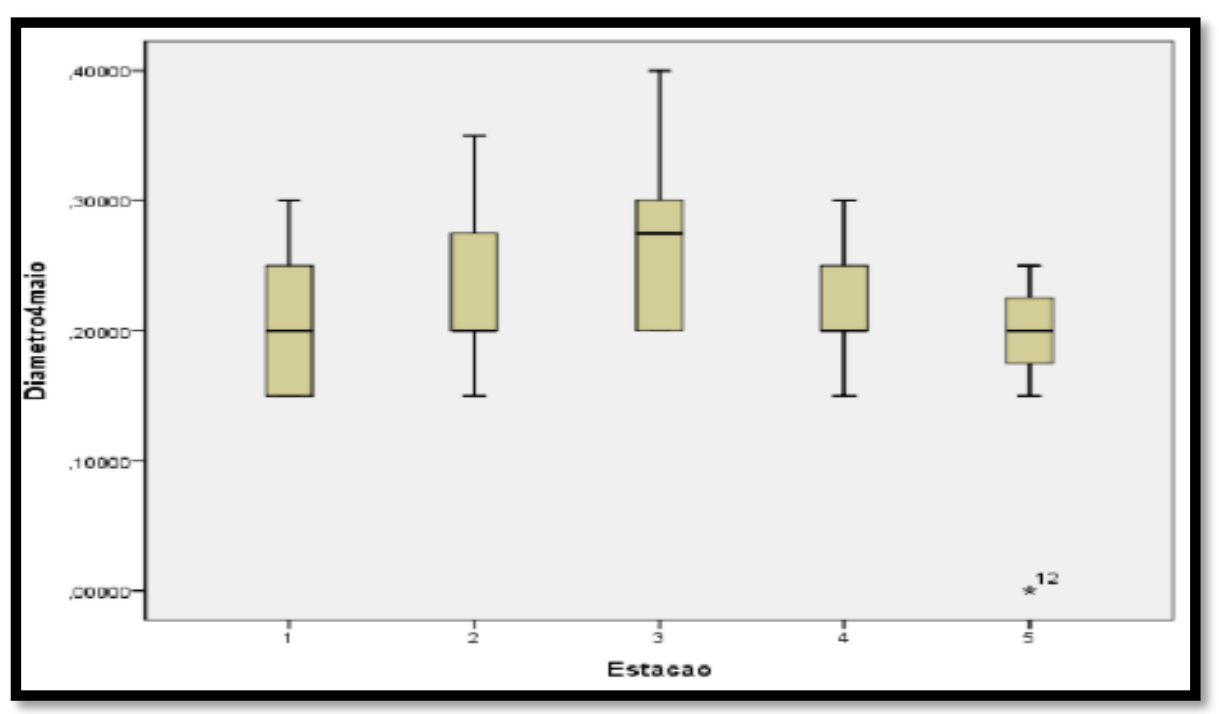

Fonte: IBM (2018).

A taxa de crescimento nos diâmetros médios das plantas apresentou os seguintes [24] 
valores: na estação $1-17 \%$, na estação $2-22 \%$, na estação $3-36 \%$, na estação $4-15 \%$ e na estação 5-11\%, esses valores foram obtidos com a diferença das medições entre o plantio e a primeira medição. Esses percentuais podem ser justificados pelo maior acumulo de água na estação 3, conforme mencionado anteriormente.

Figura 6 - Terraço de base estreita com água de chuva

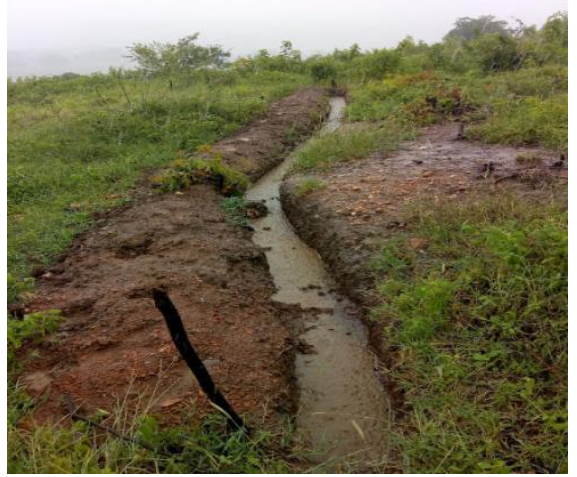

Fonte: Elaborada pelo autor.

A precipitação verificada no município de Nova Olinda, posto Nova Olinda (FUNCEME, 2019), entre o período da primeira medição 04 de maio e a segunda 04 de junho, totalizou $53 \mathrm{~mm}$. Verifica-se a ocorrência dos déficits hídricos no período de 3 a 16 de maio de 2019, com duração de 13 dias, e de 20 a 30 de maio de 2019, com duração de 10 dias, provocando uma alteração na média dos diâmetros, conforme Figura 7. Nesse período a taxa de crescimento nos diâmetros médios das plantas apresentou os seguintes valores: na estação 2- 4\%, na estação 3-19\%, na estação $4-9 \%$, na estação 5- 5\% e na estação 1 não houve alteração, em comparação a avaliação anterior. Durante o período os déficits hídricos provocaram a morte de 3 plantas, sendo 2 na estação 1,1 na estação 2 .

A mortalidade que ocorreu nas estações 1 e 2 foi devido à falta de umidade, já nas estações 3, 4 e 5 não houveram mortalidades em função do maior acúmulo de água nos terraços 2, 3 e 4, proporcionado também pelo tempo de escoamento sub-superficial do solo, ocorrido devido as chuvas de março, abril e maio.

A deficiência hídrica é um fator limitante para o desenvolvimento das plantas, devido a irregularidade de chuvas, sendo necessário o uso de práticas que armazenem a água por um maior período, concordando com Malvezzi (2007). 
Figura 7 - Bloxplot para diâmetro médio $(\mathrm{cm})$ das plantas na segunda medição

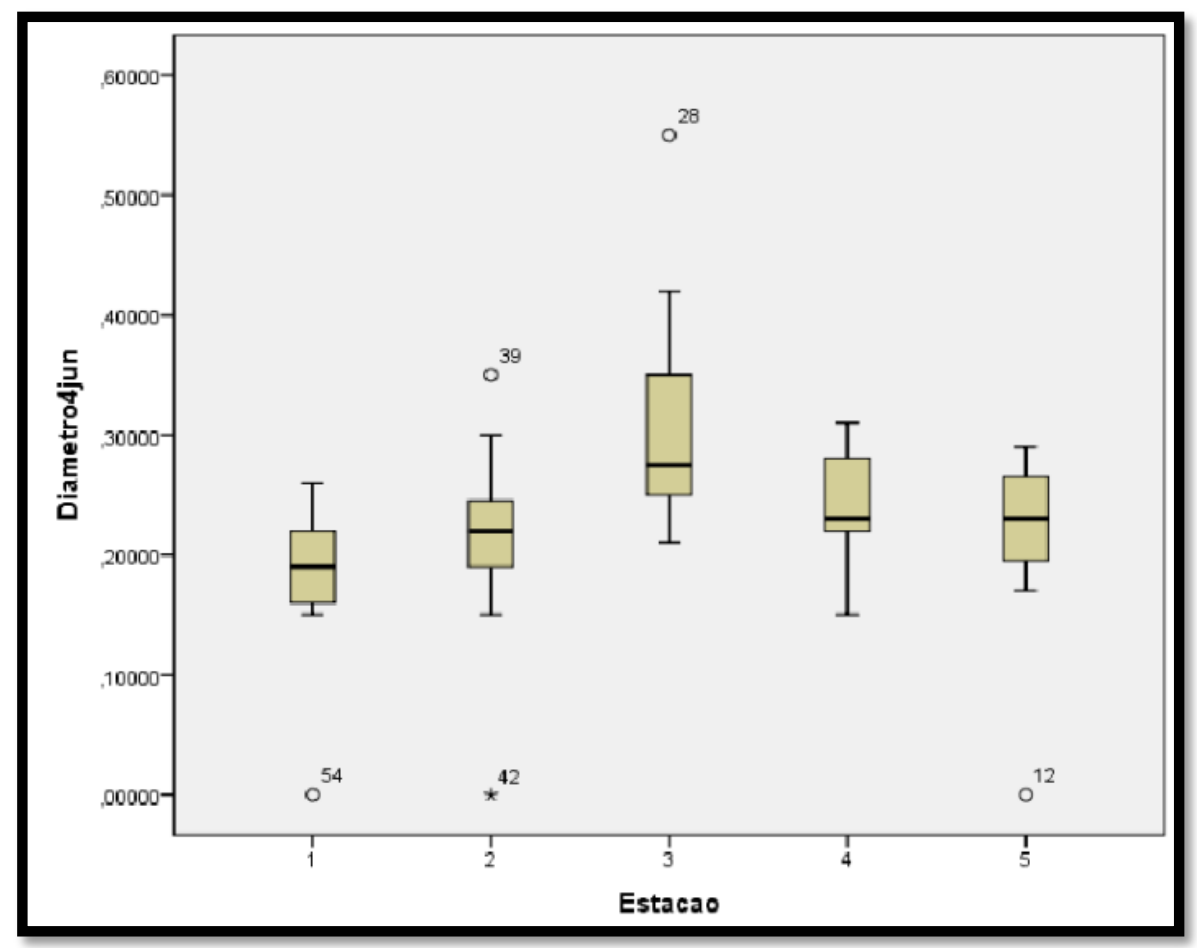

Fonte: IBM (2018)

\section{Análise dos terraços}

A análise de variância realizada para a taxa de crescimento (Tabela 1) e diâmetros das plantas (Tabela 2), entre o período de plantio e a segunda medição, indica que houve diferença significativa entre as estações 1 e 3, o que pode ser verificado pela Figura 8.

Tabela 1 - Resumo da análise de variância para taxa de crescimento (\%)

\begin{tabular}{lcl}
\hline Fonte de variação & Graus de liberdades & Quadrados médios \\
\hline Estação & 4 & $2118,19 * *$ \\
Tratamento & 3 & $465,34 \mathrm{~ns}$ \\
Estação*tratamento & 12 & $201,27 \mathrm{~ns}$ \\
Erro & 40 & 285,71 \\
Total & 59 & \\
\hline
\end{tabular}

CV $(\%)=81,82$. Média geral: 20,66

** significativo ao nível de $1 \%$ de probabilidade; ns: não significativo $(p<0,05)$

Entre as estações pode-se verificar a taxa crescimento entre o plantio e a segunda medição: estação 1- 17\%, estação 2- 35\%, estação 3- 63\%, estação 4- $26 \%$ e estação 5- 27\%. A estação 1 apresentou a menor taxa de crescimento, indicando que houve erosão hídrica de solo e lixiviação de nutrientes. O escoamento superficial provocou a perda de água da estação 1 e proporcionou esse menor desempenho no crescimento das plantas, corroborado por Dermachi et al. (2019). 
Tabela 2 - Resumo da análise de variância para diâmetro $(\mathrm{cm})$ da base do caule

\begin{tabular}{lcl}
\hline Fonte de variação & Graus de liberdades & Quadrados médios \\
\hline Estação & 4 & $0,052^{* *}$ \\
Tratamento & 3 & $0,003^{\mathrm{ns}}$ \\
Estação*tratamento & 12 & $0,012^{\mathrm{ns}}$ \\
Erro & 40 & 0,011 \\
Total & 59 & \\
\hline
\end{tabular}

CV $(\%)=49,20$. Média geral: 0,2078

** significativo ao nível de $1 \%$ de probabilidade; ns: não significativo $(p<0,05)$

Os terraços demonstraram capacidade de reter água do escoamento superficial, armazenando nas estações, em especial a estação 3, reduzindo o efeito de veranicos concordando com Denardin et al. (2011).

O uso de espécies nativas é de extrema importância na recuperação de áreas degradadas, visto que essas apresentam características particulares às áreas a serem recuperadas, se estabelecendo melhor na área, concordando com Bendito et al. (2018).

Figura 8 - Comparação de estações pelo Teste de Kruskal-Wallis de amostras idependentes

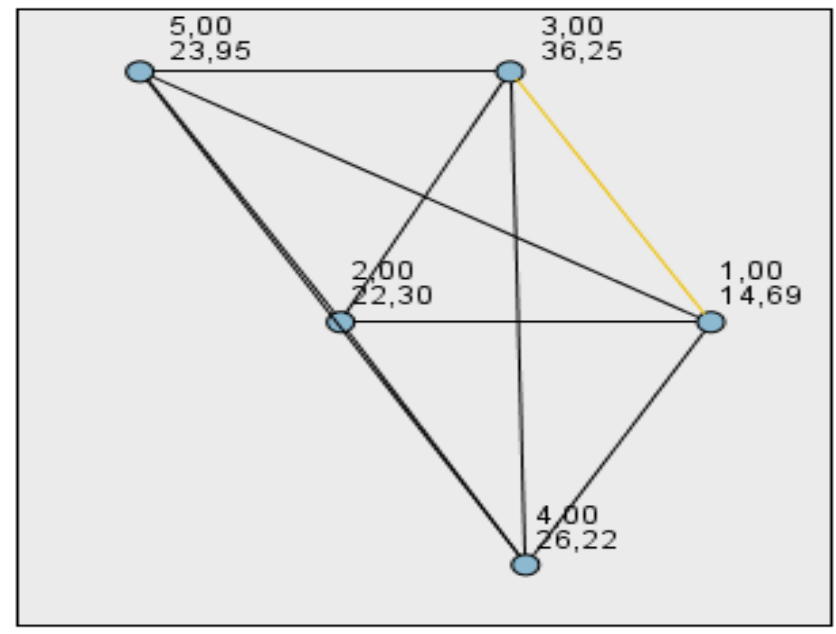

Fonte: IBM (2018).

A análise entre os terraços pelo teste de Kruskal-Wallis considerou amostras de tamanhos diferentes em função da mortalidade das plantas, que para o efeito de recuperação de áreas degradadas tem que ser levado em consideração. A mortalidade no terraço 1 poderia ter sido minimizada com a construção de um terraço no início da vertente.

Os terraços de base estreita contribuíram para minimizar a erosão, além de seus efeitos degradantes na área estudada, além de aumentar a disponibilidade de umidade para as plantas, reduzindo os efeitos dos déficits hídricos e aumentando a qualidade ambiental, conforme afirma Magalhães (2013). 


\section{Análise do pó de rocha}

O crescimento do diâmetro do caule das plantas (Tabela 3) e a taxa de crescimento (Tabela 4) em função da aplicação do pó de rocha, não apresentaram diferença significativa.

Observa-se que na estação 3, onde houve maior umidade no período, o material que mais se superou foi o pó de rocha cinza $(0,380 \mathrm{~cm})$, nas estações 4 e 5 , onde houveram menor umidade, a testemunha se sobressaiu, indicando que o pó de rocha necessita de umidade para que haja as reações químicas necessária para a liberação dos nutrientes. Como não houve umidade suficiente, visto que o plantio foi de sequeiro, o resultado obtido não foi conforme Theodoro et al. (2006) e Theodoro e Leonardos (2006).

Tabela 3 - Médias dos efeitos principais de tratamento e estação para diâmetro (cm) do caule do Handroanthus impetiginosus (Mart. ex DC.) Mattos)

\begin{tabular}{clllll}
\hline \multirow{2}{*}{ Estação } & Testemunha & $\begin{array}{l}\text { Pó de rocha } \\
\text { amarelo }\end{array}$ & $\begin{array}{l}\text { Pó de rocha } \\
\text { cinza }\end{array}$ & $\begin{array}{l}\text { Pó de rocha amarelo } \\
\text { mais cinza }\end{array}$ & Médias \\
\cline { 2 - 5 } & 0,063 & 0,123 & 0,187 & 0,160 & $0,133 \mathrm{~b}$ \\
2 & 0,170 & 0,153 & 0,227 & 0,227 & $0,194 \mathrm{ab}$ \\
3 & 0,317 & 0,240 & 0,380 & 0,310 & $0,312 \mathrm{a}$ \\
4 & 0,270 & 0,227 & 0,067 & 0,163 & $0,182 \mathrm{~b}$ \\
5 & 0,240 & 0,187 & 0,180 & 0,226 & $0,213 \mathrm{ab}$ \\
\hline Médias & 0,212 & 0,186 & 0,208 & 0,221 &
\end{tabular}

Médias seguidas pela mesma letra, na coluna, e ausência de letra nas linhas, não difere entre si pelo teste Tukey a $5 \%$ de significância.

A testemunha da estação 1 foi a que teve menor crescimento, indicando que a erosão hídrica e os déficits hídricos influenciaram no baixo crescimento das plantas, conforme afirmam Denardin et al. (2011). Em anos de melhor distribuição pluviométrica o pó de rocha poderá proporcionar melhor desenvolvimento às plantas, pois seu efeito é prolongado conforme afirma Amparo (2003).

Tabela 4 - Média percentual (\%) das interações e efeitos principais da estação e tratamento do diâmetro (cm) do caule de H. impetiginosus (Mart. ex DC.) Mattos)

\begin{tabular}{|c|c|c|c|c|c|}
\hline \multirow[b]{2}{*}{ Estação } & \multicolumn{4}{|c|}{ Tratamento } & \multirow[b]{2}{*}{ Médias } \\
\hline & Testemunha & $\begin{array}{l}\text { Pó de rocha } \\
\text { amarelo }\end{array}$ & $\begin{array}{l}\text { Pó de rocha } \\
\text { cinza }\end{array}$ & $\begin{array}{l}\text { Pó de rocha amarelo } \\
\text { mais cinza }\end{array}$ & \\
\hline 1 & 7,843 & 3,33 & 8,89 & 4,66 & $6,18 \quad b$ \\
\hline 2 & 10,00 & 35,00 & 28,33 & 20,95 & $19,40 \mathrm{ab}$ \\
\hline 3 & 35,55 & 36,66 & 58,61 & 37,22 & $42,01 \mathrm{a}$ \\
\hline 4 & 23,44 & 20,00 & 8,33 & 6,00 & $14,44 \quad b$ \\
\hline 5 & 18,66 & 13,33 & 40,00 & 13,00 & $21,25 \mathrm{ab}$ \\
\hline Médias & 19,10 & 21,66 & 28,83 & 16,36 & \\
\hline
\end{tabular}

A taxa de crescimento do tratamento $3(58,61 \%)$ na estação 3 , apesar de não ter apresentado diferença significativa entre os demais tratamentos, indica que o pó de rocha cinza apresentou melhor resultado em termos de valores absolutos. Conforme os dados dos 
dois pós de rocha utilizados (Tabela 5) observa-se que o pó de rocha cinza apresenta menor $\mathrm{pH}$, menor condutividade elétrica, que pode ter influenciado no resultado.

\begin{tabular}{lcccccccccccc}
\multicolumn{10}{c}{ Tabela 5- Análise química dos pós de rocha } \\
\hline $\begin{array}{l}\text { Nutrientes/ } \\
\text { material }\end{array}$ & $\begin{array}{c}\mathbf{P} \\
\mathbf{g} / \mathbf{k g}\end{array}$ & $\begin{array}{c}\mathbf{P}_{2} \mathbf{O}_{\mathbf{5}} \\
\mathbf{g} / \mathbf{k g}\end{array}$ & $\begin{array}{c}\mathbf{K}^{+} \\
\mathbf{g} / \mathbf{k g}\end{array}$ & $\begin{array}{c}\mathbf{K}_{\mathbf{2}} \mathbf{O} \\
\mathbf{g} / \mathbf{k g}\end{array}$ & $\begin{array}{c}\mathbf{C a}^{\mathbf{2 +}} \\
\mathbf{g} / \mathbf{k g}\end{array}$ & $\begin{array}{c}\mathbf{M g}^{\mathbf{2 +}} \\
\mathbf{g} / \mathbf{k g}\end{array}$ & $\begin{array}{c}\mathbf{S} \\
\mathbf{g} / \mathbf{k g}\end{array}$ & $\begin{array}{c}\mathbf{N a}^{+} \\
\mathbf{g} / \mathbf{k g}\end{array}$ & $\begin{array}{c}\mathbf{N} \\
\mathbf{g} / \mathbf{k g}\end{array}$ & $\begin{array}{c}\mathbf{B} \\
\mathbf{~ m g / k g}\end{array}$ & $\mathbf{p H}$ & $\begin{array}{c}\mathbf{C E} \\
\mathbf{d S} / \mathbf{m}\end{array}$ \\
\hline $\begin{array}{l}\text { Pó de } \\
\text { rocha } \\
\text { Amarelo }\end{array}$ & 0,07 & 0,17 & 0,02 & 0,03 & 36,20 & 1,20 & 7,75 & 0,40 & 0,56 & 1,4 & 8,2 & 4,21 \\
\hline $\begin{array}{l}\text { Pó de } \\
\text { rocha } \\
\text { cinza }\end{array}$ & 0,02 & 0,04 & 0,02 & 0,03 & 35,80 & 1,08 & 2,24 & 0,40 & 0,28 & 1,08 & 7,8 & 1,75 \\
\hline
\end{tabular}

Fonte: Elaborada pelo autor.

A fertilidade natural do Luvissolo, conforme afirma Manzatto et al. (2002) e SiBCS (2018), também pode ter influenciado no resultado de modo a não ter diferenças significativas entre os diferentes tipos dos pós de rocha, pelo menos no período inicial de crescimento das plantas, visto que tais produtos são de liberação e dissolução lenta. Portanto, mesmo os produtos aplicados apresentarem elevada concentração de nutrientes (Tabela 5), não foi possível uma diferença significativa nos parâmetros avaliados para os tratamentos aplicados.

\section{CONCLUSÕES}

Até o momento o uso de técnicas conservacionistas como o de terraços de base estreita apresentou-se satisfatório na melhoria das condições ambientais e influenciou na capacidade física dos solos degradados.

A dosagem dos diferentes pós de rocha em Luvissolo não foram suficientes para incrementarem o crescimento inicial das plantas.

\section{REFERÊNCIAS}

ANDA, Associação Nacional para a Difusão de Adubos. Anuário estatístico 2018. Disponível em: < http://anda.org.br/?mpg=03.00.00\&ver=por> Acesso em: 09 jun 2019.

ASSIS, Luiz Alberto Guimarães. Doenças fúngicas em espécies florestais nativas na Amazônia Central. Manaus: INPA, 2008. Dissertação. (Mestrado em Ciências de Florestas Tropicais [CFT]), Instituto Nacional de Pesquisas da Amazônia, 2008.

AMPARO, A. Farinha de Rocha e biomassa. Agroecologia hoje. Botucatu, n.20, p. 10-12, 2003.

BENDITO, Bianca Pietsch Cunha et al. DIAGNÓSTICO AMBIENTAL E PROPOSIÇÃO DE USO DE SAF PARA ÁREA DE PASTAGEM DEGRADADA. Geoambiente On-Line, n. 29, 2017.

BENDITO, B.; SOUZA, P.; PEREIRA, M.; GONÇALVES, D. DIAGNÓSTICO 
AMBIENTAL E PROPOSIÇÃO DE USO DE SAF PARA ÁREA DE PASTAGEM DEGRADADA. Geoambiente On-line, n. 29, 2018.

BERTONI, J.; LOMBARDI NETO, F. Conservação do solo. 7.ed. São Paulo, Ícone, p. 355, 2010.

CALDEIRA, M. V. W; ROSA, G. N; FENILLI, T. A. B; HARBS, R. M. P. Composto orgânico na produção de mudas de aroeira-vermelha. Scientia Agraria, v. 9, p. 27- 33, 2008.

CARVALHO, P. E. R. Espécies arbóreas brasileiras. Empresa Brasileira de Pesquisa Agropecuária- EMBRAPA, Centro nacional de Pesquisa de Florestas- CNPF, 2003.

Companhia de Pesquisa de Recursos Minerais- CPRM. Disponível em $<$ http://rigeo.cprm.gov.br/xmlui/bitstream/handle/doc/16607/Rel_Nova\%20Olinda.pdf?seque

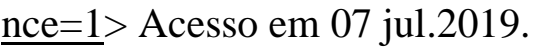

CURY, R. T. S.; CARVALHO JR. O. Manual para restauração florestal: florestas de transição. Série boas práticas 5. Canarana-MT: IPAM, 2011.

DEMARCHI, J. C.; PIROLI, E.L.; ZIMBACK, C.R.L. Estimativa de perda de solos por erosão na bacia hidrográfica do ribeirão das perobas (sp) nos anos 1962 e 2011. Raega-O Espaço Geográfico em Análise, v. 46, n. 1, p. 02, 2019.

DENARDIN, J.E. et al. Sistema plantio direto: evolução e implementação. In: PIRES, J.L.M. et al. Trigo no Brasil: bases para produção competitiva e sustentável. Passo Fundo: Embrapa Trigo, cap.7, p. 185-215, 2011.

EDUARDO, Eliete Nazaré et al. Erodibilidade, fatores cobertura e manejo e práticas conservacionistas em Argissolo Vermelho-Amarelo, sob condições de chuva natural. Revista Brasileira de Ciência do Solo, v. 37, n. 3, 2013. Disponível em: $<$ https://www.redalyc.org/articulo.oa?id=180227932026 $>$. Acesso em 8 de abril de 2019.

EMPRESA BRASILEIRA DE PESQUISA AGROPECUÁRIA - EMBRAPA. Sistema brasileiro de classificação de solos. 5.ed. Brasília, 2018.

FERNANDES, F. R. C.; LUZ, A. B.; CASTILHOS, Z. C. Agrominerais para o Brasil. CETEM/MCT, 2010.

FUNCEME- Fundação Cearense de Meteorologia e Recursos Hídricos. Disponível em: <http://www.funceme.br/> Acesso em 08 jul 2019.

GONÇALVES DOS SANTOS, H. Paulo Klinger Tito J, dos Anjos LHC, de Oliveira VÁ, Lumbreras JF, Coelho MR, et al. Sistema Brasileiro de Classificação de Solos (SiBCS). $5^{\text {a }}$ edição. Brasil: Empresa Brasileira de Pesquisa Agropecuária (Embrapa); 2018.

GONZAGA, T. W. C.; MATA, M. E. R. M.; SILVA H.; DUARTE, M. E. M. Crioconservação de sementes de aroeira (Astronium urundeuva Engl.), e baraúna (Schinopsis brasiliensis Engl.). Revista Brasileira de Produtos Agroindustriais, Campina Grande, v. 5, n. 2, p. 145-154, 2003. 
GRIEBELER, Nori Paulo et al. Modelo para o dimensionamento e a locação de sistemas de terraceamento em nível. 2005.

GRIEBELER, Nori Paulo; CARVALHO, D. F.; MATOS, A.T. Estimativa do custo de implantação de sistema de terraceamento, utilizando-se o sistema de informações geográficas. Estudo de caso: Bacia do Rio Caxangá, PR. Revista Brasileira de Engenharia Agrícola e Ambiental, v. 4, n. 2, p. 299-303, 2000.

HARVEY, C.A,; KOMAR, O.; CHAZDON, R.; FERGUSON, B. G.; FINEGAN, B.; GRIFFITH, D.M.; MARTÍNEZ-RAMOS, M.; MORALES, H.; NIGH, R.; SOTO-PINTO, L. Integrating Agricultural Landscapes with Biodiversity Conservation in the Mesoamerican Hotspot. Conservation Biology, v.22, n. 1, p. 8-15. 2008.

IBM SPSS Statistics 21. IBM. 2018. Software. Disponível em: <https://www.ibm.com/products/software> Acesso em 08 jul 2019.

IPCE, $2017 \quad$ Disponível

em https://www.ipece.ce.gov.br/wpcontent/uploads/sites/45/2018/09/NovaOlinda2017.pdf

KAGEYAMA, P. Y.; OLIVEIRA, R. E.; MORAES, L. F. D.; ENGEL, V. L.; GANDARA, F. B. Restauração ecológica de ecossistemas naturais. Botucatu-SP: FEPAF, 2003.

LIMA, M.A. Planejamento Urbano: SIG, avaliação socioeconômica e ecológica. In: Economia do Meio Ambiente. Ademar Ribeiro Romeiro, Bastiaan P. Reydon e Maria Lúcia A. Leonardi (org.) Campinas: UNICAMP, 1997.

LIMA, J. R. L.; MARCATTO, C. ; SOUZA, E. F. F.; BRONZATTO, L. A. ; NASCIMENTO M. P. R. (Coord.). Programa de ação nacional de combate à desertificação e mitigação dos efeitos da seca - PAN BRASIL. Brasília - DF: Ministério do Meio Ambiente / Secretaria de Recursos Hídricos, 2004.

LOPES, A. S. Reservas de minerais potássicos e produção de fertilizantes potássicos no Brasil. Potássio na agricultura brasileira. Piracicaba: Potafos, p. 21-32, 2005.

LORENZI, H. Árvores Brasileiras: Manual de identificação e cultivo de plantas arbóreas nativas do Brasil. Nova Odessa: Plantarum, 1992.

LOHMANN, L. G. Bignoniaceae in Lista de Espécies da Flora do Brasil. Jardim Botânico do Rio de Janeiro. 2012. Disponível em: <http://floradobrasil.jbrj.gov.br/2012/FB11409>. Acesso em: 07 mai. 2019.

MAGALHÃES, G. M. F. Análise da eficiência de terraços de retenção em sub-bacias hidrográficas do Rio São Francisco. Revista Brasileira de Engenharia Agrícola e Ambiental, v.17, n.10, p.1109-1115, 2013. Disponível em: <http://dx.doi.org/10.1590/S1415-43662013001000013> acesso em 08/04/2019

MAIA, G.N. Caatinga: árvores e arbustos e suas utilidades. São Paulo: D\&Z Computação, 2004.

MALVEZZI, Roberto. Semiárido - uma visão holística. Brasília: Ed. Confea, 2007.

MANZATTO, Celso Vainer; FREITAS JUNIOR, Elias de; PERES, José Roberto 
Rodrigues. Uso agrícola dos solos brasileiros. Rio de Janeiro: Embrapa Solos, 2002.

MONTAGNINI, F. Environmental services of agroforestry systems. First World Congress on Agroforestry, Orlando, Florida, USA, 27 June-2 July 2004. Journal of Sustainable Forestry, 2005.

OLIVEIRA, J. B. Práticas inovadoras de controle edáfico e hidroambiental para o semiárido do Ceará. Fortaleza: Secretaria de Recursos Hídricos- PRODHAM,p.190, 2010.

RODRIGUES, R.R.; BRANCALION, P.H.S.; ISERNHAGEN, I. Pacto pela restauração da Mata Atlântica: referencial dos conceitos e ações de restauração florestal. São Paulo: LERF/ESALQ. Instituto BioAtlântica, 2009.

SÁNCHEZ, Luis Enrique. Recuperação de Áreas Degradadas: Um campo multidisciplinar de pesquisas. In: Seminário Unesp. Rio Claro, 2006.

SIQUEIRA FILHO, José Alves de et al. Guia de campo de árvores da Caatinga. Petrolina: Franciscana, 2009.

SILVA, Dalva Damiana Estevam da. Avaliação da degradação ambiental a partir da prática da cultura do feijão no município de Tavares - PB, 2012.

SILVA, Roberto Marinho Alves da. Entre o Combate à Seca e a Convivência com o Semiárido: Transições Paradigmáticas e sustentabilidade do desenvolvimento. Tese (Doutorado). Centro de Desenvolvimento Sustentável. Brasília: Universidade de Brasília, 2006.

THEODORO, S. H. et al. Experiências de uso de rochas silicáticas como fonte de nutrientes. Espaço \& Geografia, Brasília, v. 9, n. 2, p. 263-292, 2006.

THEODORO, S. H.; LEONARDOS, O. H. The use of rocks to improve family agriculture in Brazil. Anais da Academia Brasileira de Ciências, Rio de Janeiro, v. 78, n. 4, p. 721-730, 2006.

VALCARCEL, ARICARDO; SILVA, ZILANDA DE SOUZA. A eficiência conservacionista de medidas de recuperação de áreas degradadas: proposta metodológica. Floresta, v. 27, n. 1, 1997.

VIDAL, Francisco Wilson Hollanda; PADILHA, Manoel William Montenegro; OLIVEIRA, R. R. Aspectos geológicos da Bacia do Araripe e do aproveitamento dos rejeitos da Pedra Cariri-Ceará. Artigo apresentado no V Simpósio de Rochas Ornamentais do Nordeste, Recife, p. 31-36, 2005.

ZUFFO, Alan Mario. As regiões Semiáridas e suas Especialidades 2. Editora Atena. Ponta Grossa (PR), 2019. 


\title{
DESEMPENHO AGRONÔMICO DE VARIEDADES DE FEIJÃO-CAUPI NO PERÍODO DE ESTIAGEM EM CASTANHAL-PA
}

\author{
RENDIMIENTO AGRÍCOLA DE LAS VARIEDADES DE CAUPI BEAN EN EL \\ PERÍODO DE ENVASADO EN CASTANHAL-PA
}

\section{AGRICULTURAL PERFORMANCE OF CAUPI BEAN VARIETIES IN THE CASING PERIOD IN CASTANHAL-PA}

\author{
Lucas Fernando da Costa Lima ${ }^{1}$; Breno Barbosa dos Santos ${ }^{2}$; Gabriel Garreto dos Santos ${ }^{3 ;}$ \\ Domingos Sávio Morais Tavares ${ }^{4}$; Juliana Simões Nobre Gama ${ }^{5}$
}

DOI: https://doi.org/10.31692/978-65-991061-4-9.33-46

\begin{abstract}
RESUMO
O estudo da época de plantio do feijão-caupi tem grande importância para a sua produção, visto que, ele é bastante sensível à precipitação, temperatura, chuvas irregulares e mal distribuídas, juntamente com o período de estiagem, causam danos enormes às lavouras. Desse modo, este trabalho teve como objetivo avaliar o desempenho de variedades de feijão-caupi (Vigna unguiculata L.) no período de estação seca, assim como, fazer um resgate das sementes crioulas produzidas no nordeste paraense. $\mathrm{O}$ experimento foi realizado em campo localizado no Instituto Federal de Educação, Ciência e Tecnologia do Pará, campus Castanhal, conduzido de setembro a novembro de 2018. Foram utilizadas 4 variedades de feijão-caupi, sendo elas: BRS Novaera (conhecido como caupi branco), caupi vermelho (conhecido como mata fome) e caupi verde (conhecido como sempre verde), sendo todas encontradas em cidades pertencentes à região nordeste paraense, como Marapanim, Santa Maria do Pará, Irituia e Castanhal. O experimento foi conduzido em blocos casualizados com área de 9x5 m cada bloco, divididos em 4 parcelas de 4x2 m, respeitando o espaçamento de 1 metro entre parcelas dentro do bloco. As plantas foram observadas durante um período de 60 dias a partir da semeadura, sendo as variáveis de crescimento analisadas, diâmetro do caule, altura das plantas e massa seca da parte aérea, avaliados a cada 12 dias. Após a colheita foram avaliadas as variáveis de rendimento: número de vagens por planta, comprimento das vagens, número de sementes por vagem e peso de 100 sementes. Os dados obtidos foram submetidos a análise de variância e as médias comparadas pelo teste Tukey a 5\% de probabilidade. Para os períodos de avaliação, foi realizada uma análise de regressão polinomial. As variedades de feijão-caupi BRS Novaera, seguida da "sempre verde" e "mata fome" apresentam desempenho satisfatório no período de estiagem, sendo uma opção para o agricultor poder cultivar mais uma safra de feijão durante o ano. A variedade "mata fome" pode ser uma alternativa para adubação verde e recuperação de solos degradados, devido a produção expressiva de matéria seca e cobertura verde no solo.
\end{abstract}

Palavras-Chave: Vigna unguiculata L., semente crioula, rendimento

\section{RESUMEN}

El estudio del tiempo de siembra del caupí es de gran importancia para su producción, ya que es muy sensible a las precipitaciones, la temperatura, las precipitaciones irregulares y mal distribuidas, junto con la estación seca, causando enormes daños a los cultivos. Por lo tanto, este trabajo tuvo como objetivo evaluar el rendimiento de las variedades de caupí (Vigna unguiculata L.) durante la estación seca, así como rescatar las semillas criollas producidas en el noreste de Pará. El experimento se realizó en un campo ubicado en el Instituto Federal de Educación, Ciencia y Tecnología de Pará, campus Castanhal, realizado de septiembre a noviembre de 2018. Se utilizaron cuatro variedades de caupí:

\footnotetext{
${ }^{1}$ Graduando em Agronomia, IFPA-Campus Castanhal, lucas.qifernando@outlook.com

${ }^{2}$ Graduado em Agronomia, IFPA-Campus Castanhal, breno_barbosaabada@ hotmail.com

${ }^{3}$ Graduando em Agronomia, IFPA-Campus Castanhal, gabryelgarreto@gmail.com

${ }^{4}$ Mestre em Desenvolvimento rural e gestão de empreendimentos agroalimentares, IFPA-Campus Castanhal, savio.tavares@ifpa.edu.br

${ }^{5}$ Dra. em Ciências, Docente do IFPA-Campus Castanhal, juliana.nobre@ifpa.edu.br
} 
BRS Novaera (conocido como caupí blanco), caupí rojo (conocido como mata hambre) y caupí verde (conocido como árbol de hoja perenne), todos encontrados en ciudades en la región noreste de Pará, como Marapanim, Santa Maria do Pará, Irituia y Castanhal. El experimento se realizó en bloques aleatorizados con un área de 9x5 m cada bloque, divididos en 4 parcelas de 4x2 $\mathrm{m}$, respetando el espacio de 1 metro entre parcelas dentro del bloque. Las plantas se observaron durante un período de 60 días desde la siembra, y las variables de crecimiento analizadas, el diámetro del tallo, la altura de la planta y la masa seca del brote se evaluaron cada 12 días. Después de la cosecha, se evaluaron las variables de rendimiento: número de vainas por planta, longitud de las vainas, número de semillas por vaina y peso de 100 semillas. Los datos obtenidos se sometieron a análisis de varianza y los promedios comparados por la prueba de Tukey con una probabilidad del 5\%. Para los períodos de evaluación, se realizó un análisis de regresión polinómica. Las variedades de caupí BRS Novaera, seguidas de "siempre verde" y "matar el hambre" muestran un rendimiento satisfactorio durante la estación seca, siendo una opción para que el agricultor pueda cultivar otra cosecha de frijoles durante el año. La variedad "matar el hambre" puede ser una alternativa para el abono verde y la recuperación de suelos degradados, debido a la producción expresiva de materia seca y cubierta verde en el suelo.

Palabras Clave: Vigna unguiculata L., semilla criolla, ceder.

\begin{abstract}
The study of cowpea planting time is of great importance for its production, since it is very sensitive to precipitation, temperature, irregular and poorly distributed rainfall, along with the dry season, causing enormous damage to crops. Thus, this work aimed to evaluate the performance of cowpea (Vigna unguiculata L.) varieties during the dry season, as well as to rescue the creole seeds produced in northeastern Pará. The experiment was conducted in a field located at the Federal Institute of Education, Science and Technology of Pará, Castanhal campus, conducted from September to November 2018. Four varieties of cowpea were used: BRS Novaera (known as white cowpea), red cowpea (known as kills hungry) and green cowpea (known as evergreen), all found in cities in the northeastern region of Pará, such as Marapanim, Santa Maria do Pará, Irituia and Castanhal. The experiment was conducted in randomized blocks with an area of 9x5 m each block, divided into 4 plots of $4 \times 2 \mathrm{~m}$, respecting the spacing of 1 meter between plots within the block. The plants were observed during a period of 60 days from sowing, and the growth variables analyzed, stem diameter, plant height and shoot dry mass were evaluated every 12 days. After harvest the yield variables were evaluated: number of pods per plant, length of pods, number of seeds per pod and weight of 100 seeds. The obtained data were submitted to analysis of variance and the averages compared by Tukey test at $5 \%$ probability. For the evaluation periods, a polynomial regression analysis was performed. The cowpea varieties BRS Novaera, followed by "always green" and "kill hunger" show satisfactory performance during the dry season, being an option for the farmer to be able to grow another crop of beans during the year. The "kill starvation" variety can be an alternative for green manure and recovery of degraded soils, due to the expressive production of dry matter and green cover in the soil.

Keywords: Vigna unguiculata L., Creole seed, yield.
\end{abstract}

\title{
INTRODUÇÃO
}

O feijão é uma das culturas mais cultivadas e consumidas no Brasil e no mundo, sua importância vai além do aspecto econômico, dada sua relevância ao fator de segurança alimentar, nutricional e cultural, na culinária de diversos países, sobretudo entre os extratos sociais menos favorecidos (INCAPER, 2010).

O feijão (Vigna unguiculata L.), conhecido por feijão-caupi, é originário do continente africano e foi introduzido no Brasil na segunda metade do século XVI pelos colonizadores portugueses no estado da Bahia, a partir de então, foi disseminado em todo o país, ganhando grande relevância nas regiões norte e nordeste (EMBRAPA, 2011). 
O feijão-caupi é o terceiro mais cultivado no território nacional, perdendo apenas para o feijão-rajado (Phaseolus vulgaris L.) que fica em primeiro lugar, e para o feijão-preto (Phaseolus vulgaris 'Black turtle) que ocupa o segundo lugar do ranking, sendo plantado na primeira safra 2017/2018 em uma área de 410.7 mil hectares (CONAB, 2018).

Com o aumento na produção a agricultura brasileira vem passando por um intenso processo de mudanças tecnológicas, desde o manejo das culturas até a seleção das melhores sementes, a produção de novas cultivares híbridas ou não, essas cada vez mais produtivas, precoces, resistentes a pragas, doenças e etc (FREIRE FILHO et al., 2011). Seguindo esse contexto, o feijão-caupi deixou de ser uma cultura voltada apenas para agricultores familiares e atualmente vem sendo cultivado por médios e grandes produtores, nas regiões Norte e Nordeste, devido à sua adaptação às condições edafoclimáticas. Sua importância não se restringe apenas ao território brasileiro, tendo relevância nos países da África e Ásia, principalmente, por suas características nutricionais, representando uma importante fonte de proteínas e aminoácidos essenciais que complementam a dieta do ser humano (FREIRE FILHO e ROCHA et al., 2011).

O feijoeiro é bastante sensível à deficiência hídrica, principalmente, quando essa ocorre na floração e período de enchimento dos grãos, por outro lado, possui diferentes variedades com ampla adaptação edafoclimática, o que permite o seu cultivo durante todo o ano, em quase todos os estados da federação (BURATTO et al., 2007).

Portanto, o estudo da época de plantio do feijão-caupi tem grande importância para a sua produção, visto que, ela é bastante sensível à precipitação e à temperatura do ar, chuvas irregulares e mal distribuídas, juntamente com o período de estiagem, causando danos enormes às lavouras. $\mathrm{O}$ que justifica o estudo da melhor época para o seu plantio, assim o conhecimento das variações climáticas de cada região exerce efeitos significativos sobre o desenvolvimento econômico e alimentar da região (SILVA et al., 2010).

Nesse sentido, verificar a variedade de feijão-caupi menos afetada pelo período seco, é extremamente importante, por oportunizar aos agricultores da região a possibilidade de se adquirir mais uma safra, no segundo semestre, já que o mesmo comumente é cultivado entre os meses de maio a julho. Portanto, este trabalho teve como objetivo avaliar o desempenho agronômico de diferentes variedades de feijão-caupi no período de estiagem em CastanhalPA.

\section{FUNDAMENTAÇÃO TEÓRICA}

O feijão é um alimento muito consumido pelos brasileiros, sendo um dos principais 
componentes da dieta alimentar, o mesmo possui características nutricionais que representam uma importante fonte de proteína, ferro e carboidratos na dieta humana, principalmente, em países de regiões tropicais e subtropicais (SALVADOR, 2012).

A nível nacional o feijão está entre as principais culturas cultivadas, tendo na safra 2016/2017 uma produção de 1,24 milhão de toneladas, sendo 787,6 mil toneladas de feijãocomum cores, 320 mil toneladas de feijão-comum preto e 127,9 mil toneladas de feijão-caupi, sua menor produtividade está relacionada às condições de plantio e de baixa tecnologia utilizada, sendo os principais estados produtores São Paulo e Minas Gerais (CONAB, 2018).

No estado do Pará a cultura do feijão-caupi tem grande expressão na produção

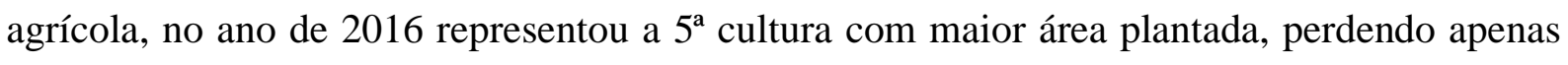
para as culturas da soja $28,71 \%$, açaí $22,70 \%$, dendê $15,66 \%$ e milho $13,29 \%$, sendo a área plantada no estado com feijão-caupi correspondendo a 13,76\% de toda área, tendo ênfase nos municípios de Capanema e Bragança. Salienta-se que os dez cultivos agrícolas de maior área plantada no Pará concentram 95\% do total destinado ao plantio no estado (FAPESPA, 2017).

Uma das grandes vantagens do feijão é sua ampla adaptação edafoclimática e suas centenas de variedades, permitindo seu cultivo durante o ano todo, em quase todos os estados brasileiros, nas diferentes épocas e safras (OLIVEIRA, 2015). Em alguns estados a seca e deficiência hídrica, causada pelos veranicos, é um dos fatores que afetam grandemente a produção agrícola do feijão-caupi, influenciando todo o processo vegetativo da cultura em questão (SILVA et al., 2016).

Os elementos climáticos são importantes para a cultura do feijão-caupi e tem a faixa ideal para o seu cultivo, pois a cultura exige uma precipitação pluvial mínima de $300 \mathrm{~mm}$ bem distribuídas, temperatura entre 18 a $34^{\circ} \mathrm{C}$, porém, algumas cultivares locais já são adaptadas ao clima de sua região (SILVA et al., 2016). Estas variedades são conhecidas como crioulas, por apresentar boa adaptação à região e por vir sendo plantado entre gerações.

São consideradas crioulas aquelas sementes que não passaram por um processo de melhoramento genético, passadas de geração a geração, e guardadas principalmente em comunidades tradicionais, como indígenas, quilombolas, ribeirinhos, caboclos e etc. (TRINDADE, 2006). Segundo Tsutsumi et al. (2012), o feijão crioulo apresenta aspecto e sabor diferenciado, possibilitando maior agregação de valor e também as variedades crioulas são mais adequadas ao cultivo orgânico, por apresentar maior resistência às doenças e pragas de sua região de origem.

As sementes crioulas fazem parte do patrimônio de diversos povos e comunidades tradicionais que ao longo dos tempos conservam, resgatam e selecionam não só sementes, 
mas também algumas raças de animais, assim conservando e mantendo sua agrobiodiversidade adaptada a cada região (NUÑEZ e MAIA, 2006).

Segundo Teixeira (2012), as sementes crioulas são de maneira geral menos produtivas do que as sementes modernas que passam por um processo de melhoramento genético e hibridação, porém, apresentam grande variabilidade genética e são resistentes a pragas, doenças e clima do seu local de origem.

Em 2003 se estabeleceu a Lei $n^{0} 10.711$ que dispõe sobre o sistema nacional de Sementes e Mudas, a mesma permitiu aos agricultores a produção, troca e venda de sementes e mudas entre si, sem precisarem aderir ao Registro Nacional de Sementes (RENASEM) e ao Registro Nacional de Cultivares (RNC), responsáveis pela fiscalização destas trocas e comercialização de sementes e mudas, essa brecha aberta na legislação foi um dos fatores que reforçaram as tentativas de legitimação das sementes crioulas por parte dos cientistas e dos agricultores ecológicos (PAULINO e GOMES, 2015).

Apesar de todos os aspectos sociais, econômicos e alimentar que permeiam às sementes crioulas e seu reconhecimento perante à legislação, muitas estão se perdendo ou deixando de ser cultivadas, sendo extremamente necessário o resgate e manutenção dessas variedades locais já adaptadas, para que o agricultor tenha autonomia, tornando-se menos dependente das sementes comerciais, melhoradas e/ou híbridas.

\section{METODOLOGIA}

O trabalho foi conduzido no período de 5 de setembro a 7 de novembro de $2018 \mathrm{em}$ campo localizado no Instituto Federal de Educação, Ciência e Tecnologia do Pará, campus Castanhal, nas coordenadas geográficas de Latitude: 1¹8'32.62'”, Longitude: 4756'51.09'”. A classificação do clima é Af de acordo com a Köppen e Geiger, apresenta temperatura média anual de $26,5^{\circ} \mathrm{C}$ e pluviosidade média de $2.432 \mathrm{~mm}$ ao ano.

A área foi previamente preparada por meio de roçagem e gradagem mecanizada. A análise de acidez potencial, macro e micronutrientes do solo foi realizada no Laboratório Terra (Goiânia-GO), cujos resultados expressaram $\mathrm{pH}=5.0, \mathrm{Ca}=2.9, \mathrm{Mg}=0.5, \mathrm{Ca}+\mathrm{Mg}=$ $3.4, \mathrm{Al}=0.00, \mathrm{H}+\mathrm{Al}=2.9, \mathrm{~K}=0.201, \mathrm{CTC}=6.40(\mathrm{Cmolc} / \mathrm{dm} 3), \mathrm{P}=14 \mathrm{Mg} / \mathrm{dm} 3($ Melich I) e M.O = $16 \mathrm{~g} / \mathrm{kg}$. Posteriormente, realizou-se a correção do solo por meio de calagem, utilizando calcário dolomítico.

A implantação ocorreu no dia 05/09/2018, período de redução das chuvas, também conhecido como verão amazônico, que vai do mês de julho a novembro. Antes da semeadura a área foi nivelada manualmente, foram semeadas sementes de 4 variedades de feijão-caupi, 
cultivadas no nordeste paraense. A aquisição dessas sementes foi por meio de doações de produtores rurais de Santa Maria do Pará, da agrovila de Bacabal (Castanhal-PA), da comunidade do Ebrom (Irituia-PA) e Boa Vista (Marapanim-PA).

Para semeadura utilizou-se o espaçamento de $20 \mathrm{~cm}$ entre plantas e $40 \mathrm{~cm}$ entre fileiras, tendo uma densidade populacional de 100 plantas por parcela. A semeadura foi feita de forma semi-mecanizada com a utilização de uma plantadeira manual, conhecida como ticotico, onde foram semeadas de 3 a 4 sementes por cova, com profundidade de 4,0 a 6,0 cm. A profundidade média de semeadura está ao redor de $4 \mathrm{~cm}$ em solos de textura argilosa e úmidos e $6 \mathrm{~cm}$ naqueles de textura arenosa, evitando-se semear muito profundamente para que não haja atraso nem estresse para a emergência da plântula, quando então, estaria mais sujeita à incidência de doenças e pragas no solo (INCAPER, 2010).

As adubações de cobertura ocorreram aos 8, 15 e 30 dias após a semeadura (DAS), a mesma foi procedida de acordo com a análise do solo, segundo as recomendações de adubação e calagem para o estado do Pará (CRAVO, 2007). Aos 12 DAS foi procedido o desbaste das plantas, deixando apenas uma em cada cova, a limpeza das parcelas se deu por meio de capina manual com o auxílio de enxadas, aos 12, 25 e 35 DAS.

O experimento foi conduzido em blocos casualizados, sendo 4 repetições $(9 \times 5 \mathrm{~m}) \mathrm{com}$ 4 parcelas de $4 \times 2 \mathrm{~m}$, na disposição nascente poente, com espaço de um metro entre cada parcela, as 4 variedades de feijão utilizadas foram: BRS Novaera (caupi branco) e variedades crioulas de feijão-caupi preto, feijão-caupi vermelho conhecido por "mata fome" e feijãocaupi verde conhecido localmente por "sempre verde".

As análises correspondentes aos componentes de crescimento iniciaram a partir dos 12 DAS, prosseguindo-se a cada 12 dias (24, 36, 48 e 60 DAS). Nas avaliações foram selecionadas 10 plantas de forma aleatória em cada parcela, respeitando o espaço de $50 \mathrm{~cm}$ das bordas, cada planta selecionada foi devidamente marcada com a utilização de um barbante de sisal, com o objetivo de analisar sempre os parâmetros das mesmas plantas durante o seu desenvolvimento. Para isso, foram avaliadas as seguintes variáveis de crescimento e rendimento:

Diâmetro do caule - utilizou-se um paquímetro analógico, tomando-se como padrão a região do colo da planta. Os resultados obtidos foram expressos em milímetros ( $\mathrm{mm}$ ).

Altura das plantas - foi realizada de acordo com a metodologia utilizada por Oliveira et al. (2015), com auxílio de fita métrica, medindo o comprimento total da planta a partir da região do colo até a inserção da folha mais alta da planta, sendo os resultados expressos em centímetros $(\mathrm{cm})$. 
Massa seca - utilizou-se a metodologia de Oliveira et al. (2015), onde foram avaliadas a parte aérea de três plantas por parcela, as plantas utilizadas para este procedimento foram colhidas manualmente aos 24 dias, repetindo a mesma análise a cada 12 dias seguintes, separando-se a parte aérea das raízes no ponto de interseção (coleto), levadas para laboratório de solos do IFPA - Campus Castanhal. No laboratório, as partes aéreas das plantas foram acondicionadas em sacos de papel kraft e levadas a estufa com circulação de ar a $65{ }^{\circ} \mathrm{C}$, durante 72 horas, em seguida, pesadas em balança de precisão, sendo os resultados expressos em gramas $(g)$.

Número de vagens por planta - foi contabilizado a partir dos 36 DAS, período em que as plantas estavam em floração e algumas já apresentavam as primeiras vagens, e então foram contabilizadas a cada 12 dias, estendendo-se até os 60 dias.

Comprimento das vagens - foram medidas 20 vagens, escolhidas aleatoriamente de cada parcela, com auxílio de régua flexível milimetrada, sendo os resultados expressos em centímetros

Número de sementes por vagem - foi contabilizado de 20 vagens aleatórias de cada parcela, as mesmas foram debulhadas e suas sementes contadas manualmente.

Peso de 100 sementes - utilizou-se 100 sementes colhidas em cada parcela, posteriormente, foram pesadas em balança de precisão, sendo os resultados expressos em gramas ( $\mathrm{g}$ ).

\section{RESULTADOS E DISCUSSÃO}

Os dados climáticos de temperatura $\left({ }^{0} \mathrm{C}\right)$ e precipitação $(\mathrm{mm})$ ocorridos em CastanhalPA em 2018, encontram-se no quadro 01. Verifica-se que no período em que o experimento foi realizado (setembro a novembro), ocorreram as menores médias de precipitação, variando de 63 a $81 \mathrm{~mm}$. Demonstrando que de fato este é um período de redução significativa das chuvas, quando comparado ao mês de março/2018 onde houve a maior concentração da precipitação $(411 \mathrm{~mm})$. Neste caso, a soma da precipitação dos 3 meses em que o trabalho foi realizado $(223 \mathrm{~mm})$, corresponde a $54 \%$ das chuvas concentradas em março.

Quadro 01: Dados meteorológicos ocorridos em Castanhal-PA, 2018.

\begin{tabular}{|c|c|c|c|c|c|c|c|c|c|c|c|c|}
\hline & JAN & FEV & MAR & ABR & MAI & JUN & JUL & AGO & SET & OUT & NOV & DEZ \\
\hline $\begin{array}{l}\text { Temp. } \\
\text { máx. }\end{array}$ & 30.4 & 29.9 & 29.5 & 30.7 & 31.1 & 31.1 & 31.4 & 31.6 & 32.9 & 32.3 & 32 & 31.6 \\
\hline $\begin{array}{l}\text { Temp. } \\
\text { mín. }\end{array}$ & 22.1 & 22.3 & 22.1 & 22,5 & 21.9 & 21.6 & 21.6 & 21.7 & 21.7 & 21.8 & 21.9 & 22 \\
\hline
\end{tabular}




\begin{tabular}{l|llllllllllll} 
Temp. & 26.2 & 26.1 & 25.8 & 26.6 & 26.6 & 26.3 & 26.5 & 26.6 & 26.8 & 27 & 26.9 & 26.8 \\
méd. & & & & & & & & & & & & \\
Chuvas & 307 & 336 & 411 & 355 & 242 & 155 & 125 & 115 & 81 & 79 & 63 & 152 \\
$(\mathbf{m m})$ & & & & & & & & & & & & \\
\hline
\end{tabular}

Fonte: Climate-Data.Org.

O resultado da análise de variância referente às variáveis de crescimento das variedades de feijão-caupi, analisadas em diferentes períodos, encontram-se na tabela 1. Verifica-se que houve interação significativa (variedades*período) apenas para a altura de plantas, no entanto, para o diâmetro de plantas, houve efeito isolado dos fatores, já para a massa seca apenas o fator período foi significativo.

Tabela 1. Resumo da análise de variância referente as variedade de feijão-caupi produzidas no período de estiagem. Castanhal-PA, 2018.

\begin{tabular}{|c|c|c|c|c|c|}
\hline \multirow[t]{2}{*}{ Fonte de variação } & \multirow[b]{2}{*}{ GL } & \multicolumn{4}{|c|}{ Quadrados médios } \\
\hline & & $\begin{array}{c}\text { Diâmetro } \\
(\mathrm{mm})\end{array}$ & $\begin{array}{l}\text { Altura } \\
(\mathrm{cm})\end{array}$ & GL & $\begin{array}{c}\text { Massa seca } \\
(\mathrm{g})\end{array}$ \\
\hline Variedade & 3 & $1.853^{*}$ & $356.703 * *$ & 3 & $6.335^{\mathrm{NS}}$ \\
\hline Período & 4 & $33.105 * *$ & $2806.682 * *$ & 3 & $33.913 *$ \\
\hline Variedade*Período & 12 & $0.241^{\mathrm{NS}}$ & $34.076^{* *}$ & 9 & $12.334^{\mathrm{NS}}$ \\
\hline Bloco & 3 & $2.216 * *$ & $20.568^{\mathrm{NS}}$ & 3 & $2.019^{\mathrm{NS}}$ \\
\hline Resíduo & 57 & 0.399 & 9.254 & 45 & 10.874 \\
\hline Total & 79 & & & 63 & \\
\hline $\begin{array}{c}\text { C.V }(\%) \\
\text { Média geral }\end{array}$ & 4.37 & 14.45 & $31.45^{9.67}$ & 4.61 & 71.42 \\
\hline
\end{tabular}

Significativo a $1 \%(* *)$ e $5 \%(*)$ de probabilidade; não significativo $\left({ }^{\mathrm{NS}}\right)$.

Com relação ao diâmetro do caule avaliado durante os diferentes períodos, observa-se um comportamento, com todas as variedades, se ajustando ao modelo quadrático da regressão. No entanto, a variedade "mata fome" obteve o maior diâmetro $(6,25 \mathrm{~mm})$ e o "sempre verde" o menor (5,22 mm) aos 60 DAS (Figura 1).

Um dos motivos para a diferença no diâmetro das plantas avaliadas, pode estar relacionado a eficiência do sistema radicular em absorver água e nutrientes do solo, mesmo em períodos de estiagem, pois todas as variedades receberam o mesmo tratamento no que diz respeito à adubação. 
Figura 2: Diâmetro do caule de plantas de feijão-caupi de diferentes variedades, avaliada no período de estiagem em Castanhal-PA, 2018.

\section{Caupi preto}

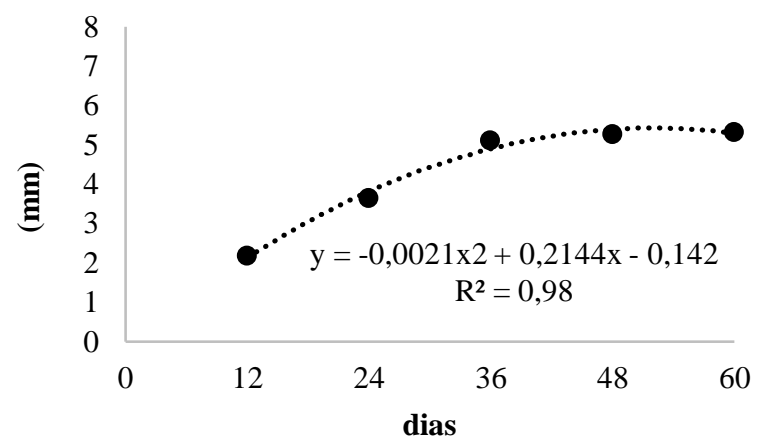

Mata fome

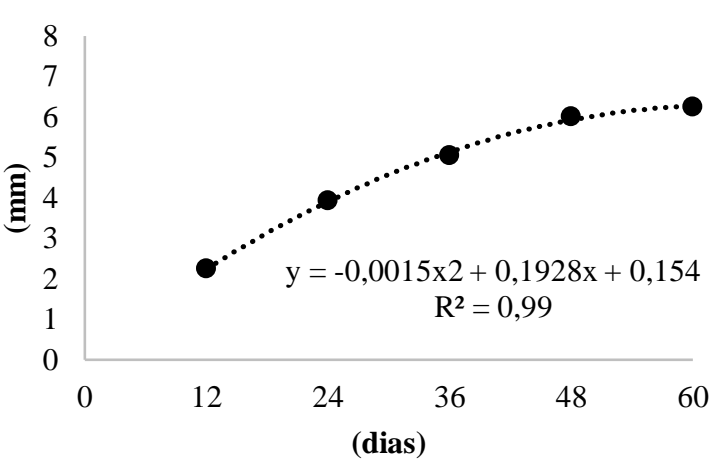

BRS Novaera

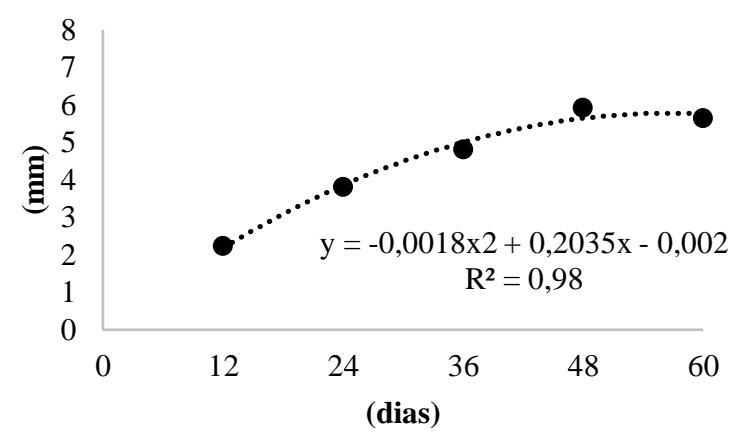

Sempre verde

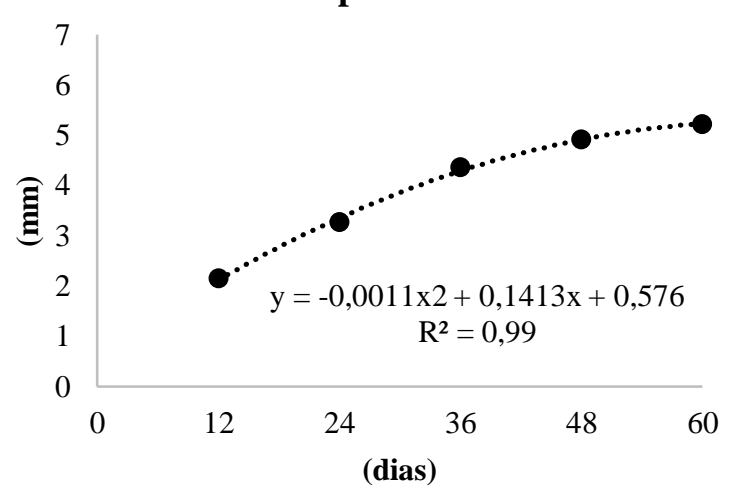

Em relação à altura das plantas (Figura 2), observa-se que as variedades que mais se destacaram no crescimento foram "mata fome" $(53,22 \mathrm{~cm})$, seguido da variedade "BRS Novaera" $(49,02 \mathrm{~cm})$, já as menores plantas foram verificadas na variedade "caupi preto" $(38,05 \mathrm{~cm})$.

Figura 3. Altura de plantas de feijão-caupi, avaliadas no período de estiagem em Castanhal-PA, 2018.

\section{Caupi preto}

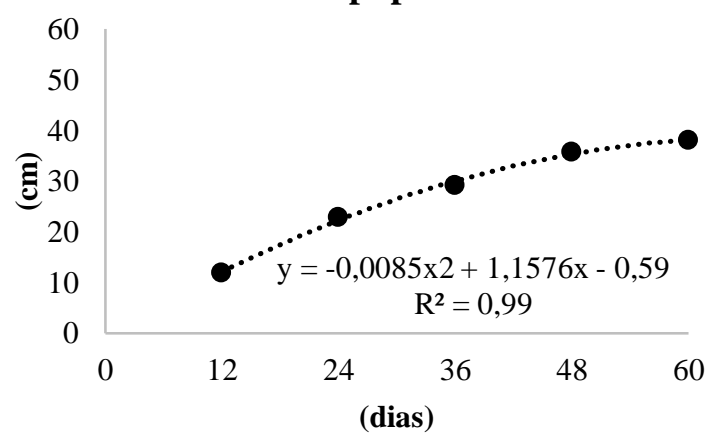

BRS Novaera

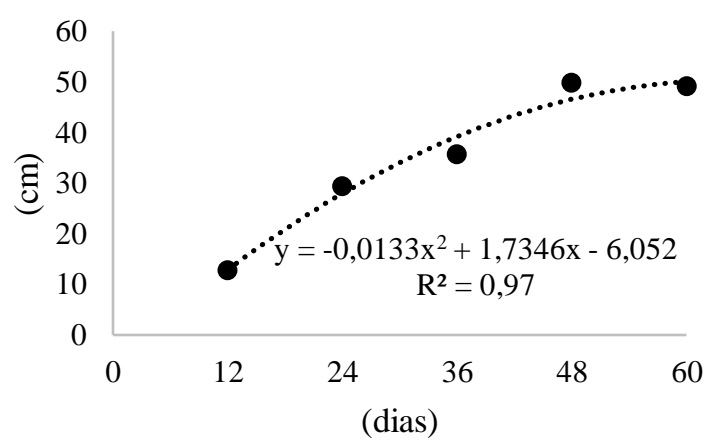



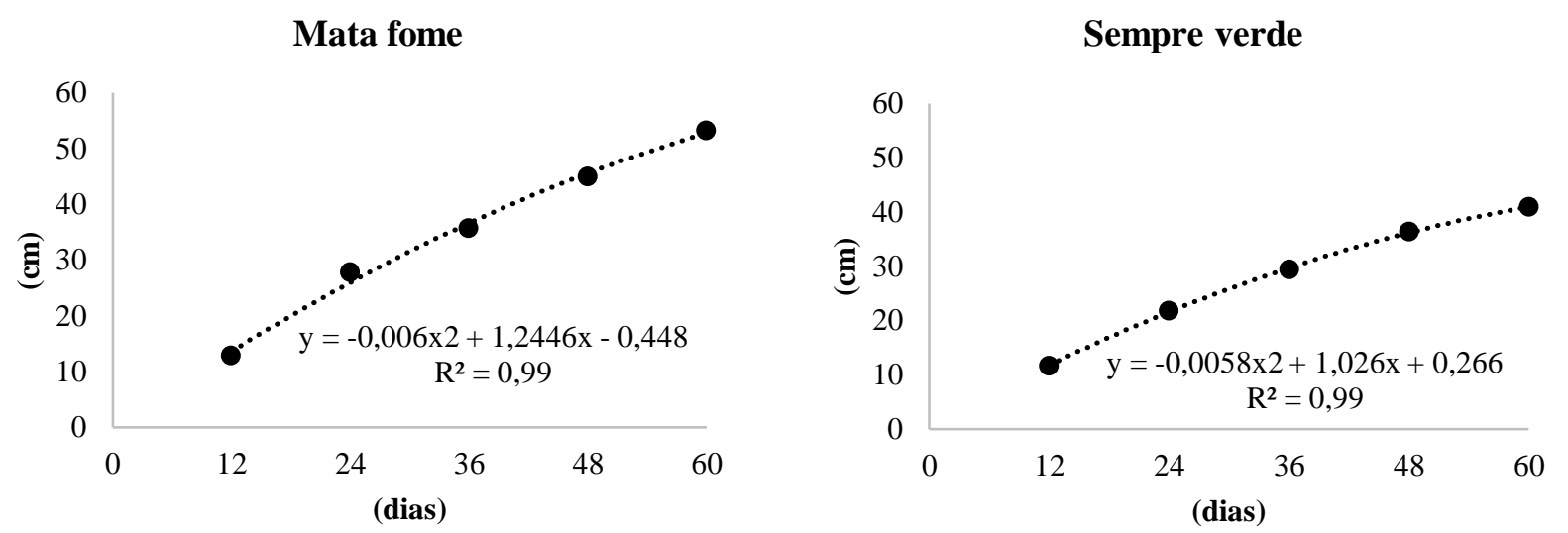

O maior peso de massa seca observado aos 60 DAS foi da variedade "Novaera" $(7,06$ g), seguida das variedades crioulas caupi preto $(6,28 \mathrm{~g})$, sempre verde $(4,79 \mathrm{~g})$ e mata fome $(3,46 \mathrm{~g})$. Vale ressaltar que para as variedades "mata fome" e "sempre verde" não houve ajuste a nenhum modelo de regressão (Figura 3).

Com os resultados de massa seca, também verifica-se que as duas variedades com maior massa podem ser boas opções de adubação verde, podendo depositar quantidade de matéria orgânica, considerando uma população de 250.000 plantas/ha ${ }^{-1}$ a variedade "Novaera" poderia depositar uma quantidade igual a $1.765 \mathrm{~kg} / \mathrm{ha}$ e a variedade caupi preto depositaria $1.570 \mathrm{~kg} / \mathrm{ha}^{-1}$, podemos chegar a esse valor multiplicando o número populacional de plantas pelo peso médio da matéria seca (Novaera 7,06 g e caupi preto 6,28 g).

Figura 4. Massa seca da parte aérea de plantas de feijão-caupi , avaliada no período de estiagem em CastanhalPA, 2018.

\section{Caupi preto}

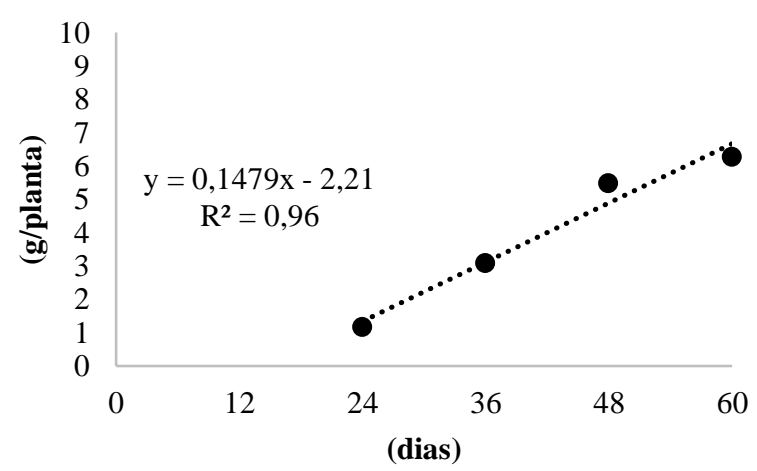

BRS Novaera

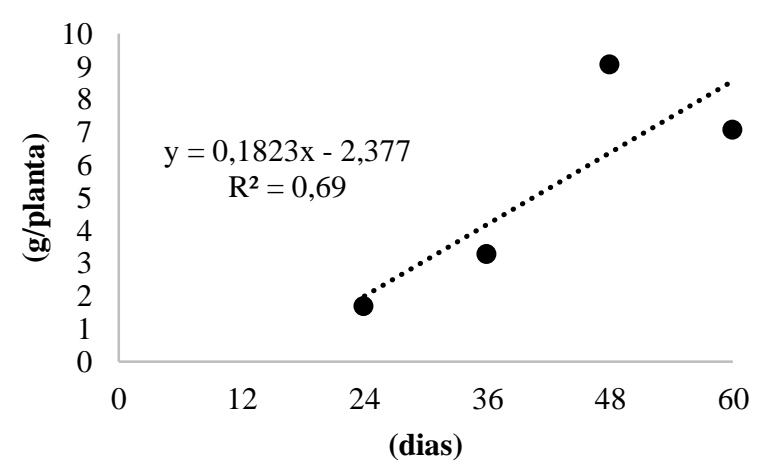


Mata fome

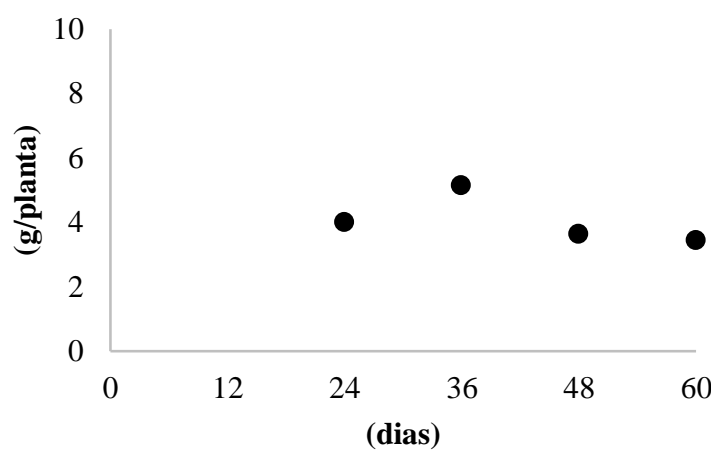

Sempre verde

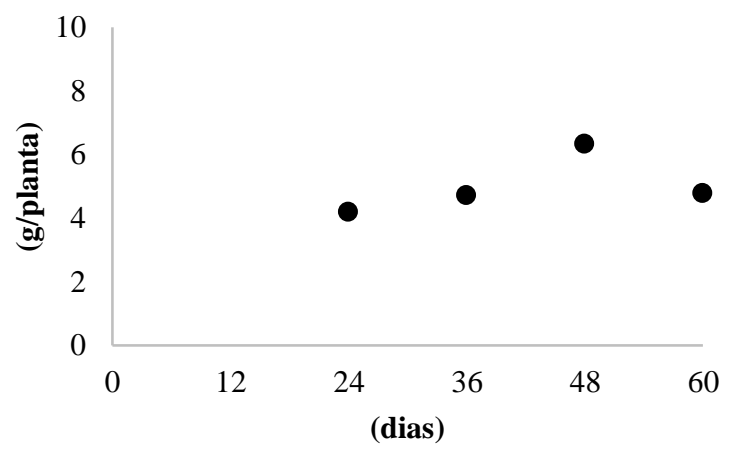

Fazendo uma abordagem geral das cultivares (Tabela 2), observa-se que para diâmetro do caule, a variedade "mata fome" apresentou a maior média, não diferindo das variedades "Novaera e caupi preto". Com relação à altura de plantas "Novaera e mata fome" foram superiores, no entanto, na massa seca todas foram iguais estatisticamente.

O maior crescimento vegetativo das variedades "mata fome" e "Novaera" podem estar associados a uma maior adaptação às condições de baixa disponibilidade hídrica, durante o cultivo.

Tabela 2. Médias referentes ao diâmetro $(\mathrm{mm})$, altura de plantas $(\mathrm{cm})$ e massa seca da parte aérea $(\mathrm{g})$ de variedades de feijão-caupi, cultivadas no período de estiagem. Castanhal-PA, 2018.

\begin{tabular}{c|ccc}
\hline Cultivar & Diâmetro & Altura & Massa seca \\
\hline Caupi preto & $4,31 \mathrm{ab}$ & $27,56 \mathrm{~b}$ & $4,08 \mathrm{a}$ \\
Novaera & $4,49 \mathrm{ab}$ & $35,29 \mathrm{a}$ & $5,28 \mathrm{a}$ \\
Mata fome & $4,70 \mathrm{a}$ & $34,91 \mathrm{a}$ & $4,06 \mathrm{a}$ \\
Sempre verde & $3,98 \mathrm{~b}$ & $28,03 \mathrm{~b}$ & $5,01 \mathrm{a}$ \\
\hline
\end{tabular}

Médias seguidas de mesma letra na coluna, não diferem entre si pelo teste de Tukey a 5\% de probabilidade.

Na tabela 3 encontram-se os resultados da análise de variância referente aos componentes de rendimento das variedades de feijão-caupi, produzidas no período de estiagem. Verifica-se que apenas o número de sementes por vagem não foi significativo, já o número de vagens por planta e peso de 100 sementes apresentaram diferença significativa com relação às variedades.

Tabela 3. Análise de variância dos componentes de rendimento das variedades de feijão-caupi, cultivadas no período de estiagem. Castanhal-PA, 2018.

\begin{tabular}{cccccc}
\hline $\begin{array}{c}\text { Fonte de } \\
\text { variação }\end{array}$ & GL & $\begin{array}{c}\text { Quadrados médios } \\
\text { Comprimento } \\
\text { de vagem } \\
(\mathrm{cm})\end{array}$ & $\begin{array}{c}\text { Número de } \\
\text { sementes } \\
\text { por vagem }\end{array}$ & $\begin{array}{c}\text { Número de } \\
\text { vagens por } \\
\text { planta }\end{array}$ & $\begin{array}{c}\text { Peso de } \\
100 \\
\text { sementes }\end{array}$ \\
\hline Cultivar & 3 & $7,310^{*}$ & $9,413^{\mathrm{NS}}$ & $12,688^{*}$ & $4,445^{* *}$ \\
Bloco & 3 & $0,843^{\mathrm{NS}}$ & $1,622^{\mathrm{NS}}$ & $0,793^{\mathrm{NS}}$ & $0,385^{\mathrm{NS}}$ \\
Resíduo & 9 & 2,654 & 3,327 & 1,167 & 0,111 \\
Total & 15 & & & & \\
CV $(\%)$ & & 9,62 & 19,29 & 38,16 & 1,81 \\
\hline
\end{tabular}




\begin{tabular}{|c|c|c|c|c|}
\hline Média geral & 16,93 & 9,50 & 2,83 & 2 \\
\hline
\end{tabular}

O comprimento de vagem foi maior para a variedade "mata fome" $18,86 \mathrm{~cm}$, no entanto, não diferiu estatisticamente das variedades "Novaera" e "sempre verde". Apesar de não ter apresentado diferença significativa, o número de sementes foi maior para a variedade "mata fome" com 12 sementes por vagem, porém, sua média de vagem por planta foi apenas 1 (uma), tornando-a pouco produtiva em relação as outras variedades. A variedade "Novaera" obteve o maior número de vagens por planta, se destacando e diferindo estatisticamente das demais.

As sementes mais pesadas foram produzidas pela variedade Novaera $(19,25 \mathrm{~g})$, não diferindo estatisticamente das variedades sempre verde e mata fome (18,86 e 18,68 g, respectivamente). No entanto, o "caupi preto" foi o mais afetado pelas condições de estiagem, não conseguindo na fase de enchimento das sementes, estocar de forma mais eficiente os nutrientes nos seus tecidos de reserva (cotilédones).

Vale ressaltar também que a variável peso de 100 sementes pode ser correlacionada ao vigor das mesmas, pois àquelas mais pesadas, teoricamente, teriam mais reservas e energia para início e manutenção da germinação, assim como, o desenvolvimento inicial das plântulas.

Tabela 4. Médias referentes aos componentes de rendimento das cultivares de feijão-caupi, cultivadas no período

\begin{tabular}{ccccc} 
Comprimento de & $\begin{array}{c}\text { Número de } \\
\text { sementes } \\
\text { vagem }(\mathrm{cm})\end{array}$ & $\begin{array}{c}\text { Número de } \\
\text { vagens por } \\
\text { planta }\end{array}$ & $\begin{array}{c}\text { Peso de } 100 \\
\text { sementes }(\mathrm{g})\end{array}$ \\
\hline Caupi preto & $15,71 \mathrm{~b}$ & $9,75 \mathrm{a}$ & $2,50 \mathrm{~b}$ & $16,88 \mathrm{~b}$ \\
Novaera & $16,69 \mathrm{ab}$ & $8,75 \mathrm{a}$ & $5,25 \mathrm{a}$ & $19,25 \mathrm{a}$ \\
Mata fome & $18,86 \mathrm{a}$ & $11,50 \mathrm{a}$ & $1,00 \mathrm{~b}$ & $18,68 \mathrm{a}$ \\
Sempre verde & $16,48 \mathrm{ab}$ & $8,00 \mathrm{a}$ & $3,00 \mathrm{~b}$ & $18,86 \mathrm{a}$ \\
\hline
\end{tabular}

Letras minúsculas seguidas na coluna não diferem estatisticamente pelo teste de Tukey a 5\% de probabilidade.

De acordo com a densidade populacional indicada por Sousa (2017), para a produção de feijão-caupi que é de 160 a 340 mil plantas há-1, se a variedade "Novaera" obtiver o mesmo desempenho alcançado no experimento, podemos utilizar a fórmula: $\left(\left(\mathrm{N}^{\circ} \mathrm{de}\right.\right.$ sementes/vagem $\times \mathrm{N}^{\circ}$ vagens/planta $\times \mathrm{N}^{\circ}$ populacional $\left.) \div(100)\right) \times($ peso de 100 sementes $\div$ 1000), ter uma estimativa de produção entre 1.415 a $3.006 \mathrm{~kg} / \mathrm{ha}^{-1}$, o que renderia uma faixa de 23 a 50 sacas de $60 \mathrm{~kg}$ por hectare, já a segunda variedade mais produtiva o "caupi preto" se fosse plantada na mesma densidade populacional teria uma produtividade estimada em 810 a $1.720 \mathrm{~kg} / \mathrm{ha}^{-1}$, o que renderia de 13 a 28 sacas por hectare. 


\section{CONCLUSÕES}

As variedades de feijão-caupi BRS Novaera, seguida da "sempre verde" e "mata fome" apresentam desempenho satisfatório no período de estiagem, sendo uma opção para o agricultor poder cultivar mais uma safra de feijão durante o ano.

A variedade "mata fome" pode ser uma alternativa para adubação verde e recuperação de solos degradados, devido a produção expressiva de matéria seca e cobertura verde no solo.

\section{REFERÊNCIAS}

BOLETIM AGROPECUÁRIO DO PARÁ 2017. Fundação Amazônia de Amparo a Estudos e Pesquisas do Pará http://www.fapespa.pa.gov.br/upload/Arquivo/anexo/1383.pdf?id=1533567716. Acessado em: 20/02/2019.

BURATTO, J. S.; MODA-CIRINO, V.; FONSECA JÚNIOR, N. S.; PRETE, C. E. C.; FARIA, R. T. de. Adaptabilidade e estabilidade produtiva em genótipos precoces de feijão do estado do Paraná. Semina: Ciências Agrárias, Londrina, v. 28, n. 3, p. 373- 380, jul./set. 2007.

CLIMATE-DATA.ORG. Pesquisado em: https://pt.climate-data.org/america-dosul/brasil/para/castanhal-26632/\#climate-graph. Acessado em: 17/03/2018.

CONAB; Observatório agrícola, acompanhamento da safra brasileira de grãos. V.5 safra 2017/2018 - N. 7 - Sétimo levantamento, Brasília. p. 66 / Abril 2018.

CONAB - COMPANIA NACIONAL DE ABASTECIMENTO; OBSERVATÓRIO AGRÍCOLA. ACOMPANHAMENTO DA SAFRA BRASILEIRA DE GRÃOS, ISSN: 23186852. V. 5 - SAFRA 2017/18- N. 4 - Quarto levantamento |JANEIRO 2018.

Fundação Amazônia de Amparo a Estudos e Pesquisas do Pará - Fapespa. Boletim agropecuário do Pará, 2017.

FILHO, F. R. F; et., al. Feijão-Caupi no Brasil Produção, melhoramento genético, avanços e desafios. Embrapa Meio-Norte. Teresina, PI, 2011.

FILHO, F. R. F. RIBEIRO, V. Q.; ROCHA, M. M.; SILVA, K. J. D.; NOGUEIRA, M. S. R.; RODRIGUES, E. V. Produção, melhoramento genético e potencialidades do feijão-caupi no Brasil. IV Reunião de Biofortificação. Teresina-PI, Brasil, 2011.

INCAPER. Informações técnicas para o cultivo do feijoeiro-comum na região centralbrasileira: 2009/2010. Vitória, ES, 2010.

NUÑEZ, P. B. P.; MAIA. A. L. Sementes crioulas: um banco de biodiversidade. Revista Brasileira de Agroecologia, v. 1, n. 2, 2006.4p. 
OLIVEIRA, L. F. R. Avaliação de genótipos de feijoeiro comum, do grupo carioca, na época de inverno, em Uberlândia-MG. Uberlândia - MG Junho/2015

Oliveira, L. F. F. A. et., al. Crescimento e produtividade de duas cultivares de feijão em função de doses de ácido 2,3,5-triiodobenzoico. Ciência Rural, Santa Maria, v.45, n.12, p.2181-2186, 2015.

PAULINO, J. S.; GOMES, R. A. Sementes da Paixão: agroecologia e resgate da tradição. Revista de Economia e Sociologia Rural, v. 53, n. 3, p.517-528, 2015.

SALVADOR, C. A.; SEAB - Secretaria de Estado da Agricultura e do Abastecimento DERAL - Departamento de Economia Rural. Feijão - Análise da Conjuntura Agropecuária. 2012.

SILVA, C. M. et. al. Época de semeadura no desempenho agronômico do feijão-caupi. I CONGRESSO INTERNACIONAL DA DIVERSIDADE DO SEMIÁRIDO. Universidade Federal do Piauí - UFPI, 2016.

SILVA, P. I. B. e; NEGREIROS, M. Z. de; MOURA, K. K. C. de F.; FREITAS, F. C. L. de; NUNES, G. H. de S.; SILVA, P. S. L. e; GRANGEIRO, L. C.; Crescimento de pimentão em diferentes arranjos espaciais. Pesquisa Agropecuária Brasileira, Brasília, v. 45, n. 2, 2010. p. 132-139.

SOUSA, R. R.; DENSIDADE POPULACIONAL E INOCULAÇÃO NA CULTIVAR DE FEIJÃO-CAUPI BRS IMPONENTE; Dissertação (Mestrado em Agronomia) - Universidade Federal do Piauí, Teresina, 2017.

TEIXEIRA, W.V., MALTA, C.G., LEANDRO, W.M. Produtividade e avaliação da capacidade de expansão de milho pipoca crioulo em cultivo isolado e consorciado com feijãode-porco. Enciclopédia Biosfera, Centro Científico Conhecer - Goiânia, v.8, N.14; p. 7782012.

TRINDADE, C.C. Sementes crioulas e transgênicos, uma reflexão sobre sua relação com as comunidades tradicionais. XV Congresso Nacional do Conpedi, Manaus, Amazonas. 2006.

TSUTSUMI, Cláudio Y. et al. Cultivares de feijão produzidos em sistema de cultivo orgânico. Cultivando o Saber. v. 5, n. 3, p. 123 - 131. Cascavel, 2012. 


\title{
DESENVOLVIMENTO INICIAL DE PLÂNTULAS DE JUÇARA IRRIGADAS COM ÁGUA SALINA
}

\author{
DESARROLLO INICIAL DE PLÁNTULAS JUSSARA REGADAS CON AGUA \\ SALINA
}

\section{INITIAL DEVELOPMENT OF JUSSARA SEEDLINGS IRRIGATED WITH SALINE WATER}

\author{
Rosana Maria dos Santos Nani de Miranda ${ }^{1}$; Rozane Franci Moraes Tavares ${ }^{2}$; Tâmara \\ Moreira Silva ${ }^{3}$; Danilo Força Baroni ${ }^{4}$; Almy Junior Cordeiro de Carvalho ${ }^{5}$
}

DOI: https://doi.org/10.31692/978-65-991061-4-9.47-60

\begin{abstract}
RESUMO
O palmiteiro juçara é uma espécie de grande importância socioeconômica devido ao seu sabor, riqueza nutricional, e presença na alimentação humana e animal. Entretanto, a maior parte de sua exploração acontece de forma intensa, ilegal e predatória, resultando em uma erosão genética substancial, causando ameaça a regeneração da espécie. Além disso, o plantio de palmeiras pode ocorrer em solos salinos, irrigados ou não com água salina, tornando um fator limitante para crescimento e produtividade da cultura. Sendo assim, o objetivo nessa pesquisa foi avaliar o efeito da salinidade do substrato na emergência e desenvolvimento inicial de plântulas de juçara. $O$ delineamento foi em

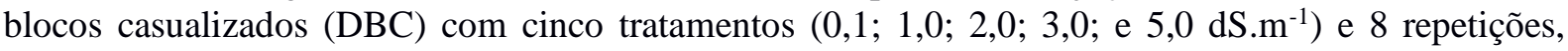
contendo 25 sementes para cada repetição, semeadas em tubetes de $290 \mathrm{~cm}^{3}$. O experimento foi conduzido por um período de 60 dias após a semeadura, aplicando diariamente $75 \mathrm{ml}$ de água por tubete, com a concentração salina determinada em cada tratamento. Foram realizadas as seguintes avaliações: emergência (E), tempo médio de emergência (TME), índice de velocidade de emergência (IVE), comprimento da parte aérea (CPA), diâmetro do coleto (DC), massa seca da parte aérea (MSPA), e massa seca do sistema radicular (MSSR). Desta forma, verificou-se que o aumento das soluções salinas acima de $1 \mathrm{dS} . \mathrm{m}^{-1}$ reduz a emergência das sementes, assim como o crescimento da parte aérea (comprimento, diâmetro, e massas secas), porém, condutividades até $5 \mathrm{dS} \cdot \mathrm{m}^{-1}$ não interferem no TME e no IVE. Portanto, a água de irrigação contendo até $5 \mathrm{dS} . \mathrm{m}^{-1}$ pode causar danos nas sementes de juçara, retardando sua emergência e prejudicando os aspectos morfológicos na produção de mudas.
\end{abstract}

Palavras-Chave: Euterpe edulis M., estresse salino, emergência.

\section{RESUMEN}

La palma de jussara es una especie de gran importancia socioeconómica debido a su sabor, riqueza nutricional y presencia en la alimentación humana y animal. Sin embargo, la mayor parte de su explotación es intensa, ilegal y depredadora, lo que resulta en una erosión genética sustancial, que amenaza la regeneración de la especie. Además, la siembra de palma puede ocurrir en suelos salinos, regados o no con agua salina, lo que lo convierte en un factor limitante para el crecimiento y rendimiento de los cultivos. Por lo tanto, el objetivo de esta investigación fue evaluar el efecto de la salinidad del sustrato en la emergencia y el desarrollo inicial de las plántulas de jussara. El diseño experimental fue un diseño de bloques al azar con cinco tratamientos $\left(0.1,1.0,2.0,3.0\right.$ y $\left.5.0 \mathrm{dS} . \mathrm{m}^{-1}\right)$ y

\footnotetext{
${ }^{1}$ Graduanda em Engenharia Agronômica, Universidade Estadual do Norte Fluminense Darcy Ribeiro, ronani.uenf@gmail.com

${ }^{2}$ Doutoranda do Programa de Pós-graduação em Produção Vegetal, Universidade Estadual do Norte Fluminense Darcy Ribeiro, rozane.franci@gmail.com

3 Doutoranda do Programa de Pós-graduação em Agronomia, Universidade Estadual do Sudoeste da Bahia, tammoreiras@gmail.com

${ }^{4}$ Doutorando do Programa de Pós-graduação em Produção Vegetal, Universidade Estadual do Norte Fluminense Darcy Ribeiro, baronidf@gmail.com

${ }^{5}$ Professor Doutor, Universidade Estadual do Norte Fluminense Darcy Ribeiro, almy@ fruticultura.org
} 
8 repeticiones, que contenían 25 semillas para cada replicación. sembrado en tubos de $290 \mathrm{~cm}^{3}$. El experimento se realizó durante 60 días después de la siembra, aplicando diariamente $75 \mathrm{ml}$ de agua por tubo, con la concentración de solución salina determinada en cada tratamiento. Se realizaron las siguientes evaluaciones: emergencia (E), tiempo medio de emergencia (TME), índice de velocidad de emergencia (IVE), longitud del brote (CPA), diámetro del tallo (DC), masa seca del brote (MSPA), y la masa seca del sistema radicular (MSSR). Por lo tanto, se encontró que el aumento de las soluciones salinas por encima de $1 \mathrm{dS} \cdot \mathrm{m}^{-1}$ redujo la aparición de semillas, así como el crecimiento de brotes (longitud, diámetro y masa seca), pero la conductividad hasta $5 \mathrm{dS} . \mathrm{m}^{-1}$ no interfiere con TME y IVE. Por lo tanto, el agua de riego que contiene hasta $5 \mathrm{dS} \cdot \mathrm{m}^{-1}$ puede causar daños a las semillas de jussara, retrasando su aparición y perjudicando los aspectos morfológicos en la producción de plántulas.

Palabras Clave: Euterpe edulis M., estrés salino, emergencia.

\begin{abstract}
The jussara palm is a species of great socioeconomic importance due to its flavor, nutritional richness, and presence in human and animal food. However, most of its exploitation is intense, illegal and predatory, resulting in substantial genetic erosion, threatening the regeneration of the species. In addition, palm planting can occur in saline soils, irrigated or not with saline water, making it a limiting factor for crop growth and yield. Therefore, the objective of this research was to evaluate the effect of substrate salinity on the emergence and initial development of jussara seedlings. The experimental design was a randomized block design with five treatments $\left(0.1,1.0,2.0,3.0\right.$, and $\left.5.0 \mathrm{dS} . \mathrm{m}^{-1}\right)$ and 8 replications, containing 25 seeds for each replication. sown in $290 \mathrm{~cm}^{3}$ tubes. The experiment was conducted for a period of 60 days after sowing, daily applying $75 \mathrm{ml}$ of water per tube, with the saline concentration determined in each treatment. The following evaluations were performed: emergency (E), mean emergency time (TME), emergency speed index (IVE), shoot length (CPA), stem diameter (DC), shoot dry mass (MSPA), and dry mass of the root system (MSSR). Thus, it was found that the increase of saline solutions above $1 \mathrm{dS} . \mathrm{m}^{-1}$ reduced seed emergence, as well as shoot growth (length, diameter, and dry mass), but conductivity up to $5 \mathrm{dS} . \mathrm{m}^{-1}$ do not interfere with TME and IVE. Therefore, irrigation water containing up to $5 \mathrm{dS} \cdot \mathrm{m}^{-1}$ can cause damage to jussara seeds, delaying their emergence and impairing morphological aspects in seedling production.
\end{abstract}

Keywords: Euterpe edulis M., saline stress, emergency.

\title{
INTRODUÇÃO
}

O palmiteiro juçara, (Euterpe edulis M.) é uma das culturas no Brasil que mais produz palmito comestível, destacando-se pelo sabor, riqueza nutricional, abundância durante o ano, e fornecendo alimento a várias espécies animais com seus frutos e sementes. Entretanto, a sua exploração ocorre de forma intensa, ilegal e predatória, resultando em uma erosão genética substancial, proporcionando uma ameaça à regeneração da espécie, levando a inclusão da espécie na Lista Oficial das Espécies da Flora Brasileira Ameaçadas de Extinção (ROYER et al., 2016). Logo, a carência por uma forma de preservação e plantios para reflorestamento tem aguçado o interesse de vários pesquisadores (FIGLIORIA et al., 1987).

Devido à conscientização pela necessidade de programas de recomposição e proteção ambiental, tem-se aumentado a demanda por mudas florestais de espécies nativas (NASCIMENTO et al., 2012), principalmente de espécies como a juçara, que tem elevada 
importância na dinâmica da floresta, devido sua abundante produção de frutos e sua amplitude de produção, tornando-a espécie-chave para a manutenção da fauna (REIS, 1995).

Entretanto, um dos principais fatores ambientais que limitam o crescimento e produtividade das plantas é a salinidade (MUNNS, 2002; L.V. et al., 2008). Assim, os efeitos tóxicos que aparecem em ambientes com elevadas concentrações de sais provocam distúrbios funcionais e danos no processo metabólico (SILVA E.N. et al., 2009). Os potenciais hídricos muitos negativos, especialmente no início da embebição, influenciam na absorção de água, podendo inviabilizar a sequência dos eventos relacionados ao processo germinativo das sementes. O dano é mais evidenciado, na fase de plântulas, onde as atividades metabólicas de desenvolvimento das sementes estão mais sujeitas a ação da salinidade (De SOUZA, 2011).

Quando há a presença de teor salino no solo ou na água de irrigação, especialmente de cloreto de sódio $(\mathrm{NaCl})$, de início, a germinação é afetada pelo fato da ação osmótica ocasionar dificuldade na absorção de água para reidratar os tecidos, e intensificar a respiração e todas as atividades metabólicas que culminam com o fornecimento de energia e nutrientes necessários para a retomada do crescimento do eixo embrionário, ocasionando no aparecimento de plantas anormais pela razão do efeito tóxico dos sais sobre a semente (LIMA et al., 2005), consequentemente, ocorre a queda de rendimento das culturas (FLOWERS, 2004). Entretanto, palmeiras, de uma maneira geral, desenvolvem-se bem sobre condições salinas. Desta forma, tem sido apresentada a possibilidade do uso de solos salinos, irrigados ou não com água salina em diversas espécies de palmeiras, como Cocos nucifera L. (FERREIRA NETO et al., 2002; MARINHO et al., 2005); Bactris gasipaes (FERNANDES et al., 2003) e Copernicia prunifera (HOLANDA, 2011), através de concentrações mais elevadas de sais com essas espécies.

Para o processo de emergência de plântulas dois fatores ocorrem: a energia contida no endosperma ou cotilédone, e a profundidade na qual a semente é inserida no substrato para semeadura (HACKBART E CORDAZZO, 2003). Com isso, para a obtenção de uma ótima formação de mudas é altamente desejável que as sementes tenham características como uma germinação rápida e uniforme, consequentemente com uma imediata emergência. Porém, se as plântulas permanecerem nos estádios iniciais de desenvolvimento, maior é a vulnerabilidade que estas terão em condições adversas do meio, e o processo de emergência do solo torna-se mais lento caso a plântula fique mais tempo a essas condições (MARTINS et al., 1999). De acordo com Fonseca (2000) e Bonfim (2007) os parâmetros que são mais utilizados para obterem uma maior facilidade nas medições, é o aspecto morfológico das plantas, pois determinam um padrão de qualidade das mudas florestais. 
Dado o exposto, o objetivo nessa pesquisa foi avaliar o efeito da salinidade no substrato em relação a emergência e desenvolvimento inicial de plântulas de juçara.

\section{FUNDAMENTAÇÃO TEÓRICA}

A juçara é uma das principais espécies com maior representatividade na Mata Atlântica, por obter um reconhecimento econômico (ROYER, 2016) e por ser de fácil identificação no interior da floresta possibilita uma alta procura pela exploração da cultura no ecossistema (REIZ et al., 1978).

Ashraf e Harris (2004) apresentam que os mecanismos de tolerância nas plantas devido ao estresse salino podem ser importantes para os processos de controle de absorção, transporte e distribuição dos íons em toda planta. De modo geral, a quantidade salina presente nas plantas pode inibir seu crescimento de acordo com os efeitos osmóticos e tóxicos dos íons (MUNNS, 2002; L.V. et al., 2008).

Contudo, o desenvolvimento de palmeiras, de uma maneira geral, em condições salinas ocorre de forma adaptável, no entanto, poucas são as informações em literaturas sobre esse efeito de estresse nas espécies com a observação em emergência e vigor das sementes (TESTER; DAVÉNPORT, 2003).

\section{METODOLOGIA}

O experimento foi instalado em casa de vegetação no Campus da Universidade Estadual do Norte Fluminense Darcy Ribeiro - UENF, situada a 2119'23" latitude Sul e $41^{\circ} 10^{\prime} 40^{\prime \prime}$ longitude Oeste; Altitude $=14$ metros acima do mar. Decorreu-se no período do dia 14 de novembro de 2017 até o dia 15 de janeiro de 2018, durante 60 dias consecutivos.

As sementes de juçara foram coletadas no Município de Venda Nova do Imigrante (Latitude $=-20^{\circ} 33^{\prime} 49^{\prime \prime}$, Longitude $=-41.130420^{\circ} 20^{\prime} 6^{\prime \prime}$ Sul, 41 ${ }^{\circ} 7^{\prime} 49^{\prime \prime}$ Oeste; Altitude $=708$ metros acima do mar), no Estado do Espírito Santo. Após a coleta, o lote das sementes foi enviado até Unidade de Apoio à Pesquisa (UAP), da Universidade Estadual do Norte Fluminense Darcy Ribeiro, no Estado do Rio de Janeiro.

Durante a condução do experimento, as condições ambientais internas da casa de vegetação foram registradas: a temperatura do ar ( $\left.\mathrm{T}_{\mathrm{ar}}\right)$, umidade relativa (UR\%) em mínimas, médias e máximas pela microestação Datalog modelo Watch Dog weather station, spectrum tecnologies 2000 séries, programado para realizar leituras em intervalos de uma hora (Figura 1), e a radiação incidente (RI) foi obtida a média de $300 \mu \mathrm{mol} \mathrm{m} \mathrm{m}^{-2} \mathrm{~s}^{-1}$.

As sementes foram lixadas superficialmente para obter uma entrada de solução com 
maior facilidade, em seguida, foram semeadas em tubetes de volume de $290 \mathrm{~cm}^{3}$ contendo substrato basaplant ${ }^{\circledR}$ Hortaliças BX, com as seguintes características: umidade de 50\%, capacidade de retenção igual a $150 \%$, condutividade elétrica de $2,5 \mathrm{mS} . \mathrm{cm}^{-1}$, e pH igual a 5,8. As sementes foram colocadas a uma profundidade de 1 centímetro, em ambiente protegido.

Figura 1: Temperatura e umidade relativa do ar (\%), em mínimas, médias e máximas durante a condução do experimento. UENF, Campos dos Goytacazes-RJ. Fonte: Silva, 2018.

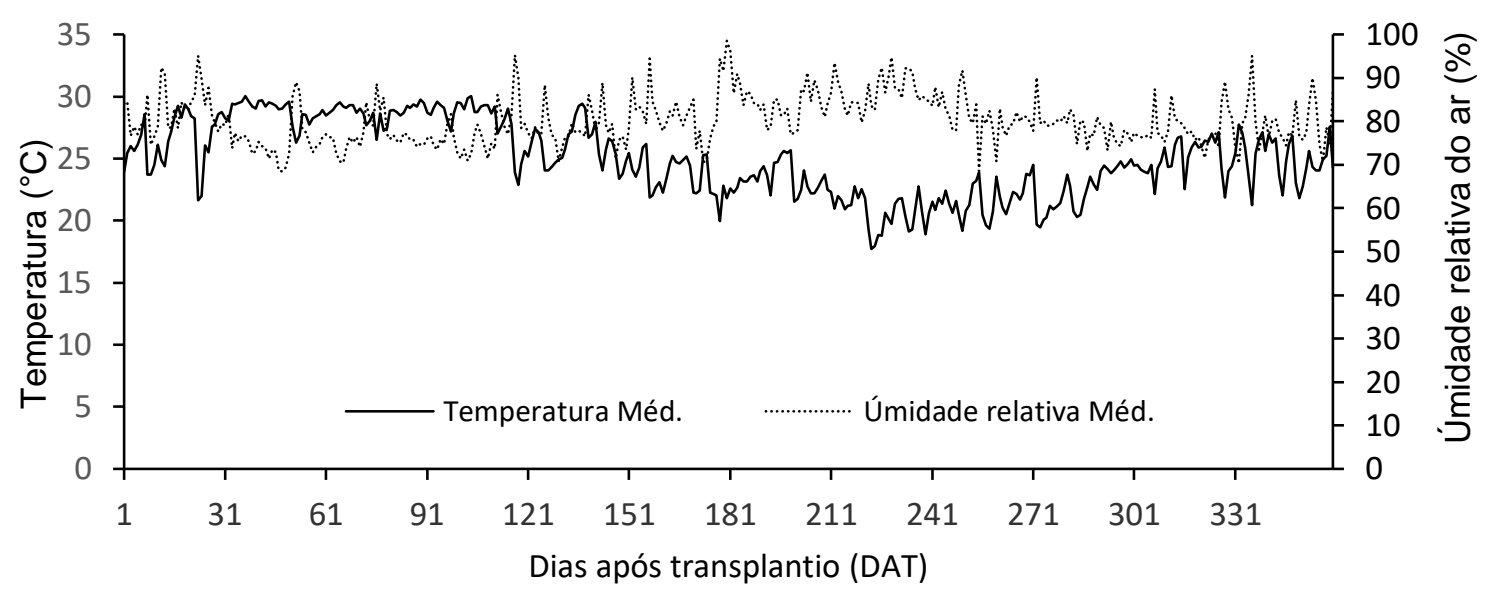

O delineamento foi em blocos casualizados (DBC) com cinco tratamentos, expresso em condutividade elétrica $\left(0,1 ; 1,0 ; 2,0 ; 3,0\right.$ e 5,0 dS.m $\left.{ }^{-1}\right)$ com oito repetições, cada repetição continha 25 tubetes com uma semente para compor a unidade experimental. As águas salinas foram preparadas por meio de adição de cloreto de sódio $(\mathrm{NaCl})$ à agua proveniente do abastecimento urbano, sendo assim, para determinar a condutividade elétrica, foi feito o cálculo para a quantidade de sal utilizada em cada tratamento, utilizando-se a equação 1, de Cavalcante et al. (2010): I) $1^{\text {a }}$ dose, tratamento controle, correspondendo a $0,1 \mathrm{dS} \cdot \mathrm{m}^{-1}$ (sendo esta a condutividade elétrica do abastecimento urbano); II) $2^{\text {a }}$ dose, solução salina contendo 0,526 g. $\mathrm{L}^{-1}$ de $\mathrm{NaCl}$ correspondendo a condutividade elétrica de $1,0 \mathrm{dS} . \mathrm{m}^{-1}$; III) $3^{\mathrm{a}}$ dose, solução salina contendo 1,111 g.L $\mathrm{L}^{-1}$ de $\mathrm{NaCl}$ referente a condutividade elétrica de 2,0 dS.m ${ }^{-1}$; IV) $4^{\mathrm{a}}$ dose, solução salina contendo 1,695 g.L.-1 de $\mathrm{NaCl}$ correspondendo a condutividade elétrica de 3,0 dS.m ${ }^{-1}$; e V) $5^{\mathrm{a}}$ dose, solução salina contendo 2,864 g.L.-1 de NaCl referente a condutividade elétrica de 5,0 dS.m ${ }^{-1}$. O grau de pureza do sal utilizado foi de $\geq 99,9 \%$ e o peso equivalente igual a 58,50 .

$$
C S=0,01\left[\frac{(C E d-C E a u)}{G P}\right] * P e q
$$

\section{Onde:}

$\mathrm{CS}=$ Concentração de cada espécie iônica $\left(\mathrm{g} . \mathrm{L}^{1}\right)$

CEd = Condutividade elétrica desejada

$\mathrm{CEau}=$ Condutividade elétrica da água oriunda do abastecimento urbano 
$\mathrm{GP}=$ Grau de pureza de cada sal

Peq $=$ Peso equivalente

Após a elaboração das soluções foi aferida a condutividade elétrica utilizando-se o condutivímetro digital de bancada para a solução aquosa, modelo MCA - 150.1. As soluções foram preparadas semanalmente e armazenadas em recipientes de polietileno hermeticamente fechados em local fresco e à sombra, de modo a evitar a evaporação e variação de temperatura da solução. A aplicação dos tratamentos foi durante a emergência das plantas, as sementes eram diariamente irrigadas, e em cada tubete aplicava-se $75 \mathrm{ml}$ de solução, desta maneira, eram irrigados $525 \mathrm{ml}$ de solução por semana.

A cada dia, foi realizada a avaliação da emergência e foram feitas contagens do número de plântulas até que a germinação ficasse ausente completamente, em um período de 60 dias. Determinou-se como critério para a avaliação da emergência a parte aérea emitida. A coleta dos dados em cada repetição do experimento foi utilizada para o cálculo do tempo médio de emergência (TME), sendo feito a contagem do número de plântulas emergidas diariamente e feito à média dos dias requeridos para emergência de cada repetição, e determinou-se também a taxa de germinação, através da média das sementes germinadas de cada repetição em porcentagem.

Para a determinação dos parâmetros morfológicos foi avaliado o comprimento da plântula com régua graduada milimetrada, com resultados expressos em centímetro, e o diâmetro do coleto, medido com paquímetro digital com 1 milímetro de precisão, resultados expressos em milímetro.

A coleta para avaliação da produção de biomassa seca das mudas foi realizada no final do experimento, separando raiz e parte aérea, sendo o sistema radicular lavado em água corrente para limpeza das raízes. No final, a soma da parte aérea e raiz forneceu a biomassa fresca total. $\mathrm{O}$ material fresco foi acondicionado em sacos de papel tipo Kraft, tarados e pesados em balança digital analítica com precisão de 0,01g. Após a pesagem da biomassa fresca, as mudas foram colocadas para secagem em estufa com circulação forçada de ar a $70{ }^{\circ} \mathrm{C}$ por 72 horas, sendo posteriormente pesada e, então, determinado os parâmetros biomassa seca da parte aérea, e a biomassa seca radicular, os resultados foram expressos em gramas.

O principal índice baseado nas relações de parâmetros morfológicos e que foi utilizado na avaliação da qualidade de mudas foi a relação da biomassa seca da parte aérea com a biomassa seca radicular (FONSECA et al., 2000).

Os dados foram submetidos à análise de variância (ANOVA) pelo teste $\mathrm{F}$ ao nível de significância de $5 \%$ de probabilidade para a comparação dos tratamentos. Utilizou-se a análise de 
regressão, com teste $\mathrm{F}$ significativo da análise de variância da regressão. O software estatístico utilizado foi o Sisvar (Versão 5.6).

\section{RESULTADOS E DISCUSSÃO}

Ao analisar os resultados da emergência das sementes de juçara (Figura 2), foi possível verificar efeito linear decrescente da regressão, em que o aumento na concentração salina da água de irrigação, causou redução de 67,0\% na emergência das sementes em 5 dS.m ${ }^{1}$ quando comparado ao controle. Sendo assim, o excesso de íons de cloreto de sódio $(\mathrm{NaCl})$ presentes no substrato, pode ter inibido a germinação causando intumescência protoplasmática, afetando a atividade enzimática e resultando na produção inadequada de energia e distúrbios na assimilação de nutrientes, principalmente o nitrogênio, isso é ocasionado devido ao baixo potencial hídrico, em função do efeito osmótico (LIMA et al.,2005). O gradiente osmótico formado pela concentração de sais limita a absorção de água pela semente (BARONI, 2018), afetando diretamente o desenvolvimento do embrião, o qual depende da pressão de turgescência das células para que os processos de divisão e expansão celulares ocorram (KLAFKE et al., 2012).

Figura 2. Emergência (\%) de sementes de juçara irrigadas com águas salinas em diferentes condutividades elétricas ao longo de 60 dias.

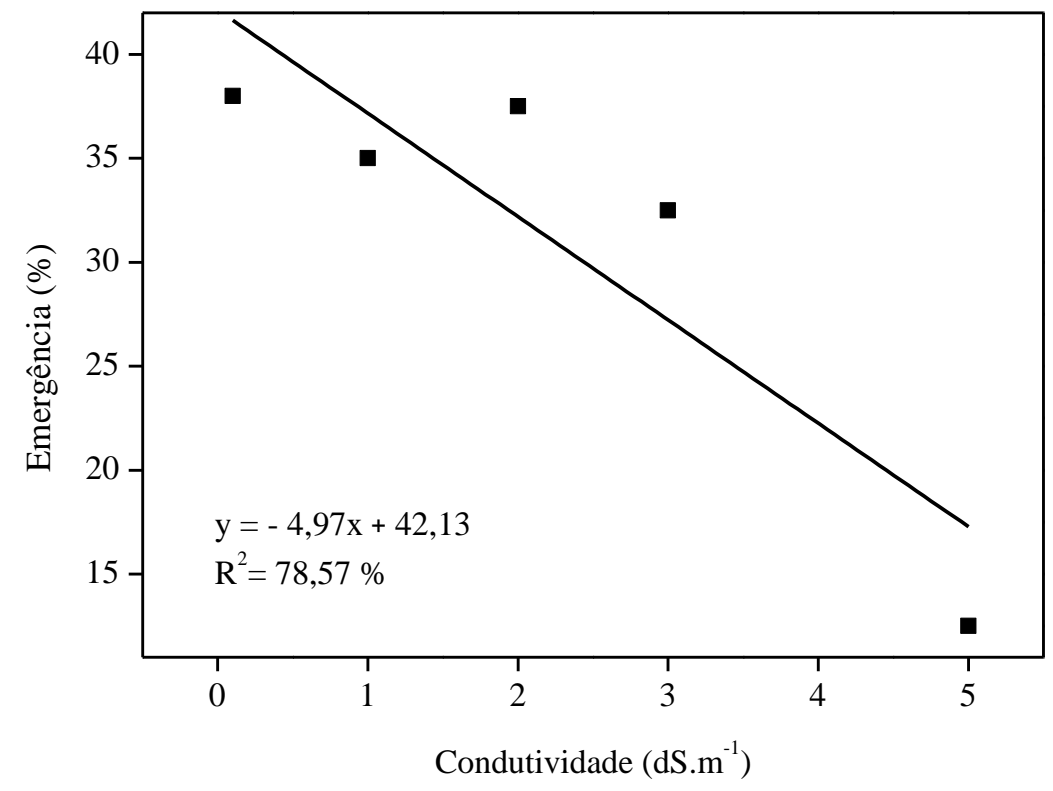

Fonte: Própria (2018)

Ao analisar o TME (Figura 3) e o IVE (Figura 4), testes recomendados para determinação do vigor de sementes, não foi encontrada diferença entre as concentrações salinas da água de irrigação. Ao correlacionar tais variáveis com a emergência (Figura 2), acredita-se que a salinização da água de irrigação em todas as doses utilizadas, tenha inibido 
apenas a germinação das sementes de menor vigor. Com isso, obteve-se uma redução significativa na emergência das sementes, enquanto que o TME e o IVE não foram afetados. Em condições inadequadas para germinação as sementes de menor vigor são menos resistentes que as vigorosas, sendo assim, possuem menor capacidade de superar tais condições (BARONI, 2018).

Figura 3. Tempo médio de emergência (TME) de sementes de juçara irrigadas com águas salinas em diferentes condutividades elétricas ao longo de 60 dias.

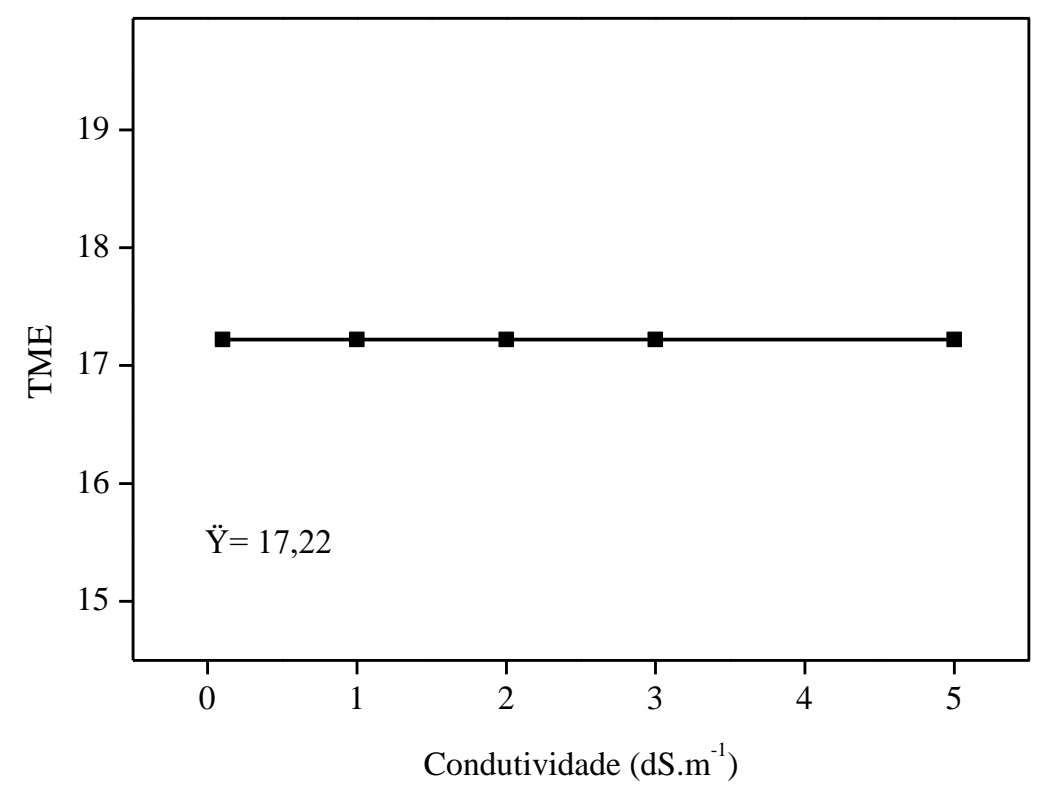

Fonte: Própria (2018)

Figura 4. Índice de velocidade de emergência (IVE) de sementes de juçara irrigadas com águas salinas em diferentes condutividades elétricas ao longo de 60 dias.

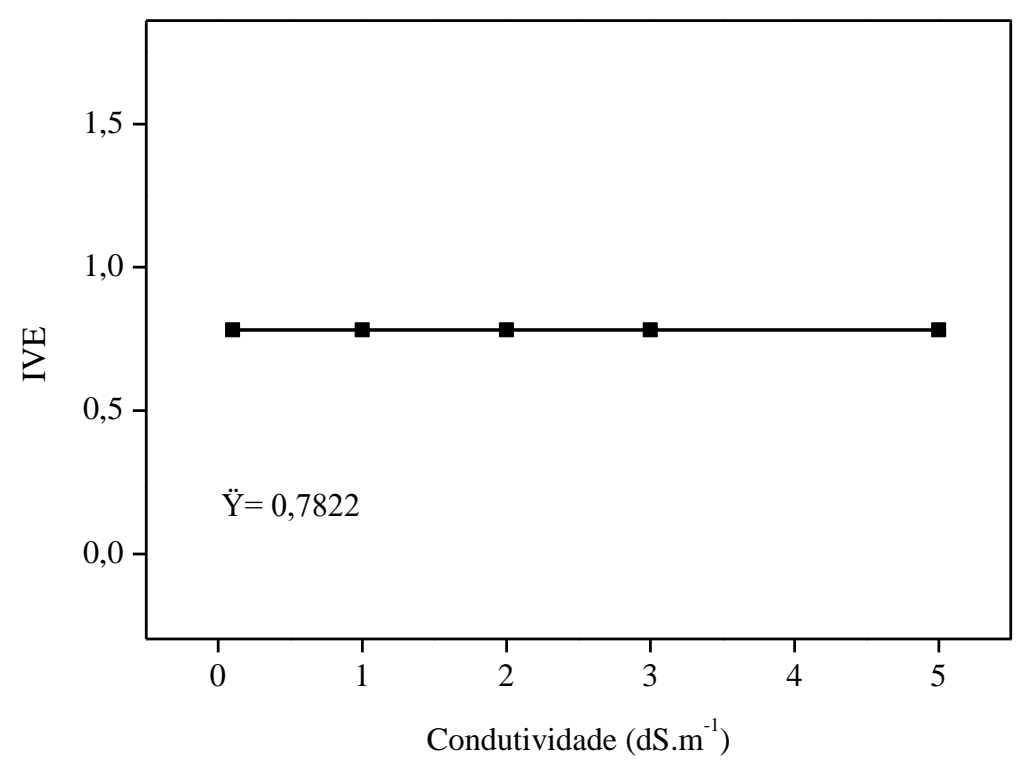

Fonte: Própria (2018) 
A salinidade da água de irrigação interferiu não somente na emergência das plântulas, mas também no desenvolvimento vegetativo das mesmas. Para a variável comprimento da parte aérea (Figura 5), houve efeito linear decrescente de regressão, em que o aumento da concentração salina até $5 \mathrm{dS} \cdot \mathrm{m}^{-1}$ causou redução de 59,3\% em comparação com o controle (água com condutividade elétrica de $0,1 \mathrm{dS} \cdot \mathrm{m}^{-1}$ ).

Figura 5. Comprimento da parte aérea (CPA) das plântulas de juçara irrigadas com águas salinas em diferentes condutividades elétricas ao longo de 60 dias.

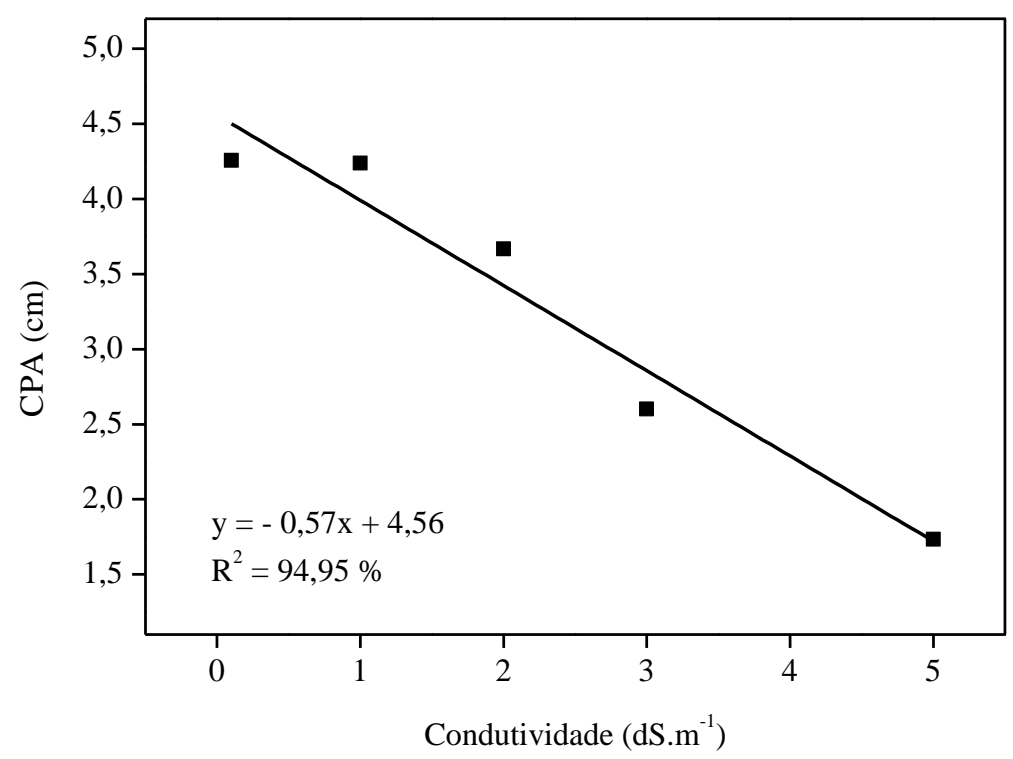

Fonte: Própria (2018)

Resultado semelhante ao CPA foi obtido para o diâmetro do coleto (DC) (Figura 6), entretanto em menor intensidade. A variável CPA sofreu uma redução de 2,64 vezes, quando as plântulas foram irrigadas com água de condutividade elétrica $5 \mathrm{dS} . \mathrm{m}^{-1}$, se comparada ao controle. O DC por sua vez, apresentou redução apenas de 1,48 vezes para as mesmas condições. A redução do comprimento das plântulas de juçara é devido às mudanças na turgescência celular, em função da redução da síntese de proteína às condições de estresse hídrico causado pela salinidade do meio, ocasionando redução na expansão celular e desta forma reduzindo o crescimento das plântulas (TAIZ E ZEIGER, 2009). 
Figura 6. Diâmetro do coleto (DC) das plântulas de Euterpe edulis M. irrigadas com águas salinas em diferentes condutividades elétricas ao longo de 60 dias.

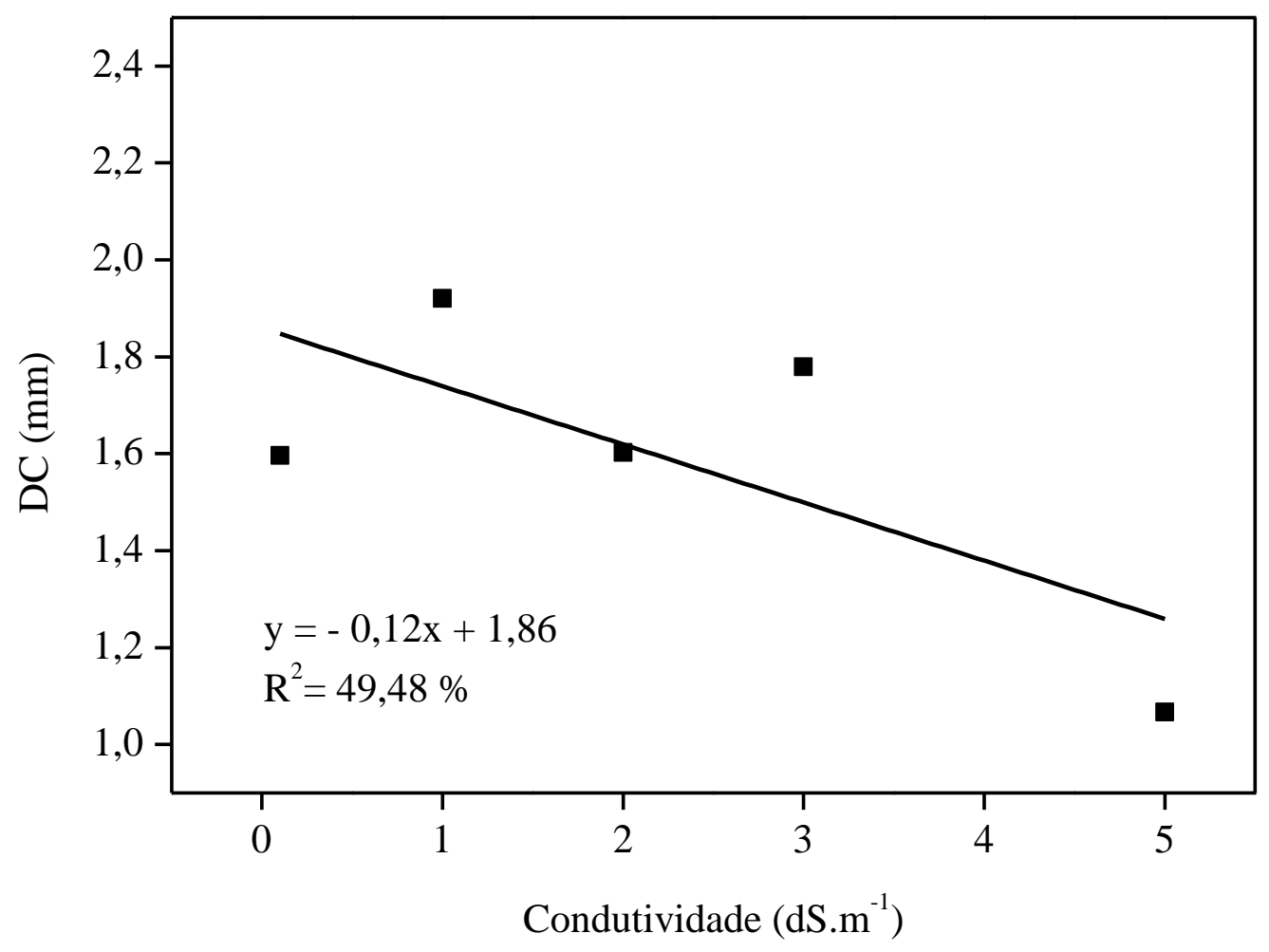

Fonte: Própria (2018)

A redução do crescimento da parte aérea observado nas Figuras 5 e 6 resultou consequentemente em uma menor deposição de massa seca pelas plantas. $\mathrm{O}$ crescimento da parte aérea e do sistema radicular está altamente relacionado, de modo que a interferência no desenvolvimento de uma parte influenciará o desenvolvimento da outra. Tal característica foi facilmente observada ao analisar as Figuras 7 e 8, ao verificar que a redução de 55,0\% do crescimento radicular em $5 \mathrm{dS} . \mathrm{m}^{-1}$ relacionado ao controle, obtido pela variável MSSR (Figura 7), causada pelo aumento da salinização do substrato via água de irrigação, reduziu também o crescimento da parte aérea, ao observar a redução das variáveis CPA, DC e MSPA (Figura 8). Essa redução tanto na biomassa seca da parte aérea quanto da raiz pode ser explicada pela redução do metabolismo das sementes, em função da menor disponibilidade de água presente para a degradação das reservas e translocação dos nutrientes metabolizados, pois a água é osmoticamente retida em solução salina, de maneira que, com o aumento dos sais na solução torna a água cada vez menos disponível para as plantas (BARTELS SUNKAR, 2005). 
Figura 7. Massa seca da parte aérea (MSPA) das plântulas de juçara irrigadas com águas salinas em diferentes condutividades elétricas ao longo de 60 dias.

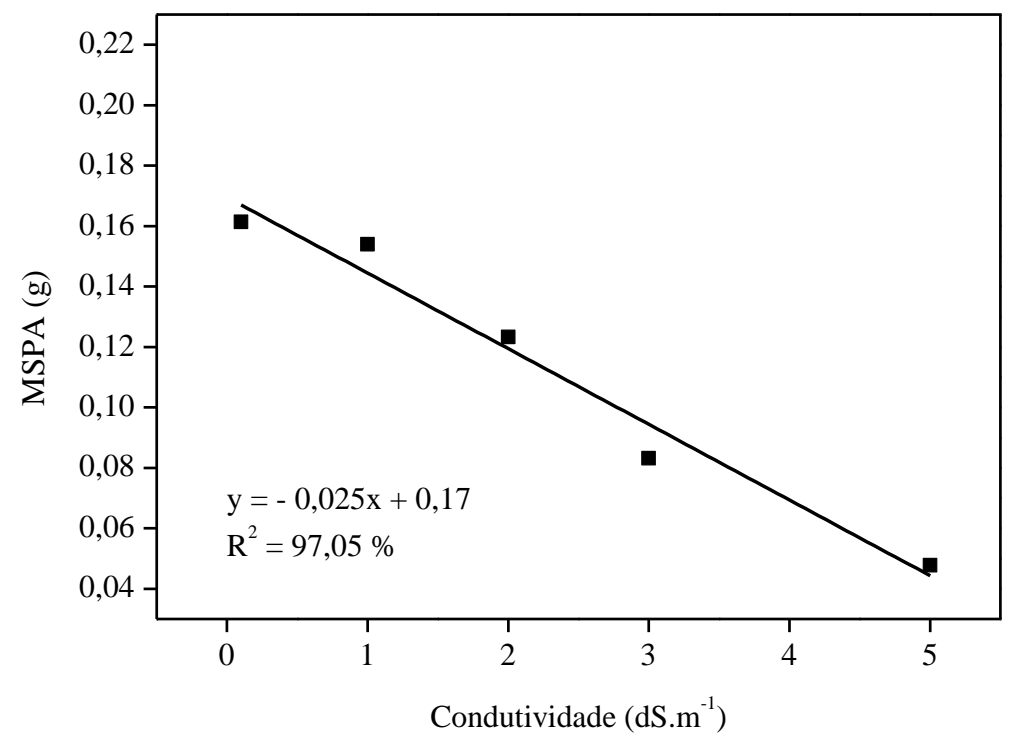

Fonte: Própria (2018)

Figura 8. Massa seca do sistema radicular (MSSR) das plântulas de juçara irrigadas com águas salinas em diferentes condutividades elétricas ao longo de 60 dias.

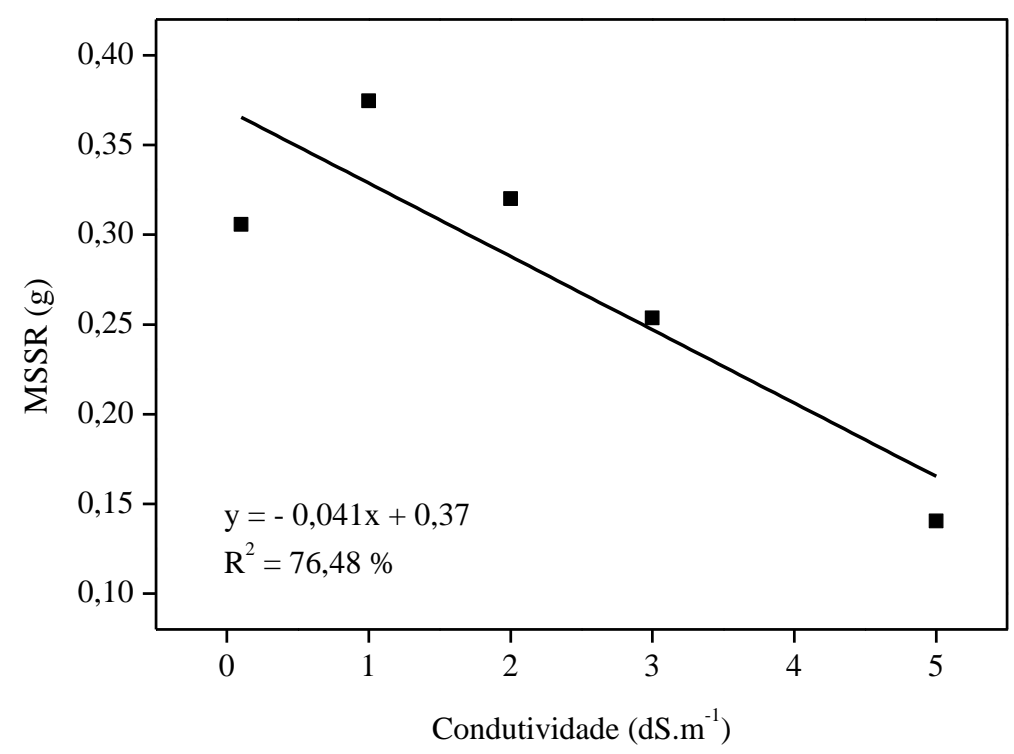

Fonte: Própria (2018)

Logo, os resultados apresentados demonstraram que a ação da salinização do substrato, dificultou o crescimento vegetativo das plântulas, com os efeitos osmóticos e tóxicos dos íons (MUNNS, 2002; L.V. et al., 2008). Portanto, a salinidade pode vir a interferir na produção de mudas de qualidade (FONSECA, 2000; BONFIM, 2007). 


\section{CONCLUSÕES}

Concentração salina superior a $1 \mathrm{dS} \cdot \mathrm{m}^{-1}$ reduz a emergência de plântulas de juçara; Concentrações salinas de até $5 \mathrm{dS} . \mathrm{m}^{-1}$ não interferem no TME e IVE de plântulas de juçara;

Plântulas de juçara têm redução do seu crescimento quando irrigadas com água com concentração salina a partir de $1 \mathrm{dS} \cdot \mathrm{m}^{-1}$.

\section{REFERÊNCIAS}

ASHRAF, M.; HARRIS, P. J. C. Potential biochemicalindicators of salinity tolerance in plants. Plant Science, v.166, p.889-899, 2004.

BARONI, D. F. Qualidade física e fisiológica de sementes de Stylosanthes capitata/macrocephala revestidas. Campos dos Goytacazes. 2018. 96 p. Dissertação (Produção Vegetal). Departamento de Fitotecnia, UENF, 2018.

BARTELS, D., SUNKAR, R. Drought and salt tolerance in plants. Critical reviews in plant sciences, v. 24, n. 1, p. 23-58, 2005.

BONFIM, A. A. Qualidade de mudas de madeira nova (Pterogyne netens Tell) produzidas em tubetes e sacolas plásticas e seu desempenho no campo. 2007. 70 p. Dissertação (Mestrado em Agronomia) - Universidade Estadual do Sudoeste da Bahia, Vitória da Conquista, 2007.

CAVALCANTE, L. F., VIEIRA, M. S., SANTOS, A. F., OLIVEIRA, W. M., NASCIMENTO, J. A. M. Água salina e esterco bovino líquido na formação de mudas de goiabeira cultivar paluma. Revista Brasileira de Fruticultura. Jaboticabal, v.32, n. 1, p. 251-261, mar. 2010.

De SOUZA, A.B.O.; BEZERRA, M.A. \& FARIAS, F.C. Germinação e desenvolvimento inicial de clones de cajueiro comum sob irrigação com água salina. Revista Brasileira de Engenharia Agrícola e Ambiental. Campina Grande - PB. v.15, n 4, p. 390-394, 2011.

FERNANDES, A. R.; CARVALHO, J. G.; CURI, N.; GUIMARÃES, P. T. G; PINTO, J. E. B. P. Crescimento de mudas de pupunheira (Bactris gasipaes H.B.K) sob diferentes níveis de salinidade. Ciência e Agrotecnologia, Lavras, v. 27, n. 2, p. 278-284, 2003.

FERREIRA NETO, M.; GHEYI, H. R.; HOLANDA, J. S. de; MEDEIROS, J. F. de; FERNANDES, P. D. Qualidade do fruto verde de coqueiro em função da irrigação com água salina. Revista Brasileira de Engenharia Agrícola e Ambiental, Campina Grande, v. 6, n.1, p. 69-75, 2002.

FIGLIORIA, M.B.; OLIVEIRA, E.C.; YAMANZOE, G.; SIQUEIRA, A.C.M.F. Conservação de sementes de Euterpe edulis Mart., em diferentes embalagens e ambientes de armazenamento. Boletim técnico do Instituto Florestal, v.41, p.355-368, 1987.

FLOWERS, T. J. Improving crop salt tolerance. Journal of Experimental Botany, Oxford, v. 55, n. 396, p. 307-319, 2004.

FONSECA, E. P. Padrão de qualidade de mudas de Trema micrantha (L.) Blume., Cedrela fissilis Vell. e Aspidosperma polyneuron Muil Arg. produzidas sob diferentes períodos de 
sombreamento. Jaboticabal, UEP, 2000. 113p. Tese (Doutorado em Agronomia) - Universidade Estadual Paulista, 2000.

HACKBART, V. C. S.; CORDAZZO, C. V. Ecologia das sementes e estabelecimento das plântulas de Hydrocotyle bonariensis Lam. Atlântica, Rio Grande, n. 25, v. 1, p. 61-65, 2003.

HOLANDA, S. J. R.; ARAUJO, F. S.; GALLÃO, M. I.; MEDEIROS FILHO, S. Impacto da salinidade no desenvolvimento e crescimento de mudas de carnaúba (Copernicia prunifera (Miller) H. E. Moore). Revista Brasileira de Engenharia Agrícola e Ambiental, Campina Grande, v. 15, n. 1, p. 47-52, 2011.

KLAFKE, A. V., LOPES, R. R., FRANKE, L. B. Desempenho de sementes nuas e revestidas de azevém-anual em condições de estresse salino. Brazilian journal of animal science, 41(5), 1093-1099. 2012.

LIMA, M. G. S.; LOPES, N. F.; MORAES, D. M.; ABREU, C. M. Qualidade fisiológica de sementes de arroz submetidas a estresse salino. Revista Brasileira de Sementes, Londrina, v. 27, n. 1, p. 54-61, 2005.

LV, S.; ZHANG, K.; GAO, Q.; LIAN, L.; YINGJIE, L.; YINGJIE, C.; ZHANG, J. Overexpression of an $\mathrm{H}+$-PPase gene from Thellungiella halophila in cotton enhances salt tolerance and improves growth and photosynthetic performance. Plant \& Cell Physiology, v. 49, n. 08 , p. 1150-1164, 2008.

MARINHO, F. J. L.; GHEYI, H. R.; FERNANDES, P. D. Germinação e formação de mudas de coqueiro irrigadas com águas. Revista Brasileira de Engenharia Agrícola e Ambiental, Campina Grande, v. 9, n. 3, p. 334-340, 2005.

MARTINS, C.C.; NAKAGAWA, J.; BOVI, M.L.A. Efeito da posição da semente no substrato e no crescimento inicial das plântulas de Palmito-Vermelho (Euterpe espiritosantensis Fernandes Palmae). Revista Brasileira de Sementes, Brasília, v. 21, n. 1, p. 164-173, 1999.

MUNNS, R. Comparative physiology of salt and water stress. Plant Cell \& Environment, v.25, p.239-250, 2002.

NASCIMENTO, D. F.; LELES, P. S. S.; OLIVEIRA NETO, S. N.; MOREIRA, R. T. S.; ALONSO, J. M. Crescimento inicial de seis espécies florestais em diferentes espaçamentos. Cerne, v.18, p.159 165, 2012.

REIS, A. Dispersão de sementes de Euterpe edulis Martius (Palmae) em uma floresta ombrófila densa Montana da Encosta Atlântica em Blumenau, SC. Tese de Doutorado - Universidade Estadual de Campinas, 162p. 1995.

REITZ, R.; KLEIN, R.M.; REIS, A. Projeto madeira de Santa Catarina. Itajaí: SUDESUL IBDE, 1978. 315p.

ROYER, M.R.; DAQUILA, B.V.; DEMIZU, F.S.B.; ZANATTA, S.C. Tratamentos para superação da dormência em sementes de palmito juçara. Congresso Nacional de Pesquisa e Ensino em Ciências. Campina Grande, Paraíba. 2016.

SILVA, E. N. et al. Acúmulo de íons e crescimento de pinhão manso sob diferentes níveis de salinidade. Revista Ciência Agronômica, v. 40, n. 02, p. 240-246, 2009. 
TAIZ, L., ZEIGER, E. Fisiologia vegetal. 4. ed. Porto Alegre: Artmed, 848p. 2009.

TESTER, M.; DAVENPORT, R. Na+ tolerance and Na+ transport in higher plants. Annals of Botany, Oxford, v. 91, n. 3, p. 503-527, 2003. 


\title{
EFEITO DA DENSIDADE NO CRESCIMENTO DE Crassostrea gasar CULTIVADA EM SISTEMA FIXO NA COSTA DE MANGUEZAIS DE MACROMARÉS DA AMAZÔNIA, BRASIL
}

\author{
EFECTO DE LA DENSIDAD EN CRECIMIENTO DE Crassostrea gasar CULTIVADA \\ EN SISTEMA FIJO EN LA COSTA DE MANGLARES DE MACROMAREAS DE \\ AMAZONÍA, BRASIL
}

\section{EFFECT OF DENSITY ON GROWTH OF Crassostrea gasar FARMED IN A FIXED SYSTEM ON AMAZON MACROTIDAL MANGROVES COAST, BRAZIL}

\author{
Ana Melissa de Moraes Câmara ${ }^{1}$; Paulo Protásio de Jesus ${ }^{2}$; Edivânia Oliveira Silva ${ }^{3}$ Josinete \\ Sampaio Monteles ${ }^{4}$; Izabel Cristina da Silva Almeida Funo ${ }^{5}$
}

DOI: https://doi.org/10.31692/978-65-991061-4-9.61-74

\begin{abstract}
RESUMO
O presente trabalho avaliou o efeito da densidade de estocagem no crescimento de Crassostrea gasar em sistema fixo na Costa de Manguezais de Macromarés da Amazônia (CMMA). O cultivo foi iniciado com 4.320 ostras de 20 a $30 \mathrm{~mm}$ de altura da valva em travesseiro de malha $9 \mathrm{~mm}$. Os animais foram submetidos a três tratamentos $\left(\mathrm{T}_{1}-600\right.$ ostras $/ \mathrm{m}^{2}, \mathrm{~T}_{2}-800 \mathrm{ostras} / \mathrm{m}^{2}$ e $\mathrm{T}_{3}-1000$ ostras $/ \mathrm{m}^{2}$ ) com 4 repetições e cultivados durante 270 dias em um sistema de cultivo fixo (cama), no município de Bequimão, Maranhão. A cada coleta foi determinado o crescimento das ostras (da altura da concha e peso vivo), as variáveis ambientais e a ocorrência da fauna incrustante e vágil associada. Foram recrutadas pós-larvas em ambiente natural, através de coletores artificiais, que permaneceram submersos por um período de, aproximadamente, 60 dias. Os dados evidenciaram que os parâmetros produtivos foram significativamente influenciados em função das densidades de estocagem testadas (ANOVA, p <0,05). Nos tratamentos com maior densidade (800 ostras/ m2 e 1.000 ostras/ m2) registrou-se crescimento (altura da concha e peso vivo) significativamente superior das ostras e menor incidência da fauna incrustante e vágil associada. Os meses com maior intensidade pluviométrica e com menor salinidade favoreceram para o menor crescimento das ostras, além de ter contribuído para a maior aglomeração de organismos indesejáveis ao cultivo. Assim, conclui-se que o crescimento da ostra nativa $C$. gasar apresentou diferença significativa em função da densidade de estocagem testada, com altura da valva e peso vivo favorecidos em alta densidade. Sugere-se que a menor incidência de organismos competidores nas densidades mais altas pode ter contribuído para o melhor desempenho produtivo da ostra nesses tratamentos.
\end{abstract}

Palavras-Chave: Ostreicultura; Densidade; Parâmetros produtivos; Macromarés

\section{RESUMEN}

El presente trabajo evaluó el efecto de la densidad de población en el crecimiento de Crassostrea gasar en un sistema fijo en la Costa de Manglares de Macromareas de Amazonía (CMMA). El cultivo fue iniciado con 4.320 ostras de 20 a $30 \mathrm{~mm}$ de altura en la valva en almohada de malla de $9 \mathrm{~mm}$. Los animales fueron sometidos a tres tratamientos $\left(\mathrm{T} 1-600 \mathrm{ostras} / \mathrm{m}^{2}, \mathrm{~T} 2-800 \mathrm{ostras} / \mathrm{m}^{2}\right.$ y T3 -1000 ostras $/ \mathrm{m}^{2}$ ) con 4 repeticiones y se cultivaron durante 270 días en un sistema de cultivo fijo (basura) en la ciudad de Bequimão, Maranhão (Brasil). En cada cosecha, se determinó el crecimiento de la ostra (altura de la concha y el peso vivo), las variables ambientales y la ocurrencia de fauna incrustante y vágil asociada. Fueron cosechadas post-larvas en el medio natural a través de recolectores artificiales, que permanecieron sumergidos durante un período de aproximadamente 60 días. Los datos

\footnotetext{
${ }^{1}$ Licenciatura em Ciências Agrárias, IFMA - Campus São Luís Maracanã, m.moraes@acad.ifma.edu.br

${ }^{2}$ Licenciatura em Ciências Agrárias, IFMA - Campus São Luís Maracanã, paulo.protasio@acad.ifma.edu.br

3 Técnico em Aquicultura, IFMA - Campus São Luís Maracanã, e-mail edivaniasilva@acad.ifma.edu.br

${ }^{4}$ Licenciatura em Biologia, IFMA - Campus Monte Castelo, josimonteles@ gmail.com

${ }^{5}$ Doutora em Recursos Pesqueiros e Aquicultura, IFMA - Campus São Luís Maracanã, izabelfuno@ifma.edu.br
} 
demostraron que los parámetros productivos fueron influenciados significativamente por las densidades de almacenamiento probadas (ANOVA, $\mathrm{p}<0.05$ ). En los tratamientos con mayor densidad de almacenamiento $\left(800 \mathrm{ostras} / \mathrm{m}^{2}\right.$ y $\left.1,000 \mathrm{ostras} / \mathrm{m}^{2}\right)$ hubo un crecimiento significativamente mayor (altura de la concha y peso vivo) de las ostras y una menor incidencia de fauna incrustante y vágil asociada. Los meses con mayor intensidad de lluvia y menor salinidad favorecieron el menor crecimiento de las ostras y contribuyeron para una mayor aglomeración de organismos indeseables en el cultivo. Por lo tanto, se puede concluir que el crecimiento de la ostra nativa C. gasar presentó una diferencia significativa en función de la densidad de almacenamiento probada, favoreciendo la alta densidad de la valva y el peso vivo. Se sugiere que la menor incidencia de organismos competidores en densidades más altas puede haber contribuido a un mejor rendimiento de la ostra en estos tratamientos.

Palabras Clave: Ostricultura; Densidad; Parámetros productivos; Macromareas.

\begin{abstract}
This work evaluated the effect of stocking density on the growth of Crassostrea gasar in a fixed system on Amazon Macrotidal Mangrove Coast (AMMC). The oyter farm was started with 4,320 oysters from 20 to $30 \mathrm{~mm}$ shell high on $9 \mathrm{~mm}$ mesh pillow. The animals were submitted to three treatments (T1 - 600 oysters $/ \mathrm{m} 2, \mathrm{~T} 2-800$ oysters $/ \mathrm{m} 2$ and T3 -1000 oysters $/ \mathrm{m} 2)$ with 4 replications and farmed for 270 days in a fixed cultivation system (bed) in the Bequimão city, Maranhão. At each collect, the oyster growth (shell height and live weight), environmental variables and the occurrence of associated foul and fouling fauna were determined. Crassostrea gasar Larvae were recruited in the natural environment through artificial collectors, which remained submerged for a period of approximately 60 days. The analyzes showed that productive parameters were significantly influenced by the stocking densities tested (ANOVA, $\mathrm{p}<0.05$ ). In treatments with higher density ( 800 oysters $/ \mathrm{m} 2$ and 1,000 oysters $/ \mathrm{m} 2$ ) the oysters growth (shell height and live weight) was significantly higher and there was lower incidence of fouling and associated fauna. The months with higher rainfall and lower salinity favored the lower oysters growth and contributed to greater agglomeration of undesirable organisms. Thus, it can be concluded that growth of $C$. gasar, native oysters, showed significant difference as a function of the stocking density tested, with the shell height and live weight favored in high density. It is suggested that lower incidence of competing organisms at higher densities may have contributed to better productive performance of oyster in these treatments.
\end{abstract}

Keywords: oyster farming; density; productive parameters; macrotidal.

\title{
INTRODUÇÃO
}

A produção aquícola mundial contribuiu com 110,2 milhões de toneladas no ano de 2016, sendo $15,5 \%$ do volume global produzido, cerca de 17,1 milhões de toneladas, provenientes da malacocultura (cultivo de moluscos), a qual representa a quarta principal atividade da aquicultura mundial (FAO, 2018). A produção de moluscos bivalves se divide em quatro grupos principais: ostras, mexilhões, vieiras e "clams" (mariscos), que é como são conhecidos os moluscos de areia (FAO, 2015). Destes, a ostreicultura é considerada uma atividade sólida no campo da produção de alimentos de procedência aquática, somando no ano de 2017 uma produção de 5.710 .522 de toneladas (FAO, 2017).

De acordo com a FAO, o Brasil é o segundo maior produtor de moluscos bivalves da América Latina (FAO, 2017). Em 2017, a produção brasileira de moluscos bivalves cultivados (ostras, vieiras e mexilhões) foi de aproximadamente 20,9 mil toneladas, sendo que somente o estado de Santa Catarina deteve cerca de 98\% dessa produção (IBGE, 2017). 
A ostreicultura já vem sendo praticada comercialmente há pouco mais de quatro décadas no Brasil e está vinculada a produção de três espécies, duas delas são endêmicas Crassostrea rhizophorae (Guilding 1828) e Crassostrea gasar (Adanson 1757 = Crassostrea brasiliana, Lamarck 1819), conhecidas popularmente como ostras do mangue, e uma exótica, a Crassostrea gigas (Thunberg 1793), conhecida como ostra japonesa. Embora a C. gasar e C. rhizophorae sejam amplamente utilizadas como alimento e como uma fonte de renda para a população local dos estuários brasileiros, tais espécies não estão bem representadas no cenário produtivo brasileiro, já que a $C$. gigas é a principal espécie cultivada (EPAGRI, 2014; FAO, 2014; IBGE, 2014).

Pesquisas destacam que as diferenças encontradas para o crescimento e sobrevivência das ostras cultivadas podem ser explicadas em função de vários fatores, tais como: condições climáticas; variáveis ambientais; espécie utilizada; genética das ostras; pela presença de organismos indesejáveis; sistema de cultivo e densidade de estocagem (HERNÁNDEZ et al., 1998; PEREIRA et al., 2001; LODEIROS et al., 2006; LOPES et al., 2013; PAIXÃO et al., 2013).

A densidade de estocagem adequada na ostreicultura pode garantir melhores resultados no crescimento e sobrevivência das ostras cultivadas aumentando a produtividade, no entanto, esta densidade ideal pode variar de uma região para outra em função de suas condições ambientais (MACCACCHERO et al., 2007; CARDOSO-JÚNIOR et al., 2012; FUNO, 2016).

Ao longo do litoral brasileiro, há alguns estudos que avaliaram o crescimento e a sobrevivência das ostras nativas em condições de cultivo. Pereira et al. (2001) registraram taxa de crescimento mensal de $C$. gasar variando de 2,2 a 2,6 mm e sobrevivência de 64 a 90,1\% no final de dez meses de cultivo para a região estuarina de Cananéia, São Paulo. Funo (2016) cultivando a ostra C. gasar em áreas estuarinas no Estado do Maranhão, registrou taxa de crescimento mensal de $4,9 \mathrm{~mm}$ e $6 \mathrm{~mm}$ e sobrevivência de $45,7 \%$ e $51,3 \%$ no final de sete meses de cultivo, para os sistemas de cultivo balsa e espinhel, respectivamente.

Ramos et al. (1986) avaliaram o crescimento da Crassostrea rhizophorae em Salina da Margarida, Bahia, onde foi observado um melhor crescimento desta espécie sob imersão contínua e um decréscimo na taxa de crescimento e da sobrevivência com o passar do tempo. Cardoso et al. (2006) avaliaram o crescimento da "ostra nativa" C. rhizophorae em diferentes densidades (50, 100 e 150 ostras/andar de lanterna) no município de Goiana, Pernambuco. E concluíram que a densidade de 400 ostras $/ \mathrm{m}^{2}$ (50 ostras/andar) apresentou o melhor resultado de produção, embora não tenham sido registradas diferenças significativas para o crescimento 
e sobrevivência das ostras durante o período de cultivo.

Deste modo, por conta da carência de trabalhos que avaliem a densidade de estocagem mais adequada para o cultivo de ostras nativas, especificamente para a espécie C. gasar são necessárias para o desenvolvimento da atividade de ostreicultura no litoral do Maranhão, considerando-se as características ambientais da região. Portanto, visando contribuir com o aprimoramento das técnicas de cultivo de ostras nativas ao longo do litoral maranhense, o objetivo do presente trabalho foi avaliar o efeito da densidade de estocagem no crescimento e sobrevivência da ostra nativa $C$. gasar cultivada na região estuarina do município de Bequimão, Maranhão.

\section{FUNDAMENTAÇÃO TEÓRICA}

Em razão da crescente demanda de organismos aquáticos e da necessidade de suprimento do déficit deixado pela pesca extrativa, a aquicultura tem se tornado uma atividade cada vez mais importante (NONÔ, 2010). A maricultura (cultivo de organismos marinhos) desenvolvida apropriadamente e comunitariamente tem o potencial de recuperar a contribuição destes recursos marinhos e estuarinos para melhorar as condições de vida das populações menos assistidas do litoral, de maneira equitativa e sustentável - provendo particularmente oportunidades apropriadas para mulheres. A mudança da atitude extrativista tradicional para a de cultivo em fazendas marinhas, vem proporcionando renda adicional pela geração de emprego, além da fixação das populações tradicionais nas áreas de origem.

Os moluscos bivalves são organismos marinhos e o cultivo destes tem se comprovado como uma importante ferramenta para a diminuição da pobreza através da geração de emprego, renda e alimento em comunidades tradicionais costeiras frente à crescente diminuição dos recursos pesqueiros no Brasil. Tal atividade ajuda a fixar populações nativas litorâneas em seu ambiente tradicional e torna-se um complemento de renda para pescadores artesanais (OLIVEIRA, 2005). Também é uma atividade sustentável pois pode colaborar com a manutenção dos estoques naturais estuarinos, onde é realizada a maior parte da pesca artesanal (BALDAN; BENDHACK, 2009).

O cultivo de ostras nativas apresenta grande potencial para ser desenvolvido em vários pontos do litoral brasileiro, porém, necessita-se de mais pesquisas para aumentar a produtividade desta atividade (MIRANDA e GUZENSKI, 1999; TURECK, 2010). Nas regiões norte e nordeste vêm sendo cultivadas apenas as espécies $C$. rhizophorae e/ou $C$. gasar, e no ano de 2017 essas regiões juntas produziram cerca de 181 toneladas de ostras, representando uma pequena porcentagem $(0,9 \%)$ da produção nacional de moluscos bivalves, 
que inclui ostras, vieiras e mexilhões (IBGE, 2017).

A zona costeira maranhense possui $640 \mathrm{~km}$ de extensão e abriga um mosaico de ecossistemas de alta relevância ambiental. Ao longo do litoral alternam-se mangues, restingas, campos inundáveis, dunas, estuários, recifes de corais e outros ambientes importantes do ponto de vista ecológico. Diferentemente de outros estados brasileiros, a zona costeira maranhense revela uma expressiva ocorrência de manguezais relativamente preservados (UFMA, 2003). Esses ecossistemas devem ser explorados por projetos que visem o uso sustentável da biodiversidade marinha e estuarina pelo homem, gerando trabalho, renda e um melhor desempenho dos aspectos socioeconômicos da população ribeirinha.

Com o apoio de órgão financiadores de pesquisas, instituições de ensino (UFMA, IFMA e UEMA) e de algumas ações pontuais do governo, nos últimos anos tem se intensificado as pesquisas sobre as ostras nativas na costa maranhense, incluindo estudos sobre a biologia reprodutiva (SOUSA, 2015), genética (LOPES, 2018), cultivo (SANTOS, 2013; FUNO et al., 2013 e FUNO, 2016) e a seleção de áreas potenciais para a implantação do cultivo (FSADU, 2010; FRANÇA et al., 2013).

O crescimento e a sobrevivência das ostras nativas do gênero Crassostrea sofrem influência estatisticamente significativa da densidade de estocagem a que ela é submetida (BRUNETTO, 2018; FREIRE, 2018). Brunetto (2018) afirma que a altura da concha da ostra nativa $C$. gasar e sua sobrevivência são favorecidas em alta densidade, no entanto, o seu comprimento em baixa densidade. Freire (2018) avaliando o desempenho da ostra C. gasar sob as densidades de estocagem de 400,600, 800 e 100 ostras $/ \mathrm{m}^{2}$, registrou crescimento médio mensal e peso médio estatisticamente superiores nas duas maiores densidades, e maior sobrevivência nas duas menores. Pereira et al. (2001) cultivando ostras da espécie $C$. brasiliana (= C. gasar), sob quatro densidades de estocagem registrou maior crescimento médio mensal e sobrevivência na maior delas.

Cardoso-Júnior et al. (2012), em experimento com a ostra nativa C. rhizophorae constatou um maior crescimento médio mensal das ostras cultivadas sob a menor densidade de estocagem, que foi de $400 \mathrm{ostras} / \mathrm{m}^{2}$. Modesto et al. (2010) avaliou o crescimento de ostras da espécie $C$. rhizophorae em travesseiros com três densidades de estocagem (250, 500 e 750 ostras/travesseiro), registrando a maior sobrevivência na menor densidade.

No Brasil, a realização de estudos sobre a exploração de moluscos comestíveis é muito importante, especialmente para o estado do Maranhão, que possui uma concentração considerável de espécies que servem para o consumo humano (Moreira, 2007; Monteles et al., 2009). Apesar de ter clima tropical e áreas favoráveis para o desenvolvimento da maricultura 
o estado do Maranhão ainda não apresenta índices representativos. Por meio de um determinado número de ações a nível institucional e governamental, seria possível fomentar o desenvolvimento da malacocultura sustentável neste estado (UFMA 2003).

Diante do exposto, são escassos os trabalhos publicados que tenham avaliado a influência da densidade de estocagem, sobre o crescimento e sobrevivência das ostras nativas ao longo do litoral brasileiro, especialmente para a espécie $C$. gasar em regiões sob regime de macromarés. Assim, pesquisas nessa área são necessárias para contribuir com o aprimoramento de metodologias de cultivo adequadas para a espécie, levando em consideração às características ambientais da região.

\section{METODOLOGIA}

Juvenis de ostras da espécie Crassostrea gasar foram obtidas através de coletores artificiais confeccionados de garrafa PET em um sementeiro localizado na comunidade de Lauro Sodré $\left(00^{\circ} 51^{\prime} 15,0^{\prime}\right.$ S e $47^{\circ}$ 53’25,0”W) no munícipio de Curuçá, Pará, Brasil. Posteriormente, as ostras foram transportadas para um estuário localizado no povoado de Paricatiua (02 $26^{\prime} 58^{\prime}$ S e $\left.44^{\circ} 46^{\prime} 57^{\prime} \mathrm{W}\right)$, no município de Bequimão, Maranhão, onde foram aclimatadas e posteriormente submetidas ao experimento.

O experimento foi realizado durante 270 dias (entre os meses de novembro de 2017 e setembro de 2018) era inteiramente casualizado com três tratamentos ( $\mathrm{T}_{1}: 600$ ostras $/ \mathrm{m}^{2} ; \mathrm{T}_{2}$ : 800 ostras $/ \mathrm{m}^{2} ; \mathrm{T}_{3}: 1.000$ ostras $/ \mathrm{m}^{2}$ ) e quatro repetições (travesseiros), perfazendo 12 unidades experimentais. Na primeira etapa deste experimento foram utilizadas ostras medindo entre 20 a $30 \mathrm{~mm}$, as quais foram acondicionadas em travesseiros ( $9 \mathrm{~mm}$ de malha) durante 3 meses. $\mathrm{Na}$ segunda etapa, quando as ostras alcançaram $40 \mathrm{~mm}$ de altura da concha, as mesmas foram remanejadas para travesseiros com abertura de malhas de $21 \mathrm{~mm}$ e foram mantidas na densidade de povoamento inicial, onde foram cultivadas por mais três meses.

A cada coleta, foi realizada a limpeza das malhas dos travesseiros e a biometria das ostras, na qual 30 organismos de cada unidade experimental (totalizando 360 por amostragem) foram medidos a altura das valvas $(\mathrm{mm})$, com auxílio de um paquímetro com precisão de 0,1 mm e pesados para determinação do peso vivo (g) com uma balança digital com precisão de três decimais. A padronização das medidas de biometria das valvas das ostras durante o experimento baseou-se no método proposto por Galtsoff (1964).

Paralelamente ao manejo era determinada a temperatura da água próximo da superfície utilizando um termômetro com precisão de $0,5^{\circ} \mathrm{C}$ e a salinidade através de um refratômetro. Os dados de precipitação pluviométrica para o município de Raposa foram cedidos pelo 
Núcleo de Geoprocessamento da Universidade Estadual do Maranhão.

Durante as amostragens, também foi realizada a coleta dos organismos incrustantes e associados (fauna vágil) presentes na tela das estruturas de cultivo e no interior dos travesseiros. O material coletado foi fixado com formalina a $4 \%$ por 24 horas, e em seguida foi transportado até ao laboratório NUMAR do IFMA - Campus Maracanã, a fim de ser congelado para preservar e manter as características naturais dos organismos, possibilitando o processo de identificação dos táxons.

As análises estatísticas foram realizadas no programa Statistica 7.0 (StatSoft Inc., USA). O teste paramétrico one-way ANOVA foi utilizada para avaliar o efeito da densidade sobre os parâmetros de produção (altura da concha e peso vivo) após a confirmação da homocedasticidade (Cochran $\mathrm{P}<0,05$ ) e normalidade (Shapiro-Wilk $\mathrm{P}<0,05$ ). O teste de Tukey $(\mathrm{P}<0,05)$ foi realizado para comparação e classificação significativa a partir dos três tratamentos.

\section{RESULTADOS E DISCUSSÃO}

Ao final dos 270 dias de experimento as ostras alcançaram a altura média da concha de $44,9 \pm 4,7 \mathrm{~mm}, 53,8 \pm 4,3 \mathrm{~mm}$ e $54,4 \pm 3,9 \mathrm{~mm}$. A taxa de crescimento médio mensal foi de 2,69 mm, 3,12 mm e 3,19 $\mathrm{mm}$ nos tratamentos $\mathrm{T}_{1}\left(600\right.$ ostras $\left./ \mathrm{m}^{2}\right), \mathrm{T}_{2}\left(800\right.$ ostras $\left./ \mathrm{m}^{2}\right)$ e $\mathrm{T}_{3}$ $\left(1000\right.$ ostras $\left./ \mathrm{m}^{2}\right)$, respectivamente. Até os 45 dias de experimento, as diferenças entre as medidas de altura dos tratamentos não foram significativas $(\mathrm{P}<0,05$, Tukey). Porém, a partir da terceira biometria (aos 90 dias de cultivo), os valores encontrados de altura no tratamento $\mathrm{T}_{1}$ mostraram-se significativamente menores $(\mathrm{P}<0,05$, Tukey) que os valores encontrados nos tratamentos $T_{2}$ e $T_{3}$, que por sua vez, não apresentaram diferenças significativas entre si (Figura 1).

Figura 1. Valores médios de altura de concha da ostra Crassostrea gasar exposta à diferentes densidades de estocagens no estuário de Paricatiua - MA. T1 - Tratamento 1, T2 - Tratamento 2 e T3 - Tratamento 3.

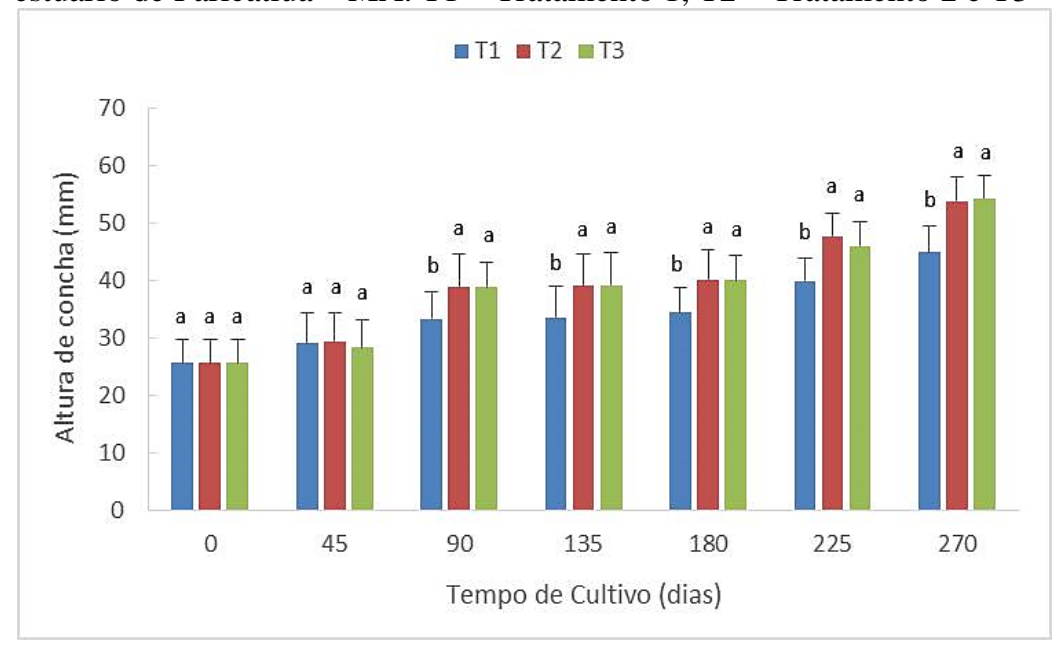

[67] 
No presente trabalho, as ostras cultivadas na maior densidade apresentaram um maior crescimento médio mensal, corroborando com os resultados obtidos no estudo realizado por Freire (2018), que em pesquisa realizada no município de Primeira Cruz - MA, cultivando a ostra nativa Crassostrea gasar em travesseiros em sistema de cultivo suspenso fixo e submetendo-as às densidades de estocagem de 400,600, 800 e 1000 ostras $/ \mathrm{m}^{2}$, obteve taxas de crescimento médio mensal variando de $1,06 \pm 1,91 \mathrm{~mm}$ a 2,42 $22,58 \mathrm{~mm}$, com valores significativamente superiores nas duas maiores densidades testadas.

Estudo realizado por Brunetto (2018), em sistema de cultivo suspenso flutuante (longline) evidenciou que a alta densidade de estocagem em cultivo influencia positivamente na altura de concha das ostras da espécie Crassostrea gasar, corroborando com os dados do presente trabalho. Vale ressaltar que as taxas de crescimento médio mensal registradas neste estudo para as densidades de 600, 800 e 1000 ostras $/ \mathrm{m}^{2}$ foram superiores às registradas no trabalho de Freire (2018), tal fato pode ser justificado por serem estuários com condições ambientais diferentes.

No entanto, Cardoso-Júnior et al. (2012) observou em experimento realizado com a espécie C. rhizophorae em Goiana - PE, uma taxa de crescimento maior para as ostras cultivadas na menor densidade, de 400 ostras $/ \mathrm{m}^{2}$, onde estas apresentaram um crescimento médio mensal de $5,53 \mathrm{~mm}$. No estudo realizado por estes autores as ostras apresentaram uma taxa de crescimento médio mensal superior à do presente estudo, tal fato pode ser atribuído ao sistema de cultivo adotado na pesquisa, eles utilizaram lanternas alocadas em sistema suspenso flutuante balsa, no qual as ostras ficaram sempre submersas, possuindo assim disponibilidade de alimento a todo o tempo.

Em experimento realizado na cidade de Cananéia - SP, em sistema suspenso fixo foram testadas quatro densidades em três locais diferentes, as ostras cultivadas na maior densidade, 25 dúzias ostras $/ \mathrm{m}^{2}$, apresentaram o melhor crescimento médio mensal nesses três locais $(2,64 \mathrm{~mm}, 2,16 \mathrm{~mm}$ e 2,18 $\mathrm{mm})$, embora a diferença entre o crescimento nas outras densidades testadas não tenha sido estatisticamente significante (PEREIRA et al., 2001). As taxas de crescimento média mensal registrada no presente estudo variaram de 2,69 $\mathrm{mm}$ a 3,19 $\mathrm{mm}$, ou seja, valores superiores aos registrados no experimento realizado por Pereira et al. (2001).

Os resultados do presente estudo evidenciaram que o peso dos organismos cultivados foi influenciado significativamente em função da densidade de estocagem, sendo que as ostras cultivadas nas maiores densidades $\left(\mathrm{T}_{2}\right.$ e $\left.\mathrm{T}_{3}\right)$ apresentaram ganho de peso estatisticamente superior $(\mathrm{P}<0,05$, Tukey). Vale ressaltar que essa diferença estatística ocorreu a partir 135 
dias de cultivo (quarta biometria), e tal comportamento se manteve até o término do experimento (Figura 2).

Figura 2. Valores médios de ganho de peso da ostra Crassostrea gasar exposta à diferentes densidades de estocagens no estuário de Paricatiua - MA. $\mathrm{T}_{1}$ - Tratamento $1, \mathrm{~T}_{2}$ - Tratamento 2 e $\mathrm{T}_{3}$ - Tratamento 3.

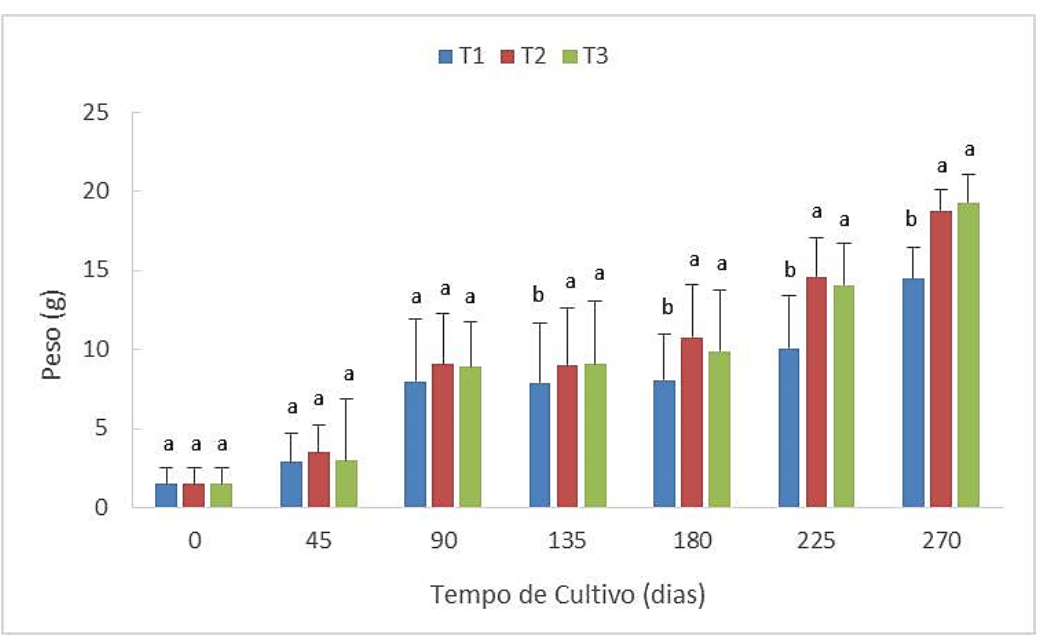

Freire (2018) cultivando a mesma espécie no município de Primeira Cruz (Maranhão), obteve resultados semelhantes, pois cultivando da mesma forma a ostra nativa $C$. gasar em sistema suspenso fixo e submetendo-as às densidades 400, 600, 800 e 1000 ostras $/ \mathrm{m}^{2}$ registrou no final do cultivo, maiores valores de peso médio nas maiores densidades de estocagem $\left(22,73 \pm 7,28 \mathrm{~g}\right.$ e $19,01 \pm 7,62 \mathrm{~g}$ para as densidades de 800 e 1000 ostras $/ \mathrm{m}^{2}$, respectivamente). Pesquisa realizada Brunetto (2018), testou diferentes densidades de estocagem em sistema de cultivo suspenso flutuante (long-line) para a ostra Crassostrea gasar e os resultados indicaram maior ganho de peso nas ostras cultivadas sob maior densidade na fase definitiva (180 ostras/andar de lanterna).

No presente estudo, durante o período experimental, a salinidade da água variou de $5,0 \pm 3,5$ a $31,0 \pm 3,5$ g. $\mathrm{Kg}^{-1}$; a temperatura de $28,0 \pm 0,6$ a $29,3 \pm 1,1^{\circ} \mathrm{C}$ e a precipitação de 0 a 805,5 mm. Avaliando os resultados das variáveis ambientais em função do crescimento das ostras durante o período experimental, constatou-se que nos meses de maior precipitação pluviométrica e menor salinidade ocorreu crescimento mensal (altura da concha e peso vivo das ostras) significativamente inferior, quando comparado com os valores obtidos nos outros períodos de amostragem. Estudo realizado por Funo et al. (2015) constatou que o crescimento das ostras C. gasar é afetado pela salinidade, apresentando melhor desempenho em salinidades variando de 15 a 35. Brito (2008) cultivando ostras Crassostrea rhizophorae em laboratório e submetidas a salinidades de 20, 25, 30 e 35 obteve melhor resultado de crescimento ao final de 150 dias de cultivo, na salinidade 25 . 
Nos primeiros 30 dias de cultivo a salinidade oscilou de 0 a $31 \mathrm{~g} \cdot \mathrm{Kg}^{-1}$, coincidindo com maior fixação de cracas (Amphibalanus sp.) e ocorrência do parasita poliqueta (Alitta succinea) nas ostras cultivadas de todos os tratamentos testados, no entanto, quanto maior era a densidade menor era incidência desses organismos. Posteriormente, no período de 90 a 180 dias de cultivo, a pluviosidade da região foi elevada $(198,1$ a $805,5 \mathrm{~mm})$, nesta ocasião foi registrada diminuição da salinidade (10 a $26 \mathrm{~g} \cdot \mathrm{Kg}^{-1}$,) e uma intensa infestação de sementes de sururu (competidor) da espécie Mytella charruana fixadas nas estruturas de cultivo e nas conchas das ostras cultivadas. Outros organismos foram observados esporadicamente associados às estruturas de cultivo, como a ascídias, planárias e pequenos caranguejos.

Pesquisas evidenciaram que o "fouling", que cresce nas paredes e malhas das estruturas de cultivo, pode influenciar no rendimento do produto final, como o trabalho realizado por Hernández et al. (1998), o qual evidenciou que os organismos incrustantes (macroalgas, bivalves, ascídias, cracas, briozoários, hidrozoários e esponjas) fixados nas malhas das estruturas de cultivo reduzem a circulação, oxigenação e o aporte de partículas suspensas na água no interior dessas estruturas de cultivo, afetando o crescimento das ostras cultivadas.

Em todas as densidades avaliadas, a taxa de crescimento mensal (altura da concha e peso vivo) foi significativamente menor aos 135 dias de cultivo $(\mathrm{p}<0,5)$, coincidindo com o período que houve elevada aglomeração de sementes de $M$. charruana fixadas nas estruturas de cultivo e nas valvas das ostras. Funo (2016) constatou que os mitilídeos (M. charruana e M. guyanensis) sintetizam sua estrutura de fixação (bisso), aderindo-se nas redes e pratos das lanternas, e que esses filamentos de bisso, por serem pegajosos, formavam aglomerações de lodo no interior das lanternas, tal comportamento interferia no processo de alimentação das ostras e consequentemente no seu crescimento.

Monteles et al. (2018) avaliaram o recrutamento de sementes de sururu (Mytella charruana) na região estuarina de Paricatiua (Bequimão - MA), e concluíram que o recrutamento de semente desta espécie é sazonal, ocorrendo a fixação da semente nos coletores no período de maior precipitação pluviométrica e menor salinidade. Assim, no presente estudo constatou-se que a grande fixação de semente de $M$. charruana no cultivo de ostra pode afetar os parâmetros produtivos das ostras cultivadas.

Os resultados obtidos no presente estudo evidenciaram que a densidade de estocagem influencia no crescimento da ostra C. gasar, com crescimento significativamente superior nas maiores densidades, onde foram registrado menor incidência de organismos incrustantes. Estudos comprovaram que a adoção de altas densidades no cultivo desta espécie tem 
proporcionado maior crescimento da ostra, uma vez que as estruturas de cultivo com maior quantidade de ostras proporcionam menor competição por espaço e alimento com os organismos incrustantes (BRUNETTO, 2018; FREIRE, 2018; PEREIRA et al., 2001).

\section{CONCLUSÕES}

O crescimento de C. gasar apresentou diferença significativa em função da densidade de estocagem. A altura da concha e o peso vivo foram favorecidos em alta densidade (800 ostras/ $\mathrm{m}^{2}$ e 1.000 ostras/ $\mathrm{m}^{2}$ ), devido à menor interferência da fauna incrustante e vágil associada nas estruturas de cultivo.

Os meses com maior intensidade pluviométrica e com menor salinidade favoreceram para o menor crescimento das ostras, além de ter contribuído para a maior aglomeração da fauna incrustante e vágil associada.

\section{REFERÊNCIAS}

BALDAN, A. P.; BENDHACK, F. MARICULTURA SUSTENTÁVEL NO LITORAL DO PARANÁ, BRASIL: atualidades e perspectivas. Rev. Acad., Ciênc. Agrár. Ambient., Curitiba, v. 7, n. 4, p.491-497, out. 2009.

BRITO, L. de. Efeito da salinidade sobre o crescimento da ostra nativa Crassostrea sp. como subsídio ao desenvolvimento da maricultura de espécies nativas em mar aberto. 2008. $38 \mathrm{f}$. Dissertação (Mestrado) - Curso de Sistemas Costeiro e Oceânico, Setor de Ciências da Terra, Centro de Estudos do Mar, Universidade Federal do Paraná, Pontal do Paraná, 2008.

BRUNETTO, L. J. CULTIVO DA OSTRA Crassostrea gasar EM DIFERENTES DENSIDADES. 2018. 71 f. Dissertação (Mestrado) - Curso de Aquicultura, Centro de Ciências Agrárias, Universidade Federal de Santa Catarina, Florianópolis, 2018.

CARDOSO, L. O.; Galvez, A. O. Avaliação do crescimento da C. rhizophorae (Guilding,1828). 2006. 40p. Monografia (Graduação) - Universidade Federal Rural de Pernambuco, Recife.

CARDOSO-JÚNIOR, L.O.; LAVANDER, H.D.; NETO, S.R.S.; SOUZA, A.B.S.; SILVA, L.O.B.; GÁLVEZ, A.O. Crescimento da ostra Crassostrea rhizophorae cultivada em diferentes densidades de estocagem no Litoral Norte de Pernambuco. Revista de Pesquisa Agropecuária, v.17, n.1, p.10-14, 2012.

EPAGRI. Empresa de Pesquisa Agropecuária e Extensão Rural de Santa Catarina. Síntese Informativa da Maricultura. Florianópolis, 2014. Disponível em: http://www.epagri.sc.gov.br/wpcontent/uploads/2013/08/Sintese_informativa_da_maricultura _2014.pdf. Acesso em: 5 set 2018.

FAO - Fisheries and Aquaculture Information and Statistics Branch, 2017. Disponível em: http://www.fao.org/fishery/statistics/global-aquaculture-production/query/en. Acesso em 
24 de junho de 2019.

FAO - Food and Agriculture Organization of the United Nations. The State of World Fisheries and Aquaculture 2018: Meeting the sustainable development goals. Rome: FAO, 2018.

FAO. Fisheries Department, Fishery Information, Data and Statistics Unit. Fisheries and aquaculture software. FishStatJ: software for fishery statistical time series. Version 2.3. Rome, 2015. Disponível em: http://www.fao.org/fishery/statistics/software/en. Acesso em: 9 $\operatorname{dez} 2018$.

FAO. Fisheries Department, Fishery Information, Data and Statistics Unit. FishStat Plus: Universal Software For Fishery Statistical Time Series. Version 2.3. Rome, 2014. Disponível em: http://www.fao.org/fishery/statistics/software/en. Acesso em: 2 setembro 2018.

FRANÇA, V.L. de; MONTELES, J.S.; ALMEIDA FUNO, I.C.S.; CASTRO, A.C.L. de. Seleção de áreas potenciais para o cultivo de Ostra nativa, Crassostrea spp. e Sururu, Mytella falcata, em Raposa, Maranhão. Arquivo Ciências do Mar, v.46, n.1, p.62-75, 2013.

FREIRE, T. B. Efeito da densidade de estocagem no crescimento e sobrevivência da ostra nativa Crassostrea gasar (Adanson, 1757) cultivada em ambiente de macromaré de Primeira Cruz - MA. 2018. 43 folhas. Monografia (Graduação) - Curso de Engenharia de Pesca, Universidade Estadual do Maranhão, São Luís, 2018.

FSADU. Fundação Sousândrade de Apoio. Plano Local de Desenvolvimento da Maricultura - PLDM's do Maranhão: Icatu, Humberto de Campos e Primeira Cruz. São Luís, 2010. Disponível em: http://berbeladomar.bio.br/documentos/ RELATORIO_PLDM_2010/RELATORIO_PLDM_2010.pdf. Acesso em: 26 junho 2019.

FUNO, I. C. da S. A. Avaliação de parâmetros produtivos e biológicos da ostra nativa Crassostrea gasar (ADANSON, 1757) como subsídio ao desenvolvimento da ostreicultura em ambientes estuarinos do Estado do Maranhão. 2016. 122 f. Tese (Doutorado) -Recursos Pesqueiros e Aquicultura - Universidade Federal Rural de Pernambuco. Recife, 2016.

FUNO, I. C. da S. A. et al. Influência da salinidade sobre a sobrevivência e crescimento de Crassostrea gasar. Bol. Inst. Pesca, São Paulo, v. 41, n. 4, p.837-847, 2015.

FUNO, I. C. da S. A.; ANTONIO, I.G.; MONTELES, J.S.; PEREIRA, A.J.; GUTERRES, I.R.; GALVEZ, A.O. Crescimento e mortalidade da ostra nativa Crassostrea gasar no município de Raposa, Maranhão. In: Congresso Brasileiro de Aquicultura de Espécies Nativa, 4., 2013, Belém. Anais. Belém/PA. UFPA, 2013. p. 12-12.

HERNÁNDEZ, O. D.; TROCCOLI, G.; J. MILlÁN, Q. Crecimiento, Engorde y Sobrevivencia de la Ostra de Mangle Crassostrea rhizophorae Guilding, 1828 en la Isla de Cubagüa, Venezuela. Caribbean Journal of Science, Mayagüez, v. 34, n. 1, p. 243-249, 1998.

IBGE - INSTITUTO BRASILEIRO DE GEOGRAFIA E ESTATÍSTICA. 2014. Pesquisa da Pecuária Municipal. Disponível em: https://sidra.ibge.gov.br/tabela/3940. Acesso em: 22 jun 2019. 
IBGE - INSTITUTO BRASILEIRO DE GEOGRAFIA E ESTATÍSTICA. 2017. Pesquisa da Pecuária Municipal. Disponível em: https://sidra.ibge.gov.br/tabela/3940. Acesso em: 22 jun 2019.

LODEIROS, C.; BUITRAGO, E.; GUERRA, A. Evaluación del tipo de cestos de cultivo para la ostra de mangle Crassostrea rhizophorae suspendidas em long line y balsa. Ciencias Marinas, v.32, n.2, p.331-337, 2006.

LOPES, G. R.; GOMES, C.H.A.M.; TURECK, C.R.; MELO, C.M.R. Growth of Crassostrea gasar cultured in marine and estuary environments in Brazilian waters. Pesquisa Agropecuária Brasileira, v.8, n.7, p.975-982, 2013.

LOPES, R. G. P. S. et al. Molecular identification of native oysters on the coast of Maranhão, Brazil. Boletim do Instituto de Pesca, [s.1.], v. 44, n. 4, p.377, 21 set. 2018.

MACCACCHERO, G. B.; FERREIRA, J.F.; GUZENSKI, J. Influence of stocking density and culture management on growth and mortality of the mangrove native oyster Crassostrea sp. in southern Brazil. Biotemas, v.20, p.47-53, 2007.

MIRANDA, M. B. B. de; GUZENSKI, J. Cultivo larval da ostra do mangue, Crassostrea rhizophorae (Guilding, 1828), em diferentes condições de temperatura, salinidade e densidade. Arq. Ciên. Mar., Fortaleza, n. 32, p.73-84, 1999.

MODESTO, G. A. et al. Utilização de Crassostrea rhizophorae (Guilding 1828) no tratamento dos efluentes do cultivo de Litopenaeus vannamei (Boone 1931). Pan-american Journal Of Aquatic Sciences, [s.i.], v. 5, n. 3, p.367-375, jan. 2010.

MONTELES, J. S. et al. Percepção sócio-ambiental das marisqueiras no município de Raposa, Maranhão, Brasil. Rev. Bras. Eng. Pesca, v.4, n. 2, p. 34-45, 2009.

MONTELES, J. S. et al. Recrutamento de semente do sururu Mytella falcata em manguezais de macromaré no litoral maranhense, usando materiais reciclados. In: VII AQUACIÊNCIA. Anais. Natal. 2018.

MOREIRA, I.C.N. 2007. Impactos do extrativismo da Anomalocardia brasiliana (Gmelin, 1791) nos estuários dos Rios Paciência e Cururuca, São Luís, Maranhão: uma visão etnoconservacionista. Dissertação (Mestrado). Universidade Federal do Maranhão, São Luís, Brasil.

NONÔ, Ricardo Gomes de Barros. Cultivo de Ostras em Alagoas. Maceió: Sebrae/al, 2010.

OLIVEIRA, B. de L. Impacto da Mitilicultura no desenvolvimento das comunidades tradicionais ao entorno das Praias da Cerca e Guaibura, Guarapari, ES. 2005. 67 f. Monografia (Especialização) - Curso de Oceanografia, Universidade Federal do Espírito Santo, Vitória, 2005.

PAIXÃO, L.; FERREIRA, M. A.; NUNES, Z.; FONSECA-SIZO, F.; ROCHA, R. Effects of salinity and rainfall on the reproductive biology of the mangrove oyster (Crassostrea gasar): Implications for the collection of broodstock oysters. Aquaculture, v.6, n.12, p.380-383, 
2013.

PEREIRA, O. M.; MACHADO, I. C.; HENRIQUES, M. B.; YAMANAKA, N. Crescimento da ostra Crassostrea brasiliana semeada sobre tabuleiro em diferentes densidades na região estuarino-lagunar de Cananéia-SP $\left(25^{\circ} \mathrm{S}, 48^{\circ} \mathrm{W}\right)$. Boletim do Instituto de Pesca, v.27, p.163$174,2001$.

RAMOS, M. I. S.; NASCIMENTO, I.A; SILVA, J. DE L. The comparative growth survival of pacific oyster and C. rhizophorae in Todos os Santos Bay, Brazil. Ciência e Cultura, v.38, p.1604-1615, 1986.

SANTOS, G.M. Caracterização das marisqueiras e cultivo experimental de Crassostrea gasar no município de Raposa-MA. 2013. 51p. Monografia (graduação) - Universidade Estadual do Maranhão, São Luís.

SOUSA, A.K.R. Biologia reprodutiva da "ostra nativa" Crassostrea rhizophorae na ilha do maranhão - MA. 2015. 30p. Monografia (Graduação) - Universidade Estadual do Maranhão, São Luís.

TURECK, T.R. Sementes de ostras nativas no litoral de Santa Catarina/Brasil, como subsidio ao cultivo. 2010. 140p. Dissertação (Mestrado). Universidade Federal de Santa Catarina, Florianópolis.

UFMA/DEPARTAMENTO DE OCEANOGRAFIA E LIMNOLOGIA. Zoneamento Costeiro do Estado do Maranhão. 2003, 242p. 


\title{
A CONFECÇÃO E USO DE UMA MINI ECOSFERA COMO PROPOSTA DE RECURSO DIDÁTICO NO ENSINO DE EDUCAÇÃO AMBIENTAL E SUSTENTABILIDADE
}

\author{
LA CONFECCIÓN Y USO DE UNA MINI ECOSFERA COMO PROPUESTA DE \\ RECURSO DIDÁCTICO EN LA ENSEÑANZA DE LA EDUCACIÓN AMBIENTAL Y \\ LA SOSTENIBILIDAD
}

\section{THE CONFECTION AND USE OF A MINI ECOSPHERE AS PROPOSAL OF DIDACTIC RESOURCE IN TEACHING OF ENVIRONMENTAL EDUCATION AND SUSTAINABILITY}

\author{
Levi Araujo Bezerra ${ }^{1}$; Luiz Carlos Alves de Souza ${ }^{2}$.
}

DOI: https://doi.org/10.31692/978-65-991061-4-9.75-91

\begin{abstract}
RESUMO
O ensino de ciências apresenta-se cada vez mais importante em nossa sociedade, principalmente pelo fato de vivenciarmos a ciência no nosso dia a dia. Dessa forma, a alfabetização científica torna-se essencial para instrumentalizar o discente para a linguagem científica. Entretanto, apesar dos avanços no campo da educação, o ensino de biologia tem sido realizado de forma com que o aluno seja um sujeito passivo, apenas recebendo o conteúdo, não participando de maneira ativa no processo de construção da sua aprendizagem. Desta forma, novas práticas para o ensino de ciências e biologia surgem com a demanda de tornar o aprendizado mais significativo e adequado a realidade do estudante. Diante disso, o uso de recursos didáticos como ferramenta pedagógica em disciplinas muitas vezes consideradas difíceis, pode ser uma excelente alternativa para facilitar o entendimento destas disciplinas, pois, o ensino, quando contextualizado, permite ao aluno interligar o conteúdo visto em sala com os assuntos do seu cotidiano, contribuindo assim na formação crítica e na construção do conhecimento, influenciando assim na participação e comprometimento. Como proposta para uma prática pedagógica diferenciada, este trabalho teve por objetivo descrever o processo de confecção de uma mini ecosfera, desenvolvida para auxiliar o professor em sala de aula quando o mesmo estiver trabalhando temas relacionados com ciências e biologia. Para a confecção do modelo foi utilizada como referência a Ecosfera original (Ecosferas $\left.{ }^{\circledR}\right)$, que surgiu a partir de pesquisas aeroespaciais desenvolvidas pela NASA. O presente modelo foi avaliado de forma positiva por alunos e o professor da disciplina de agroecologia do curso técnico em zootecnia do Instituto Federal de Educação Ciências e Tecnologia de Pernambuco - Campus Vitoria de santo Antão.
\end{abstract}

Palavras-Chave: Ecosfera, Educação Ambiental, Sustentabilidade, Recurso Didático.

\section{RESUMEN}

La enseñanza de las ciencias es cada vez más importante en nuestra sociedad, principalmente porque experimentamos la ciencia en nuestra vida diaria. Por lo tanto, la alfabetización científica se vuelve esencial para instrumentalizar al estudiante para el lenguaje científico. Sin embargo, a pesar de los avances en el campo de la educación, la enseñanza de la biología se ha llevado a cabo para que el alumno sea una asignatura pasiva, que solo recibe el contenido, no participa activamente en el proceso de construcción de su aprendizaje. Por lo tanto, surgen nuevas prácticas para la enseñanza de la ciencia y la biología con la demanda de hacer que el aprendizaje sea más significativo y apropiado para la realidad del estudiante. Dado esto, el uso de recursos didácticos como herramienta pedagógica en asignaturas que a menudo se consideran difíciles puede ser una excelente alternativa para facilitar la comprensión de estas asignaturas, ya que la enseñanza, cuando está contextualizada, permite al alumno vincular el contenido visto en el aula con las asignaturas. contribuyendo así a la formación

\footnotetext{
${ }^{1}$ Licenciando em Ciências Biológicas, Universidade Federal de Pernambuco, levitj1.lab@gmail.com

${ }^{2}$ Mestre em educação agrícola, professor do Instituto Federal de Pernambuco Campus Vitória de Santo Antão, nagusto.eaf@ hotmail.com
} 
crítica y la construcción del conocimiento, influyendo así en la participación y el compromiso. Como una propuesta para una práctica pedagógica diferenciada, este trabajo tuvo como objetivo describir el proceso de hacer una mini ecosfera, desarrollada para ayudar al maestro de aula cuando está trabajando en temas relacionados con la ciencia y la biología. Para hacer el modelo se utilizó como referencia la Ecosfera original (Ecospheres $\left.{ }^{\circledR}\right)$, que surgió de la investigación aeroespacial desarrollada por la NASA. El presente modelo fue evaluado positivamente por los estudiantes y el profesor de la disciplina de agroecología del curso técnico en zootecnia del Instituto Federal de Ciencias de la Educación y Tecnología de Pernambuco - Campus Vitoria de santo Antão.

Palabras Clave: Ecosfera, Educación ambiental, Sostenibilidad, Recurso didáctico.

\section{ABSTRACT}

Science teaching is becoming increasingly important in our society, mainly because we experience science in our daily lives. Thus, scientific literacy becomes essential to instrumentalize the student for scientific language. However, despite advances in the field of education, the teaching of biology has been carried out so that the student is a passive subject, only receiving the content, not actively participating in the process of building their learning. Thus, new practices for science and biology teaching arise with the demand to make learning more meaningful and appropriate to the student's reality. Given this, the use of teaching resources as a pedagogical tool in subjects that are often considered difficult may be an excellent alternative to facilitate the understanding of these subjects, since teaching, when contextualized, allows the student to link the content seen in the classroom with the subjects. thus contributing to the critical formation and construction of knowledge, thus influencing participation and commitment. As a proposal for a differentiated pedagogical practice, this work aimed to describe the process of making a mini ecosphere, developed to assist the classroom teacher when he is working on science and biology related topics. To make the model was used as reference the original Ecosphere (Ecospheres $\left.{ }^{\circledR}\right)$, which emerged from aerospace research developed by NASA. The present model was positively evaluated by students and teacher of the agroecology discipline of the technical course in zootechnics of the Federal Institute of Education Sciences and Technology of Pernambuco - Campus Vitoria de santo Antão.

Keywords: Ecosphere, Environmental education, Sustainability, didactic Resource.

\section{INTRODUÇÃO}

A ausência de responsabilidade ambiental da sociedade é consequência da desinformação, falta de participação e envolvimento da população com temas relacionados ao meio ambiente. E neste sentido, a educação ambiental representa um instrumento essencial para superar este problema. A relação entre meio ambiente e educação, assume um papel cada vez mais importante, demandando a necessidade de novos conhecimentos e métodos para o entendimento de processos e riscos ambientais que surgem em nossa realidade (PERETTI, 2012).

O ensino de educação ambiental e sustentabilidade tem um papel relevante para a compreensão dos ciclos biogeoquímicos que ocorrem em diferentes escalas em todo o mundo, pois, as informações adquiridas através de seus conteúdos vão desde o entendimento de conceitos básicos, até as mais complexas relações ecológicas desenvolvidas entre os organismos e o meio ambiente.

Mas, pela forma tradicional de como os conteúdos são ensinados, a compreensão, por parte do estudante, muitas vezes é dificultada, fragmentada e descontextualizada de sua 
realidade social sendo assim, a maneira como o ensino vem sendo abordado, pouco desperta o interesse de buscar novos conhecimentos (ZANELLA, 2013).

O reflexo do ensino tradicional é a fragmentação e a memorização dos conteúdos, o que acaba tornando o ensino e aprendizagem em sala pouco produtivo. O conhecimento científico, por exemplo, da forma como ele é ministrado nas escolas, termina por aumentar o desinteresse dos educandos que apenas memorizam de forma fragmentada. Nesse sentido, no que tange aos professores, o trabalho interdisciplinar pode auxiliar a superação desses currículos fragmentados e desarticulados com a realidade discente. Dessa forma, Fazenda (1994), afirma que a prática interdisciplinar pressupõe a possibilidade do "encontro", da "partilha", da cooperação e do diálogo entre os envolvidos na ação. Sendo assim o cotidiano escolar deverá mudar significativamente. ${ }^{3}$

Como consequência dessa concepção de educação tradicional, o estudante é visto como sujeito passivo, um mero ouvinte e o professor, muitas vezes, como o detentor do conhecimento. Sendo assim, a disciplina acaba sendo vista como um conjunto de conteúdo específicos de uma área e o objetivo do professor com sua disciplina acaba, muitas vezes, resumindo-se a ministrar o conteúdo proposto no livro didático, esquecendo-se como aponta Carvalho (2013), que o objetivo central da educação formal é a aprendizagem e do ensino, especificamente, é "ensinar a falar ciências", conduzir os estudantes da linguagem cotidiana para linguagem científica.

Para que os estudantes sejam alfabetizados cientificamente, as aulas devem estar organizadas de forma interativa e dinâmica, buscando compreender a concepção prévia dos discentes por meio da participação ao longo das aulas (CARVALHO, 2013). Portanto, cabe também ao professor quebrar o pensamento tradicionalista, fazendo com que o estudante se torne protagonista do processo de construção do seu conhecimento, partindo de uma situação real, em que o estudante encontre significado no conteúdo apresentado (CORDEIRO, 2017).

Diante do apresentado e bebendo da fonte de Carvalho e Gil-Perez (2011) dentre outros pesquisadores, compreende-se que o ambiente escolar independente de seu nível, deve

\footnotetext{
${ }^{3}$ Diante disso, e da própria organização dos sistemas escolares, que de modo implícito possuem como parâmetros para a construção dos novos currículos as provas de grande escala (Um forte exemplo é a Lei de 13.417/2007 que propôs uma nova reforma no Ensino Médio com o objetivo de tornar o currículo mais flexível, composto pela Base Nacional Comum Curricular (BNCC) e pelos seguintes itinerários formativos. Segundo seus idealizadores, tal proposta vem com o objetivo de melhorar os índices educacionais (Ideb) que não estavam tendo melhoras nos últimos anos. A própria organização da BNCC vem priorizando as disciplinas que são avaliadas nas grandes avaliações educacionais que são: português e matemática), os mecanismos utilizados para a aprendizagem acabam sendo memorísticos, tendo em vista que, muitas vezes os conteúdos acabam não sendo compreendidos pelos estudantes.
} 
ser visto também como espaço de pesquisa, capaz de produzir conhecimento. Desta forma, as concepções de ensino de ciências bem como das metodologias de ensino precisam ser revistas, o estudante precisa ser levado em consideração dentro desse processo.

Segundo Amorim (2013), os modelos didáticos, são facilitadores do processo de ensino, contribuem para a aprendizagem significava, pois permitem ao discente ter participação ativa em seu processo de ensino e aprendizagem. Os modelos complementam o conteúdo dos livros didáticos, que na maioria das vezes são encarados pelo estudante, como algo composto por termos a serem decorados, com imagens que não são compreendidas (ORLANDO, et al., 2009, p. 2).

Para Cavalcante e Silva (2008, p.01), os modelos didáticos permitem a experimentação e a prática, propiciam diferentes condições para a compreensão dos conceitos mais complexos, aqueles que exigem grande capacidade de abstração, estimulando o engajamento intelectual dos alunos com os objetos e fenômenos apresentados, contribuindo, também, para reflexões sobre o mundo em que vivem.

Diante dos problemas diários em sala de aula, o professor sente a necessidade de aprimorar suas aulas com métodos que venham a amenizar problemas como a dificuldade de perceber estruturas e processos, para Setúval e Bejarano (2009, p.04) “os modelos didáticos são instrumentos sugestivos e que podem ser eficazes na prática docente diante da abordagem de conteúdos que, muitas vezes, são de difícil compreensão pelos estudantes”.

Dentre as diversas estratégias a que o professor pode recorrer, os modelos didáticos podem constituir uma excelente alternativa que proporciona explorar múltiplas possibilidades de aprendizagem para os estudantes. Até mesmo para o próprio professor que, muitas vezes, demonstra insegurança ao ensinar alguns conteúdos de maior complexidade.

Segundo Carvalho e Gil-Pérez (2011) para modificar as concepções e metodologias no ensino, faz-se necessária uma profunda revisão da formação inicial e continuada dos professores, estendendo também ao avanço das pesquisas sobre aprendizagem das ciências e, em especial, as propostas de orientação construtivistas. Desta forma, este estudo tem por objetivo apresentar o processo de confecção de uma mini ecosfera e as contribuições deste recurso didático no ensino e aprendizagem de conteúdos como educação ambiental e sustentabilidade nas turmas de agroecologia do curso técnico subsequente em zootecnia do IFPE - Campus Vitória de Santo Antão.

\section{FUNDAMENTAÇÃO TEÓRICA}

Desde o início da humanidade, o ser humano sempre fez uso de objetos para facilitar a 
execução de suas atividades diárias. Pesquisas indicam que os primeiros objetos produzidos pelo homem eram simples, feitos manualmente. Acredita-se que eles eram utilizados como martelos, objetos de corte, caça e defesa. Todo esse processo de desenvolvimento foi impulsionado pela pressão natural e necessidade de sobrevivência no planeta. (FREITAS, 2007)

De acordo com Burg, Fronza e Silva (2013) no começo, os materiais eram usados da maneira como eram encontrados e com o decorrer do tempo, passaram a ser mais sofisticados. O ser humano passou a desenvolver novas formas de interagir entre si e com o meio, inicialmente com os desenhos de seu dia a dia, como figuras próprias e de animais pintados em cavernas, passando pela escrita cuneiforme, a escrita mais antiga que se tem conhecimento, até chegarmos ao primeiro alfabeto fonético, precursor do alfabeto utilizado atualmente. (PARELLADA, 2009).

Os primeiros grupos humanos a fixarem-se na terra, dominando a agricultura e domesticando animais, preocuparam-se com a transmissão do conhecimento aos mais jovens, tendo em vista prepará-los para a sobrevivência e defesa. Nesse período, além da observação e imitação por parte dos mais novos, a exposição oral era a ferramenta utilizada para transmitir o aprendizado e os costumes do grupo. (FREITAS, 2007; MORETTI, 2011)

A necessidade em desenvolver métodos de comunicação, demonstra uma preocupação em facilitar o processo de ensino aprendizagem, uma vez que era preciso garantir a atenção e estimular a atenção de seus descendentes. O lúdico é outro aspecto percebido nas técnicas utilizadas para transmitir o conhecimento, uma vez que as dramatizações proporcionam prazer aos aprendizes. (DAVIS, 2009)

Esses são alguns exemplos de como o ser humano, sempre lançou mão de desenvolver diferentes métodos para melhoram sua qualidade de vida, até mesmo na educação. Essa é, portanto, uma característica humana, buscar estratégias facilitadoras de seu processo de aprendizagem. (FREITAS, 2007)

Atualmente, a necessidade em desenvolver novos métodos de ensino e aprendizagem, surge pelas novas exigências deste sistema social. E como forma de responder a essas exigências, surgem os recursos didático - pedagógicos que permitem ao professor desenvolver um tipo de aula diferenciada, dinâmica e proveitosa. Não se sabe quando começaram a ser utilizados em aula, mas, esses recursos já são desenvolvidos há muito tempo, geração após geração, tendo alcançado bons resultados. (BRAGA, 2007, p. 4).

Esta ferramenta didática, quando corretamente utilizada, propícia o desenvolvimento espontâneo e criativo dos estudantes, permitindo também ao professor ampliar seus 
conhecimentos acerca das técnicas de ensino e o desenvolvimento de capacidades pessoais e profissionais para estimular nos estudantes a capacidade de expressão e argumentação, mostrando-lhes uma maneira mais prazerosa de relacionar-se com o conteúdo ensinado, levando-os à uma maior apropriação dos conteúdos trabalhados.

Segundo Santos, (2013) a partir do momento que se desenvolve uma relação entre o indivíduo com as atividades na sala de aula, cria-se um ambiente de socialização e troca de informações, revelando outro ponto importante dos recursos didáticos que desperta a curiosidade, a capacidade de observar, de questionar e uma melhor interação nas atividades. Estes recursos são instrumentos sugestivos e que podem ser eficazes na prática docente diante da abordagem de conteúdos que, muitas vezes, são de difícil compreensão. (SETÚVAL E BEJARANO, 2009, p. 04)

Muitos professores utilizam quase que unicamente o livro didático, pois é o recurso mais acessível, já que as escolas públicas recebem livros para utilização dos professores. Sendo um recurso acessível, muitas vezes por comodismo, a única opção utilizada pelo professor em suas aulas, deixando de incorporar outras ferramentas que poderiam auxiliar no ensino-aprendizagem. (NICOLA, PANIZ, 2017)

Para Cavalcante e Silva (2008), os recursos didáticos em que os alunos possam visualizar, são de grande importância, pois o professor consegue mostrar de forma explicita o que pretende trabalhar e o estudante, através da visualização, pode ter uma melhor fixação do conteúdo. As apresentações em PowerPoint, são um excelente exemplo, onde é possível associar texto, imagens e animações, demonstrando o que está sendo estudado. (NICOLA, PANIZ, 2017)

Ainda, segundo Nicola e Paniz, (2017) Independentemente do tipo de recurso, o seu uso, exige do professor planejamento e clareza de objetivos a serem alcançados, ou seja, o que se quer e quais conhecimentos podem ser construídos ou ampliados a partir destes recursos.

Para formar adultos cientes de suas responsabilidades ambientais com a natureza e que optem por um estilo de vida sustentável, a escola é o melhor ambiente para estimular uma consciência sustentável, pois os estudantes são mais suscetíveis a determinadas ponderações. "Pelo fato de encontrarem-se em uma fase de tomada de decisões, onde viver de forma sustentável é uma opção plausível”. (COSTA, 2018)

Segundo Amorim (2013), neste contexto, os modelos didáticos, são facilitadores do processo de ensino, contribuem para a aprendizagem significava, pois permitem ao discente ter participação ativa em seu processo de ensino e aprendizagem. Os modelos complementam o conteúdo dos livros didáticos, que na maioria das vezes são encarados pelo estudante, como 
algo composto por termos a serem decorados, com imagens que não são compreendidas (ORLANDO, et al., 2009, p. 2).

\section{METODOLOGIA}

O presente recurso, foi produzido por um discente do curso de Ciências Biológicas da UFPE-CAV, durante os meses de abril e junho de 2018, para ser exposto como recurso didático no ensino de educação ambiental, como requisito para obtenção de aprovação parcial na referida disciplina. Foi utilizado como recurso didático nas dependências do instituto Federal de Educação Ciências e Tecnologia de Pernambuco - Campus Vitoria de Santo Antão, na Disciplina de Agroecologia do curso técnico subsequente em zootecnia.

Para a confecção do modelo foi utilizada como referência a Ecosfera original $\left(\text { Ecosferas }{ }^{\circledR}\right)^{4}$, que surgiu de pesquisas aeroespaciais desenvolvidas pela NASA, que procuravam construir um sistema fechado no espaço onde os astronautas poderiam sobreviver durante longas viagens, em um ambiente autossuficiente, que fosse capaz de produzir recursos e manter o ar e a água limpos e reutilizáveis. Como resultado surgiram as Ecosferas produzidas pelo grupo internacional Ecospheres ${ }^{5}$.

A NASA cedeu esta tecnologia para que a sociedade pudesse entender o equilíbrio e funcionamento da natureza, a Ecosfera, é um ecossistema fechado e autossuficiente que pode ser usado como um excelente recurso de ensino e aprendizagem capaz de fornecer informações acerca da vida e de seu delicado equilíbrio em nosso planeta.

A Ecosfera, funciona como uma bateria biológica que armazena a energia luminosa transformada bioquimicamente, é um globo de vidro, com um ecossistema marinho, já o modelo que será apresntado a seguir, é a representação de um ecossistema contendo um grupo de organismos de ambiente dulcícola, sendo composto por um recipiente de acrílico lacrado, contendo água doce, basalto e quartzo triturados, substrato fértil, plantas aquáticas Echinodorus amazonicus, musgos Taxiphyllum barbieri, quatro camarões Neocaridina davidi e um casal de limpa vidro Parotocinclus maculicauda.

Figura 1: (A) Echinodorus amazonicus ${ }^{6}$; (B) Taxiphyllum Barbieri ${ }^{7}$; (C) Neocaridina davidi ${ }^{8}$ e (D) Parotocinclus maculicauda?.

\footnotetext{
${ }^{4}$ Objeto utilizado como modelo, (https://www.ecosferas.com/view_ecosferas/es/inicio.html. ).

${ }^{5}$ Endereço digital da empresa Ecospheres (https://eco-sphere.com/ ).

${ }^{6}$ Fonte: http://akvarium.dp.ua/wp-content/uploads/ngg featured/ehinodorus-blehera-400x533.jpeg

${ }^{7}$ Fonte: http://peixesdeaquario.com.br/plantas-2/musgo-de-java/

${ }^{8}$ Fonte: http://peixesdeaquario.com.br/wp-content/uploads/CAmar\%C3\%A3o-Red-Cherry-672x372.jpg

${ }^{9}$ Fonte: https://i.pinimg.com/736x/5f/d5/9a/5fd59a3db5126c07c35781e1485d4bb0--aquaria-tropical-fish.jpg
} 

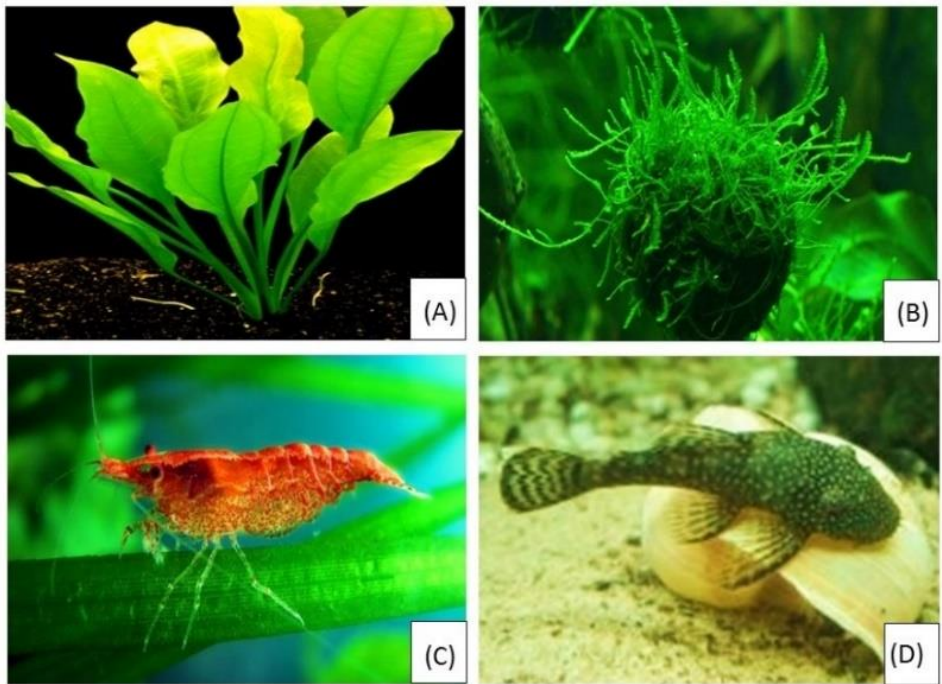

Antes de iniciar a confecção do modelo, foram produzidos dois protótipos, com outras variedades de plantas aquáticas e animais, para verificar quais seriam os organismos mais adequados para esse tipo de ambiente. Após montados e observados num período de três meses, optou-se pelo uso dos organismos citados acima, pois foram os mais adequados aos critérios como: organismos que não apresentam comportamento agressivo entre si, resistência a variação de parâmetros de $\mathrm{PH}$, oxigênio diluído na água, variação de temperatura, ciclo de vida de pelo menos dois anos e baixo custo.

Figura 2: (E) imagem de modelo de protótipo colado e em fase de secagem do silicone; (F) imagem de protótipo pronto com plantas já cultivadas e em desenvolvimento, $(\mathrm{G})$ imagem de protótipo 2, montado com plantas e animais em desenvolvimento.

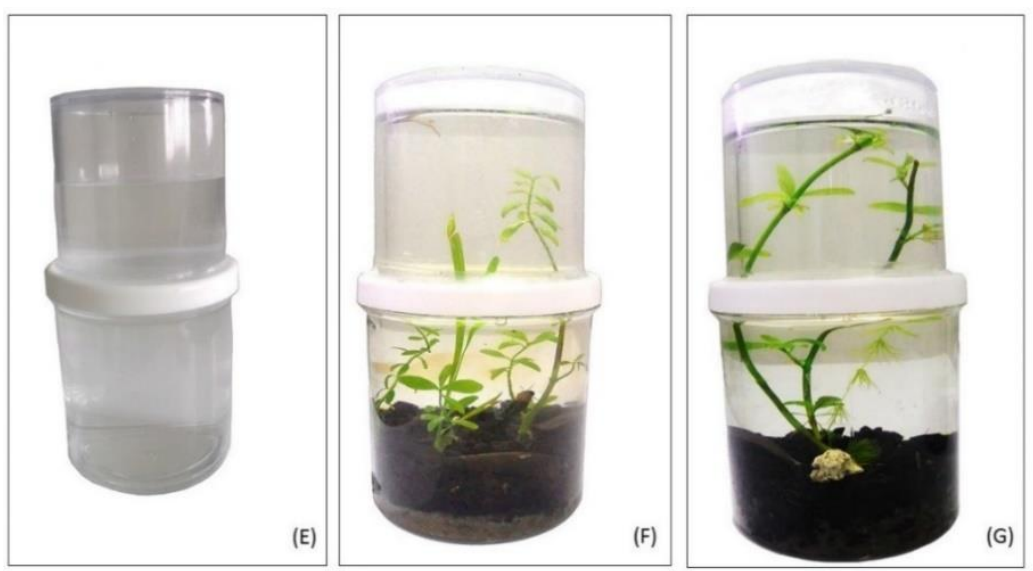

Fonte: Própria, 2019

Para a confecção do modelo definitivo, foram utilizados dois potes de acrílico cilíndricos, (600 ml e $2.000 \mathrm{ml})$ e silicone Sil Trade próprio para montagem de aquários, as tampas dos dois potes, foram cortadas para que ambas fossem coladas de forma perpendicular, servindo de apoio para fixar o pote menor sobre o maior.

Após o corte, as tampas foram coladas com o silicone sobre o pote maior, foi aguardado um período de dez dias para a secagem completa do silicone. Em seguida, para 
montagem do substrato, foi colocado duzentos gramas de basalto negro e cem gramas de quartzo triturado, sobre uma camada de dois centímetros de humos de minhoca, depois foram colocadas as plantas aquáticas, água tratada com os parâmetros adequados para os animais e plantas que farão parte do ecossistema e por fim, os camarões e os limpa vidro.

Para acelerar o processo de maturação do sistema, foi adicionado $100 \mathrm{ml}$ da água de um aquário já estabilizado com uma microbiota de algas e bactérias bem estabelecidas. Após serem colocados todos os itens, o pote menor foi colocado sobre o maior e fixado com fita isolante e silicone resistente a água.

Cada componente deste ecossistema desempenha um papel vital no equilíbrio do mesmo, as plantas aquáticas recebem a luz solar e iniciam a fotossíntese liberando oxigênio que será consumido pelos camarões e os limpa vidro que também serão nutridos com algas e bactérias que se desenvolvem a todo momento dentro da estrutura.

As bactérias nitrificantes, decompõem os dejetos dos animais, disponibilizando recursos para que as plantas aquáticas continuem seu desenvolvimento, os crustáceos, peixes e bactérias também produzem dióxido de carbono que é utilizado pelas algas e plantas aquáticas no processo de fotossíntese.

Todos os animais são consumidores. Os herbívoros, alimentam-se de plantas, são, portanto, consumidores primários. Os animais que se alimentam de herbívoros são consumidores secundários, os que se alimentam dos secundários são consumidores terciários e assim por diante; os decompositores, degradam a matéria orgânica presente em produtores e consumidores de todas as cadeias citadas, utilizam os produtos da decomposição como alimento e liberam no meio ambiente minerais e outras substâncias, que podem ser novamente utilizados pelos produtores.

Figura 3: (H) Modelo de mini ecosfera, montada e em desenvolvimento.

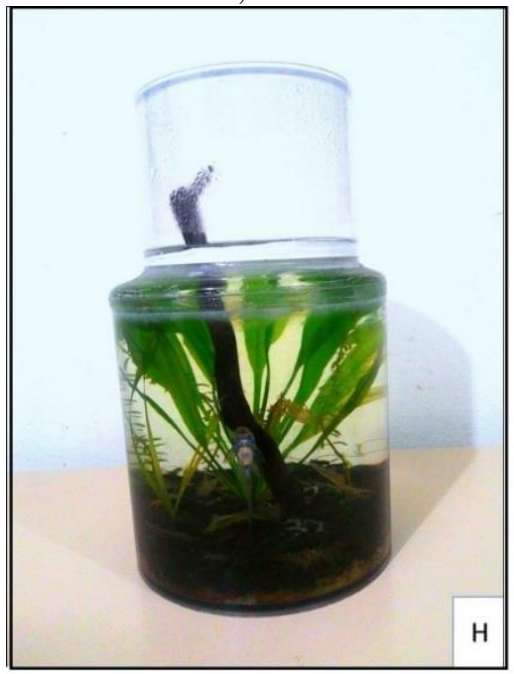

Fonte: Própria, 2019. 
Após a elaboração do recurso didático, foram selecionadas duas turmas do curso técnico em zootecnia do IFPE- Campus Vitoria de Santo Antão, para uma turma (turma A), foi planejada e ministrada, uma aula, fazendo uso da ecosfera como recurso didático e de apresentações em Power point, para a outra turma, (turma B) foi realizada a exposição oral e apresentações em Power point do mesmo conteúdo apresentado a turma A. Em seguida, foi elaborado um questionário com 6 questões acerca do conteúdo da aula. Na turma A, haviam 25 alunos e na turma B, 30 alunos.

Após o termino da aula, foi aplicado um mesmo questionário sobre meio ambiente e sustentabilidade para todos os alunos, e em seguida coletados, os resultados foram analisados como descrito a seguir.

\section{RESULTADOS E DISCUSSÃO}

Os alunos da turma A, durante a apresentação deste modelo, tiveram a oportunidade de montar um exemplar e relembrar os conteúdos previamente estudados na disciplina de agroecologia como por exemplo, as relações ecológicas e sustentabilidade. A partir dos dados obtidos, as discursões e observações foram realizadas e para facilitar o entendimento dos dados, foram construídos gráficos.

$\mathrm{Na}$ questão número 1 , foi solicitado que os alunos conceituassem o que seria sustentabilidade, observou-se que as duas turmas, Turma A e turma B, apresentaram o mesmo índice de acerto (50\% de acertos em ambas as turmas) a similaridade no índice de erros e acertos, pode ser justificada pelo fato de os alunos responderem essa questão tendo como base o material exposto em Power point. Segundo Nicola e Paniz (2017), a apresentação em PowerPoint, é um excelente recurso, onde é possível associar texto com as imagens e animações, demonstrando claramente o que está sendo estudado.

$\mathrm{Na}$ questão número 2, os alunos tinham cinco figuras com diferentes significados, e deveriam relacionar uma das figuras com o tema sustentabilidade, dessas figuras, apenas uma representava o foco de abordagem da sustentabilidade, para assinalar essa alternativa, era necessário que o aluno conseguisse associar a figura adequada com a palavra, nesta questão, a Turma A apresentou $90 \%$ de acertos enquanto que a turma B apresentou $60 \%$ de acertos. 
Gráfico 1. Índice de acertos na associação de imagens ao conceito.

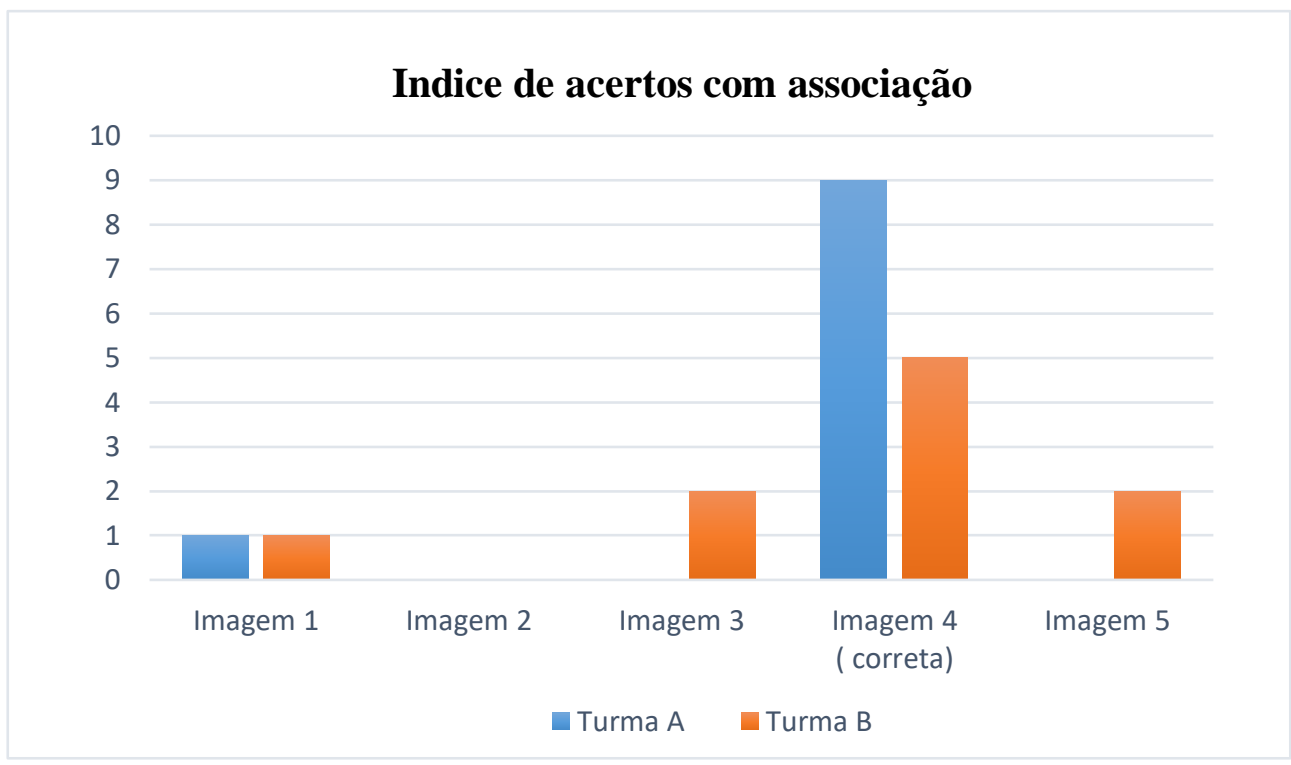

Fonte: Própria, 2019.

O diferencial de acertos entre as turmas, pode ser atribuído ao fato de os alunos da turma A, além de observarem as imagens apresentadas puderam interagir com o recurso didático e relacionar o conteúdo estudado com o funcionamento do ecossistema. Segundo Amorim (2013), os modelos didáticos, são facilitadores do processo de ensino contribuindo para a aprendizagem significava, pois permitem ao discente ter participação ativa em seu aprendizado.

$\mathrm{Na}$ questão número 3 , os alunos deveriam conceituar a palavra agroecologia, ao analisar as respostas apresentadas pela turma A, 45\% dos alunos apresentaram o conceito da palavra agroecologia associando com o funcionamento da ecosfera, como exemplo, é possível citar a resposta do aluno A1 $1^{10}$, que diz: “ A agroecologia é uma parte da ecologia que estuda a agricultura sustentável, tentando manter o melhor equilíbrio possível na produção e na preservação do solo e do ambiente, tentando chegar no equilíbrio similar ao que a gente pode ver na ecosfera, que os animais comem as plantas mas só o que precisam, fazendo com que a planta consiga se renovar e tudo ficar em equilíbrio". No geral, a turma A apresentou um índice de $70 \%$ de acertos definindo a agroecologia, enquanto que a turma B apresentou 55\% de acertos.

Em seguida, na questão número 4, era necessário associar a agroecologia com algumas imagens, indicando a imagem que melhor trouxesse elementos importantes para associação

\footnotetext{
${ }^{10}$ Cada questionário respondido foi nomeado com a letra referente a turma (A ou B) e enumerado de acordo com a ordem de analise, como exemplo: A11, A14 e B2.
} 
com os três pontos de foco e abordagem da agroecologia. A turma A, apresentou $90 \%$ de acertos enquanto que a Turma B apresentou $60 \%$.

$\mathrm{Na}$ questão número 5, foi solicitado que os alunos descrevessem um ecossistema e apontassem como o extrativismo descontrolado poderia desequilibrar ou destruir o ecossistema. Nesta questão, 30\% dos alunos da turma A, descreveram ecossistemas similares ou iguais ao da ecosfera, e apontaram fatores como a extração exacerbada de nutrientes do solo, a destruição de produtores primários e redução da variedade de indivíduos. No geral $80 \%$ dos alunos da turma A, responderam esta questão de maneira satisfatória. Enquanto que $45 \%$ dos alunos da turma B, responderam satisfatoriamente esta questão.

$\mathrm{O}$ fato de parte dos alunos da turma A descreverem ecossistemas similares ou iguais a ecosfera e boa parte da turma conseguir responder à questão 5, pode estar associado a circunstância de terem a oportunidade de montar uma ecosfera e entender a função de cada componente presente no sistema. No estudo realizado por Cavalcante (2008), professores foram questionados a respeito de qual a melhor maneira de ensinar, eles enfatizaram a necessidade de permitir aos alunos ter oportunidades onde possam relacionar teoria e a prática, ou seja, para que ambos não se tornem independentes e sim que haja uma complementação para o um melhor entendimento.

No item 6, os alunos foram questionados a respeito de como suas ações como futuros profissionais poderiam interferir no equilíbrio do meio ambiente. Os alunos de ambas as turmas, apontaram a importância de observar o ambiente, planejar as ações que serão desenvolvidas para evitar possíveis prejuízos ambientais, o respeito ao meio ambiente e a visão de preservar para os que virão a seguir. Mas comparando as respostas das turmas, é possível identificar maior investimento por parte dos alunos da turma $\mathrm{A}$, em justificar a importância de seu papel como futuro profissional, o aluno A 14, afirmou que " é preciso ter muito respeito pela natureza porque, quando eu for técnico em zootecnia e precisar trabalhar com animais como abelhas, vou precisar saber a importância desses animais para o meio ambiente e para a manutenção da natureza tendo que maneja-las com muito cuidado para não sobrecarregar o ambiente e respeitar os animais".

A constatação acima, corrobora com as afirmações de Nery et al (2017), o uso de modelos didáticos para o ensino da educação ambiental deve ser considerado devido sua relevância, uma vez que, não somente uma atividade mecânica, mas que possibilita ao aluno estabelecer interações que promovam um maior rendimento e sobretudo, quando se dá o estimulo participativo de forma a construir novas discussões e a formulação de novas hipóteses sobre o tema abordado. 
A questão número 7, apresentava uma escala de satisfação do tipo likert, solicitando a opinião dos alunos quanto a dificuldade em compreender o conteúdo apresentado. O gráfico abaixo apresenta em porcentagem o grau de dificuldade apontado por ambas as turmas, onde 0 corresponde a nenhuma dificuldade e 10, muita dificuldade em compreender o conteúdo, ficando claro uma maior dificuldade de entendimento por parte dos alunos da turma B.

Gráfico 2. Indicação de grau de dificuldade apontado pelos alunos de ambas as turmas.

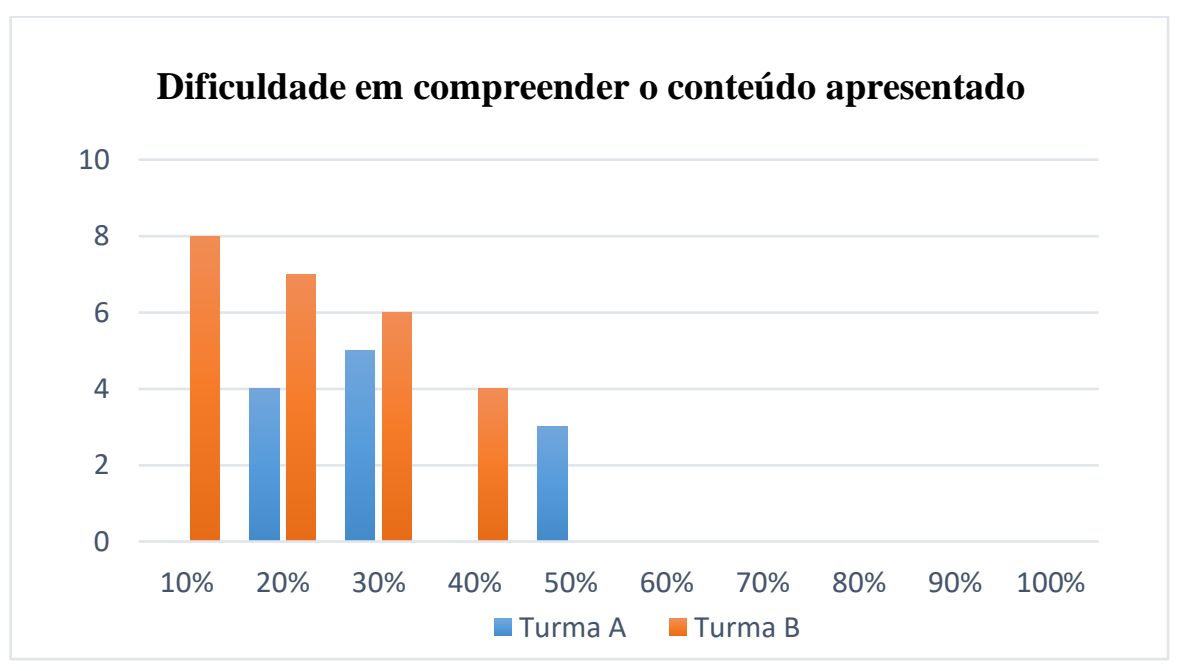

Fonte: Própria, 2019.

Por fim, na questão 8, os alunos da turma A responderam a seguinte indagação: "Em sua opinião, o uso da ecosfera como recurso didático, contribuiu para o entendimento dos conteúdos ensinados? Justifique". Enquanto que os alunos da turma B, foram incentivados a apontar possíveis sugestões para melhorar a metodologia utilizada com a turma. Como resposta para a questão $8,100 \%$ dos alunos da turma $\mathrm{A}$, afirmaram que a ecosfera contribuiu positivamente no seu processo de aprendizado, o aluno A10 afirmou que " a ecosfera é muito legal, porque funciona como um planeta terra em miniatura e dá para ver na pratica o que a gente acabou de ver sobre sustentabilidade", o aluno A13, relatou que " a ecosfera me ajudou a identificar como um organismo é dependente do outro, do mesmo jeito que nós dependemos das florestas e dos mares".

O aluno A16 afirmou que "me ajudou a entender o assunto apresentado e me incentivou a pensar no meu papel como indivíduo que faz parte de um grande ecossistema, que é o planeta terra". Os relatos acima permitem afirmar que, os recursos didáticos auxiliam a aproximação dos alunos com a contextualização da sua realidade e dos fenômenos naturais que ocorrem ao seu entorno, como afirma Silva e Bertazzo (2013), "ao utilizá-lo como proposta didática e pedagógica é possível não só tornar as aulas mais estimulantes e criativas, como também contextualizar o processo de ensino e aprendizagem. " 
Como resposta para a questão 8 , a turma $\mathrm{B}$, fez várias sugestões de melhoras para tornar as aulas mais interessantes, as recomendações com maior frequência foram, o uso de maquetes, aulas práticas para visualização dos fenômenos comentados em aula e exibição de vídeos e documentários.

É importante ressaltar o entusiasmo dos alunos da turma A, ao saberem que sairiam da rotina cotidiana de apenas assistir apresentações de slides, para uma atividade pratica e dinâmica. Com isso, notou-se o engajamento de todos os alunos em participar da atividade proposta de montar a ecosfera. Segundo Oliveira (2006), é por meio do processo de aprendizagem e do pensar sobre a realidade, que se rompe com as enlaças do ensino tradicional, da extensa e exaustiva descrição e memorização de conceitos.

\section{CONCLUSÕES}

A construção do modelo aqui apresentado possibilitou o aprimoramento e desenvolvimento de novas habilidades, mostrou-se um facilitador no ensino de novos saberes, de forma eficaz, permitindo observar os conteúdos de maneira dinâmica.

Relatos como os demonstrados neste estudo evidenciam que recursos didáticos possuem uma grande importância para a construção do conhecimento dos alunos, auxiliando na compreensão e complementando o conteúdo apresentado nos livros e trazendo a dinâmica das relações ecológicas e do meio ambiente, de uma formar que as figuras planas e, muitas vezes, descoloridas dos livros não podem trazer.

É importante destacar a necessidade do desenvolvimento de novos métodos e recursos educacionais, capazes de estimular o interesse do aluno em participar ativamente em seu processo de ensino e aprendizagem.

\section{REFERÊNCIAS}

AMORIM, A.S. A influência do uso de jogos e modelos didáticos no ensino de biologia para alunos de ensino médio. 2013. 49f. Monografia (Licenciatura em Ciências Biológicas) - Universidade Aberta do Brasil, Centro de Ciências e Saúde, Universidade Estadual do Ceará, Ceará, 2013. Disponível em: http://www.uece.br/sate/index.php/downloads/doc_download/2146-biobeberibeamorim>. Acesso em: 29 jul. 2019.

BURG, Silvana Montibeller; FRONZA, Silvio Luiz; SILVA, Thiago Rodrigo da. História da Educação: Caderno de estudos. Indaial: UNIASSELVI, 2013.

BRAGA, Andréa Jovane. Usos dos jogos didáticos em sala de aula. 2007. 
CARVAlHO, Anna Maria Pessoa. O ensino de ciências e a proposição de sequências de ensino investigativas. Em: CARVALHO, Anna Maria Pessoa. (Org.) Ensino de Ciências por investigação: condições para implementação em sala de aula. São Paulo: Cengage Learning, 2017.

CARVAlHO, Anna Maria Pessoa; GIL- PÉREZ, Daniel. Formação de professores de Ciências: tendências e inovações. São Paulo: Cortez, 10 ed, 2011.

CAVALCANTE, Dannuza; SILVA, Aparecida. MODELOS DIDATICOS E PROFESSORES: CONCEPÇÕES DE ENSINO-APRENDIZAGEM E EXPERIMENTAÇÕES. In: XIV Encontro Nacional de Ensino de Química, Curitiba, UFPR, jul de 2008. Disponível $\quad$ em: http://www.quimica.ufpr.br/eduquim/eneq2008/resumos/R0519-1.pdf> Acesso em 03 jul, 2019.

CORDEIRO, K. F. S.; SANTOS, L. R. F.; W. P. SANTOS. A utilização do júri simulado como metodologia alternativa de ensino nas séries finais do ensino fundamental na escola estadual pio XII - Irati-PR. In: XII Congresso Nacional de Educação, Curitiba. 2017. Disponível em: < http://educere.bruc.com.br/arquivo/pdf2017/24092_12021.pdf> Acesso em 01 jul, 2018.

COSTA, E.B: Visita Técnica Como Estratégia de Construção da Cidadania Ambiental com Alunos de Escola Pública em Teresina-PI. Trabalho de Conclusão de Curso (Graduação em Ciências Biológicas) - Instituto Federal de Ciências, Educação e Tecnologia do Piauí. Teresina-PI, p. 24. 2018.

DAVIS, H, A.; PAVAM, C.A. Coleção Enciclopédia Ilustrada de História, São Paulo, Brasil, Duetto Editorial, 2009.

MATOS, Cláudia; OLIVEIRA, Carlos Romero; SANTOS, Maria Patrícia; FERRAZ, Célia. Utilização de Modelos Didáticos no Ensino de Entomologia. Revista de Biologia e Ciências da Terra. Vol. 09, $\mathrm{n}^{\mathrm{o}}$ 01. Paraíba, 2009. Disponível em: < http://joaootavio.com.br/bioterra/workspace/uploads/artigos/3matos-51816c32b2719.pdf > Acesso em 01 Jul 2019.

FREITAS, Olga. Equipamentos e materiais didáticos. Brasília: Universidade Federal de Brasília, 2007. 132 p. Disponível em: http://portal.mec.gov.br/seb/arquivos/pdf/profunc/equip_mat_dit.pdf $>$ acesso em 01 Ago. 2019.

MORETTI, Vanessa Dias; ASBAHR, Flávia da Silva Ferreira; RIGON, Algacir José. O humano no homem: os pressupostos teórico-metodológicos da teoria histórico-cultural. Psicol. Soc., Florianópolis , v. 23, n. 3, p. 477-485, Dez. 2011 . Disponível em: < http://www.scielo.br/scielo.php?script=sci_arttext\&pid=S0102-71822011000300005 >.

Acesso em 09 Ago. 2019.

NERY, Gleydson, Kleyton Moura; NERY, Janiele, França; FERREIRA, Larissa, Macena.

Construção de modelos didáticos como ferramenta para o ensino de ciências. In: II Congresso Nacional de Pesquisa e Ensino em Ciências, Campina Grande, PB, junho de 2017. Disponívelem:<http://www.editorarealize.com.br/revistas/conapesc/trabalhos/TRABALHO_E V058_MD1_SA93_ID41_17052016220135.pdf> acesso em 01 jul 2019. 
NICOLA, Jéssica Anese; PANIZ, Catiane Mazocco. A importância da utilização de diferentes recursos didáticos no Ensino de Ciências e Biologia. InFor, [S.1.], v. 2, n. 1, p. 355-381, mai 2017. Disponível em: <https://ojs.ead.unesp.br/index.php/nead/article/view/InFor2120167>. Acesso em: 10 ago. 2019.

OLIVEIRA, M. M. A geografia escolar: reflexões sobre o processo didático-pedagógico do ensino. Revista Discente Expressões Geográficas, n. 2, p. 10-24. Florianópolis, 2006. Disponível em: < http://www.geograficas.cfh.ufsc.br/arquivo/ed02/artigo01.pdf >. Acesso em: 10 jun. 2019.

ORLANDO, T.C. et al. Planejamento, montagem e aplicação de modelos didáticos para abordagem de biologia celular e molecular no ensino médio por graduandos de ciências biológicas. Revista brasileira de ensino de bioquímica e biologia molecular, v.1, n.1, p.117, 2009. Disponível em: < http://bioquimica.org.br/revista/ojs/index.php/REB/article/view/33/29 >. Acesso em: 29 jul. 2019.

PARELLADA, Claudia Inês. ARTE RUPESTRE NO PARANÁ. Revista Científica/FAP, [S.1.], jun. 2009. ISSN 1980-5071. Disponível em: $<$ http://periodicos.unespar.edu.br/index.php/revistacientifica/article/view/1592>. Acesso em: 09 Ago. 2019.

PERETTI, Vanessa Aline. "Educação Ambiental na escola pública: o caso da EEEF José Ferreira Ramos-Gaurama/RS." Revista Eletrônica em Gestão, Educação e Tecnologia Ambiental. Rio Grande do Sul. Vol. 05, nº 05, p, 841 - 849, 2012. Disponível em: < https://periodicos.ufsm.br/reget/article/viewFile/4246/2814> acesso em: 09 ago, 2019

SANTOS, Ovídia Kaliandra Costa; Belmino; José Franscidavid Barbosa. RECURSOS DIDÁTICOS: UMA MELHORIA NA QUALIDADE DA APRENDIZAGEM. In: Fórum Internacional de Pedagogia, 5., 2013, Campina Grande. Anais... [...]. Campina Grande.Realize. 2013. Disponível em: < http://editorarealize.com.br/revistas/fiped/trabalhos/Trabalho_Comunicacao_oral_idinscrito__ fde094c18ce8ce27adf61aedf31dd2d6.pdf> acesso em 10 Ago, 2019.

SETUVAL, Francisco; BEJARANO, Nelson. Os modelos didáticos com conteúdos de genética e a sua importância na formação inicial de professores para o ensino de ciências e biologia. Bahia, 2008. Disponível em: http://posgrad.fae.ufmg.br/posgrad/viienpec/pdfs/1751.pdf>. Acesso em 12 de Jan de 2019.

SILVA, Laydiane Cristina da; BERTAZZO, Claudio Jose. O LÚDICO, A GEOGRAFIA E A MEDIAÇÃO DIDÁTICA. Revista Geoaraguaia, [S.1.], dec. 2013. ISSN 2236-9716. Disponível em: <http://periodicoscientificos.ufmt.br/ojs/index.php/geo/article/view/4868/3278>. Acesso em: 03 ago. 2019

THIESEN, Juares da Silva. A interdisciplinaridade como um movimento articulador no processo ensino-aprendizagem. Rev. Bras. Educ. Rio de Janeiro, v. 13, n. 39, p. 545-554, 2008. Disponível em: < <http://www.scielo.br/scielo.php?script=sci_arttext\&pid=S141324782008000300010\&lng=en\&nrm=iso >. Acesso em 02 ago. 2019. 
ZANELLA, Camila. As dificuldades que os professores enfrentam em sala de aula nos anos iniciais da docência. In: XI Congresso Nacional de Educação, Curitiba, PUCPR, setembro de 2013. Disponível em:

http://educere.bruc.com.br/arquivo/pdf2013/9875_6234.pdf > Acesso em 01 jul, 2019. 


\title{
DESEMPENHO E RENDIMENTO DE CARCAÇA DE FRANGO DE CORTE DE CRESCIMENTO LENTO ALIMENTADOS COM FARELO DE PALMA FORRAGEIRA
}

\author{
RENDIMIENTO Y RENDIMIENTO DE CRECIMIENTO DE POLLO DE \\ CRECIMIENTO LENTO ALIMENTADO CON FORMA DE PALMA
}

\section{PERFORMANCE AND YIELD OF SLOW GROWTH CHICKEN CHICKEN FED WITH PALM FORAGE}

\author{
Cicero Cordeiro Pinheiro ${ }^{1}$; Francisco Luan Fernandes Ferreira ${ }^{2}$; Alexsandro de Andrade silva ${ }^{3}$ \\ Ednardo Rodrigues Freitas ${ }^{4}$; Irani Ribeiro Vieira Lopes ${ }^{5}$
}

DOI: https://doi.org/10.31692/978-65-991061-4-9.92-105

\begin{abstract}
RESUMO
A avicultura é uma atividade econômica internacionalizada e uniforme sem fronteiras geográficas, gerando grande impacto na economia brasileira. Inúmeros trabalhos buscam a implementação de alimentos com menor custo de produção visando diminuir os custos com ração sem diminuir o desempenho e o rendimento de carcaça. Com isso objetivo dessa pesquisa foi avaliar o uso de farelo de palma forrageira na alimentação de frangos de corte de crescimento lento. O experimento foi conduzido no Setor de Avicultura da Universidade Federal do Cariri, no período de 18 de setembro a 12 de dezembro de 2018 (abatidas aos 85 dias de idade). Foram adquiridos 200 pintos não sexados da linhagem pesadão vermelho, de um dia de idade. De 1 a 27 dias de idade, todos os pintos receberam, à vontade, ração inicial vendida no comércio local apropriada para frangos de corte tipo caipira. Quando os frangos completaram 27 dias, foram pesados e distribuídos em um delineamento inteiramente casualizado com três tratamentos (ração controle; ração com 5\% de farelo; e ração com 10\% de farelo de palma) e cinco repetições de 10 unidades cada, totalizando 50 aves por tratamento. As aves que receberam dieta contendo $90 \%$ de ração e $10 \%$ de palma forrageira apresentaram menor consumo alimentar. Entretanto, a conversão alimentar desses frangos não diferiu significativamente daqueles alimentos somente com ração comercial, As variáveis peito, coxa + (mais) sobrecoxa, peito e coração, não apresentaram diferença estatística significativa enquanto que as variáveis carcaça, fígado e moela apresentaram diferença pelo teste de SNK $(\mathrm{P}<0,05) \mathrm{O}$ farelo de palma pode ser utilizado na alimentação de frangos de corte de crescimento lento até o nível de $10 \%$.

Palavras-Chave: Galinha caipira, Alimentação alternativa, Cactácea, Farelo de palma forrageira, Opuntia.
\end{abstract}

\section{RESUMEN}

La avicultura es una actividad económica internacionalizada y uniforme sin fronteras geográficas, que genera un gran impacto en la economía brasileña. Numerosos estudios buscan implementar alimentos con menores costos de producción para reducir los costos de alimentación sin disminuir el rendimiento y el rendimiento de la canal. El objetivo de esta investigación fue evaluar el uso de harina de palma forrajera en la alimentación de pollos de engorde de crecimiento lento. El experimento se realizó en el Departamento de Industria Avícola de la Universidad Federal de Cariri, del 18 de septiembre al 12 de diciembre de 2018 (sacrificado a los 85 días). Compramos 200 polluelos no sexados de la línea roja pesada de un día. De 1 a 27 días de edad, todos los pollos recibieron alimento inicial gratuito vendido en el comercio local apropiado para pollos de corral. Cuando los pollos tenían 27 días de edad, se pesaron y se distribuyeron en un diseño completamente al azar con tres tratamientos (dieta de control,

\footnotetext{
${ }^{1}$ Engenharia Agronômica, Universidade Federal do Cariri, cicero.cordeiro@aluno.ufca.edu.br

${ }^{2}$ Engenharia Agronômica, Universidade Federal do Cariri, luanfernadesdp@ gmail.com

${ }^{3}$ Engenharia Agronômica, Universidade Federal do Cariri, aleandsil06@gmail.com

${ }^{4}$ Doutor em Zootecnia, Universidade Federal do Ceará, ednardo@ufc.br

${ }^{5}$ Doutora em Produção e Nutrição Animal, Universidade Federal do Cariri, irani.ribeiro@ufca.edu.br
} 
dieta de 5\% de salvado y $10 \%$ de dieta de salvado de palma) y cinco réplicas de 10 unidades cada una, totalizando 50 tratamientos. pájaros por tratamiento. Las aves que recibieron una dieta que contenía el $90 \%$ del alimento y el $10 \%$ de la palma forrajera presentaron una menor ingesta de alimentos. Sin embargo, la conversión alimenticia de estos pollos no difirió significativamente de la alimentación comercial solamente. Las variables pechuga, muslo + (más) muslo, pechuga y corazón no mostraron diferencias estadísticamente significativas, mientras que las variables de canal, hígado y molleja diferían según la prueba. SNK $(\mathrm{P}<0.05)$ El salvado de palma se puede utilizar para alimentar pollos de engorde de crecimiento lento hasta el nivel del $10 \%$.

Palabras Clave: Pollo campero, Alimentación alternativa, Cactus, Salvado de palma forrajera, Opuntia.

\begin{abstract}
Poultry farming is an internationalized and uniform economic activity without geographical borders, generating a great impact on the Brazilian economy. Numerous studies seek the implementation of foods with lower production cost aiming to reduce feed costs without decreasing performance and carcass yield. The objective of this research was to evaluate the use of forage palm meal in the feeding of slow growing broilers. The experiment was conducted at the Poultry Industry Department of the Federal University of Cariri, from September 18 to December 12, 2018 (slaughtered at 85 days old). We purchased 200 non-sexed chicks of the heavy, one day old red line. From 1 to 27 days of age, all chicks were free to receive initial ration sold at the local trade appropriate for free-range chickens. When the chickens were 27 days old, they were weighed and distributed in a completely randomized design with three treatments (control diet, $5 \%$ bran diet, and $10 \%$ palm bran diet) and five replications of 10 units each, totaling 50 treatments. birds by treatment. The birds that received diet containing $90 \%$ of feed and $10 \%$ of forage palm presented lower food intake. However, the feed conversion of these chickens did not differ significantly from commercial feed only. The variables breast, thigh + (plus) thigh, breast and heart showed no statistically significant difference while the carcass, liver and gizzard variables differed by the test. SNK $(\mathrm{P}<0.05)$ Palm bran can be used to feed slow growing broilers up to the $10 \%$ level.
\end{abstract}

Keywords: Country Chicken, Alternative Feeding, Cactus, Forage Palm Bran, Opuntia.

\title{
INTRODUÇÃO
}

A avicultura é uma atividade econômica internacionalizada e uniforme sem fronteiras geográficas de tecnologia sendo, considerada por Vieira e Dias (2005), um complexo industrial que não deve ser analisado apenas sob o aspecto de produção e distribuição, e sim através de uma abordagem sistêmica do setor.

No Brasil, a produção avícola tem forte impacto sobre a economia nacional por gerar 3,5 milhões de empregos e por impulsionar a agroindústria fortalecendo vários setores como de equipamentos, máquinas, insumos, logística e transporte (BRFRURAL, 2016).

Inicialmente concentrada nas regiões Sul e Sudeste, a atividade vem se espalhando pelo território nacional, aproximando-se não só das regiões produtoras de matérias-primas como é o caso do deslocamento de criatórios e abatedouros para a região Centro-Oeste mas também das regiões consumidoras, o que explica em parte o seu crescimento na Região Nordeste. Conquanto a avicultura nordestina não se tenha ainda lançado ao mercado externo (com raras exceções), já se constitui em importante geradora de renda e de emprego (EVANGELISTA, et al., 2008). 
A criação avícola tradicional é considerada uma alternativa de emprego e renda para a agricultura familiar na região Nordeste do Brasil. Além disso, a atividade representa grande importância tanto na questão de segurança alimentar para as famílias quanto no aspecto econômico. Outro ponto relevante é que o esterco pode ser utilizado nos cultivos agrícolas e as aves apresentam maior rusticidade, resistência as doenças e as condições adversas de clima e aproveitam os restos de plantios e dos refugos de frutas e hortaliças e outros produtos e resíduos produzidos no seu próprio imóvel rural e ainda fazer uso da mão de obra familiar disponível. Para Amando (2018) a produção de galinha caipira é uma atividade viável, pois gera renda no campo e evita o êxodo rural.

De acordo com Silva et al. (2003), a exploração de frangos de corte em sistema semiintensivo com livre acesso a áreas de pastejo e exercício resulta em diferenças particulares na qualidade da carne dos mesmos quando comparados aqueles criados em confinamento. Takahashi et al. (2006) destacam que as características sensoriais diferenciadas se referem a uma carne mais escura e firme, sabor acentuado e menor teor de gordura na carcaça.

Uma problemática que cresce sobre a produção avícola são os custos com alimentação que representam mais de $70 \%$ devido ao aumento de preços nos dois principais insumos componentes das rações, o milho e o farelo de soja (SANTOS et al., 2017).

Inúmeros trabalhos buscam a implementação de alimentos com menor custo de produção visando diminuir os custos com ração sem diminuir o desempenho e o rendimento de carcaça.

Estudos realizados com a palma desidratada e posteriormente triturada em forma de farelo mostraram ser possível alimentar outras espécies de animais, como as aves. Assim, o objetivo dessa pesquisa foi avaliar o uso de farelo de palma forrageira na alimentação de frangos de corte de crescimento lento.

\section{FUNDAMENTAÇÃO TEÓRICA}

No Brasil a produção de carne de frango no ano de 2017 foi de 13.056 (mil ton), valor inferior apenas à dos Estados Unidos. Entretanto, com 4.320 (mil ton), o Brasil é o maior exportador mundial (ABPA, 2017).

De acordo com Amaral et al. (2015) a grande competitividade e a produção intensiva de frangos de corte e poedeiras comerciais têm contribuído para o surgimento de novas tendências voltadas para o consumo de carne de frangos e ovos oriundos de sistemas de produção que garantam a segurança alimentar (alimentação isenta de antibióticos, ingredientes de origem animal, promotores de crescimento, etc) ou que sejam ligados à 
qualidade e ao bem estar do animal (grande densidade de criação, aves alojadas em gaiolas).

As aves caipiras são naturalmente mais rústicas e resistentes que os frangos de corte ou poedeiras comerciais, o que facilita o manejo. No entanto, os produtos da avicultura alternativa são direcionados a um nicho de mercado bastante exigente, tornando essa atividade cada vez mais tecnificada, eficiente e rentável. A carne e os ovos das aves caipiras alcançam preços mais elevados do que os das aves industriais no mercado varejista devido, principalmente, aos requisitos de produção (crescimento lento dos frangos e menor produção de ovos) e ao marketing diferenciado (FILHO e MENDES, 2001). Esse novo segmento do mercado, composto por consumidores dispostos a pagar mais caro por produtos de certificação diferenciada de qualidade, tem contribuído para o desenvolvimento da agricultura familiar, gerando emprego e ampliando a renda.

O grande gargalo da avicultura alternativa de corte é o fato da carne de aves caipiras chegarem ao mercado varejista a um preço mais elevado em relação àquele oriundo de aves industriais. Embora a exploração comercial de galinhas caipiras criadas em regime semiintensivo utilize material genético melhorado (híbridos), o custo adicional da criação se deve, principalmente, ao crescimento mais lento dos frangos; aves caipiras levam maior período de tempo para alcançarem peso de abate ( 80 a 90 dias de idade) o que resulta em maior quantidade de alimento consumido durante a criação de um lote.

A alimentação é um dos itens mais onerosos na exploração econômica de aves, correspondendo a mais de $70 \%$ do custo total da produção, devido ao aumento de preços nos dois principais insumos componentes das rações, o milho e o farelo de soja. A busca por alimentos alternativos a substituição do milho-soja tem possibilitado um grande avanço no conhecimento na área de avaliação dos alimentos e das exigências nutricionais de aves e nos programas de alimentação que utilizem as matérias primas regionais (FERNANDES et al., 2013).

Segundo Benício et al. (1993), a escolha de um alimento alternativo deve considerar não só seu valor nutricional, como também sua disponibilidade em uma determinada região, por um período mínimo de tempo e em quantidade que permita substituir parcial ou totalmente os alimentos convencionalmente utilizados nas rações de aves (BENÍCIO et al., 1993).

Das diversas famílias de plantas existentes nas regiões áridas e semiáridas do nordeste brasileiro, as Cactáceas são uma das mais importantes, em virtude do seu mecanismo de adaptação à escassez de água, assim como seu metabolismo CAM, o que permite maior perenidade em ambientes algumas vezes de extrema condição de aridez (ROJAS-ARÉCHIGA e VÁZQUEZ-YANES, 2000).

A palma é um cacto suculento, ramos clorofilados achatados, ramificação superficial, 
arbustiva, atingindo uma altura entre 1,5 e 3,0 m, de coloração verde-claro a verde-escuro, indo de espinhosos até desprovidos de espinhos. As folhas são excepcionalmente pequenas. Peixoto (2004) constatou que a capacidade de fixar o $\mathrm{CO}_{2}$ no escuro, oriundo do metabolismo ácido das crassuláceas (CAM) e de suas células fotossintetizantes, que mantêm os estômatos fechados durante o dia evitando a perda de água para o ambiente, são características fisiológicas fundamentais para a adaptação da planta as condições de alta intensidade e estresse hídrico, peculiar as zonas áridas e semiáridas.

Muitas são as pesquisas desenvolvidas sobre o cultivo da palma forrageira, objetivando-se atingir as melhores condições, com altos índices de produção e redução dos custos para possibilitar ao pequeno produtor uma melhor condição de alimentar o rebanho bovino, caprino e ovino no período de seca. Oliveira et al. (2010) afirmam que, nesta área, é preciso valorizar as plantas forrageiras que melhor se adaptam as suas condições climáticas.

Para Chiacchio et al. (2006) a palma forrageira tem sido de imenso valor nos períodos de estiagem, servindo de suprimento alimentar para o gado e ao mesmo tempo como fonte de água. Os autores também constataram que as diferentes espécies de palma desempenham papel importante na conservação do meio ambiente e segurança alimentar dos rebanhos.

Estudos realizados com a palma desidratada e posteriormente triturada em forma de farelo mostraram ser possível alimentar outras espécies de animais. Ludke et al. (2006), trabalhando com suínos na fase de crescimento e terminação, observaram ser possível a inclusão de até $21 \%$ de farelo de palma forrageira em dietas isonutricionais de suínos, sem prejuízos na qualidade de carne e no rendimento de cortes na carcaça.

Muitas são as pesquisas desenvolvidas sobre o cultivo da palma forrageira, objetivando-se atingir as melhores condições, com altos índices de produção e redução dos custos para possibilitar ao pequeno produtor uma melhor condição de alimentar o rebanho bovino, caprino e ovino no período de seca.

Apesar de trabalhos com farelo de palma na alimentação de aves ainda serem bastante escassos, alguns têm demonstrado ser promissor o uso deste produto no arraçoamento de codornas, frangos de corte comerciais e de aves caipiras.

As características mais importantes a serem levadas em consideração na escolha de um alimento alternativo, além do valor nutricional, é a sua disponibilidade em uma determinada região, por um período mínimo de tempo e em quantidade que permita substituir parcial ou totalmente os alimentos convencionalmente utilizados nas rações de aves (BENÍCIO et al., 1993).

Santos et al. (2012) analisando níveis de inclusão do farelo de palma miúda (Nopalea 
cochelinifera Salm Dyck) na dieta de codornas japonesas (Coturnix japonica) verificaram ser possível a inclusão de até $10 \%$ do farelo na fase inicial (8 a 21 dias) sem prejuízos ao desempenho zootécnico dos animais. Para a fase de crescimento (22 a 35 dias), é possível incluir até $20 \%$ do farelo de palma na dieta.

Carvalho et al. (2012) recomendam a utilização de até 5\% de farelo de palma forrageira em substituição ao milho nas rações de codornas europeias no semiárido.

\section{METODOLOGIA}

O experimento foi conduzido no Setor de Avicultura do Centro de Ciências Agrárias e da Biodiversidade (CCAB) da Universidade Federal do Cariri (UFCA), Campus Crato, no período de 18 de setembro a 12 de dezembro de 2018. O CCAB está localizado a $7^{\circ} 13$ '56" de latitude Sul e 39²2'11" de longitude Oeste, com altitude média de aproximadamente $440 \mathrm{~m}$.

$\mathrm{O}$ farelo de palma forrageira $(\mathrm{FPF})$ foi produzido a partir de raquetes provenientes do Instituto Federal do Ceará - IFCE Campus Crato. Após ser fatiado em cortador manual e triturado em triturador forrageiro em peneira de $12 \mathrm{~mm}$, o material foi distribuído em lonas plásticas de polietileno e revolvido constantemente a fim de acelerar a desidratação, secando totalmente em três dias. Em seguida foi triturado novamente em peneira de $4 \mathrm{~mm}$ a fim de deixar a granulometria semelhante à da ração comercial e armazenado em baldes plásticos fechados. Uma amostra foi retirada e enviada para análise bromatológica no Laboratório de Nutrição Animal do Departamento de Zootecnia da Universidade Federal do Ceará (LANA/UFC).

Foram adquiridos 200 pintos não sexados da linhagem pesadão vermelho, de um dia de idade, vacinados, no incubatório contra Bouba aviária, Marek e Gumboro.

Ao chegaram ao Setor de Avicultura, os pintinhos foram pesados a fim de formar grupos uniformes em cada unidade experimental, conforme recomendações propostas por Sakomura e Rostagno (2007) e alojados em grupos de 12 em 15 piquetes. Cada piquete era constituído por uma área de alvenaria medindo $2 \mathrm{~m}^{2}$, coberta por telha de barro, piso de cimento, com pé direito de 2,40 m e, uma área descoberta de $28 \mathrm{~m}^{2}$, cercada com tela de arame.

$\mathrm{Na}$ fase inicial (1 a 27 dias de idade) todos os pintos ficaram restritos a área coberta, recebendo água e ração comercial apropriada para frangos de corte tipo caipira com $20 \%$ de proteína bruta $(\mathrm{PB})$ e $2.950 \mathrm{kcal} / \mathrm{kg}$ de energia metabolizável $(\mathrm{EM})$, à vontade. Durante a primeira semana de vida, as aves foram mantidas aquecidas por lâmpadas incandescentes e com o uso de cortinas durante o período diurno e noturno. A partir do oitavo dia, as lâmpadas 
ficavam acesas e as cortinas fechadas somente no turno da noite. Aos 18 dias de idade todos os pintos foram vacinados contra a doença de New Castle e Gumboro por via ocular.

A temperatura e a umidade relativa do ar foram registradas no período da manhã e à tarde através de dois termohigrômetros digitais de máxima e mínima instalados no interior dos galpões.

A ração inicial foi pesada no primeiro dia do experimento e ao final da fase sendo o consumo alimentar (kg ave/semana) comparado aos valores definidos no manual da linhagem. Com base nesse consumo, foi calculada a quantidade de ração e de farelo de palma que seriam disponibilizados nas semanas seguintes.

Quando os frangos completaram 27 dias, foram novamente pesados e distribuídos em um delineamento inteiramente casualizado com três tratamentos e cinco repetições de 10 unidades cada, totalizando 50 aves por tratamento. Os tratamentos testados foram: (T1) ração controle, com 0\% de farelo de palma; (T2) ração com 5\% de farelo; e (T3) ração com 10\% de farelo de palma. A partir desse período, os frangos passaram a ter acesso a área descoberta.

As rações comerciais fornecidas as aves nas fases de crescimento e final foram formuladas com $18 \%$ de PB e $3.050 \mathrm{kcal} / \mathrm{kg}$ de EM e $17,5 \%$ de PB e $3.150 \mathrm{kcal} / \mathrm{kg}$ de EM, respectivamente. Os frangos submetidos ao T1 (ração controle) foram alimentados com ração comercial sem inclusão do farelo de palma; os do T2 receberam dieta com 95\% de ração e 5\% de FPF, enquanto que para os do T3 foi disponibilizada dieta constituída de $90 \%$ de ração e $10 \%$ de FPF.

A ração fornecida e as sobras foram pesadas no início e no final de cada fase, a fim de determinar a quantidade de ração consumida. O peso médio da parcela foi calculado no dia da chegada dos pintos aos, 27, 54 e 79 dias de idade. A conversão alimentar foi obtida pela relação entre o consumo de ração (kg/ave) e o ganho de peso dos frangos (kg/ave).

As aves foram abatidas aos 85 dias de idade. Na noite anterior ao abate foi retirada a ração sendo os frangos submetidos a jejum alimentar de seis horas. Pela manhã, após a pesagem de todas as aves, foram selecionadas duas unidades de cada piquete com pesos próximos ao peso médio da parcela sendo uma unidade macho e a outra fêmea, identificadas e sacrificadas manualmente por deslocamento cervical, seguido de sangria, escaldagem (água a $60^{\circ} \mathrm{C}$ por $3 \mathrm{~min}$.), depena e evisceração. No momento da evisceração, o fígado e a moela de cada ave foram retirados, identificados e pesados.

As carcaças limpas, sem cabeça e pés foram pesadas para determinar o rendimento de carcaça (expresso em percentagem do peso vivo). Em seguida, foram realizados os cortes para calcular o peso relativo da coxa, sobrecoxa e peito inteiro. Os dados de rendimento de carcaça 
$(\%)$, peito (\%), coxa e sobrecoxa (\%), das vísceras comestíveis (fígado, moela e coração) foram obtidos pela relação entre o peso da parte ou órgão avaliado e o peso da carcaça quente.

Os resultados foram submetidos à análise de variância, pelo procedimento análise se variância ANOVA do programa SAS (2000), e as médias comparadas pelo teste SNK a 5\% de probabilidade.

\section{RESULTADOS E DISCUSSÃO}

Os valores médios da temperatura máxima e mínima e da umidade relativa do ar também, máxima e mínima, no interior dos galpões no período experimental, foram de 37,3 ${ }^{\circ} \mathrm{C} \pm 3,2$ e $25,5^{\circ} \mathrm{C} \pm 3,2$ e de $66,9 \% \pm 12,9$ e $29,1 \% \pm 10,9$; respectivamente.

A composição da matéria seca apresentou, após secagem em estufa, 9,62\% de água. Com base na matéria seca $(90,38 \%)$, o farelo obteve valores de $6,78 \%$ PB, 1,36\% de extrato etéreo, $15,67 \%$ de matéria mineral, $15,85 \%$ de fibra em detergente neutro, $14,61 \%$ de fibra em detergente ácido e $3.295 \mathrm{kcal} \mathrm{EB/kg}$.

De acordo com os resultados apresentados na Tabela 1, não se observou diferença significativa no ganho de peso e na conversão alimentar das aves alimentadas com rações contendo 0,5 ou $10 \%$ de FPF. No entanto, os frangos que receberam o farelo de palma na proporção de $5 \%$ e $10 \%$ apresentaram menor consumo de ração, do que aqueles do tratamento controle.

Tabela 1: Desempenho de frangos de corte de crescimento lento alimentados com rações contendo palma forrageira no período de 1 a 79 dias de idade.

\begin{tabular}{cccccc}
\hline \multirow{2}{*}{ Parâmetros } & \multicolumn{2}{c}{ Inclusão de Palma forrageira } & \multirow{2}{*}{ Média } & \multirow{2}{*}{ CV } \\
\cline { 2 - 4 } & $0 \%$ & $5 \%$ & $10 \%$ & \\
\hline Consumo de ração (Kg/ave) & $8,597^{\mathrm{a}}$ & $7,822^{\mathrm{b}}$ & $7,666^{\mathrm{b}}$ & 8,028 & 6,44 \\
Ganho de peso (Kg/ave) & $3,268^{\mathrm{a}}$ & $2,985^{\mathrm{a}}$ & $2,932^{\mathrm{a}}$ & 3,062 & 7,37 \\
Conversão alimentar & $2,63^{\mathrm{a}}$ & $2,62^{\mathrm{a}}$ & $2,62^{\mathrm{a}}$ & 2,62 & 2,40 \\
\hline Na linha, médias seguidas de letras diferentes diferem entre si pelo teste SNK (P<0,05). \\
\multicolumn{5}{c}{ Fonte: Própria (2019) }
\end{tabular}

Freitas (2012) trabalhado com frangos de corte alimentados com níveis crescentes $(0 \%, 3 \%, 6 \%, 9 \%$ e 12\%) de FPF durante 1 a 45 dias, relatou aumentaram no consumo de ração. Santos et al. (2017) trabalhando com a inclusão de 0\%, 5\%, 10\% 15\% e 20\% de FPF na dieta de codornas no período de 08 a 35 dias não identificaram efeitos significativos com a inclusão dos níveis de FPF (P>0,01) para o CR. Para Carvalho et al. (2012) trabalhando com farelo de palma forrageira na fase final de criação (36 a 45 dias de idade), sobre o desempenho de codornas de corte submetidas a quatro níveis do FPF (0, 5, 10 e 15\%) na ração, o menor dado para CR foi obtido com o nível de $10 \%$ do FPF na dieta. Geron et al. 
(2015) observaram que a inclusão de mais que 10\% de raspa de mandioca residual desidratada na alimentação de frangos de corte durante o período de 1 a 42 dias de idade reduz o consumo de ração.

Um dos fatores que podem afetar o consumo pelas aves é o teor de fibra na dieta. O consumo alimentar de frangos de corte diminui principalmente em aves mais jovens, quando o teor de fibra aumenta devido a esses animais apresentarem deficiência no aproveitamento de alimentos fibrosos em função da sua baixa capacidade de fermentação no intestino grosso (BARRETO et al., 2012). De acordo com Leite (2018) a literatura também ressalta que o maior tempo de retenção do alimento no trato digestivo, principalmente na moela, ocasionado pelo nível de fibra na ração também confere as aves uma sensação de saciedade, reduzindo a ingestão. As fibras podem causar aumento do volume do bolo alimentar, proporcionando sensação de saciedade devido à dilatação da parede estomacal e interferindo na disponibilidade dos demais nutrientes (LEITE, 2009). É possível que o conteúdo fibroso do farelo de palma possa ter contribuído para a menor ingestão alimentar nessa pesquisa.

$\mathrm{O}$ ganho de peso das aves no período de 1 a 79 dias de idade não foi afetado $(\mathrm{P}<0,05)$ pelos níveis de FPF incluso na alimentação dos frangos. Freitas (2012) trabalhando com a inclusão de $0 \%, 3 \%, 6 \%, 9 \%$ e $12 \%$ de FPF na alimentação de frangos de corte, obteve resultados semelhantes com a inclusão de $9 \%$ e $12 \%$ de inclusão de farelo de palma forrageira. Santos e Granjeiro (2012) trabalhado com aves caipiras no período de 1 a 80 dias de idade testaram os seguintes tratamentos: T1 - Alimentação convencional (70\% de milho + $30 \%$ de concentrado); T2 - 50\% de farelo de mandioca enriquecido com levedura a $2 \%+20 \%$ de milho $+30 \%$ de concentrado; $\mathrm{T} 3-50 \%$ de farelo de mandioca in natura $+20 \%$ de milho + $30 \%$ de concentrado; T4 - 40\% de farelo de palma forrageira enriquecido com levedura a $2 \%$ $+30 \%$ de milho $+30 \%$ de concentrado. Não houve diferença significativa entre tratamentos sobre o ganho de peso. $\mathrm{O}$ farelo da mandioca e o farelo de palma forrageira enriquecido com levedura a $2 \%$ adicionados de $1 \%$ de óleo de soja podem ser utilizados em dietas para aves caipiras em níveis de $71 \%$ e $57 \%$, respectivamente, em substituição ao milho. No entanto Santos et al. (2017) trabalhando com a inclusão de 0\%, 5\%, 10\% 15\% e 20\% de FPF na alimentação codornas no período de 8 a 35 dias de idade, observou que, à medida que se aumentou o nível de FPF as aves reduziram o índice de ganho de peso.

A conversão alimentar não diferiu significativamente entre os tratamentos $(\mathrm{P}<0,05)$, resultados semelhantes foram obtidos por Santos et al. (2017) em codorna com a inclusão de $0 \%, 5 \%, 10 \%, 15 \%$ e $20 \%$ de farelo de palma no período de 8 a 35 dias. Carvalho et al. (2012) trabalhando com codornas submetidas a quatro níveis do FPF (0, 5, 10 e 15\%) na 
ração, observou que o melhor resultado para conversão alimentar foi para as aves cuja ração continha 5\% de FPF. De acordo com Geron et al. (2015) a CA de frangos de corte alimentados com rações contendo raspa de mandioca residual desidratada durante a fase de 1 a 42 dias de idade apresentou aumento linear $(\mathrm{P}<0,05)$.

As variáveis peito, coxa + (mais) sobrecoxa, peito e coração, não apresentaram diferença estatística significativa enquanto que as variáveis carcaça, fígado e moela apresentaram diferença pelo teste de SNK $(\mathrm{P}<0,05)$ (Tabela 2).

Tabela 2: Características de carcaça de frangos de corte de crescimento lento alimentados com rações contendo palma forrageira

\begin{tabular}{ccccccc}
\hline \multirow{2}{*}{ Parâmetros $(\%)$} & \multicolumn{3}{c}{ Inclusão de Palma forrageira } & \multirow{2}{*}{ Média } & ${ }^{1} \mathrm{CV}$ \\
\cline { 2 - 4 } & $0 \%$ & $5 \%$ & $10 \%$ & \\
\hline${ }^{2}$ Carcaça & $75,20^{\mathrm{a}}$ & $73,61^{\mathrm{b}}$ & $74,03^{\mathrm{b}}$ & 74,28 & 0,89 \\
Peito & $26,86^{\mathrm{a}}$ & $25,46^{\mathrm{a}}$ & $26,72^{\mathrm{a}}$ & 26,35 & 8,26 \\
Coxa + sobrecoxa & $28,66^{\mathrm{a}}$ & $28,33^{\mathrm{a}}$ & $28,80^{\mathrm{a}}$ & 28,60 & 4,98 \\
Fígado & $1,47^{\mathrm{b}}$ & $1,84^{\mathrm{a}}$ & $1,73^{\mathrm{ab}}$ & 1,68 & 12,21 \\
Moela & $1,49^{\mathrm{b}}$ & $1,74^{\mathrm{a}}$ & $1,82^{\mathrm{a}}$ & & 1,68 & 8,71 \\
\hline
\end{tabular}

. ${ }^{1} \mathrm{CV}=$ Coeficiente de variação. ${ }^{2}$ Relação entre o peso da carcaça (sem cabeça, pés e vísceras) e o peso da ave viva em jejum. Na linha, médias seguidas de letras diferentes diferem entre si pelo teste $\mathrm{SNK}(\mathrm{P}<0,05)$. Fonte: Própria (2019)

As aves que foram alimentadas com 5\% e 10\% de FPF apresentam menor rendimento de carcaça comparados ao tratamento controle. No entanto Brandão (2011) trabalhando com codornas européias (Coturnix coturnix) observou a possibilidade de substituir o milho em até 5\% pelo farelo de palma na dieta sem prejuízos para a carcaça. Silva et al. (2018) trabalhado com níveis de substituição de $0 \%, 1 \%, 2 \%$ e $3 \%$ de farinha de Ora-Pro-Nobis (pereskia aculeata) uma outra cactácea, na dieta de frangos de corte no período 1 a 42 dias, não foram verificadas diferenças entre os parâmetros de rendimento de carcaça.

As aves que receberam o FPF na sua dieta apresentaram maior peso da moela proporcionalmente a quantidade recebida. Quando há redução da fibra bruta da dieta o tamanho e o conteúdo da moela são afetados pela falta de estimulação, que é provocada pela presença de partículas maiores e que, posteriormente, compromete o desenvolvimento do trato gastrintestinal (HETLAND et al., 2004). De acordo com Rufino et al. (2017) a influência da alimentação nas características da moela encontra-se associada com o estímulo mecânico deste órgão, que depende do nível, do tipo e da fonte de fibra utilizada, além das propriedades físico-químicas da ração, e, consequentemente, maior atividade dos músculos da moela. Assim possivelmente a fibra proveniente do FPF fez com que o peso da moela aumentasse.

As aves nutridas com ração contendo 5\% FPF apresentaram maior peso de fígado, isso 
pode ter sido influenciado pela quantidade de matéria mineral $(15,67 \%)$, acrescida na ração proveniente do FPF. Furtado et al. (2011) trabalhando com aves caipiras alimentadas com feno de erva-sal (Atriplex nummularia Lindl.) relataram aumento no peso relativo do fígado com a substituição de $15 \%$ da ração pelo feno de erva-sal, fato que pode ser atribuído a capacidade que esta planta tem de acumular sais em suas células.

O farelo de palma não influenciou as variáveis peito e coxa + sobrecoxa. Silva et al. (2018) relatou resultados parecidos para frangos alimentadas com farinha da folha de OraPro-Nobis, com níveis crescente $(0 \%, 1 \%, 2 \%$ e 3\%) aos 42 de idade. A inclusão de níveis crescentes de raspa de mandioca residual desidratada teve também efeito quadrático $(\mathrm{P}<0,05)$. Segundo Almeida et al. (2009), os dados de rendimento de cortes apresentam muita variação entre diferentes estudos na literatura o que pode ser atribuído, entre vários fatores, ao padrão de cortes empregado.

Rações contendo diferentes níveis $(0 \%, 3 \%, 6 \%, 9 \%$ e $12 \%)$ de farelo de palma foram fornecidas para frangos de corte de 1 a 45 dias de idade e os resultados mostraram que a palma apresenta potencial para ser utilizado como alimento alternativo, substituindo parcialmente o milho (FREITAS, 2012). Brandão (2011), trabalhando com codornas européias (Coturnix coturnix), observou a possibilidade de substituir o milho em até $5 \%$ pelo farelo de palma na dieta das codornas sem prejuízos para questões ligadas ao desempenho produtivo e rendimento de carcaça.

Santos et al. (2017) propõem a inclusão de $10 \%$ de FPF na alimentação de codornas no periode de 08 a 21 dias e a inclusão de $20 \%$ no período de 22 a 35 dias, sem prejudicar seu desempenho.

\section{CONCLUSÕES}

O farelo de palma forrageira pode ser incluído na ração de frangos de corte de crescimento lento até o nível de $10 \%$.

\section{REFERÊNCIAS}

ABPA-ASSOCIAÇÃO BRASILEIRA DE PROTEÍNA ANIMAL. Relatório Anual 2017. Disponívelem:<http://abpa-br.com.br/storage/files/3678c_final_abpa_relatorio_anual_2016_p ortugues_web_reduzido.pdf>. Acesso em: Acesso em 14 de Out. de 2019.

ALMEIDA, A. P. S.; PINTO, M. F.; POLONI, L. B.; PONSANO, E. H. G.; GARCIA NETO, M. Efeito do consumo de óleo de linhaça e de vitamina E no desempenho e nas características de carcaça de frango de corte. Arquivo Brasileiro de medicina Veterinária e Zootecnia, Belo Horizonte, v. 61. N. 3, p. 698-705, 2009. 
AMANDO, M. R. DA S. A importância da criação de galinhas como fonte de renda no assentamento mandassaia-orocó/pe. Orocó, 2018.17 p. Monografia (especialização em Educação no Campo). Programa Nacional De Educação Na Reforma Agraria, UNIVASF, 2018.

AMARAL, G.; GUIMARÃES, D.; NASCIMENTO, J. C.; CUSTODIO, S. Avicultura de postura: estrutura da cadeia produtiva, panorama do setor no Brasil e no mundo e o apoio do BNDES. BNDES Setorial 43, p. 167-207, 2015.

BARRETO, V. N. S.; MENEZES, D. R.; PERREIRA, L. G. R.; ARAÚJO, G. G. L. A.; SILVA, A. E. V. N.; SOUSA, L. N.; BARBOSA, A. L.; COSTA, J. M. S.; MOREIRA, R. F. Atriplex nummularia como alternativa alimentar para frangos Caipira Francês. Revista Brasileira de Saúde e Produção Animal, v.13, p.214-223, 2012.

BENÍCIO, L. A. S.; FONSECA, J. B.; SILVA, D. J. da; ROSTAGNO, H. S.; SILVA, M. A. A utilização do aguapé (Eichhornia crassipes) em rações prensadas para poedeiras comerciais. Revista da Sociedade Brasileira de Zootecnia, 22(1):155-166, 1993.

BENÍCIO, L. A. S.; FONSECA, J. B.; SILVA, D. J. da; ROSTAGNO, H. S.; SILVA, M. A. A utilização do aguapé (Eichhornia crassipes) em rações prensadas para poedeiras comerciais. Revista da Sociedade Brasileira de Zootecnia, 22(1):155-166, 1993.

BRANDÃO, J. S. Substituição do milho pelo farelo de palma forrageira nas rações de codornas europeias no semiárido. Dissertação (Mestrado em Zootecnia) - Universidade Federal de Campina Grande, Patos, 2011. 37 f.

BRFRURAL. Publicação da área de agropecuária da BRF-n³0. Curitiba: Agosto 2016. $16 \mathrm{p}$.

CARVALHO, A. V. DE; BRANDÃO, J. S.; BRANDÃO, P. A.; SOUZA, B. B. DE; FERREIRA, D. H. SILVA, D. R. P. DA; ALMEIDA, A. P.; BATISTA, N. L. Farelo de palma forrageira na fase final de criação, sobre o desempenho de codornas de corte criadas no semiárido. Rev. Cient. Prod. Anim., v.14, n.2, p.177-180, 2012.

CHIACCHIO, F.P.B.; MESQUITA, A.S.; SANTOS, J.R. Palma forrageira: uma oportunidade econômica ainda desperdiçada para o Semiárido baiano. Bahia Agrícola, v.7, n.3. 2006.

EVANGELISTA, F. R.; NOGUEIRA FILHO, A.; OLIVEIRA, A. A. P. A avicultura industrial de corte no nordeste: aspectos econômicos e organizacionais. 2008.

Fernandes, R. T. V., Vasconcelos, N. V. B., França Lopes, F., Arruda, A. M. V. \& Pinto, A. R. M. (2013). Aspectos gerais sobre alimentos alternativos na nutrição de aves. Revista Verde de Agroecologia e Desenvolvimento Sustentável, 7, 67-72.

FILHO, L.C.D.; MENDES, C. M. I. Viabilidade técnica e econômica na criação alternativa de frangos. In: CONFERÊNCIA APINCO DE CIÊNCIA E TECNOLOGIA AVÍCOLAS, 2001. Campinas. Anais... Campinas: FACTA, 2001, p. 254-266. 
FREITAS, J. C. P. Efeito da substituição do farelo de milho (Zea mays) pelo farelo de palma (Opuntia fícus-indica Mill) na alimentação de frangos de corte. Monografia (Graduação em Ciências Agrárias) - Universidade Federal da Paraíba, Catolé do Rocha, 2012. 12f.

FURTADO, D. A.; CARVALHO JUNIOR, S. B. DE; LIMA, I. DA S. P.; COSTA, F. G. P.; SOUZA, J. G. DE. Desempenho e características de carcaça de aves caipiras alimentadas com feno de erva-sal (atriplex nummularia lindl.). Revista Caatinga, Mossoró, v. 24, n. 3, p. 182189, jul.-set., 2011.

GERON, L. J. V.; COSTA, F. G. DA; MORAES, K. J. S; OLIVEIRA, E. M. DE; GOMES, R. D.; PEREIRA, S. R.; SILVA, A. P. DA; CRUZ, C. DA; PELICIA, K. Consumo, desempenho e rendimento de carcaça de frangos de corte alimentados com rações contendo raspa de mandioca residual desidratada. B. Indústr. Anim., Nova Odessa, v.72 n.4 p.304-310, 2015.

HETLAND, H.; CHOCT, M.; SVIHUS, B. Role of insoluble non-starch polysaccharides in poultry nutrition. World's Poultry Science Journal, v. 60, n. 4, p. 415-422, 2004.

LEITE, B.G. DE S. Fibra na dieta de poedeiras comerciais. 2018.47 f. Dissertação (Mestrado em ciências) - Universidade de São Paulo, Pirassununga, 2018.

LEITE, M. L. M. V. Avaliação de clones de Palma forrageira submetidos a adubações e sistematização de informações em propriedades do Semiárido paraibano. 2009. 186 f. Tese (Doutorado em Zootecnia) - Universidade Federal da Paraíba, Areia, 2009.

LUDKE, J.V.; ANDRADE, M.A.A.; LUDKE, M.C.M.M. et al. Farelo de palma forrageira na alimentação de suínos em crescimento e terminação - características de carcaça e de carne. Anais... IV Congresso Nordestino de Produção Animal, Petrolina, Pernambuco, 2006.

OLIVEIRA, F. T. de; SOUTO, J. S.; SILVA, R.P. da; ANDRADE FILHO, F.C. de; PEREIRA JÚNIOR, E.B. Palma forrageira: Adaptação e importância para os ecossistemas áridos e semiáridos. Revista Verde de Agroecologia e Desenvolvimento Sustentável, v. 05, p. 27-37, 2010.

PEIXOTO, M. J. A. Aclimatização de plantas micropropagadas de palma forrageira Opuntia fícus-indica (L.) Mill. em diferentes substratos. 2004. 46f. Dissertação (Mestrado em Zootecnia) - Universidade Federal do Ceará, Fortaleza.

ROJAS-AREHCHIGA, M.; VAHZQUEZ-YANES, C.; Cactus seed germination: a review. Journal of Arid Environments, (2000) 44: 85-104.

RUFINO, J. P.F.; CRUZ, F.G.G.C.; OLIVEIRA FILHO, P. A.; MELO, R.D.; FEIJÓ, J. C.; MELO, L. D. Fibra alimentar em dietas para aves - Uma revisão. Revista Científica de Avicultura e Suinocultura, v. 3, n. 2, p. 033-042, 2017.

SAKOMURA, N.K.; ROSTAGNO, H.S. Métodos de pesquisa em nutrição de monogástricos. Jaboticabal: FUNEP, 2007. 283p.

SANTOS, J. F. dos; GRANGEIRO, J. I. T. Desempenho de aves caipira de corte alimentadas com mandioca e palma forrageira enriquecidas com levedura. Tecnologia \& Ciência 
Agropecuária, João Pessoa, v.6, n.2, p.49-54, 2012.

SANTOS, J. S.; CUNHA, F. S. DE A.; DA SILVA R. A. C.; SOARES, A. L.S. Farelo de palma na alimentação de codornas. Nutritime Revista Eletrônica, Vol. 13, No 04, 2017.

SANTOS, J.S.; CUNHA, F.S.A.; SILVA, R.A.C. et al. Desempenho de codornas japonesas (Coturnix japonica) na fase de 22 a 35 dias alimentadas com dietas contendo diferentes níveis de inclusão do farelo de palma (Nopalea cochenilifera Salm Dyck). Anais... VII Congresso Nordestino de Produção Animal, Maceió, Alagoas, 2012.

SANTOS, J.S.; CUNHA, F.S.A.; SILVA, R.A.C. et al. Desempenho de codornas japonesas (Coturnix japonica) na fase de 08 a 21 dias alimentadas com dietas contendo diferentes níveis de inclusão do farelo de palma (Nopalea cochenilifera Salm Dyck). Anais... VII Congresso Nordestino de Produção Animal, Maceió, Alagoas, 2012.

SILVA, M. A. N.; FILHO, P. H.; ROSÁRIO, M. F.; COELHO, A. A. D.; SAVINO, V. J. M.; GARCIA, A. A. F.; SILVA, I. J. O. MENTEN, J. F. M. Influência do Sistema de Criação sobre o Desempenho, a Condição Fisiológica e o Comportamento de Linhagens de Frangos para Corte. Revista Brasileira de Zootecnia, v.32, n.1, p.208-213, 2003.

SILVA, V. B. M. da; BRAINER, M. M. de A. B.; MARTINS, J. de S.; OLIVEIRA, H. B. de; SOUZA, V. B. de L.; CÂNDIDO, G. de P. Rendimento de carcaça e cortes nobres de frangos alimentadas com farinha da folha de ora-pro-nobis (pereskia aculeata). 2018. Disponível em: $<$ https://even3.blob.core.windows.net/anais/110817.pdf $>$. Acesso em 04 de out. de 2019.

TAKAHASHI, S. E.; et al., QUINTEIRO, R. R. Efeito do sistema de criação sobre o desenvolvimento e rendimento de carcaça de frangos de corte tipo colonial. Revista Bras. Med. Vet. Zootec. Belo Horizonte, v. 58, n.4, p. 624-632, 2006.

VIEIRA, N. M.; DIAS, R. S. Uma abordagem sistêmica da avicultura de corte na economia brasileira. Artigo Científico. Universidade Federal de Viçosa, Viçosa, 2005. 


\title{
DESEMPENHO AGRONÔMICO DA ABÓBORA HÍBRIDA POLINIZADA COM DIFERENTES DOSES DE FITORREGULADORES NA REGIÃO OESTE DA BAHIA
}

\author{
Naiane de Macedo Oliveira ${ }^{1}$; Loanny de Souza Santos ${ }^{2}$; Lucas Miguel Carvalho da Silva ${ }^{3}$; \\ Marilucia de Jesus Gomes ${ }^{4}$; Alberto do Nascimento Silva ${ }^{5}$
}

DOI: https://doi.org/10.31692/978-65-991061-4-9.106-110

\section{INTRODUÇÃO}

As olerícolas são plantas cultivadas em todas as regiões do Brasil, especialmente no Nordeste, onde apresenta boas condições de solo e clima favoráveis ao crescimento e desenvolvimento dessas espécies. Neste meio, destaca-se a família das cucurbitáceas, como a abóbora, que nessa região é considerada como uma cultura de subsistência (DO CARMO et al., 2011).

Dentre as espécies de abóboras cultivadas, evidencia-se a abóbora híbrida Tetsukabuto, também conhecida como abóbora japonesa ou kabutiá que é derivada do cruzamento entre linhagens selecionadas de moranga Curcubita máxima e linhagens de abóbora Curcubita moschata, no qual houve a junção das boas características das duas espécies em uma só espécie. (AMARO, 2014).

Apesar da abóbora híbrida Tetsukabuto obter expressão sexual monoica, ou seja, produz flores femininas e masculinas na mesma planta, são considerados machos estéreis, pois a maturação das flores masculinas e femininas ocorre em períodos diferentes. Assim para contornar as falhas no processo de polinização e qualidades dos frutos é necessário o plantio sincronizado de outras abóboras ou morangas que auxiliarão no fornecimento de pólen para a polinização cruzada entomófila ou mesmo o uso de mecanismos indutores de partenocarpia via aplicação de reguladores de crescimento. (AMARO, 2014)

Tendo em vista estes problemas a solução viável seria utilizar reguladores de crescimento, encontrado no hormônio vegetal conhecido como auxina. Utilizando o método de partenocarpia, é possível obter o fruto sem recorrer a polinização natural, pois a pulverização é realizada na flor aberta, diretamente sobre o pistilo (KRISHNAMOORTHY, 1981; WITTWER, 1983).

Todavia na literatura não dispõe de informações suficientes acerca da aplicação de

\footnotetext{
${ }^{1}$ Graduando em Engenharia Agronômica, Universidade do Estado da Bahia - UNEB, macedonay80@ gmail.com

2 Graduando em Engenharia Agronômica, Universidade do Estado da Bahia - UNEB, loanny.ssantos@gmail.com

3 Graduando em Engenharia Agronômica, Universidade do Estado da Bahia UNEB,lucas_jmiguel@hotmail.com

${ }^{4}$ Graduando em Engenharia Agronômica, Universidade do Estado da Bahia - UNEB, mariluciamjg@gmail.com

${ }^{5}$ Mestre em Agronomia, Universidade do Estado da Bahia, albnsilva@uneb.br
} 
doses de 2,4-D em flores femininas de abóbora (PEREIRA, 2012). No Oeste da Bahia o cenário não se difere, são poucas as informações a respeito e é baixo o número de produtores que utiliza essa tecnologia de produção. Consequentemente, o presente trabalho tem como objetivo, avaliar o desempenho agronômico da abóbora hibrida Tetsukabuto polinizada com diferentes doses do fitorregulador 2,4 -D.

\section{FUNDAMENTAÇÃOTEÓRICA}

\section{Aspectos gerais do cultivo da abóbora tetsukabuto}

A abóbora híbrida Tetsukabuto é de expressão sexual monoica produz flores femininas e masculinas na mesma planta. Entretanto, por apresentarem uma taxa ou nula de abertura das flores masculinas, essas são consideradas machos estéreis, sendo assim é necessário o plantio sincronizado de outras abóboras ou morangas para frutificação da planta, por meio do fornecimento de pólen para a polinização cruzada entomófila ou mesmo o uso de técnicas indutoras de partenocarpia via aplicação de reguladores de crescimento. (Cheng; Gavilanes, 1980; Pereira, 1999; Amaro et al., 2014)

\section{Importância dos fitorreguladores na frutificação das abóboras}

A frutificação assexuada é feita através da aplicação externa de um fitohormônio com característica da auxina. A formação de frutos partenocárpicos é possível via aplicação externa de um hormônio sintético (ácido indol acético, alfa naftaleno acetato de sódio) ou produto com efeitos semelhantes da auxina, tal como o 2,4-D (ácido 2,4diclorofenoxiacético). Dessa forma, promovem o crescimento, principalmente pela elongação de células, quando aplicadas em concentrações de $10^{9}$ Molar, aproximadamente. (AMARO, 2014).

Durante as aplicações diárias deve-se evitar o escorrimento da solução nas ramas e folhas. Isto porque plantas de abóbora híbrida não toleram concentrações maiores que $0,4 \mathrm{a}$ 0,5 mg do ingrediente ativo do 2,4-D. Essa aplicação da substância reguladora de crescimento deve ser feita no período matutino (6:00 às 11:00h) quando as flores estão abertas e receptivas à fecundação, durante toda a fase de florescimento, e na dosagem correta, pois o 2,4-D aplicado em concentrações altas atua de maneira inversa à auxina natural existente no interior das plantas, causando uma desregulação nos principais processos metabólicos da planta. (AMARO,2014).

\section{METODOLOGIA}

A natureza da pesquisa constitui do tipo quantitativa experimental. Dessa forma o [107] 
experimento foi conduzido na Fazenda Modelo Paulo Mizote, em Barreiras, BA, Brasil (latitude $12^{\circ} 05^{\prime} 17.7^{\prime}$ S S, longitude $44^{\circ} 55^{\prime} 16.7^{\prime}$ 'W) no período de maio a agosto de 2019 . A região encontra-se no bioma Cerrado e o clima, segundo Köppen e Geiger é classificado como Aw e o solo da área experimental é identificado como ARGISSOLO VERMELHO. Foi utilizado o delineamento de blocos ao acaso com seis tratamentos e cinco repetições, totalizando 30 unidades experimentais. Os tratamentos foram compostos por: T0 - controle (0 $\mathrm{mL}$ de 2,4-D); T1 - 0,1 mL de 2,4-D; T2 - 0,2 mL de 2,4-D; T3 - 0,3 mL de 2,4-D; T4 - 0,4 $\mathrm{mL}$ de 2,4-D; T5 - 0,5 mL de 2,4-D. Cada parcela foi composta por três plantas com espaçamento de $2,5 \mathrm{~m}$ entre plantas e $2 \mathrm{~m}$ entre linhas.

A semeadura ocorreu início do mês de maio, em covas previamente adubadas, com recomendação feita de acordo com análise de solo. Foram utilizadas duas sementes por cova. Aos 20 dias de emergência (DAE) foi realizado o desbaste, deixando apenas uma planta por cova. A variedade utilizada foi Abóbora Híbrida Tetsukabuto F1.

No surgimento das primeiras flores, iniciou-se o processo de polinização artificial no período matinal.

Aos 93 dias, após a semeadura realizou-se a colheita, onde procedeu-se a avaliação da eficiência do fitorregulador no desenvolvimento dos frutos, analisando as seguintes variáveis: número de frutos por planta e peso médio dos frutos. Os dados obtidos foram submetidos a análise de variância pelo teste F, para efeito de doses de 2,4-D foram ajustadas equações de regressão para que melhor representassem os valores observados. As análises foram feitas com auxílio do software SISVAR.

\section{RESULTADOS E DISCUSSÃO}

Na figura 1, estão apresentados os valores da variável, números de frutos por planta.

Figura 1: Número de frutos por planta da abóbora híbrida Tetsukabuto, em função de doses de 2,4-D, na região Oeste da Bahia.

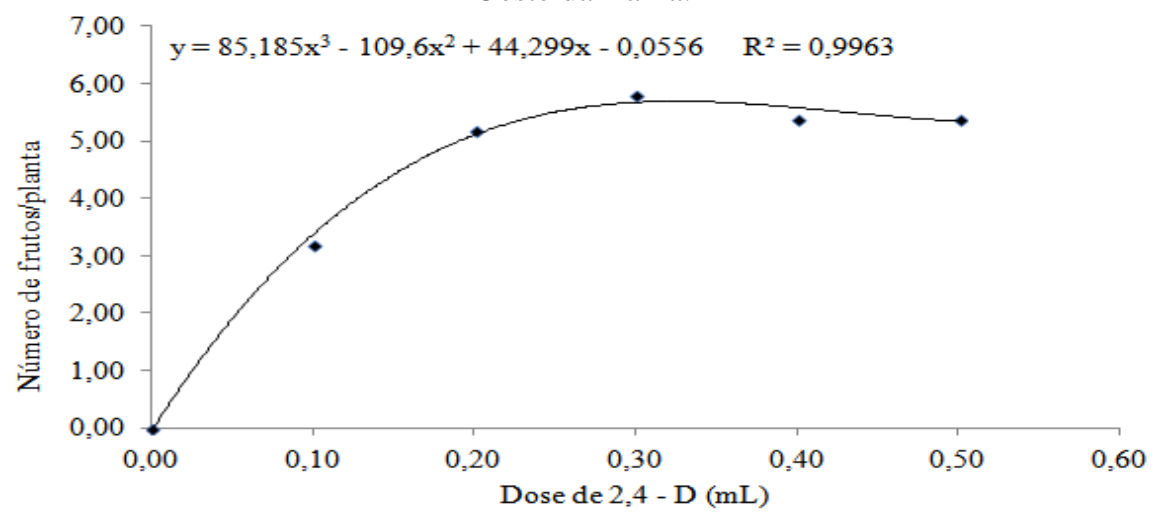

De acordo com a figura 1 observou-se que utilizando a dosagem do tratamento T1 $(0,0$ $[108]$ 
$\mathrm{mL}$ de 2,4 - D) não foi obtido nenhum fruto, no entanto, a partir do tratamento $\mathrm{T} 2(0,1 \mathrm{~mL})$ foi possível verificar o aumento no número de frutos, porém o tratamento T2 proporcionou uma pequena quantidade, com três frutos por planta, diferentemente dos tratamentos T3 $(0,2$ $\mathrm{mL})$ à T6 $(0,5 \mathrm{~mL})$ que apresentou cerca de cinco. Resultados semelhantes foram obtidos por Pasqualetto et al. (2001) quanto ao número de frutos por planta, houve tendência de aumento de valores à medida que a dose de 2,4-D foi sendo elevada.

Portanto, de acordo com a equação do gráfico de regressão foi possível obter a melhor dose para frutos por plantas, sendo o ponto máximo de eficiência técnica a dose de $0,34 \mathrm{~mL}$ de 2,4 - D, sendo assim, doses superiores provocaram decréscimo na taxa de frutos. Dessa forma, pode-se concluir que para próximos experimentos testando esta dose poderá possibilitar uma quantidade de 5,68 frutos por planta.

Figura 2: Peso médio de frutos da abóbora híbrida Tetsukabuto, em função de doses de 2,4-D, na região Oeste da Bahia.

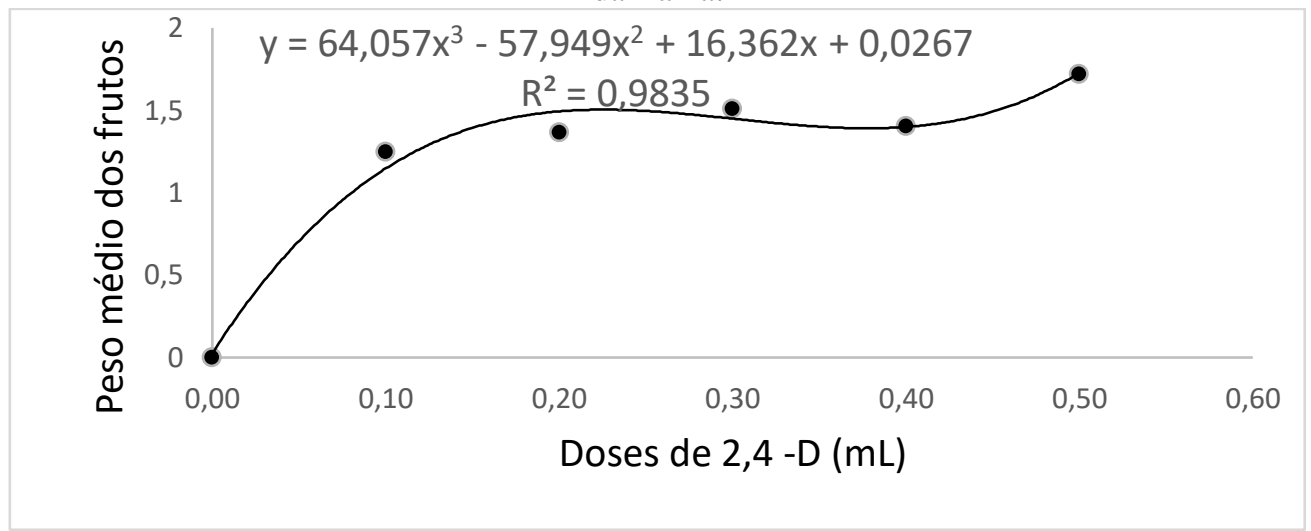

Para figura 2, verificou-se que com a aplicação do fitorregulador, os pesos médios dos frutos variavam entre 1,20 a $1,7 \mathrm{~kg}$, no qual no presente trabalho não mostrou-se viável sendo valores inferiores apresentados por Amaro et al. (2014), o peso médio ideal para frutos de Tetsukabuto, é aproximadamente de 2,0 a 3,0 kg. Tal fato pode ter ocorrido devido a um período de estresse hídrico o qual a cultura passou durante a fase de frutificação. As fases de frutificação até a maturação dos frutos são as que apresentam maior exigência hídrica (AMARO,2014). Estresses nessa fase comprometem significativamente o enchimento dos frutos.

De acordo com a equação do gráfico de regressão foi possível obter as melhores doses para peso dos frutos, onde observou-se que a medida que foi aumentando as doses de 2,4 - D também elevou-se o peso. As doses de 0,48 a 0,50 $\mathrm{mL}$ foram as que apresentaram maiores valores referente ao peso médio dos frutos, podendo chegar a $1,72 \mathrm{~kg}$. Diferente dos resultados obtidos por Nomura et al. (2019) quanto ao peso dos frutos, houve aumento de valores à medida que a dose de 2,4-D foi sendo elevada, até 141,5 mgL-1. Esse resultado 
demonstrou que esta dose estimulou a produção de frutos mais pesados, com mais de 1,08 kg de peso. A partir desta dosagem, há uma diminuição progressiva do peso dos frutos.

\section{CONCLUSÕES}

De acordo com as doses analisadas, a aplicação do regulador de crescimento nas flores femininas da abobora hibrida Tetsukabuto promoveu um desempenho satisfatórios das suas características agronômicas, descartando o plantio de culturas polinizadoras (abóbora ou moranga), possibilitando o aproveitamento de toda área com o cultivo somente do híbrido Tetsukabuto. Dessa forma o produtor, ao adotar essa pratica na região do Oeste da Bahia, pode utilizar qualquer dose a partir de 0,3 a $0,5 \mathrm{~mL}$ de 2,4-D, já que apresentaram resultados superiores as doses 0,$0 ; 0,1$ e $0,2 \mathrm{~mL}$, sendo comprovados pela análise de regressão.

\section{REFERENCIAS}

AMARO, G. B.; PINHEIRO, J. B.; LOPES, J. F.; CARVALHO, A. D. F de C.; MICHEREFF FILHO, M.; VILELA, N. J. Recomendações técnicas para o cultivo de abóbora híbrida do tipo japonesa. Circular técnica, EMBRAPA. Brasília, DF. 2014.

CARMO GA; OLIVEIRA FRA; MEDEIROS JF; OLIVEIRA FA; CAMPOS MS; FREITAS DC. 2011. Teores foliares, acúmulo e partição de macronutrientes na cultura da abóbora irrigada com água salina. Revista Brasileira de Engenharia Agrícola e Ambiental 15: 512 518.

KRISHNAMOORTHY, H.N. Plant growth substances. New Delhi: McGraw-Hill, 1981. p. 214

NOMURA, M. et al. Produção de frutos partenocárpicos de abóbora híbrida "tetsukabuto" sob aplicação de 2,4-D. Bagé-RS. Revista Científica Rural, volume 21, n², 2019. Disponível em: <http://revista.urcamp.tche.br/index.php/RCR/article/view/2729>. Acesso em: 24 de set. 2019.

PASQUALETTO, A. et al. Produção de frutos de abóbora híbrida pela aplicação de 2,4-D nas flores. Goiânia-Go. Pesquisa Agropecuária Tropical, 31(1):23-27, 2001.Disponível em: <https://www.revistas.ufg.br/pat/article/view/2522>. Acesso em: 24 de set. 2019.

PEREIRA, A. M.; SILVA, G. D.; ALMEIDA, R. R. P.; SILVA, A. B.; QUEIROGA, R. C. F. Frutificação de abóbora Tetsukabuto sobe aplicação de doses de 2,4-D na época seca em Pombal - PB. Revista Verde de Agroecologia e Desenvolvimento Sustentável, v. 7, n. 4, p. 38-43, 2012.

WITTWER, S.H. Vegetables. In: NICKELL, L.G. (ed). Plant growth regulating chemicals. Vol. 2. Florida: CRC Press, 1983. p. 213-231. 


\section{DIAGNOSE FOLIAR DE FÓSFORO EM CULTIVARES DE CANA DE AÇÚCAR SOB IRRIGAÇÃO SUBTERRÂNEA: FOLHA +1 E FOLHA +3 \\ PHOSPHOR FOLIAR DIAGNOSIS IN SUGAR CANE CULTIVARS UNDER UNDERGROUND IRRIGATION: LEAF +1 AND LEAF +3}

Thayane Leonel Alves ${ }^{1}$; José de Arruda Barbosa ${ }^{2}$; Victor Hugo de Farias Guedes ${ }^{3}$; Mara Cristina Pessôa da Cruz ; Vinicius Marchioro ${ }^{5}$

DOI: https://doi.org/10.31692/978-65-991061-4-9.111-116

\section{INTRODUÇÃO}

A cana de açúcar (Saccharum spp.) é uma importante cultura no cenário agrícola mundial, apresentando variados subprodutos, desde gêneros alimentícios a biocombustíveis. O Brasil é o maior produtor e exportado do etanol no mundo, apresentando uma produtividade média de 70,2 t ha-1 (FAOSTAT, 2017). Nesse sentido, estudos nutricionais e bioquímicos sobre a cultura são de interesse nacional.

O fósforo (P) é um dos elementos mais importantes para a cultura da cana de açúcar, participando direta e indiretamente dos processos metabólicos da planta. Atua principalmente no desenvolvimento das raízes, aumenta a produção de colmos, aumenta o pol (\%), pureza do caldo e clarificação, e sua deficiência pode levar à diminuição na formação de sacarose (SIMÕES NETO et al., 2009).

Devido à importância do $\mathrm{P}$ para o desenvolvimento, produtividade e longevidade da cana de açúcar e sua alta taxa de fixação nos solos tropicais, torna-se pertinente o estudo de níveis adequados desse elemento (CAIONE et al., 2011) para que ocorra sua adequada absorção, proporcionando maior crescimento e elevada eficiência dos fertilizantes fosfatados (NUNES et al., 2011). Desde modo saber os níveis deste nutriente na planta proporciona um melhor entendimento sobre a nutrição e as necessidades de adubação da cultura

O uso de técnicas de amostragem é aplicado pela impossibilidade da análise ou caracterização de todos os indivíduos de uma população. Uma dúvida frequente que surge nos estudos para determinação de nutriente é a folha a ser amostrada. A cana-de-açúcar pode

\footnotetext{
${ }^{1}$ Mestranda em Agronomia (Ciência do Solo), UNESP - Campus de Jaboticabal - Jaboticabal / São Paulo, Email: thayaneleonel@hotmail.com

${ }^{2}$ Mestrando em Agronomia (Ciência do Solo), UNESP - Campus de Jaboticabal - Jaboticabal / São Paulo, Email: josearruda777@gmail.com

${ }^{3}$ Mestrando em Agronomia (Ciência do Solo), UNESP - Campus de Jaboticabal - Jaboticabal / São Paulo, Email: victorhguedes1@gmail.com

${ }^{4}$ Profa. Dra. Mara Cristina Pessôa da Cruz, UNESP - Campus de Jaboticabal - Jaboticabal / São Paulo; E-mail: mcp.cruz@unesp.br

${ }^{5}$ Mestrando em Agronomia (Produção Vegetal), UNESP - Campus de Jaboticabal - Jaboticabal / São Paulo, Email: vinicius_marchioro@ hotmail.com
} 
apresentar variado número de folhas verdes, dependendo principalmente do genótipo e da disponibilidade de água (SMIT; SINGELS, 2006).

A maioria dos autores que avaliam nutrientes em cana-de-açúcar tem escolhido a folha +3 para a determinação, observando-se uma tendência de uso dessa folha por ser a mais indicada para diagnóstico nutricional (folha +3 ). Portanto, objetivou-se avaliar a diferença do estado nutricional de cultivares de cana de açúcar sob irrigação subterrânea por meio da coleta da folha+1 e folha+3.

\section{METODOLOGIA}

O experimento foi conduzido na Área Experimental de Irrigação da FCAV/UNESP Câmpus de Jaboticabal, SP. As coordenadas geográficas são $21^{\circ} 14^{\prime} 50^{\prime \prime}$ de latitude Sul e $48^{\circ} 17^{\prime} 05^{\prime}$ ' de longitude Oeste, com altitude média de $570 \mathrm{~m}$. O clima, segundo a classificação climática de Köppen (1948), é do tipo Cwa, temperado úmido com inverno seco e verão chuvoso. Este trabalho estudou-se o quinto ciclo da cana de açúcar, após a colheita do quarto ciclo no dia 03 de julho de 2018.

O local possui elevado teor de argila em todas as camadas analisadas. A Tabela 1 apresenta a análise química do solo da área experimental nos perfis 0 - 20 e 20 - 40, para as parcelas do tratamento não irrigado (sequeiro) e irrigado (deficitária e suplementar).

Tabela 1: Atributos químicos da área experimental

\begin{tabular}{|l|c|c|c|c|c|c|c|c|c|c|c|}
\hline \multicolumn{1}{|c|}{ AMOSTRA } & pH & MO & P & K & Ca & Mg & H+Al & Al & SB & CTC & V\% \\
\hline Sequeiro 0-20 & 4,2 & 24 & 12 & 1,8 & 13 & 6 & 58 & 7 & 20,8 & 79 & 26 \\
\hline Sequeiro 20-40 & 4,3 & 24 & 9 & 1,5 & 12 & 5 & 52 & 8 & 18,5 & 71 & 36 \\
\hline Deficitária 0-20 & 4,4 & 18 & 8 & 1,4 & 14 & 5 & 42 & 3 & 20,4 & 62 & 33 \\
\hline Deficitária 20-40 & 5,8 & 25 & 52 & 0,6 & 40 & 15 & 21 & 0 & 55,6 & 77 & 72 \\
\hline Suplementar 0-20 & 5,8 & 24 & 28 & 0,8 & 40 & 15 & 22 & 0 & 55,8 & 78 & 72 \\
\hline Suplementar 20-40 & 5,9 & 25 & 30 & 0,9 & 38 & 15 & 24 & 0 & 53,9 & 78 & 69 \\
\hline
\end{tabular}

Fonte: Própria (2019).

Adubação da cultura foi definida em função da análise do solo, seguindo as recomendações e as doses com base em sistemas de alta produtividade, segundo Vitti e Mazza (2002). Sendo aplicado em cada tratamento o equivalente a $180 \mathrm{~kg} \mathrm{ha}^{-1} \mathrm{de} \mathrm{N}, 240 \mathrm{~kg} \mathrm{ha}^{-1} \mathrm{de}$ $\mathrm{K}_{2} \mathrm{O}, 90 \mathrm{~kg} \mathrm{ha}^{-1}$ de $\mathrm{P}_{2} \mathrm{O}_{5}$ e $45 \mathrm{~kg} \mathrm{ha}^{-1}$ de $\mathrm{S}$. Nos tratamentos irrigados, as aplicações de $\mathrm{N}$, $\mathrm{K}_{2} \mathrm{O}, \mathrm{P}_{2} \mathrm{O}_{5}$ e $\mathrm{S}$ foram realizadas via água de irrigação, ou seja, via fertirrigação. Já no tratamento não irrigado a aplicação dos fertilizantes foi realizada manualmente, em duas doses, uma após a colheita e uma de cobertura, 90 dias após a colheita. A fertirrigação foi 
parcelada em oito vezes, ou seja, foram aplicados $12,5 \%$ da recomendação em intervalos mensais, do terceiro ao décimo mês. A primeira fertirrigação ocorreu no mês de setembro de 2018, e a última aplicação ocorreu no mês de maio de 2019.

Aplicou-se na área experimental o equivalente a 1,0 $\mathrm{t} \mathrm{ha}^{-1}$ de calcário. Foi realizada também a adubação de manutenção com Zinco e Boro, nas dosagens de 3,0 $\mathrm{kg} \mathrm{ha}^{-1}$, na forma de sulfato de zinco, e 1,0 $\mathrm{kg} \mathrm{ha}^{-1}$, na forma de ácido bórico. Nos tratamentos irrigados, os micronutrientes foram aplicados via água de irrigação, parcelados em três doses, juntamente com as aplicações de macronutrientes, e no tratamento não irrigado as aplicações foram realizadas via pulverizador costal.

O experimento consiste em três fatores: Irrigação Suplementar, Irrigação Deficitária e Sequeiro (não irrigado), com 12 repetições. Esses fatores foram alocados nas parcelas e os cultivares (CTC 4, IACSP93-3046, RB86-7515, IACSP95-5000 e IAC91-1099) foram alocados nas subparcelas. O delineamento experimental é em Blocos Incompletos Parcialmente Balanceados (BIPB).

O manejo da irrigação foi via clima, com dados obtidos diariamente na Estação Agroclimatológica Automatizada da FCAV/UNESP. A evapotranspiração de referência (ETo) é estimada diariamente pela equação de Penman-Monteith (ALLEN et al., 1998). Neste projeto, a irrigação deficitária consiste em suprir o deficit hídrico da cana-de-açúcar de modo parcial (50\%), e a irrigação suplementar visa suprir totalmente a deficiência hídrica (100\%), complementando a água das chuvas. A irrigação foi realizada sempre que ocorre um déficit hídrico acumulado da cultura de $20 \mathrm{~mm}$, ou seja, a cultura é irrigada sempre que o somatório da evapotranspiração da cultura menos a precipitação é maior que $20 \mathrm{~mm}$. Na suplementar há reposição da total, com aplicação de uma lâmina de $20 \mathrm{~mm}$, sendo a lâmina líquida aplicada igual a $\Sigma E T c$, enquanto na deficitária há aplicação de metade da lâmina, aplicando somente 10 $\mathrm{mm}$, ou seja, lâmina líquida da deficitária será de $50 \%$ da $\Sigma$ Etc. A cultura de sequeiro recebe apenas água das precipitações.

Em novembro de 2018, foram coletadas 204 amostras foliares de cana de açúcar de todas as parcelas da posição +3 e +1 , cada amostra foi constituída de 6 folhas coletadas aletoriamente em cada parcela. Das folhas amostradas, foram utilizados na análise química os 20 centímetros medianos, descartando-se a nervura central. Estas amostras foram submetidas à secagem em estufa a $60^{\circ} \mathrm{C}$ com circulação forçada de ar por $72 \mathrm{~h}$ e moídas em moinho tipo Wiley. A análise de fósforo foi realizada pelo método de digestão seca segundo a metodologia da Embrapa (2009). Foi utilizado o programa estatístico SAS® versão 9.3 para análise estatística do experimento. Foi utilizado o teste t para efeito de comparação de médias. 


\section{RESULTADOS E DISCUSSÃO}

A Figura 1 apresenta os valores médios referente ao teor de fósforo da folha +3 de cada tratamento. Observa-se que houve diferença estatística entre os tratamentos. Pode-se verificar que a utilização da irrigação suplementar para todas as cultivares, menos a IAC1099, propiciou maiores teores de nutriente na folha coletada. A cultivar que apresentou maiores médias foi a CTC4, sendo 2,2 $\mathrm{gr} / \mathrm{kg}$ de fósforo na suplementar, 2,1 na deficitária e 2,0 no sequeiro, e a que apresentou menores médias foi a RB7515, sendo 1,7 gr/kg de fósforo na suplementar, 1,6 na deficitária e 1,7 no sequeiro, sendo a CTC4 na irrigação suplementar a cultivar que respondeu mais a adubação, utilizando-se a folha +3 como parâmetro.

Figura 1: Análise foliar do nutriente fósforo da folha +3 .

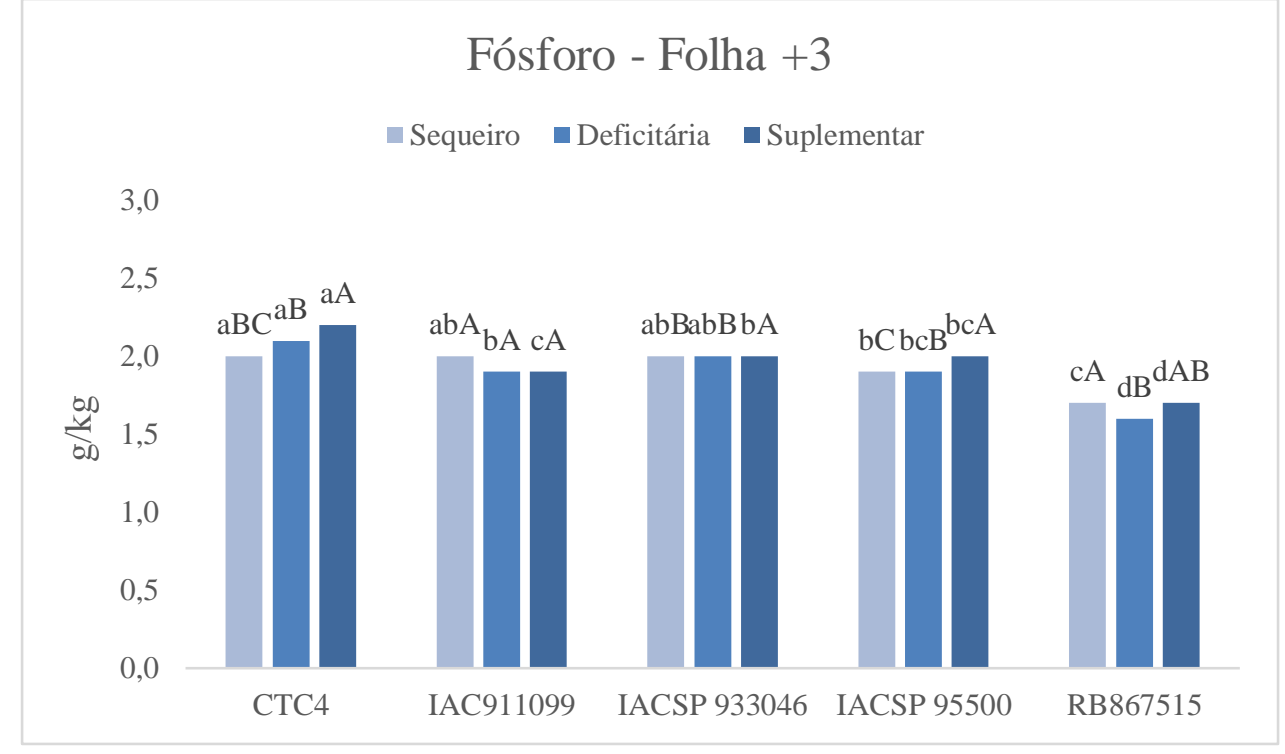

Fonte: Própria (2019)

A Figura 2 apresenta os valores médios referente ao teor de fósforo da folha +1 de cada tratamento. Observa-se que houve diferença estatística entre os tratamentos. Pode-se verificar que a utilização da irrigação para todas as cultivares, propiciou maiores teores de nutriente na folha coletada, sendo a suplementar melhor para CTC4, IAC5000 e RB7515. A cultivar que apresentou maiores médias foi a CTC4, sendo 2,4 gr/kg de fósforo na suplementar, 2,2 na deficitária e 2,0 no sequeiro, e a que apresentou menores médias foi a RB7515, sendo 2,0 gr/kg de fósforo na suplementar, 1,8 na deficitária e 1,7 no sequeiro, sendo a CTC4 na irrigação suplementar a cultivar que respondeu mais a adubação, utilizandose a folha +1 como parâmetro.

Figura 2: Análise foliar do nutriente fósforo da folha +1 .

[114] 


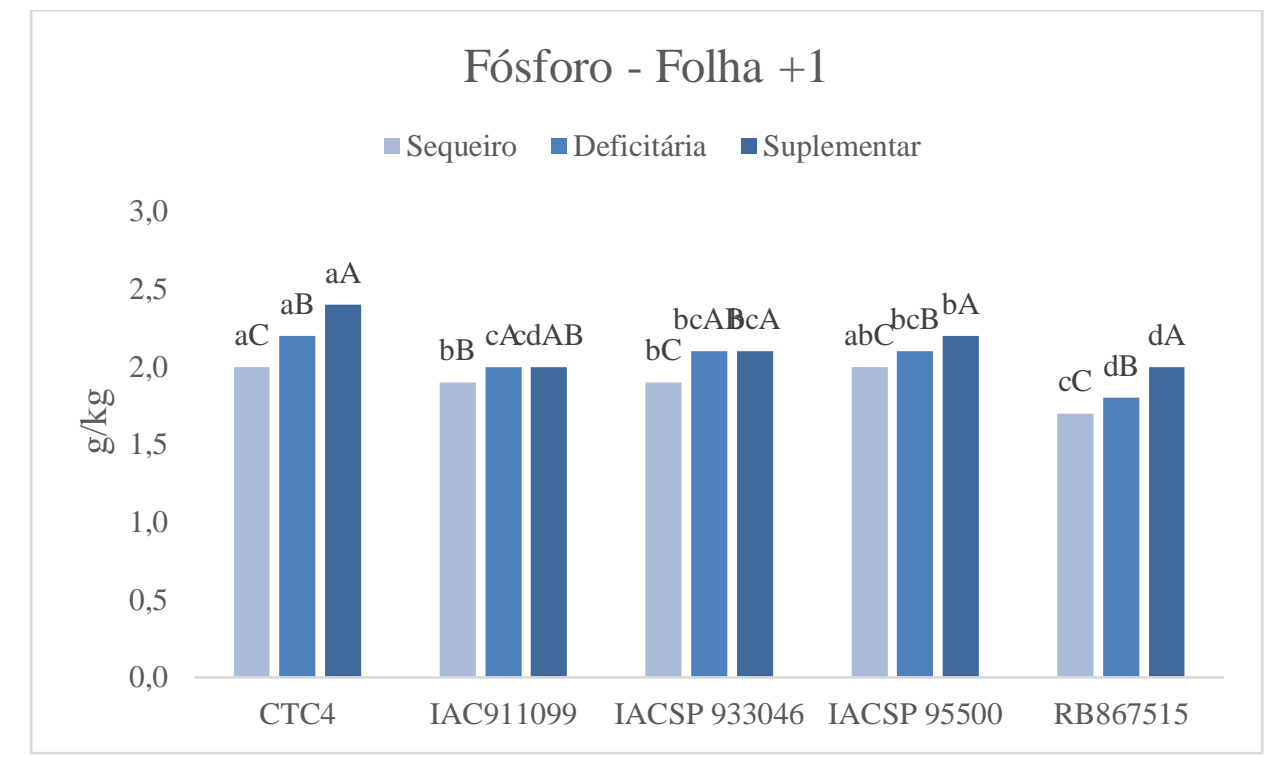

Fonte: Própria (2019)

\section{CONCLUSÕES}

Independentemente de qual folha coletada, +3 ou +1 , a CTC4, no sistema de irrigação subterrânea utilizando-se lâmina de $100 \%$ da ETc acumulada, foi a que respondeu mais a adubação e a cultivar RB7515 a que teve menos resposta.

\section{REFERÊNCIAS}

ALLEN, R. G.; PEREIRA, L. S.; RAES, D.; SMITH, M. Crop evapotranspiration Guidelines for computing crop water requirements. Rome: FAO. 1998. 300 p. (FAO Irrigation and Drainage Paper 56).

CAIONE, G.; LANGE, A.; BENETT, C. G. S.; FERNANDES F. M. Fontes de fósforo para adubação de cana-de-açúcar forrageira no cerrado. Pesquisa Agropecuária Tropical, Goiânia, v.41, n.1, p.66-73, 2011.

EMBRAPA - Empresa Brasileira de Pesquisa Agropecuária. Manual de análises químicas de solos, plantas e fertilizantes. Brasília, DF: Embrapa Informação Tecnológica, 2009.

FAOSTAT, F. 2017. Disponível em: http://www.fao.org/faostat/en/\#data/QD Acesso em: 22 de junho de 2019.

KÖPPEN, W. Climatologia: com um estúdio de los climas de la tierra. México: Fondo de Cultura Economica, 1948. 478 p.

NUNES, R.S.; SOUSA, D.M.G.; GOEDERT, W.J.; VIVALDI, L. Distribuição de fósforo no solo em razão do sistema de cultivo e manejo da adubação fosfatada. Revista Brasileira de Ciência do Solo, v.35, n.3, p.877-888, 2011.

SIMÕES NETO, D.E.; OLIVEIRA, A.C. de; FREIRE, F.J.; FREIRE, M.B.G. dos S.; 
NASCIMENTO, C.W.A. do; ROCHA, A.T. da. Extração de fósforo em solos cultivados com cana-de-açúcar e suas relações com a capacidade tampão. Revista Brasileira de Engenharia Agrícola e Ambiental, v.13, p.840-848, 2009.

SMIT, M. A.; SINGELS, A. The response of sugarcane canopy development to water stress. Field Crops Research, v.98, p.91-97, 2006.

VITTI, G. C.; MAZZA, J. A. Planejamento, estratégias de manejo e nutrição da cultura de cana-de-açúcar. Informações Agronômicas, n.97, 2002. 16p. (POTAFOS. Encarte Técnico). 


\title{
MORFOLOGIA DE CULTIVARES DE SOJA SUBMETIDO A ESTRESSE HÍDRICO
}

\author{
MORFOLOGÍA DE LOS CULTIVARES DE SOJA SOMETIDOS A ESTRÉS \\ HÍDRICO
}

\section{MORFOLOGÍA DE LOS CULTIVARES DE SOJA SOMETIDOS A ESTRÉS HÍDRICO}

Acássio Nadson Gomes Freitas ${ }^{1}$; Elaine de Souza Prado ${ }^{2}$; Cleuber Oliveira de Sousa ${ }^{3}$; Daniel Souza Barboza ${ }^{4}$; Alberto do Nascimento Silva ${ }^{5}$.

DOI: https://doi.org/10.31692/978-65-991061-4-9.117-122

\section{INTRODUÇÃO}

No Oeste da Bahia o agronegócio se desenvolveu apresentando um desempenho altamente significativo, possibilitando o produtor desenvolver atividades envolvidas com maior segurança. O sistema agroindustrial da soja (Gleycine max) é um dos mais importantes no cenário do agronegócio mundial, consumida in natura ou como matéria-prima básica na produção do farelo e do óleo, dentre outros produtos, é uma das principais commodities, sendo cultivada comercialmente no Brasil há pouco mais de 40 anos (CASTRO; REIS; LIMA, 2006). Dentre os fatores que contribui para o avanço da sojicultura nos sistema de produção brasileiro, destaca-se o uso de variedades adaptadas o que confere alta produtividade e estabilidade (PEREIRA; SILVA NETO, 2016).

No entanto, a sojicultura não deixa de ser uma atividade empresarial de alto risco, visto que existem fatores que independem da dedicação e aporte tecnológico do empresário, tais como o clima e o preço do produto. O cultivo de soja transgênica no Brasil é de extrema importância para a agricultura e economia do país, de acordo com o Conselho de Informações sobre Biotecnologia - CIB (2018), 92\% da área total de plantio da oleaginosa é de soja geneticamente modificada (GM). Nos últimos anos variações climáticas indesejáveis para o estabelecimento da soja, comuns na região Oeste da Bahia, vem causando impactos negativos na produtividade.

Nesse contexto, novos problemas surgem anualmente, e buscar por caraterísticas genéticas que auxiliem o produtor a ter sucesso na atividade agrícola são fundamentais. Com isso objetivou-se nesse trabalho, analisar a morfologia de três variedades de soja nos estádios

\footnotetext{
${ }^{1}$ Engenharia Agronômica Universidade do Estado da Bahia - UNEB, Campus IX, acassionadson@live.com

${ }^{2}$ Engenharia Agronômica, Universidade do Estado da Bahia - UNEB, Campus IX, elaineprado17@ gmail.com

${ }^{3}$ Engenharia Agronômica, Universidade do Estado da Bahia - UNEB, Campus IX, cleuberoliveira3@gmail.com

4 Engenharia Agronômica, Universidade do Estado da Bahia - UNEB, Campus IX, danielsbarboza.19@gmail.com

${ }^{5}$ Mestre, Universidade do Estado da Bahia - UNEB, Campus IX, albertosilvasamavi@gmail.com
} 
de floração (R1) e enchimento de grão (R5), sob condições de déficit hídrico regular.

\section{FUNDAMENTAÇÃO TEÓRICA}

Adversidades climáticas é o principal fator que interfere no desenvolvimento do cultivo da soja, onde ao se referir à importância da água para a cultura em questão, aproximadamente $90 \%$ de seu peso é composto por água. O estresse hídrico na soja ocasiona diversas transformações em suas características, estando diretamente ligado ao estádio fenológico, principalmente em fases críticas como germinação/emergência e floração/enchimento (SILVEIRA, 2018).

Na germinação/emergência a semente necessita absorver, no mínimo, 50\% de seu peso em água para assegurar boa germinação (EMBRAPA, 2009). E essa necessidade de água vai aumentando com o desenvolvimento da planta, atingindo o máximo durante da floração/enchimento de grãos (7 a $8 \mathrm{~mm} / \mathrm{dia}$ ), decrescendo após esse período (FARIAS; NEPOMUCENO; NEUMAIER, 2007).

O efeito do déficit hídrico sobre o rendimento da cultura, vai depender da intensidade e duração do déficit hídrico, da época de ocorrência, do cultivar, do estádio do desenvolvimento da planta e da interação com outros fatores determinantes do rendimento (FARIAS; NEPOMUCENO; NEUMAIER, 2007).

Desta maneira, vários aspectos fisiológicos são afetados, como: alterações no teor de clorofila, redução da condutância estomática, na atividade de algumas enzimas, proteínas e na absorção de nutrientes, bem como, redução na altura da planta, taxa de crescimento relativo, índice de área foliar e na taxa fotossintética (CATUCHI et al., 2012).

\section{METODOLOGIA}

O experimento foi realizado entre abril e junho de 2019, em casa de vegetação, no Campus IX da Universidade do Estado da Bahia, localizada na cidade de Barreiras - BA (12 ${ }^{\circ}$ 8'39.57"S e $\left.44^{\circ} 57^{\prime} 49.20^{\prime \prime} \mathrm{W}\right)$. A região encontra-se no bioma Cerrado e o clima, segundo Köppen e Geiger é classificado como Aw (clima tropical com estação seca de inverno). A temperatura média anual em Barreiras é $24.9^{\circ} \mathrm{C}$. $1045 \mathrm{~mm}$ é o valor da pluviosidade média anual, sendo junho o mês mais seco e a maioria da precipitação ocorrem em dezembro, com uma média de $217 \mathrm{~mm}$.

O solo da área experimental é classificado como LATOSSOLO VERMELHOAMARELO Eutrófico típico de textura arenosa e apresenta as seguintes características químicas na camada de 0-20 cm: pH em água = 5,98; $\mathrm{P}(\mathrm{Mel})=22,49 \mathrm{mg} / \mathrm{dm}^{3} ; \mathrm{K}^{+}=72,21$ 
$\mathrm{mg} / \mathrm{dm}^{3} ; \mathrm{Ca}^{2+}=1,85 \mathrm{cmol}_{\mathrm{d}} / \mathrm{dm}^{3}, \mathrm{Ca}^{2+}+\mathrm{Mg}^{2+}=2,47 \mathrm{cmol}_{\mathrm{c}} / \mathrm{dm}^{3}, \mathrm{Al}^{3+}+\mathrm{H}^{+}=2,30 \mathrm{cmol}_{\mathrm{d}} / \mathrm{dm}^{3}$, $\mathrm{T}=4,96 \mathrm{cmol}_{\mathcal{c}} / \mathrm{dm}^{3}, \quad \mathrm{~V}=53,58 \%$ e uma composição granulométrica de 75,24\% de areia, $12,54 \%$ de silte e $12,22 \%$ de argila.

Foi utilizado o delineamento inteiramente casualizado, em esquema fatorial $3 \times 2$, sendo três variedades de soja (V1= M 8349 IPRO, V2=BRS 8980 IPRO e V3=BRS 8781 RR) e duas lâminas de água (L1= 100\% e L2=50\% da evapotranspiração da cultura - ETc) dispostos em 4 repetições, totalizando 24 unidades experimentais.

Para a realização do cálculo das lâminas de $100 \%$ e $50 \%$ da ETc, obteve-se os dados climáticos de temperatura e umidade relativa do ar máxima e mínima, pressão atmosférica, velocidade do vento, radiação global, no site do Instituto Nacional de Meteorologia - INMET, para a estação automática localizada no município de Barreiras. Após a obtenção dos dados, calculou-se a evapotranspiração de referência - ET0 pelo método de Penman Monteith recomendada pela FAO/56 (ALLEN et al., 1998). A evapotranspiração da cultura - ETc foi obtida pelo produto entre a ET0 e os coeficientes de cultivo - Kc para a cultura da soja propostos por Pereira et al. (2002). Durante os primeiros 25 DAE, a irrigação foi realizada de forma uniforme para todos os tratamentos. Após esse período, aplicou-se duas lâminas correspondentes a 100 e $50 \%$ da ETc.

Para avaliação do efeito do estresse hídrico nas três variedades de soja, foram avaliados a altura das plantas, diâmetro da haste, número médio das folhas, largura média das folhas e comprimento médio das folhas. Sendo realizadas duas avaliações, uma no estádio R1 (39 DAE), quando se iniciou a floração e a outra em R5 (60 DAE), na fase de enchimento de grão.

Os dados foram submetidos à análise de variância (ANOVA) e ao teste de Tukey a 5\% de probabilidade para comparação das médias, utilizando o software SISVAR.

\section{RESULTADOS E DISCUSSÃO}

Ao analisar os dados foi observado que não houve interação entre variedades e lâminas de irrigação, portanto os dados foram interpretados separadamente. Entre as cultivares na fase da floração, como retratados na tabela 1, pôde-se observar que a cultivar BRS 8781 RR se destacou, apresentando valores significativos para quase todas as variáveis com exceção de número de folhas. $\mathrm{O}$ alto desempenho em altura pode ocasionar acamamento, porém, ao apresentar também valores elevados para diâmetro houve assim um equilíbrio, diminuindo as chances desse acamamento. Essa diferença pode ser atribuída ao alto vigor da semente, possibilitando maior taxa de crescimento da cultivar, atingindo o estádio V6 em 32 DAE com 
facilidade, fato que confirma os resultados dos estudos de Kolchinski et al. (2006), apresentando maiores taxas de crescimento da cultura nos períodos de 10 a $30 \mathrm{DAE}$, o que resulta em maior captura de luz pelas folhas, favorecendo que o índice de área foliar máximo seja atingido mais rapidamente.

Tabela 1: Valores médios de altura de planta $(\mathrm{cm})$, diâmetro da haste $(\mathrm{mm})$, comprimento $(\mathrm{cm})$, largura $(\mathrm{cm})$ e número de folhas, na fase de florescimento inicial (R1) em variedades de soja submetidas a estresse hídrico.

\begin{tabular}{llllll}
\hline Tratamentos & Altura & Diâmetro & Comp. Folhas & Larg. Folhas & $\mathbf{N}^{\mathbf{0}}$ Folhas \\
\hline BRS 8781 RR & $44,92 \mathrm{a}$ & $3,47 \mathrm{a}$ & $5,06 \mathrm{a}$ & $4,55 \mathrm{a}$ & $6,25 \mathrm{a}$ \\
BRS 8980 IPRO & $36,22 \mathrm{~b}$ & $3,25 \mathrm{ab}$ & $3,47 \mathrm{~b}$ & $4,31 \mathrm{ab}$ & $5,75 \mathrm{a}$ \\
M 8349 IPRO & $32,70 \mathrm{~b}$ & $2,94 \mathrm{~b}$ & $2,94 \mathrm{~b}$ & $3,55 \mathrm{~b}$ & $5,37 \mathrm{a}$ \\
\hline DMS & 4,64 & 0,49 & 1,13 & 0,79 & 2,06 \\
CV $(\%)$ & 9.57 & 11.99 & 23.05 & 14.88 & 27.83 \\
\hline
\end{tabular}

Médias seguidas pela mesma letra na coluna pertencem ao mesmo grupo estatístico ao nível de 5\% de probabilidade, pelo teste tukey. CV: Coeficiente de Variação; DMS: Diferença Mínima Significativa.

Já nos resultados relacionados à fase de enchimento do grão, ilustrados na tabela 2, o destaque da cultivar BRS 8781 RR antes observada perdurou nas variáveis altura de plantas, comprimento e largura de folhas, entretanto para largura de folhas foi semelhante a BRS 8980 IPRO. Observou-se também que a cultivar M 8349 IPRO, sofreu um declínio no número de folhas, essa resposta da planta nesse período pode ser atribuída ao fechamento estomático, enrolamento das folhas e consequentemente a queda das mesmas (FARIAS; NEPOMUCENO; NEUMAIER, 2007).

Tabela 2: Valores médios de altura de planta $(\mathrm{cm})$, diâmetro da haste $(\mathrm{mm})$, comprimento $(\mathrm{cm})$, largura $(\mathrm{cm}) \mathrm{e}$ número de folhas, na fase de enchimento de grão (R5) em variedades de soja submetidas a estresse hídrico.

\begin{tabular}{llllll}
\hline Tratamentos & Altura & Diâmetro & Comp. Folhas & Larg. Folhas & $\mathbf{N}^{\mathbf{0}}$ Folhas \\
\hline BRS 8781 RR & $56,76 \mathrm{a}$ & $3,65 \mathrm{a}$ & $7,36 \mathrm{a}$ & $5,25 \mathrm{a}$ & $11,33 \mathrm{a}$ \\
BRS 8980 IPRO & $44,13 \mathrm{~b}$ & $3,60 \mathrm{a}$ & $6,51 \mathrm{a}$ & $4,41 \mathrm{ab}$ & $11,12 \mathrm{a}$ \\
M 8349 IPRO & $39,58 \mathrm{~b}$ & $3,22 \mathrm{a}$ & $3,98 \mathrm{~b}$ & $3,98 \mathrm{~b}$ & $7,75 \mathrm{~b}$ \\
\hline DMS & 10,41 & 0,48 & 0,86 & 0,98 & 2,72 \\
CV $(\%)$ & 16.11 & 11.01 & 11.52 & 17.44 & 21.54 \\
\hline
\end{tabular}

Médias seguidas pela mesma letra na coluna pertencem ao mesmo grupo estatístico ao nível de 5\% de probabilidade, pelo teste tukey. CV: Coeficiente de Variação; DMS: Diferença Mínima Significativa.

Os resultados apresentados na Tabela 3 mostram que os tratamentos com estresse induzido (lâmina 50\%) apresentou diferença significativa somente na variável altura de planta, a qual foi observada uma redução de cerca 22\%. De acordo com Taiz e Zeiger (2006) a resistência à seca é expressa nas plantas através de genes que promovem maior adaptação a condições climáticas adversas. Algumas das primeiras respostas ao estresse podem ser medidas predominantemente por acontecimentos biofísicos. Um dos processos biofísicos visíveis devido ao estresse das plantas é a redução no crescimento. À medida que o conteúdo de água diminui, a célula fica cada vez mais flácida e as paredes relaxam, os solutos ficam 
cada vez mais concentrados e a membrana plasmática torna-se mais espessa, uma vez que cobre uma área menor. Como a perda de turgidez é o primeiro efeito biofísico da carência hídrica, as atividades relacionadas com a turgidez são as mais sensíveis ao déficit hídrico.

Tabela 3: Valores médios de altura de planta $(\mathrm{cm})$, diâmetro da haste $(\mathrm{mm})$, comprimento $(\mathrm{cm})$, largura $(\mathrm{cm})$ e número de folhas, na fase de florescimento inicial (R1) submetidas as lâminas de $100 \%$ e $50 \%$ de ETc.

\begin{tabular}{llllll}
\hline Tratamentos & Altura & Diâmetro & Comp. Folhas & Larg. Folhas & $\mathbf{N}^{\mathbf{0}}$ Folhas \\
\hline Lâmina 100\% & $42,72 \mathrm{a}$ & $3,29 \mathrm{a}$ & $3,85 \mathrm{a}$ & $4,10 \mathrm{a}$ & $7,25 \mathrm{a}$ \\
Lâmina 50\% & $33,18 \mathrm{~b}$ & $3,14 \mathrm{a}$ & $3,80 \mathrm{a}$ & $4,17 \mathrm{a}$ & $7,25 \mathrm{a}$ \\
\hline DMS & 3,11 & 0,33 & 0,76 & 0,53 & 1,38 \\
CV (\%) & 9.57 & 11.99 & 23.05 & 14.88 & 27.83 \\
\hline
\end{tabular}

Médias seguidas pela mesma letra na coluna pertencem ao mesmo grupo estatístico ao nível de 5\% de probabilidade, pelo teste tukey. CV: Coeficiente de Variação; DMS: Diferença Mínima Significativa.

Porém, quando comparados aos valores da tabela 4, quando a soja já se apresentava em fase de enchimento de grão essa variável se iguala, mostrando diferença em diâmetro e número médio de folhas. Segundo Palharini (2016), devido ao crescimento exponencial em altura da soja próximo a $60 \mathrm{DAE}$ e um crescimento linear após esse período (enchimento dos grãos), pode-se verificar influência significativas do estresse hídrico na altura das plantas no desenvolvimento na fase de florescimento inicial (tabela 3), posteriormente nenhuma interferência em R5 (tabela 4).

Tabela 4: Valores médios de altura de planta $(\mathrm{cm})$, diâmetro da haste $(\mathrm{mm})$, comprimento $(\mathrm{cm})$, largura $(\mathrm{cm})$ e número de folhas, na fase de enchimento de grão (R5) submetidas as lâminas de $100 \%$ e $50 \%$ de ETc .

\begin{tabular}{llllll}
\hline Tratamentos & Altura & Diâmetro & Comp. Folhas & Larg. Folhas & $\mathbf{N}^{\mathbf{0}}$ Folhas \\
\hline Lâmina 100\% & $49,08 \mathrm{a}$ & $3,83 \mathrm{a}$ & $6,03 \mathrm{a}$ & $4,69 \mathrm{a}$ & $12,00 \mathrm{a}$ \\
Lâmina 50\% & $45,51 \mathrm{a}$ & $3,19 \mathrm{~b}$ & $5,99 \mathrm{a}$ & $4,40 \mathrm{a}$ & $8,38 \mathrm{~b}$ \\
\hline DMS & 6,98 & 0,32 & 0,58 & 0,66 & 1,82 \\
CV $(\boldsymbol{\%})$ & 16.11 & 11.01 & 11.52 & 17.44 & 21.54 \\
\hline
\end{tabular}

Médias seguidas pela mesma letra na coluna pertencem ao mesmo grupo estatístico ao nível de 5\% de probabilidade, pelo teste tukey. CV: Coeficiente de Variação; DMS: Diferença Mínima Significativa.

\section{CONCLUSÕES}

O estresse hídrico influenciou no crescimento em altura e espessura, bem como, a área foliar. Sendo que as lâminas influenciaram principalmente na altura de planta no estádio de floração e em área foliar na fase de enchimento de grão. A cultivar BRS 8781 RR se destaca em todas as variáveis analisadas por apresentar maior média.

\section{REFERÊNCIAS}

ALLEN, R. G.; PEREIRA, L. S.; RAES, D.; SMITH, M. Crop evapotranspiration: guidelines for computing crop water requirements. Rome: FAO, 1998. (Irrigation and drainage paper, $56)$.

CASTRO, S. H.; REIS, R. P.; LIMA, A. L. R. Custos de produção da soja cultivada sob 
sistema de plantio direto: estudo de multicasos no oeste da Bahia, 2006. Disponivel em: http://www.scielo. br/pdf/\%0D/cagro/v30n6/a17v30n6.pdf. Acesso em: 25 ago. 2019.

CATUCHI, T. A.; GUIDORIZZI, F. V. C.; GUIDORIZI, K. A.; MORAES, A. B.; SOUZA, G. M. Respostas fisiológicas de cultivares de soja à adubação potássica sob diferentes regimes hídricos. Pesquisa agropecuária brasileira, v. 47, n. 4, p. 519-527, 2012.

CIB, Conselho de Informações sobre Biotecnologia. Benefícios ambientais, econômicos e sociais no Brasil. 20 anos de transgênicos, 2018. Disponível em: https://cib.org.br/sojatransgenica-no-brasil. Acesso em: 27 jul. 2019.

EMBRAPA. Cultivo de Soja no Cerrado de Roraima - Exigências climáticas. Embrapa, 2009. (Sistemas de Produção, $1^{\mathrm{a}}$ edição).

FARIAS, J. R. B.; NEPOMUCENO, A. L.; NEUMAIER, N. Ecofisiologia da soja. Embrapa Soja-Circular Técnica (INFOTECA-E), 2007.

KOLCHINSKI, E. M.; SCHUCH, L. O. B.; PESKE, S. T. Crescimento inicial de soja em função do vigor das sementes. Current Agricultural Science and Technology, v. 12, n. 2, 2006.

PALHARINI, W. G. Influência do estresse hídrico sobre caracteres agronômicos, fisiológicos e abertura de vagens imaturas em soja. Tese de Doutorado. Universidade Federal de Viçosa, MG, 2016.

PEREIRA, L.S.; ALLEN, R.G. Novas aproximações aos coeficientes culturais. Engenharia Agrícola, Jaboticabal, v.16, n.4, p.118-43, 2002.

PEREIRA, A. F.; SILVA NETO, S. P. Cultivares de Soja da Parceria Embrapa Cerrados e Fundação Bahia Recomendados para as Condições Edafoclimáticas do Oeste Baiano. Boletim Técnico: Divulgação dos Resultados de Pesquisas Safra 2015/16. Anais [...] No 03, 2016.

SILVEIRA, I. C. Diversidade genética e respostas de genótipos de soja sob déficit hídrico induzido por PEG 6000. 2018.

TAIZ, L.; ZEIGER, E. Fisiologia do estresse. In: Fisiologia vegetal. Trad. SANTARÉM et al. São Paulo: Artmed, p.613-641, 2006. 


\section{CARACTERÍSTICAS AGRONÔMICAS DE SORGO SOB NUTRIÇÃO FOLIAR DE MAGNÉSIO COM PRESENÇA E AUSÊNCIA DE SILÍCIO}

\section{AGRONOMIC CHARACTERISTICS OF SORGHUM UNDER FOLIARY MAGNESIUM NUTRITION WITH PRESENCE AND ABSENCE OF SILICON}

Victor Hugo de Farias Guedes ${ }^{1}$; Renato de Mello Prado ${ }^{2}$; Antônio Carlos Buchelt ${ }^{3}$; Thayane Leonel Alves ${ }^{4}$; José Lucas Farias da Silva ${ }^{5}$

DOI: https://doi.org/10.31692/978-65-991061-4-9.123-126

\section{INTRODUÇÃO}

O magnésio $(\mathrm{Mg})$ exerce diversas funções nas plantas cultivadas, tais como: auxilia na fixação fotossintética do $\mathrm{CO}_{2}$, no carreamento no floema, atua na síntese proteica, na utilização dos fotoassimilados, participa do processos da fotofosforilação (HERMANS et al., 2005). Assim, vários processos fisiológicos e bioquímicos nas plantas podem ser alterados tanto pela deficiência quanto pelo excesso de Mg (MOREIRA et al. 2013, HERMANS et al. 2005). Porém acredita-se que os benefícios desse macronutriente pode ser maximizado com a interação com o silício (Si).

Há a hipótese que os benefícios do $\mathrm{Si}$, citadas anteriormente, poderiam melhorar a eficiência de uso de nutrientes, como o $\mathrm{Mg}$, o que levaria a uma redução na dose sem que haja perdas de produtividade. Porém, ainda são incipientes os estudos de interação do $\mathrm{Mg}$ e o Si em plantas de sorgo. Com isso, é necessário entender os mecanismos do Si na mitigação de deficiência de nutrientes e aumento de produtividade.

Assim, objetivou-se nesse trabalho avaliar as características morfológicas das plantas de sorgo com a aplicação foliar de concentrações magnésio com e sem Si na correção da deficiência moderada de $\mathrm{Mg}$ em plantas de sorgo.

\section{METODOLOGIA}

Com intuito de avaliar o efeito de concentrações de magnésio na ausência e presença de silício em plantas de sorgo cultivar DOW 1G244 foi realizado o experimento no período de

\footnotetext{
${ }^{1}$ Mestrando em Agronomia (Ciência do Solo), UNESP - Campus de Jaboticabal - Jaboticabal / São Paulo, Email: victorhguedes1@gmail.com

${ }^{2}$ Prof. Dr. Renato de Mello Prado, UNESP - Campus de Jaboticabal - Jaboticabal / São Paulo; Email:rmprado@fcav.unesp.br

${ }^{3}$ Doutorando em Agronomia (Produção Vegetal), UNESP - Campus de Jaboticabal - Jaboticabal / São Paulo, Email: antoniobuchett@hotmail.com

${ }^{4}$ Mestranda em Agronomia (Ciência do Solo), UNESP - Campus de Jaboticabal - Jaboticabal / São Paulo, Email: thayaneleonel@hotmail.com

${ }^{5}$ Mestrando em Agronomia (Ciência do Solo), UNESP - Campus de Jaboticabal - Jaboticabal / São Paulo, Email:fariaslucasf@gmail.com
} 
agosto a dezembro de 2018, em casa de vegetação na Universidade Estadual Paulista-UNESP, localizado no município de Jaboticabal, Brasil.

O delineamento experimental utilizado foi em blocos inteiramente casualizados, em esquema fatorial $3 \times 2$, sendo trêsconcentrações de magnésio $\left(0,17,0,34\right.$ e $\left.0,51 \mathrm{~g} \mathrm{~L}^{-1}\right)$ utilizando como fonte o quelato de magnésio (Quelmax - magnésio 6\%, quelatizado com EDTA) e duas concentrações de $\mathrm{Si}: 0,00$ e $0,50 \mathrm{~g} \mathrm{~L}^{-1}$ de $\mathrm{Si}$ utilizando como fonte o silicato de sódio e potássio alcalino estabilizado (107 $\mathrm{g} \mathrm{L}^{-1}$ de $\mathrm{Si}$ e $28,4 \mathrm{~g} \mathrm{~L}^{-1}$ de $\left.\mathrm{K}_{2} \mathrm{O}\right)$. Foram realizadas três pulverizações, em quatro repetições. Com a finalidade de se equilibrar as quantidades de potássio na aplicação dos tratamentos com e sem silício, foram realizadas aplicações foliares de cloreto de potássio.

A unidade experimental foi constituída de vaso de plástico com capacidade para $7 \mathrm{dm}^{3}$ (diâmetro superior: $16 \mathrm{~cm}$; diâmetro inferior: $11 \mathrm{~cm}$, altura: $33 \mathrm{~cm}$ ) preenchidos com $6 \mathrm{dm}^{3} \mathrm{de}$ areia textura média. As sementes de sorgo foram semeadas em bandeja contendo vermiculita. Após germinação foram transferidas três plantas para cada vaso. Com o desenvolvimento das mesmas realizou-se desbaste de modo a ficar uma planta por vaso. Depois de transplantadas, as plantas foram irrigadas com água deionizada.

Uma semana após, iniciou-se aplicação de solução nutritiva completa de Hoagland e Arnon (1950), de modo a manter 70\% da capacidade de campo, com pH entre 5,0 e 5,5 e com modificação na fonte de ferro, de Fe-EDTA para Fe-EDDHMA. Inicialmente, por um período de sete dias, a solução nutritiva foi aplicada a $10 \%$ da concentração. Após este período, a concentração da solução nutritiva foi aumentada para 20, 40 e $60 \%$ por uma semana em cada concentração e, transcorrido este período, para $70 \%$, a qual foi mantida até o final do período experimental. Uma vez por semana, foi realizada a drenagem do substrato com a aplicação de água deionizada para se evitar salinização. A partir do estádio V3 (plantas apresentando três folhas completamente desenvolvidas), foi retirado o magnésio da solução nutritiva para induzir a deficiência nas plantas.

As aplicações foliares foram realizadas em três estágios fenológicos: V4; V6, V8 e V10. A temperatura $\left({ }^{\circ} \mathrm{C}\right)$ e a umidade relativa do ar $(\%)$ foram medidas durante a primeira, segunda e terceira pulverizações foliares obtendo-se os seguintes valores: 23,5 e 59, 20 e 75, 20,1 e 68 e 18,9 e 99 , respectivamente.

A calda de pulverização foi preparada utilizado o Sorbitol como adjuvante, sendo o valor $\mathrm{pH}$ ajustado entre 6,9 e 7,0. A aplicação foliar foi realizada imediatamente após o preparo da calda com pulverizador manual, visando à cobertura total da parte aérea. O volume de calda aplicado variou de acordo com o tamanho das plantas, sendo aplicados 3,0; 4,0 e 5,0 
$\mathrm{mL}$ da solução, para a primeira, segunda e terceira pulverizações, respectivamente. Durante as aplicações foliares, a superfície do substrato foi coberta com papel toalha para evitar escorrimento da solução pulverizada para o substrato, de modo a se garantir que a absorção das soluções fosse totalmente via foliar.

Após a maturação fisiológica foram avaliadas as seguintes características: altura de planta, número de folhas, tamanho de panícula, diâmetro de colmo. A altura de planta e tamanho de panícula foram determinadas por uma régua graduada, o número de folha foi pela contagem e o diâmetro de colmo foi utilizado um paquímetro digital $150 \mathrm{~mm} / 6$ " $316119 \mathrm{mtx}$.

Os dados obtidos foram submetidos à análise de variância pelo teste $\mathrm{F}$ e, quando significativo, ao teste de comparação t de Student (LSD), a 5\% de probabilidade, utilizando-se o software AgroEstat® (Barbosa; Maldonado Júnior, 2010).

\section{RESULTADOS E DISCUSSÃO}

Os resultados obtidos com as pulverizações foliares de magnésio e silício na cultura do sorgo não apresentaram efeito de interação entre os elementos para nenhuma variável avaliada, portanto, a discussão será realizada apenas em relação aos efeitos dos elementos separadamente nos parâmetros avaliados.

Em relação à altura de planta, número de folhas, tamanho de panículas e diâmetro de colmo, somente a altura de planta foi influenciada pela a aplicação do magnésio o mesmo não ocorreu com a aplicação do silício (Tabela 1). Os maiores valores em relação à altura das plantas foram observados nas maiores concentrações de magnésio 0,34 e 0,51 g L $\mathrm{L}^{-1}$ com valores respectivos de 75,00 e 78,25 cm. Plantas fertilizadas com o Mg em níveis adequados tem funções fisiológicas maximizadas, tais como, síntese proteica e melhor utilização dos fotoassimilados (HERMANS et al., 2005), isso favoreceu o melhor desempenho em relação à altura das plantas que receberam as maiores concentrações de $\mathrm{Mg}$ via foliar.

Flores et al. (2018) avaliando o efeito da aplicação foliar do Si na qualidade fisiológica, produção de biomassa e acúmulo de silício em sorgo observaram que o suprimento de Si via foliar não afetou a taxa de crescimento, resultado que corrobora com o presente trabalho.

Tabela 1: Altura de planta (AP), número de folhas (NF), tamanho de panículas (TP) e diâmetro de colmo (DC) na cultura de sorgo submetida à aplicação foliar de concentrações de magnésio $(\mathrm{Mg})$ e silício $(\mathrm{Si})$.

\begin{tabular}{|l|l|l|l|l|}
\hline \multirow{2}{*}{ Tratamentos } & AP & NF & TP & DC \\
\cline { 2 - 5 } & $(\mathbf{c m})$ & - & $(\mathbf{c m})$ & $(\mathbf{m m})$ \\
\hline $\begin{array}{l}\text { Concentrações de } \\
\text { Mg }\left(\mathbf{g ~ L}^{-1}\right)\end{array}$ & $\mathbf{0 , 0 0 2} *$ & $\mathbf{0 , 9 7 5}^{\text {ns }}$ & $\mathbf{0 , 4 7 2}$ & \\
\hline 0,17 & $70,50 \mathrm{~b}$ & 6,87 & 23,50 & 13,25 \\
\hline
\end{tabular}




\begin{tabular}{|c|c|c|c|c|}
\hline 0,34 & $75,00 \mathrm{a}$ & 6,87 & 23,00 & 12,75 \\
\hline 0,51 & $78,25 \mathrm{a}$ & 7,00 & 21,75 & 12,62 \\
\hline $\begin{array}{l}\text { Concentrações de } \\
\mathrm{Si}\left(\mathrm{g} \mathrm{L} \mathrm{L}^{-1}\right)\end{array}$ & $0,104^{\mathrm{ns}}$ & $\mathbf{0 , 5 3 5 ^ { \mathrm { ns } }}$ & $0,272^{\text {ns }}$ & $0,715^{\mathrm{ns}}$ \\
\hline 0,00 & 73,25 & 7,08 & 23,42 & 13,00 \\
\hline 0,50 & 75,92 & 6,75 & 22,08 & 12,75 \\
\hline CV(\%) & 5,11 & 18,66 & 12,67 & 12,85 \\
\hline Média & 74,58 & 6,92 & 22,75 & 12,87 \\
\hline MgxSi & $0,72^{\mathrm{ns}}$ & $0,727^{\mathrm{ns}}$ & $0,729^{n s}$ & $0,212^{\text {ns }}$ \\
\hline
\end{tabular}

Legenda: ns e *- não significativo e significativo a $5 \%$ de probabilidade pelo teste $\mathrm{F}$. Letras iguais não diferem pelo teste $\mathrm{t}$ de Student a 5\% de significância.

Fonte: Própria (2019)

\section{CONCLUSÕES}

O fornecimento de quelato de magnésio via pulverização foliar aumenta a altura de planta, massa seca de 500 grãos e o acúmulo do elemento na parte aérea na cultura do sorgo.

\section{REFERÊNCIAS}

BARBOSA, J. C.; MALDONADO JÚNIOR, W. AgroEstat: sistema para análises estatísticas de ensaios agronômicos.Jaboticabal: Faculdade de Ciências Agrárias e Veterinárias, Unesp, 2010 .

FLORES, R. A., ARRUDA, E. M., DAMIN, V., JUNIOR, J. P. S., MARANHAO, D. D. C., CORREIA, M. A. R., \& DE MELLO PRADO, R. PhysiologicalqualityanddrymassproductionofSorghum bicolor followingsilicon (Si) foliar application. AustralianJournalofCrop Science, v. 12, n. 4, p. 631, 2018.

HERMANS, C., BOURGIS, F., FAUCHER, M., DELROT, S., STRASSER, R. J., VERBRUGGEN, N. 2005. Magnesiumdeficiency in sugar beetalters sugar partitioningandphloemloading in young mature leaves. Planta, 220, 541-549.

HOAGLAND, D. R.; ARNON, D. I. The waterculturemethod for growingplantswithoutSoil.Calif. Agr. Exp. STA. Cir, 347p., 1950.

MOREIRA, W. R., RESENDE, R. S., RODRIGUES, F. A., ANDRADE, C. C. L., NASCIMENTO, C. W. A. (2013). Influência do magnésio na resistência do arroz à mancha parda. Bragantia, 72(2), 154-161. 


\title{
PROPRIEDADES QUÍMICAS DE UM LATOSSOLO VERMELHO IMPLANTADO COM PASTOS DE CAPIM-MOMBACCA SOB EFEITO RESIDUAL DO NITROGÊNIO
}

\author{
PROPIEDADES QUÍMICAS DE UN LATOSOL ROJO IMPLANTADO CON CAPIM- \\ MOMBAÇA PASTAS BAJO EFECTO RESIDUAL DE NITRÓGENO
}

\section{CHEMICAL PROPERTIES OF A RED LATOSOL IMPLANTED WITH CAPIM- MOMBAÇA PASTES UNDER RESIDUAL EFFECT OF NITROGEN}

Antonio Leandro Chaves Gurgel ${ }^{1}$; Gelson dos Santos Difante ${ }^{2}$; Alexandre Romeiro de Araújo $^{3}$; Manuel Cláudio Motta Macedo ${ }^{4}$; Denise Baptaglin Montagner ${ }^{5}$

DOI: https://doi.org/10.31692/978-65-991061-4-9.127-132

\section{INTRODUÇÃO}

O principal fator responsável por tornar a bovinocultura de corte brasileira competitiva em nível mundial é a produção quase que exclusivamente em pasto. A adubação nitrogenada, juntamente com a adubação de manutenção com os demais nutrientes essenciais às plantas são fundamentais para garantir a produtividade agropecuária (LIU et al., 2010; ARLAUSKIENE் et al., 2019). O uso de nitrogênio aumenta a produtividade das pastagens e permite intensificar a utilização por meio de maiores taxas de lotação (MOREIRA et al., 2011).

Essa maior produção de forragem observada com a adoção de maiores doses de nitrogênio (BERNADI et al., 2018) promove maior extração e incorporação de nutrientes no tecido vegetal (MAGALHÃES et al., 2002). Soma-se a isso a condição dos solos de Cerrado, que são considerados de baixa fertilidade natural, acidez elevada e baixo teor de matéria orgânica (BRAZ et al., 2004), o que torna essencial os cuidados com a fertilidade do solo. Por outro lado, há escassez de informações na literatura que avaliem o efeito residual de doses de nitrogênio nos atributos químicos do solo.

Diante do exposto, o objetivo foi avaliar o efeito residual de doses de nitrogênio nas características químicas de um Latossolo vermelho implantado com pastos de capimmombaça.

\section{FUNDAMENTAÇÃO TEÓRICA}

O nitrogênio é o elemento mais abundante na atmosfera terrestre (70\%), e exigido em maior quantidade pela maioria das plantas, desempenha inúmeras funções e constitui

\footnotetext{
${ }^{1}$ Doutorando em Ciência Animal, Universidade Federal de Mato Grosso do Sul, antonioleandro09@gmail.com

2 Professor, Doutor, Universidade Federal de Mato Grosso do Sul, gdifante@ hotmail.com

${ }^{3}$ Pesquisador, Doutor, EMPRAPA Gado de Corte, alexandre.araujo@embrapa.br

${ }^{4}$ Pesquisador, Doutor, EMPRAPA Gado de Corte, manuel.macedo@embrapa.br

${ }^{5}$ Pesquisadora, Doutora, EMPRAPA Gado de Corte, Denise.montagner@embrapa.br
} 
molécula de importância para a vida na terra. Especificamente na planta, é um dos mais importantes constituintes de aminoácidos, proteínas, ácidos nucléicos e enzimas; promove o crescimento e dá a pigmentação verde das plantas (TAIZ e ZEIGUER, 2006).

Estima-se que apenas $47 \%$ do nitrogênio adicionado globalmente aos solos é convertido e colhido em forma de produtos (LASSALETTA et al., 2014). Mais de 50\% do N é perdido no meio ambiente (FOYER et al., 2016), o que gera desperdiço de recursos financeiros, ameaças os corpos de águas, a biodiversidade e aumenta emissões de gases poluentes (GODINOT et al. 2014). Esses fatos tornam imprescindível que nos sistemas pecuários atuais sejam adotadas medidas potenciais que promovam a máxima eficiência de uso desse nutriente. Tendo em vista a sua reconhecida essencialidade para produção de alimentos (ŚWITEK et al., 2019).

A fertilidade do solo desempenha um papel importante no desenvolvimento e produtividade das plantas. Magalhães et al. (2002) avaliaram as relações entre produção de forragem e exportação de nutrientes, em solos sob cerrado durante seis anos de utilização com Brachiaria brizantha, e observaram que a produção de forragem altera a quantidade de nutrientes exportada. Malavolta (1980) demonstrou valores de produção forragem que

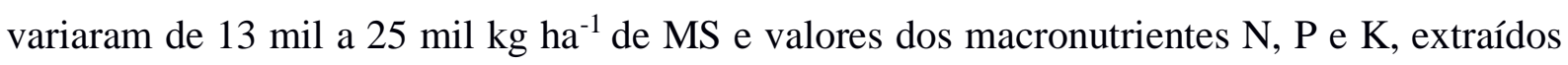
pela parte aérea de, respectivamente, 200 a $300 \mathrm{~kg} \mathrm{ha}^{-1}, 30$ a $70 \mathrm{~kg} \mathrm{ha}^{-1}$ e 200 a $500 \mathrm{~kg} \mathrm{ha}^{-1}$. Portanto, quanto maior a intensificação do sistema, maiores os cuidados com a fertilidade do solo.

\section{METODOLOGIA}

O experimento foi realizado na Embrapa Gado de Corte, em Campo Grande, MS $\left(20^{\circ} 27^{\prime} \mathrm{S}\right.$ e $54^{\circ} 37^{\prime} \mathrm{W}$, a $530 \mathrm{~m}$ de altitude). O período experimental foi de 20/11/2017 a 22/05/2018. O clima da região, segundo a classificação de Köppen, é do tipo AW, tropical chuvoso de savana. A área experimental possui 13,5 ha, dividida em três blocos, cada bloco foi subdividido em três módulos de 1,5 ha, e estes, em seis piquetes de 0,25 ha cada. O solo da área experimental é classificado como Latossolo Vermelho (Embrapa, 2013), com teores de argila entre 30 e $35 \%$.

Os pastos receberam três doses anuais de nitrogênio na forma de ureia (100, 200 e 300 $\mathrm{kg} \mathrm{ha}^{-1} \mathrm{de} \mathrm{N}$ ) por três anos consecutivos 2014/2015, 2015/2016 e 2016/2017, além de adubação de cobertura com $80 \mathrm{~kg} \mathrm{ha}^{-1}$ de $\mathrm{P}_{2} \mathrm{O}_{5}$ e $80 \mathrm{~kg} \mathrm{ha}^{-1}$ de $\mathrm{K}_{2} \mathrm{O}$. A partir das águas de 2017 não foi utilizada adubação de manutenção, nem nitrogenada, caracterizando a avaliação do efeito residual das doses de nitrogênio. Para desfolhação foram utilizados bovinos machos 
inteiros da raça Nelore. Os pastos foram manejados pelo método de pastejo com lotação intermitente, com taxa de lotação variável de modo a garantir uma altura pós pastejo de 40 a $50 \mathrm{~cm}$ (EUCLIDES et al., 2017). Nos cinco primeiros ciclos de pastejo (verão), foi preconizado cinco dias de ocupação e 25 dias de descanso, no sexto ciclo (outono), os pastos foram manejados com sete dias de ocupação e 35 dias de descanso.

As diferentes doses residuais de nitrogênio proporcionaram taxas de acúmulo de forragem distintas entre os tratamentos que, por sua vez, definiram diferentes taxas de lotação no decorrer do período experimental (Tabela 1).

Tabela 1. Indicadores médios de produção animal e de forragem, em pastos de capim-mombaça sob efeito residual de nitrogênio.

\begin{tabular}{cccc}
\hline Variáveis & \multicolumn{3}{c}{ Doses de $\mathrm{N}\left(\mathrm{kg} \mathrm{ha}^{-1} \mathrm{de} \mathrm{N}\right)$} \\
\cline { 2 - 4 } & 100 & 200 & 300 \\
\hline Taxa de acúmulo de forragem $\left(\mathrm{kg} \mathrm{ha}^{-1}\right.$ por dia) & 26,7 & 36,3 & 43,4 \\
Massa de forragem no pré-pastejo $\left(\mathrm{kg} \mathrm{ha}^{-1} \mathrm{MS}\right)$ & 3371,8 & 3637,6 & 3853,9 \\
Taxa de lotação $(\mathrm{UA} \mathrm{ha})^{-1}$ & 2,7 & 3,1 & 4,0 \\
\hline
\end{tabular}

*UA= Unidade anima de $450 \mathrm{~kg}$. Fonte: Própria (2019).

As amostras de solo para análise química foram coletadas em maio de 2018, em três profundidades ( 0 a 10, a 20 e 20 a $40 \mathrm{~cm}$ ). Para a coleta foram escavadas trincheiras com um metro de profundidade em dois piquetes de cada bloco experimental. As amostra de solo foram armazenadas em saco plástico, identificadas e encaminhadas ao Laboratório de Solos da Empresa Brasileira de Pesquisa Agropecuária (EMBRAPA - Gado de Corte). Os atributos químicos avaliados foram: $\mathrm{pH} \mathrm{CaCl}_{2}$ (proporção 1: 2,5), acidez total $\mathrm{pH} 7,0(\mathrm{H}+\mathrm{Al})$, teor de fósforo, potássio trocável, cálcio trocável, magnésio trocável, saturação por bases, capacidade de troca catiônica $(\mathrm{CTC}$ em $\mathrm{pH}=7,0)$, e teor de matéria orgânica, conforme a metodologia de Embrapa, (2017).

O delineamento adotado foi o de casualização em blocos com arranjo em parcelas subdivididas, sendo o efeito residual das doses de nitrogênio alocado na parcela e as profundidades na subparcela. Os dados foram submetidos à análise de variância, quando significativos pelo teste $\mathrm{F}$, o efeito residual do nitrogênio, das profundidades e suas interações, foram analisados pelo teste de Tukey, a 5\% de significância.

\section{RESULTADOS E DISCUSSÃO}

A interação entre dose residual de nitrogênio $\times$ profundidade do solo não foi significativa para as variáveis estudadas (Tabela 2). Não houve efeito das doses residuais de 
nitrogênio para o $\mathrm{pH}$ do solo, cálcio trocável, potássio trocável, acidez potencial, capacidade de troca catiônica, saturação por bases e fósforo. No entanto, as doses residuais de nitrogênio influenciaram os teores de magnésio trocável, com as maiores concentrações no solo sob efeito das doses residuais de 100 e $200 \mathrm{~kg} \mathrm{ha}^{-1}$ de $\mathrm{N}$, e de matéria orgânica, com os maiores valores no solo sob efeito das doses residuais de 200 e $300 \mathrm{~kg} \mathrm{ha}^{-1}$ de $\mathrm{N}$ (Tabela 2).

As pequenas alterações nos atributos químicos do solo, ocorreram, provavelmente, devido à similaridade do manejo da adubação de manutenção adotado nos anos que antecederam a coleta de dados. Por outro lado, os pastos sob efeito da dose residual de 300 $\mathrm{kg} \mathrm{ha}^{-1}$ de $\mathrm{N}$ acumularam mais forragem (Tabela 1) o que levou a maior extração de magnésio do solo, pois, as gramíneas forrageiras são mais eficientes na absorção e acumulação de magnésio nos tecidos (BRAZ et al., 2004; ANDREOLE e PRADO, 2012; ENSINAS et al., 2016).

Tabela 1. Características químicas de um Latossolo Vermelho implantado com pastos de capim-mombaça sob efeito residual do nitrogênio em diferentes profundidades.

\begin{tabular}{|c|c|c|c|c|c|c|c|c|c|c|}
\hline \multirow{2}{*}{ Propriedades } & \multicolumn{3}{|c|}{ Doses de $\mathrm{N}\left(\mathrm{Kg} \mathrm{ha}^{-1}\right)$} & \multicolumn{3}{|c|}{ Profundidades $(\mathrm{cm})$} & \multirow{2}{*}{ EPM } & \multicolumn{3}{|c|}{ Valor P } \\
\hline & 100 & 200 & 30 & 0 a 10 & 0 a 20 & 20 a 40 & & $\mathrm{~N}$ & $\mathrm{P}$ & $\mathrm{N} \times \mathrm{P}$ \\
\hline $\mathrm{pH}\left(\mathrm{CaCl}_{2}\right)$ & 5,3 & 5,3 & & 5,2 & 5,3 & 5,3 & 0,024 & 0,182 & 0,074 & 0,855 \\
\hline Cálcio $\left(\mathrm{cmol}_{\mathrm{c}} \mathrm{dm}^{-3}\right)$ & 2,3 & 2,1 & 2,0 & $2,6^{\mathrm{a}}$ & $2,5^{\mathrm{a}}$ & $1,3^{b}$ & 0,097 & 0,223 & 0,001 & 0,393 \\
\hline Magnésio $\left(\mathrm{cmol}_{\mathrm{c}} \mathrm{dm}^{-3}\right)$ & $1,2^{\mathrm{a}}$ & $1,2^{\mathrm{a}}$ & 1 & $1,3^{\mathrm{a}}$ & $1,2^{\mathrm{a}}$ & $0,9^{\mathrm{b}}$ & 0,017 & 0,022 & 0,001 & 0,931 \\
\hline Potássio $\left(\mathrm{cmol}_{\mathrm{c}} \mathrm{dm}^{-3}\right)$ & 0,2 & 0,2 & 0,2 & $0,3^{\mathrm{a}}$ & $0,3^{\mathrm{a}}$ & 0,1 & 0,012 & 0,337 & 0,001 & 0,732 \\
\hline $\mathrm{H}+\mathrm{AL}\left(\mathrm{cmol}_{\mathrm{c}} \mathrm{dm}\right.$ & 3,4 & 3 & 3,8 & $4,1^{\mathrm{a}}$ & $3.4^{\mathrm{b}}$ & $3,0^{\mathrm{b}}$ & 0,141 & 0,183 & 0,001 & 0,169 \\
\hline $\mathrm{CTC}\left(\mathrm{cmol}_{\mathrm{c}} \mathrm{dm}^{-3}\right)$ & 6,9 & 7,0 & 7,1 & $8,4^{\mathrm{a}}$ & $7,4^{\mathrm{b}}$ & $5,3^{\mathrm{c}}$ & 0,068 & 0,415 & 0,001 & 0,943 \\
\hline $\mathrm{V}(\%)$ & 51,6 & 49,8 & 46,6 & $50,9^{\mathrm{a}}$ & $54,0^{\mathrm{a}}$ & $43,0^{\mathrm{b}}$ & 1,372 & 0,135 & 0,002 & 0,629 \\
\hline Matéria orgânica (\%) & $3,2 b$ & $3,5^{\mathrm{a}}$ & $3,6^{\mathrm{a}}$ & $4,1^{\mathrm{a}}$ & $3,7^{\mathrm{b}}$ & $2,5^{\mathrm{c}}$ & 0,411 & 0,005 & 0,001 & 0,913 \\
\hline Fósforo $\left(\mathrm{mg} \mathrm{dm}^{-3}\right)$ & 3,2 & 3,9 & 5,0 & $7,4^{\mathrm{a}}$ & $3,7^{\mathrm{b}}$ & $0,9^{c}$ & 0,738 & 0,323 & 0,001 & 0,101 \\
\hline
\end{tabular}

Capacidade de troca catiônica (CTC), saturação por bases (V). Valor de probabilidade (valor P) para as doses de nitrogênio $(\mathrm{N})$ e profundidades $(\mathrm{P})$. EPM: erro padrão da média. Médias seguidas de letras distintas na linha diferem entre si $(\mathrm{P}>0,05)$ pelo teste de Tukey. Fonte: Própria (2019).

O efeito das profundidades não foi significativo para o $\mathrm{pH}$ do solo. A acidez potencial $(\mathrm{H}+\mathrm{Al})$ apresentou maiores valores nas profundidades de 0 a 10 e 10 a $20 \mathrm{~cm}$. Mesma tendência observada para os teores de potássio trocável, cálcio trocável, magnésio trocável, e saturação por bases. A capacidade de troca catiônica, os teores de fósforo e de matéria orgânica diminuíram com o aumento da profundidade (Tabela 2). A redução nos atributos químicos do solo com o aumento em profundidade, pode ser explicada pela particularidade dos sistemas de produção em pastos tropicais, onde não ocorre a incorporação de nutrientes em camadas mais profundas por meio de adubações de cobertura. Essa prática ocorre, geralmente, apenas na implantação do pasto (MAGALHÂES et al., 2002). 


\section{CONCLUSÕES}

As doses residuais de nitrogênio tiveram pouca interferência nos atributos químicos do Latossolo Vermelho de textura média cultivado com capim-mombaça. Ocorreram modificações apenas para os teores de magnésio trocável e matéria orgânica no solo.

\section{REFERÊNCIAS}

ANDRIOLE, I.; PRADO, R. M. Plantas de cobertura em pré-safra e adubação nitrogenada na fertilidade do solo em diferentes camadas, cultivado com milho em sistema de plantio direto e convencional. Semina Ciências Agrarias. v. 33, n. 3, p. 963-978. 2012.

ARLAUSKIENĖA, A.; CESEVIČIENĖB, J.; VELYKISA, A. Improving mineral nitrogen control by combining catch crops, fertilisation, and straw management in a clay loam soil. Acta Agriculturae Scandinavica, Section B - Soil \& Plant Science. v. 69, n. 1, p. 422-431. 2019.

BERNARDI, A.; SILVA, A. W. L.; BARETTA, D. Estudo metanalítico da resposta de gramíneas perenes de verão à adubação nitrogenada. Arquivos Brasileiro de Medicina Veterinária e Zootecnia. v. 70, n. 2, p .545-553, 2018.

BRAZ, A. J. B. P.; SILVEIRA, P. M.; KLIEMANN, H. J.; ZIMMERMANN, F. J. P.; Acumulação de nutrientes em folhas de milheto e dos capins braquiária e mombaça. Pesquisa Agropecuária Tropical. v. 34, n. 2, p. 83-87. 2004.

EMBRAPA - EMPRESA BRASILEIRA DE PESQUISA AGROPECUÁRIA. Centro Nacional de Pesquisa de Solos (Rio de Janeiro, RJ). $3^{\text {a }}$ Ed. Manual de métodos de análises de Solos. Rio de Janeiro: CNPS. 573 p. 2017.

EMPRESA BRASILEIRA DE PESQUISA AGROPECUÁRIA. Centro Nacional de Pesquisa de Solos (Rio de Janeiro, RJ). $3^{\text {a }}$ Ed. Sistema Brasileiro de Classificação de Solos. Rio de Janeiro: CNPS. 353 p. 2013.

ENSINAS, S. C.; SERRA, A. P.; MARCHETTI, M. E.; SILVA, E. F.; LOURENTE, E. R. P.; PRADO, E. A. F.; MATOS, F. A.; ALTOMAR, P. H.; MARTINEZ, M. A.; POTRICH, D. C.; CONRAD, V. A.; JESUS, M. V.; TÁRIK KADRI, C. E. Cover crops affect the soil chemical properties under no-till system. Australian Journal of Crop Scienc. v. 10, n. 8, p. 1104-1111. 2016.

EUCLIDES, V. B. P.; CARPEJANI, G. C.; MONTAGNER, D. B.; NASCIMENTO JUNIOR, D.; BARBOSA, R. A.; DIFANTE, G. S. Maintaining post-grazing sward height of Panicum maximum (cv. Mombaça) at $50 \mathrm{~cm}$ led to higher animal performance compared with postgrazing height of $30 \mathrm{~cm}$. Grass and Forage Science. v. 73, n. 1, 174-182, 2017.

FOYER, C. H.; LAM, H-M., NGUYEN, H. T.; SIDDIQUE, K. H. M.; VARSHNEY, R. K.; COLMER, T. D.; COWLING, W.; BRAMLEY, H.; MORIS, T. A, HODGSON, J. M. Neglecting legumes has compromised human health and sustainable food production. Nature Plants. v. 2, n.1, p. 1-10, 2016. 
GODINOT, O.; CAROF, M.; VERTES, F.; LETERME, P. SyNE: an improved indicator to assess nitrogen efficiency of farming. Agricultural Systems. v. 127, n. 1, p. 41-52. 2014.

LASSALETTA, L.; BILLEN, G.; GRIZZETTI B.; ANGLADE, J.; GARNIER, J. 50 year trends in nitrogen use efficiency of world cropping systems: the relationship between yield and nitrogen input to cropland. Environmental Research Letters. v. 9, n.1, p. 1-9, 2014.

LIU, E.; YAN, C.; MEI, X.; BING, S. H.; DING, L.; LIU, Q.; LIU, S.; FAN, T. Long-term effect of chemical fertilizer, straw, and manure on soil chemical and biological properties in northwest China. Geoderma. v. 158, n. 1, p. 173-180. 2010.

MAGALHÃES, R. T.; OLIVEIRA, I. P.; KLIEMANN, H. J. Relações da produção de massa seca e as quantidades de nutrientes exportados por Brachiaria brizantha em solos sob o manejo pelo sistema "Barreirão". Pesquisa Agropecuária Tropical. v. 32, n. 1, p. 13-20. 2002.

MALAVOLTA, E. Elementos de nutrição de plantas. Agronômica Ceres, São Paulo. 251 p. 1980.

MOREIRA, L. M.; SANTOS, M. E. R.; FONSECA, D. M.; MARTUSCELLO, J. A.; MORAIS, R. V.; MISTURA, C. Produção animal em pastagem de capim-braquiária adubada com nitrogênio. Arquivo Brasileiro de Medicina Veterinária e Zootecnia. v. 63, n. 4, p. 914-921. 2011.

ŚWITEK, S.; TAKACS, V.; SAWINSKA, Z.; KOSIADA, T.; TRYJANOWSKIA, P. Mineral nitrogen fertilisers remain a crucial factor even in the ecological intensification of agriculture. Acta Agriculturae Scandinavica, Section B - Soil \& Plant Science. v. 69, n. 4, p. 311-316. 2019.

TAIZ, L e ZEIGER E. Fisiologia vegetal. 3rd. edn. Artmed, Porto Alegre. 722p. 2006. 


\section{DINÂMICA DA ATIVIDADE MICROBIANA DO SOLO SOB DIFERENTES AGROSSISTEMAS NO CERRADO BAIANO}

Vitória Oliveira Andrade ${ }^{1}$; Inglid Lais Batista Cunha de Souza ${ }^{2}$; Gabriel Amorim Luduvico³; Thais dos Santos Rodrigues ${ }^{4}$; Msc. Cristiane Nair Fabrício Nunes ${ }^{5}$

DOI: $\underline{\text { https://doi.org/10.31692/978-65-991061-4-9.133-138 }}$

\section{INTRODUÇÃO}

A ocorrência da perturbação causada pela ação humana em sistemas estáveis (solo + cobertura vegetal), tende a acarretar perdas maiores do que ganhos de carbono, ocasionando assim, a redução da qualidade do solo ao longo do tempo. Com isso, pode-se relacionar essas perdas com a liberação de carbono na forma de $\mathrm{CO}_{2}$ do sistema solo para a atmosfera, através do processo de respiração, provenientes da decomposição da matéria orgânica do solo por hidrólise microbiana (ARAÚJO,2009).

Neste sentido, de forma complementar, a respiração edáfica pode ser definida como a produção de $\mathrm{CO}_{2}$, ou consumo de $\mathrm{O}_{2}$, como decorrência de processos metabólicos de organismos vivos no solo e abrange dois processos gerais: redução de C pelo sistema solo e reciclagem de nutrientes (SILVA, 2010). Desta forma, a respiração edáfica pode ser utilizada para registrar mudanças na dinâmica do carbono do solo em áreas que sofreram desmatamento para implantação de culturas (SOUTO et al.,2009).

Segundo Grisi (1976) os componentes bióticos do ecossistema são responsáveis por grande parte da respiração total do solo e que, quando em condições favoráveis de temperatura e umidade, seus valores tendem a se elevar, podendo ser possível que tais condições não sejam favoráveis durante o dia. Ou ainda, as condições ecológicas características de solo e clima da região levariam os microrganismos a tal comportamento. Dessa maneira, faz-se necessário esclarecer melhor essa particularidade relacionada à elevação e diminuição da atividade microbiana no solo.

Portanto, o presente trabalho tem como objetivo avaliar o comportamento da atividade microbiana diurna em três tipos de agrossistemas: Mandioca, Pinhão Manso e Mata nativa em decorrência da variação climática associada a esses diferentes tipos de uso do solo.

\footnotetext{
1 Graduando em Engenharia Agronômica, Universidade do Estado da Bahia- UNEB, Campus IX, vitoriasaogabriel2@gmail.com

2 Graduando Engenharia Agronômica, Universidade do Estado da Bahia, - UNEB, Campus IX, inglidlaiscunha@gmail.com

3 Graduando em Engenharia Agronômica, Universidade do Estado da Bahia- UNEB, Campus IX, luduvicoga@gmail.com

4 Graduando em Engenharia Agronômica, Universidade do Estado da Bahia - UNEB, Campus IX, thaissan98@gmail.com

${ }^{5}$ Mestrado em Ciências Ambientais, Universidade Federal da Bahia - UFBA, crisfabricio@ hotmail.com
}

[133] 


\section{Matéria Orgânica do Solo (MOS)}

A qualidade e a quantidade da matéria orgânica no solo é um fator determinante para os atributos edáficos, já que a mesma influência nas propriedades físicas, químicas e biológicas de solo. A matéria orgânica adicionada ao solo tem a planta como componente ativo no seu principal processo, desse modo, o estoque de MOS é consequência dos processos de perda e adição de material orgânico (ALMEIDA \& SANCHES, 2014).

A "respiração microbiana do solo" ou emissão de $\mathrm{CO}_{2}$ está intimamente relacionada a qualidade e ao teor de MOS e, como consequência, a própria diversidade biológica estará refletindo, a qualidade da matéria orgânica do solo (MAIA \& PARRON, 2015). O solo em suas condições naturais possui um conteúdo de carbono orgânico estabilizado, que representa as condições ambientais estabelecidas pelo clima, vegetação, topografia e por características do próprio solo. No entanto, as formas de uso e manejo do solo também são relevantes, particularmente, quando os ecossistemas nativos são transformados em áreas agrícolas (BALIM et al.,2017).

\section{Emissão de $\mathrm{CO}_{2}$ e Agrossistemas}

A contribuição do dióxido de carbono atmosférico para o aquecimento global tem aumentado o interesse pelo carbono orgânico do solo, por ser um dos principais compartimentos do ciclo terrestre deste elemento (BALDOTTO et al.,2015). A entrada e saída de carbono, em sistemas agrícolas, é influenciada pelo preparo do solo, espécies utilizadas, rotações de cultura, adubação e, principalmente, pelo manejo dos resíduos das culturas (COSER et al., 2016).

\section{METODOLOGIA}

O experimento foi executado no mês de agosto de 2019, na área experimental da Universidade do Estado da Bahia- Campus IX, município de Barreiras- BA, cujas coordenadas geográficas ( $44^{\circ} 59^{\prime} 33^{\prime}$ W W e $12^{\circ} 8$ ' 54” S), com altitude de $454 \mathrm{~m}$. O clima predominante na região é o Clima tropical com estação seca, baseado na Classificação climática Köeppen- Geiger: Aw. O solo, sendo classificado como LATOSSOLO VERMELHO-AMARELO Distrófico típico e o bioma Cerrado. A pesquisa tem como natureza, quantitativa do tipo experimental exploratória.

A quantificação do $\mathrm{CO}_{2}$ foi realizada de acordo com a metodologia de Grisi (1978), durante 12 horas (6:00 - 18:00) de hora em hora, e consiste na absorção do $\mathrm{CO}_{2}$ liberado do solo, pela solução de KOH 0,5 N. Para as análises, foram colocados $10 \mathrm{ml}$ da solução alcalina em potes de $500 \mathrm{ml}$, em triplicata, estas foram colocadas em um sistema campânula, contendo 
um balde de capacidade de 29 L juntamente com o frasco controle hermeticamente fechado. Após uma hora, foram titulados com $\mathrm{HCl} 0,1 \mathrm{~N}$ utilizando dois indicadores, a fenolftaleína à $1 \%$ e alaranjado de metila a $1 \%$ para a primeira e segunda viragem respectivamente. A massa de $\mathrm{CO}_{2}$ desprendido por unidade da área e tempo $\left(\mathrm{mg} \mathrm{m}^{-2} \mathrm{~h}^{-1}\right)$ foi calculada segundo a fórmula de Valentini (2015), como visto na equação 1.

$$
\mathrm{CO}_{2}\left(\mathrm{mg} \mathrm{m} \mathrm{m}^{-2} h^{-1}\right)=\frac{(\mathrm{VA}-\mathrm{VB}) \mathrm{NHCL} \times \mathrm{Eq} \mathrm{CO}_{2}}{A \times T} \times 10^{4} \times 4 / 3
$$

Equação 1

Em que VB representa a $\neq$ do volume do ácido clorídrico gasto na titulação do branco com os dois indicadores. VA $\neq$ dos volumes do ácido clorídrico gasto na titulação da amostra com os dois indicadores; $\mathrm{NHCl}$ é a normalidade do ácido clorídrico $(0,1 \mathrm{~N})$; Eq $\mathrm{CO}_{2}$ é a equivalente grama de CO2 (22); A é a área da campânula; T é o tempo de coleta em horas. 4/3 é o fator que corrige o valor do efluxo de $\mathrm{CO}_{2}$ no solo que pelo método químico é subestimado em $25 \%$.

Para o estudo da influência de temperatura e umidade sob a atividade microbiana nos solos, foram coletados dados climáticos no site oficial do Instituto Nacional de Meteorologia (IMNET).

\section{RESULTADOS E DISCUSSÃO}

Na medição da atividade microbiana, por um período de 12 horas em cada um dos agrossistemas (figura 1), nota-se que os valores mais elevados na mandioca, pinhão manso e mata nativa foram observados às 10 horas, 6 horas e 17 horas, respectivamente.

Figura 1: Variação diurna da respiração edáfica do solo nos diferentes agrossistemas estudados.

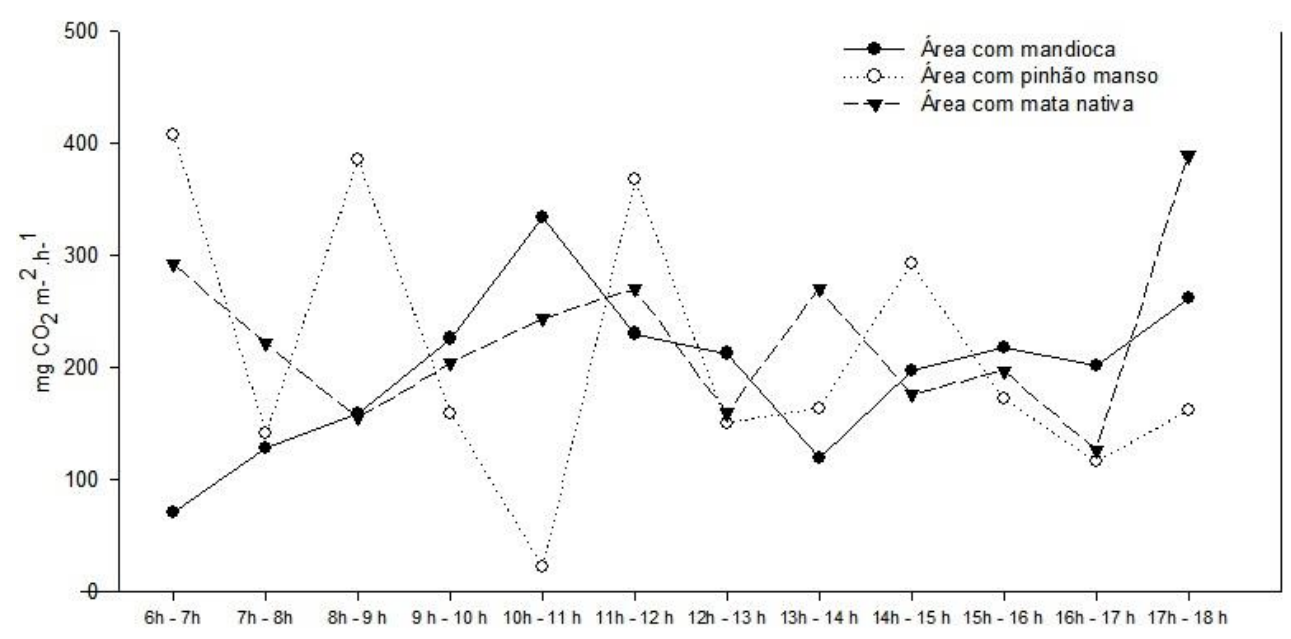

Fonte: Própria (2019) 
A mandioca (Manihot esculenta Crantz) é considerada a cultura com a mais alta produtividade de calorias e de maior eficiência biológica. Devido à necessidade de capinas e movimento do solo durante os estádios de desenvolvimento, pode deixar o solo descoberto e desprotegido, ocasionando a passagem de muita radiação solar (FERREIRA et al., 2015). Neste sentido, é importante ressair que a temperatura corresponde à um dos fatores que tende a influenciar na biótica do solo, alterando tanto a sua população, quanto as suas atividades.

Com isso, ao comparar a área da mandioca com a mata nativa (Stricto sensu), no primeiro horário (6-7 horas), observou-se que a mandioca apresentou uma taxa de respiração $75,75 \%$ menor do que a mata nativa. A umidade e temperatura média do ar nesse horário eram iguais a 44 a $46 \%$ e 24,7 a $22,9{ }^{\circ} \mathrm{C}$ respectivamente.

Do contrário, no período de 10 a 11 horas o solo cultivado com mandioca apresentou uma taxa respiratória de 37,28\% superior a mata nativa, com umidade de 53 a $51 \%$ e temperatura ambiente máxima de 20,9 a $21,9^{\circ} \mathrm{C}$. Ao final da tarde, das $16-17 \mathrm{~h}$, a taxa respiratória na área com mandioca se elevou em $60 \%$ de emissão de $\mathrm{CO}_{2}$ relacionada com a mata nativa. Essa elevação de emissão de $\mathrm{C}$ se dá por meio da temperatura que pode ser expressada devido ao ponto ótimo que os microrganismos estão ativos, assim, a partir deste ponto os mesmos podem desnaturar e com isso, diminuir sua atividade.

Em relação ao Pinhão Manso, o mesmo apresenta semelhança com os sistemas naturais, podendo representar uma combinação ideal no favorecimento da biota do solo, disponibilizando matéria orgânica e refúgio aos microrganismos, já que não há interferência do manejo intensivo (AGOSTINHO, 2017). Segundo Chagas (2008), o mesmo possui uma alta eficiência para a estocagem de carbono no solo. Porém, por estar consorciado com o Nim indiano que possui um princípio ativo chamado Azadiractina, extraído da sua parte aérea e tendo capacidade antimicrobiana e inseticida, o pinhão manso pode apresentar uma diminuição acentuada na atividade microbiana.

Neste sentido, quando confrontado a Pinhão Manso com a área de Mata nativa consorciado ao Nim indiano, os valores correspondentes as taxas de emissão de $\mathrm{CO}_{2}$ na área de Pinhão Manso que foram mais elevadas são: das 6-7 h; 8-9 h; 11-12 h e 14-15h; com os seguintes valores: 39,39\%; 148,32\%; 36,06\% e 65,70\% respectivamente . Dessa forma, notase que a área da mata nativa se manteve estabilizada em relação ao seu conteúdo de carbono orgânico, cujo a sua constância associa-se às condições ambientais do próprio solo, já que o mesmo não sofreu nenhum tipo de perturbação antrópica. 


\section{CONSIDERAÇÕES FINAIS}

Portanto, analisando as medições de hora em hora por um período de 12 horas, os diferentes tipos de sistemas de manejo trazem consigo diferentes condições ambientais, preparo do solo, manejo de resíduos, espécies utilizadas, dentre outros aspectos que favorecem a biota edáfica do solo, a qual irá influenciar na liberação de $\mathrm{C}$ na forma de $\mathrm{CO}_{2}$ do solo para a atmosfera pelo processo de respiração.

\section{REFRÊNCIAS}

AGOSTINHO, P. R. Indicadores biológicos de qualidade de solo em sistemas agroflorestais biodiversos para fins de recuperação de áreas degradadas. Embrapa Agropecuária OesteTese/dissertação (ALICE), 2017.

ALMEIDA, R. F.; SANCHES, B. C. Disponibilidade de carbono orgânico dos solos no cerrado brasileiro. Scientia Agraria Paranaensis, Marechal Candido Rondon, v.13, n. 4, p. 259-264, 2014.

ARAÙJO, Kallianna Dantas et al. Liberação de dióxido de carbono $\left(\mathrm{CO}_{2}\right)$ em área de caatinga no semiárido no Paraíba. Geoambiente Online, n. 12, p. 01-12 pág., 2009.

BALDOTTO, M. A. et al. Estoque e frações de carbono orgânico e fertilidade de solo sob floresta, agricultura e pecuária. Rev. Ceres, Viçosa, v.62, n. 3, p.301-309, 2015.

BALIN, N. M. et al. frações da matéria orgânica, índice de manejo do carbono e atributos físicos de um Latossolo vermelho sob diferentes sistemas de uso. Rev. Scientia Agraria, Curitiba, PR, v.18, n.3, p. 85-94, 2017.

CHAGAS, P. D. Esperança Nacional. Revista do Biodiselbr, Curitiba, v. 1, p. 24-34, 2008.

COSER, T. R. et al. Propriedades microbiológicas do solo e disponibilidade de nitrogênio para milho em monocultura e em consórcio com forrageiras. Pesq. Agropecuária. bras. Brasília, v.51, n.9, p.1660-1667,2016.

DA SILVA, Ruy Borges; DOS SANTOS, Antonio Clementino; BATISTA, Ruy Bezerra. Respiração Edáfica como indicativo na qualidade do solo em três Agrossistemas. 2010.

FERREIRA, Evander Alves et al. Atividade microbiana de solos cultivados com mandioca em sistema de policultivo. MAGISTRA, v.27, n.3/4, p.395-400, 2017.

GRISI, Breno Machado. Biodinâmica de solo cultivado com cacaueiros sombreados e ao sol. Rev. theobr, v. 6, p. 87-99, 1976.

GRISI, B. M. Metodo quimico de medicao da respiracao edafica; alguns aspectos tecnicos. Ciência e Cultura, 1978.

MAIA, C. M. B. F; PARRON, L. M. Matéria orgânica como indicador da qualidade do solo e 
da prestação de serviços ambientais. EMBRAPA, DF, 2015.

MARTINS, Lima Deleon et al. Efeito do corretivo escória de siderurgia e diferentes adubações no teor nutricional de folha de mamona e pinhão-manso. Revista Verde de Agroecologia e Desenvolvimento Sustentável, p. 135-145, 2009.

SANTOS, Adriana Avelino. Implantação do pinhão-manso em solo degradado inoculado e acrescido de macrófita, cinza e hidrogel. Ilha Solteira: UNESP, f.75, 2013.

SOUTO, Patrícia Carneiro et al. CINÉTICA DA RESPIRAÇÃO EDÁFICA EM DOIS AMBIENTES DISTINTOS NO SEMI-ÁRIDO DA PARAIBA, BRASIL. Revista Caatinga, v. 22, n.3, p. 52-58, 2009.

VALENTINI, Carla Maria Abido; DE ABREU, Joadil Gonçalves; DE FARIA, Rozilaine Aparecida Pelegrine Gomes. Respiração do solo como bioindicador em áreas degradadas. Revista Internacional de Ciências, v. 5, n. 2, p. 127-142, 2015. 


\section{AVALIAÇÃO DA EFICÁCIA DA IVERMECTINA SOBRE NEMATOIDES GASTRINTESTINAIS DE ASININOS Equus asinus Linnaeus, 1758}

\section{EFFECTIVENESS EVALUATION OF IVERMECTIN ON GASTRINTESTINAL NEMATOIDS OF DONKEYS Equus asinus Linnaeus, 1758}

\section{EVALUACIÓN DE LA EFECTIVIDAD DE LA IVERMECTINA EN LOS NEMATOIDES GASTRINTESTINALES DE LOS BURROS Equus asinus Linnaeus, 1758}

Ruana Rafaela Lira Torquato Paiva ${ }^{1}$; Lígia Vanessa Leandro Gomes ${ }^{2}$; Maria de Lara Oliveira Lima $^{3}$; Eylha Pricilla Fernandes Menezes ${ }^{4}$; Josivania Soares Pereira ${ }^{5}$

DOI: https://doi.org/10.31692/978-65-991061-4-9.139-144

\section{INTRODUÇÃO}

Dentre os asininos, a espécie Equus asinus Linnaeus, 1978 apresenta características peculiares, que garantem sua grande utilização em regiões semiáridas, tais como: força, rusticidade e resistência, principalmente, ao clima quente e à escassez de alimentos (MARQUES et al., 2013). São usados para serviços de carga, transporte e, principalmente produção de híbridos (muares e bardotos), atividade esta que cresce a cada dia (SILVA et al., 2018).

Para utilização como modelos experimentais ou em asininoterapia, bem como evitar que os mesmos sejam disseminadores de patógenos a outros organismos (cavalos), estes animais precisam estar livres de uma carga parasitária alta e considerada patogênica. Infelizmente, é sabido que na busca por um controle total, no qual o objetivo é tratar com frequência suficiente para manter a carga parasitária e a contagem de ovos por grama de fezes (OPG) próximo de zero, cada vez mais se observa o uso indiscriminado e frequente dos antihelmínticos disponíveis, o que contribui para seleção de parasitos resistentes (FORTES, 2013). O objetivo do presente trabalho é avaliar a eficácia da Ivermectina sobre nematoides gastrintestinais de asininos Equus asinus Linnaeus, 1758.

\section{FUNDAMENTAÇÃO TEÓRICA}

É sabido que os equídeos silvestres ou domesticados podem ser parasitados por helmintos que afetam a sua saúde e bem-estar por ocasionar letargia, perda de peso, cólica

\footnotetext{
${ }^{1}$ Medicina Veterinária, Universidade Federal Rural do Semi-árido, ruanatorquato@ gmail.com

${ }^{2}$ Zootecnia, Universidade Federal Rural do Semi-árido, ligiavanessssa@ hotmail.com

${ }^{3}$ Medicina Veterinária, Universidade Federal Rural do Semi-árido, mlara.oliveira@ hotmail.com

${ }^{4}$ Medicina Veterinária, Universidade Federal Rural do Semi-árido, pryscylla_gt@ hotmail.com

${ }^{5}$ Docente adjunta da Universidade Federal Rural do Semi-árido, josigej@ufersa.edu.br
} 
potencialmente grave, diarreia e até a morte. (BEVILAQUA, 1988; CANEVER, 2012). Dentre os equídeos, os asininos, apesar de sua robustez, são animais vulneráveis às parasitoses. Nestes, a fauna parasitária é composta por mais de 100 espécies diferentes de helmintos gastrintestinais, incluindo Cestoda, Trematoda, Ascaridida e Strongylida (KRECEK, 2014; SOUSA, 2016). No semiárido brasileiro, entre os criadores, há uma tendência de considerar um conceito tradicional de que asininos são animais muito resistentes e que não requerem cuidados em seu manejo. Além disso, os estudos sobre doenças parasitárias em asininos têm sido negligenciados e, consequentemente, são raras as publicações científicas detalhadas sobre a biodiversidade parasitária assim como a sua prevalência, incidência e efeitos na saúde dos asininos (VILELA; FEITOSA, 2018). Isto representa uma grande preocupação, pois E. asinus são hospedeiros naturais de parasitas gastrintestinais do cavalo (Equus caballus).

Os protocolos terapêuticos são frequentemente administrados nos asininos com base na dosagem e nos intervalos recomendados para cavalos (GROSENBAUGH; REINEMEYER; FIGUEIREDO, 2011). Isso ocorre porque dados relativamente limitados estão disponíveis em parasitas internos e na farmacologia de drogas anti-helmínticas em jumentos e mulas quando comparados a ruminantes e cavalos, porque tais espécies foram consideradas de baixo interesse econômico e por isso negligenciadas em tais pesquisas. $\mathrm{O}$ tratamento anti-helmíntico é, portanto, um desafio, já que muitos fármacos não são licenciados para uso em asininos e muares (GOKBULUT; MCKELLAR, 2018). Contudo, jumentos e cavalos compartilham suscetibilidade à maioria dos endoparasitas e essas drogas têm se mostrado eficazes para o controle de infecção parasitária natural em jumentos mesmo em doses determinadas para cavalos (GROSENBAUGH; REINEMEYER; FIGUEIREDO, 2011).

\section{METODOLOGIA}

Foram utilizados vinte espécimes machos e fêmeas adultos de Equus asinus, provenientes de uma propriedade localizada no município de Felipe Guerra, Rio Grande do Norte. Coletou-se dos referidos asininos, amostras de fezes diretamente da ampola retal nos dias zero (antes do tratamento) e 14 dias após tratamento. Finalizadas as coletas, os mesmos permaneceram na sua propriedade de origem. Nos animais alocados no grupo controle (10 animais) apenas coletou-se as fezes enquanto que no grupo tratado (10 animais) foi aplicado uma única dose subcutânea de Ivermectina a $1 \%(0.2 \mathrm{mg} / \mathrm{kg}$ peso vivo) para posterior análise da resistência de endoparasitos. 
Para composição dos grupos experimentais, os animais tiveram sua massa corpórea medida e foram marcados através de colares confeccionados em plástico e com cores estabelecidas para cada grupo. Todos os procedimentos de manipulação e coleta de fezes nos animais foram executados conforme as recomendações propostas pela Comissão de Ética no uso de animais em pesquisa da UFERSA (projeto protocolo n. 23091.003873/2017-54, aprovado pela CEUA-UFERSA parecer número 07/2017).

Para realização da coleta das fezes, os animais foram contidos fisicamente (uso de cabresto) e em seguida foram submetidos a palpação retal. As amostras fecais coletadas diretamente da ampola retal foram enviadas ao Laboratório de Parasitologia Animal da UFERSA para análise. As fezes foram analisadas segundo técnica de Gordon e Whitlock (1939) modificado segundo Chagas et al. (2011). Para identificação dos gêneros e quando possível, espécies de endoparasitos foi realizado cultivo das fezes nos dias 0 e 14 dias póstratamento, segundo método de Roberts e O'Sullivan (1950) modificado (BLOOD et al., 1989; MEDICA; SUKHDEO, 1997).

Os dados obtidos foram expressos nos valores de média, desvio padrão bem como mínimos, máximos e porcentagem através do programa estatístico SPSS versão 23.0 Para distinguir a diferença estatística dos grupos experimentais, dentro e entre os momentos, foi utilizado o teste de Mann-Whitney. Para avaliar a eficácia do produto, foi usado o teste de redução na contagem de ovos por grama de fezes (TRCOF). Tomaram-se como dados, os resultados obtidos do exame de $\mathrm{OPG}$, que se fez as médias aritméticas do número de ovos nas fezes, para cada grupo tratado (OPGt), comparadas com as médias contadas no grupo controle (OPGc) determinada pela fórmula descrita por Coles et al., (1992).

\section{RESULTADOS E DISCUSSÃO}

Nas análises parasitológicas realizadas durante o período experimental e nos vinte animais estudados, foram encontrados ovos do tipo estrongilídeos, Strongyloides e larvas de Cyathostomum tipo A, Strongyloides westeri, Strongylus vulgaris e Posteriostomum sp.

Os animais do grupo tratado apresentaram no dia zero (D0) um OPG em média de 1435 ovos por gramas de fezes (valor mínimo 800 e máximo 3975 ovos por grama de fezes). Através da análise do teste de resistência realizado observou-se que os animais do grupo tratado apresentaram $100 \%$ de sensibilidade a ação da ivermectina a $1 \%$. Esse resultado foi percebido no décimo quarto dia (D14), no qual não houve detecção de ovos no OPG (Tabela $1)$.

No grupo controle, não houve diferença estatística $(p>0,05)$ nos diferentes momentos 
de avaliação, demonstrando que a infecção se manteve inalterada durante todo o estudo. Estes apresentaram em média um OPG de 1936 ovos por gramas de fezes (valor mínimo 800 e máximo 3700 ovos por grama de fezes) (Tabela 1).

Tabela 1 - Valores de média \pm desvio padrão de contagem de ovos por grama de fezes (OPG) nos asininos $(\mathrm{N}=10$ animais por grupo).

\begin{tabular}{|c|c|c|c|c|}
\hline \multirow{3}{*}{ OPG } & \multicolumn{4}{|c|}{ Momentos (dias) } \\
\hline & \multicolumn{2}{|c|}{ Grupo tratado } & \multicolumn{2}{|c|}{ Grupo controle } \\
\hline & D0 & $\mathrm{D}+14$ & D0 & $\mathrm{D}+14$ \\
\hline Média & $1435 \mathrm{~A}$ & OB & 1936A & $1477 \mathrm{~A}$ \\
\hline $\mathrm{DP}$ & 997 & 0 & 1133 & 1021 \\
\hline Máximo & 3975 & 0 & 3700 & 2650 \\
\hline Mínimo & 800 & 0 & 800 & 500 \\
\hline \% Redução & - & 100 & - & - \\
\hline
\end{tabular}

A, B. Médias seguidas de letras maiúsculas diferentes na linha significa diferença estatística ( $\mathrm{p}<0,05$ - Mann-Whitney) entre grupos nos diversos momentos.

D0. Primeiro dia de tratamento com ivermectina a $1 \%$.

D14. Décimo quarto dia após o tratamento com ivermectina a $1 \%$.

Fonte: Própria (2019)

Ao analisar a coprocultura do grupo tratado, considerando-se o dia zero (D0), os ovos cultivados desenvolveram-se em larvas de Cyathostomum tipo A (23\%), Strongyloides westeri (54\%) e de Strongylus vulgaris (23\%). No D14 percebeu-se a redução do potencial de larvas em 100\% nas coproculturas (Tabela 2).

No grupo controle a identificação das larvas infectantes obtidas das coproculturas, realizadas antes e após tratamento, possibilitou identificar larvas L3 com características morfológicas de Cyathostomum tipo A (44\%), de Strongyloides westeri (34\%) e de Strongylus vulgaris (22\%). Contudo, no D14 percebeu-se um aumento de Cyathostomum tipo A que passou aos 64\%, implicando na redução dos demais parasitos anteriormente encontrados, além da recuperação de 3\% de Posteriostomum sp. (Tabela 2).

Tabela 2 - Distribuição (\%) dos helmintos encontrados nas coproculturas realizadas antes (dia zero) e após o tratamento (14 dias) nos asininos ( $\mathrm{N}=10$ animais por grupo).

\begin{tabular}{ccccccc}
\hline \multirow{2}{*}{ Helmintos } & \multicolumn{3}{c}{ Dia 0} & & \multicolumn{3}{c}{ Dia 14 } \\
\cline { 2 - 3 } \cline { 6 - 7 } \cline { 5 - 7 } Controle $\%$ & Tratado $\%$ & & Controle \% & Tratado \% \\
\hline Cyathostomum Tipo A & 44 & 23 & & 64 & 0 \\
Strongyloides westeri & 34 & 54 & & 23 & 0 \\
Strongylus vulgaris & 22 & 23 & & 10 & 0 \\
Posteriostomum sp. & 0 & 0 & & 3 & 0 \\
\hline Total & 100 & 100 & & 100 & 100 \\
\hline
\end{tabular}

Fonte: Própria (2019)

Os resultados obtidos neste trabalho sugerem que os animais estavam com uma elevada infecção por formas adultas de estrongilídeos e Strongyloides sp. Considerando que uma contagem de 800 ovos por gramas de fezes já é um indicativo de infecção com 
necessidade de tratamento anti-helmíntico, o grau de parasitismo dos animais foi, portanto, considerado adequado para a avaliação do presente estudo (CHAGAS et al, 2011). A recuperação de ovos do tipo estrongilídeos em asininos já foi descrita de forma cosmopolita por muitos autores (FERREIRA et al., 2014; ASOKAN et al., 2016; ANTENEH; GETACHEW, 2017 ATTIA; KHALIFA; ATWA, 2018). Da mesma forma é descrito para ovos do tipo Strongyloides (WELLS et al., 1998; LUCENA; FIGHERA; BARROS, 2012).

No entanto, os valores mínimos e máximos de recuperação desses ovos divergem de Carvalho et al. (2007), que em Portugal, avaliando o grau de parasitismo em asininos estabulados, encontraram níveis de OPG de estrongilídeos, que variaram entre 200 e 2.000 ovos por grama de fezes. No presente caso, entre os dois grupos avaliados, os valores mínimos e máximos ficaram 800 e 3975 ovos por grama de fezes, respectivamente. Aproximando-se mais dos achados de Ferreira et al. (2014) que obtiveram valores de 600 a 6.900 OPG.

As larvas de terceiro estádio de Cyathostomum foram relativamente predominantes em ambos os grupos, confirmando a importância crescente dos estrongilídeos da subfamília Cyathostominae nos asininos do Brasil. Segundo Pfister e van Door (2018), a maioria dos estudos classificam os ciatostomíneos como uma entidade única, embora esse grupo englobe muitos morfotipos. Os valores médios do OPG do grupo tratado nos dias D0 e D14 foram significativamente menores $(\mathrm{p}<0,05)$ que os do grupo controle (Tabela 1). Portanto, os resultados do presente estudo com asininos naturalmente infectados demonstraram a eficácia da ivermectina, avaliada pelo teste de redução da contagem de ovos nas fezes, conforme relatado por outros autores (MADEIRA DE CARVALHO et al, 2007; DEDAR et al., 2011).

\section{CONCLUSÕES}

Nas análises parasitológicas realizadas durante o período experimental e nos vinte animais estudados, foram encontrados ovos do tipo estrongilídeos e Strongyloides identificouse larvas do tipo Cyathostomum tipo A, Strongyloides westeri, Strongylus vulgaris e Posteriostomum sp.

Os resultados do presente estudo com asininos naturalmente infectados demonstraram a eficácia de $100 \%$ da ivermectina sobre os nematoides gastrintestinais de Equus asinus.

\section{REFERENCIAS}

ASOKAN, S. et al. Study of endoparasitic infection in donkeys - a report. International [143] 
Journal Of Science, Environment Issn 2278-3687 (o) And Technology, v. 5, n. 6, p. 45454549, 2016.

ATTIA, M. M.; KHALIFA, M. M.; ATWA, M. Th..The prevalence and intensity of external and internal parasites in working donkeys (Equus asinus) in Egypt. Veterinary World, v. 11, n. 9, p. 1298-1306, 2018.

CANEVER, R.J. Diagnóstico da resistência anti-helmíntica em cíatostomineos de equinos por meio de testes in vivo e in vitro. 2012. 99p. Dissertação (Mestrado em Ciências Veterinárias) - Universidade Federal do Paraná, Curitiba, 2012.

CHAGAS, A. C. S.; NICIURA, S. C. M.; MOLENTO, M. B. Manual Prático: metodologias de diagnóstico da resistência e de detecção de substâncias ativas em parasitas ruminantes. Brasília: Embrapa Informação Tecnológica, 2011, 153 p.

DEDAR, R. K. et al. Therapeutic evaluation of ivermectin against Endoparasites of donkey. Veterinary Practitioner, v. 12, n. 1, p. 86-87, 2011.

FERREIRA, G. M. S. et al. Parasitismo gastrintestinal e hematologia em equinos e asininos da mesorregião da aglomeração urbana, São Luiz, Maranhão. Archives Of Veterinary Science, v. 19, n. 2, p. 22-30, 2014.

FORTES, F. S.; MOLENTO, M. B. Resistência anti-helmíntica em nematoides gastrintestinais de pequenos ruminantes: avanços e limitações para seu diagnóstico. Pesquisa Veterinária Brasileira, v. 33, n. 12, p. 1391-1402, 2013.

GOKBULUT, C.; MCKELLAR, Q. A.. Anthelmintic drugs used in equine species. Veterinary Parasitology, v. 261, p. 27-52, 2018.

GROSENBAUGH, D. A.; REINEMEYER, C. R.; FIGUEIREDO, M. D.. Pharmacology and therapeutics in donkeys. Equine Veterinary Education, v. 23, n. 10, p. 523-530, 2011.

LUCENA, R. B.; FIGHERA, R. A.; BARROS, C. S.L.. Mortalidade em potros associada ao parasitismo por Strongyloides westeri. Pesquisa Veterinária Brasileira, v. 32, n. 5, p. 401404, 2012.

MARQUES, D.D.; NÓBREGA NETO, P.I.; CARVAL, K. S. Emprego da cola de cianoacrilato em feridas cutâneas de asininos. Ciência Animal Brasileira, v. 14, n. 1, p. 7480, 2013.

MEDICA, D.L.; SUKHDEO, M.V.K. Role of lipids in the transmission of the infective stage (L3) of Strongylus vulgaris (Namatoda: Strongyloidea). Journal of Parasitology, v. 83, n. 5, p. 775-779, 1997.

SILVA, P. C. A. et al. Taxa de recuperação e características morfológicas de embriões muares (Equus caballus $x$ Equus asinus). Pesquisa Veterinária Brasileira, v. 38, n. 7, p. 1453-1457, 2018. 


\section{EFEITO DA ASSOCIAÇÃO DO FATOR DE CRESCIMENTO EPIDERMAL COM CISTEAMINA DURANTE A MATURAÇÃO IN VITRO DE OÓCITOS BOVINOS}

\section{EFECTO DE LA ASOCIACIÓN DEL FACTOR DE CRECIMIENTO EPIDÉRMICO CON CISTEAMINA DURANTE LA MADURACIÓN IN VITRO DE OVÓCITOS BOVINOS}

\section{EFFECT OF EPIDERMAL GROWTH FACTOR ASSOCIATION WITH CYSTEAMINE DURING IN VITRO MATURATION OF BOVINE OOCYTES}

Antonia Rafaela da Silva Oliveira ${ }^{1}$; Maria Valéria de Oliveira Santos ${ }^{2}$; Lhara Ricarliany Medeiros de Oliveira ${ }^{3}$; Alexsandra Fernandes Pereira ${ }^{4}$

DOI: $\underline{\text { https://doi.org/10.31692/978-65-991061-4-9.145-150 }}$

\section{INTRODUÇÃO}

As biotécnicas reprodutivas como a produção in vitro de embriões (PIVE) têm sido amplamente empregadas para melhorar a produtividade de bovinos de grande interesse econômico. Contudo, a eficiência da PIVE ainda é variável e alguns ajustes podem ser realizados nas suas etapas para alcançar melhores resultados. Assim, na etapa de maturação in vitro, a suplementação do meio com substâncias capazes de promover a maturação e garantir a competência oocitária, como a cisteamina (CIS) e o fator de crescimento epidermal (EGF), tem sido uma estratégia interessante (OYAMADA et al., 2004; SOVERNIGO et al., 2017). Assim, o objetivo foi avaliar o efeito de CIS e do EGF em combinação durante a maturação de oócitos bovinos. Para tanto, oócitos foram maturados por $24 \mathrm{~h}$ em meio contendo CIS, EGF e a combinação de CIS e EGF. Após esse período, oócitos foram avaliados quanto à expansão e viabilidade das células do cumulus, maturação nuclear oocitária e níveis de espécies reativas de oxigênio em oócitos maturados. Finalmente, os resultados obtidos mostraram que a combinação CIS e EGF não influencia na maturação nuclear de oócitos bovinos; contudo, a cisteamina é importante para a viabilidade das células do cumulus.

\section{FUNDAMENTAÇÃO TEÓRICA}

A bovinocultura para produção de carne e leite tem passado por um constante processo de modernização diretamente relacionado aos avanços tecnológicos associados às biotécnicas

\footnotetext{
${ }^{1}$ Bolsista do Programa de Educação Tutorial (PET) - Zootecnia, Universidade Federal Rural do Semi-Árido (UFERSA), rafacosta2@live.com

${ }^{2}$ Doutoranda em Ciência Animal, UFERSA, valeriasnts07@gmail.com

${ }^{3}$ Mestranda em Ciência Animal, UFERSA, lharagirs@ hotmail.com

${ }^{4}$ Doutora em Ciências Veterinárias, Prof. UFERSA, alexsandra.pereira@ufersa.edu.br
} 
reprodutivas (SINGH et al., 2019). Nesse contexto, a produção in vitro de embriões (PIVE) tem sido amplamente empregada, permitindo a obtenção de um maior número de crias por fêmea, seleção de doadores de gametas de alto valor genético, aproveitamento genético de indivíduos jovens e senis e de animais com dificuldade reprodutiva adquirida por questões filogenéticas (RUMPF, 2007).

A PIVE pode ser dividida em algumas etapas principais, iniciando com a maturação in vitro (MIV) de oócitos, fecundação in vitro (FIV) e desenvolvimento embrionário in vitro (DIV). Assim, sendo a MIV a primeira etapa de cultivo e o momento no qual os oócitos adquirem competência para o desenvolvimento embrionário posterior, faz-se necessário aperfeiçoar as condições de cultivo para aumentar a taxa de maturação e a qualidade do oócito maturado.

Estudos mostraram que oócitos maturados in vivo são mais competentes que oócitos maturados in vitro e, provavelmente, isso está relacionado à maturação citoplasmática e expressão gênica (DIELEMAN et al., 2002; SIRARD et al., 2007). Nesse contexto, algumas suplementações têm sido associadas a melhorias na competência oocitária, como o fator de crescimento epidermal (EGF) e a cisteamina (CIS). O EGF promove a retomada meiótica do oócito e a expansão da matriz das células cumulus, melhorando a competência de desenvolvimento embrionário (WATSON et al., 2000; OYAMADA et al., 2004). Já a cisteamina atua como antioxidante e estimula a produção de glutationa que está relacionada à competência do oócito (SOVERNIGO et al., 2017). Assim, acredita-se que a associação desses dois suplementos no meio de MIV poderia melhorar a taxa de maturação e qualidade do oócito bovino. Portanto, o objetivo foi avaliar o efeito da associação de EGF e CIS durante a MIV sobre a expansão e viabilidade das células do cumulus, bem como a maturação nuclear oocitária e níveis de espécies reativas de oxigênio em oócitos.

\section{METODOLOGIA}

Os ovários foram recuperados de fêmeas bovinas oriundas de um abatedouro local e transportados ao laboratório em solução salina aquecida $\left(35-37^{\circ} \mathrm{C} ; \mathrm{NaCl} 0,9 \%\right)$. No laboratório, os folículos com diâmetro de 2-8 mm foram aspirados usando agulha de $21 \mathrm{G} \mathrm{e}$ seringa de $5 \mathrm{~mL}$ contendo meio de colheita e manipulação (MCM: TCM199 suplementado com 2,2 g/L de bicarbonato sódio, $25 \mathrm{mM}$ de HEPES, 10\% de SFB, 0,2 $\mathrm{mM}$ de piruvato de sódio e $1 \%$ de solução de antibióticos e antimicóticos).

Em seguida, os oócitos recuperados foram classificados e somente aqueles com mais de uma camada de células do cumulus e citoplasma homogêneo foram utilizados para a MIV. 
Portanto, para este estudo experimental de natureza quantitativa, oócitos imaturos viáveis foram divididos em três grupos experimentais: (i) $100 \mu \mathrm{M}$ de cisteamina, (ii) $10 \mathrm{ng} / \mathrm{mL}$ de EGF; e (iii) $100 \mu \mathrm{M}$ de cisteamina combinado com $10 \mathrm{ng} / \mathrm{mL}$ de EGF. Para a MIV, os oócitos foram incubados em MCM suplementado com $20 \mu \mathrm{g} / \mathrm{mL}$ de hormônio folículo estimulante (FSH) associado ao hormônio luteinizante (Pluset®, Hertape Calier, Juatuba, MG) e cisteamina e/ou EGF de acordo com o grupo experimental. A incubação foi realizada em gotas $(100 \mu \mathrm{L})$ cobertas de óleo mineral durante $24 \mathrm{~h}$ a $38,5^{\circ} \mathrm{C}$ e $5 \%$ de $\mathrm{CO}_{2}$.

Para avaliação das células do cumulus após a MIV, os oócitos com estas células expandidas foram considerados maturados sob estereomicroscópio. Para a viabilidade celular, as células do cumulus foram removidas por pipetagens sucessivas em meio com $0,1 \%$ de hialuronidase por $2 \mathrm{~min}$. A suspensão celular resultante foi corada com azul de tripan $(0,2 \%) \mathrm{e}$ as células viáveis (não coradas) e não viáveis (coradas em azul) foram contadas nos quatro quadrantes externos utilizando câmara de Neubauer.

Para avaliação da maturação nuclear, os oócitos desnudos foram observados sob estereomicroscópio para verificação do primeiro corpúsculo polar que indicou a maturação. Em seguida, os oócitos foram fixados em paraformaldeído a 4\% em PBS por 30 min, lavados em PBS/BSA 0,4\% e marcados com Hoechst $33342(10 \mu \mathrm{g} / \mathrm{mL})$ por $15 \mathrm{~min}$. Os oócitos foram transferidos para lâminas de vidro e visualizados por microscopia de fluorescência onde somente oócitos apresentando núcleo na metáfase II (MII) e primeiro corpúsculo polar foram considerados maturados.

Além disso, os níveis de espécies reativas de oxigênio (EROs) foram quantificados utilizando o diacetato de 2',7'-diclorodihidrofluoresceína ( $\left.\mathrm{H}_{2} \mathrm{DCFDA}\right)$. Para tanto, os oócitos desnudados foram incubados com $5 \mu \mathrm{M}$ de $\mathrm{H}_{2}$ DCFDA por 30 min, colocados em lâminas de vidro e fotografados sob microscópio de fluorescência para quantificar a intensidade do sinal de fluorescência (pixels) utilizando o software ImageJ.

Para análise estatística, foram consideradas quatro repetições e os resultados foram expressos como média \pm erro padrão sendo analisados no StatView 5.0 (SAS Institute Inc., Cary, NC, EUA) considerando $\mathrm{P}<0,05$. A normalidade foi verificada com o teste de ShapiroWilk e a homocedasticidade foi verificada com o teste de Levene. Os níveis de EROs foram transformados em arco seno e analisados pela análise de variância (ANOVA), seguida do teste de Tukey. Todos demais dados foram comparados com um teste qui-quadrado.

\section{RESULTADOS E DISCUSSÃO}

Após quatro repetições, um total de 84 ovários bovinos foi obtido, resultando em 285 
oócitos viáveis, perfazendo uma média de 3,4 oócitos viáveis por ovário. Quanto à avaliação das células do cumulus (Tabela 1), inicialmente não foram observadas diferenças quanto às taxas de expansão dessas células, que variou de 68 a 73\% entre os tratamentos. Já em relação à viabilidade, os grupos CIS e EGF/CIS mostraram resultados superiores comparados ao grupo suplementado apenas com EGF $(\mathrm{P}<0,05)$. Esse resultado sugere que a presença de um antioxidante no meio (CIS) é essencial para manutenção da integridade celular, especialmente sabendo que as células do cumulus estão mais expostas aos processos de manipulação in vitro (DEUS et al., 2018). Dessa forma, estas células podem ser mais susceptíveis aos danos causados pelo estresse oxidativo na membrana plasmática e sua viabilidade contribui para a manutenção da qualidade oocitária (SANTOS et al., 2019). As células do cumulus atuam como proteção e como meio de comunicação do oócito com o meio de cultivo, permitindo a passagem de nutrientes e hormônios importantes para a adequada maturação (CALDER et al., 2003).

Tabela 1: Efeito da associação do EGF com cisteamina durante a MIV bovina.

\begin{tabular}{|c|c|c|c|c|}
\hline \multirow[t]{2}{*}{ Grupo } & \multicolumn{2}{|c|}{ Avaliação das células do cumulus } & \multicolumn{2}{|l|}{ Maturação nuclear } \\
\hline & Expansão, \% (n) & Viabilidade, $\%\left(n^{*}\right)$ & $1 \mathrm{~PB}, \%(n)$ & MII, \% (n) \\
\hline CIS & $68,0 \pm 11,0(51 / 75)^{a}$ & $68,6 \pm 3,2(1490 / 2172)^{\mathrm{a}}$ & $82,5 \pm 7,4(47 / 57)^{\mathrm{a}}$ & $83,3 \pm 4,1(20 / 24)^{\mathrm{a}}$ \\
\hline EGF & $70,0 \pm 10,8(56 / 80)^{\mathrm{a}}$ & $62,0 \pm 1,5(1536 / 2479)^{b}$ & $73,3 \pm 8,6(44 / 60)^{\mathrm{ab}}$ & $78,3 \pm 4,2(18 / 23)^{\mathrm{a}}$ \\
\hline EGF/CIS & $73,0 \pm 12,9(54 / 74)^{\mathrm{a}}$ & $66,4 \pm 2,3(1569 / 2364)^{\mathrm{a}}$ & $61,4 \pm 13,6(35 / 57)^{\mathrm{b}}$ & $60,9 \pm 9,1(14 / 23)^{\mathrm{a}}$ \\
\hline
\end{tabular}

a,b: letras diferentes na mesma coluna indicam diferença entre os grupos $(\mathrm{P}<0,05) .{ }^{*}$ Células do cumulus.

A maturação nuclear é o principal indicativo de que o oócito está pronto para a fecundação. No presente trabalho, a presença do primeiro crepúsculo polar foi maior no grupo CIS em comparação ao EGF/CIS; enquanto o grupo suplementado apenas com EGF foi semelhante aos demais meios (Tabela 1). Essa avaliação da maturação, apesar de ser muito usada como método menos invasivo, ainda é considerada subjetiva especialmente devido à característica esférica do oócito. Por essa razão, é sempre interessante associar a avaliação subjetiva a avaliações mais específicas, como no presente trabalho que utilizamos a marcação fluorescente para avaliação mais precisa do estágio nuclear (Figura 1A). Nesse caso, não foi observada diferença entre os tratamentos quanto ao estágio nuclear de metáfase II (P > 0,05). Isso mostra que o EGF e a cisteamina podem não influenciar diretamente na maturação nuclear, mas sim na competência de desenvolvimento embrionário, sendo necessários mais estudos para esta avaliação.

Finalmente, com relação aos níveis de EROs (Figura 1E) também não houve diferença entre as suplementações adicionadas ao meio de maturação (Figura 1B, C, D). Sovernigo et al. (2017) também não observaram efeito da cisteamina sobre os níveis de EROs e maturação, 
porém o desenvolvimento embrionário foi melhor na presença desse antioxidante em comparação ao meio sem a presença do mesmo.

Figura 1: Oócitos bovinos avaliados quanto à maturação nuclear (A: oócito em metáfase II) e níveis de espécies reativas de oxigênio (B,C, D e E).

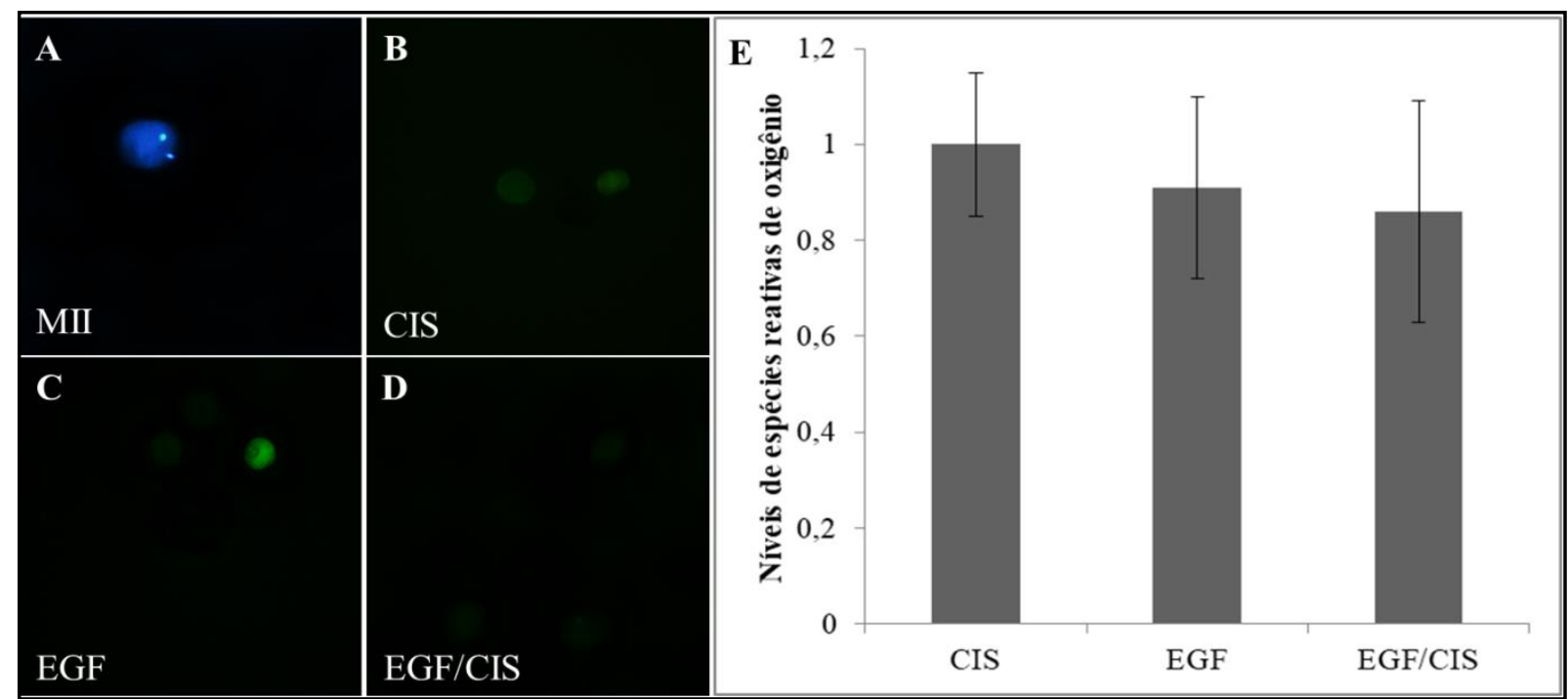

Fonte: Própria (2019).

\section{CONCLUSÕES}

A associação do EGF com a cisteamina não influencia a maturação oocitária de acordo com a avaliação do estágio nuclear. Contudo, a presença de cisteamina é essencial para a manutenção da viabilidade das células do cumulus e, consequentemente, da qualidade oocitária. Acredita-se que estudos avaliado o desenvolvimento embrionário desses oócitos após a MIV podem contribuir para uma melhor elucidação do papel do EGF associado à cisteamina.

\section{REFERÊNCIAS}

CALDER, M.D.; CAVENEY, A.N.; SMITH, L.C.; WATSON, A.J. Responsiveness of bovine cumulus oocyte-complexes (COC) to porcine and recombinant human FSH, and the effect of COC quality on gonadotropin receptor and $\mathrm{Cx} 43$ marker gene mRNAs during maturation in vitro. Reproductive Biology and Endocrinology, v. 1, p. 14-19, 2003.

DEUS, A.R.S.; SILVA, M.B.; SANTOS, M.V.O.; QUEIROZ NETA L.B.; BORGES, A.A.; PEREIRA, A.F. Influence of storage media during transport of bovine ovaries at $4^{\circ} \mathrm{C}$ on oocyte recovery and quality. ARS Veterinária, v. 33, p. 44-50, 2018.

DIELEMAN, S.J.; HENDRIKSEN, P.J.M.; VIUF, D.; THOMSEN, P.D.; HYTTEL, P.; KNIJN, H.M.; WRENZYCK, C.; KRUIP, T.A.M.; NIEMANN, H.; GADELLA, B.M.; BEVERS, M.M.; VOS, P.L.A.M. Effects of in vivo prematuration and in vivo final maturation on developmental capacity and quality of pre-implantation embryos. Theriogenology, v. 57, p. 5-20, 2002. 
OYAMADA, T; IWAYAMA, H; FUKUI, Y. Additional effect of epidermal growth factor during in vitro maturation for individual bovine oocytes using a chemically defined medium. Zygote, v. 12, p. 143-150, 2004.

RUMPF, R. Avanços metodológicos na produção in vitro de embriões. Revista Brasileira de Zootecnia, v. 36, p. 229-233, 2007.

SINGH, B.; MAL, G.; GAUTAM, S.K.; MUKESH, M. Reproduction biotechnology in cattle. Advances in Animal Biotechnology, p. 155-167, 2019.

SIRARD, M.A.; DESROSIER, S.; ASSIDI, M. In vivo and in vitro effects of FSH on oocyte maturation and developmental competence. Theriogenology, v. 68S, p. 71-76, 2007.

SOVERNIGO, T.C.; ADONA, P.R.; MONZANI, P.S.; GUEMRA, S.; BARROS, F.D.A.; LOPES, F.G.; LEAL, C.L.V. Effects of supplementation of medium with different antioxidants during in vitro maturation of bovine oocytes on subsequent embryo production. Reproduction in Domestic Animal, v. 52, p. 561-569, 2017.

WATSON, A.J.; SOUSA, P.; CAVENEY, A.; BARCROFT, L.C.; NATALE, D.; URQUHART, J.; WESTHUSIN, M.E. Impact of bovine oocyte maturation media on oocyte transcript levels, blastocyst development, cell number, and apoptosis. Biology of Reproduction, v. 62, p. 355-364, 2000. 


\title{
ANÁLISE ESPAÇO-TEMPORAL DE FOCOS DE CALOR NA ÁREA DE PROTEÇÃO AMBIENTAL DO MARAJÓ
}

\section{ANÁLISIS TEMPORAL DE ENFOQUE DE CALOR EN EL ÁREA DE PROTECCIÓN AMBIENTAL DE MARAJÓ}

\section{TEMPORAL HEAT FOCUS ANALYSIS AT MARAJÓ ENVIRONMENTAL PROTECTION AREA}

\begin{abstract}
Heloise de Sousa Castro ${ }^{1}$; Eduarda Emilia Magalhães Cristóvão ${ }^{2}$; Ingrid Leão Campos ${ }^{3}$; Wenderson Holanda de Oliveira ${ }^{4}$; Breno Pinto Rayol ${ }^{5}$
\end{abstract}

DOI: https://doi.org/10.31692/978-65-991061-4-9.151-156

\section{INTRODUÇÃO}

A descoberta do fogo nos primórdios da humanidade mudou o curso, forma de interação e sobrevivência da nossa espécie, principalmente ao se falar de agricultura. Sinônimo de praticidade para limpeza de área, fertilidade gratuita e baixo custo de aplicação é utilizado amplamente por produtores de grande ou pequeno porte. Destaca-se a estreita relação da silvicultura com o uso do fogo, enfatizando que mesmo adotando práticas de controle é comum ocorrer descontrole na queima o que pode acarretar a incêndios florestais de grande proporção (SOARES \& BATISTA in apud, 2007).

Assim, há uma linha tênue entre vantagens e desvantagens da utilização do fogo no campo. O novo código florestal (2012), permite o uso desta técnica em determinadas situações, como em áreas de práticas agropastoris e florestais mediante um planejamento específico e aprovação do Sistema Nacional do Meio Ambiente (SISNAMA). A análise prévia de acordo com o bioma, biodiversidade e atividades ocorridas no espaço onde se deseja fazer uso do fogo devem ser levadas em consideração para evitar acidentes e imprevistos. Nesse contexto, aplica-se o estudo de análise espaço-temporal que é ferramenta de grande suporte para aplicação de variadas técnicas na agricultura e em outras áreas.

Dentre as problemáticas relevantes em se tratando de monitoramento, prevenção e proteção florestal e a extensão do território nacional que dificulta ações mais incisivas. Dos biomas presentes que se destacam em nosso país está a Amazônia, sua vastidão a torna vulnerável ultrapassando fronteiras nacionais que podem dificultar as ações de combate (LIMA, 2018). Portanto, objetivou-se analisar as possíveis causas da ocorrência de focos de

\footnotetext{
${ }^{1}$ Engenharia florestal, Universidade Federal Rural da Amazônia, heloise_castro14@hotmail.com

${ }^{2}$ Engenharia florestal, Universidade Federal Rural da Amazônia, eduardamaga30@ gmail.com

${ }^{3}$ Engenharia Florestal, Universidade Federal Rural da Amazônia, milenaa.santoss@ outlook.com

${ }^{4}$ Engenharia Florestal, Universidade Federal Rural da Amazônia, whowenderson@ gmail.com

${ }^{5}$ Professor adjunto, Universidade Federal Rural da Amazônia, bprayol@yahoo.com.br
} 
calor na área de proteção ambiental do Marajó através do estudo espaço-temporal.

\section{FUNDAMENTAÇÃO TEÓRICA}

Segundo a Secretaria de Meio Ambiente do Pará (2008), o Estado é de grande expressividade em se tratando de queimadas e focos de calor tendo em vista sua extensão e o pouco serviço florestal, se relacionarmos dimensão territorial e número de prestadores de serviço. Assim, áreas de proteção ambiental (APA), como a do Marajó, sofrem com índices exacerbados de queimadas e focos de calor, estes são caracterizados como uma das principais ameaças à manutenção de flora, fauna e economia local. Portanto, as queimadas podem ser objetos principais os quais coordenam a dinâmica social, econômica e ambiental ao entorno de onde ocorrem que compreende na Amazônia a agropecuária e atividades relacionadas (MORELLO, 2017). Como ferramenta de auxílio para esses casos está o estudo de análise espaço-temporal, com o qual é possível verificar as mudanças ocorridas dentro dos limites estabelecidos tentando compreender o modo como as relações acontecem dentro de determinada unidade societária levando em consideração aspectos sociais e culturais desses povos. Assim, torna-se imprescindível para tomadas de decisão e melhoria nas medidas estratégicas escolhidas para cada localidade (TOMZHINSKI, 2011).

\section{METODOLOGIA}

A APA do Marajó está localizada na mesorregião do Marajó que representa umas das mais ricas regiões do país em questão de recursos hídricos e biológicos, tendo destaque por ser formada por um conjunto de ilhas, que ao todo, representa a maior ilha flúvio marítima do mundo. Abrange uma área de 5.904.322ha, compreendendo 12 municípios e sendo considerada a maior Unidade de Conservação na costa norte do Brasil. A pluviosidade na mesorregião varia de $3100 \mathrm{~mm}$ na estação de Soure, na costa leste da ilha à 2500mm na região central, representada pelas estações de Cachoeira do Arari e Santa Cruz. O clima da região é caracterizado por dois períodos: a estação menos chuvosa, compreendida entre os meses de junho a novembro, e a estação mais chuvosa, com chuvas persistentes registradas todos os dias no período de dezembro a maio (LIMA et. al. 2004).

A quantificação de focos de calor foi realizada a partir de dados fornecidos pelo Instituto Nacional de Pesquisas Espaciais (INPE) através do Programa de Queimadas e estimadas utilizando sistema de informações geográficas, o software ArcMap 10.5. Foi considerada a divisão do ano em dois períodos (menos chuvoso e mais chuvoso), proposta por Lima et. al. (2004), a fim de verificar a relação entre quantidades de focos de calor e 
pluviosidade na região.

Objetivando analisar possíveis causas, utilizou-se dados de uso e ocupação do solo disponibilizados pelo programa TerraClass, que qualifica o desflorestamento na Amazônia Legal Brasileira, obtidos do mapeamento no ano de 2014 a partir das órbitas-ponto 223/60, 223/61, 224/60, 224/61, 225/60 e 225/61 do satélite Landsat 8 (sensor OLI), no Sistema de Projeção Lat/Long e Sistema Geodésico de Referência $S A D$ 69. Além disso, informações sobre a pluviosidade da região foram obtidos a partir do Instituto Nacional de Meteorologia (INMET) através do Banco de Dados Meteorológicos para Ensino e Pesquisa da estação de Soure.

\section{RESULTADOS E DISCUSSÃO}

Ao analisar os mapas de distribuição de focos de calor (Figura 1), pode-se verificar que estão distribuídos em maior parte em faixa litorânea, banhado pelas águas salgadas do Oceano Atlântico ao norte, pelas águas fluviais da foz do Rio Pará e Tocantins, ao sul. Em se tratando de uso e cobertura de solo da região do Arquipélago do Marajó, de acordo com os dados disponibilizados pelo programa TerraClass, os focos abrangem diferentes tipos de ambientes e estão concentrados principalmente em regiões de vegetação secundária com mosaico de ocupações e áreas de não florestas, todavia, abrange áreas de florestas nativas.

Figura 1: Mapa de distribuição de focos de calor para a região de estudo entre os anos de 2014 e 2018.
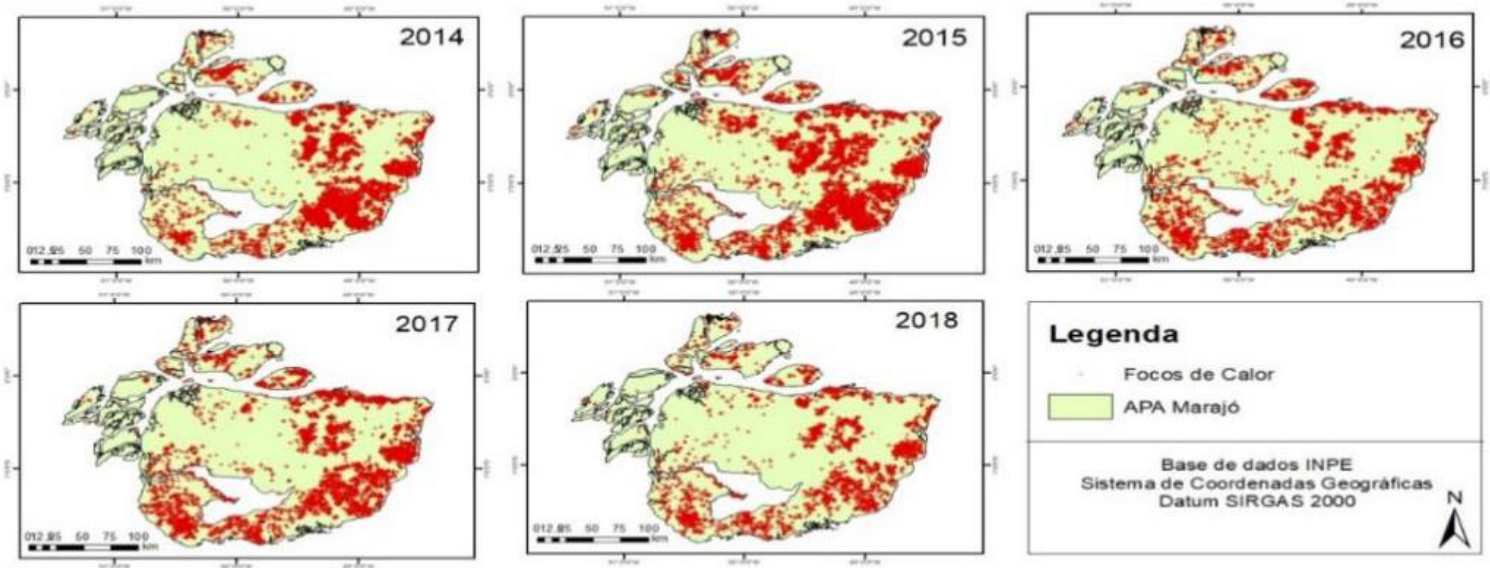

Fonte: Própria (2019)

Quanto a relação entre pluviosidade e quantidade de focos, nota-se que durante a estação mais chuvosa, culturalmente descrita como inverno amazônico, que compreende o período de dezembro a maio, é possível notar a redução no número de focos de calor, representando em média de $13,3 \%$ em relação ao total anual para a Unidade de Conservação. Todavia, apesar de dezembro ser considerado para efeito de estudo como parte 
da estação mais chuvosa, durante esse mês a média de focos de calor anual é de $968 \mathrm{~mm}$, cerca de $82,5 \%$ em relação ao total da estação, superior, por exemplo, a meses como agosto, que possui uma média anual de 343,4 focos de calor por ano (Figura 2).

FIGURA 2: Quantidade de focos de calor entre os anos de 2014 e 2018.

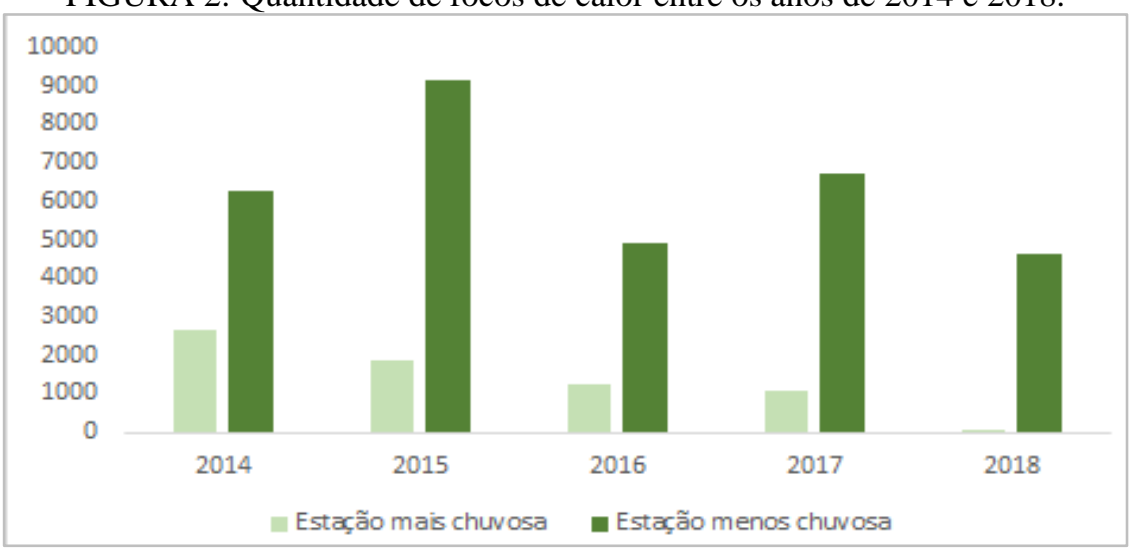

Fonte: Própria (2019).

De acordo com a Secretaria de Estado de Meio Ambiente e Sustentabilidade (SEMAS), houveram superávits pluviométricos registrados em maio de 2018, principalmente sobre áreas do Nordeste, Marajó, Região Metropolitana de Belém (RMB) e pequena parte do Sudoeste paraense. Esses superávits refletem na quantidade de focos de calor, uma vez que 2018 correspondeu ao ano com menor taxa de incidência. Segundo Homma et. al. (1992), há uma estreita relação entre os focos de calor e as formas de cultivo existentes na região. $\mathrm{O}$ modo de preparo do solo na região amazônica utiliza o processo de queima da vegetação como pré-plantio, isto garante uma fertilização gratuita, principalmente de potássio, se relacionada a outras medidas de cultivo. Deste modo, a expansão das fronteiras agrícolas é fator de extrema relevância nesta discussão.

O desenvolvimento na região aliado a baixa escolaridade e acesso a informação do homem rural amazônico associado a técnicas hereditárias com resultado a curto prazo, além de menos oneroso, formam o cenário no qual a queima é prática corriqueira. Quando o tamanho dos lotes não é expressivo, de modo que o que for produzido não supra as necessidades dos alocados, dá-se o esgotamento das áreas de florestas densas e, consequentemente, as capoeiras que já foram derrubadas pelo menos por 4 ou 5 vezes começam a apresentar problemas como a queda de produtividade das culturas (HOMMA, 1992).

Na Amazônia, em termos culturais, o aumento no número de dependentes por família exige o desmatamento de áreas maiores na busca de uma produção que garanta o nível mínimo de subsistência. Em se tratando de êxodo rural, áreas improdutivas podem ser tratadas 
como uma das principais causas deste acontecimento atrelada a isto está a falta de mão de obra no campo, o que pode justificar o uso de técnicas de mais fácil empregabilidade nos cultivos (PRATES, 2011).

\section{CONCLUSÕES}

É possível observar a existência de uma forte relação entre os focos de calor e pluviosidade na região da APA Marajó, além disso, a distribuição desses focos ocorre principalmente em regiões de não floresta e de vegetação secundária próximos a mosaicos de ocupação, entretanto, atinge também áreas de florestas estabelecidas. Vale ressaltar que a inserção de políticas públicas que possam, de fato, contribuir com o desenvolvimento das áreas rurais são de extrema importância nesse contexto.

\section{REFERÊNCIAS}

BRASIL. Plano de desenvolvimento territorial sustentável do arquipélago do Marajó. Casa Civil. 2006. Plano de desenvolvimento territorial sustentável do arquipélago do Marajó. Disponível em: <http://www.casacivil.gov.br/.arquivos/marajo.pdf> acesso em: jun. 2019.

FEARNSIDE, Philip M. Fogo e emissão de gases de efeito estufa dos ecossistemas florestais da Amazônia brasileira. Estudos avançados. v.16 n(44). 2002. Disponível em: <http://www.scielo.br/pdf/ea/v16n44/v16n44a07.pdf> acesso em: jun. 2019.

GONÇALVES, Karen dos Santos. CASTRO, Hermano Albuquerque de. HACON, Sandra de Souza. As queimadas na região amazônica e o adoecimento respiratório. Ciência \& Saúde Coletiva, 17(6):1523-1532, 2012. Disponível em: <http://www.scielo.br/pdf/csc/v17n6/v17n6a16.pdf> acesso em: jun. 2019.

HOMMA, Alfredo Kingo Oyama. WALKER, Robert T. SCALENA, Fredcrick N. CONTO, Amaldo José de. CARVALHO, Rui de Amorim. ROCHA; Antonio Carlos Paula Neves da. FERREIRA, Célio Armando Palheta. SANTOS, Antônio Itayguara Moreira dos. A dinâmica dos desmatamentos e das queimadas na Amazônia: uma análise microeconômica. Recursos naturais, ambiente e desenvolvimento sustentável. 1992. Disponível em: <https://ainfo.cnptia.embrapa.br/digital/bitstream/item/125066/1/DINAMICA-DOSDESMATAMENTOS.pdf> acesso em: jun.2019.

LIMA, A. M.M. OLIVEIRA, L.L. FONTINHAS, R.L. LIMA, J.S. Ilha do Marajó: histórica, hidroclimatologia, bacias hidrográficas e propostas de gestão. Holos environment. v.5. n.1, 2005- P. 65. ISSN: 1519-8634. Disponível em: <http://Users/Aluno\%2032.gnutecaHP/Desktop/331-1464-1-PB.pdf> acesso em: jun. 2019.

LIMA, Isabella Caixeta. Monitoramento dos focos de queimadas nos biomas Amazônia e Cerrado nas estações seca e chuvosa de 2017. Uberlândia-MG.2018. Trabalho de conclusão de curso. Disponível em: <https://repositorio.ufu.br/bitstream/123456789/22348/1/MonitoramentoFocosQueimadas.pdf 
> Acesso em: maio 2019.

Miranda, H. S.; Saito, C. H. \& Dias, B. F. S. 1996. Impactos de Queimadas em Áreas de Cerrado e Restinga. Departamento de Ecologia, Universidade de Brasília, 187p. Disponível em:

<http://www.pgecl.unb.br/images/sampledata/arquivos/teses/2000a2010/2007/Beatriz\%20Cas tro\%20Neves.pdf $>$. Acesso em: ago. 2019.

MORELLO, Thiago Fonseca. RAMOS, Rossano. STEIL, Lara. PARRY, Luke. BARLOW, Jos. MARKUSSON, Nils. FERREIRA, Amanda. Queimadas e incêndios florestais na Amazônia brasileira: por que as políticas públicas tem efeito limitado? Ambiente \& Sociedade. São Paulo. v. XX, n. 4 n p. 19-40 n out.-dez. 2017. Disponível em: <http://www.scielo.br/pdf/asoc/v20n4/pt_1809-4422-asoc-20-04-00019.pdf> Acesso em: jun. 2019.

NOVO código florestal. Curitiba: Sistema FAEP, 2012. Disponível em:<http://codigoflorestal.sistemafaep.org.br/wp-content/uploads/2012/11/novo-codigoflorestal.pdf>. Acesso em: ago. 2019.

PRATES, Rodolfo Coelho. BACHA, Carlos José Caetano. Os processos de desenvolvimento e desmatamento da Amazônia. Economia e Sociedade. Campinas. v. 20. n. 3 (43), p. 601-636, dez. 2011. Disponível em: <http://www.scielo.br/pdf/ecos/v20n3/a06v20n3.pdf> acesso em: jun. 2019.

Secretaria de Estado de Meio Ambiente. Área de preservação Arquipélago do Marajó. Disponível em: <https://uc.socioambiental.org/arp/1362> acesso em: jun. 2019.

SOARES, R. V.; BATISTA, A. C. Incêndios florestais: controle, efeitos e uso do fogo. Curitiba, 2007. 264p. In apud: SANTOS, Juliana Andressa Costa dos. PAULETTO, Daniella. MOTA, Cléo Gomes da. SILVA, Saulo Ubiratan Pinheiro da. NASCIMENTO, Gabriela de Cássia Santos do. GOMES, Vanessa de Sousa. Uso do fogo na agricultura: medidas preventivas e queima controlada no projeto de desenvolvimento sustentável Terra Nossa, Novo Progresso, Pará. Disponível em:<file:///C:/Users/ALUNO10/Downloads/5211-20750-1PB\%20(1).pdf>.Acesso em: ago. 2019.

TOMZHINSKI, Gustavo Wanderley. COURA, Pedro Henrique Ferreira. FERNANDES, Manoel do Couto. Avaliação da Detecção de Focos de Calor por Sensoriamento Remoto para o Parque Nacional do Itatiaia. Número Temático: Ecologia e Manejo de Fogo em Áreas Protegidas. Biodiversidade Brasileira (2011) Ano I, No 2, 201-211. Disponível em:< file:///C:/Users/User/Downloads/140-510-1-PB.pdf>. Acesso em: ago. 2019. 


\title{
PRODUTIVIDADE E ACÚMULO DE N EM CANA-DE-AÇÚCAR SOB SISTEMAS DE COLHEITA SEM QUEIMA
}

\section{PRODUCTIVIDAD Y ACUMULACIÓN DE NITRÓGENO ENSISTEMA DE COSECHA DE CAÑA DE AZÚCAR BAJO QUEMA}

\section{PRODUCTIVITY AND N ACCUMULATION IN SUGAR CANE UNDER BURNING HARVESTING SYSTEM}

\author{
Victor Vinicius Silva Barros ${ }^{1}$; José Mauro de Sousa Paiva ${ }^{2}$ \\ DOI: https://doi.org/10.31692/978-65-991061-4-9.157-162
}

\section{INTRODUÇÃO}

A cana-de-açúcar é uma planta perene que pertence à família das Poáceas, originaria do Sudeste Asiático, possui seu metabolismo fotossintético $\mathrm{C}_{4}$, pois possui alta capacidade fotossintética, com um alto acúmulo de massa seca tanto em sua parte área como na sua zona radicular, seguindo a sua fase final onde ocorre a maturação e um alto acumulo de sacarose nos seus colmos (RAMOS et al., 2009).

O Brasil é o maior produtor de cana-de-açúcar, sendo o terceiro em áreas plantadas, ficando atrás apenas de soja e milho, tendo em toda sua área territorial um clima favorável para seu cultivo, desde que o cultivo seja cultivares adaptadas, principalmente, ao clima, que geralmente é caracterizado por apresentar um elevado déficit hídrico anual, precipitações irregulares e a falta de instrução científica da cultura para a região cultivada.

O potencial de produção da cana-de-açúcar, é caracterizado por seus subprodutos açúcar, etanol e energia elétrica, entre outras, tanto na agricultura quanto na indústria, o que faz dessa cultura uma das mais importantes atividades da agroindústria nacional e mundial, já que sua atividade é responsável por geração de emprego (CORPERSUCAR, 2010). A produtividade dessa planta é regulada por diversos fatores de produção, dentre as quais se destacam: planta, solo, clima, práticas culturais, controle de pragas e doenças, colheita maturação e corte (ORLANDO FILHO et al., 1999). Sempre que possível devemos manejar os fatores de produção adequadamente e gerenciados pelo homem através de sistemas de planejamento, controle e execução, visando a maximização das produtividades econômicas. $\mathrm{O}$ objetivo final de uma exploração agrícola comercial é o lucro.

A fonte nitrogenada mais utilizada na cultura é a ureia, e quando aplicada sobre a palha, apresenta elevada perda de $\mathrm{N}-\mathrm{NH}_{3}$ por volatilização, o que pode afetar a absorção de $\mathrm{N}$

\footnotetext{
${ }^{1}$ Engenharia Agronômica, Instituto Federal de Educação Ciência e tecnologia do Piauí, vb40987@gmail.com

2 Engenheiro Agrônomo, Engenheiro agrônomo do SENAR, josemaurosp-10@ hotmail.com
} 
pela cultura (PRAMMANEE et al., 1989; DENMEAD et al., 1990; CANTARELLA et al., 1999). Dessa forma a produtividade agrícola no Brasil não se relacionam apenas a radiação solar, temperatura e água, e sim a disponibilidade de quantidades adequadas de nutrientes (CARMONA et al., 1990). O manejo inadequado de um canavial, especialmente a adubação nitrogenada, pode ter redução tanto na produção quanto na sua longevidade, dessa forma reduzindo, por conseguinte o número de colheitas ou cortes entre as reformas (BOLOGNA, 2007).

\section{FUNDAMENTAÇÃO TEÓRICA}

O Brasil é o maior produtor da cultura da cana-de-açúcar, com aproximadamente $33 \%$ de todo o montante produzido no mundo (JADOSKI ET al. 2010), essa liderança tem marcado a importância dessa cultura para a economia mundial, considerando o panorama de produtividade dos canaviais da região.

A deficiência de $\mathrm{N}$ nas plantas causa a redução da síntese de clorofila, de aminoácidos que são essenciais para a produção de carboidratos e esqueletos carbônicos (EPSTEIN e BLOOM, 2006). A adubação nitrogenada destaca-se como uma das práticas culturais mais estudadas em cana de açúcar, visto que todos os estudos sobre nitrogênio apresentam resultados variáveis e muitas vezes até contraditórios. A necessidade do N pela cana-deaçúcar é crucial no período de desenvolvimento da planta, que vai do período imediatamente após a germinação até o fechamento do canavial.

A resposta à fertilização nitrogenada reflete em maior vigor das soqueiras, tornando-se necessário manejar a cana-de-açúcar como uma cultura perene. Apesar da instabilidade climática em algumas regiões produtoras neste primeiro trimestre, como é o caso do Nordeste, a perspectiva é de crescimento de 5,9\% no rendimento da cultura, a produtividade média brasileira está estimada em $73.5 \mathrm{mil} \mathrm{kg/ha,} \mathrm{maior} \mathrm{que} \mathrm{a} \mathrm{safra} \mathrm{2012/13,} \mathrm{que} \mathrm{foi} \mathrm{de} 69 \mathrm{mil}$ kg/ha. (Conab 2013/2014).

A queimada da cana-de-açúcar é uma atividade tipicamente poluidora, que degrada o meio ambiente, afetando a saúde pública. Esta prática vem sendo questionada pela alta emissão de $\mathrm{CO}_{2}$ e gases de nitrogênio e enxofre que são responsáveis pelas chuvas ácidas, além de provocar perdas significativas de nutrientes para as plantas (BIO, 1999).

A obrigatoriedade de colheita da cana-de-açúcar sem queima da palhada aliada aos custos crescentes de produção torna imprescindível a adoção de novas tecnologias no manejo agrícola dessa cultura, como métodos de preparo do solo com menor mobilização do solo e consumo de combustível e no uso racional de fertilizantes (SOUZA et al., 2005; ROSSETTO 
et al. 2010).

\section{METODOLOGIA}

O experimento foi conduzido na Fazenda Várzea, no município Brejo - MA, Região

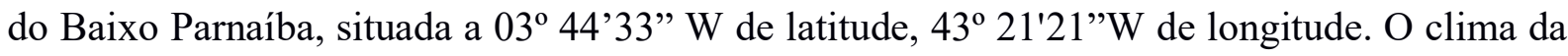
região corresponde na classificação de Koppen ao tipo Aw, caracterizado por chuvas no verão e seca no inverno. A temperatura média foi de $29^{\circ} \mathrm{C}$.

O experimento teve duração de dois anos em cana-soca $\left(2^{\circ}\right.$ e $3^{\circ}$ corte $)$ no período de 2011 e 2012. Nesse período, as médias das temperaturas máximas e mínimas foram respectivamente $28^{\circ} \mathrm{C}$ e $29^{\circ} \mathrm{C}$. Os dados de temperaturas e precipitações foram obtidos pelo Programa de Monitoramento Climático em Tempo Real da Região Nordeste (PROCLIMA), o solo e classificado como Latossolo Amarelo. O delineamento experimental utilizado foi de blocos ao acaso com três repetições, sendo os blocos separados por ruas de 2,0 m, e cada bloco foi composto por 3 parcelas, com um total do experimento foi de $7920 \mathrm{~m}^{2}$. Cada parcela foi subdividida em 6 (seis) parcelas e adubadas com diferentes doses de ureia, sendo elas, 60, 80, 100, 120 e $140 \mathrm{~kg} \mathrm{~N} \mathrm{ha}^{-1}$, e uma parcela testemunha, onde não foi adubada.

Para a variedade RB 863129 a dose de $100 \mathrm{~kg} \mathrm{~N}$ ha $^{-1}$ foi substituída por adubação com vinhoto, oriundo de destilaria da própria fazenda, com dose de $80 \mathrm{~m}^{3} \mathrm{ha}^{-1}$. Cada parcela experimental constituiu-se de sete linhas com 1 metro de espaçamento entre sulco e 18 metros de comprimento e 7 metros de largura, totalizando $126 \mathrm{~m}^{2}$ de área.

$\mathrm{Na}$ adubação, além do $\mathrm{N}$, foi aplicado potássio em todos os tratamentos, na dose de $140 \mathrm{~kg} \mathrm{ha}^{-1}$ de $\mathrm{K}_{2} \mathrm{O}$ (cloreto de potássio). As variedades utilizadas e estudada cana-de-açúcar, com 3 (três) variedades avaliadas, que são: RB 867515, RB 863129 e RB 92579.

Foram coletadas amostras no centro das parcelas, para evitar o efeito de bordadura. As amostras foram secas em estufa de aeração forçada, com temperatura de $60-65^{\circ} \mathrm{C}$, até massa constante. O material seco da fração da planta (colmo) foi moído com auxílio de um moinho forrageiro com peneira de $1 \mathrm{~mm}$. Depois, foram armazenadas em envelopes de papel e submetidas à digestão para determinação dos teores de $\mathrm{N}\left(\mathrm{g} \mathrm{ha}^{-1}\right)$, utilizando-se a metodologia proposta por Vaccaro et al. (2004).

O teor de Nitrogênio $(\mathrm{N})$ foi obtido por uma mistura digestora (sulfato de potássio + sulfato de cobre) e ácido sulfúrico, com digestão-destilação sulfúrica, utilizando-se o método semimicro Kjeldahl.

Os resultados obtidos foram submetidos à análise de variância e as médias comparadas entre si pelo teste $t$ de Student Para a análise estatística dos dados foi utilizado o programa 


\section{INFOSTAT.}

\section{RESULTADOS E DISCUSSÃO}

Pelos resultados da $1^{\mathrm{a}}$ soqueira a melhor resposta para adubação nitrogenada foi obtida

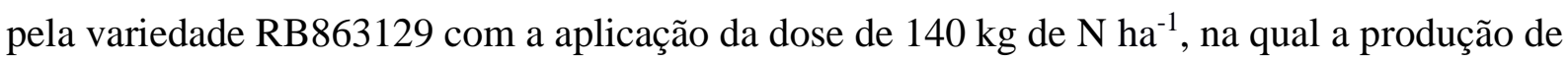
colmos em 63\% quando comparada com a testemunha. As doses 80 e $120 \mathrm{Kg} \mathrm{N} \mathrm{ha-1}$ incrementaram a produção em 47 e $46 \%$, em relação a testemunha. O tratamento onde o vinhoto aplicado obteve resultado semelhante a dose de $60 \mathrm{Kg} \mathrm{ha}^{-1}$ respectivamente.

Para a variedade RB867515, a maior produtividade de colmos foi obtida com a dose de $120 \mathrm{~kg}$ de $\mathrm{N} \mathrm{ha}^{-1}$ a produção de colmos em $46 \%$ quando comparado com a testemunha. A aplicação de $\mathrm{N}$ nas doses de 60,80 e $100 \mathrm{Kg} \mathrm{ha}^{-1}$ obtiveram resultados semelhantes na produtividade de colmos, sendo estas $82,44,80,78$ e 81,44 ton ha $^{-1}$ respectivamente. A produção de colmos para a dose de $140 \mathrm{~kg}$ de $\mathrm{N} \mathrm{ha}^{-1}$ não diferiu significativamente da testemunha.

Para a variedade RB92579, a maior produtividade em termos de peso fresco de colmos

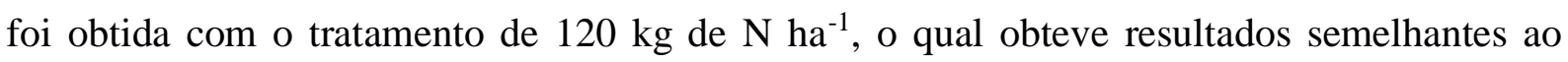
tratamento de $80 \mathrm{~kg} \mathrm{~N} \mathrm{ha}^{-1}$, sendo estes em média $23 \%$ superiores em relação a testemunha, o

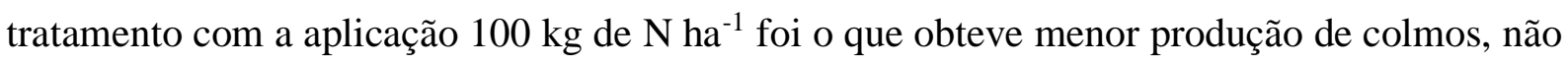
diferindo da testemunha $(\mathrm{P}>0,05)$. O efeito benéfico da aplicação de $\mathrm{N}$ corrobora os resultados obtidos por Orlando Filho et al. (1999).

Resultados semelhantes foram encontrados por Cardoso (2002) em cana-de açúcar, sem despalha a fogo, observou que a redução na aplicação de nitrogênio de 100 para $30 \mathrm{~kg} \mathrm{~N}$ $\mathrm{ha}^{-1}$ causou queda drástica no rendimento dos colmos.

Pelos resultados da $2^{\mathrm{a}}$ soqueira a variedade RB863129 os melhores resultados foram encontrados para os tratamentos com aplicação de 80 e novamente, como na primeira soca, com a dose de $140 \mathrm{Kg}$ de $\mathrm{N} \mathrm{ha}^{-1}$, os quais apresentaram o mesmo valor para produção de colmos, representando um incremento de $61 \%$ na produtividade quando comparados com a testemunha.

Assim como na $1^{\text {a }}$ soqueira, a variedade RB867515 apresentou melhor desempenho quando foi aplicada a dose de $120 \mathrm{Kg}$ de $\mathrm{N}$ ha-1, enquanto as doses de 60,80 e $100 \mathrm{Kg}$ de $\mathrm{N}$ $\mathrm{ha}^{-1}$ apresentaram produtividade de 82,4; 80,7; e 81,4 ton ha ${ }^{-1}$. E novamente, para dose de 140 $\mathrm{Kg}$ de $\mathrm{N} \mathrm{ha}^{-1}$ mesma tendência foi observada comparando-se com a $1^{\mathbf{a}}$ uma vez que essa não diferiu da testemunha com valores de produtividade de 65,73 e 68,1 e 65,7 ton ha${ }^{1}$ respectivamente. No entanto, comparando-se as testemunhas da $1^{\mathbf{a}}$ e $2^{\mathbf{a}}$ soca, observa-se que a 
produtividade se manteve constante.

A maior produtividade de colmos para a variedade RB92579 foi observada com a dose de $140 \mathrm{~kg} \mathrm{ha}^{-1}$ de $\mathrm{N}$, diferindo significativamente dos demais tratamentos, os quais apresentaram produtividade de 75,47,81,37, 108,93 e 102,57 ton ha ${ }^{-1}$ para as doses de 60, 80, 100 e $120 \mathrm{Kg} \mathrm{ha}^{-1}$ de $\mathrm{N}$ respectivamente. Com relação a testemunha, observou-se decréscimo de produtividade em $31 \%$ comparando-se com a $1^{\mathbf{a}}$ soca, indicando a importância do manejo da adubação nitrogenada ao longo dos ciclos, e ao que tudo indica em doses superiores a 120 kg N ha ${ }^{-1}$. Neste sentido, Faroni (2008) em experimento com cana-de-açúcar avaliando a resposta da cultura a aplicação de $\mathrm{N}\left(0-120 \mathrm{~kg} \mathrm{ha}^{-1}\right)$ em duas áreas distintas, também observou aumento de produtividade da cultura com a aplicação desse nutriente.

\section{CONCLUSÕES}

A variedade RB92579 apesentou a maior produtividade de colmos na primeira e na segunda soqueira de cana-de-açúcar. A melhor dose observada para essa variedade foi de 120 $\mathrm{ha}^{-1}$.

\section{REFERÊNCIAS}

BIO. Revista Brasileira de Saneamento e Meio Ambiente.n.10, p.42-45, abril/junho.1999.

BOLOGNA, I. R. Produtividade da cana-de-açúcar relacionada ao nitrogênio residual da adubação e do sistema radicular. Brasília: Pesq. agropec. bras, v.42, n.2, p.249-256, fev. 2007.

CANTARELLA, H. et al. Perdas de nitrogênio por volatilização da amônia e resposta da cana-de-açúcar à adubação nitrogenada, em sistema de colheita de cana sem queima prévia. In: CONGRESSO NACIONAL DA STAB, 7, Londrina,1999. Anais... Londrina: STAB, 1999. p.82-87.

CARDOSO, F.P. Plantio direto em cana-de-açúcar. Direto no Cerrado, Passo Fundo, v. 7, p. 4, 2002.

CARMONA G., CHRISTIANSON C.B., BYRNES B.H. Temperature and low concentration effects of the urease inhibitor N-n-butyl thiophosphoric triamide (NBPT) on ammonia volatilization from urea. Soil Biology \& Biochemistry. v. 7, p. 933-937, 1990.

COPERSUCAR. Dados de produtividade safra 2010. Disponível em www.Copersucar. Com.br. Acesso as 12:00 do dia 01 de dezembro de 2010.

DENMEAD, O.T. et al. Volatilization of ammonia from urea and ammonium sulfate applied to sugarcane trash in North Queensland. Proceedings of the Australian Society of. Sugar Cane Technology, v.12, p.72-78, 1990. 
EPSTEIN, E.; BLOOM, A. Nutrição mineral de plantas: princípios e perspectivas. 2. ed. Londrina: Planta, 2006. 402 p.

FARONI, C.E. Eficiência agronômica das adubações nitrogenadas de plantio e após o primeiro corte avaliada na primeira soca da cana-de-açúcar. 2008. 190f. Tese (Doutor em Solos e Nutrição de Plantas) - Escola Superior de Agricultura 'Luiz de Queiroz', Universidade de São Paulo, Piracicaba, 2008.

JADOSKI, C.J.; TOPPA, B.E.V.; JULIANETTI, A.; HULSBOF, T.; ONO, E.O.; RODRIGUES, J.D.; Fisiologia do desenvolvimento do estádio vegetativo da cana, Pesquisa aplicada e agrotecnologia, v3, n2 Mai-Ago 2010.

ORLANDO FILHO, J.; RODELLA, A.A.; BELTRAME, J.A.; LAVORENTI, N.A. Doses, fontes e formas de aplicação de nitrogênio em cana-de-açúcar. STAB. Açúcar, Álcool e Subprodutos, Piracicaba, v. 17, n.4, p.39-41, 1999.

PRAMMANEE, P.; SAFFIGNA, P.G. ; WOOD, A.W. Loss of nitrogen from urea and ammonium sulfate applied to sugar cane crop residues. In: AUSTRALIAN SOCIETY OF SUGARCANE TECHNOLOGISTS, 11., Mackay, 1989. Proceedings. Mackay: Watson Fergunson, 1989. p.76-84.

RAMOS et al., Guia da Cana-de-açúcar- Avanço cientifico beneficia o País, v. 01, n. 6, p.6-7, setembro de 2009.

ROSSETTO. R.; F. L. LANDELL, M. G. A. ; CANTARELLA, H.; TAVARES, S.; VITTI, A. C.; PERECIN, D.N and K fertilisation of sugarcane rations harvested Without burnig. In: INTERNATIONAL SOCIETY OF SUGAR CANE TECHNOLOGISTES CONGRESS, 27. 2010, Procedings... Veracruz, México: D. M. Horgarth, 2010. 1CD-ROM.

SOUZA, Z. M. de; PRADO, R de M.; PAIXÃO, A. C. S.; CESARIN, L. G. Sistemas de colheita e manejo da palhada da cana-de-açúcar. Pesquisa Agropecuária Brasileira, v. 40, n. 3, p. 271-278. Março, 2005. 


\title{
INTERFERÊNCIA DE PLANTAS DANINHAS NA CULTURA DA CENOURA EM DOIS SISTEMAS DE IRRIGAÇÃO LOCALIZADA
}

\author{
INTERFERENCIA DE LAS PLANTAS DE DANIN EN LA CULTURA DE \\ ZANAHORIAS EM DOS SISTEMAS DE RIEGO UBICADOS
}

\section{INTERFERENCE OF WEED PLANTS IN THE CARROT CULTURE IN TWO LOCATED IRRIGATION SYSTEMS}

Antônio batista C. Bisneto ${ }^{1}$; Laís Tereza Rêgo Tereza. Reginaldo²; Maria Alice Formiga. Porto $^{3}$; Tatiane Severo Silva ${ }^{4}$; Daniel Valadão Silva ${ }^{5}$

DOI: https://doi.org/10.31692/978-65-991061-4-9.163-168

\section{INTRODUÇÃO}

A cenoura (Daucus carota L.) é uma hortaliça da família Apiaceae, considerada um dos vegetais de raiz mais valiosos economicamente. O consumo mundial de cenoura é de aproximadamente 4,29 $\mathrm{kg}$ por pessoa ao ano, sendo uma importante fonte de alimento e nutrição (FREITAS et al., 2009). No Brasil a cenoura é de grande relevância para o setor hortícola, ocupando a quinta posição entre as hortaliças com maior participação na produção do país (CARVALHO et al., 2017).

A irrigação da cenoura, como na maioria das olerícolas, além de ser um importante fator de produção, é o que mais favorece o aumento da produtividade. No entanto o déficit e ou excesso de água, podem propiciar condições desfavoráveis ao desenvolvimento da cenoura e levar a queda na produtividade dessa cultura (LIMA JÚNIOR, 2011). A região de Mossoró, Estado do Rio Grande do Norte, Brasil, é uma região que está dentro do semiárido Brasileiro, onde um dos fatores limitante para a produção agrícola é os limitados recursos hídricos naturais, que são altamente explorados. A agricultura irrigada é uma das principais atividades econômicas nessa região, e as olerícolas são cultivadas sob o método de irrigação localizada, com a utilização dos sistemas de irrigação por gotejamento e microaspersão, o que permite obtenção de colheitas nas épocas secas do ano.

Embora a irrigação contribua para melhoria do rendimento das culturas agrícolas, a interferência causada pelas plantas daninhas constitui um fator importante de limitação da produção na cultura da cenoura. A competição entre as daninhas e a cultura pode promover

\footnotetext{
${ }^{1}$ Agronomia, UFERSA, bisneto.ribeiro@gmail.com

${ }^{2}$ Graduada em Agronomia, UFERSA, laisttorquato@gmail.com

${ }^{3}$ Msc Fitotecnia, UFERSA, mariaalice6@hotmail.com

${ }^{4}$ Msc Fitotecnia, UFERSA, tatiane.severosilva@gmail.com

${ }^{5}$ Doutor, UFERSA, daniel.valadao@ufersa.edu.br
} 
significativas alterações na fisiologia da planta cultivada, podendo comprometer seu crescimento, produtividade e a qualidade do produto colhido (SARDANA et al., 2017).

Normalmente, os períodos de interferência das plantas daninhas são determinados por análises do decréscimo de características quantitativas e qualitativas. Em função da época de convivência e controle, é possível estimar o período anterior à interferência (PAI), o período total de prevenção à interferência (PTPI) e o período crítico de prevenção à interferência (PCPI), a partir dos quais é determinado o momento teoricamente mais adequado para o controle da comunidade de plantas daninhas (PITELLI, 1985 apud COELHO et al., 2017).

A cenoura apresenta baixa competitividade com plantas daninhas devido à sua lenta emergência e crescimento no início do ciclo de cultivo. Portanto, o objetivo desse estudo foi determinar os períodos de interferência de plantas daninhas em cenoura sob o sistema de irrigação por gotejamento e microaspersão.

\section{FUNDAMENTAÇÃO TEÓRICA}

As plantas daninhas representam um dos principais obstáculos para o sucesso da produção agrícola e são responsáveis por consideráveis perdas de rendimento nos sistemas de produção. A cenoura exerce fraca competição em relação às espécies de plantas daninhas, por apresentar características de crescimento inicial lento e porte baixo (NASCIMENTO et al., 2007). Os sistemas de produção de cenoura abrangem alta fertilização, preparo intensivo do solo e fornecimento constante de água. Este sistema favorece o estabelecimento de plantas daninhas, que, quando manuseado incorretamente, pode reduzir a produtividade e qualidade da raiz (TEÓFILO et al., 2009; SASNAUSKAS et al., 2012).

O método mais utilizado para o controle de plantas daninhas em lavouras de cenoura em larga escala tem sido a aplicação de herbicidas (KONIECZKA et al., 2009; SASNAUSKAS et al., 2012). No entanto, para um manejo de plantas daninhas mais sustentável economicamente e ambientalmente é necessário identificar o período crítico de interferência das plantas daninhas, visando conhecer o momento mais adequado para início e fim do controle das plantas daninhas durante o ciclo de cultivo.

A competição exercida pelas plantas daninhas constitui um dos fatores que mais limitam a produtividade da cultura da cenoura. A intensidade da competição normalmente é avaliada por meio de decréscimos de produção ou pela redução no crescimento da planta cultivada, como respostas à competição pelos recursos de crescimento disponíveis no ambiente (AGOSTINETO et al., 2008). Assim, é importante conhecer as limitações da cultura em relação a interferência causada pelas plantas daninhas que auxiliem na tomada de decisão 
para o controle.

\section{METODOLOGIA}

O experimento foi conduzido entre os meses de julho a novembro de 2018 na fazenda experimental Rafael Fernandes da Universidade Federal Rural do Semi-Árido, Mossoró-RN,

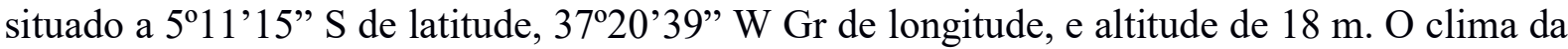
região, segundo a classificação de Köppen, é BSwh', seco e muito quente (CARMO FILHO et al., 1991). O preparo do solo foi realizado no sistema convencional, com aração, gradagem e formação dos canteiros com enxada rotativa. Para adubação de plantio foi realizada a análise química do solo. Considerando a recomendação do IPA (2008), aplicando $220 \mathrm{~kg} \mathrm{ha}^{-1}$ de $\mathrm{P}_{2} \mathrm{O}_{5}$ por ocasião do plantio.

A cenoura utilizada para desenvolvimento do experimento foi a cultivar "Suprema", semeada manualmente, depositando quatro sementes por cova de plantio, em seis linhas. O espaçamento utilizado foi de 0,15 m entre linhas e 0,08 m entre plantas. Aos 15 dias após a emergência (DAE) foi realizado o desbaste na cultura, deixando apenas uma planta por cova. Para adubação de cobertura foi aplicado $40 \mathrm{~kg} \mathrm{ha}^{-1}$ de nitrogênio, $60 \mathrm{~kg} \mathrm{ha}^{-1}$ de $\mathrm{P}_{2} \mathrm{O}_{5}$ e $30 \mathrm{~kg}$ $\mathrm{ha}^{-1}$ de $\mathrm{K}_{2} \mathrm{O}$, na forma de ureia, superfosfato simples e cloreto de potássio, respectivamente. A capina foi realizada por meio do arranquio manual, e não foram utilizados herbicidas.

O delineamento experimental utilizado foi o de blocos casualizados, com três repetições, no esquema de parcelas subdivididas. As parcelas foram constituídas dos dois sistemas de irrigação (gotejamento e microaspersão), e as subparcelas corresponderam à duração de convivência de plantas daninhas nos tratamentos, sendo divididos em dois grupos, constituídos de períodos de controle (no limpo) ou convivência (no mato) das plantas daninhas com a cultura.

Os tratamentos foram implementados desde o início da emergência da cenoura: (i) as parcelas foram deixadas com plantas daninhas durante 10, 20, 30, 40, 50, e 120 dias após emergência (DAE) para avaliar o início do período crítico de remoção das plantas daninhas e (ii) as parcelas foram mantidas sem plantas daninhas por 10, 20, 30, 40, 50, e 120 DAE para determinar o fim do período crítico.

A frequência e matéria seca de plantas daninhas foram avaliadas descritivamente entre os tratamentos ao longo dos 120 dias de cultivo da cenoura. Para definir os períodos de interferências nos diferentes tratamentos, foi utilizado o Modelo Sigmoidal 4 parâmetros. Os valores do período anterior a interferência (PAI), período crítico de prevenção a interferência (PCPI) e período total de prevenção a interferência (PTPI) foram comparados 
descritivamente.

\section{RESULTADOS E DISCUSSÃO}

A produtividade relativa da cenoura foi afetada em ambos os sistemas de irrigação utilizados, porém observa-se que no sistema de irrigação por microaspersão o período de início e do final do PCPI foi reduzido em comparação ao sistema de gotejamento que apresentou maior período de interferência (Figura 1).

Figura 1. Produtividade relativa da cenoura (\%), sem e com competição com plantas daninhas, em sistema de gotejo (a) e microaspersão (b) durante 120 dias após a emergência.
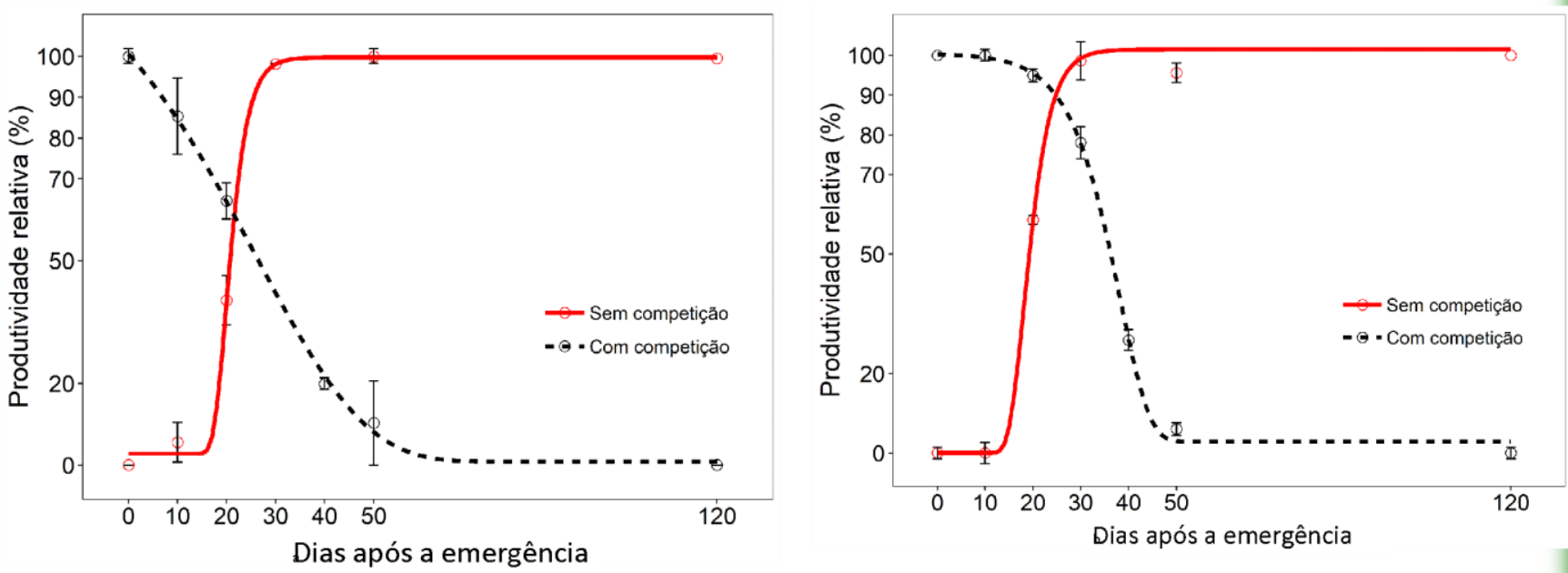

O rendimento das raízes de cenoura foi reduzido por atrasos prolongados na remoção de plantas daninhas nos dois sistemas de irrigação. Por outro lado, o rendimento das raízes de cenoura aumentou com a crescente duração do período livre de plantas daninhas nos dois sistemas de irrigação (Figura 1).

Os períodos de interferência das plantas daninhas variaram entre os sistemas de irrigação (Figura 1). Considerando uma perda aceitável de $5 \%$ para o sistema de gotejamento o PAI estabelecido foi de 4 DAE, e o PCPI de 23 dias, obtendo um PTPI de 27 DAE (Tabela 1). No sistema de microaspersão considerando a perda aceitável de $5 \%$, o PAI estabelecido para a cultura foi de 20 DAE, com PCPI de 7 dias e PTPI de 27 DAE (Tabela 5).

Tabela 1. Período anterior a interferência (PAI), período crítico de prevenção a interferência (PCPI) e período total de prevenção a interferência (PTPI) para o controle de plantas daninhas em dois sistemas de irrigação (gotejo e microaspersão) na cultura da cenoura, considerando uma perda aceitável de 5,0\%.

\begin{tabular}{lllll}
\hline \multirow{2}{*}{ Perda aceitável $(\%)$} & \multirow{2}{*}{ Sistema } & \multicolumn{3}{l}{ Períodos de interferência } \\
& & PAI & PCPI & PTPI \\
\cline { 2 - 5 } 5 & Gotejo & 4 & 23 & 27 \\
\cline { 2 - 5 } & Microaspersão & 20 & 7 & 27 \\
\hline
\end{tabular}

No presente estudo o PCPI variou nos dois cultivos da cenoura devido aos sistemas de [166] 
irrigação utilizados. No sistema de irrigação por gotejamento a capina das plantas daninhas deve ser iniciada mais cedo e o período em que a cultura deve ser mantida livre das plantas daninhas (PCPI) é maior, quando comparado ao sistema de irrigação por microaspersão.

A alta infestação de Digitaria. horizontalis Willd. no início de desenvolvimento da cultura pode ter sido o que mais influenciou para o controle de plantas daninhas mais cedo durante o ciclo de cultivo da cenoura no sistema de irrigação por gotejamento. Essa espécie daninha por ser uma planta de metabolismo $\mathrm{C}_{4}$ é melhor adaptada à temperatura e luz mais intensas, apresentando maior eficiência no uso da água (TAYLOR et al., 2011). Com isso, a menor disponibilidade de água nesse sistema pode ter intensificado a competição por esse recurso, limitando o crescimento e desenvolvimento da cultura. No sistema de irrigação por microaspersão devido a maior disponibilidade e distribuição da água, a competição por esse recurso pode ter sido menor e, portanto, a necessidade de iniciar o controle de plantas daninhas foi um pouco mais tardio.

\section{CONCLUSÕES}

O sistema de irrigação influencia o início e o fim do PCPI. O comprimento do PCPI no sistema de irrigação por gotejamento foi de 3,3 semanas (23 dias) e 1,0 semana (7 dias) considerando perdas de rendimento de 5,0 \%. No sistema de irrigação por gotejamento a capina das plantas daninhas deve ser iniciada mais cedo e o período em que a cultura deve ser mantida livre das plantas daninhas é maior, comparado ao sistema de irrigação por microaspersão. Os dados obtidos nesse estudo fornecem uma base inicial para os produtores de cenoura tomarem uma decisão em relação às medidas de controle oportunas de plantas daninhas.

\section{REFERÊNCIAS}

CARVALHO, A. D.F; SILVA, G. O. Divergência genética entre genótipos de cenoura através de caracteres agronômicos. Revista Agro@mbiente On-line, v. 11, n. 2, p. 137-144, abriljunho, 2017.

LIMA JUNIOR, J. A.; PEREIRA, G. M.; GEISENHOFF, L. O.; SILVA, W. G.; VILAS BOAS, R. C.; SOUZA, R. J. Desempenho de cultivares de cenoura em função da água no solo. Revista Brasileira de Engenharia Agrícola e Ambiental, Campina Grande, v. 16, n. 5, p. 514-520, 2012.

SARDANA, V. et al. Role of competition in managing weeds: An introduction to the special issue. Crop Protection, v. 95, p. 1-7, 2017.

PITELLI, R.A. A interferência de plantas daninhas em culturas agrícolas. Informativo 
Agropecuário, v.11, p.16-17, 1985.

DOSSA, D; FUCHS, F. CENOURA: Produção, mercado e preços na CEASA-PR. Boletim Técnico 04. CENOURA: Setembro de 2017.

VIEIRA, J. V et al. Cenoura (Daucus carota). Embrapa hortaliças. Sistema de Produção ,5, 2008.

EMBRAPA. Manual de Segurança e Qualidade para a Cultura da Cenoura. Brasília: EMBRAPA/SEDE, 61 p. 2004.

CARMO FILHO, F.; ESPÍNOLA SOBRINHO, J.; MAIA NETO, J. M. Dados climatológicos de Mossoró: um município semi-árido nordestino. Mossoró: UFERSA, 1991. (Coleção Mossoroense, C.30).

SILVA, ANA CAROLINA BIZINOTO; SCHUQUEL, LUENDA CAMILE DOS SANTOS,; SILVA, CASSIANO OLIVEIRA,; PASCOAL, GRAZIELI BENEDETI. Qualidade Nutricional e Físico-química em Cenoura (Daucus carota l.) In Natura e Minimamente Processada. Demetra; 2016; 11(2); 355-367 


\section{CARACTERIZAÇÃO DA FERTILIDADE DO SOLO DE UMA COMUNIDADE PERIURBANA EM BARCARENA, PARÁ, BRASIL}

Henrique Caetano Alencar ${ }^{1}$; Gilson Sergio Bastos de Matos ${ }^{2}$; Amanda Nascimento Monteiro ${ }^{3}$; Vitória Malcher Nogueira Lima ${ }^{4}$; Marcos André Piedade Gama ${ }^{5}$

DOI: https://doi.org/10.31692/978-65-991061-4-9.169-173

\section{INTRODUÇÃO}

As zonas de transição entre o meio urbano e o rural são denominadas periurbanas. Nessas as variáveis ambientais assumem o papel de fator dinamizador das alterações destes espaços através da dinâmica e complementaridade de funções (PATO, 2011).

Uma importante variável de avaliação ambiental é o solo, e assim suas características físico-químicas podem indicar, por exemplo, a sua aptidão para o uso agrícola (PEREIRA; NETO, 2004).

O município de Barcarena pertence à mesorregião Metropolitana de Belém classificado como uma cidade industrial, comercial, portuária, turística, de serviços e de grande demanda na construção naval e civil (BARCARENA, 2016), possuindo comunidades que podem ser caracterizadas como rural, periurbanas e urbanas, sendo as duas primeiras o espaço de produção agrícola e animal.

O trabalho teve por objetivo caracterizar e avaliar os parâmetros de fertilidade dos solos da comunidade Vila Nova em Barcarena, Pará.

\section{FUNDAMENTAÇÃO TEÓRICA}

A sociedade aumentou o nível de exigência quanto aos produtos que consome e a forma na qual são produzidos, dessa forma, a agricultura periurbana incumbe-se do papel de fornecer aos consumidores alimentos nutritivos, saudáveis, seguros e frescos. A proximidade entre as propriedades produtivas e o mercado consumidor desenvolve o comércio local, criando um laço de proximidade entre o produtor e consumidor (SERRANO, 2015).

Um dos fatores limitantes da produção agrícola, seja ela rural, urbana ou periurbana, são as características químicas do solo. A maioria dos solos amazônicos apresenta uma acidez elevada e baixa capacidade de troca catiônica, consequentemente baixa fertilidade

\footnotetext{
${ }_{1}^{1}$ Agronomia, Universidade Federal rural da Amazônia (UFRA), henrique_alencar@hotmail.com.br

2 Doutor, Universidade Federal Rural da Amazônia (UFRA), gilsonsbm@gmail.com

${ }^{3}$ Agronomia, Universidade Federal rural da Amazônia (UFRA), amandamonteiro788@ gmail.com

${ }^{4}$ Agronomia, Universidade Federal rural da Amazônia (UFRA), viclimaufra@gmail.com

${ }^{5}$ Doutor, Universidade Federal Rural da Amazônia (UFRA), gama_map@yahoo.com.br
} 
(MOREIRA; MALAVOLTA, 2002).

Assim, dado que o manejo da fertilidade do solo é um dos principais limitantes da produtividade das culturas, a caracterização edáfica é procedimento fundamental e norteador do gerenciamento agronômico (RESENDE; COELHO, 2017).

\section{METODOLOGIA}

O trabalho foi conduzido na comunidade de Vila Nova, no município de Barcarena, que fica cerca de $22 \mathrm{Km}$ de Belém (PA) localizado entre os paralelos $1^{\circ} 30^{\prime} \mathrm{S}$ a $1^{\circ} 40^{\prime} \mathrm{S}$ e entre os meridianos $48^{\circ} 30^{\prime} \mathrm{W}$ a $48^{\circ} 50^{\prime} \mathrm{W}$. O clima é tropical úmido segundo Köppen e Geiger classificado como Am (ALVARES, 2013). O município faz parte da Região de Integração do Tocantins que é composta por uma variedade de solos com predominância de 79,06\% de Latossolo Amarelo Distrófico (LAd), classificados em sua maioria como boa aptidão para agricultura (EMBRAPA, 2016).

A pesquisa foi dividida em duas etapas, sendo a primeira pela aplicação de questionário e a segunda pela coleta de amostras para avaliação da fertilidade do solo. Assim, na primeira fase, foram entrevistados 75 produtores na comunidade, com aplicação de questionário com perguntas abertas, direcionadas para o membro familiar responsável pela produção na propriedade, sendo que em alguns casos havia mais de um produtor por família. Dentre as questões procurou-se abordar: manejo realizado no solo, histórico da área, as culturas existentes e qual a cultura de interesse atual e futuro para plantio. Para a avaliação da fertilidade do solo foram coletadas de 15 a 20 amostras simples para formar uma composta por área previamente determinada por cada produtor, na profundidade de 0-20 cm. As amostras foram encaminhadas à Universidade Federal Rural da Amazônia para preparo com secagem ao ar e moagem, obtendo amostra tipo terra fina seca ao ar (TFSA), as quais então foram enviadas para um laboratório com controle de qualidade. As análise foram realizadas conforme metodologia Embrapa (2007), considerando os seguintes parâmetos: pH em $\mathrm{H}_{2} \mathrm{O}$, matéria orgânica (M.O.), fósforo disponível $(\mathrm{P})$, enxofre $(\mathrm{S})$, potássio $(\mathrm{K})$, cálcio $(\mathrm{Ca})$, magnésio $(\mathrm{Mg})$, alumínio trocável, acidez potencial, boro $(\mathrm{B})$, cobre $(\mathrm{Cu})$, ferro $(\mathrm{Fe})$, manganês (Mn) e zinco (Zn), procedendo os cálculos de CTC pH 7, soma de bases (SB), CTC efetiva, saturação por base (V\%) e saturação por alumínio (m\%).

\section{RESULTADOS DISCUSSÃO}

A comunidade recebeu orientações técnicas da Secretaria de Meio Ambiente do município quanto às práticas de cultivo agrícola. Entretanto, uma boa parcela dos moradores 
não faz o manejo nutricional do solo de acordo com tais orientações, ou jamais fizeram.

Os resultados demonstram elevado coeficiente de variação para todos os parâmetros considerados (Tabela 1), o que segundo Coelho (2005) pode ser justificado pela alta variabilidade natural dos parâmetros de fertilidade do solo, e que são influenciados por atividades antrópicas e pelo material de origem. No caso da área avaliada há uma grande diversidade de uso do solo nas propriedades.

Os resultados de matéria orgânica (MO) demonstraram valores baixos ou médios, o que se deve principalmente à rápida e contínua decomposição que esse atributo é submetido na região amazônica (LIMA, 2001), além das constantes queimadas realizadas nas propriedades.

$\mathrm{O}$ pH, Tabela 2, da maioria das amostras mostrou nível de acidez elevada resultante de um intenso processo de lixiviação, da decomposição da $\mathrm{MO}$, do grau de distrofismo e das características dos solos predominantes (LIMA, 2001; EMBRAPA, 2016). Além disso, os produtores ou moradores não costumam utilizar corretivos de acidez do solo.

Tabela 1: Estatística Descritiva dos Parâmetros de Qualidade Química do Solo na Comunidade Vila Nova, Barcarena - Pará.

\begin{tabular}{ccccccc}
\hline Determinação & Média & Mediana & Mínimo & Máximo & Desvio Padrão & CV \\
\hline $\mathrm{M} . \mathrm{O}$ & 1,89 & 1,90 & 1,10 & 3,30 & 0,48 & $25,36 \%$ \\
$\mathrm{pH} \mathrm{em} \mathrm{H} 2 \mathrm{O}$ & 5,05 & 4,90 & 4,20 & 6,70 & 0,63 & $12,45 \%$ \\
$\mathrm{P} \mathrm{Mehlich}$ & 31,09 & 11,70 & 0,90 & 264,60 & 47,01 & $151,20 \%$ \\
$\mathrm{~K}$ & 28,21 & 23,00 & 2,00 & 133,00 & 22,25 & $78,86 \%$ \\
$\mathrm{Ca}$ & 2,09 & 1,50 & 0,10 & 8,60 & 1,69 & $81,09 \%$ \\
$\mathrm{Mg}$ & 0,26 & 0,20 & 0,10 & 0,70 & 0,16 & $59,47 \%$ \\
$\mathrm{Al}$ & 0,53 & 0,45 & 0,00 & 1,80 & 0,45 & $85,82 \%$ \\
$\mathrm{H}+\mathrm{Al}$ & 4,30 & 4,50 & 1,00 & 7,90 & 1,48 & $34,45 \%$ \\
$\mathrm{SB}$ & 2,43 & 1,81 & 1,00 & 7,90 & 1,48 & $61,02 \%$ \\
$\mathrm{~T}$ & 6,73 & 6,55 & 4,26 & 11,59 & 1,52 & $22,65 \%$ \\
$\mathrm{~T}$ & 2,96 & 2,44 & 1,34 & 9,49 & 1,59 & $53,74 \%$ \\
$\mathrm{~V} \%$ & 34,68 & 30,70 & 3,80 & 90,30 & 19,27 & $55,57 \%$ \\
$\mathrm{~m} \%$ & 23,44 & 19,90 & 0,00 & 87,20 & 20,31 & $86,65 \%$ \\
$\mathrm{Na}$ & 2,37 & 2,00 & 0,00 & 17,00 & 2,64 & $111,21 \%$ \\
$\% \mathrm{Na}$ & 0,15 & 0,09 & 0,00 & 0,71 & 0,14 & $96,99 \%$ \\
$\mathrm{~S}$ & 17,57 & 16,00 & 8,00 & 40,00 & 6,94 & $39,47 \%$ \\
$\mathrm{~B}$ & 1,68 & 0,90 & 0,25 & 9,54 & 2,33 & $139,34 \%$ \\
$\mathrm{Zn}$ & 3,30 & 2,00 & 0,50 & 32,20 & 4,86 & $147,18 \%$ \\
$\mathrm{Mn}$ & 11,86 & 8,60 & 2,10 & 72,90 & 10,98 & $92,64 \%$ \\
$\mathrm{Cu}$ & 3,57 & 1,30 & 0,20 & 45,80 & 7,41 & 207,36 \\
$\mathrm{Fe}$ & 278,57 & 273,00 & 83,00 & 512,00 & 92,77 & 33,30 \\
\hline
\end{tabular}

Fonte: Própria (2019).

Tabela 2: Classificação e Frequência Relativa de ocorrência de alguns atributos químicos dos solos na Comunidade Vila Nova, em Barcarena - Pará.

\begin{tabular}{ccccccccc|cc}
\hline Classificação & M.O & P & K & Ca & Mg & t & T & V\% & Acidez (pH) & \\
\hline Muito baixo a baixo & $59 \%$ & $45 \%$ & $81 \%$ & $36 \%$ & $84 \%$ & $37 \%$ & $1 \%$ & $65 \%$ & Elevada & $56 \%$ \\
Médio & $41 \%$ & $27 \%$ & $15 \%$ & $40 \%$ & $16 \%$ & $51 \%$ & $87 \%$ & $20 \%$ & Média & $33 \%$ \\
Bom a muito bom & $0 \%$ & $28 \%$ & $4 \%$ & $24 \%$ & $0 \%$ & $12 \%$ & $12 \%$ & $15 \%$ & Fraca & $11 \%$ \\
\hline
\end{tabular}


Fonte: Própria (2019).

Tabela 3: Frequência Relativa da Textura do Solo da Comunidade Vila Nova.

\begin{tabular}{ccc}
\hline Textura & $\mathbf{N}^{\circ}$ de Propriedades & Textura \\
\hline Arenosa & 0 & $0 \%$ \\
Média & 26 & $35 \%$ \\
Argilosa & 49 & $65 \%$ \\
\hline Total & 75 & $100 \%$ \\
\hline
\end{tabular}

Fonte: Própria (2019).

Os solos apresentam, em geral, altos teores de $\mathrm{Al}^{3+}$ e baixos valores de CTC. Isso, aliado aos baixos teores de MO, contribuem para os baixos teores de bases trocáveis, como Ca, Mg e K. Esses resultado são apoiados pelo trabalho de MACHADO et al., 2017.

Os resultados de $\mathrm{P}$ indicam alta variabilidade, com teores muito baixos até altos, conform coeficiente de variação (Tabela 1). Nos solos das regiões tropicais do Brasil há baixa disponibilidade de $\mathrm{P}$ devida, principalmente, à intensa adsorção a qual esse elemento é submetido dada pela alta afinidade por óxidos e hidróxidos de Fe e de Al (FINK, 2016), o que explicaria os baixos teores nas amostras avaliadas. Contudo, essa alta variabilidade de P na área avaliada também pode ocorrer em função do manejo do solo, já que ocorrem queimadas de lixo e do mato.

Quanto à textura do solo (Tabela 3), a análise granulométrica mostrou que a maioria das amostras apresenta textura argilosa. Quando o conteúdo de matéria orgânica é abaixo de 20 g. $\mathrm{kg}^{-1}$ (Tabela 1) há uma forte correlação entre a CTC e o teor de argila (ESSINGTON, 2005) isso poderia explicar as médias CTC's.

\section{CONCLUSÕES}

Os dados dos parâmetros de qualidade química do solo da comunidade Vila Nova condizem com os estudos existentes, para a região amazônica, voltados à fertilidade do solo.

Os baixos teores de MO indicam necessidade de manejo do solo com resíduos orgânicos, diminuindo práticas de queimadas;

Os resultados demonstram que para uso do solo com finalidade agrícola é necessário um trabalho de correção dos solos e então adubações para melhoria do nível de fertilidade dessas áreas avaliadas.

\section{REFERÊNCIAS}

ALVARES, Clayton Alcarde et al. Köppen's climate classification map for Brazil. Meteorologische Zeitschrift, v. 22, n. 6, p. 711-728, 2013. 
BARCARENA. Prefeitura Municipal de Barcarena. Plano Diretor de Desenvolvimento Urbano. Lei Complementar Municipal No 49. Anexo II. Mapa Político Administrativo Ilustrativo. Barcarena: Prefeitura de Barcarena, 2016.

COELHO, A. M. Agricultura de Precisão: manejo da variabilidade espacial e temporal dos solos e culturas. 1. ed. Documentos. n. 46. Sete Lagoas: Embrapa Milho e Sorgo, 2005.

EMPRESA BRASILEIRA DE PESQUISA AGROPECUÁRIA - EMBRAPA. mapas de solos e de aptidão agrícola das áreas alteradas do Pará. Belém, PA: Embrapa Amazônia Oriental, 2016.

EMPRESA BRASILEIRA DE PESQUISA AGROPECUÁRIA - EMBRAPA. Ed. téc.: Cravo, M. da S.; Viégas, I. de J. M.; Brasil, E. C. Recomendações de adubação e calagem para o Estado do Pará. 1. ed. 262 p. Belém, PA: Embrapa Amazônia Oriental, 2007.

ESSINGTON, M. E. Soil and water chemistry: a interactive approach. 1. ed. New York: Taylor \& Francis, 2005. 534 p.

FINK, J. R.; INDA, A. V.; TIECHER, T.; BARÓN, V. Iron oxides and organic matter on soil phosphorus availability. Review. Lavras: UFLA. Revista Ciência e Agrotecnologia. v. 40, n. 4, p. 369-379, jul.-ago. 2016.

LIMA, H. N. Gênese, química, mineralogia e micromorfologia de solos da Amazônia Ocidental. 2001. 176 p. Tese (Doutorado) - Universidade Federal de Viçosa, Viçosa, 2001.

MACHADO, M. R. et al. Land cover changes affect soil chemical attributes in the Brazilian Amazon. Maringá: ActaScientiarum. Agronomy. v. 39, n. 3, p. 385-391, jul.-set. 2017.

MOREIRA, A.; MALAVOLTA, E. Variação das propriedades químicas e físicas do solo e na matéria orgânica em agroecossistemas da Amazônia Ocidental (Amazonas). 79p. Piracicaba: CENA/USP, 2002.

PATO, R. L.; MAGALHÃES, M. C; TAVARES, A. O. Análise ambiental e edáfica em área de transformação periurbana. Revista de Ciências Agrárias. Vol. XXXIV, 2. ed. p. 218-233. Coimbra: 2011.

PEREIRA, L. C.; NETO, F. L. Avaliação da aptidão agrícola das terras: proposta metodológica. Jaguariúna: Embrapa Meio Ambiente, 2004. 36 p.

RESENDE, A. V.; COELHO, A. M. Amostragem para mapeamento e manejo de fertilidade do solo na abordagem de agricultura de precisão. Informações agronômicas. Piracicaba: International Plant Nutrition Institute- Brasil, 2017, n. 159, 8 p.

SERRANO, J. A. S. Agricultura periurbana, parques naturales agrarios y mercados agropecuarios locales: una respuesta territorial y productiva a la subordinación del campo a la ciudad. Revista electrónica de geografía y ciencias sociales. Barcelona: Scripta Nova, 2015, Vol. XIX, n. 502. 


\section{AVALIAÇÃO DE ATRIBUTOS FÍSICOS EM CANAVIAL FERTIRRIGADO COM VINHAÇA E ADUBAÇÃO QUÍMICA}

\section{EVALUACIÓN DE ATRIBUTOS FÍSICOS EN CANEVIAL FERTIRRIGADO CON VINTAGE Y FERTILIZACIÓN QUÍMICA}

\section{EVALUATION OF PHYSICAL ATTRIBUTES IN FERTIRRIGATED CANEVIAL WITH VINTAGE AND CHEMICAL FERTILIZATION}

Adjair José da Silva ${ }^{1}$; Anderson Ricardo Galdino da Silva ${ }^{2}$; Andréa Renilda Silva Soares $^{3}$; Joanna Rafaella da Silva ${ }^{4}$; Sandro Augusto Bezerra ${ }^{5}$

DOI: $\underline{\text { https://doi.org/10.31692/978-65-991061-4-9.174-178 }}$

\section{INTRODUÇÃO}

Os solos, quando submetidos a determinados sistemas de cultivo, tendem a um novo estado de equilíbrio, refletido em diferentes manifestações de seus atributos, as quais podem ser desfavoráveis à conservação da capacidade produtiva destes solos (CARDOSO, 2014). A física do solo tem como objetivo qualificar e quantificar as propriedades físicas do solo como sua medição, predição e controle, além de entender os mecanismos que governam a funcionalidade dos solos e seu papel na biosfera (REINERT; REICHER, 2006). Os atributos físicos do solo como a densidade do solo, densidade de partículas e a porosidade total podem indicar se o solo apresenta problemas significativos de infiltração, permeabilidade, aeração e drenagem. Enquanto que o atributo umidade do solo indica a capacidade de armazenamento e de distribuição da água no solo (SIQUEIRA, 2006). O objetivo deste trabalho é avaliar os atributos físicos do solo cultivado com cana-de-açúcar adubada com adubos químicos e fertirrigados com vinhaça.

\section{FUNDAMENTAÇÃO TEÓRICA}

Os sistemas agrícolas que associam a monocultura ao uso de equipamentos inadequados de preparo do solo resultam em rápida degradação do solo (FERREIRA et al., 2010). A busca por alternativas que proporcionem a sustentabilidade do ambiente agrícola e minimização dos custos de produção vem mudando o comportamento das unidades produtoras de cana-de-açúcar (SOUZA et al., 2005).

$\mathrm{O}$ uso do solo e seu manejo interferem diretamente nas propriedades do solo. Adição

\footnotetext{
${ }^{1}$ Agronomia, IFPE Campus Vitória de Santo Antão, adjairsilva.agronomia.ifpe@gmail.com

2 Agronomia, IFPE Campus Vitória de Santo Antão, andersonrgs2013@gmail.com

${ }^{3}$ Agronomia, IFPE Campus Vitória de Santo Antão, andrearenildaagronomia@gmail.com

${ }^{4}$ Agronomia, IFPE Campus Vitória de Santo Antão, rafaelly hta@ hotmail.com

${ }^{5}$ Dr. Ciência do Solo, IFPE Campus Vitória de Santo Antão, sandro.augusto@ vitoria.ifpe.edu.br
} 
no teor de matéria orgânica no solo influencia no aumento de retenção de água e em modificações de atributos físicos direta e indiretamente relacionado com o crescimento e a produção das plantas (BLAINSKI et al., 2012). O uso interfere também nos índices de compactação, que representam as condições nas quais poderá ocorrer impedimento ao crescimento radicular de determinada espécie vegetal (LIMA et al., 2013).

Com o manejo adequado do solo, alguns problemas podem ser evitados. Ao avaliar as propriedades físicas de um solo relacionando com o manejo, pode-se determinar de maneira mais conclusiva a importância de propriedades como, densidade, na avaliação da qualidade dos solos (BONO et al., 2013).

Baseados em parâmetros físicos do solo como a densidade e a porosidade podem indicar problemas significativos de infiltração, permeabilidade, aeração e drenagem. As variações espaciais dos atributos físicos tais como a densidade e a porosidade condicionam a distribuição da água no solo e consequentemente o rendimento das culturas. A medida da umidade é essencial para a pesquisa e entendimento do comportamento de distribuição e armazenamento de água através dos mais variados fatores: intensidade da radiação solar, temperatura do ar, temperatura do solo, vento e umidade do ar.

A Densidade do Solo tem sido bastante utilizada para analisar os atributos físicos do solo, sendo de grande importância pelo motivo de proporcionar a avaliação de outros atributos como a porosidade. Sendo os mesmos, normalmente, utilizados para avaliações mais comuns e difundidas na identificação de camadas compactadas no solo.

\section{METODOLOGIA}

A área em estudo pertence ao Grupo JB - Companhia Alcoolquímica Nacional, localizado no Município de Vitória de Santo Antão - PE. O município está localizado na mesorregião Mata e na Microrregião Vitória de Santo Antão do Estado de Pernambuco, com área municipal de 345,7 km2 correspondendo a 0,35\% do Estado de Pernambuco e distante 45,1 km da capital (CPRM, 2005).

Foi escolhida área com a variedade CT 93-3094 na $4^{\mathrm{a}}$ folha e fertirrigada com vinhaça. Onde a última aplicação de vinhaça tinha sido no dia 30-03-2016. A outra área escolhida era plantada com a SP 78-4764 na $4^{\text {a }}$ folha e adubada com adubo químico na formulação 17-0022.

Foram realizadas 6 coletas nas entrelinhas de cultivo em cada sistema de cultivo, sendo 3 em profundidade de $0-10 \mathrm{~cm}$ e mais 3 coletas de $10-20 \mathrm{~cm}$ com o anel volumétrico. Além de coletas com potes para verificar a umidade do solo. Num total de 12 cilindros e 6 
potes. Sendo descartado o cilindro 3 da área com vinhaça por deformar durante o transporte. As amostras foram condicionadas ao Laboratório de Física, Manejo e Conservação do Solo e da Água pertencente ao campus do IFPE de Vitória de Santo Antão.

As amostras retiradas com anéis volumétricos foram utilizadas para a determinação da densidade do solo e de partículas, além da porosidade total. A densidade do solo foi calculada pela relação entre a massa da amostra de solo do anel volumétrico, seca a $110{ }^{\circ} \mathrm{C}$ durante 24 hs, e o volume do mesmo anel tanto na profundidade de $0-10$ como de $10-20 \mathrm{~cm}$. A densidade de partículas foi calculada a partir do método do balão volumétrico, contendo solo seco em estufa. A porosidade total foi obtida pela diferença entre a massa do solo saturado e a massa do solo seco em estufa a $110^{\circ} \mathrm{C}$ durante 48 hs, conforme EMBRAPA (1997).

\section{RESULTADOS E DISCUSSÃO}

Pode-se observar na Tabela 1 os valores de Densidade do Solo (Ds), Densidade de Partículas (Dp) e Porosidade Total (Pt) das áreas de cultivo de cana-de-açúcar com vinhaça e adubação química.

Tabela 1. Dados Obtidos na Análise Física do Solo da área de Vinhaça e Adubação Química, onde S (superficial) e SB (subsuperficial) correspondem aos cilindros e as ordens das coletas em ambas as áreas. IFPE,

\begin{tabular}{|c|c|c|c|c|c|c|}
\hline \multirow[b]{2}{*}{ Cilindro } & \multicolumn{2}{|c|}{ Ds $\left(\mathrm{g} \mathrm{cm}^{-3}\right)$} & \multicolumn{2}{|c|}{$\mathrm{Dp}\left(\mathrm{g} \mathrm{cm}^{-3}\right)$} & \multicolumn{2}{|c|}{$\overline{P t}(\%)$} \\
\hline & Vinhaça & $\begin{array}{c}\text { Ad. } \\
\text { Química }\end{array}$ & Vinhaça & $\begin{array}{c}\text { Ad. } \\
\text { Química }\end{array}$ & Vinhaça & $\begin{array}{c}\text { Ad. } \\
\text { Química }\end{array}$ \\
\hline S1 & 1,30 & 1,26 & 2,82 & 2,35 & 53,99 & 50,14 \\
\hline S2 & 1,36 & 1,32 & 2,63 & 2,41 & 48,39 & 47,12 \\
\hline S3 & $X$ & 1,29 & $X$ & 2,38 & $\mathrm{X}$ & 49,13 \\
\hline SB1 & 1,39 & 1,30 & 2,94 & 2,40 & 52,69 & 50,11 \\
\hline SB2 & 1,51 & 1,65 & 2,70 & 2,84 & 43,96 & 44,57 \\
\hline SB3 & 1,44 & 1,49 & 2,94 & 2,57 & 51,16 & 44,21 \\
\hline
\end{tabular}

Fonte: Própria (2016).

Os valores encontrados de Densidade do Solo na área de vinhaça variaram de 1,30 a $1,51 \mathrm{~g} \mathrm{~cm}^{-3}$, enquanto que na área com adubação química variaram de 1,26 a $1,65 \mathrm{~g} \mathrm{~cm}^{-3}$. Conforme FERREIRA et al. (2010), a densidade do solo entre 1,27 e 1,57 g cm-3 é restritiva ao crescimento radicular e à infiltração de água no solo. Sendo assim, os valores que foram encontrados encontram-se dentro da faixa citada restringindo o desenvolvimento radicular indicando solo com camada compactada. Com exceção da amostra Solo 1 (S1) e Subsolo 2 (SB2), que apresenta valores acima em ambos os solos da área com adubação química.

Em relação à Densidade de Partículas, os valores variaram de 2,63 a 2,94 $\mathrm{g} \mathrm{cm}^{-3}$ para a área com vinhaça e de 2,35 a 2,84 $\mathrm{g} \mathrm{cm}^{-3}$ para a área com adubação química. Os valores encontrados estão dentro dos limites médios para os mais diversos solos brasileiros que é de 
2,65 $\mathrm{g} \mathrm{cm}^{-3}$ (AMARO FILHO, 2008). Como a Dp é um atributo físico do solo estável, não se espera variações com a profundidade o que foi encontrado neste trabalho.

Comparando os valores de Pt de ambas as amostras, verifica-se que não há variação expressiva entre elas, tendo uma redução já prevista em relação a profundidade. No entanto, a área com vinhaça apresentou maior porosidade em relação a adubação química.

A Tabela 2 demonstra os valores de Umidade em 48 hs após secagem na estufa à temperatura de $110^{\circ} \mathrm{C}$ de ambas as áreas. Onde se pode verificar que o solo da área onde foi aplicada a vinhaça apresenta uma maior capacidade de armazenamento de água em comparação com a que foi realizada adubação química.

Tabela 2. Dados da Umidade dos Solos com 48 hs após secagem na estufa à temperatura de $110^{\circ} \mathrm{C}$ da área de Vinhaça e Adubação Química, onde U são as sequências dos potes. IFPE, 2016.

\begin{tabular}{ccc}
\hline & & \\
\cline { 2 - 3 } Potes & Vinhaça & Ad. Química \\
\cline { 2 - 3 } U1 & 35,08 & 25,17 \\
U2 & 35,29 & 19,80 \\
U3 & 23,55 & 19,26 \\
\hline
\end{tabular}

Fonte: Própria (2016).

\section{CONCLUSÕES}

O estudo demonstrou que a aplicação de vinhaça há uma melhoria do solo na retenção de umidade. Mas em relação aos atributos físicos, como a Densidade do Solo, Densidade de Partículas e Porosidade Total não houve muita diferença entre as amostras de solo, sendo que as de vinhaça tendiam para os valores médios, enquanto as amostragens de adubação química tendiam a valores maiores que o de solo com vinhaça.

\section{REFERÊNCIAS}

ABREU, S. L.; REICHERT, J. M.; REINERT, D. J. Escarificação mecânica e biológica para a redução da compactação em argissolo franco-arenoso sob plantio direto. Revista Brasileira de Ciência do Solo, Viçosa, v. 28, p. 519-531, 2004.

AMARO FILHO, J. Física do Solo: conceitos e aplicações. Fortaleza: Imprensa Universitária, 2008.

BONO, J. A. M; MACEDO, M. C. M; TORMENA, C. A. Qualidade física do solo em um latossolo vermelho da região sudoeste dos cerrados sob diferentes sistemas de uso e manejo. Revista Brasileira de Ciência do Solo, Viçosa,v. 37, n. 3, p. 743-753, maio/jun. 2013.

BLAINSKI, É. et al. Qualidade física de um latossolo sob plantio direto influenciada pela cobertura do solo. Revista Brasileira de Ciência do Solo, Viçosa, v. 36, n. 1, p. 79-87, 
jan./fev. 2012.

CARDOSO, J.A.F. Atributos químicos e físicos do solo e matéria orgânica do solo sob mangueira irrigada e caatinga nativa na região do Vale do Submédio São Francisco. 2014. 78f. Dissertação (Mestrado) - Universidade Federal do Vale do São Francisco, UNIVASF, Juazeiro/BA, 2014.

CPRM. Projeto cadastro de fontes de abastecimento por água subterrânea. Diagnóstico do município de Vitória de Santo Antônio, estado de Pernambuco. Org. Mascarenhas, J. C. et al. 22p. il. 2005.

EMBRAPA. Centro Nacional de Pesquisa de Solos. Manual de métodos de análise de solos. 2. ed. Rio de Janeiro, 1997. 212 p.

FERREIRA, R. R. M.; TAVARES FILHO, J. FERREIRA, V. M. Efeitos dos Sistemas de Manejo de Pastagens nas Propriedades Físicas do Solo. Semina: Ciências Agrárias, Londrina, v. 31, n. 4, p. 913-932, out./dez. 2010.

LIMA, R. P; LEÓN, M. J. D; SILVA, A. R. Comparação entre dois penetrômetros na avaliação da resistência mecânica do solo à penetração. Revista Ceres, Viçosa, v. 60, n. 4, p. 577-581, jul./ago. 2013.

REINERT, D. J.; REICHERT, R. M. Propriedades físicas do solo. Santa Maria, UFSM, 18 p., 2006.

SIQUEIRA, G. M. Variabilidade de Atributos Físicos do Solo Determinados por Métodos Diversos. 2006. 163 f. Dissertação (Mestrado em Agricultura Tropical e Subtropical) Instituto Agronômico, IAC, Campinas, 2006.

SOUZA, Z. M. et al. Sistemas de colheita e manejo da palhada de cana-de-açúcar. Pesquisa Agropecuária Brasileira, Brasília, v.40, p.271-278, 2005. 


\section{CARACTERÍSTICAS DE RENDIMENTO DE FRUTOS DE NOVOS HÍBRIDOS DE MAMOEIROS EM BARAÚNA - RN}

\section{CARACTERÍSTICAS DEL RENDIMIENTO DE FRUTA DE LOS NUEVOS HÍBRIDOS DE PAPAYA EN BARAÚNA - RN}

\section{FRUIT YIELD CHARACTERISTICS OF NEW HYBRIDS OF PAPAYA IN BARAÚNA - RN}

Lucas Matheus da Silva Sousa ${ }^{1}$; Otacílio Filho Alves de Anchieta ${ }^{2}$; Ivan Gabriel Garcia Peixoto ${ }^{3}$; Patrícia Lígia Dantas de Morais ${ }^{4}$; Jaeveson da Silva ${ }^{5}$

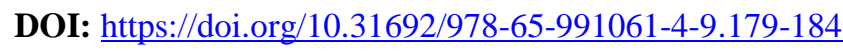

\section{INTRODUÇÃO}

O mamão é originário da América Central e seu cultivo é praticado em diversas regiões do mundo, apresentando importância econômica em países tropicais e subtropicais, sendo o Brasil um dos maiores produtores (FAO, 2016). O Rio Grande do Norte contribui com uma parcela considerável deste montante, porém tem capacidade de aumentos significativos da produção.

Para que seja melhorada a produção agrícola, é de fundamental importância melhorar a genética de plantas, com isso surge a necessidade de se padronizar e classificar os atributos de qualidade dos frutos oriundos de novos genótipos. Porém, a produção de mamão do Brasil é oriunda de poucas cultivares, constituindo-se em fator preocupante para manutenção e sustentabilidade do agronegócio do mamão e sua expansão, principalmente em regiões semiáridas com mamoeiros do grupo Solo. A caracterização de todo e qualquer fruto de novo genótipo é de extrema importância para o cenário frutícola do país (BORGES, V. P. et al., 2018).

O peso do fruto, tamanho, rendimento de polpa e outras características são decisivas para o consumidor aceitar o produto. Diante do exposto, o objetivo deste trabalho foi de caracterizar atributos pós-colheitas de frutos que condiz com rendimento de sete híbridos do grupo Solo, oriundos do programa de melhoramento genético da Embrapa Mandioca e Fruticultura.

\footnotetext{
${ }^{1}$ Agronomia, Universidade Federal Rural do Semi-Árido, tecnicolucasmatheus@ hotmail.com

2 Agronomia, Universidade Federal Rural do Semi-Árido, filhooanchieta@ gmail.com

${ }^{3}$ Agronomia, Universidade Federal Rural do Semi-Árido, gabrielpeixoto72@ hotmail.com

${ }^{4}$ Dra. Professora, Universidade Federal Rural do Semi-Árido, plmorais@ufersa.edu.br

${ }^{5}$ Doutor, Embrapa Mandioca e Fruticultura, jaeveson.silva@embrapa.br
} 


\section{FUNDAMENTAÇÃO TEÓRICA}

O Brasil é o segundo maior produtor mundial de mamão (Carica papaya L.), com produção equivalente a 1,42 milhões de toneladas (FAO, 2018). O estado da Bahia destaca-se como o maior produtor nacional, com 368,87 mil toneladas produzidas no ano 2017, superando toda a região sudeste em termo de produção. Já o estado do Rio Grande do Norte produziu 86,3 mil toneladas (IBGE, 2018). Mesmo a cultura do mamão sendo de extrema importância no que diz respeito a fruticultura brasileira, ainda se sobrepõe apenas quatro cultivares, que dominam quase toda a produção nacional (Tainung N.01 e Calimosa, grupo Formosa; Golden e Sunrise Solo, grupo Solo) (REIS, 2015). Os do grupo Solo apresentam frutos pequenos e de polpa avermelhada, e são os preferidos para exportação, se destacando no Rio Grande do Norte, Litoral Leste do Estado, o cultivar Golden, com sua maior parte exportada para Europa.

O melhoramento genético é uma valiosa ferramenta para ampliação da variabilidade genética da cultura do mamoeiro, necessária para a obtenção de genótipos superiores com distintas constituições gênicas, podendo contribuir efetivamente para aumentar a disponibilidade de híbridos no mercado nacional, com maior produtividade, melhoria na qualidade e no aspecto do mamão, o que se permitiria a obtenção de um produto final de melhor qualidade, com características físico-químicas e sensoriais superiores (BORGES, V. P. et al., 2018).

Características como tamanho, peso, qualidade nutricional, entre outras, devem ser consideradas para satisfazer às exigências do mercado nacional e internacional, o que levaria o Brasil à condição de grande exportador (Viana et al., 2013). Essas características podem ser influenciadas por condições edafoclimáticas, cultivar, época e local de colheita, tratos culturais e manuseio na colheita e na pós-colheita.

O grupo Solo, apresenta frutos com menor rendimento em comparação com as variedades do tipo Formosa, se destacando as cultivares Golden e Sunrise Solo (LUZ, 2015). Dentre os novos genótipos melhorados, é de fundamental importância que seus rendimentos sejam igual ou superior a esses dois cultivares, pois assim aumentará a aceitabilidade do mercado.

\section{METODOLOGIA}

O pomar de mamão com os híbridos CMF52.78, CMFH54.H78, CMFH56.H78, CMFH60.H78, CMFH72.H78, CMFH78.H83 e CMFH78.H84. Foi implantado no campo de produção da empresa WG Fruticultura, que fica localizada na cidade Baraúna - RN no início 
de outubro de 2018. O clima da região é o semiárido com temperaturas médias anuais de $27,3^{\circ} \mathrm{C}$, umidade relativa média anual de $70 \%$, apresenta estações bem definidas sendo uma estação seca de julho a dezembro e uma estação chuvosa de fevereiro a junho, com média anual de pluviosidade é de $859 \mathrm{~mm}$. O espaçamento de plantio foi 4,0 m x 2,0 m. A irrigação foi do tipo localizada por gotejamento, com duas linhas laterais por fileira de plantas e vazão de $1,5 \mathrm{~L} \mathrm{~h}^{-1}$, turno de rega diário, com duração de 2,5 horas. A adubação de fundação foi com MAP (250 Kg ha-1) e ade cobertura usou-se o adubo NPK 6-24-12, também com 250 g por planta, via fertirrigação.

Os frutos foram colhidos quando apresentaram estrias ou faixas com $25 \%$ de coloração amarela, entre o quarto e sexto mês após a abertura da flor, em que foram selecionados ao acaso oito frutos de cada híbrido. As avaliações foram feitas quando os frutos se encontravam maduros, ou seja, com a casca totalmente amarela. Durante os dias para mudança da coloração da casca, os mesmos permaneceram em temperatura ambiente $(25 \pm$ $2^{\circ} \mathrm{C}$ ), no laboratório de Pós-Colheita da Universidade Federal Rural do Semi-Árido, em Mossoró - RN.

Quando maduros, a partir de 10 de julho de 2019, avaliou-se os frutos, através da a massa fresca (balança de precisão de $1 \mathrm{~g}$ ) e o comprimento, diâmetro, espessura da polpa e diâmetro da cavidade central, utilizando um paquímetro de precisão de $0,1 \mathrm{~mm}$. Foram avaliados oito frutos de cada genótipo para a obtenção dos dados.

Os dados foram submetidos a análise de variância e as médias dos tratamentos ao teste de Scott-Knott, considerando-se o nível de 5\% de probabilidade, utilizando-se o programa estatístico SISVAR, versão 5.3 (FERREIRA, 2014).

\section{RESULTADOS E DISCUSSÃO}

Para todas as características avaliadas houve diferenças significativas (Tabela 1). Os híbridos avaliados responderam de forma distinta ao ambiente semiárido de estudo, o que mostra que os genótipos apresentam, sugerindo que há potencial para a seleção de plantas, com qualidade de frutos com padrões que possam atender o mercado, sejam de consumidores de frutos in natura ou agroindústrias.

\begin{tabular}{lccccc} 
& \multicolumn{5}{c}{ Tabela 1: Avaliação de rendimento de frutos híbridos de mamões grupo Formosa. } \\
\hline Genótipo & $\begin{array}{c}\text { Massa do } \\
\text { fruto }(\mathrm{g})\end{array}$ & $\begin{array}{c}\text { Comprimento do } \\
\text { fruto }(\mathrm{cm})\end{array}$ & $\begin{array}{c}\text { Diâmetro do } \\
\text { fruto }(\mathrm{cm})\end{array}$ & $\begin{array}{c}\text { Diâmetro da } \\
\text { cavidade } \\
\text { interna }(\mathrm{mm})\end{array}$ & $\begin{array}{c}\text { Espessura } \\
\text { da polpa } \\
(\mathrm{mm})\end{array}$ \\
\hline CMF52.78 & $307,5 \mathrm{~b}$ & $13,8 \mathrm{~b}$ & $6,9 \mathrm{c}$ & $34,1 \mathrm{~b}$ & $17,6 \mathrm{c}$ \\
CMF54.78 & $391,5 \mathrm{~b}$ & $13,5 \mathrm{~b}$ & $7,7 \mathrm{~b}$ & $35,9 \mathrm{~b}$ & $20,6 \mathrm{~b}$ \\
CMF56.78 & $482,0 \mathrm{a}$ & $16,1 \mathrm{a}$ & $8,1 \mathrm{~b}$ & $36,3 \mathrm{~b}$ & $20,9 \mathrm{~b}$
\end{tabular}




\begin{tabular}{lccccc} 
CMF60.78 & $571,0 \mathrm{a}$ & $14,1 \mathrm{~b}$ & $9,1 \mathrm{a}$ & $42,9 \mathrm{a}$ & $23,9 \mathrm{a}$ \\
CMF72.78 & $410,6 \mathrm{~b}$ & $13,9 \mathrm{~b}$ & $7,6 \mathrm{~b}$ & $31,6 \mathrm{~b}$ & $21,0 \mathrm{~b}$ \\
CMF78.83 & $411,0 \mathrm{~b}$ & $13,5 \mathrm{~b}$ & $8,2 \mathrm{~b}$ & $32,5 \mathrm{~b}$ & $22,9 \mathrm{a}$ \\
CMF78.84 & $588,5 \mathrm{a}$ & $14,7 \mathrm{~b}$ & $9,0 \mathrm{a}$ & $37,0 \mathrm{~b}$ & $24,8 \mathrm{a}$ \\
\hline Média & 457,3 & 143,3 & 8,1 & 35,9 & 21,8 \\
F (p<0,05) & $6,61^{* *}$ & $6,04^{* *}$ & $7,96^{* *}$ & $6,37^{* *}$ & $5,19^{* *}$ \\
CV $\%$ & 18,5 & 7,0 & 7,2 & 8,9 & 10,3 \\
\hline
\end{tabular}

${ }^{1}$ Valores seguidos por letras iguais na coluna não diferem entre si, pelo teste de Scott-Knott.

A principal característica relacionada com a capacidade produtiva dos híbridos é a massa do fruto, embora que, para atender o mercado de consumidores de frutos do grupo solo, deva apresentar massas próximas de cultivares do mesmo grupo, como o Golden, variando de 300 a 650 (SILVA, 2013; SCHMILDT et al., 2016; SILVA, 2017). Todos os híbridos apresentaram massas para atender o padrão exigido pelo mercado (Tabela 1). A classificação dos frutos, que é determinada pela massa do fruto, neste trabalho variou entre B, E, F e H, sendo a maior parte classificados na classe E e F, que compreendem frutos com peso de 380 a 500g (HORTIBRASIL 2016).

Os formatos dos frutos deste experimento foram piriformes, ou seja, uma relação maior que 1 quando analisado comprimento/diâmetro, segundo SILVA et al. (2010) este é o formato preferível do mercado. O comprimento dos frutos que variou de 13,8 a 14,7 cm e a largura de 6,9 a 9,0 cm, valores que se encontram acima daqueles encontrados por SILVA et al. (2017) para 'Golden THB'. Em relação ao diâmetro da cavidade interna dos frutos, a CMF60.78. Segundo DIAS et al. (2011), essa característica está relacionada à qualidade dos frutos, sendo que aqueles que apresentam menor diâmetro, geralmente também apresentam maior quantidade de polpa, sendo assim uma característica importante para o mercado externo, REIS et al. (2015) também concorda quando fala que frutos com maior comprimento, diâmetro e menor diâmetro da cavidade interna tendem a apresentar maior peso e espessura de polpa, impulsionando a produtividade. Entretanto, no presente trabalho, entre os frutos que apresentaram os menores diâmetros de cavidade interna, somente os híbridos CMF78.83 e CMF78.84 apresentaram maior espessura da polpa com 22,9 e 24,8 mm de espessura, respectivamente.

SILVA et al. (2010) testando cultivares Golden observaram espessuras médias a partir de $20 \mathrm{~mm}$, YAMANISHI et al. (2006) afirmam que espessura média acima de 20mm é considerada de valor ideal para comercialização, sendo o híbrido CMF52.78 o único deste experimento que não se adequa a este quesito. 


\section{CONCLUSÕES}

Há ampla variabilidade genética em relação aos caracteres de rendimento de frutos dos híbridos avaliados neste experimento, porém, é possível indicar híbridos que podem ser comerciáveis tanto no mercado interno como no externo, com destaque para CMF56.78, CMF78.83 e CMF78.84 que apresentaram características promissoras.

\section{REFERÊNCIAS}

BORGES, V. P. SILVA, J. R. R.; CASTRO, A. M. P. B.; SILVA, S. O.; LEDO, C. A. S. Caracterização Agronômica se Novos Híbridos de Mamoeiro. VII Simpósio do Papaya Brasileiro. 2018. Disponível em: 〈https://www.alice.cnptia.embrapa.br〉. Acesso em: 28 de julho de 2019.

DANTAS, J. L. L; OLIVEIRA, E. J. de. Avances en el mejoramiento de papaya. In: CONGRESSO ARGENTINO DE HORTICULTURA, 32; SIMPÓSIO LATINO AMERICANO DE FRUTICULTURA TROPICAL, 1, 2009, Salta. Anais... Salta: Instituto Nacional de Tecnologia Agropecuária, 2009.

DIAS, N.L.P.; OLIVEIRA, E.J. de; DANTAS, J.L.L. Avaliação de genótipos de mamoeiro com uso de descritores agronômicos e estimação de parâmetros genéticos. Pesquisa Agropecuária Brasileira, v.46, p.1471-1479, 2011. DOI: 10.1590/ S0100-204X2011001100008

FAO - Food and Agriculture Organization of the United Nations. The agricultural production. 2018. Disponível em: <http://faostat.fao.org/>. Acessado em: 28 de julho de 2019.

FAO (2016). Food and Agriculture Organization of the United Organizations. Productio. Crops Primary. Disponível em: 〈http://faostat.fao.org/>. Acesso em: 28 de julho de 2019.

FERREIRA, D. F. Sisvar: a Guide for its Bootstrap procedures in multiple comparisons. Ciência e Agrotecnologia, v.38, n.2, p.109-112, 2014.

HORTIBRASIL. 2016. Programa Brasileiro para Modernização da Agricultura. Maracujáazedo: cartilha para classificação. Disponível em: <http://www.hortibrasil.org.br>. Acesso em: 27 de julho de 2019.

IBGE - Instituto Brasileiro de Geografia e Estatística / Sistema IBGE de Recuperação Automática - SIDRA - Produção Agrícola Municipal. Disponível em: <https://sidra.ibge.gov.br/tabela/5457>. Acesso em: 27 de julho de 2019.

LUZ, L. N.; PEREIRA, M. G.; BARROS, F. R.; BARROS, G. B.; FERREGUETTI, G. A. Novos híbridos de mamoeiro avaliados nas condições de cultivo tradicional e no semiárido brasileiro. Revista Brasileira de Fruticultura, v. 37, n. 1, p. 159-171, 2015. Disponível em: < http://dx.doi.org/10.1590/0100-2945-069/14>. Acesso em 30 Júlio 2019.

SILVA, C.A. Divergência genética entre acessos de mamoeiro e correlação entre suas 
características no norte do Espírito Santo. 2013. 62 f. Dissertação (Mestrado em Agricultura Tropical) - Universidade Federal do Espírito Santo, São Mateus.

Silva, M. M.; BROETTO, S. G.; VAlBÃO, S. C.; COSTA, A. F. S.; SIlvA, D. M. Características vegetativas e de frutos de mamoeiros obtidos por seleção massal. Semina: Ciências Agrárias, Londrina, v. 31, n. 1, p. 29-38, 2010.

SILVA, W. S.; SCHMILDT, E. R.; SCHMILDT, O.; FERREGUETTI, G. A. Dimensionamento amostral para frutos de mamoeiro 'Golden THB' destinados ao mercado nacional e à exportação. Revista Agro@mbiente On-line, v. 11, n. 2, p. 128-136, abriljunho, 2017.

SCHMILDT, E.R.; SCHMILDT, O.; CRUZ, C.D.; CATTANEO, L.F.; FERREGUETTI, G.A. Optimum plot size and number of replications in papaya field experiment. Revista Brasileira de Fruticultura, v. 38, n. 2, p. 1-9, 2016.

REIS, R. C.; VIANA, E. S.; JESUS, J. L.; DANTAS, J. 1. L.; LUCENA, R. S. Caracterização físico-química de frutos de novos híbridos e linhagens de mamoeiro. Pesq. agropec. bras., Brasília, v.50, n.3, p.210-217, mar. 2015.

VIANA, E. de S.; REIS, R.C.; JESUS, J.L. de; JUNGHANS, D.T.; SOUZA, F.V.D. Caracterização físico-química de novos híbridos de abacaxi resistentes à fusariose. Ciência Rural, v.43, 2013.

YAMANISHI, O. K.; MELLO, R. M.; MARTINS, V. A.; LIMA, L. A.; FAGUNDES, G. R. Comportamento do mamoeiro Sekati nas condições do oeste da Bahia. Revista Brasileira de Fruticultura, Jaboticabal, v. 28, n.1, p. 79-82, jan. 2006. 


\section{COMPORTAMENTO DE MANDIOCA PARA DUPLA APTIDÃO, MESA E INDUSTRIAL, NO CULTIVO IRRIGADO, EM SOLO ARENOSO E APÓS MAMOEIRO, EM CEARÁ MIRIM, RN}

\section{COMPORTAMIENTO DE LA YUCA PARA DOBLE APTITUD, MESA E INDUSTRIAL, EN CULTIVO IRRIGADO, EN SUELO Y DESPUÉS DE LA PAPAYA, EN CEARÁ MIRIM, RN}

\section{MANIOC BEHAVIOR FOR DOUBLE FITNESS, TABLE AND INDUSTRIAL, IN IRRIGATED CROP, IN SANDY SOIL AND AFTER PAPAYA, IN CEARÁ MIRIM, RN}

\section{Lucas Matheus da Silva Sousa ${ }^{1}$; Jonas Carapinta de Sousa ${ }^{2}$; Enoch de Souza Ferreira ${ }^{3}$; José Gleidson Laranjeira da silva ${ }^{4} ;$ Jaeveson da Silva ${ }^{5}$}

DOI: https://doi.org/10.31692/978-65-991061-4-9.185-191

\section{INTRODUÇÃ̃O}

A mandioca é bastante produzida e consumida no Brasil, com alta adaptabilidade conferida pelo elevado número de cultivares disponíveis, a maioria com alta produtividade, influenciada principalmente por fatores ambientais e de manejo (CASTRO et al., 2017). A região nordeste do Brasil, na safra de 2017, participou com 25,1\% de produção de todo o país, com maior participação do estado da Bahia $(10,1 \%)$. A maior produção atual se concentra no estado do Pará, com 20,5\% (IBGE, 2018). O Rio Grande do Norte tem uma pequena participação na produção nacional, embora com potencial de crescimento da produção.

De acordo com a variedade cultivada, as raízes podem seguir diferentes nichos de mercados, por exemplo, ir para o consumo de mesa, para a indústria ou alimentação animal. Porém, ainda são poucas as cultivares que podem ser destinadas à mais de um segmento de mercado. Caso o produtor tenha uma cultivar de dupla aptidão abre-se alternativas de venda da mandioca, não só na comercialização de raízes em feiras livres e centrais de distribuição, mas também na indústria de farinha e amido, a depender do preço praticado e demanda de mercado (DINIZ et al., 2014). Mandiocas com baixos teores de HCN em raízes e folhas, geralmente são mais bem aceitas pelos criadores de animais, considerando menores possibilidade de envenenamento no consumo in natura.

O trabalho teve o objetivo de avaliar cultivares de mandioca, com características de mesa, irrigado, e considerar o potencial de uso para indústria, no município de Ceará Mirim,

\footnotetext{
${ }^{1}$ Agronomia, Universidade Federal Rural do Semi-Árido, tecnicolucasmatheus@ hotmail.com

${ }^{2}$ Agronomia, Universidade Federal Rural do Semi-Árido, jonas carapinta@ hotmail.com

${ }^{3}$ Agronomia, Universidade Federal Rural do Semi-Árido, soldado.ferreira75@gmail.com

${ }^{4}$ Agronomia, Universidade Federal Rural do Semi-Árido, gleidsonsylva26@ gmail.com

${ }^{5}$ Doutor, Embrapa Mandioca e Fruticultura, jaeveson.silva@embrapa.br
} 
RN.

\section{FUNDAMENTAÇÃO TEÓRICA}

A mandioca (Manihot esculenta Crantz) apresenta diversas possibilidades de uso, a depender do cultivar utilizada, são classificadas como mandioca de mesa (macaxeira, aipim, mandioca doce) e industrial (mandioca brava), baseado no teor de precursores do ácido cianídrico presentes em suas raízes, sendo o limite de $100 \mathrm{mg} \mathrm{kg}^{-1}$ de massa fresca de raízes, que ultrapassando, são tidas como 'bravas' e destinam-se exclusivamente para a indústria (SILVA et al., 2018).

Altas produtividades de raízes de mandioca podem ser obtidas com novas cultivares e manejos de adensamento de plantas, adubação e irrigação (PEIXOTO et al., 2018). Na média nacional, a produtividades de raízes encontra-se em 14,3 $\mathrm{t} \mathrm{ha}^{-1}$. No Rio Grande do Norte de 10,7 t ha ${ }^{-1}$ (cultivo de sequeiro, com chuvas concentradas). No Sul e Sudeste, em estados do Paraná e São Paulo, que usam maiores tecnologias de produção, a média é de $23,4 \mathrm{t} \mathrm{ha}{ }^{-1}$, produtividades que favorecem maiores competividades comerciais (IBGE, 2018).

O uso da irrigação e da melhoria da fertilidade do solo pode aumentar significativamente a produção de raízes de mandioca, com alto percentual de amido, com produtividades que ultrapassam os $40 \mathrm{t} \mathrm{ha}^{-1}$, com aplicação de demais manejos de forma adequada, e obtido em menores cilcos (8 a 10 meses de idade da planta), possibilitando, considerando a rendimento comercial, o uso de mandioca de mesa também para a indústria de processamento (NASCIMENTO et al., 2018).

Cultivares tradicionais e melhoradas são selecionadas pelos produtores e programas de melhoramento com o objetivo de alcançar alta produtividade e boa qualidade das raízes, o que pode ser um caminho importante para se verificar outras aptidões além daquelas para as quais são comumente cultivadas (CEBALLOS et al., 2012). Cultivares como a BRS Kiriris, inicialmente lançada para a indústria, por apresentar características de mandioca de mesa, tem sido indicada para dupla aptidão (ARAÚJO \& ALMEIDA, 2013).

\section{METODOLOGIA}

O trabalho foi realizado em área comercial de mandioca de mesa, na Fazenda Santa Mônica, localizada no município de Ceará Mirim, RN, em solo do tipo Arenoso, no período de junho de 2018 a maio de 2019, em cultivo irrigado.

Após o cultivo do mamão e o preparo da área, plantou-se manivas com $8 \mathrm{~cm}$ de comprimento, de nove cultivares de mandioca, tipicamente de mesa, tradicionais (cv. 
Venâncio, cv. Água Morna e cv. Recife) e melhoradas (BRS Gema de Ovo, CMF33.01, CMF33.18, CMF33.21, CMF33.41 e CMF48.18) do programa de melhoramento da Embrapa Mandioca e Fruticultura. Utilizou-se delineamento de blocos casualizados, com três repetições. Cada parcela útil foi constituída por doze plantas. Foi utilizado espaçamento de $0,8 \mathrm{~m} \times 0,8 \mathrm{~m}$ (15.625 plantas por hectare). Aplicou-se em fundação, $150 \mathrm{~kg} \mathrm{ha}^{-1}$ do formulado 19-04-19.

A irrigação foi do tipo aspersão convencional, com aspersores espaçados de 12 m x 12 m, com vazão de $362 \mathrm{~L} \mathrm{~h}^{-1}$, em turno de rega diário (exceto aos domingos) e tempo de 3h00 $(4,7 \mathrm{~mm})$.

Por ocasião da colheita, aos 12 meses de idade da lavoura, avaliou-se visualmente o porte das plantas (notas de 1 a 4, onde a nota 1 representa ausência de bifurcação e a nota 4 as plantas com bifurcação mais baixa), e por contagem e pesagem, o número e massa de raízes, comerciais e refugo. O percentual de matéria seca e de amido na foi avaliado pelo método da balança hidrostática (GROSMANN \& FREITAS,1950).

Os dados foram submetidos a análise de variância (teste F), de comparação de médias (Skott-Knott), de normalidade para dados de contagem e de transformação de dados $\left(\mathrm{X}^{0.5}\right.$, raiz quadrada), caso ocorresse distribuição não-normal, considerando a probabilidade de $5 \%$, com o uso do software Sisvar v.5.3 (FERREIRA, 2014).

\section{RESULTADOS E DISCUSSÃO}

Nas Tabelas 1 e 2 estão apresentadas as características de qualidade e produção de raízes das cultivares avaliadas. A maioria das características avaliadas neste experimento deferiram estatisticamente em um nível de probabilidade de 5\%, exceto as características de peso de raízes não comerciais por planta e o peso médio de raízes não comerciais, estas foram não significativas.

Tabela 1: Características de produção de raízes e plantas de híbridos de mandioca.

\begin{tabular}{|c|c|c|c|c|c|c|c|c|}
\hline \multirow[t]{2}{*}{ Cultivares } & \multicolumn{2}{|c|}{$\begin{array}{l}\text { Altura de } \\
\text { ramificação }\end{array}$} & \multirow{2}{*}{$\begin{array}{c}\mathrm{N}^{\circ} \text { raízes } \\
\text { comerciais } \\
\text { por planta } \\
\text { Médias } \\
\end{array}$} & \multicolumn{2}{|c|}{$\begin{array}{c}\text { Número de } \\
\text { raízes } \\
\text { comerciais/raízes } \\
\text { refugo }\end{array}$} & \multirow{2}{*}{$\begin{array}{c}\text { Produção } \\
\text { de raízes } \\
\text { comerciais } \\
\text { por planta } \\
(\mathrm{Kg}) \\
\text { Médias } \\
\end{array}$} & \multicolumn{2}{|c|}{$\begin{array}{c}\text { Produção de } \\
\text { raízes } \\
\text { comerciais/raízes } \\
\text { refugo }\end{array}$} \\
\hline & Médias & $X^{0,5}$ & & Médias & $\mathrm{X}^{0,5}$ & & Médias & $\mathrm{X}^{0,5}$ \\
\hline CMF33.41 & $1,00 \mathrm{~b}$ & $1,00 \mathrm{~b}$ & $2,33 \mathrm{~b}$ & 0,97 & $0,97 \mathrm{~b}$ & $1,30 \mathrm{c}$ & $7,52 \mathrm{~b}$ & $2,58 \mathrm{~b}$ \\
\hline CMF33.01 & $1,00 \mathrm{~b}$ & $1,00 \mathrm{~b}$ & $3,80 \mathrm{a}$ & 1,75 & $1,32 \mathrm{~b}$ & $1,58 \mathrm{c}$ & $6,75 \mathrm{~b}$ & $2,59 \mathrm{~b}$ \\
\hline $\begin{array}{l}\text { BRS Gema } \\
\text { de Ovo }\end{array}$ & $3,17 \mathrm{a}$ & $1,78 \mathrm{a}$ & $2,91 \mathrm{~b}$ & 1,44 & $1,18 \mathrm{~b}$ & $1,56 \mathrm{c}$ & $7,02 \mathrm{~b}$ & $2,59 \mathrm{~b}$ \\
\hline cv. Recife & $3,67 \mathrm{a}$ & $1,91 \mathrm{a}$ & $4,35 \mathrm{a}$ & 3,57 & $1,89 \mathrm{a}$ & $3,27 \mathrm{a}$ & $35,11 \mathrm{a}$ & $5,77 \mathrm{a}$ \\
\hline CMF33.21 & $3,33 \mathrm{a}$ & $1,82 \mathrm{a}$ & $2,33 \mathrm{~b}$ & 1,00 & $1,00 \mathrm{~b}$ & $0,79 \mathrm{c}$ & $3,40 \mathrm{~b}$ & $1,82 \mathrm{~b}$ \\
\hline
\end{tabular}




\begin{tabular}{lcccccccc} 
CMF33.18 & $1,67 \mathrm{~b}$ & $1,24 \mathrm{~b}$ & $1,86 \mathrm{~b}$ & 1,68 & $1,22 \mathrm{~b}$ & $0,67 \mathrm{c}$ & $6,27 \mathrm{~b}$ & $2,47 \mathrm{~b}$ \\
cv. Água & & & & & & & & \\
Morna & $1,67 \mathrm{~b}$ & $1,28 \mathrm{~b}$ & $4,55 \mathrm{a}$ & 1,66 & $1,28 \mathrm{~b}$ & $2,25 \mathrm{~b}$ & $4,64 \mathrm{~b}$ & $2,14 \mathrm{~b}$ \\
CMF48.18 & $4,00 \mathrm{a}$ & $2,00 \mathrm{a}$ & $3,92 \mathrm{a}$ & 2,12 & $1,41 \mathrm{~b}$ & $2,42 \mathrm{~b}$ & $10,87 \mathrm{~b}$ & $3,20 \mathrm{~b}$ \\
cv. & & & & & & & & \\
Venâncio & $4,00 \mathrm{a}$ & $2,00 \mathrm{a}$ & $2,69 \mathrm{~b}$ & 1,51 & $1,22 \mathrm{~b}$ & $2,05 \mathrm{~b}$ & $10,59 \mathrm{~b}$ & $3,25 \mathrm{~b}$ \\
\hline Média Geral & & 1,56 & 3,19 & & 1,28 & 1,77 & & 2,94 \\
CV $(\%)$ & 11,84 & 23,38 & & 18,00 & 28,93 & & 23,36 \\
& & 15,78 & & & 4,054 & & & \\
$\mathrm{Fc}(\operatorname{Pr}>\mathrm{Fc})$ & & $* *$ & $5,17 * *$ & & $* *$ & $7,84 * *$ & & $8,52 * *$ \\
\hline
\end{tabular}

${ }^{1}$ Médias seguidas de letras iguais, nas colunas, não diferem entre si, pelo teste de Scott-Knott. Fonte: Própria (2019)

Tabela 2: Características de produção de raízes de híbridos de mandioca.

\begin{tabular}{|c|c|c|c|c|c|c|c|}
\hline \multirow[t]{2}{*}{ Cultivares } & \multirow{2}{*}{$\begin{array}{l}\text { Massa de } \\
\text { raiz } \\
\text { comercial } \\
\quad(\mathrm{g})\end{array}$} & \multirow{2}{*}{$\begin{array}{l}\text { Massa de } \\
\text { raiz não } \\
\text { comercial } \\
\quad(\mathrm{g})\end{array}$} & \multicolumn{2}{|c|}{$\begin{array}{c}\text { Massa de raiz } \\
\text { comercial/raiz } \\
\text { refugo }\end{array}$} & \multirow{2}{*}{$\begin{array}{l}\text { Rendimento } \\
\text { de raízes } \\
\left(\mathrm{t} \mathrm{ha}^{-1}\right)\end{array}$} & \multirow{2}{*}{$\begin{array}{c}\text { Matéria } \\
\text { seca na } \\
\text { raiz } \\
(\%)\end{array}$} & \multirow{2}{*}{$\begin{array}{c}\text { Amido } \\
\text { na raiz } \\
(\%)\end{array}$} \\
\hline & & & Médias & $X^{0,5}$ & & & \\
\hline CMF33.41 & $589,56 \mathrm{~b}$ & $140,91 \mathrm{a}$ & $6,53 \mathrm{a}$ & $2,48 \mathrm{a}$ & $20,23 \mathrm{c}$ & $30,23 \mathrm{c}$ & $25,98 \mathrm{c}$ \\
\hline CMF33.01 & $396,96 \mathrm{c}$ & $102,78 \mathrm{a}$ & $3,87 \mathrm{~b}$ & $1,97 \mathrm{~b}$ & $24,69 \mathrm{c}$ & $34,55 \mathrm{~b}$ & $30,30 \mathrm{~b}$ \\
\hline $\begin{array}{l}\text { BRS Gema } \\
\text { de Ovo }\end{array}$ & $548,61 \mathrm{~b}$ & $111,46 \mathrm{a}$ & $4,95 \mathrm{~b}$ & $2,21 \mathrm{~b}$ & $24,40 \mathrm{c}$ & $37,33 \mathrm{a}$ & $33,08 \mathrm{a}$ \\
\hline cv. Recife & $753,92 \mathrm{a}$ & $97,50 \mathrm{a}$ & $9,35 \mathrm{a}$ & $3,01 \mathrm{a}$ & $51,09 \mathrm{a}$ & $34,45 \mathrm{~b}$ & $30,20 \mathrm{~b}$ \\
\hline CMF33.21 & $343,00 \mathrm{c}$ & $113,91 \mathrm{a}$ & $3,45 \mathrm{~b}$ & $1,84 \mathrm{~b}$ & $12,35 \mathrm{c}$ & $38,26 \mathrm{a}$ & $34,01 \mathrm{a}$ \\
\hline $\begin{array}{c}\text { CMF33.18 } \\
\text { cv. Água }\end{array}$ & $387,04 \mathrm{c}$ & $103,51 \mathrm{a}$ & $4,18 \mathrm{~b}$ & $2,03 \mathrm{~b}$ & $10,53 \mathrm{c}$ & $35,60 \mathrm{~b}$ & $31,35 \mathrm{~b}$ \\
\hline Morna & $486,37 \mathrm{~b}$ & $174,58 \mathrm{a}$ & $2,78 \mathrm{~b}$ & $1,67 \mathrm{~b}$ & $35,17 \mathrm{~b}$ & $36,78 \mathrm{a}$ & $32,53 \mathrm{a}$ \\
\hline $\begin{array}{c}\text { CMF48.18 } \\
\text { cv. }\end{array}$ & $604,86 \mathrm{~b}$ & $116,77 \mathrm{a}$ & $5,19 \mathrm{~b}$ & $2,28 \mathrm{~b}$ & $37,81 \mathrm{~b}$ & $32,45 \mathrm{c}$ & $28,20 \mathrm{c}$ \\
\hline Venâncio & $889,17 \mathrm{a}$ & $114,15 \mathrm{a}$ & $7,81 \mathrm{a}$ & $2,78 \mathrm{a}$ & $32,01 \mathrm{~b}$ & $36,84 \mathrm{a}$ & $32,59 \mathrm{a}$ \\
\hline Média & 555,50 & 119,51 & & 2,25 & 27,59 & 35,17 & 30,92 \\
\hline $\mathrm{CV}(\%)$ & 19,3 & 35,98 & & 16,07 & 28,96 & 4,03 & 4,59 \\
\hline $\mathrm{Fc}(\mathrm{p}<0,05)$ & $8,41 * *$ & 0,94 ns & & $4,44 * *$ & $7,82 * *$ & $9,77 * *$ & $9,77 * *$ \\
\hline
\end{tabular}

${ }^{1}$ Médias seguidas de letras iguais, nas colunas, não diferem entre si, pelo teste de Scott-Knott.

Fonte: Própria (2019)

A quantidade e massa (comercial e total) de raízes por planta contribuíram para as altas produtividades $\left(24,4\right.$ a $\left.51,0 \mathrm{t} \mathrm{ha}^{-1}\right)$ obtidas por seis cultivares, como mostra a tabela 1 . A produtividade da mandioca é um dos parâmetros de maior representatividade econômica e mercadológica (GOMES et al., 2007). A variação do percentual de amido (28 a 34\%) qualifica as cultivares para uso industrial, desde que associado a boa produtividade de raízes (SANTOS et al., 2011), deste modo destacou-se a maioria das cultivares, exceto a cultivar CMF33.41 que obteve rendimento de amido inferior a 28\%, compara-se as regiões do sul e sudeste, que são os centros de exploração comercial de grandes empresas de amido.

A produção por planta neste trabalho (média $1,77 \mathrm{Kg}$ ) foi abaixo do esperado, quando 
se cultiva em solo fértil e com irrigação espera-se produções por planta superiores a $4 \mathrm{~kg}$ de raízes comerciais (FATIGATTI et al., 2015; MATOS et al., 2016). A baixa produção pode ter relação com a presença de plantas daninhas em todo o período de interferência das cultivares, um solo com excesso de adubos que foram utilizados no cultivo do mamão, além de um adensamento inadequado para as plantas com tipo de crescimento igual e superior a 2. Em experimento realizado por SOUSA et al. (2018) no RN com as mesmas cultivares, também irrigadas, eles observaram média inferior a $4 \mathrm{Kg}$ de raízes por planta. Deixando claro que deve ser feito estudo em relação ao manejo das cultivares promissoras.

O tipo de crescimento foi ereto (Tipo 1) para CMF33.41 e CMF33.01, semiereto (Tipo 2) para CMF33.18 e cv. Água Morna, com ramificação no meio da planta (Tipo 3) para BRS Gema de Ovo, cv. Recife e CMF33.21 e com ramificação na parte inferior para CMF48.18 e cv. Venâncio. Cultivares do Tipo 1 tem maior facilidade em aumento de produção, já que se pode ter um maior adensamento de plantas em comparação com cultivares de outros tipos.

A média de número de raízes comerciais por planta $(3,19)$ deste experimento foi semelhante à média observada por SILVA et al. (2018) utilizando as mesmas cultivares, que foi de 3,4. Tratando-se da relação entre número de raízes comerciais e não comerciais a cultivar Recife se destacou, sendo a única a deferir estatisticamente das demais. Já a relação entre peso médio de raízes comerciais e não comerciais, as cultivares que obtiveram superioridade foram cv. Recife novamente, e a cv. Venâncio. Tais características são bastante importantes para o mercado de mandioca de mesa, sendo as melhores aquelas que produzem mais raízes comerciais, já que não se difere raízes comerciais e não comerciais quando se trata de mercado industrial.

\section{CONCLUSÕES}

Considerando as características de produção e qualidade de raízes avaliadas, é possível indicar cultivares para dupla aptidão, consumo de mesa e indústria, em que apresentaram produtividades superiores a $20 \mathrm{t} \mathrm{ha}^{-1}$ e percentual de amido variando de 28 a $34 \%$. Com destaque para as cultivares CMF48.18, cv. Água Morna, cv. Venâncio e cv. Recife, em ordem crescente.

\section{REFERÊNCIAS}

ARAÚJO, J. C.; ALMEIDA, C. O. Inventário de variedades de mandioca lançadas pela Embrapa Mandioca e Fruticultura no período de 1996 a 2009. Circular Técnica 107 CNPMF, Cruz das Almas, 2013. 
CASTRO, F. C.; FERREIRA, E. G.; MURAISHI, C. T. Aspectos Socioeconômicos e Agronômicos da Mandioca - Embrapa revista Integralização Universitária - RIU, Palmas, v.11, n.17, dez, 2017.

CEBAllos, H.; KUlAKOW, P.; HERSHEY, C. Cassava breeding: Current status, bottlenecks and the potential of biotechnology tools. Tropical Plant Biology, v.5, p.73-87, 2012.

DINIZ, M. de S.; SILVA, J.; ARRAIS, Í. G.; ALVES, M. C. S.; FERREIRA, K. C. Z. Comportamento de cultivares de mandioca (Manihot esculentaCrantz) DE mesa no Município de Belmonte, Bahia. Embrapa Mandioca e Fruticultura - Artigo em anais de congresso (ALICE), 2014. Disponível em: <http://www.alice.cnptia.embrapa.br>. Acesso em: 11 agosto 2019.

FATIGATTI, D. A.; SILVA, J.; ALVES, M. C. S.; SILVA, J. R.; TORRES, J. F.; ARRAIS, I. G.; PRATA, R. C.; DANTAS, R. P. Adubação, densidade de plantio e idade da planta na dimensão e massa de raízes comerciais de macaxeira irrigada. Encontro Nacional da Agroindústria, 1, Bananeiras, 2015. UFPB, Bananeiras, 2015.

FERREIRA, D. F. Sisvar - sistema de análise de variância para dados balanceados. Lavras: UFLA, 1998. 19 p.

GCEA - IBGE: Grupo de Coordenação de Estatísticas Agropecuárias - Instituto Brasileiro de Geografia e Estatística / Embrapa Amazônia Oriental - Chefia de Pesquisa \& Desenvolvimento. Disponível em: <https://www.embrapa.br/amazonia-oriental>. Acesso em: 11 agosto 2019.

GOMES, C. N.; CARVALHO, S. P. de; JESUS, A. M. S.; CUSTÓDIO, T. N. Caracterização morfoagronômica e coeficientes de trilha de caracteres componentes da produção em mandioca. Pesquisa Agropecuária Brasileira, v. 42, n. 8, 2007.

GROSSMAN, J.; FREITAS, A. C. Determinação do teor de matéria seca pelo peso específico em mandioca. Revista Agronômica, Porto Alegre, v. 14, n. 160/162, p. 75-80, 1950.

MATOS, F. S.; FELÍCIO, R.; SILVEIRA, P. S.; GUIMARÃES, R. R.; SANTOS, P. G. F.; NASCENTE, A. C. S.; CUSTÓDIO, J. P. C.; SILVA, L. M. Produtividade de mandioca sob déficit hídrico. Revista Agri-Environmental Sciences, v.2, n.1, p.15-24, 2016.

NASCIMENTO, C. M.; SILVA, L. M.; SOUSA, L. M. S.; MEDEIROS, S. J.; SILVA, J. R.; SILVA, J. Cultivares de Mandioca para Dupla Aptidão, Consumo de Mesa e Indústria, em Área Irrigada e Pós Cultivo do Melão. IV Encontro Nacional da Agroindústria. Campinas. Anal Eletrônico, GALOÁ. 2018. Disponível em: <https://proceedings.science>. Acesso em: 11 agosto 2019.

PEIXOTO, Y. G. G.; SOUSA, L. M. S.; SILVA, L. M.; LIMA, Y. B.; ANCHIETA, O. F. A.; SILVA, J. Produção de Mandioca para Industria, Irrigada e em Diferentes Manejos e Locais no Rio Grande do Norte. IV Encontro Nacional da Agroindústria. Campinas. Anal Eletrônico, GALOÁ. 2018. Disponível em: <https://proceedings.science>. Acesso em: 11 agosto 2019. 
SANTOS, T.T.; SOUZA, E.X.N. de; SILVA, L.C. da; CAZETTA, M.L. Avaliação microbiológica e físico-química da farinha de mandioca comercializada no mercado municipal de Cruz das Almas - BA. Magistra, v. 23, n. 3, p. 149-153, 2011.

SILVA, L. M.; SOUSA, L. M. S.; NASCIMENTO, C. M.; MEDEIROS, S. J.; ALVES, M. C. S.; SILVA, J. Avaliação de Mandioca para o Consumo de Mesa e uso Industrial Cultivadas em Solo Arenoso, Irrigado e com Resíduo de Adubo do Mamão. IV Encontro Nacional da Agroindústria. Campinas. Anal Eletrônico, GALOÁ. 2018. Disponível em: <https://proceedings.science>. Acesso em: 11 agosto 2019.

SOUSA, L. M. S.; NASCIMENTO, F. G. O.; NASCIMENTO, C. M SILVA, L. M.; J SILVA, J.; ALVES, M. C. S. Avaliação de Mandiocas para Dupla Aptidão, Mesa e Industrial, Cultivadas em Solo Argiloso e Irrigado. IV Encontro Nacional da Agroindústria. Campinas. Anal Eletrônico, GALOÁ. 2018. Disponível em: <https://proceedings.science>. Acesso em: 11 agosto 2019. 


\section{SALINIDADE NA GERMINAÇÃO DE SEMENTES DE MADEIRA-NOVA INDUZIDA POR DIFERENTES SAIS}

\section{SALINIDAD EN LA ALEMINACIÓN DE SEMILLAS DE MADEIRA-NOVA INDUCIDA POR DIFERENTES SALES}

\section{SALINITY IN GERMINATION OF MADEIRA-NOVA SEED INDUCED BY DIFFERENT SALTS}

Emanuelle Marques Coutinho ${ }^{1}$; Andrei dos Santos Souza ${ }^{2}$; Mateus Pereira dos Santos ${ }^{3}$; Jamil Sousa Silva ${ }^{4}$; Gisele Brito Rodrigues ${ }^{5}$

DOI: https://doi.org/10.31692/978-65-991061-4-9.192-198

\section{INTRODUÇÃO}

A Madeira-nova (Pterogyne nitens Tul.) se destaca entre as espécies nativas mais cultivadas no Brasil, sendo de grande importância econômica para a produção madeireira e geração de energia, bem como tem sido muito utilizada na reposição de matas ciliares e recuperação de vegetação (FIGUEIREDO et al., 2018). A produção de mudas requerida na recuperação de áreas degradas é dificultada em decorrência da dormência das sementes desta espécie, dificultando a sua germinação.

Para germinar, além de superar a dormência, a espécie requer condições de luz, temperatura e disponibilidade de água. Em condições de solos com alta concentração salina, as sementes apresentam dificuldades para germinar, visto que o alto teor de sais, especialmente de cloreto de sódio $(\mathrm{NaCl})$, pode inibir a germinação devido a diminuição do potencial osmótico, ocasionando prejuízos as demais fases do processo. Além disso, o sal absorvido, acumulado no interior das células, pode causar toxidez (AVRELLA, 2019).

Segundo Santos (2011), a salinidade é um fator abiótico que afeta negativamente o processo de germinação, o desenvolvimento vegetativo das culturas, e nos casos mais graves, leva a morte das plântulas. Portanto, torna-se necessário obter informações sobre o efeito da salinidade no processo germinativo, a fim de possibilitá-lo nessas condições. Assim, o objetivo desse trabalho foi avaliar o efeito de diferentes potencias osmóticos induzidos pelos

\footnotetext{
1 Curso de graduação em Agronomia, Universidade Estadual do Sudoeste da Bahia - UESB, e-mail: emanuellemarques321@gmail.com

2 Curso de graduação em Agronomia, Universidade Estadual do Sudoeste da Bahia - UESB, e-mail: andrei_souza37@hotmail.com

3 Curso de graduação em Agronomia, Universidade Estadual do Sudoeste da Bahia - UESB, e-mail: mateus.santos.0712@gmail.com

4 Curso de graduação em Agronomia, Universidade Estadual do Sudoeste da Bahia - UESB, e-mail: jamilsousa13@gmail.com

${ }^{5}$ Doutora em Agronomia (Fitotecnia)/Departamento de Fitotecnia e Zootecnia da UESB, Universidade Estadual do Sudoeste da Bahia - UESB, e-mail: gisele.rodrigues@uesb.edu.br
} 
agente salinos $\mathrm{CaCl}_{2} 2 \mathrm{H}_{2} \mathrm{O}$ e $\mathrm{NaCl}$ na germinação de sementes de Pterogyne nitens.

\section{FUNDAMENTAÇÃO TEÓRICA}

A busca pelo entendimento sobre a capacidade de alguns vegetais em tolerar condições de baixa disponibilidade hídrica e a caracterização dos problemas de ordem fisiológica ou ecológica causada pela escassez de água merecem significativa importância para o meio científico, de forma que sejam geradas tecnologias que permita a exploração dessas espécies, sobretudo para a sua utilização em recuperação de locais onde ocorre esse tipo de limitação (SÁ et al., 2013).

A madeira-nova pertence à família Fabaceae (Subfamília Caesalpinoideae) e apresenta características importantes como rusticidade e crescimento rápido, por esta razão, é muito utilizada em plantio para recuperação de áreas degradadas e de preservação permanente. Além disso, possui ampla distribuição natural por todo o Brasil, ocorrendo em biomas como Mata Atlântica, Cerrado, Caatinga, em também em áreas caracterizadas pela elevada umidade e vegetação florestal (LORENZI, 2009). Contudo, um dos principais problemas para a propagação dessa espécie é a dormência apresentada pelas suas sementes, causando germinação lenta e desuniforme.

Para que ocorra a germinação, a disponibilidade de água se torna um fator limitante, e nessas condições o potencial germinativo de sementes de determinadas espécies podem indicar se a mesma apresentará tolerância à deficiência hídrica ou salinidade em estádios subsequentes do seu desenvolvimento (TAIZ; ZEIGER, 2013). Deste modo, há importância do estudo dos efeitos da condição de estresse ocasionado pela salinidade no processo germinativo de algumas espécies.

Ressalta-se que, quando este tipo de estresse ocorre de forma severa na planta-mãe, os efeitos refletem de forma indireta na germinação das sementes produzidas, pois estas, quando submetidas à potenciais osmóticos muitos negativos, não conseguirão absorver água, tendo o processo germinativo e a velocidade de germinação prejudicados, além disso, a plântula formada tende a apresentar menor resistência as condições ambientais adversas e de fatores bióticos como o ao ataque de patógenos e pragas (KAPPES et al., 2010).

\section{METODOLOGIA}

O experimento foi conduzido no Laboratório de Tecnologia e Produção de Sementes da Universidade Estadual do Sudoeste da Bahia - UESB, Campus Vitória da Conquista, BA (1450'19" S e 4450'19"W). Foram coletadas frutos de Madeira-nova em diferentes matrizes 
localizadas no referido campus. Após as coletas, as sementes foram extraídas manualmente dos frutos com o auxílio de uma tesoura e selecionadas quanto à integridade física e ausência de ataques de patógenos e insetos.

O delineamento experimental utilizado foi o inteiramente casualizado em esquema fatorial $5 \times 2$, composto por cinco potenciais osmóticos $(-0,1 ;-0,2 ;-0,3 ;-0,4$ e $-0,5 \mathrm{MPa})$ e dois agentes salinizantes (Cloreto de Cálcio Dihidratado - $\mathrm{CaCl}_{2} 2 \mathrm{H}_{2} \mathrm{O}$ e Cloreto de Sódio - $\mathrm{NaCl}$ ), com quatro repetições de 25 sementes, totalizando 40 parcelas. As soluções foram preparadas nas concentrações de cada potencial indicado seguindo a fórmula de Van’t Hoff:

$$
\Psi_{\text {osm }}=-\mathrm{RTC}
$$

Onde: $\Psi_{\text {osm }}$ é o potencial osmótico (atm); R é a constante geral dos gases $=0,082 \mathrm{~atm}$ $\mathrm{L} \mathrm{mol}^{-1}{ }^{\circ} \mathrm{K}^{-1}$; T é a temperatura $\left({ }^{\circ} \mathrm{K}\right)$ e $\mathrm{C}$ a concentração molar (mols de soluto $10^{-3} \mathrm{~g}^{-1} \mathrm{de}$ água).

As sementes de madeira-nova, antes dos testes, foram submetidas à superação de dormência através de escarificação química com Ácido Sulfúrico $\left(\mathrm{H}_{2} \mathrm{SO}_{4}\right)$, onde ficaram imersas por 10 minutos, sendo logo em seguida, desinfestadas com Hipoclorito de sódio à $1,5 \%$.

As sementes foram distribuídas uniformemente sobre uma folha de papel Germitest ${ }^{\circledR}$ e foram cobertas por outra folha. Esses papeis foram umedecidos com as soluções salinas na proporção de 2,5 vezes o peso do papel seco, segundo a metodologia padrão para teste de germinação das Regras para Análise de Sementes (BRASIL, 2009). Os papeis foram organizados em rolos acondicionados em sacos plásticos e mantidos em câmara B.O.D regulada à $25 \pm 0,3{ }^{\circ} \mathrm{C}$. A contagem das sementes germinadas foi feita diariamente, considerando germinadas as sementes que apresentaram a protrusão da radícula maior ou igual a 5 mm (BRASIL, 2009).

Avaliou-se a Porcentagem de Germinação (\%), o Índice de Velocidade de Germinação (IVG), o Tempo Médio de Germinação (dias), a Velocidade Média de Germinação $\left(\operatorname{dias}^{-1}\right)$, o Índice de Sincronização de Germinação ou incerteza (bits) e o Coeficiente de Uniformidade de Germinação. As variáveis foram analisadas pelo pacote germinationmetrics do Programa livre R (R Development Core Team, 2016) e em seguida, os dados foram submetidos à análise de variância e regressão, sendo comparados pelo teste Tukey à 5\% de probabilidade pelo mesmo programa através do pacote Expdes.pt.

\section{RESULTADOS E DISCUSSÃO}


Os resultados da análise de variância indicaram interação significativa entre os potenciais osmóticos e os agentes salinizantes (Tabela 1).

Tabela 1. Médias de Germinação (\%), Índice de Velocidade de Germinação (IVG), Tempo Médio e Velocidade Média de Germinação (TMG), (VMG), Índice de Sincronização de germinação (E) e Coeficiente de Uniformidade de Germinação (CUG) de sementes de $P$. nitens submetidas à estresse salino induzido por

\begin{tabular}{|c|c|c|c|c|c|c|}
\hline \multirow{2}{*}{ Agente osmótico } & Germinação (\%) & IVG & TMG (dias) & VMG $\left(\operatorname{dias}^{-1}\right)$ & $\mathrm{E}$ (bits) & CUG \\
\hline & \multicolumn{6}{|c|}{$-0,1 \mathrm{MPa}$} \\
\hline $\mathrm{CaCl}_{2} 2 \mathrm{H}_{2} \mathrm{O}$ & $63,71 \mathrm{~B}$ & $5,36 \mathrm{~B}$ & $3,98 \mathrm{~A}$ & $0,25 \mathrm{~B}$ & $0,37 \mathrm{~A}$ & $0,28 \mathrm{~A}$ \\
\hline \multirow[t]{2}{*}{$\mathrm{NaCl}$} & $74,22 \mathrm{~A}$ & $9,83 \mathrm{~A}$ & $2,59 \mathrm{~B}$ & $0,38 \mathrm{~A}$ & $0,48 \mathrm{~A}$ & $0,14 \mathrm{~B}$ \\
\hline & \multicolumn{6}{|c|}{$-0,2 \mathrm{MPa}$} \\
\hline $\mathrm{CaCl}_{2} 2 \mathrm{H}_{2} \mathrm{O}$ & $62,23 \mathrm{~A}$ & $4,22 \mathrm{~B}$ & $4,72 \mathrm{~A}$ & $0,21 \mathrm{~B}$ & $0,39 \mathrm{~B}$ & $0,47 \mathrm{~A}$ \\
\hline \multirow[t]{2}{*}{$\mathrm{NaCl}$} & $66,76 \mathrm{~A}$ & $9,44 \mathrm{~A}$ & $2,38 \mathrm{~B}$ & $0,42 \mathrm{~A}$ & $0,66 \mathrm{~A}$ & $0,13 \mathrm{~B}$ \\
\hline & \multicolumn{6}{|c|}{$-0,3 \mathrm{MPa}$} \\
\hline $\mathrm{CaCl}_{2} 2 \mathrm{H}_{2} \mathrm{O}$ & $0,00 \mathrm{~B}$ & $0,00 \mathrm{~B}$ & $0,00 \mathrm{~B}$ & $0,00 \mathrm{~B}$ & $0,00 \mathrm{~B}$ & $0,00 \mathrm{~B}$ \\
\hline \multirow[t]{2}{*}{$\mathrm{NaCl}$} & $61,35 \mathrm{~A}$ & $6,91 \mathrm{~A}$ & $2,98 \mathrm{~A}$ & $0,33 \mathrm{~A}$ & $0,56 \mathrm{~A}$ & $0,16 \mathrm{~A}$ \\
\hline & \multicolumn{6}{|c|}{$-0,4 \mathrm{MPa}$} \\
\hline $\mathrm{CaCl}_{2} 2 \mathrm{H}_{2} \mathrm{O}$ & $0,00 \mathrm{~B}$ & $0,00 \mathrm{~B}$ & $0,00 \mathrm{~B}$ & $0,00 \mathrm{~B}$ & $0,00 \mathrm{~B}$ & $0,00 \mathrm{~B}$ \\
\hline \multirow[t]{2}{*}{$\mathrm{NaCl}$} & $63,23 \mathrm{~A}$ & $8,59 \mathrm{~A}$ & $2,44 \mathrm{~A}$ & $0,41 \mathrm{~A}$ & $0,57 \mathrm{~A}$ & $0,13 \mathrm{~A}$ \\
\hline & \multicolumn{6}{|c|}{$-0,5 \mathrm{MPa}$} \\
\hline $\mathrm{CaCl}_{2} 2 \mathrm{H}_{2} \mathrm{O}$ & $0,00 \mathrm{~B}$ & $0,00 \mathrm{~B}$ & $0,00 \mathrm{~B}$ & $0,00 \mathrm{~B}$ & $0,00 \mathrm{~B}$ & $0,00 \mathrm{~B}$ \\
\hline $\mathrm{NaCl}$ & $60,86 \mathrm{~A}$ & $4,84 \mathrm{~A}$ & $4,23 \mathrm{~A}$ & $0,23 \mathrm{~A}$ & $0,34 \mathrm{~A}$ & $0,32 \mathrm{~A}$ \\
\hline
\end{tabular}

Médias seguidas de mesma letra maiúscula na coluna, não diferem entre si pelo teste Tukey à 5\% de probabilidade.

Fonte: Própria (2019)

As médias de Germinação e IVG com $\mathrm{NaCl}$ foram superiores às médias das mesmas variáveis para os tratamentos com $\mathrm{CaCl}_{2} 2 \mathrm{H}_{2} \mathrm{O}$ dentro de todos os potenciais osmóticos, exceto -0,2 MPa, onde as médias de Germinação não diferiram entre si. Verifica-se que, para $\mathrm{CaCl}_{2} 2 \mathrm{H}_{2} \mathrm{O}$, a germinação foi nula a partir $-0,3 \mathrm{MPa}$.

O mesmo comportamento foi observado por Santos et al. (2016) para as espécies Poincianela pyramidalis (Tul.) L. P. Queiroz e Anadenanthera colubrina (Vell.), os autores observaram que a germinação e o IVG dessas espécies sob solução de $\mathrm{CaCl}_{2}$ foi nula a partir de -0,8 MPa, possivelmente devido alterações na concentração dos íons $\mathrm{Na}^{+}$e $\mathrm{Cl}^{-}$no interior das células, ocasionando estresse iônico e descontrole em algumas atividades metabólicas durante o processo de germinação.

Os valores de TMG foram maiores nos tratamentos $\mathrm{CaCl}_{2} 2 \mathrm{H}_{2} \mathrm{O}$, nos potenciais de 0,1 e -0,2 $\mathrm{MPa}$ em relação aos tratamentos com $\mathrm{NaCl}$, indicando atraso na germinação das sementes em contato com esse sal, o que já era esperado. Ressalta-se que, os valores nulos de 
TMG obtidos nos potenciais de 0,$3 ;-0,4$ e - 0,5 MPa foram em decorrência da não germinação das sementes, por isso, as médias dos tratamentos com $\mathrm{NaCl}$ foram superiores nos referidos potenciais. Já para a VMG, que é inversamente proporcional ao TMG, maiores médias foram obtidas com $\mathrm{NaCl}$ em todos os potenciais osmóticos quando comparados com $\mathrm{CaCl}_{2} 2 \mathrm{H}_{2} \mathrm{O}$, evidenciando que as sementes apresentaram germinação mais veloz quando tratadas com $\mathrm{NaCl}$.

Os tratamentos com $\mathrm{CaCl}_{2} 2 \mathrm{H}_{2} \mathrm{O}$ apresentaram germinação mais sincronizada do que os tratamentos com $\mathrm{NaCl}$, devido ao menor valor E encontrado, já para o CUG, verificou-se baixos valores para esta variável, indicando germinação desuniforme em todos os tratamentos, possivelmente esses resultados ocorreram em função da alta concentração dos íons $\mathrm{Na}^{+} \mathrm{e} \mathrm{Cl}^{-}$ no interior celular que foi suficiente para provocar respostas diferentes quanto à uniformização e sincronia da germinação.

A análise de regressão indicou efeito linear negativo para todas as variáveis dos tratamentos com $\mathrm{CaCl}_{2} 2 \mathrm{H}_{2} \mathrm{O}$, ou seja, a medida que o potencial osmótico é reduzido, as características da germinação também se reduzem (Figura 1). Já para os tratamentos com $\mathrm{NaCl}$, foi verificado efeito linear negativo para Germinação e IVG, efeito linear positivo para TMG, efeito quadrático positivo para VMG e Índice de sincronização (E) e quadrático negativo para CUG (Figura 1).

Figura 1. Estimativa da Germinação (\%) (A), Índice de Velocidade de Germinação (IVG) (B), Tempo Médio de Germinação (TMG) (dias) (C), Velocidade Média de Germinação (VMG) (dias ${ }^{-1}$ ) (D), Índice de Sincronização de Germinação (E) (bits) (E) e Coeficiente de Uniformidade de Germinação (CUG) (F) de sementes de $P$. nitens submetidas à salinidade $\mathrm{com} \mathrm{CaCl}_{2}$ $2 \mathrm{H}_{2} \mathrm{O}$ e NaCl, Vitória da Conquista, BA, 2019. * e ** significativo à 1 e $5 \%$ de probabilidade.
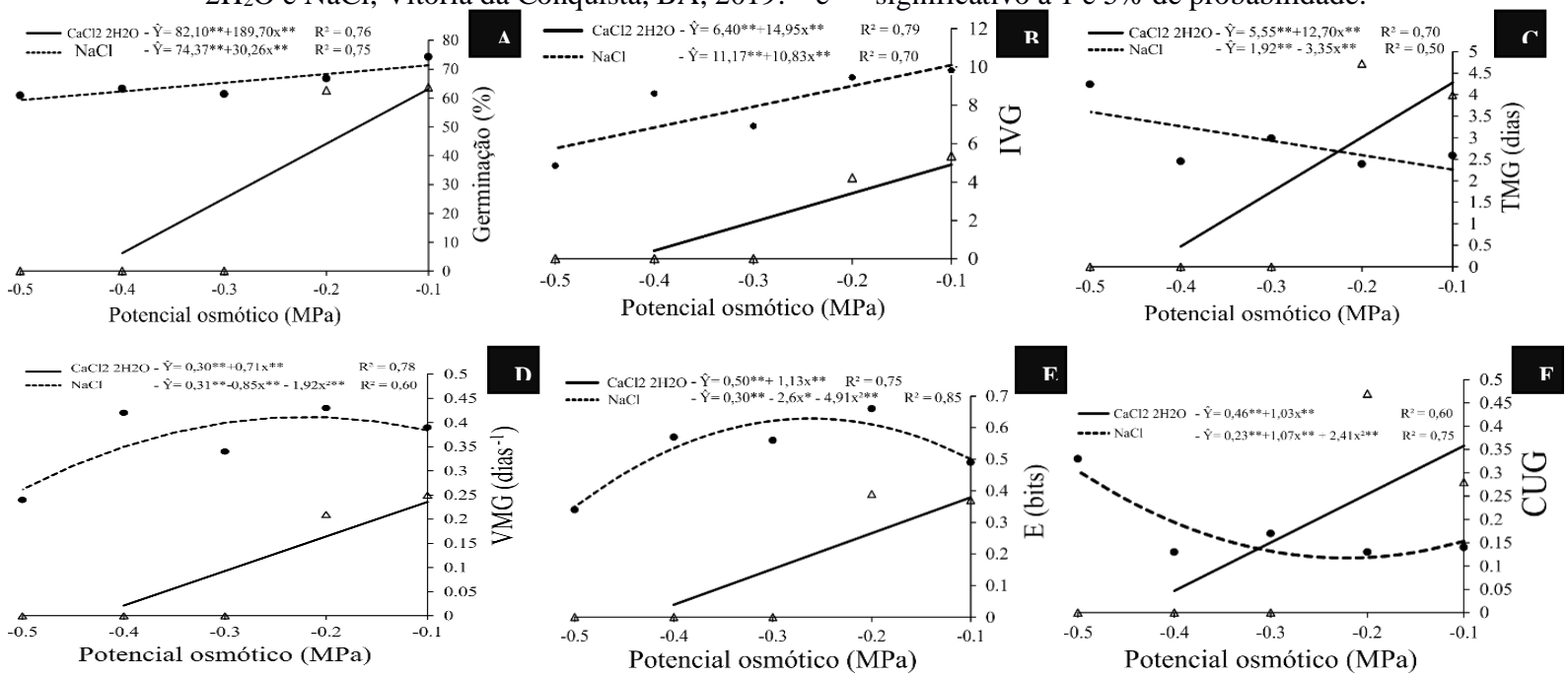

Os pontos de máxima de VMG foi de -0,22 $\mathrm{MPa}$, atingindo o valor de 0,41 dias ${ }^{-1}$ depois desse valor a VMG decresce. Para o Índice de sincronização o ponto de máxima foi de -0,26 MPa, alcançando valor máximo de 0,62 bits decrescendo a partir desse ponto. Para 
CUG, o ponto de mínima atingindo foi -0,22 MPa resultando num valor de 0,11 e aumentado a partir daí.

Esses resultados corroboram com os obtidos por Dutra et al. (2017), os autores encontraram efeitos lineares negativos para quase todas as variáveis avaliadas, principalmente a porcentagem de germinação. Esses resultados indicam que essa espécie apresenta pouca tolerância à salinidade induzida por $\mathrm{CaCl}_{2} 2 \mathrm{H}_{2} \mathrm{O}$, de forma que, a sua germinação pode ser prejudicada caso seja submetida à solos com alto teor de cálcio e cloro com potenciais osmóticos acima de -0,3 MPa. Em contrapartida, a Madeira-nova apresentou potencial germinativo tolerante ao $\mathrm{NaCl}$, contudo, em concentrações de potencial osmótico não muito negativos, já que a tendência de germinação dessa espécie é reduzir com o aumento da concentração salina.

\section{CONCLUSÃO}

A germinação de sementes de Madeira-nova é severamente reduzida em potenciais osmóticos induzidos por $\mathrm{CaCl}_{2} 2 \mathrm{H}_{2} \mathrm{O}$ e pouco prejudicada por $\mathrm{NaCl}$, indicando que a germinação das sementes dessa espécie apresenta certa tolerância à esse tipo de sal.

\section{REFERÊNCIAS}

AVREllA, E. D., EMER, A. A., PAIM, L. P., FIOR, C. S., \& SCHAFER, G. Efeito da salinidade no desenvolvimento inicial de mudas de Mimosa scabrella Benth. Iheringia. Série Botânica. v. 74, 2019.

Brasil. Ministério da Agricultura e Reforma Agrária. Secretária de Defesa Agropecuária. Regras para análise de sementes. Brasília, DF, 2009. 399 p.

DUTRA, T. R.; MASSAD, M.D.; MOREIRA, P.R.; RIBEIRO, E.S.M. Efeito da salinidade na germinação e crescimento inicial de plântulas de três espécies arbóreas florestais. Pesquisa Florestal Brasileira, v. 37, n. 91, p. 323-330, 2017.

FIGUEIREDO, M. E. O., LONGUE JÚNIOR, D., PEREIRA, A. K. S., CARNEIRO, A. D. C. O., SILVA, C. M. S. D. Potential of Pterogyne nitens tul. wood (Madeira-nova) for charcoal production. Ciência Florestal, v. 28, n. 1, p. 420-431, 2018.

KAPPES, C. et al. Germinação, vigor de sementes e crescimento de plântulas de milho sob condições de déficit hídrico. Scientia Agraria, Piracicaba, v.11, n.2, p.125-134, 2010.

LORENZI, H. Árvores brasileiras: Manual de identificação e cultivo de plantas arbóreas nativas do Brasil. Nova Odessa: Plantarum, 2009. p. 197.

R Core Team. R: a language and environment for statistical computing. Vienna: R Foundation for Statistical Computing, 2015. Disponível em:< http://www.R-project.org/.>. Acesso em: 01 
ago. 2019.

SÁ, F. V. S. et al. Crescimento inicial de arbóreas nativas em solo salino-sódico do Nordeste brasileiro tratado com corretivos. Revista Ceres, Viçosa, v. 60, n. 3, p. 388-396, 2013.

SANTOS, A. R.; SILVA-MANN, R.; FERREIRA, R. A. Restrição hídrica em sementes de jenipapo (Genipa americana L.). Revista Árvore, Viçosa, v.35, n.2, p.213-220, 2011.

SANTOS, C.A. dos; SILVA, N.V da; WALTER, L.S; SILVA, E.C.A da; NOGUEIRA, R.J.M.C. Germinação de duas espécies da caatinga sob déficit hídrico e salinidade. Pesquisa Florestal Brasileira, v. 36, n. 87, p. 219-224, 2016.

TAIZ, L.; ZEIGER, E. Fisiologia vegetal. 5.ed. Porto Alegre: Artmed, 2013. 954 p. 


\title{
NUANCES DA EXTENSÃO RURAL NO MUNICÍPIO DE ANGICAL, BAHIA
}

\section{MATICES DE LA EXTENSIÓN RURAL EN LA CIUDAD ANGICAL, BAHIA}

NUANCES OF EXTENSION SYSTEM IN ANGICAL CITY, BAHIA

\author{
Kelly Santos Silva ${ }^{1}$; Nattália Matos da Rocha ${ }^{2}$; Rafael Guimarães Farias ${ }^{3}$
}

DOI: https://doi.org/10.31692/978-65-991061-4-9.199-204

\section{INTRODUÇÃO}

A lei de Ater, 12.188/2010 instituiu formalmente a Política Nacional de Assistência Técnica e Extensão Rural - PNATER que representa o reconhecimento formal e legal dos serviços de Assistência Técnica e Extensão Rural - ATER dedicados exclusivamente à agricultura familiar, trabalhando com princípios e diretrizes voltados para o desenvolvimento sustentável, a participação social, a produção de base agroecológica e a qualificação das políticas públicas, entre outros.

A PNATER optou por trabalhar exclusivamente com o público da agricultura familiar. De acordo a Lei $\mathrm{n}^{\mathrm{o}} 11.326 / 2006$, são considerados agricultores e agricultoras familiares àqueles que desenvolvam práticas no meio rural e atendam a quatro critérios específicos: (i) detenham área de até quatro módulos fiscais; (ii) utilizem predominantemente mão-de-obra da própria família nas atividades econômicas rurais; (iii) tenham renda familiar mínima originária de atividades econômicas rurais em seu estabelecimento e/ou empreendimento; (iv) dirija seu estabelecimento ou empreendimento com sua família.

Todos os agricultores familiares devem possuir uma Declaração de Aptidão ao pronaf - DAP para acessar as políticas públicas do setor. Com a DAP, o produtor rural comprova que está enquadrado na lei e é agricultor familiar, potencial beneficiário das políticas públicas de extensão rural. De acordo o IBGE, o Brasil possui cerca de 4,3 milhões de estabelecimentos rurais que utilizam a terra para a agricultura familiar, ocupando uma área total de aproximadamente 80 milhões de hectares.

Nesse ensejo, buscamos analisar alguns dados para conhecer as nuances da agricultura no Município de Angical, Bahia. Com esses dados sobre agricultura familiar podemos suscitar questões relevantes para a ATER pública, como o acesso as políticas públicas e perfil do produtor rural.

\footnotetext{
${ }^{1}$ Engenharia Agronômica, Universidade do Estado da Bahia, silvakelly399@gmail.com

${ }^{2}$ Engenharia Agronômica, Universidade do Estado da Bahia, matosnattalia@gmail.com

${ }^{3}$ Mestre em Extensão Rural pela Universidade de Viçosa, rgfarias@uneb.br
} 


\section{FUNDAMENTAÇÃO TEÓRICA}

\section{Serviço de Extensão Rural para Agricultura no Brasil}

A primeira ação de Extensão rural institucionalizada, conforme alguns pesquisadores é a semana do fazendeiro de 1929 em Viçosa-MG. Atualmente, ainda são promovidas as semanas do fazendeiro e conta com a visita de pessoas de todo país, segundo Olinger (1996), os impactos são mais regionais e locais, conta com a colaboração do Ministério da Agricultura e a secretaria de agricultura do estado de Minas Gerais.

Os momentos vividos pela Assistência Técnica e Extensão Rural - ATER no Brasil, enquanto políticas públicas de desenvolvimento rural são agrupadas em três fases que permitem enquadrar a evolução e a crise no período entre 1948 - 1989. Na definição da política de desenvolvimento rural, e sem objetivo de separar rigorosamente, os três momentos da evolução da Extensão Rural - ER no Brasil são: 1- Humanismo assistencialista, 2Difusionismo produtivista, 3- Humanismo crítico.

Na década de 1940 o humanismo assistencialista prevaleceu na extensão rural enquanto o Estado brasileiro dava reduzida importância ao desenvolvimento econômico no campo brasileiro, Minas Gerais e São Paulo se desenvolvia como pioneiros da ER nacional. (LIMA, 1985).

A concepção da ER voltada para a família se esgota passando para um novo momento marcado nos planos de governo e elegendo como novo público alvo os grandes e médios produtores. Na medida em que o Brasil ia seguindo este caminho da modernização os novos objetivos nacionais iam tomando o espaço do humanismo antes presente na ER. No lugar de equipe com o agrônomo e uma economista doméstica passou a contratar agrônomos e veterinários comprometidos com a produtividade. Assim os serviços de ATER ficaram conhecidos como difusionismo produtivo com características persuasivas. Havia uma clara seletividade das políticas públicas em prol dos grandes e médios produtores que passaram a deter, cada vez mais, o monopólio da terra e modernizar-se tecnologicamente (RODRIGUES, 1997).

Após o período da modernização do campo no Brasil, o modelo de ATER é duramente questionado, tanto pela seletividade do público atendido e baixa abrangência no serviço, quanto a sua concepção teórica de desenvolvimento agrícola insustentável. Assim abre-se o período do humanismo crítico baseado principalmente na crítica freiriana ao difusionismo. $\mathrm{Na}$ visão freiriana, o pacote tecnológico fechado antidialógico e persuasivo, não deveriam existir. A extensão deve funcionar como um processo educativo que observa o todo e não simplesmente as técnicas mais avançadas, o extensionista deve estimular a participação dos 
beneficiários estabelecendo uma comunicação horizontal com os agricultores (FREIRE, 2011).

Assim, a partir de 2003, o Brasil abre um novo momento político e os serviços de ATER reformula suas bases e concepções. Insere-se um conjunto perspectivas antes negligenciadas como a agroecologia, a pluriatividade da agricultura, o desenvolvimento sustentável, desenvolvimento local, eco desenvolvimento, e outras. Foi então a criação da Lei de ATER n 12.188, de 11 de janeiro de 2010 para amparar a Política Nacional de Assistência Técnica e Extensão Rural - PNATER.

Atualmente a ER baseada na PNATER tem se preocupado com ações mais sustentáveis e dialógicas para superar o modelo convencional institucionalmente e conceitualmente. Os programas governamentais apresentam um conjunto de elementos teóricos e metodológicos para o desenvolvimento rural que apontam: A realização de ações capazes de melhorar o acesso dos agricultores familiares às políticas públicas como o Programa Nacional de Fortalecimento da Agricultura Familiar - PRONAF, o Programa Nacional de Alimentação Escolar - PNAE e o Programa de Aquisição de Alimentos - PAA; que, sem dúvidas, são estratégias participativas e democráticas que incluem os imperativos da inclusão socioprodutiva, da segurança alimentar, conservação dos recursos naturais, produção de alimentos sadios, organização e comercialização da produção.

Dentre estes outros pilares fundamentais que sustentam a Política de ATER, destaca-se o respeito à pluralidade e às diversidades sociais, econômicas, étnicas, culturais e ambientais do país, o que implica na necessidade de incluir enfoques de gênero, de geração, de raça e de etnia nas orientações de projetos e programas, buscando a inclusão social da população rural brasileira mais pobre nas atividades orientadas pela Política Nacional de Ater.

\section{METODOLOGIA}

Esta pesquisa será de natureza quantitativa, uma vez que as suas características referese ao que pode ser quantificável por meio de números e informações. Uma pesquisa quantitativa se trata de uma classificação do método científico que se utiliza de diferentes técnicas estatísticas para quantificar opiniões e informações para um determinado estudo.

A técnica utilizada foi análise documental, obtemos dados do site do IBGE cidades e do SEAD. Uma vez feita a coleta dos dados, foi realizada tabulação e estatística dos dados com o auxílio do software Statistical Package for the Social Sciences - SPSS. Os dados foram organizados e analisados a partir da dimensão socioeconômico, da agricultura familiar e de resultados absolutos acerca da extensão rural no município de Angical, Bahia. 
O município de Angical está $853 \mathrm{~km}$ de Salvador e situado na zona fisiográfica de Barreiras pertencente à bacia do São Francisco (Território Bacia do Rio Grande). Faz limite com os municípios de Barreiras, Catolândia, Cristópolis, Cotegipe e Riachão da Neves. Atualmente o município tem cerca de 14073 habitantes, segundo o IBGE (2010). Sendo 7542 moradores da zona rural.

\section{RESULTADOS E DISCUSSÃO}

Atualmente o município de Angical possui 1294 agricultores sendo 83\% homens e $17 \%$ mulheres. Onde apenas uma pequena parte dos agricultores tem acesso as políticas públicas de ATER, que são de extrema importância para o desenvolvimento rural. No gráfico 1, percebe-se a proporção de agricultores que não recebem assistência técnica de 96,59\% enquanto apenas 3,41\% tem acesso a ATER. Esse baixo índice de atendidos, dificulta o desenvolvimento rural da agricultura familiar.

O órgão responsável pela Extensão rural no estado da Bahia é a Bahiater, que tem a finalidade de promover a execução de políticas de desenvolvimento da assistência técnica e extensão rural, sendo também muito importante para a Emissão da Declaração de Aptidão ao PRONAF - DAP documento que possibilita acesso as políticas públicas da agricultura familiar.

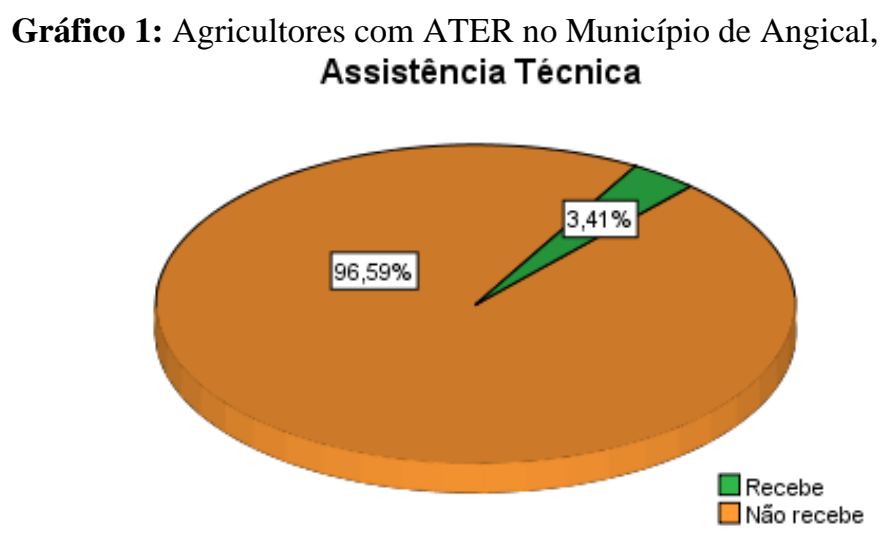

Fonte dos dados: IBGE, 2017. Elaboração do autor.

No municipio de Angical-BA de acordo ao gráfico 2 as DAP são emitidas em maioria pela Bahiater 66,5\%, seguido pelo Sindicado dos trabalhadores rurais- Angical com 24,4\% da emissão de DAP , o INCRA com 8,0\% e em menor parte estao outras entidades de ATER (Ministério da pesca, Associação brasileira das entidades estaduais de ATER, STRParipiranga). 
Gráfico 2: Órgão Emissor da DAP no município de Angical, Bahia. Órgão Emissor da DAP

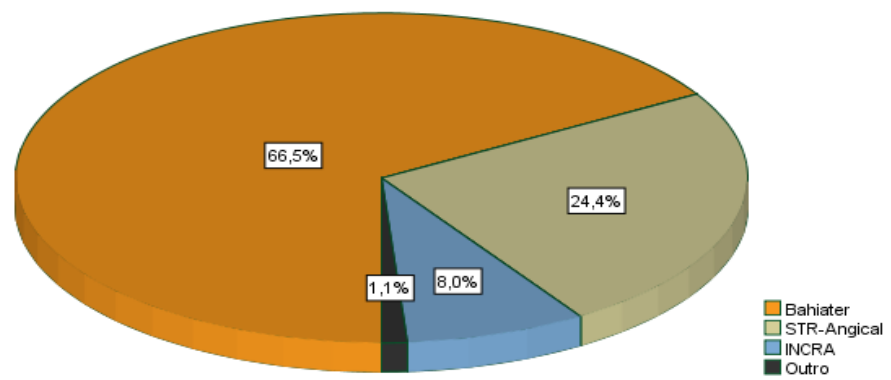

Fonte dos dados: SEAD, 2019, Elaboração do autor.

Apesar dos dados apontarem seis entidades de ATER que emitem DAP no município, grande parte dessas DAP, conforme a tabela 1, estão inativas e atualmente apenas três órgãos emissores tem registros de DAP regularizada.

Tabela 1: Situação da DAP em relação a cada órgão emissor

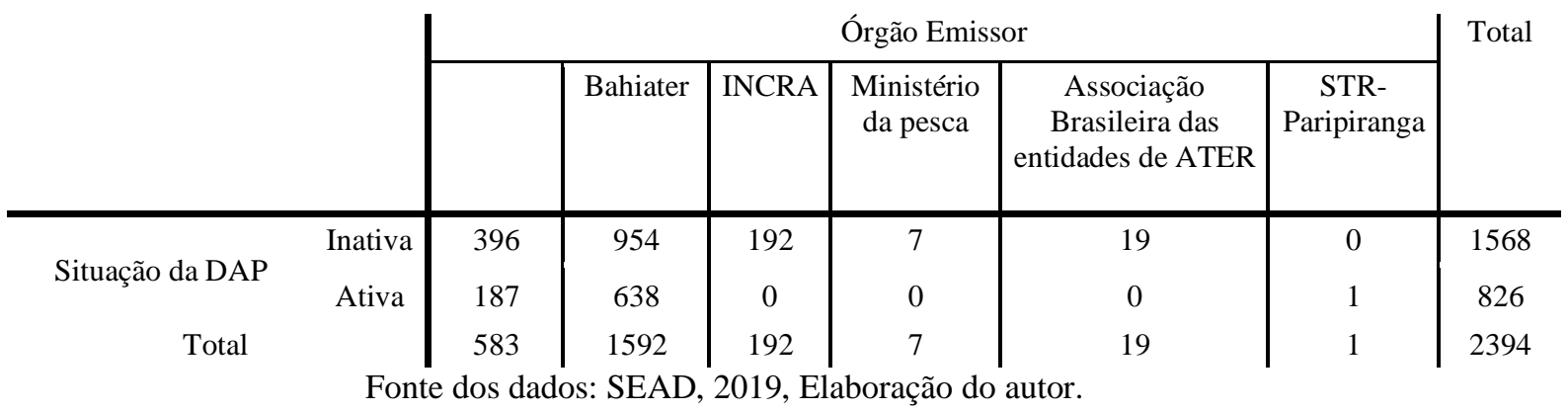

Sendo assim, o baixo número de agricultores com DAP regularizadas dificulta o acesso as políticas públicas destinadas à agricultura familiar e torna um entrave ao desenvolvimento rural no município de Angical, Bahia.

\section{CONCLUSÃO}

Os dados deste trabalho apontam a necessidade de maior cobertura da extensão rural no município de Angical- Bahia para atender de maneira satisfatória os agricultores. Percebese também a necessidade de maior celeridade dos órgãos emissores de DAP para aumentar o número de produtores com o documento indispensável para acesso as políticas públicas da agricultura familiar como PRONAF, PAA e PNAE.

Após a realização desse trabalho, despertou-se a necessidade de aprofundamento no estudo acerca dos órgãos de extensão rural que atuam no em Angical, Bahia, visando compreender quais principais limites e potencialidades do serviço de ATER no município. 


\section{REFERÊNCIAS}

IBGE, BRASIL em sintese. Angical-ba: 2010. Disponível em: <https://cidades.ibge.gov.br/brasil/ba/angical/panorama>. Acesso em: 30 ago. 2019.

FREIRE, P. Extensão ou Comunicação? 15a . ed. Rio de Janeiro: Paz e Terra, 2011. LIMA, L. O. Mutações em Educação Segundo McLuhan. Petrópolis: Vozes, 1985. OLINGER, G. Ascensão e decadência da extensão rural no Brasil. Florianópolis: EPAGRI, 1996.

RODRIGUES, C. M. Conceito de seletividade de políticas públicas e sua aplicação no contexto da política de extensão rural no Brasil. Cadernos de Ciência \& Tecnologia, Brasília, v. 14, n. 1, p. 113-154, 1997. 


\title{
QUALIDADE PÓS COLHEITA DE MELOIRO FERTIRRIGADO COM DIFERENTES DOSES DE POTÁSSIO NA SOLUÇÃO NUTRITIVA SALINIZADA
}

\author{
Giordanio Bruno Silva Oliveira ${ }^{1}$; Sandy Thomaz dos Santos ${ }^{2}$; Jessilanne Plinia Barbosa de \\ Medeiros Costa ${ }^{3}$; Paulo Victor Menezes ${ }^{4}$; Francisco de Assis de Oliveira ${ }^{5}$
}

DOI: https://doi.org/10.31692/978-65-991061-4-9.205-210

\section{INTRODUÇÃO}

O meloeiro (Cucumis melo L.) é uma espécie da família das cucurbitáceas, de clima tropical, originário dos quentes vales do Irã e do noroeste da Índia (Filgueira, 2008), é uma cultura adaptada às regiões com condições de clima áridos e semiáridos como observado no Nordeste brasileiro.

A água e os nutrientes são os principais fatores que podem limitar o crescimento e o rendimento do meloeiro, sendo o potássio o nutriente mais requerido pela cultura, necessário para a ocorrência de diversos processos biológicos nas células das plantas, tais como, ativação enzimática, respiração, fotossíntese e melhoria no balanço hídrico (Oliveira et al., 2016). Porém, a salinidade da água e ou do solo, bastante comum nessas regiões, torna-se um dos principais empecilhos para uma produção agrícola rentável (Botía et al., 2005).

Dentre os diversos sistemas de cultivo, a hidroponia tem ganhado destaque entre os produtores, com destaque para o cultivo em substrato, principalmente aqueles que necessitam utilizar águas com nível de salinidade elevado, uma vez que o cultivo hidropônico proporciona um maior controle no fornecimento de água e nutrientes necessários para o desenvolvimento da planta, diminuindo assim os efeitos negativos da salinidade.

Assim, o presente trabalho teve como objetivo avaliar a qualidade pós-colheita de frutos de meloeiro do tipo Gália, cultivar McLaren submetida a estresse salino, em função de diferentes doses de potássio.

\section{FUNDAMENTAÇÃO TEÓRICA}

O melão (Cucumis melo L.) é uma hortaliça muito apreciada e de grande popularidade no mundo. Na atualidade, é a segunda fruta fresca mais exportada pelo Brasil em termos de volume (ABRAFRUTAS, 2018). Os Estados do Rio Grande do Norte e Ceará se destacam como os principais produtores contribuindo com mais de $85 \%$ da produção nacional da

\footnotetext{
${ }^{1}$ Mestrando em Manejo de Solo e Água, UFERSA, E-mail: giordaniobruno@yahoo.com

${ }^{2}$ Doutorando em Manejo de Solo e Água, UFERSA, E-mail: sandy thomaz@ hotmail.com

${ }^{3}$ Mestranda em Manejo de Solo e Água, UFERSA, E-mail: jessilannyplinia@ hotmail.com

${ }^{4}$ Graduando em agronomia, UFERSA, E-mail: paulo_escoteiro39@hotmail.com

${ }^{5}$ P. Dr, UFERSA, E-mail: thikaoamigao@ufersa.edu.br
} 
hortaliça (IBGE, 2017).

Os sistemas de cultivo hidropônicos são conhecidos pela eficiência na absorção de água e nutrientes pelas plantas (Santos Júnior et al., 2011). A qualidade da água utilizada no cultivo hidropônico, seja em sistema NFT ou em substrato, é fator primordial para se obter êxito na produção, pois a elevada salinidade do meio pode influenciar o desenvolvimento das plantas ao longo de todo o seu ciclo de vida, afetando negativamente a germinação, o crescimento, a reprodução e o seu rendimento (Marschner, 2012).

De acordo com Aktas et al. (2009), a absorção radicular de K é prejudicada com o aumento da salinidade da água ou da solução do solo, interferindo nas funções fisiológicas das plantas. O K embora não tenha função estrutural, ou seja, não faça parte de molécula orgânica ou estrutura da planta, é um importante ativador enzimático, participando de inúmeros processos bioquímicos e fisiológicos do metabolismo das plantas (Prado, 2014).

$\mathrm{Na}$ cultura do meloeiro foram feitos alguns estudos com absorção de nutrientes em função do tempo (Gurgel et al., 2008; Medeiros et al., 2008), no entanto, são encontrados poucos estudos abordando o emprego de águas salinas combinadas com o aumento da dose de potássio na adubação, visando mitigar os efeitos prejudiciais da salinidade (Prazeres et al., 2015).

\section{METODOLOGIA}

O experimento foi realizado nos meses de julho a setembro de 2018, em casa de vegetação da Universidade Federal Rural do Semi-Árido (UFERSA), em Mossoró, RN (5 12' 04"S; 37 19' 39"'O, altitude de $18 \mathrm{~m}$ ). O delineamento experimental utilizado foi em blocos casualizados, sendo os tratamentos constituídos por quatro doses de potássio nas soluções nutritivas mais a adição de $\mathrm{NaCl}$ (S1- solução nutritiva padrão, SNP; S2 - SNP + $\mathrm{NaCl}$ (3,5 dS $\left.\left.\mathrm{m}^{-1}\right) ; \mathrm{S} 3-\mathrm{SNP}+\mathrm{NaCl}\left(3,5 \mathrm{dS} \mathrm{m}^{-1}\right)+\mathrm{K} 50 \% ; \mathrm{S} 4-\mathrm{SNP}+\mathrm{NaCl}\left(3,5 \mathrm{dS} \mathrm{m}^{-1}\right)+\mathrm{K} 100 \%\right)$ e três repetições, sendo a unidade experimental representada por três vasos com capacidade para 10 $\mathrm{dm}^{3}$ cada, num total de 36 vasos.

O plantio foi realizado a partir de mudas produzidas em casa de vegetação, com bandejas de poliestireno com capacidade de 128 células, utilizando substrato formulado pela mistura de húmus de minhoca e fibra de coco $(1: 1,5)$ e, em seguidas, transplantadas para vasos plásticos com capacidade para $10 \mathrm{dm}^{3}$ preenchidos com fibra de coco e areia lavada (2:1), colocando-se uma planta por vaso da cultivar de meloeiro Mc Laren.

Os vasos foram dispostos no interior da casa de vegetação, sobre blocos de concreto, espaçados em $100 \mathrm{~cm}$ entre linhas e $50 \mathrm{~cm}$ entre plantas. As plantas foram conduzidas na 
vertical com o auxílio de estacas de madeiras, fios de aço inoxidável e barbantes.

O sistema de irrigação adotado foi por gotejamento. Para cada solução nutritiva foi utilizado um sistema de irrigação independente, formado por um motor bomba e um reservatório (caixa d'água com capacidade para $310 \mathrm{~L}$ ), mangueiras (16 mm), microtubos e um temporizador (Timer) para o controle da irrigação, adotando-se a frequência de 6 irrigações diárias, ajustando-se o tempo de cada irrigação de acordo com a necessidade da cultura.

A solução nutritiva padrão seguiu a recomendação de Castellane \& Araújo (1994), contendo a seguinte quantidade de fertilizantes, g para 1000 litros: 900; 455; 170; 246 e 100g de $\mathrm{Ca}\left(\mathrm{NO}_{3}\right)_{2} ; \mathrm{KNO}_{3} ; \mathrm{MAP} ; \mathrm{MgSO}_{4}$ e $\mathrm{KCl}$, respectivamente. $\mathrm{O}$ fornecimento de micronutrientes foi por meio do fertilizante Rexolim ${ }^{\circledR}$, na dose de 30 g para 1000 litros, conforme recomendado na embalagem para hortaliças em geral.

Polinizações manuais foram feitas à medida que as flores masculinas e femininas foram surgindo. Ao final do experimento (70 DAT) os frutos foram coletados e avaliados quanto as seguintes variáveis: Peso do fruto, diâmetro do fruto, espessura da polpa, $\mathrm{pH}$, sólidos solúveis e firmeza da polpa.

Os dados obtidos foram submetidos a análise de variância e as médias comparadas pelo teste de Tukey ao nível 5\% de probabilidade.

\section{RESULTADOS E DISCUSSÃO}

Para as variáveis espessura de polpa, sólidos solúveis e firmeza de polpa, observou-se que não houve resposta significativa as soluções nutritivas, tanto pela adição de $\mathrm{NaCl}$ quanto pelo incremento de potássio na solução nutritiva salinizada, apresentando médias de 23,8 mm, 9,3 ${ }^{\circ}$ Brix e 9,1 N, respectivamente, como demonstrado nas Figuras 1A, 1E e 1F.

Estes resultados estão de acordo com os obtidos por Gratieri (2012), trabalhando com meloeiro cantaloupe (bônus n² 2 hibrido f1) e Queiroz (2016), trabalhando com meloeiro Gália (cultivar Babilonia RZ F1-Hybrid) verificaram pouco efeito do potássio sobre essas variáveis.

De acordo com Morais et al. (2009), os frutos adequados para exportação devem apresentar ${ }^{\circ}$ Brix variando de 8 a 10 , assim pode-se aferir que os frutos obtidos no presente trabalho apresentam qualidade satisfatória

Não houve efeito direto da salinidade sobre o peso do fruto apesar de ter ocorrido uma perda absoluta de 21,3\%. Por outro lado, o excesso de potássio na solução nutritiva salinizada (S3 e S4) foi mais prejudicial ao crescimento do fruto do que a adição de $\mathrm{NaCl}$ (S2), proporcionando uma redução de $42,4 \%$ na $\mathrm{S} 3$ e $39,22 \%$ na $\mathrm{S} 4$, quando comparadas com a 
solução padrão (S1) (Figura 1C). Resposta significativa do meloeiro submetido a dose elevada de potássio sobre o peso dos frutos também foi observado por Queiroz (2016), também em estudo desenvolvido em fibra de coco. Por outro lado Preciado-Rangel, et al, (2018), trabalhando com meloeiro cultivado em areia lavada, verificaram resposta positiva do aumento da dose de potássio sobre o peso dos frutos, no entanto, vale ressaltar que esses autores não trabalharam em condições de estresse salino, o que altera as respostas das plantas ao manejo nutricional

Para a variável pH, observou-se que não houve efeito da salinidade (S2) sobre esta variável, porém, houve resposta negativa para a adição de $50 \%$ de potássio na solução nutritiva salinizada (S3), apresentando uma redução de 7,3\% comparando com a solução nutritiva padrão. Esse resultado difere em parte, do obtido por Queiroz (2016), o qual não observou efeito significativo do potássio sobre o $\mathrm{pH}$ da polpa do fruto (S1) (Figura 1D).

Conforme apresentado, o uso de agua salinizada no preparo da solução nutritiva não afetou a produção nem a qualidade dos frutos devido, possivelmente, a maior tolerância da cultura à salinidade no cultivo em substrato. Além disso, o excesso de potássio pode ter afetado de forma negativa algumas variáveis devido ao aumento da salinidade da solução nutritiva provocando um desbalanço osmótico e/ou pelo efeito antagônico do potássio com outros cátions como cálcio e magnésio 
Figura 1: Peso do fruto (A), espessura da polpa (B), firmeza da polpa (C), sólidos Solúveis (D) e pH (E) de frutos de melão cultivar Mc Laren submetidas à diferentes doses de potássio na solução nutritiva salinizada.

A.
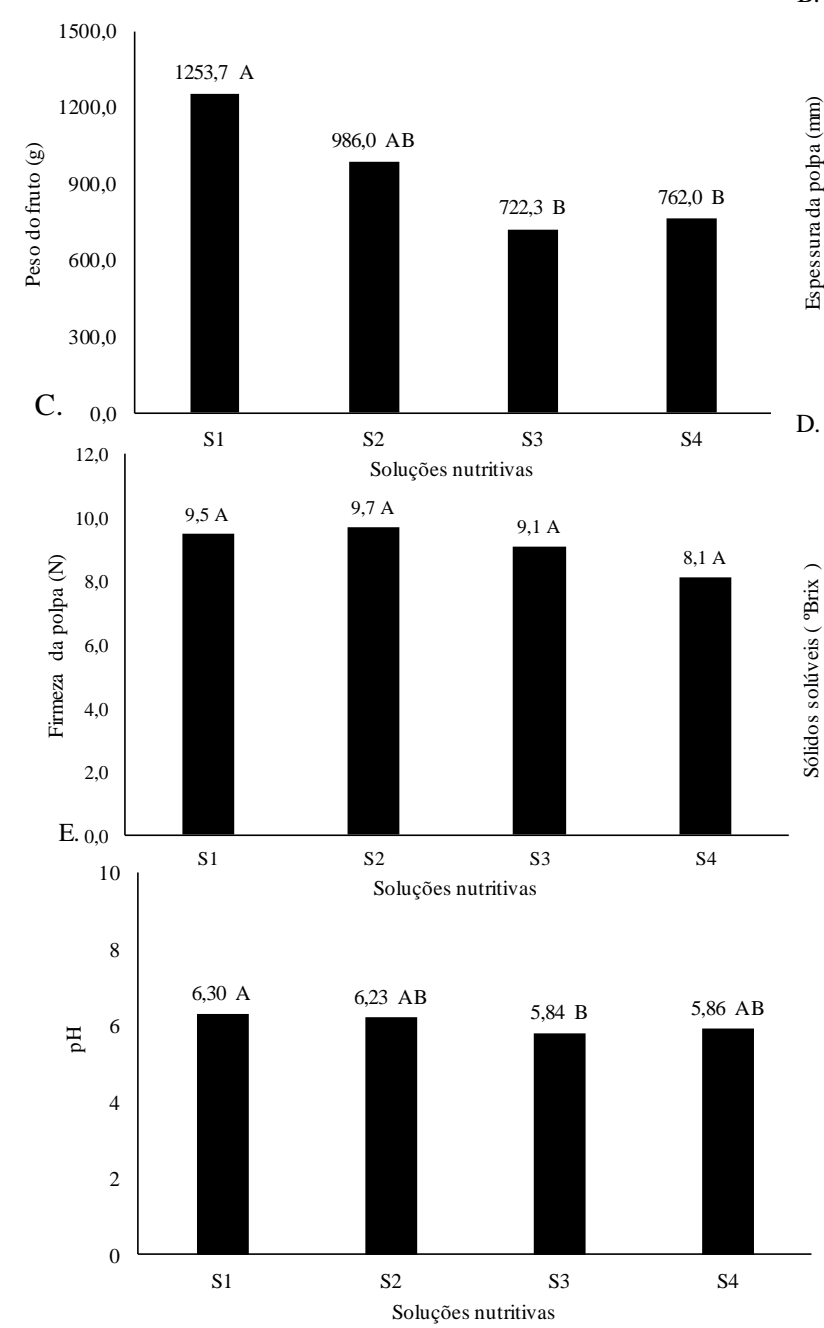

B.
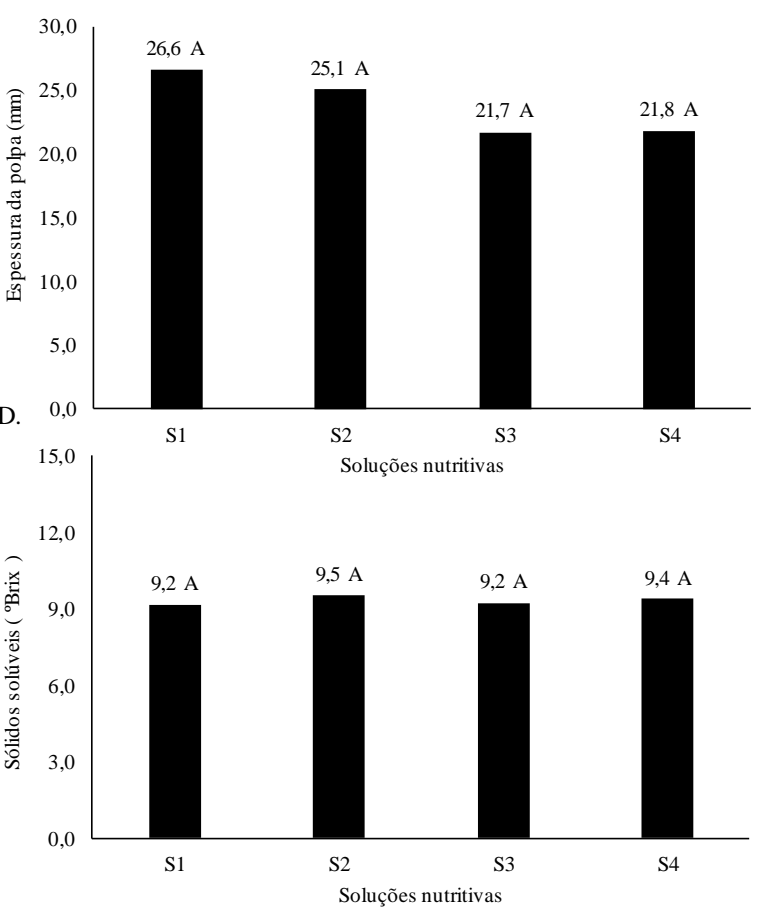

S1: Solução Nutritiva Padrão

$\mathrm{S} 2: \mathrm{SNP}+\mathrm{NaCl}\left(3,5 \mathrm{dS} \mathrm{m}^{-1}\right)$

$\mathrm{S} 3: \mathrm{SNP}+\mathrm{NaCl}\left(3,5 \mathrm{dS} \mathrm{m} \mathrm{m}^{-1}\right)+\mathrm{K} 50 \%$

S4: $\mathrm{SNP}+\mathrm{NaCl}\left(3,5 \mathrm{dS} \mathrm{m}^{-1}\right)+\mathrm{K} 100 \%$

\section{CONCLUSÕES}

A salinidade não afetou a produção nem a qualidade dos frutos de meloeiro cultivados em fibra de coco. O excesso de potássio foi prejudicial a produção de meloeiro cultivar Mc Laren cultivado em fibra de coco fertirrigado com solução nutritiva salinizada.

\section{REFERÊNCIAS}

ABRAFRUTAS - Associação Brasileira dos Produtores Exportadores de Frutas e Derivados. Exportações brasileiras de frutas janeiro a dezembro 2018. Disponível em:< https://abrafrutas.org/2019/05/09/exportacoes-brasileiras-de-frutas-janeiro-a-dezembro2018/>. Acesso em 30 jul. 2019.

AKTAS, H.; ABAK, K.; CAKMAK, I. Genotypic variation in the response of pepper to salinity. Scientiae Horticulturae, v.110, p.260-266, 2009.

BOTÍA, P.; NAVARRO, J. M.; CERDÁ, A.; MARTÍNEZ, V. Yield and fruit quality of two melon cultivars irrigated with saline water at different stages of development. European 
QUALIDADE PÓS COLHEITA DE MELOIRO FERTIRRIGADO COM DIFERENTES

DOSES DE POTÁSSIO NA SOLUÇÃO NUTRITIVA SALINIZADA

Journal of Agronomy, v. 23, p. 243- 253, 2005.

CASTEllane, P. D.; ARAÚJO, J. A. C. Cultivo sem solo-Hidroponia. Jaboticabal. FUNEP. 1994. 43p.

FILGUEIRA, F. A. R. Novo Manual de olericultura. Viçosa, UFV. 2008. 402p.

GURGEL, M. T.; GHEYI, H. R.; OLIVEIRA, F. H.; FERNANDES, P. D.; da SILVA, F. V. Nutrição de cultivares de meloeiro irrigadas com águas de baixa e alta salinidade. Revista Caatinga, v. 21, p.36-43, 2008.

IBGE - Instituto Brasileiro de Geografia e Estatística. Censo Agropecuário 2017. Disponível em:< https://sidra.ibge.gov.br/tabela/6615\#resultado>. Acesso em 15 jan. 2019.

MARSCHNER, H. Mineral nutrition of higher plants. 3. ed London: Elsevier, 2012. 643 p.

MEDEIROS, J. F.; DUARTE, S. R.; FERNANDES, P. D.; SILVA DIAS, N.; GHEYI, H. R. Crecimento e acúmulo de N, P e K pelo meloeiro irrigado com agua salina. Horticultura Brasileira, v. 26, p. 452-457, 2008.

OLIVEIRA, F. S.; OLIVEIRA, F. S.; ARAUJO, J. L.; ROCHA, R. C.; ROCHA, G. H. C. Partição e acumulação de nutrientes no meloeiro amarelo fertirrigado em condições semiáridas. Irriga, v.21, p.545-560, 2016.

PRADO, R. de M. 500 perguntas e respostas sobre nutrição de plantas. 2. ed. Jaboticabal: FUNEP, 2014. p. 39-47, 55-60, 107-110.

PRAZERES, S. S.; LACERDA, C. F.; BARBOSA, F. E. L.; AMORIM, A. V.; SILVA ARAUJO, I. C.; CAVALCANTE, L. F. Crescimento e trocas gasosas de plantas de feijãocaupi sob irrigação salina e doses de potássio. Revista Agro@mbiente On-line, v.9, p.111$118,2015$.

SANTOS JÚNIOR, J. A.; GHEYI, H. R.; GUEDES FILHO, D. H.; DIAS, N. S.; SOARES, F. A. L. Cultivo de girassol em sistema hidropônico sob diferentes níveis de salinidade. Revista Ciência Agronômica, v. 42, p. 842-849, 2011.

MORAIS, P. L. D.; SILVA, G. G.; MAIA, E. N.; MENEZES, J. B. Avaliação das tecnologias póscolheita utilizadas e da qualidade de melões nobres produzidos para exportação. Ciência $\mathbf{e}$ Tecnologia de Alimentos, v. 29, p. 214-218, 2009.

QUEIROZ, I. S. R. Cultivo do meloeiro em sistema semi-hidropônico sob diferentes concentrações de potássio na solução nutritiva. 2016. 72 f. Dissertação (Mestrado) - Curso de Manejo de Solo e Água, Universidade Federal Rural do Semi-Árido, Mossoró, 2016.

GRATIERI, L. A. Nitrogênio e potássio para meloeiro cultivado em fibra de coco, sem drenagem. 2012. 78 f. Tese (Doutorado) - Curso de Produção Vegetal, Universidade Estadual Paulista-unesp, Jaboticabal, 2012.

PRECIADO-RANGEL, P.; SALAS-PÉREZ, L.; GALLEGOS-ROBLES, M. Á.; RUIZESPINOZA, F. H.; AYALA-GARAY, A. V.; FORTIS-HERNÁNDEZ, M.; MURILLOAMADOR, B. Increasing doses of potassium increases yield and quality of muskmelon fruits under greenhouse. Horticultura Brasileira, Vitoria da Conquista, v. 36, p.184-188, 2018. 


\section{DESEMPENHO AGRONÔMICO DE CULTIVARES DE FEIJÃO-CAUPI DE PORTE ERETO E PROSTRADO NO CERRADO DO ESTADO DO PIAUÍ}

\section{RENDIMIENTO AGRONÓMICO DE CULTIVARES DE PORTE ERETO CAUPI Y PROSTRADOS EN EL ESTADO CERRADO DE PIAUÍ}

\section{AGRONOMIC PERFORMANCE OF COWPEA CULTIVARS OF ERECT AND PROSTRATE PORT IN THE CERRADO OF PIAUÍ STATE}

Williany Rêgo Lima ${ }^{1}$; Jean Lucas Costa dos $\operatorname{Santos}^{1}$; Gustavo Nobre Lima ${ }^{1}$; Adão Vinicius Abreu Rabelo de Sousa ${ }^{1}$; Wallace de Sousa Leite ${ }^{2}$

DOI: https://doi.org/10.31692/978-65-991061-4-9.211-216

\section{INTRODUÇÃO}

A produção brasileira de feijão-caupi estimada no ano agrícola 2018/19 foi de 637.700 t, em uma área plantada de 1.276.200 ha, alcançando uma produtividade média de grãos de $500 \mathrm{~kg} \mathrm{ha}^{-1}$. No estado do Piauí, a estimativa de área cultivada com feijão-caupi no ano agrícola 2018/19 foi de 197.200 hectares e produção de 82.700 t. Essa baixa produção, é consequência da baixa produtividade média de grãos alcançada no estado, cerca de $420 \mathrm{~kg} \mathrm{ha}{ }^{-}$ 1 (CONAB, 2019).

No Piauí, na maioria dos campos agrícolas são utilizados genótipos tradicionais não melhorados ou oriundos de programas de melhoramento conduzidos em outras localidades. $\mathrm{O}$ uso de genótipos de baixo potencial produtivo é um dos fatores que levam às baixas produtividades observadas nesta cultura. Para Freire Filho et al. (2005), o feijão-caupi apresenta potencial de produtividades superiores a $6000 \mathrm{~kg} \mathrm{há}^{-1}$ com a utilização de cultivares provenientes da atividade do melhoramento genético.

A escolha adequada da cultivar de feijão-caupi a ser utilizada para o cultivo, é um ponto importante na busca de bons resultados de produtividade. Contudo, cabe ao produtor escolher cultivares que apresentem boa adaptação às características do local onde sua propriedade está situada, com o objetivo de melhorar o aproveitamento dos recursos naturais e insumos agrícolas e, consequentemente, aumentar a produtividade. Neste sentido, a identificação de cultivares com alto desempenho produtivo, adaptadas a colheita mecânica e com boa adaptação às condições edafoclimáticas da região do Cerrado, é fundamental para a indicação em cultivos comerciais e importante para a consolidação da expansão da cultura.

\footnotetext{
${ }^{1}$ Graduando em Engenharia Agronômica, Instituto Federal de Educação, Ciências e Tecnologia do PiauíCampus Uruçuí, willy.regolima@gmail.com, jeanlcsantos1998@gmail.com, gustavonobreagro@gmail.com, adaoviniciusabreu@gmail.com

2 Professor Mestre, Instituto Federal de Educação, Ciências e Tecnologia do Piauí-Campus Uruçuí, wallace.leite@ifpi.edu.br
} 
Dessa forma, torna-se importante a realização de estudos regionais/locais para a identificação e indicação de cultivos de cultivares de feijão-caupi com superioridade agronômica em função das condições as quais são submetidas.

Entretanto, o objetivo do trabalho foi avaliar o desempenho agronômico de cultivares de feijão-caupi de porte ereto e prostrado em condição de sequeiro no Cerrado do estado do Piauí.

\section{FUNDAMENTAÇÃO TEÓRICA}

O feijão-caupi possui alta tolerância a altas temperaturas e baixas pluviosidades, o que acentua a grande variação nos índices produtivos (OLIVEIRA et al., 2011). Essas características reforçam a importância do conhecimento sobre a interação entre genótipo e ambiente, verificadas por diversos autores (ALMEIDA et al., 2017; SANTOS et al., 2014; SOUSA et al.,2017; TEIXEIRA et al., 2010).

Para a indicação de uma cultivar para um determinado local ou época de cultivo, o mesmo deve ser previamente testado para as condições específicas desse local (ALMEIDA et al., 2017; SANTOS et al., 2014). A recomendação de cultivares constitui a última etapa dos programas de melhoramento genético, que visam principalmente, incrementar ganhos em produtividade, e requerem a adequada seleção de linhas superiores. Devido à importância que a cultura assume no país, especialmente na região Nordeste, é necessário que estudos sejam feitos para avaliar o comportamento agronômico de genótipos, visando à seleção de genótipos de maior potencial produtivo para uso comercial e futuros trabalhos de melhoramento.

\section{METODOLOGIA}

O experimento foi instalado e conduzido em condição de sequeiro na área experimental do Instituto Federal do Piauí-IFPI, em Uruçuí - PI (7²16'32,7"S, 44³0'21,2"O e altitude de $378 \mathrm{~m}$ ). O clima da região é Aw, de acordo com a classificação Köppen, apresentando pluviosidade média anual de $1.069 \mathrm{~mm}$ e temperatura média anual de $27,2^{\circ} \mathrm{C}$. O solo da área experimental foi classificado como Latossolo com textura arenosa. A área experimental foi convertida de mata nativa (Cerrado) à agricultura no ano de 2012, sendo na época aplicada 4,0 t ha ${ }^{-1}$ de calcário dolomítico. Foi realizado preparo convencional do solo, com uma operação de gradagem. Os atributos químicos de fertilidade do solo e a granulometria foram determinados na camada de 0 a $0,20 \mathrm{~m}$ de profundidade, previamente à semeadura do feijão, por meio da análise química do solo.

Os tratamentos foram dispostos no delineamento experimental de blocos ao acaso, 
com quatro repetições, e constituídos por dez cultivares de feijão-caupi (BRS Guariba, BRS Xiquexique, BRS Novaera, BRS Imponente, BRS Tumucumaque, BRS Cauamé, BRS Itaim, BRS Aracê, BRS Pajeú, BRS Marataoã). Cada parcela experimental foi composta por quatro linhas de $5 \mathrm{~m}$ de comprimento, espaçadas de $0,5 \mathrm{~m}$ entre si, considerando as duas linhas centrais como a área de avaliação (útil), desprezando-se $0,5 \mathrm{~m}$ de cada extremidade, totalizando $4 \mathrm{~m}^{2}$. A semeadura das cultivares de feijão-caupi foi realizada manualmente em 11 de dezembro de 2018, distribuindo-se 16 sementes por metro. Após a emergência das plântulas, fez-se o desbaste, mantendo um estande médio em dez plantas por metro, o que corresponde a uma população de 200.000 plantas por hectare (CARDOSO; MELO; LIMA, 2005).

A adubação de semeadura foi realizada com $40 \mathrm{~kg} \mathrm{ha}^{-1} \mathrm{P}_{2} \mathrm{O}_{5}$ (superfosfato simples) e $40 \mathrm{~kg} \mathrm{ha}^{-1}$ de $\mathrm{K}_{2} \mathrm{O}$ (cloreto de potássio) no sulco de semeadura. A adubação de cobertura foi realizada aos 25 dias após a emergência das plântulas com $25 \mathrm{~kg} \mathrm{ha}^{-1}$ de $\mathrm{N}$ (sulfato de amônio) em filete contínuo a 0,10 m da linha de plantas (MELO; CARDOSO; SALVIANO, 2005). O controle de plantas daninhas foi realizado com capina manual aos 15 e 30 dias após a emergência das plântulas. Com relação aos tratos fitossanitários, foi realizado monitoramento da cultura e realizadas aplicações alternadas dos inseticidas à base de Tiametoxam e Acetamiprido, visando ao controle da mosca branca (Bemisia tabaci).

Foram avaliados os seguintes caracteres agronômicos: ciclo (dias para a maturação); número de vagens por planta $\left(\mathrm{n}^{\circ}\right)$; número de grãos por vagem $\left(\mathrm{n}^{\circ}\right)$; massa de 100 grãos $(\mathrm{g})$ e produtividade de grãos $\left(\mathrm{kg} \mathrm{ha}^{-1}\right)$. Para a massa de 100 grãos e produtividade de grãos, foi determinado o grau de umidade dos grãos, padronizando-se para $0,13 \mathrm{~kg} \mathrm{~kg}^{-1}$ em base úmida. Os dados foram submetidos a análise de variância pelo teste F. Em seguida, as médias foram submetidas a análise de agrupamento pelo teste de Scott-Knott, a nível de 5\% de probabilidade. Para o processamento das análises estatísticas foi utilizado o software computacional Genes (CRUZ, 2013).

\section{RESULTADOS E DISCUSSÃO}

As cultivares de feijão-caupi apresentaram comportamento diferenciado para todas as características avaliadas, o que indica a existência de ampla variabilidade entre os diferentes genótipos estudados (Tabela 1).

Tabela 1: Quadrado médio (QM), coeficiente de variação (CV) e médias dos caracteres ciclo, componentes da produção e produtividade de grãos de dez cultivares de feijão-caupi em condição de sequeiro no bioma Cerrado. Uruçuí, Piauí, Brasil 2018/2019.

\begin{tabular}{cccccc}
\hline \multirow{2}{*}{ Cultivares } & $\begin{array}{c}\text { Ciclo } \\
\text { (dia) }\end{array}$ & $\begin{array}{c}\text { Vagens por } \\
\text { planta }\end{array}$ & $\begin{array}{c}\text { Grãos por } \\
\text { vagens }\end{array}$ & $\begin{array}{c}\text { Peso de 100 } \\
\text { grãos (g) }\end{array}$ & $\begin{array}{c}\text { Produtividade de } \\
\text { grãos kg ha }^{-1}\end{array}$ \\
\hline
\end{tabular}




\begin{tabular}{cccccc}
\hline BRS Guariba & $70 \mathrm{~b}$ & $15 \mathrm{~b}$ & $12.2 \mathrm{c}$ & $21.5 \mathrm{c}$ & $1.354 \mathrm{a}$ \\
BRS Marataoã & $74 \mathrm{a}$ & $11 \mathrm{c}$ & $14.6 \mathrm{a}$ & $18.4 \mathrm{~d}$ & $794 \mathrm{~b}$ \\
BRS Novaera & $71 \mathrm{~b}$ & $19 \mathrm{a}$ & $10.4 \mathrm{~d}$ & $23.5 \mathrm{~b}$ & $640 \mathrm{~b}$ \\
BRS Itaim & $65 \mathrm{c}$ & $22 \mathrm{a}$ & $12.9 \mathrm{~b}$ & $23.0 \mathrm{~b}$ & $572 \mathrm{~b}$ \\
BRS Pajeú & $74 \mathrm{a}$ & $8 \mathrm{c}$ & $13.6 \mathrm{~b}$ & $21.0 \mathrm{c}$ & $1.388 \mathrm{a}$ \\
BRS Tumucumaque & $71 \mathrm{~b}$ & $14 \mathrm{~b}$ & $12.1 \mathrm{c}$ & $22.0 \mathrm{~b}$ & $1.379 \mathrm{a}$ \\
BRS Aracê & $74 \mathrm{a}$ & $14 \mathrm{~b}$ & $12.9 \mathrm{~b}$ & $15.6 \mathrm{e}$ & $938 \mathrm{~b}$ \\
BRS Cauamé & $70 \mathrm{~b}$ & $11 \mathrm{c}$ & $11.2 \mathrm{~d}$ & $19.8 \mathrm{c}$ & $866 \mathrm{~b}$ \\
BRS Imponente & $65 \mathrm{c}$ & $15 \mathrm{~b}$ & $10.1 \mathrm{~d}$ & $32.6 \mathrm{a}$ & $851 \mathrm{~b}$ \\
BRS Xiquexique & $65 \mathrm{c}$ & $10 \mathrm{c}$ & $14.7 \mathrm{a}$ & $17.6 \mathrm{~d}$ & $765 \mathrm{~b}$ \\
\hline Média geral & 71 & 13,98 & 12,50 & 21,54 & 955,12 \\
CV (\%) & 1,71 & 19,19 & 8,68 & 5,00 & 26,11 \\
QM & $51,35^{* *}$ & $70,75^{* *}$ & $10,20^{* *}$ & $85,20^{* *}$ & $379186,76^{* *}$ \\
\hline
\end{tabular}

** Significativo a $1 \%$ pelo teste F; médias seguidas da mesma letra na coluna não diferem entre si pelo teste de Scott e Knott a 5\% de significância.

Fonte: Própria (2019).

As cultivares BRS Marataoã, BRS Pajeú e BRS Aracê, apresentaram o ciclo mais longo, enquanto BRS Itaim, BRS Imponente e BRS Xiquexique apresentaram o ciclo mais curto. A média geral desse caráter foi de 71 dias, o que de acordo com Freire Filho et al. (2005), as cultivares em estudo são classificadas como de ciclo médio-precoce. Isso representa a possibilidade de aumentar e, ou, estabilizar a produção em regiões com longos períodos de estiagem.

As cultivares BRS Novaera e BRS Itaim obtiveram as maiores quantidades de vagens por planta. Os valores encontrados foram bem superiores à média (7 vagens por planta) observada por Almeida et al. (2017) e Sousa et al. (2017). Oliveira et al. (2013) encontraram uma correlação alta e positiva $(r=0,98)$ entre o número de vagens por planta e produtividade de grãos do feijão-caupi, indicando que o componente de produção número de vagens por planta exerce grande influência na produtividade de grãos.

Com relação ao número de grãos por vagem, as cultivares foram agrupados em quatro grupos. O grupo das maiores médias de número de grãos por vagem foi constituído por 2 cultivares, a BRS Marataoã $(14,6)$ e a BRS Xiquexique $(14,7)$. No segundo grupo as cultivares estudadas apresentaram médias de grãos por vagem variando de 12,9 a 13,6. Almeida et al. (2017) em condição de Cerrado observaram variação de 5,6 a 8,4 grãos e 12,95 a 14,95 grãos por vagem, respectivamente.

Para a característica peso de 100 grãos, as cultivares foram agrupadas em cinco grupos, verificando ampla variabilidade genética entre as cultivares, com médias variando de 15,6 a 32,6 g. A cultivar BRS Imponente apresentou o maior peso de 100 grãos (32,6 g). O segundo grupo foi constituído pelas cultivares BRS Novaera, BRS Itaim e BRS Tumucumaque, onde as médias para peso de 100 grãos variaram entre 22,0 e 23,5 g. Almeida 
et al. (2017) relataram resultados semelhantes para a BRS Itaim e BRS Tumucumaque, em Uberaba, Minas Gerais. As cultivares BRS Guariba, BRS Pajeú e BRS Cauamé apresentaram médias para peso de 100 grãos que variaram entre 19,8 e 21,5 g, indicando que estas apresentam grande potencial para aceitação pelo consumidor. De acordo com Oliveira et al. (2015), existe uma preferência por grãos com peso de 100 grãos em torno de $18 \mathrm{~g}$.

Em relação à produtividade de grãos, as cultivares foram agrupadas em dois grupos. As maiores produtividades foram obtidas pelas cultivares BRS Pajeú, Tumucumaque e BRS Guariba, que obtiveram 1.388, 1.379 e $1.354 \mathrm{~kg} \mathrm{ha}^{-1}$, respectivamente. Almeida et al. (2017) relataram resultados semelhantes para a BRS Tumucumaque e BRS Guariba, que obtiveram 1.530 e $1.373 \mathrm{~kg} \mathrm{ha}^{-1}$, respectivamente, em época de semeadura realizada no final da primeira quinzena de dezembro de 2012, em condições de Cerrado em Uberaba, Minas Gerais. As maiores produtividades obtidas pelas três cultivares no presente estudado podem ser explicadas pelos valores médios de número de vagens por planta, número de grãos por vagem e peso de 100 grãos satisfatórios (médio-alto).

De modo geral, as cultivares de feijão-caupi estudadas apresentaram produtividade média de grãos satisfatória, apresentando rendimentos superiores à média nacional (444 kg $\mathrm{ha}^{-1}$ ) e do Estado do Piauí (402 $\mathrm{kg} \mathrm{ha}^{-1}$ ) considerando as estimativas da primeira safra do ano agrícola 2018/2019 (CONAB, 2019). Os resultados mostram que o feijão-caupi tem um potencial produtivo significativo, com boa adaptação às condições edafoclimáticas do bioma Cerrado, em Uruçuí, Piauí.

\section{CONCLUSÕES}

As cultivares BRS Tumucumaque, BRS Pajeú e BRS Guariba destacam-se por apresentarem, maiores valores para a produtividade de grãos e ótimos valores para os componentes da produção e, também por apresentarem porte de plantas e boa adaptação para o cultivo nas condições de Cerrado piauiense.

\section{REFERÊNCIAS}

ALMEIDA, F. S.; MingotTe, F. L. C.; LEMOS, L. B.; SANTANA, M. J. Agronomic performance of cowpea cultivars depending on sowing seasons in the cerrado biome. Revista Caatinga, Mossoró, v. 30, n. 2, p. 361-369, 2017.

CARDOSO, M. J.; MELO, F. B. de.; LIMA, M. G. de. Ecofisiologia e manejo de plantio. In: FREIRE FILHO, F. R.; LIMA, J. A. de A.; RIBEIRO, V. Q. (Eds.). Feijão-caupi: avanços tecnológicos. Brasília: Embrapa Informação Tecnológica, 2005. p. 213-225 
CONAB (Companhia Nacional de Abastecimento). Acompanhamento da safra brasileira de grãos. $12^{\circ}$ Levantamento Grãos Safra 2018/19 - Setembro 2019. Disponível em: https://www.conab.gov.br/info agro/safras/graos/boletim-da-safra-de-graos. Acesso em: 31 jul. 2019.

CRUZ, C. D. Genes: a software package for analysis in experimental statistics and quantitative genetics. Acta Scientiarum. Agronomy, v. 35, n. 3, p. 271-276, 2013.

FREIRE FILHO, F. R.; RIBEIRO, V. Q.; ALCÂNTARA, J. dos P.; BELARMINO FILHO, J.; ROCHA, M. de M. BRS Marataoã: nova cultivar de feijão-caupi com grão tipo sempreverde. Revista Ceres, Viçosa, v. 52, n. 303, p. 771-777, 2005.

MELO, F. de B.; CARDOSO, M. J.; SALVIANO, A. A. C. Fertilidade do solo e adubação. In: FREIRE FILHO, F. R.; LIMA, J. A. de A.; RIBEIRO, V. Q. (Eds.). Feijãocaupi: avanços tecnológicos. Brasília: Embrapa Informação Tecnológica, 2005. p. 231-241.

OLIVEIRA, G. A.; ARAÚJO, W. F.; CRUZ, P. L. S.; SILVA, W. L .M.; FERREIRA, G. B. Resposta do feijão-caupi as lâminas de irrigação e as doses de fósforo no cerrado de Roraima. Revista de Ciência Agronômica, vol. 42, n. 4, p. 872-882, 2011.

OLIVEIRA, Eliane de et al. Descrição de cultivares locais de feijão-caupi coletados na microrregião Cruzeiro do Sul, Acre, Brasil. Acta Amazônica. vol.45, n.3, pp.243-254, 2015.

SANTOS, Jeferson Antônio da Silva et al. Desempenho agronômico e divergência genética entre genótipos de feijão-caupi cultivados no ecótono Cerrado/Pantanal. Bragantia, Campinas, 2014.

TEIXEIRA, I. R.; SILVA, G. C. da.; OLIVEIRA, J. P. R. de.; SILVA, A. G. da.; PÊLA, A. Desempenho agronômico e qualidade de sementes e cultivares de feijão-caupi na região do cerrado. Revista Ciência Agronômica, Fortaleza, v. 41, p. 300-307, 2010. 


\section{AVALIAÇÃO DA PREFERÊNCIA ALIMENTAR DE BARATAS DE MADAGASCAR (Gromphadorhina portentosa)}

\section{EVALUACIÓN DE LA PREFERENCIA DE ALIMENTOS DE MADAGASCAR CHEAPS (Gromphadorhina portentosa)}

\section{EVALUATION OF THE FOOD PREFERENCE OF MADAGASCAR CHEAPS (Gromphadorhina portentosa)}

Breno Noronha Rodrigues ${ }^{1}$; Jackeline Freire Moura ${ }^{2}$; Lindolfo Henrique Gomes Simão ${ }^{3}$; Maria Mariana Freitas Soares ${ }^{4}$; Aracely Rafaelle Fernandes Ricarte ${ }^{5}$

DOI: https://doi.org/10.31692/978-65-991061-4-9.217-220

\section{INTRODUÇÃO}

Com o desenvolvimento da criação de pets exóticos, foi intensificado os estudos aplicados a esses animais, seja para facilitar manejo ou melhorar alimentação e reprodução dos mesmos. Dentre os insetos mais criados estão as baratas de Madagascar, famosas por serem consideradas as maiores baratas do mundo (GREEN NATION, 2013).

Conhecer o animal que se tem em casa pode levar ao maior bem estar na vida dele, maior economia com os utensílios e alimentação adequada além de promover maior segurança a quem o rodeia. As Baratas de Madagascar, possuem alimentação variada e sua fonte hídrica baseia-se em frutas suculentas, dessa forma uso de frutas da estação pode baratear os custos com alimentação dos mesmos (REGAÇONI, 2016)

Partindo da necessidade da dessedentação adequada desses animais pelo menor custo, o presente trabalho possui o objetivo de avaliar a preferência alimentar da Barata de Madagascar dentre as principais fontes hídricas encontradas rotineiramente nas habitações nordestinas.

\section{FUNDAMENTAÇÃO TEÓRICA}

A Gromphadorhina portentosa, inseto da família Blaberidea, conhecida popularmente como barata de Madagascar é considerada a maior barata que se tem registro, podendo atingir até $10 \mathrm{~cm}$ de comprimento. Originária da ilha de Madagascar, situada na costa leste do continente africano, pode ser facilmente encontrada vivendo em solos de florestas,

\footnotetext{
${ }^{1}$ Zootecnia, UFERSA - Universidade Federal Rural do Semi-Árido, brenonoronhar@gmail.com

2 Zootecnia, UFERSA - Universidade Federal Rural do Semi-Árido, jackelynemoura15@ hotmail.com

${ }^{3}$ Zootecnia, UFERSA - Universidade Federal Rural do Semi-Árido, lindolfogomes1@gmail.com

${ }^{4}$ Zootecnia, UFERSA - Universidade Federal Rural do Semi-Árido, marianafreittas@ outlook.com.br

${ }^{5}$ Docente, UFERSA - Universidade Federal Rural do Semi-Árido, aracely@ufersa.edu.br
} 
serrapilheira e troncos.

Diferentemente da maioria das baratas, ela não possui asas, e é caracterizada por um "assobio" proveniente da passagem do ar expirado por um espiráculo presente em seu abdômen, que tem por função afastar possíveis predadores. Seu corpo é bicolor e recoberto por um exoesqueleto rígido formado por placas horizontais. Possuem também chifres e antenas, que pode ajudar na sexagem e tem função na orientação ambiental desses animais.

Essas baratas começaram a ser criadas nos Estados Unidos, inicialmente com função de alimento vivo, mas posteriormente passou a ser visto como um possível animal pet, por possuir bom comportamento e não oferecer qualquer tipo de ameaça ao seu manejador. Atualmente é um animal bastante difundido em todo o mundo, sendo muito apreciada pelos amantes dos pets exóticos também pelo seu longo tempo de vida, que pode chegar aos 5 anos.

No ambiente natural sua alimentação baseia-se em legumes, frutas e folhas, sendo seu hábito alimentar predominantemente noturno. Já em criações domésticas, utiliza-se frutas, legumes e rações comerciais para sua espécie como também adaptada de outros animais. Suas fontes hídricas são oriundas principalmente de alimentos suculentos, onde a falta deles pode desencadear atos de canibalismo na colônia.

Tendo baixo custo com alimentação, ciclo de vida curto, necessidade de pouco espaço para a sua criação, além de serem uma excelente fonte proteica, as Baratas de Madagascar vem sendo utilizadas como fonte alternativa na alimentação de aves, onde são administradas na forma de farinha, incorporadas na ração. Outro benefício da farinha, quando adicionada à alimentação de aves, pode influenciar positivamente nas características produtivas e reprodutivas (CARVALHO, 2017).

\section{METODOLOGIA}

A pesquisa teve cunho experimental de natureza qualitativa, a mesma foi executada na cidade de Mossoró-RN (Latitude: 05 11' 15” S; Longitude: 37²0’39” W). Foram avaliados 18 baratas da espécie Gromphadorhina portentosa, de diferentes idades e ambos os sexos.

Para a análise, foi utilizado um recinto de vidro, nas dimensões de $35 \mathrm{~cm}$ x $30 \mathrm{~cm}$ x $60 \mathrm{~cm}$, com toca para refúgio e enriquecimento ambiental. A observação foi realizada com o auxílio de aplicativos computacionais para cronometragem de períodos, onde eram registrados todo o comportamento alimentar dos insetos. Os mesmos se encontravam sem alimentação durante 24 horas.

As baratas foram divididas em 6 unidades experimentais, de 3 animais cada, onde foram ofertados 3 alimentos suculentos (mamão, laranja e cajarana) com livre acesso, sendo 
distribuídos de forma alternada nas repetições, buscando-se observar a predileção por um dos alimentos. Foram cronometrados 10 minutos para a observação de cada grupo e seu comportamento detalhadamente anotado. Foi calculada a média do tempo de consumo de cada alimento e avaliada sua escolha pelo animal.

\section{RESULTADOS E DISCUSSÃO}

$\mathrm{Na}$ realização do experimento foi observado que o mamão foi o alimento mais consumido, seguido da laranja e cajarana, respectivamente, como mostrado na tabela 1. Viuse também que 7 animais se alimentaram de duas ou mais amostras e 3 não demostraram comportamento alimentar durante o período avaliado.

Tabela 1 - Número de Baratas de Madagascar que consumiram cada alimento fornecido no experimento

\begin{tabular}{cccc} 
& Cajarana & Laranja & Mamão \\
\hline $\mathrm{N}^{\circ}$ de animais & 4 & 6 & 12 \\
\hline
\end{tabular}

A tabela 1 prova que nenhum dos alimentos se mostrou desagradável aos animais, afirmando que há palatabilidade dos mesmos, entretanto o mamão foi o mais aceito pelo inseto. O tempo médio que cada inseto realizou o seu consumo está expresso na tabela 2, o que permite deduzir qual alimento mais aceito quanto ao seu gosto ou fonte de nutrientes exigidos pelo animal.

Tabela 2 - Tempo médio de consumo de cada animal (Gromphadorhina portentosa) nas repetições (minutos).

\begin{tabular}{cccc}
\hline & Cajarana & Laranja & Mamão \\
\hline R1 & 2,75 & - & 3,81 \\
R2 & - & 0,5 & 4,92 \\
R3 & 3,00 & - & 6,03 \\
R4 & 1,00 & 1,40 & 6,68 \\
R5 & 0,17 & 5,08 & 4,23 \\
R6 & - & 2,04 & 6,49 \\
\hline Média geral & 1,73 & 2,08 & 5,19
\end{tabular}

Com a tabela 2, pode-se afirmar que o mamão além de ser o mais escolhido para o consumo também foi o alimento em que os animais passaram mais tempo consumindo dentro do período avaliado, mostrando uma forte preferência da espécie pela fruta em questão, o que poderia ser justificado pelo seu amplo uso no dia-a-dia nos ambientes criatórios e gerado uma certa adaptação as características sensoriais da fruta. Além disso, a pouca escolha dos animais pela laranja pode ser justificada pela sua acidez, e na cajarana o seu marcante sabor pode ter levado a queda do consumo pelos insetos em estudo. 


\section{CONCLUSÕES}

Com a experimentação realizada pôde-se caracterizar o mamão como a principal fonte hídrica para as baratas de Madagascar entre os alimentos testados, o que justifica o seu amplo uso na criação destes animais. Além disso, foi possível observar que nas condições propostas pelo experimento houve uma boa aceitação pelos três alimentos de forma limitada.

Observou-se também que ao consumir o mamão os insetos permaneceram até a saciedade, mostrando a sua alta palatabilidade para a espécie, o que não ocorreu com os outros dois alimentos testados. Tal fato leva a necessidade de um maior cuidado na utilização de laranja e cajarana como fonte hídrica, devendo ser administrados somente como ingredientes auxiliares na dieta.

\section{REFERÊNCIAS}

CARVALHO, T. S. GONZAGA. Farinha de barata de madagascar (Gromphadorhina portentosa) em dietas para calopsitas (Nymphicus hollandicus) mantidas em cativeiro. Tese (Doutorado em Produção e nutrição de não-ruminantes) - Universidade Federal de Lavras. Minas Gerais, p. 6. 2017.

GREENNATION. Bicho do dia: Barata gigante de Madagascar. Disponível em: $<$ http://greennation.com.br/noticia/bicho-do-dia-baratagigantedemadagascar/3268> Acesso em: 10/08/2019.

REGAÇONI, T. da SILVA; RIBEIRO, N. C. GONZALEZ, As baratas gigantes de Madagascar: Museu dinâmico interdisciplinar. Disponível em: <https://museudinamicointerdisciplinar.wordpress.com/2016/04/22/as-baratas-gigantes-demadagascar/> Acesso em: 08/08/2019. 


\title{
DIAGNÓSTICO DO PERFIL DOS AGRICULTORES FAMILIARES FEIRANTES E OS PRODUTOS COMERCIALIZADOS NA FEIRA MUNICIPAL DE SÃO MIGUEL DO GUAMÁ
}

\author{
DIAGNÓSTICO DE PERFIL DE LA FAMILIA DE AGRICYLTORES Y \\ PRODUCTOS COMERCIALIZADOS EN LA FERIA MUNICIPAL DE SÃO \\ MIGUEL DO GUAMÁ
}

\section{DIAGNOSIS OF THE PROFILE OF THE FARMERS' FAMILY FARMERS AND THE PRODUCTS MARKETED IN THE MUNICIPAL FAIR OF SÃO MIGUEL DO GUAMÁ}

\begin{abstract}
Marinara de Fátima Souza da Silva ${ }^{1}$; Adrielly Sousa da Cunha ${ }^{2}$; Milton Garcia Costa $^{3}$; Washington Duarte Silva da Silva ${ }^{4}$; Carlos Douglas de Sousa Oliveira ${ }^{5}$
\end{abstract}

DOI: https://doi.org/10.31692/978-65-991061-4-9.221-226

\section{INTRODUÇÃO}

A agricultura brasileira tem destaque no cenário internacional por ser uma das maiores do mundo e representa fonte de matéria prima e alimentos para muitos países. A agricultura brasileira contém diversos modos de fazer agricultura, entre as quais a produção agrícola familiar, encontrada em extensas e importantes regiões do país (DELGADO \& BARGAMASCO, 2017).

Nas últimas décadas, no Brasil, a agricultura familiar estabeleceu a sua importância no contexto econômico e desenvolvimento do campo, esse processo representa a conjunção da luta dos movimentos sociais do campo, organizados por agricultores familiares, em prol de uma política pública específica para a agricultura familiar (MATTEI, 2014).

Agricultura familiar tem se apresentado como uma alternativa modeladora de um desenvolvimento menos excludente e mais equilibrado ambientalmente (SANTOS \& MITJA, 2016). Atualmente, a agricultura familiar brasileira é responsável por $87 \%$ da produção total da mandioca, $70 \%$ da produção total do feijão, $46 \%$ da produção total do milho, $38 \%$ da produção total do café, $58 \%$ produção total do leite, $59 \%$ produção total de suínos, $50 \%$ do plantel de aves e 30\% do plantel de bovinos (MATTEI, 2014).

\footnotetext{
${ }^{1}$ Acadêmica de Agronomia, Universidade Federal Rural da Amazônia (UFRA), Capitão Poço - PA, marinarasilva@live.com

${ }^{2}$ Acadêmica de Agronomia, Universidade Federal Rural da Amazônia (UFRA), Capitão Poço, drykasouzaa@gmail.com

${ }^{3}$ Bolsista PIBIC-CNPq, Universidade Federal Rural da Amazônia (UFRA), Capitão Poço - PA, miltongarciacosta.2010@gmail.com

${ }^{4}$ Acadêmico de Engenharia Florestal, Universidade Federal Rural da Amazônia (UFRA), Capitão Poço - PA, washingtons.duarte00@gmail.com

${ }_{5}^{5}$ Doutor em Desenvolvimento Rural, Docente da Universidade Federal Rural da Amazônia, Paragominas, douglasoliv72@gmail.com
} 
$\mathrm{Na}$ região amazônica, a agricultura familiar apresenta-se com características específicas, em comparação com as outras regiões do país, sobretudo porque apresenta características extrativista e a maioria dos agricultores trabalha principalmente com a produção de alimentos (SANTOS \& MITJA, 2016).

Diante desse contexto, constata-se que um importante canal de comercialização dos produtos dos agricultores familiares são as feiras-livres, onde tais produtos se tornam mais atrativos em relação a supermercados e fruteiras, em função da maior diversidade e qualidade dos mesmos, da dinâmica peculiar da negociação dos preços e atendimento diferenciado, possibilitando uma relação mais próxima entre feirante produtor e consumidor (MICHELLON; MOLINA; COSTA, 2009).

As feiras são locais tradicionais que os agricultores familiares podem comercializar os seus produtos diretamente da propriedade rural. Nesse sentido, considera-se que as feiras podem ser uma forma de organização formal ou informal que pretende buscar interação entre atores sociais (produtores, consumidores e público geral), podendo ser considerada uma estratégia para o desenvolvimento regional e local (CHUQUILLANQUE, 2015).

Embora não seja a totalidade, mas a maioria dos feirantes são também agricultores familiares, ou seja, são os que produzem parte dos produtos comercializados ou a totalidade dos produtos, sendo estes produtores de frutas, legumes e grãos (MICHELLON; MOLINA; COSTA, 2009).

Desta maneira, o objetivo do trabalho foi avaliar a importância da agricultura familiar e como seus produtos são produzidos e comercializados na feira municipal do munícipio de São Miguel do Guamá - PA, buscando mapear o uso de práticas agroecológicas nesse sistema de produção familiar.

\section{FUNDAMENTAÇÃO TEÓRICA}

Segundo dos dados do censo agropecuário de 2017, foram identificados 5.072.152 estabelecimentos de agricultores familiares, $87 \%$ dos estabelecimentos brasileiros. Com isso, ressaltamos a grande importância dos agricultores familiares para a vida do cidadão.

O desenvolvimento dos agricultores segundo Buarque (1999), é dado por iniciativas que buscam inovar e mobilizar os agricultores, o que buscar saber a qualidade dos locais em que os agricultores vendem seus produtos. Esse desenvolvimento é feito através de agentes locais, que buscam incentivar os agricultores a inovarem e variarem seus produtos.

Porém, a economia não ocorre de maneira igualitária em todos os locais, então o agricultor precisa se adaptar de acordo com a economia do local a qual ele vende seus 
produtos.

\section{METODOLOGIA}

O estudo foi realizado no mês de abril de 2018 no munícipio de São Miguel do Guamá (Figura 1) no Nordeste Paraense. O munícipio possui uma população de 57.364 habitantes e densidade de 46,45 hab/ $\mathrm{km}^{2}$ (IBGE, 2017). O estudo foi realizado por meio de metodologia qualitativa e qualitativa, por análises e aplicações de questionário na feira municipal de São Miguel do Guamá.

FIGURA 1: Localização do Munícipio de São Miguel do Guamá - PA

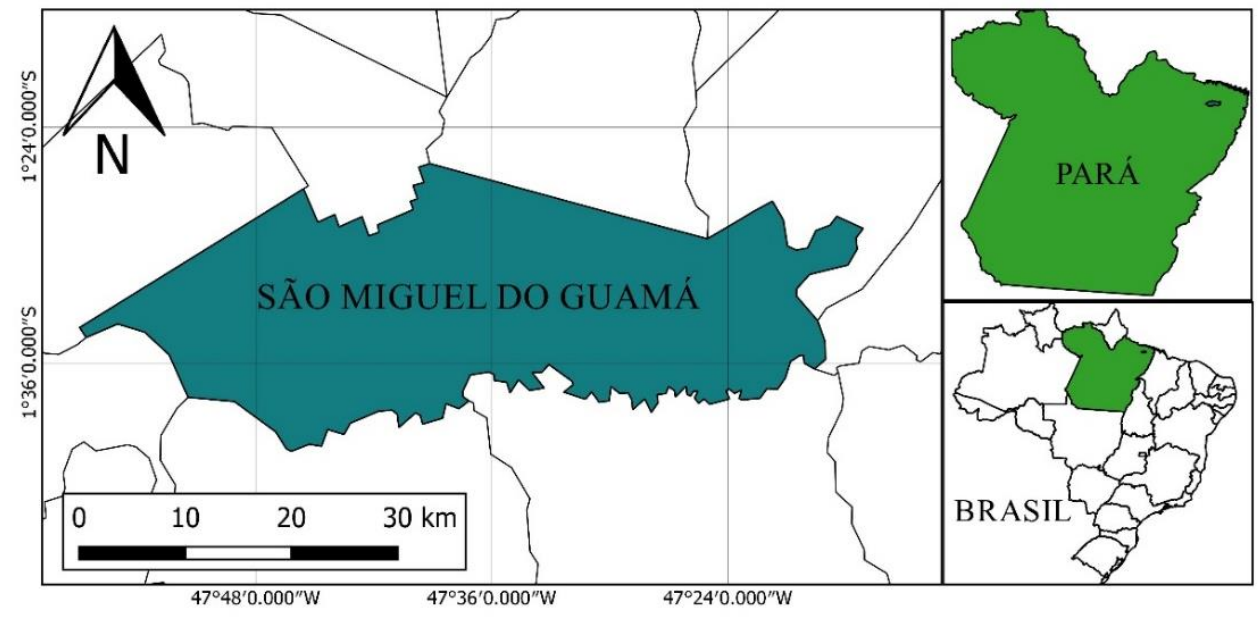

Foram aplicados questionários para oito (08) feirantes e agricultores familiares. Para o acesso às informações sobre os feirantes e sua produção foram elaborados questionários contendo questionamentos objetivos e subjetivos.

\section{RESULTADOS E DISCUSSÕES}

Os feirantes produtores apresentaram uma variação de idade de 21 a 58 anos. Onde quatro entrevistados têm idades de 20 a 30 anos, dois entrevistados têm idades de 30 a 40 anos e dois têm idade acima de 40 anos. Podendo observar que os jovens estão inseridos nas atividades de agricultura familiar. Isso se justifica pela baixa oferta de oportunidades de trabalho na região urbana do munícipio, onde somente $11,2 \%$ da população do munícipio são considerados como ocupados pelo IBGE em 2015. Sendo que 87,5\% dos entrevistados foram mulheres, indicando que no munícipio de São Miguel do Guamá as mulheres são responsáveis na maioria dos casos pela comercialização dos produtos produzidos no campo, considerando a feira aqui pesquisada.

Constatou-se que $37,5 \%$ dos feirantes produtores vieram de outros munícipios do nordeste paraense, como Bonito, Bragança e Santa Maria do Pará. Foi constado também, que 
$62,5 \%$ dos feirantes produtores possuem o ensino fundamental completo, $25 \%$ somente ensino fundamental completo e 12,5\% ensino médio incompleto. Portanto, observa-se que os feirantes produtores do município de São Miguel do Guamá possuem baixa escolaridade, podendo ser justificado pela dupla jornadas que os jovens do campo muitas vezes desenvolvem, tendo que ajudar nas atividades ligadas à agricultura familiar e seus estudos, podendo ocorrer o abandono muitas vezes dos estudos para se dedicarem às atividades produtivas familiares.

Verificou-se através dessa pesquisa, que os agricultores familiares entendiam a agricultura familiar como um meio de sobrevivência dos pequenos produtores, sendo que os agricultores consideram a atividade importante, pois resulta em melhorias para a sociedade, uma vez que oferta produtos mais saudáveis e, por outro lado, esse modelo de agricultura representa um meio de sobrevivência para os pequenos produtores.

Os feirantes produtores veem que a agricultura familiar necessita de melhorias, que falta recursos para um trabalho digno, mas que ocorreu melhoramento no decorrer do tempo. Contatou-se que $50 \%$ dos feirantes produtores produzem todos os produtos comercializados na feira e $50 \%$ dos feirantes produtores produzem uma parte e compra outra parte de outros agricultores familiares do próprio município.

Os produtos mais vendidos e mais procurados pelos consumidores na feira são alface (Lactuca sativa L.), cheiro verde (Coriandrum sativum L.), couve (Brassica oleracea L.), jambú (Acmella oleracea (L.) R.K. Jansen), pimentinha (Capsicum frutescens L.), chicória (Cichorium intybus L.), cominho e colorau, sendo estes dois últimos adquiridos pelos feirantes em forma já processada.

Verificou-se também, que os produtos procurados pelos consumidores, porém não presentes na feira, foram Salsa (Petroselinum crispum (Mill.)Mansf.), Rúcula (Eruca sativa Lam.), feijão de corda (Vigna unguiculata (L.) Walp.), quiabo (Abelmoschus esculentus (L.) Moench), jerimum (Cucurbita spp.), cenoura (Daucus carota subsp. sativus (Hoffm.) Arcang.), orégano (Origanum vulgare L.), alecrim (Rosmarinus officinalis L.), alfazema (Lavandula angustifólia Mill.) e alfavaca (Ocimum basilicum L.).

Questionou-se os feirantes produtores sobre o significado da produção ecológica. Nesse sentido, constatou-se que os mesmos não são esclarecidos sobre esse tema, especialmente sobre os conhecimentos agroecológicos. Assim, demonstra a necessidade de políticas públicas voltadas para o campo para fortalecimento da agricultura familiar. Tais políticas são necessárias para que possam garantir aos agricultores familiares qualidades de vida e dignidade no campo, possibilitando a fixação do homem no campo, assim 
interrompendo o intenso fluxo do êxodo rural. Por outro lado, apesar de os agricultores familiares feirantes não conhecerem o tema da agroecologia, constata-se por meio do discurso dos mesmos que, na prática, eles praticam de alguma forma atividades produtivas agroecológicas.

Entre as práticas de produção ecológicas, foram relatadas pelos interlocutores a utilização de estercos bovinos, estercos de galinha e serragem. Segundo os produtores rurais feirantes, a sua produção é $46 \%$ comercializada na feira, tendo uma variação de $10 \%$ a $80 \%$ entre os agricultores familiares, conforme observado no gráfico 1:

GRÁFICO 1: Variação de porcentagens de produtos produzidos por agricultores familiares comercializado na feira do munícipio de São Miguel do Guamá em 2018

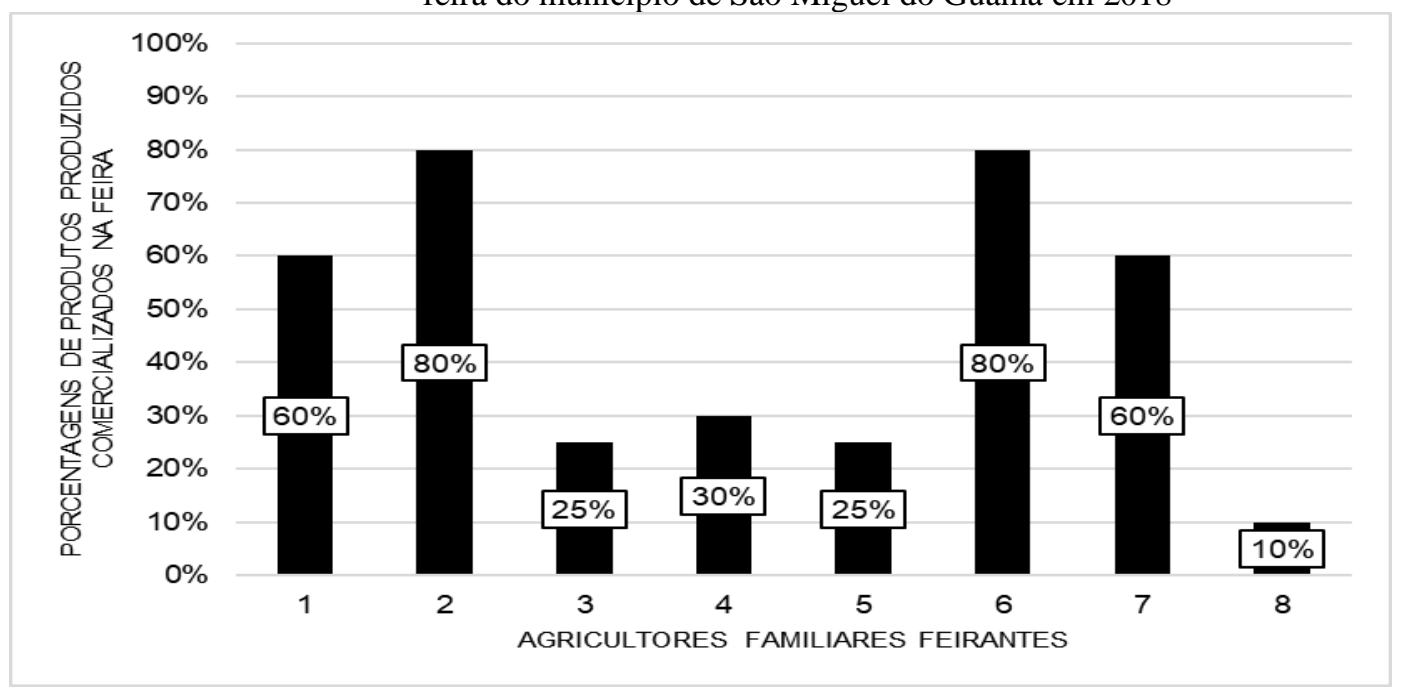

Fonte: dados de campo da pesquisa.

\section{CONCLUSÃO}

A feira municipal de São Miguel do Guamá constitui um importante local para comercialização dos produtos dos agricultores familiares, sendo essencial para o contato com os consumidores. Os produtos da agricultura familiar garantem maior segurança alimentar, tanto para os agricultores familiares, quanto para a população em geral, além de fornecer a maior parte dos alimentos para sociedade brasileira na atualidade.

Os resultados desta pesquisa aponta para a necessidade de elaboração ou proposição de políticas públicas socioeconômicas e agroecológicas, uma vez que os mesmos realizam essas práticas ecológicas de forma tímida e desorganizada, sem uma consciência para a importância desse tipo de produção.

Observa-se também, que a feira municipal de São Miguel do Guamá não oferta todos os produtos que a população de forma geral busca, talvez por falta de assistência técnica e extensão rural eficaz, que busque auxiliar os agricultores familiares a desenvolverem 
alternativas de produção, de acordo com a demanda local.

Portanto, a feira municipal é essencial para comercialização dos produtos da agricultura familiar, porém os agricultores familiares precisam de uma atenção maior dos gestores públicos, para que possam fortalecer a agricultura, inclusive com práticas agroecológicas e gerar condições dignas e promoção da qualidade de vida desses agricultores.

\section{REFERÊNCIAS}

BUARQUE, Sérgio C. Metodologia de planejamento do desenvolvimento local e municipal sustentável. Material para orientação técnica e treinamento de multiplicadores e técnicos em planejamento local e municipal. Brasília, DF: IICA, 1999.

CHUQUILlANQUE, D. A. et al. Caracterização da produção agrícola e dos feirantes da agricultura familiar no Município de São Lourenço do Sul-RS. In: V Congreso Latinoamericano de Agroecología-SOCLA (La Plata, 2015). 2015.

DELGADO, Guilherme Costa; BERGAMASCO, Sonia Maria Pessoa Pereira (Org.). Agricultura familiar brasileira: desafios e perspectivas de futuro. Brasília, DF: NEAD, 2017.

IBGE. Instituo Brasileiro de Geografia e Estatistica - IBGE. Censo Agro2017. Disponível em:

https://censoagro2017.ibge.gov.br/templates/censo_agro/resultadosagro/estabelecimentos.htm 1_Acesso em: 28 de agosto de 2019.

IBGE. Instituo Brasileiro de Geografia e Estatistica - IBGE. Censo Agro2017. Disponível em: https://censoagro2017.ibge.gov.br/templates/censo_agro/resultadosagro/produtores.html Acesso em: 28 de agosto de 2019.

INSTITUTO BRASILEIRO DE GEOGRÁFIA E ESTATÍSTICA (IBGE). São Miguel do Guamá. Disponível em: https://cidades.ibge.gov.br/brasil/pa/sao-miguel-do-guama/panorama. Acessado em 25 de Abril de 2018.

JUNIOR, Edgar Reyes; SEABRA, Luiz Fernando Gomes. Relações entre o nível socioeconômico e qualidade de vida na agricultura familiar da Amazônia. Revista de Administração de Roraima-RARR, v. 2, n. 1, p. 88-109, 2015.

MATTEI, Lauro. O papel e a importância da agricultura familiar no desenvolvimento rural brasileiro contemporâneo. Revista Econômica do Nordeste, v. 45, n. 5, p. 83-92, 2014.

MICHELlON, Ednaldo; MOLINA, Simone Correia; COSTA, Thiago Ribeiro da. Feira do produtor rural pela visão dos consumidores. In: Encontro Internacional de Produção Científica Cesumar. VI EPCC. 2009.

SANTOS, Alessio Moreira dos; MITJA, Danielle. Agricultura familiar e desenvolvimento local: os desafios para a sustentabilidade econômico-ecológica na comunidade de Palmares II, Parauapebas, PA. Interações (Campo Grande), v. 13, n. 1, 2016. 


\section{ASSENTAMENTO SERRA GRANDE: APROVEITANDO RESÍDUOS AGROINDÚSTRIAIS}

\section{ASENTIAMENTO SERRA GRANDE: DISFRUTANDO RESIDUOS AGRICOLA \\ SETTLEMENT SERRA GRANDE: TAKING ADVANTAGE OF AGRIBUSINESS WASTE}

Valdenora Mateus da Silva Neta ${ }^{1}$; Suelen Samili da Silva ${ }^{2}$; Júlia Karoline de Lima Barbosa ${ }^{3}$; Vínicius de Barros Monteiro; ${ }^{4}$ Djalma Vitorino Costa Filho ${ }^{5}$

DOI: $\underline{\text { https://doi.org/10.31692/978-65-991061-4-9.227-229 }}$

\section{INTRODUÇÃO}

No Brasil, formas diferentes de produção agroindustrial funcionam em paralelo com a produção agrícola. Em sua maioria o beneficiamento está condicionado diretamente à geração de produtos e, consequentemente a geração de resíduos. A produção de resíduos oriundos dos trabalhos agroindustriais são originalmente derivados do processamento de couro, fibras, alimentos, madeira, produção da indústria sucroalcooleira. Sua produção é geralmente estacional, atrelada pela maturidade da cultura ou oferta da matéria-prima. A característica e quantidade de resíduos agroindustriais produzidos são versáteis com o tempo (MATOS, 2014).

Os resíduos do beneficiamento de alimentos surgem durante o preparo destes, para a sua conversão em produtos alimentícios. Pertencem a este tipo, os resíduos que não se integram aos produtos como componentes e que por esse motivo necessitam serem deles excluídos. Este tipo de resíduo é eliminado dos alimentos durante o seu processamento e, por estratégias tecnológicas se tornam subprodutos.

Resíduos podem representar perda de biomassa e de nutrientes, além de aumentar o potencial poluidor associado à disposição inadequada que, além da poluição de solos e de corpos hídricos quando da lixiviação de compostos, acarreta problemas de saúde pública. Por outro lado, o elevado custo associado ao tratamento, ao transporte e à disposição final dos resíduos gerados tem efeito direto sobre o preço do produto final (ROSA, et al. 2011).

\section{RELATO DE EXPERIÊNCIA}

O assentamento de reforma agrária Serra Grande, localizado na Zona Rural do

\footnotetext{
${ }^{1}$ Agronomia, IFPE - campus Vitória de Santo Antão, valdenora456@ gmail.com

2 Agronomia, IFPE - campus Vitória de Santo Antão, suelensamili14@gmail.com

${ }^{3}$ Agronomia, IFPE - campus Vitória de Santo Antão, juliakarolineb@gmail.com

${ }^{4}$ Agronomia, IFPE - campus Vitória de Santo Antão, vb4rr0s.31@ gmail.com

5 Especialista em vigilância sanitária e qualidade dos alimentos, IFPE - campus Vitória de Santo Antão, djalma.vitorino@vitoria.ifpe.edu.br
} 
munícipio de Vitória de Santo Antão, pertencente à microrregião de Vitória de Santo Antão, estado de Pernambuco, destaca-se pela produção de diversas matérias-primas de origem vegetal. No ano de 2018, a comunidade notabilizou-se no cenário local pela quantidade expressiva de produção de folhosas e frutos como banana (Musa spp.), jaca (Artocarpus heterophyllus) e caju (Anacardium occidentale). Diante disso, surgiu a preocupação do descarte consciente do excedente da produção.

Através da Associação Comercial de Indústrias Atacadistas e Varejo - ACIAV do munícipio de Vitória de Santo Antão, foi realizado um levantamento exploratório in loco, da necessidade de conhecimentos teóricos e práticos, a qual destino deveria se dá ao resíduo gerado naquela comunidade. O destaque se deu na proporção de resíduos gerado de jaca (Artocarpus heterophyllus).

O Programa Internacional Despertando Vocações para as Ciências Agrárias PDVAgro, através de seu Grupo de Trabalho (GT) de Ciência e Tecnologia de Alimentos, sendo agente de extensão com viés educativo, realizou com 15 produtoras, oficinas direcionadas a cinco áreas: Boas Práticas Agrícola - BPA, Boas Práticas de Fabricação $\mathrm{BPF}$, temáticas e dinâmicas de conhecimento prático, sobre a produção de fluxogramas de produção de subprodutos, avaliações didáticas e empreendedorismo potencial de alimentos.

Para a oferta da oficina de BPA, foi utilizado como ferramenta didática cartilhas da Empresa Brasileira de Pesquisa Agropecuária - EMBRAPA, que têm como foco o uso consciente do solo, o não desperdício da água de irrigação dos pomares e o descarte correto de lixo gerado na agricultura. A oferta das BPF's teve como foco a segurança de alimentos, a higienização de alimentos no seu beneficiamento, processamento e armazenamento de produtos.

Na elaboração dos fluxogramas, utilizaram-se cartilhas educativas com explicações práticas da carga nutricional de cada resíduo gerado, o seu potencial agregador de valor comercial, como também a estratégia empreendedora de ofertar produtos que tenham uma politica sustentável e educação ambiental.

Nutricionalmente, a jaca apresenta, em 100 g, uma média de 72 a 94\% de umidade, 1,2 a $1,9 \%$ de proteínas, 0,1 a $0,4 \%$ de lipídeos, 0,8 a $0,9 \%$ de cinzas; 16 a $25 \%$ de carboidratos; 1,0 a 1,5\% de fibras, 20 a $37 \mathrm{mg}$ de cálcio, $27 \mathrm{mg}$ de magnésio, 38 a $41 \mathrm{mg}$ de fósforo, 191 a $407 \mathrm{mg}$ de potássio, 2 a $41 \mathrm{mg}$ de sódio, 0,5 a 1,1 mg de ferro; 540 U.I de vitamina A, 30 U.I. de vitamina B1 e 88 a 410 calorias (VAZHACHARICKAL et al., 2015)

Inicialmente as cascas de jacas foram higienizadas conforme determina a legislação sanitária e submetidas a cocção em panela de pressão durante 25 minutos. A montagem do 
prato de lasanha de "carne" de jaca é bastante consumida em comunidades de vegetarianos e veganos. A estratégia nesse contexto foi elaborar uma lasanha de jaca com a casca do fruto, Utilizando ingredientes da produção comum do "prato", o deixando com características análogas a do consumo cotidiano.

Imagem 1: Prato de lasanha de "carne" de jaca e agricultoras do Assentamento de Serra Grande;

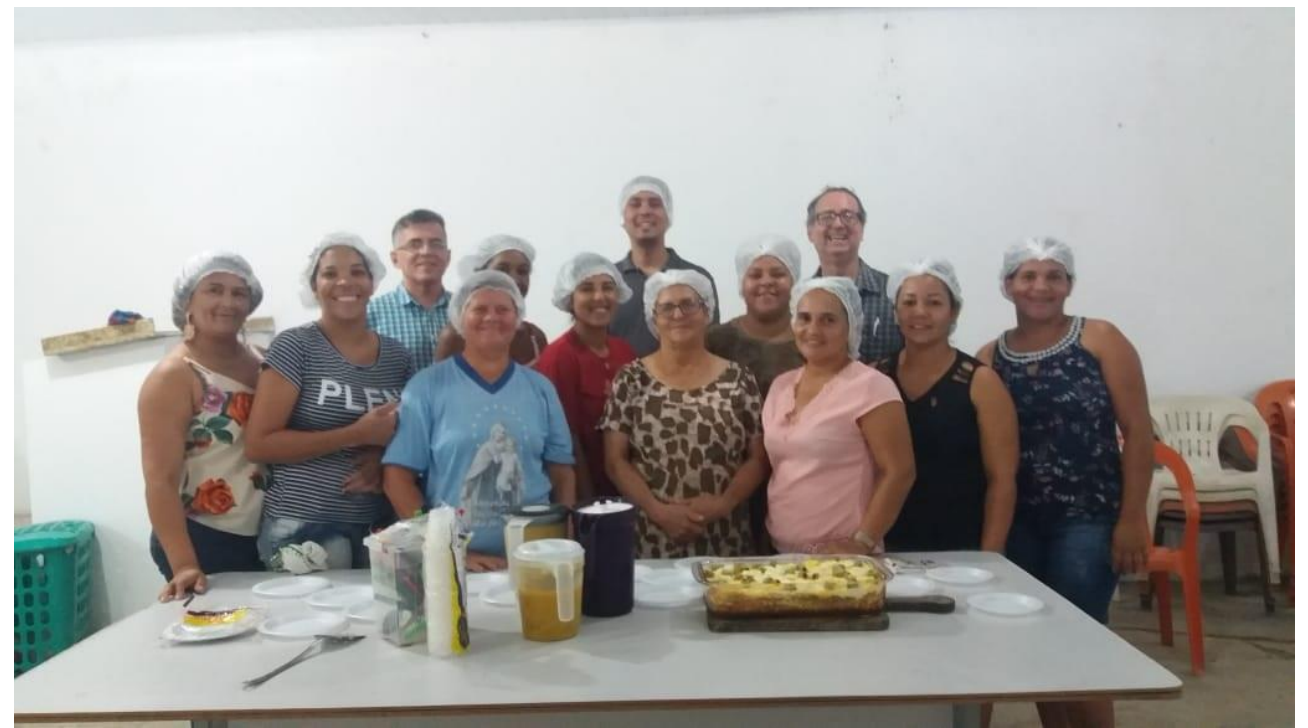

\section{CONSIDERAÇÕES}

As oficinas puderam oferecer as 15 agricultoras do assentamento Serra Grande a oportunidade de aliar o conhecimento pessoal/científico, sobre como aproveitar resíduos agroindustriais na geração de rendas, agregando valor ao descarte consciente e a não agressão ao meio ambiente.

\section{REFERÊNCIAS}

MATOS, A. T. Tratamento e Aproveitamento Agrícola de Resíduos Sólidos. Viçosa, Minas Gerais: Ed. UFV, 2014.

ROSA, M. F.; SOUZA FILHO, M S. M.; FIGUEIREDO, M. C. B.; MORAIS, J. P. S.; SANTAELLA, S. T. LEITÃO, R. C. Valorização de resíduos da agroindústria. II Simpósio Internacional sobre Gerenciamento de Resíduos Agropecuários e Agroindustriais - II SIGERA 15 a 17 de março de 2011 - Foz do Iguaçu, PR Volume I - Palestras.

VAZHACHARICKAL, P. J.; SAJESHKUMAR, N. K.; JIBY, J. M.; AJESH C.; URIAKOSE, B. A.; RENJITH, J. M.; ALEN, N. A.; DEENAMOL, T.; RINY, S. T.; NIJAMOL, V.; SOPHYIAMOL, J. "Chemistry and medicinal properties of jackfruit (Artocarpus heterophyllus): A Review on current status of knowledge", International Journal of Innovative Research and Review, v.3, n.2, p.83-95, 2015. 


\section{ELABORAÇÃO DE UM LICOR À BASE DA VINAGREIRA}

Eulane Rys Rufino Abreu; Weshyngton Grehnti Rufino Abreu; Ísis Valéria Borges da Silva; Oswaldo Palma Lopes Sobrinho; Álvaro Itaúna Schalcher Pereira

DOI: https://doi.org/10.31692/978-65-991061-4-9.230-233

\section{INTRODUÇÃO}

A vinagreira (Hibiscus sabdariffa L.) é proveniente da África Oriental e introduzida no Brasil pelos escravos, sendo popularmente conhecida como: azedinha, azeda-da-guiné, caruru-azedo, caruru-da-guiné, papoula, quiabeiro-azedo, quiabo-azedo, quiabo-de-angola, quiabo-róseo, quiabo-roxo, rosélia, vinagreira, papoula hibisco e/ou graxa-de-estudante (YAMAMOTO et al., 2007; SOUZA et al., 2015).

A vinagreira trata-se de uma espécie que apresenta floração durante todo o ano, com flores de diversos formatos e cores (LORENZI, 2008). É um arbusto compacto anual ou perene, que possui em torno de 1,8 a 3 metros de altura. É visado por suas folhas, flores, sementes e caule. No entanto, o cálice da planta também é bastante procurado devido seu potencial farmacêutico e alimentar (BARBOSA et al., 2016). Assim sendo, o hibisco é amplamente utilizado pelo público por ser considerado um alimento não convencional rico em cálcio, magnésio, ferro, açúcares redutores, vitamina A e C, fibra alimentar e pectina (CUNHA et al., 2016).

Desta forma, o Ministério da Agricultura, Pecuária e Abastecimento (MAPA) classifica as plantas alimentícias não convencionais (PANC's), como sendo aquelas que não são muito estudadas cientificamente e exploradas pela sociedade, ou seja, plantas de consumo regional (MAPA, 2010). Nesse contexto, as PANC's possuem restrição a determinadas localidades ou regiões e exercem grande influência na cultura e na alimentação de populações tradicionais (DUARTE, 2017).

Segundo a legislação de no 8.918, de 14 de julho de 1994 dispõe sobre a padronização, registro, inspeção, classificação, produção e a fiscalização de bebidas e classifica o licor como uma bebida com percentual de açúcar superior a 30g.L-1, e graduação alcoólica de 15-54\%, elaborado com álcool etílico potável de origem agrícola e/ou bebidas alcoólicas, adicionado de extrato ou substâncias de origem vegetal ou animal (BRASIL, 1994).

Para tanto, a flor do hibisco vem sendo bastante utilizada como chá, considerado um fitoterápico no tratamento da diminuição de peso, controle da obesidade, tratamento gastrointestinal e cálculo renal. Nessa perspectiva deste cenário, o desenvolvimento de licores artesanais surge como uma alternativa na geração de renda para os pequenos agricultores rurais e na diminuição de problemas relacionados ao excedente de produtos perecíveis (SIMÕES, 
2011), além de auxiliar na valorização e no desenvolvimento socioeconômico regional.

\title{
Relato de Experiência
}

A elaboração do licor da vinagreira (Hibiscus) foi realizada no Laboratório de Processamento de Leite, pertencente ao Instituto Federal de Educação, Ciência e Tecnologia do Maranhão - Campus Codó (IFMA) seguindo os procedimentos:

\section{Formulação}

- Água (50\%);

- Cachaça $(100 \%)$;

- Hibiscus (100\%); e

- Açúcar (até 45\%).

Veja-se o fluxograma para elaboração de um licor à base da vinagreira.

\section{Fluxograma do processamento}

\author{
Pesagem

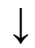 \\ Fervura \\ $\downarrow$ \\ Resfriamento \\ $\downarrow$ \\ Adição da cachaça
}

\author{
Envase \\ $\downarrow$ \\ Maturação \\ $\downarrow$ \\ Filtração \\ $\downarrow$ \\ Armazenamento
}

\section{Procedimento}

A vinagreira foi adquirida do IFMA-Campus Codó. O processamento de elaboração do licor foi adaptado pelo Manual da Empresa Brasileira de Pesquisa Agropecuária (EMBRAPA) (PENHA, 2006). Pesou-se os ingredientes (açúcar e hibisco). Em um recipiente foi adicionado açúcar, água e flores de Hibiscus e em seguida levou-se ao fogo até o ponto de fervura. Posteriormente, deixou-se a água e o açúcar ferverem até ficarem dissolvidos e 
homogeneizados e resfriou-se a calda a mais ou menos $40^{\circ} \mathrm{C}$. Adicionou-se a cachaça e realizou-se o envase para o processo de maturação por 30 dias. Após este período fez-se a filtração para retirada das partículas em suspensão depositadas no fundo da garrafa e realizouse o engarrafamento final do material (Figura 1).

Figura 1: Licor à base da vinagreira feito no Laboratório de Processamento de Leite do IFMA-

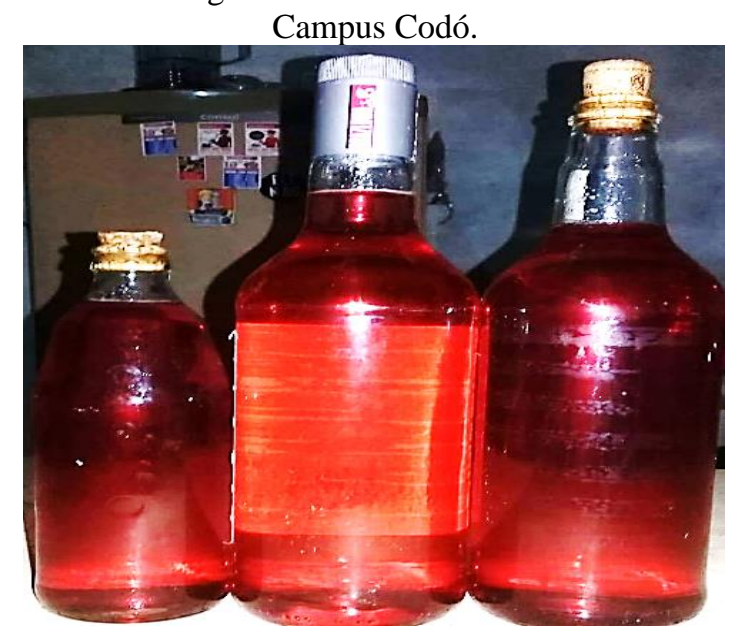

Fonte: Própria.

Após a maturação dos licores, os produtos elaborados foram apresentados na Semana Nacional de Ciência e Tecnologia (SNCT, 2018) do IFMA-Campus Codó visando expor à comunidade interna e externa os métodos de elaboração de produtos não convencionais. No decorrer da semana científica foram realizadas palestras, mesas redondas, exibição de curtas metragens, minicursos, oficinas, apresentações culturais e sessões de apresentação de trabalhos. Esta é aberta ao público com o intuito da inclusão e fomentar o uso social da ciência e da tecnologia permitindo a socialização a partir da popularização, divulgação da ciência e tecnologia.

Durante a apresentação dos produtos notou-se a carência de informações dos pequenos agricultores sobre o uso do hibisco como licor para consumo, sendo de grande importância socioeconômica como fonte na geração de renda.

\section{CONSIDERAÇÕES}

A experiência vivenciada possibilitou a comunidade informações relacionada a todo o processo de elaboração do licor, além da degustação do produto. A partir da elaboração deste sugere-se a realização de minicursos e palestras socioeducativas para toda a comunidade visando possibilitar o aproveitamento de produtos não convencionais como o Hibiscus.

\section{AGRADECIMENTOS}


Ao Grupo de Pesquisa cadastrado no Conselho Nacional de Desenvolvimento Científico e Tecnológico (CNPq) em Alimentos, Química, Agronomia e Recursos Hídricos (AQARH).

\section{REFERÊNCIAS}

BARBOSA, S. J.; FAlCI, V.; BARBETTA, P. V. C.; CALliARI, C. M. Atividade antioxidante de bebidas alcoólicas à base de hibisco. In... XXV Congresso Brasileiro de Ciência e Tecnologia de Alimentos, Anais. Gramado-RS. Out. 2016.

BRASIL, Ministério da Agricultura, Pecuária e Abastecimento. Dispõe sobre a padronização, a classificação, o registro, a inspeção, a produção e a fiscalização de bebidas (Lei no 8.918 de 14 de julho de 1994). 1994.

CUNHA, J. M.; VIANA, E. S. M; SOUZA, J. T. SILVA, S. S. Os efeitos do hibisco (Hibiscos sabdariffa) no emagrecimento. Revista Científica Univiçosa. v. 8, n. 1, p. 657-661, 2016.

DUARTE, G. Levantamento e Caracterização das Plantas Alimentícias Não Convencionais do Parque Florestal de Monsanto - Lisboa FCSH - UNL. Dissertação de Mestrado em Ecologia Humana e Problemas Sociais Contemporâneos, 2017.

LORENZI, H. Plantas ornamentais no Brasil: arbustivas, herbáceas e trepadeiras. Instituto Plantarum, Nova Odessa, Brasil. 1130 p. 2008.

MINISTÉRIO DA AGRICULTURA, PECUÁRIA E ABASTECIMENTO - MAPA. Manual de hortaliças não convencionais. Secretaria de Desenvolvimento Agropecuário e Cooperativismo. - Brasília: Mapa/ACS, 2010.

PENHA, E. M. Empresa Brasileira de Pesquisa Agropecuária - EMBRAPA. Licor de Frutas. Embrapa Agroindústria de Alimentos. - Brasília, DF: Embrapa Informação Tecnológica, 2006.

SIMÕES, L. S., TEIXEIRA, L. J. Q.; SARAIVA1, S. H.; JUNQUEIRA, M. S.; SARTORI, M. A. Estudo da cinética de extração alcoólica do processamento do licor de abacaxi. Enciclopédia Biosfera, v.7, n.13, p. 717-726, 2011.

SOUZA, R. R; CAVAlCANTE, M. Z. B.; LIMA, M. P. D.; ALIXANDRE, T. F.; NASCIMENTO, R. T. Propagação vegetativa de hibisco com diferentes tipos de estacas e concentrações de ácido indolbutírico. Comunicata Scientiae, v. 6, n. 3, p. 291-296, 2015.

YAMAMOTO, N. T.; RAMOS, D. D.; GOUVÊA, A. B.; SCALON, S. P. Q. Desenvolvimento de (Hibiscus sabdariffa L.) cultivadas em diferentes substratos. Revista Brasileira de Biociências, Porto Alegre, v. 5, n. 2, p. 771-773, 2007. 


\section{PARTICIPAÇÃO AO PROGRAMA DE MONITORIA NA DISCPLINA DE CONTROLE DE QUALIDADE E ANÁLISE DE ALIMENTOS: UM RELATO DE EXPERIÊNCIA}

\section{PARTICIPACIÓN EN EL PROGRAMA DE MONITOREO EN LA DISCIPLINA DE CONTROL DE CALIDAD Y ANÁLISIS DE ALIMENTOS: UN INFORME DE EXPERIENCIA}

\section{PARTICIPATION IN THE MONITORING PROGRAM IN THE QUALITY CONTROL AND FOOD ANALYSIS DISCIPLINE: AN EXPERIENCE REPORT}

Robson da Silveira Espíndola ${ }^{1}$; Evelyn Ivana Trindade Damasceno Alves ${ }^{2}$

DOI: https://doi.org/10.31692/978-65-991061-4-9.234-237

\section{INTRODUÇÃO}

A importância da monitoria nas disciplinas do ensino superior excede o caráter de obtenção de um título, seja no aspecto pessoal de ganho intelectual do monitor, seja na contribuição dada aos alunos monitorados e, principalmente, na relação interpessoal de troca de conhecimentos entre os professores da disciplina e o aluno monitor (MATOSO, 2014).

O programa de Monitoria nas universidades brasileiras foi iniciado com o advento da Lei 5540, de 28 de novembro de 1968, que fixou normas de organização e funcionamento para o ensino superior (Dias 2007). A monitoria acadêmica constitui-se como um instrumento de ensino aprendizagem que auxilia a compreensão e a produção do conhecimento universitário, visto que na maioria das vezes o aluno se envolve com a ciência assim como programas de iniciação cientifica e extensão.

Para o controle de qualidade e análise dos alimentos, a segurança sanitária dos alimentos ofertados para consumo da população é um dos desafios da Saúde Pública. A produção de refeições industrializados, não industrializados ou elaborados e enriquecidos com condimentos envolvem um conjunto de ferramentas para a garantia da qualidade e segurança. A análise de alimentos atua na avaliação das propriedades nutricionais dos alimentos assim como na detecção e rápida correção de falhas no processamento dos alimentos, bem como a adoção de medidas preventivas, são hoje a principal estratégia para o controle de qualidade desses produtos (SHIBAO, et al. 2009).

Este estudo teve por objetivo enfatizar a importância do Programa de Monitoria para o ensino do curso de Bacharelado em Engenharia de Alimentos visando a disciplina Controle de Qualidade e Análise de Alimentos que foram desenvolvidas no curso Técnico em

\footnotetext{
${ }^{1}$ Graduando em Engenharia de Alimentos, IFPA Campus-Castanhal, robsonespindola4@gmail.com

${ }^{2}$ Professora Dra., IFPA Campus-Castanhal, evelyndamas@gmail.com
} 
Agroindústria do IFPA Castanhal, e enfatizar a importância que a monitoria exerce sobre o ensino do curso de Engenharia de Alimentos do IFPA Campus Castanhal.

\section{RELATO DE EXPERIÊNCIA}

Devido a uma grande demanda de turmas do curso técnico em Agroindústria e com quantidades consideráveis de alunos, além de atender o curso superior em Engenharia de alimentos e, atividades de iniciação cientifica como projetos de pesquisa, os professores ficavam sobrecarregados devido a essas atividades e ociosos por alguém que o ajudassem.

Pôr a apelo de professores e a uma grande demanda por monitores, laçou-se então o edital de participação ao Programa de Monitoria para bolsistas e voluntários a partir dos projetos elaborados por cada professor interessado e fundamentados em suas disciplinas.

Após ser selecionado ao programa de monitoria, inicialmente, juntamente com a professora supervisora, foram elaborados planos de ensino do semestre em questão para a execução das atividades do Programa de Monitoria por volta de três meses. A monitoria desenvolveu-se nas aulas práticas do curso Técnico em Agroindústria da turma de 2018, e para que fosse aplicável a disciplina de Controle de Qualidade e Análise de Alimentos, foram elaboras as seguintes etapas:

\section{Etapa 1: Plano de aula}

Traçou-se um plano de aula em conjunto com a professora supervisora como o objetivo de trabalhar o ensino e aprendizagem da aula prática em laboratório de físicoquímica com análises dos alimentos, onde foi discutido a aula de acidez/pH, umidade e, pôr fim, a aula de cinzas.

O plano de aula é de suma importância para que o monitor possa se organizar e criar métodos participativos de interação entre os alunos e despertando o interesse da disciplina mesmo que o tempo programa seja curto.

\section{Etapa 2: Aplicação da aula prática.}

Após ser traçado o plano de aula, desenvolveu-se a execução da disciplina da seguinte maneira:

Com o roteiro de aula prática em mãos, uma hora de antes de dar início as aulas, preparava-se todo o material a ser utilizado em aula prática de acordo com as divisões de grupo. As atividades aconteciam no laboratório de físico-química do IFPA com a preparação de vidrarias e soluções juntamente com a técnica do laboratório auxiliando neste primeiro momento.

Com os alunos e professora já em laboratório, iniciou-se a aula de acidez/pH. Cada 
grupo trouxe uma amostra de um determinado produto para que fosse feita a pesagem e, em seguida, acidez e posteriormente o $\mathrm{pH}$. O monitor acompanhava dois grupos na pesagem e a professora mais outro dois na análise de acidez e $\mathrm{pH}$ e posteriormente houve o revezamento para que o monitor obtivesse a mesma experiência.

No final da prática, cada grupo com o seu roteiro em mãos, desenvolvia um relatório da aula prática com todos as metodologias e ferramentas aplicadas na prática. Onde o monitor pode orientar no desenvolvimento desse material. A mesma dinâmica e metodologia de preparar e organizar as aulas prática e, na orientação de relatórios, foi desenvolvida para todas as aulas (análise de Umidade e análise de Cinzas) em conjunto com a professora supervisora até ao fim do programa de monitoria de acordo com o fluxograma 1.

Fluxograma 1: Etapas da Monitoria

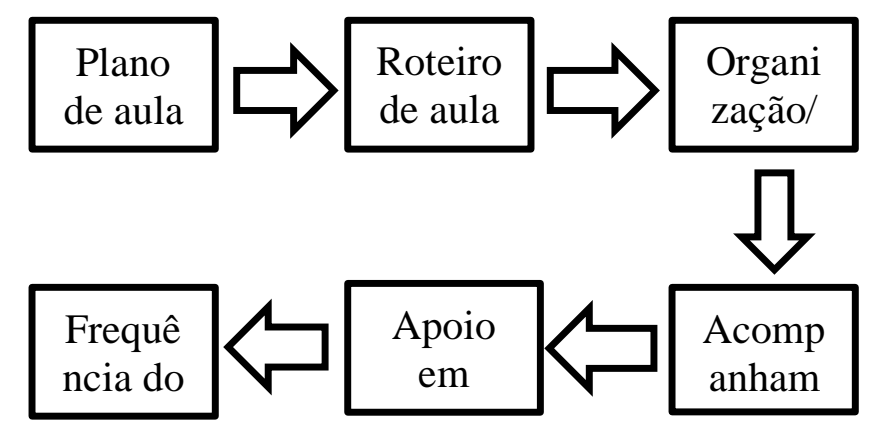

Fonte Própria (2019).

Nesse contexto, a experiência adquirida com o advento ao programa de monitoria traz grandes perspectivas quanto a arte de aprender e ensinar, estar à frente, dedicação e vivenciar por pouco que seja, a carreira da docência e, estimular sempre mais aos estudos e buscar formas e maneiras para uma boa compreensão de todos do conteúdo ministrados em aula. Tendo em vista que o aluno se sente muito mais confortável em perguntar e tirar possíveis duvidas com o monitor devido a interação do mesmo com a turma.

Para o curso de Engenharia de Alimentos do IFPA, a monitoria é de extrema importância devido as práticas desenvolvidas em laboratório e que reforçam o conteúdo visto em aula, dando muito mais propriedade ao monitor acerca da disciplina ministrada. Em vista disso, é necessário que os professores se envolvam e elaborem projetos que demostrem interesses por esses monitores de acordo com sua disciplina.

Desse modo, é essencial que as universidades e instituições de ensino estejam desenvolvendo com mais frequência o programa de monitoria para oportunizar aos estudantes a inserção as atividades complementares. Com a monitoria o monitor tem a oportunidade de vivenciar experiência à docência, apoiarem os professores na tomada de decisão quanto a metodologia adotada em aula e aos projetos de iniciação cientifica desenvolvidos nas 
universidades.

\section{CONSIDERAÇÕES}

O programa de monitoria do IFPA, a partir deste estudo, apresenta-se como importante para a comunidade acadêmica. Para o monitor é importante por ser uma experiência que pode acarretar numa futura carreira docente. E para o professor é importante pelo fato de ter alguém para auxiliar os alunos, visto que, as turmas são em geral numerosas. Com a participação no Programa, o monitor pode aprender mais, tem a possibilidade de novas formas de aprender o conteúdo que está ajudando a ministrar. Assim, o Programa de Monitoria influência de maneira positiva ao curso de Engenharia de alimentos, fortalecendo o ensino e promovendo interação de toda a comunidade acadêmica.

\section{REFERÊNCIAS}

DIAS, A. M. I. A monitoria como elemento de iniciação à docência: ideias para uma reflexão. Coleção Pedagógica. Natal, 2017. Disponível em: file://C:/Users/ROBSON\%20ESPÍNDOLA/Downloads/Monitoria\%20(2).pdf. Acesso em: 19 de out. de 2019.

MATOSO, L. M. L. A importância da monitoria na formação acadêmica do monitor: um relato de experiência. Universidade Potiguar-UNP. Mossoró, 2013. Disponível em: file:///C:/Users/ROBSON\%20ESP\%C3\%8DNDOLA/Downloads/567Texto\%20do\%20artigo-2847-1-10-20140603.pdf. Acesso em: 19 de out. de 2019.

Lei $\mathrm{n}^{\circ}$ 5540, 28 de novembro de 1968. Dispões sobre fixa norma de organização e funcionamento do ensino superior e sua articulação com a escola média, e dá outras providências. Disponível em: Acesso em: 14 mar. 2016.

SHIBAO, J.; BARSOTTI, R. C. F.; PASSOS, E. C.; MARONO, L. C.; ROUSSENG, Y. L. C. et al. Avaliação da qualidade físico-química de alimentos comercializados em restaurantes self-service. Rev Inst Adolfo Lutz, São Paulo, 20019. Disponível em: http://periodicos.ses.sp.bvs.br/pdf/rial/v68n2/v68n2a17.pdf. Acesso em: 19 de out. de 2019. 


\section{HORTA COMUNITÁRIA COMO PROMOÇÃO DE QUALIDADE DE VIDA PARA AS FAMÍLIAS EM SITUAÇÃO DE VULNERABILIDADE SOCIAL}

\section{COMMUNITY HOUR AS A PROMOTION OF QUALITY OF LIFE FOR FAMILIES IN SOCIAL VULNERABILITY}

\section{HORA COMUNITARIA COMO PROMOCIÓN DE LA CALIDAD DE VIDA PARA LAS FAMILIAS EN VULNERABILIDAD SOCIAL}

\section{Lorhana Franco Mesquita ${ }^{1}$; David Aimar Sousa Silva ${ }^{2}$; Mayara Pereira da Luz ${ }^{3}$; Fernando José Sousa Borges ${ }^{4}$; Edvar de Sousa da Silva ${ }^{5}$.}

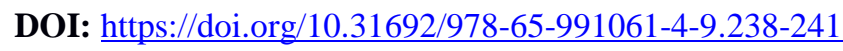

\section{INTRODUÇÃOO}

A integração de atividades comunitárias em pequenas cidades é engrenagem fundamental para promover a participação social no desenvolvimento local. Agindo como um estimulador do comércio de alimentos orgânicos e da independência financeira de famílias de baixa renda. A implantação de hortas comunitárias acata uma série de vantagens à distribuição de recursos de forma justa.

De acordo com Silva (2011) a horta comunitária tem sua importância sob o ponto de vista nutricional, como forma de terapia ocupacional, na melhoria do habito de consumo das pessoas, na economia das famílias até na manutenção e/ou melhoria da saúde e prevenção de doenças. Os benefícios de tal atividade são: produzir alimentos promovendo o acesso e a disponibilidade dos mesmos de forma solidária; garantir a segurança alimentar para as comunidades carentes; propiciar igualmente oportunidades de trabalho; geração de renda; e aproveitamento de áreas públicas ociosas (ALBUQUERQUE, 2016).

A política de funcionamento de projetos de horta comunitária é simples, o que viabiliza ainda mais sua contribuição para o desenvolvimento social. Estes projetos se desenvolvem a partir da utilização de áreas públicas dentro da cidade fazendo o seu aproveitamento para a produção de alimentos, através do trabalho.

Objetiva-se por meio deste trabalho, apresentar observações dos efeitos sociais e econômicos de uma horta comunitária na vida de famílias em situação de vulnerabilidade social, através do relato de uma atividade acadêmica que analisou o funcionamento de tal projeto no município de Araguatins por meio de ações extensionistas.

\footnotetext{
${ }^{1}$ Engenharia Agronômica, Instituto Federal do Tocantins, lorhanafrancomesquita@gmail.com

2 Engenharia Agronômica, Instituto Federal do Tocantins, david.asousa07@ gmail.com

${ }^{3}$ Engenharia Agronômica, Instituto Federal do Tocantins, mayaraluzm21309@ gmail.com

${ }^{4}$ Engenharia Agronômica, Instituto Federal do Tocantins, fernandoborges agro@ @otmail.com

5 Doutor, Instituto Federal de Educação, Ciência e Tecnologia do Tocantins, edvar.silva@ifto.edu.br
} 


\section{RELATO DE EXPERIÊNCIA}

A constituição deste trabalho deu-se a partir de uma experiência vivenciada na Horta Comunitária da cidade de Araguatins - TO, a partir da implementação de um trabalho de extensão. De acordo com Calgaro et al., (2013) a realização de projetos de extensão, como a implementação de hortas, busca principalmente a produção sustentável. Diante disto, desenvolveram-se várias iniciativas, sendo a primeira dedicada a entender o funcionamento da horta, se as pessoas diretamente envolvidas na produção das hortaliças seguiam um padrão de cultivo, se alguma entidade pública fora envolvida nesse projeto e quem cuida diretamente da horta.

A horta está localizada no setor denominado Irial, região noroeste da cidade de Araguatins - TO e interfere de modo positivo na economia municipal e na renda pessoal dos horticultores envolvidos, sendo estes pertencentes ao sistema de agricultura familiar. $\mathrm{O}$ projeto é uma iniciativa da prefeitura municipal e de moradores do bairro Irial que intensifica atividades agrícolas sustentáveis na região.

Em média cinquenta produtores trabalham na horta, cada um tem seu espaço para as plantações e o desenvolvimento de instalações como canteiros e telas de sombreamento é feito através do trabalho braçal individual em conjunto com o auxílio de seus familiares.

Quanto aos aspectos de manejo das culturas, observou-se que a maioria dos produtores utilizava adubo orgânico, fazendo uso de esterco bovino devido facilidade de obtenção na região. Além do esterco de gado, alguns poucos adubos químicos também são utilizados. A maioria das famílias não tem conhecimento sobre adubação e acabam utilizando os métodos convencionais que encontram disponíveis, devido à carência de informação e de orientação técnica. Além disso, foi observado que grande parte dos produtores não tem conhecimento dos métodos alternativos para o controle de pragas.

De acordo com Galvão et al. (2005) um nível de dependência de mão-de-obra externa bastante baixo na composição da renda familiar, pode ser entendido como sinal positivo de sustentabilidade econômica. As principais hortaliças cultivadas são: alface, couve, coentro e cebolinha, devido sua produção ser rápida e de baixo custo. Segundo Silva et al. (2015), tal predominância reflete á grande demanda local relacionada com a culinária regional tradicional. Grande parte do cultivo é destinada à comercialização no município, outra parte ao consumo próprio dos horticultores, o que contribui para a inclusão de alimentos orgânicos na mesa dos mesmos.

Indubitavelmente, é plausível dizer que o projeto trás vantagens e benefícios tanto em questões econômicas, quanto para a saúde humana, conscientização e preservação ambiental, 
devido ao uso mínimo ou até mesmo a não utilização de produtos químicos, como, defensivos e adubos.

Imagem 1: Atividade Experimental

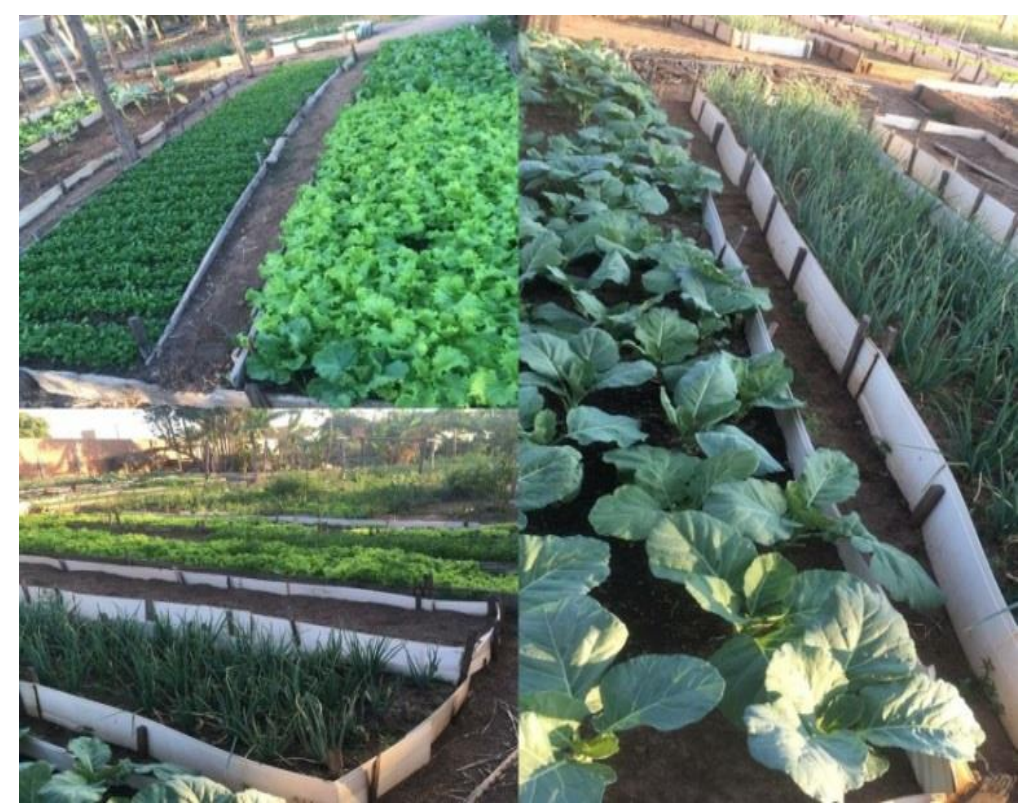

Fonte: Própria

\section{CONSIDERAÇÕES}

O objetivo de promover autonomia financeira de famílias de menor renda e de fornecer uma alimentação saudável de alto valor nutricional é o que movimenta a realização do projeto. Contudo, observou-se que a mobilidade e coletividade dos produtores responsáveis pela horta promove efetividade na produção, no abastecimento local e nas relações sociais.

Observou-se também que cultivar horta em conjunto com outras pessoas pode unir a comunidade e serve como terapia ocupacional. Isso se deve grande parte, ao aumento da importância do componente social nas atividades e nos processos dos projetos de hortas. Essa temática é englobada no conceito de agricultura social, pela realização de atividades em explorações agrícolas no âmbito de utilização da natureza para produzir saúde, benefícios sociais e educacionais nos diversos cenários da agricultura urbana.

\section{REFERÊNCIAS}

ALBUQUERQUE, J. O. Horta comunitária: inclusão social e produtiva. Banco de tecnologia sociais. Maringá, 2016.2 DR, em: http://tecnologiasocial.fbb.org.br/tecnologiasocial/banco-de-tecnologias-sociais/pesquisartecnologias/horta-comunitaria-inclusao-social-e-produtiva.htm. Acesso em: 19 set. 2019. 
CALGARO, H. F.; ALFONSO, L. A.; ARAÚJO, C. A. M. Projeto horta viva: um relato de experiência de extensão universitária. Rev. Ciênc. Ext. v. 9, p. 150-166. 2013. Disponível em: https://ojs.unesp.br/index.php/revista_proex/article/view/728. Acesso em: 26 set.de 2019.

SILVA, T. C. C. MARQUES, A. R. R. S.; PIRES, A. P. A. Horta comunitária: um relato de experiência. In: Congresso Estadual de Iniciação Científica e Tecnológica do IF Goiano, 5., 2016, Iporá. Anais [...]. Goiânia: IF Goiano, 2016. Disponível em: https://even3.azureedge.net/anais/35683.pdf. Acesso em: 19 set. 2019.

SILVA-FREITAS, S.; et al. Análise da produção de hortas no município de Araguatins. In: Jornada de iniciação científica e extensão do IFTO, 2015, Palmas. Anais [...]. Palmas: IFTO, 2015. Disponível

em: http://propi.ifto.edu.br/ocs/index.php/jice/6jice/paper/viewFile/7150/3429. Acesso em: 20 set. 2019.

SILVA, E. C. R; FONSECA, A. B. Hortas em escolas urbanas, complexidade e transdisciplinaridade: contribuições para o ensino de ciências e para a educação em saúde, Semantic Scholar, UFRJ-RJ, 2011. Disponível em: https://www.semanticscholar.org/paper/Hortas-em-escolas-urbanas\%2C-Complexidade-epara-a-e-Silva-Fonseca/f8f0fb62d0e3c6f7a1372153a3f3ca2c0d678d0b. Acesso em: 18 set. 2019. 


\section{DO PLANTIO AO PRATO: APRENDENDO DE FORMA LÚDICA A CONSUMIR ALIMENTOS SAUDÁVEIS E CUIDAR DA NATUREZA ATRAVÉS DE HORTA ESCOLAR NA PRIMEIRA INFÂNCIA}

\section{DE LA PLANTA AL PLATO: APRENDER OCIO PARA CONSUMIR ALIMENTOS SALUDABLES Y CUIDAR LA NATURALEZA A TRAVÉS DE LA ESCUELA INFANTIL}

\section{FROM PLANT TO DISH: LEARNING LEISURE TO CONSUME HEALTHY FOOD AND CARE FOR NATURE THROUGH EARLY CHILD SCHOOL}

Samantha Santos Vieira ${ }^{1}$; Juliane Carneiro Martins ${ }^{2}$; Idenilson Lobo Santos 3 ; Mario Augusto Pereira Junior ${ }^{4}$; Ana Maria Aquino dos Anjos Ottati ${ }^{5}$

DOI: https://doi.org/10.31692/978-65-991061-4-9.242-245

\section{INTRODUÇÃO}

A primeira infância é a fase que compreende a gestação, o nascimento e os primeiros seis anos de vida da criança, fase importante para o processo de desenvolvimento que irão refletir na fase adulta. Levando em consideração as etapas da Educação Básica definidas pelas Diretrizes Curriculares Nacionais Gerais para a Educação Básica, encontramos a fase da Educação Infantil e o $1^{o}$ ano do Ensino Fundamental. A Educação Infantil se subdivide em duas: Creche (crianças com até 3 anos e 11 meses) e na Pré-Escola (crianças com 4 e 5 anos), já aos 6 anos, a criança inicia o Ensino Fundamental (BRASIL, 2010a).

Os itens II e IV do Relatório sobre as Diretrizes Curriculares Nacionais Gerais para a Educação Básica do Ministério da Educação/Conselho Nacional de Educação de 2010 que trata da Educação Infantil, chama a atenção sobre a importância das atividades escolares incluírem a educação alimentar e ambiental desde a fase infantil, pois, por ser uma fase de aprendizagem, a criança é muito influenciada pelo meio em que ela está inserida, assim como, pelos cinco sentidos: cor, cheiro, sabor, tato e audição, por isso, uma fase importante para despertar hábitos saudáveis nelas, como por exemplo, o consumo de hortaliças e a preservação do meio ambiente (BRASIL, 2010b).

Neste contexto, o objetivo do projeto é estimular o consumo de hortaliças e repassar noções sobre educação ambiental através do plantio de hortas em uma escola comunitária, assim, nesta relação entre educação infantil, saúde e educação ambiental que o trabalho com hortas escolares vem ganhando destaque nas escolas públicas no Brasil. Além do trabalho

\footnotetext{
${ }^{1}$ Agronomia, Universidade Estadual do Maranhão, samantavieira39@gmail.com

2 Agronomia, Universidade Estadual do Maranhão, juliane.martins24@ gmail.com

${ }^{3}$ Agronomia, Universidade Estadual do Maranhão, idenilsonlobosantos@gmail.com

${ }^{4}$ Agronomia, Universidade Estadual do Maranhão, juniors204@ hotmail.com

${ }^{5}$ Doutora, Departamento de Economia Rural/Universidade Estadual do Maranhão, anjosottati@gmail.com
} 
manual, a horta escolar também incentiva os alunos a terem uma alimentação saudável.

\section{RELATO DE EXPERIÊNCIA}

Em uma época em que as frituras, pizzas, hambúrgueres, biscoitos recheados, achocolatados e sucos prontos fazem parte da merenda diária da maioria das crianças, cresce o número de crianças obesas e, consequentemente, crianças/adultos com doenças cardíacas e diabetes. Fato confirmado por Levy et al. (2010, p. 3086) quando cita em sua pesquisa que, "se os alunos não modificarem os seus hábitos alimentares inadequados na infância e na adolescência poderá ter possivelmente fatores de risco para doenças crônicas na fase adulta" e, ainda completa dizendo que os alunos têm usualmente uma "dieta rica em gorduras, açúcares e sódio, com pequena participação de frutas e hortaliças" Por isso, torna-se necessário e urgente trabalhar com as crianças da primeira infância hábitos alimentares saudáveis, como por exemplo, o consumo de hortaliças, alimentos ricos em vitaminas, minerais e nutrientes indispensáveis para o equilíbrio e funcionamento do organismo.

O trabalho está sendo desenvolvido na Escola Comunitária São Lázaro, localizada no bairro de Santa Clara, um dos muitos bairros carentes de São Luís - MA. Trabalhamos com crianças de 4 e 5 anos e envolvemos na Escola a direção, os professores e os pais dos alunos. As atividades envolvem músicas, filmes, desenhos e vídeos ilustrativos para melhor compreensão das crianças durante as conversas. Nas hortas utilizamos material orgânico, garrafas PETs e vasilhames plásticos em geral, pois na Escola falta área adequada para hortas no chão.

A primeira ação foi uma conversa educativa com as crianças, realizada de forma lúdica e de fácil linguagem sobre os benefícios dos vegetais, legumes e frutas para o corpo, isto, sempre associando o produto aos órgãos, unhas, cabelos, crescimento, ganho de peso etc.. No final houve a degustação de vegetais cozidos (batata, beterraba e cenoura) e de uma salada de frutas. Percebe-se que mesmo nesta idade, a criança já conhece pelo nome esses produtos, mas o consumo é muito restrito de hortaliças, a aceitação das frutas é bem maior (Figuras 1). A carência financeira e, em geral, a falta de hábito de consumo dos pais, ajuda no baixo consumo desses produtos pelas crianças. 


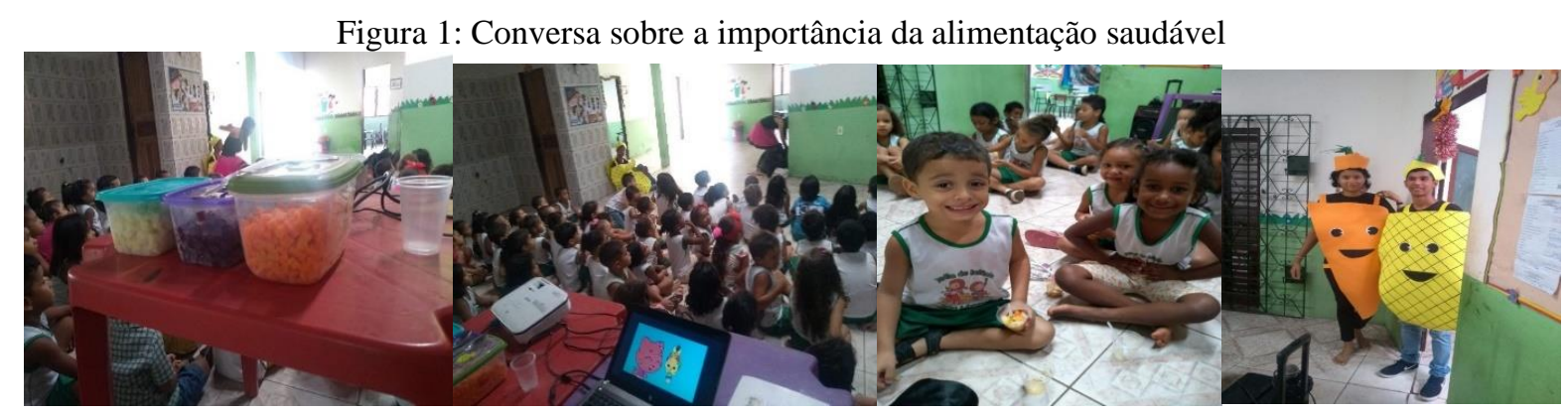

Fonte: Própria.

Em outra ação, abordamos com as crianças temas como germinação das sementes, crescimento das plantas e cuidados necessários para a planta crescer. O objetivo foi mostrar para as crianças a origem dos alimentos. Neste mesmo dia houve uma oficina com os alunos, onde estes fizeram o experimento da germinação do feijão no algodão a fim de que entendessem o processo de germinação na prática (Figura 2).

Figura 2: Conversa sobre a germinação das sementes e o experimento com a semente de feijão
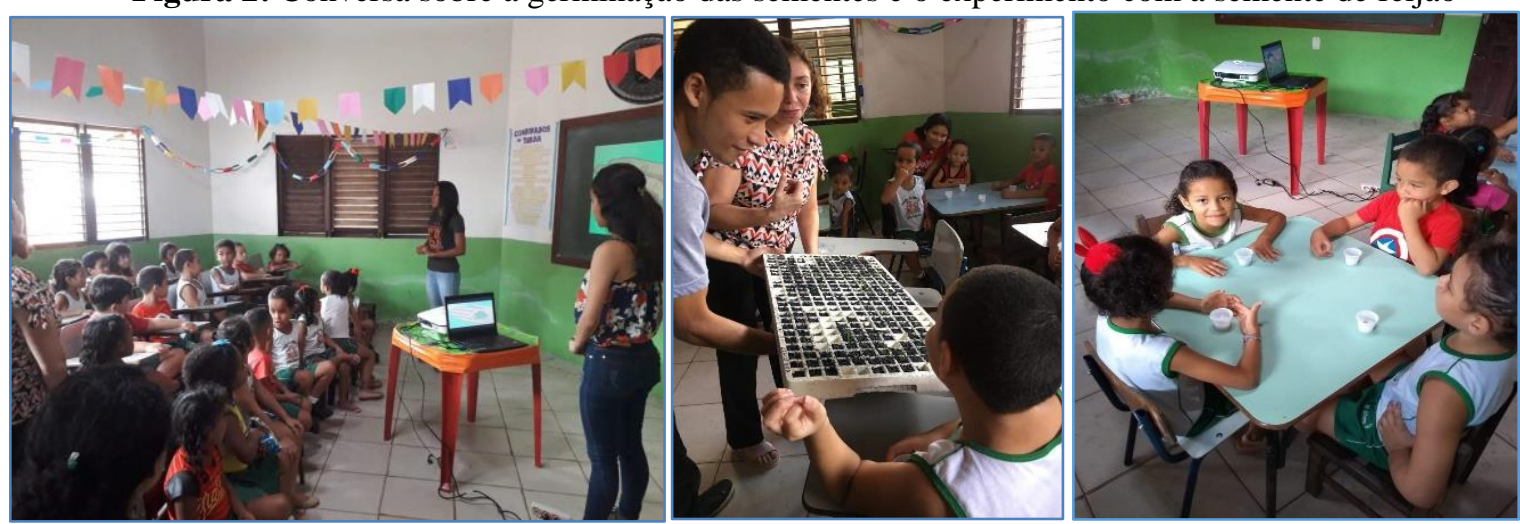

Fonte: Própria.

Também foi realizada uma oficina com os pais dos alunos sobre o cultivo de hortas em casa utilizando canteiros ou recipientes alternativos. Na oportunidade, foi ensinado fazer horta suspensa com garrafas PETs, o preparo de substrato e o manejo adequado de algumas culturas. Neste mesmo dia, cada criança plantou a sua hortinha, mas primeiro elas aprenderam através de vídeos mais sobre a importância de cuidar do meio ambiente e de como cuidar da sua hortinha. Depois fizeram o transplantio de mudas de alface e cebolinha (Figura 3).

As próximas etapas serão a construção de mais hortas, trabalhar mais com os pais para introduzir o consumo de hortaliças em casa através de receitas diversificadas e buscar através da parceria com outra Instituição de Ensino Superior que tenha o Curso de Nutrição ajuda para melhorar o cardápio da Escola. 
Figura 3: Oficina sobre horta caseira para os pais dos alunos e crianças enchendo os porquinhos com substrato e

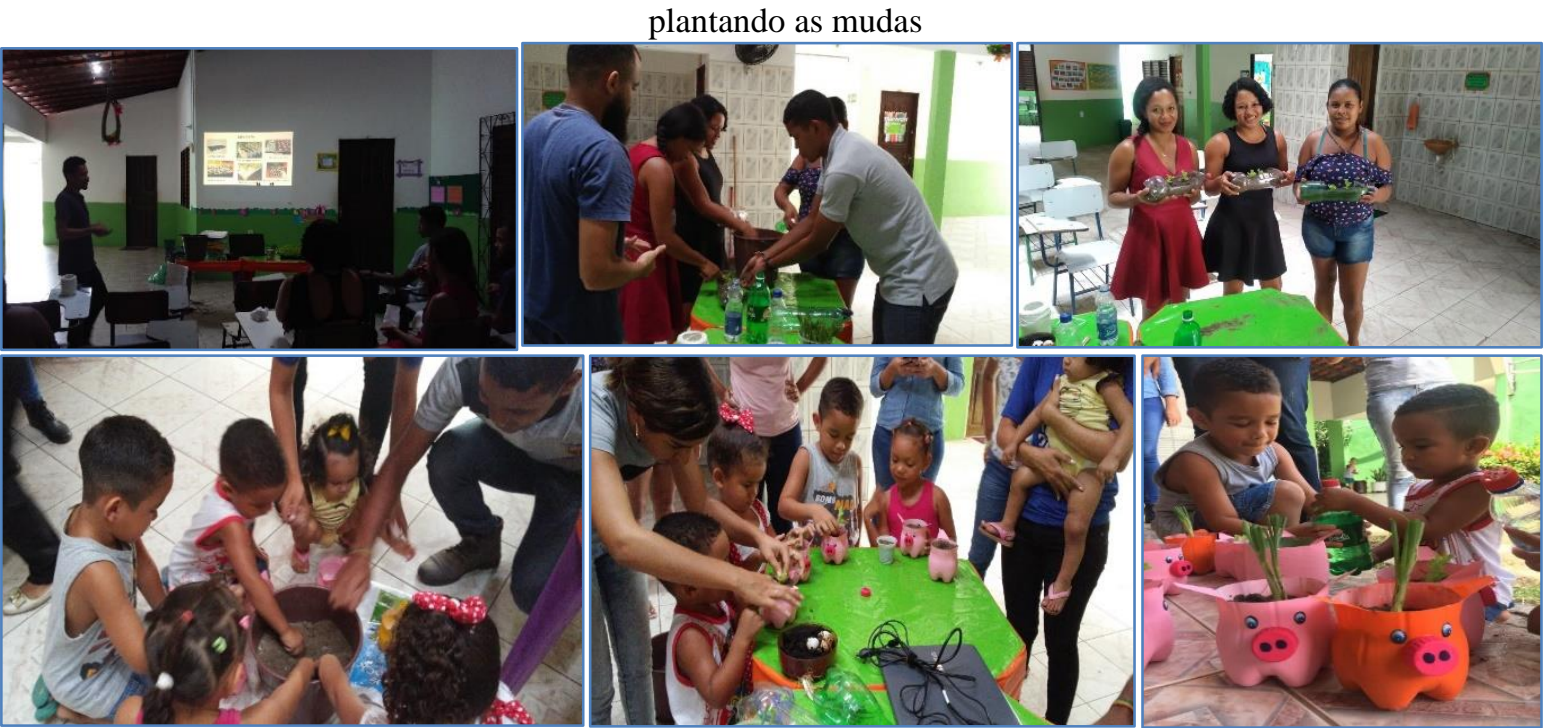

Fonte: Própria.

\section{CONSIDERAÇÕES}

O trabalho tem nos mostrado que as crianças já possuem conhecimentos sobre a aparência e nome das hortaliças e frutas, mas o hábito de consumo é muito baixo, principalmente das hortaliças, tanto que algumas não aceitaram nem provar o que foi oferecido, o que nos fez ver que precisamos trabalhar também com a Escola e com os pais formas alternativas de usar esses produtos.

\section{REFERÊNCIAS}

BRASIL. Ministério da Educação. Resolução No 4/2010: Diretrizes Curriculares Nacionais Gerais para a Educação Básica. 2010a. Disponível em: <http://portal.mec.gov.br/index.php?option=com_docman\&view=download\&alias=6704rceb004-10-1\&category_slug=setembro-2010-pdf\&Itemid=30192>. Acesso em: 28 abr. 2018.

- Ministério da Educação. Diretrizes Curriculares Nacionais Gerais para a Educação Básica. 2010b. Disponível em:

LEVY, Renata Bertazzi et al. Consumo e comportamento alimentar entre adolescentes brasileiros: pesquisa nacional de saúde do escolar (PENSE), 2009. Ciência \& Saúde Coletiva, v.15, suppl.2, p.3085-3097, 2010. 


\section{FORMAÇÃO DOS ALUNOS DA REDE MUNICIPAL DE ENSINO SOBRE AS ZOONOSES E OS POSSÍVEIS IMPACTOS NA SAÚDE PÚBLICA}

\section{FORMACIÓN DE ESTUDIANTES EN LA RED DE EDUCACIÓN MUNICIPAL SOBRE ZOONOSIS Y POSIBLES IMPACTOS EN LA SALUD PÚBLICA}

\section{TRAINING STUDENTS IN THE MUNICIPAL EDUCATION NETWORK ON ZOONOSES AND POSSIBLE IMPACTS IN PUBLIC HEALTH}

Italo Gleison Tarquinio da Silva ${ }^{1}$;Maria Lucivania Diniz da Silva ${ }^{2}$; Laércio Nogueira Medeiros $^{3}$; João Victor Dionísio da Silva ${ }^{4}$;Viviane da Silva Medeiros ${ }^{5}$

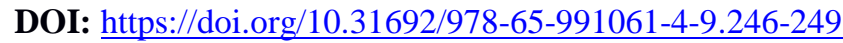

\section{INTRODUÇÃO}

Zoonoses são definidas como enfermidades transmissíveis entre os animais vertebrados e humanos (WORLD HEALTH ORGANIZATION, 1967). Mesmo vivendo-se em um mundo globalizado, são importantíssimas as informações sobre esse tema, o que possibilita novas maneiras para prevenção dessas doenças (LANGONI et al., 2015). Desta maneira, a permanência dos programas de extensão universitária, que trabalham com educação em saúde, são necessários para levar aos estudantes a compreensão sobre como evitar a propagação de enfermidades.

A educação é uma das formas mais seguras no auxílio de controle e prevenção das enfermidades. Com efeito, o conhecimento adquirido dificilmente retrocede, tornando-se assim ação consciente de caráter permanente. Entre as zoonoses encontramos a raiva, exemplo de uma grave doença de etiologia viral e que atinge o sistema nervoso central dos mamíferos, sua transmissão ocorre pela mordedura, arranhadura ou lambedura de um animal infectado para outro. Ademais, a taxa de letalidade da raiva é muito alta chegando a aproximadamente $100 \%$ dos casos registrados (WADA et al., 2011).

Outro exemplo de zoonose é a leishmaniose, doença caracterizada como uma antropozoonose (doença primária em animais e que pode ser transmitida para outros animais e humanos), tem como principal vetor um Flebotomíneo, que se reproduz em ambientes escuros e com grande quantidade de matéria orgânica. Os riscos de adoecimento após contato com o agente etiológico são bem mais altos para aqueles indivíduos imunossuprimidos, pois o

\footnotetext{
${ }^{1}$ Farmácia, Universidade Federal do Rio Grande do Norte, italogleison.out@gmail.com

${ }^{2}$ Zootecnia, Universidade Federal do Rio Grande do Norte, lucivania18diniz@ gmail.com

${ }^{3}$ Graduado em Tecnologia em Análise e de desenvolvimento de sistemas, Universidade Federal do Rio Grande do Norte, laerciomedeiros2015@gmail.com

${ }^{4}$ Ciências Biologica, Universidade Federal do Rio Grande do Norte, joao2016@ufrn.edu.br

${ }^{5}$ Doutora em Psicobiologia, Universidade Federal do Rio Grande do Norte, vivianemedeiros.eaj@ gmail.com
} 
sistema imunológico destas pessoas já está debilitado (ALVES; BEVILACQUA, 2004).

Levar informações sobre temas relacionados a enfermidades zoonóticas, saúde pública e bem-estar animal para escolas da rede municipal e estadual de ensino, com o intuito de que os alunos obtenham informações sobre os riscos de contaminação e que também incorporem os hábitos preventivos ao seu dia a dia é o objetivo deste trabalho e para tal tem desenvolvido ações no ano de 2019 como projeto de extensão Xerimbabo.

\section{RELATO DE EXPERIÊNCIA}

O projeto de Extensão Xerimbabo desde o ano de 2012 atua nas escolas da zona rural e urbana do município de Macaíba, estado do Rio Grande do Norte. A Equipe é composta por estudantes de diversas áreas de formação oriundos de cursos técnicos e graduação da UFRN e UNP, coordenados por professoras e profissionais da área de saúde humana e animal, é portanto um grupo multidisciplinar, cujo conhecimento de cada indivíduo é compartilhado com o grupo.

Neste ano as ações iniciaram-se em fevereiro de 2019. A primeira atividade do Xerimbabo foram as reuniões entre os participantes para decidir quais os temas que teriam maior relevância para o município, sempre abordando as principais zoonoses que ocorrem no local ou que apresentam riscos maiores de morte. Foram abordadas no primeiro semestre as zoonoses raiva e leishmaniose visceral, para o segundo semestre estão programadas as zoonoses esporotricose e toxoplasmose. As escolas selecionadas para realização das atividades foram Escola Municipal Auta de Souza (alunos de duas turmas do $6^{\circ}$ ano, com aproximadamente 60 alunos participantes) e Escola Municipal Pedro Gomes (alunos do $8^{\circ}$ ano, com cerca de 40 alunos participantes) na zona urbana do município de Macaíba/RN. Tal prática de extensão universitária vista no projeto Xerimbabo é semelhante a ações de outras universidades, como é vista no projeto de extensão universitária da UNESP (LANGONI et al., 2015), onde alunos de graduação do curso de Medicina Veterinária levam aos estudantes do ensino médio de escolas públicas, temas que envolvem medidas que devem ser tomadas para a evitar a contaminação com zoonoses.

O primeiro assunto abordado nas escolas selecionadas foi a raiva, iniciou-se de forma teórica seguida por atividade lúdica a partir da apresentação de slide contendo tópicos sobre a zoonose: o agente causador da doença, principais reservatórios e a importância da conscientização de todos. Após a apresentação fez-se uma dinâmica, utilizando um tabuleiro e dado, em cada quadrado do tabuleiro haviam obstáculos com o nome do agente causador da doença e também formas de prevenção, os alunos foram divididos em grupos, foram feitas 
perguntas para cada grupo, quem acertava ganhava o direito de jogar o dado e liderar o jogo. O jogo teve como objetivo de tornar a relação ensino/aprendizagem divertida, pois observouse que desta forma a atividade despertou mais interesse aos alunos participantes.

Na segunda visita foi apresentado a leishmaniose visceral, doença caracterizada por ser transmitida pela picada do inseto flebotomíneo, em slides com bastantes fotos sobre a zoonose. Os slides abordavam como essa doença afeta os animais e humanos, apresentando os sinais dos animais e os sinais e sintomas nos humanos, medidas de prevenção para minimizar a entrada dos insetos em residências e canis, o tratamento adequado, e as principais ações que podem ser difundidas para reduzir a proliferação do mosquito nas proximidades das residências. Após a apresentação sobre leishmaniose foi realizado um bingo, foram confeccionadas cartelas com palavras que pudessem aprimorar e fixar os conteúdos informados durante a atividade, de forma que todos os integrantes da turma brincassem.

A participação dos alunos nas duas visitas foi extremamente importante para a dinâmica e isso pode melhorar o aprendizado, pois a cada etapa da apresentação eram realizadas perguntas para que ocorresse a interação e os alunos participassem dando explicação do assunto. Ademais, os docentes e corpo administrativo das escolas ajudaram de forma determinante para que as apresentações ocorressem de forma adequada e participativa.

As atividades possibilitam aos estudantes participantes de exercerem o papel de agentes difusores das informações e dos conhecimentos abordados em sala, levando tais conhecimentos e práticas de como evitar algumas enfermidades zoonóticas a partir de atitudes simples do cotidiano para seus familiares e sua comunidade. Neste ponto o Xerimbabo se assemelha ao trabalho realizado na monografia de especialização de Silva (2014), cujo o objetivo foi levar para a comunidade Rural do Campo da Pedra o conhecimento sobre as zoonoses, realizando ações educativas com intuito de informar à população sobre medidas que devem ser tomadas para melhorar o saneamento e a qualidade de vida de todos.

\section{CONSIDERAÇÕES}

As ações de prevenção de enfermidades muitas vezes exigem mudança de hábito e por isso são medidas em longo prazo, requerem educação para formação de um cidadão responsável sobre o tema em questão. O Projeto de Extensão Xerimbabo é um parceiro da Secretaria de Educação e de Saúde do município de Macaíba, e atua levando informações relevantes sobre saúde, comportamento e bem estar em animais e suas relações com humanos às escolas. Essa é a motivação do Projeto, esses são seus objetivos atuar na formação de uma população que respeita os animais, cuida e que entende que ainda que seja uma relação 
humano/animal milenar e satisfatória envolve riscos a saúde de todas as espécies envolvidas. Nada melhor que o trabalho com crianças e pré-adolescentes, pois esses estão abertos à discussão, ao conhecimento e podem formar um posicionamento ético, salutar sobre as espécies envolvidas.

\section{REFERÊNCIAS}

JOINT, F. A. O. et al. Joint FAO/WHO Expert Committee on Zoonoses. Third report. Geneva, 6-12 Dec. 1966. Joint FAO/WHO Expert Committee on Zoonoses. Third report. Geneva, 6-12 Dec. 1966., 1967.

LANGONI, Helio et al. Educação em saúde nas escolas: o papel do médico veterinário no controle das zoonoses. In: Congresso de extensão universitária da UNESP. Universidade Estadual Paulista (UNESP), 2015. p. 1-4.

ALVES, Waneska Alexandre; BEVILACQUA, Paula Dias. Quality of diagnosis of canine visceral Leishmaniasis in epidemiological surveys: an epidemic in Belo Horizonte, Minas Gerais, Brazil, 1993-1997. Cadernos de saude publica, v. 20, n. 1, p. 259-265, 2004.

WADA, Marcelo Yoshito; ROCHA, Silene Manrique; MAIA-ELKHOURY, Ana Nilce Silveira. Situação da raiva no Brasil, 2000 a 2009. Epidemiologia e Serviços de Saúde, v. 20, n. 4, p. 509-518, 2011.

SILVA, Daniele da. Prevenção de zoonoses na comunidade rural do Campo da Pedra no município de Dilermando de Aguiar-RS. 2014. 
PROJETO IMPLANTAÇÃO DE HORTA ORGÂNICA NA QUALIDADE DE VIDA E BEM-ESTAR DE IDOSOS EM ASILOS DE VITÓRIA DE SANTO ANTÃO-PE

IMPLEMENTACIÓN DE PROYECTO DE CASA ORGÁNICA SOBRE CALIDAD DE VIDA Y BIENESTAR DE PERSONAS MAYORES EN SANTO ANTÍO-PE VICTORIA ASILOS

\section{PROJECT IMPLEMENTATION OF ORGANIC HOUSE ON QUALITY OF LIFE AND WELFARE OF ELDERLY IN SANTO ANTÃO-PE VICTORY ASYLOS}

Lenira Batista da Silva; Mércia Cardoso da Costa Guimarães; Marta Xavier; Marismênia de Siqueira Campos Moura; José Marcos Freitas de Oliveira

DOI: https://doi.org/10.31692/978-65-991061-4-9.250-253

\section{INTRODUÇÃO}

A inovação da proposta dos orgânicos nos asilos de terceira idade em Vitória de Santo Antão e cidades vizinhas, um dos eixos onde agrega a criatividade, inovação e conexão social, é uma iniciativa que possibilita a convergência de ações cooperativas e colaborativas de vários parceiros e de setores do órgãos públicos e empresas privadas parceiras de um município em prol da melhoria da nutrição dos idosos e da própria comunidade do entorno. $\mathrm{O}$ presente projeto tem por finalidade, promover a interação dos idosos asilados para assim oferecer melhor qualidade de vida e bem-estar, com esta atividade eles terão a relação equilibrada do ser humano com a natureza, que é o princípio básico de manutenção da saúde, que foi abalada principalmente, a partir do século XVIII, dentro do enfoque relacional reducionista baseado em causa - efeito, que embasa o paradigma da medicina científica.

\section{RELATO DE EXPERIÊNCIA}

Todo conteúdo apresentado, discorre sobre o projeto de implantação de horta orgânica nos asilos de idosos de Vitória de Santo Antão-PE, onde tem por objetivos gerais e específicos o bem-estar dos mesmos promovendo atividades terapêutica e ocupacional para que não permaneçam no sedentarismo, ou seja, atualmente os idosos do abrigo Lar Espírita São Francisco localizado nesta mesma cidade, possuem maior qualidade de vida perspectivas de dias melhores, haja visto que grande maioria são acamados e tem dificuldade de locomoção por não praticarem atividades físicas e pedagógicas. 
Imagem 1: Atividade Preparação dos canteiros de alfaces
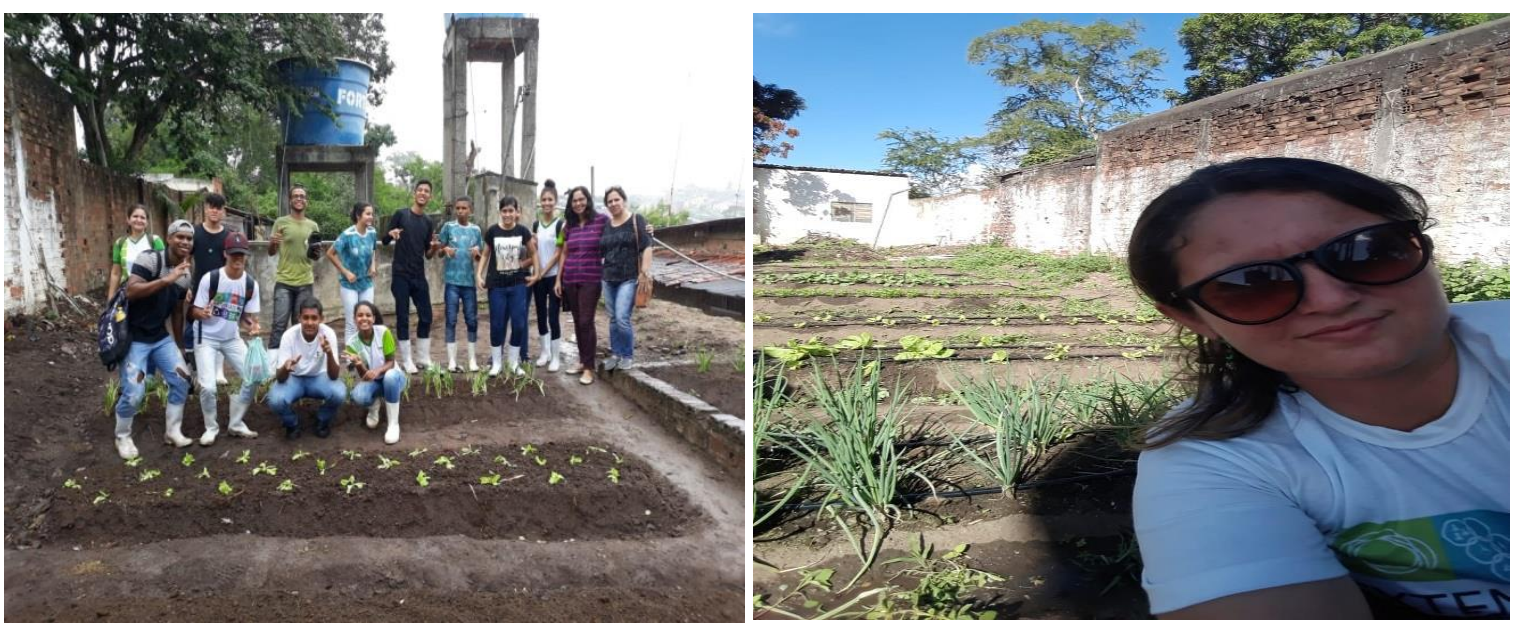

Fonte: Própria

Nesta primeira etapa foram atendidos os asilos Casa dos Pobres e Lar Espírita São Francisco nos bairros da Matriz e Alto do Reservatório - Vitória de Santo Antão - PE. Para realização do diagnóstico sobre a situação da segurança alimentar e nutricional dos idosos foi utilizado técnicas de metodologias participativas em extensão rural, utilizamos método individual, com entrevistas semiestruturadas que possibilitaram uma visão ampla de conhecimento do sistema para os agricultores e em seguida a aplicação de questionários. Essa ferramenta nos permitiu coletar informações e determinar o perfil dos asilos.

Durante as visitas aos asilos: Casa dos Pobres e Lar Espírita São Francisco, localizados na cidade de Vitória de Santo Antão - PE aplicamos questionários e realizamos palestras onde contamos com a participação de em média cinquenta idosos e uns trinta colaboradores voluntários do sexo masculino e feminino. As comunidades tiveram grandes interesses em aderir ao projeto em outras comunidades, porém há uma grande preocupação por causa do acesso, em especial é bastante dificultoso por não ter rampas de acesso, corrimãos nas mediações dos canteiros de hortaliças e ervas medicinais, que segundo alguns colaboradores seriam necessário a criação desses acessos uma vez que eles já tiveram sérios problemas com os mesmos, pois quando desejam participar das atividades não tem condições de exercer por causa dos obstáculos existentes. Essa integração pode ser muito bem-vinda, desde que sejam tomados os cuidados necessários, para que não sejam tão complicados. Os idosos ganham muito com este projeto porque tem uma alimentação rica, sadia e além de tudo atividades terapêuticas ocupacionais. Vale salientar que o exposto, ganha com alimentação de hortaliças e as ervas medicinais pra realização de chás que visa a cura ou minimizar os sintomas de algumas patologias, além de alimenta-se com um produto sem nenhum uso de agrotóxicos. Aos idosos desses asilos foi proposto pelo que viessem até o Instituto Federal 
para conhecer melhor o nosso sistema no intuito de que eles possam formar uma outra conclusão e possivelmente consolidar o modelo de produção proposto.

Imagem 2: Atividade transporte das mudas de frutíferas

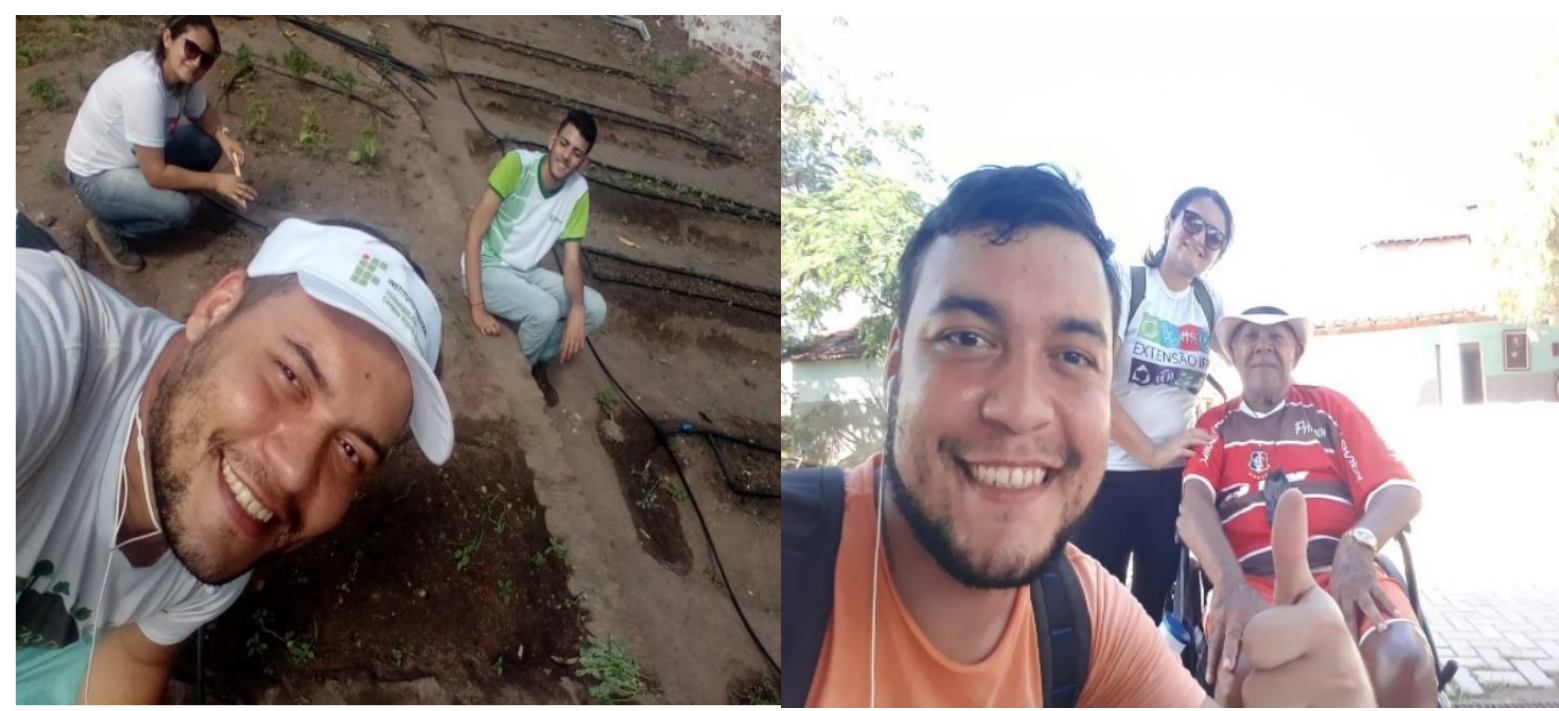

Fonte: Própria

\section{REFERÊNCIAS}

CONSELHO NACIONAL DE SEGURANÇA ALIMENTAR E NUTRICIONAL. Conceitos: Segurança Alimentar e Nutricional e Soberania Alimentar. Disponível em: $<$ http://www4.planalto.gov.br/consea/acesso-a-informacao/institucional/conceitos $>$. Acesso em: 20 nov. 2016.

FETAES. PAIS - Produção Agroecológica Integrada e Sustentável. Disponível em:

BERGER P; LUCKMANN T. 2001. A construção social da realidade. Trad. de Floriano Souza Fernandes. Petrópolis: Vozes. p. 174.

FILGUEIRA FAR. 2002. Novo Manual de Olericultura: agrotecnologia moderna na produção e comercialização de hortaliças. Viçosa: UFV. 412p.

MONTEIRO D; MENDONÇA M M. 2004. Quintais na Cidade: a experiência de moradores da periferia do Rio de Janeiro. Agriculturas 1: 29-31.

NASCIMENTO APB; ALVES MC; MOLINA SMG. 2005. Quintais domésticos e sua relação com estado nutricional de crianças rurais, migrantes e urbanas. MultiCiência 5. Disponível BXCFDV em: < http://www.multiciencia.unicamp.br/rede_3_5.htm>. Acessado em 13 de agosto de 2008.<http://www.fetaes.org.br/main.asp?link=indep\&id=37>. Acesso em: 20 nov. 2016.

INSTITUTO AGRONÔMICO DE PERNAMBUCO. CARTILHA PAIS: CONSTRUÇÃO E MANUTENÇÃO DO SISTEMA. Recife: IPA, 2011.

SEBRAE. PAIS. Território Nacional: SEBRAE, 2012. 
SILVA, et al.

IPA. PAIS Território Nacional. 


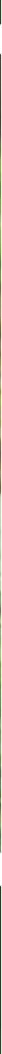

